\title{
Corticolous lichens as potential bioindicators of fire history: a study in the cerrado of the Distrito Federal, central Brazil
}

\author{
Jayalaxshmi Mistry
}

THESIS SUBMITTED FOR THE DEGREE OF Ph.D.

DEPARTMENT OF GEOGRAPHY, SCHOOL OF ORIENTAL AND AFRICAN STUDIES, UNIVERSITY OF LONDON.

1996 
ProQuest Number: 10752724

All rights reserved

INFORMATION TO ALL USERS

The quality of this reproduction is dependent upon the quality of the copy submitted.

In the unlikely event that the author did not send a complete manuscript and there are missing pages, these will be noted. Also, if material had to be removed, a note will indicate the deletion.

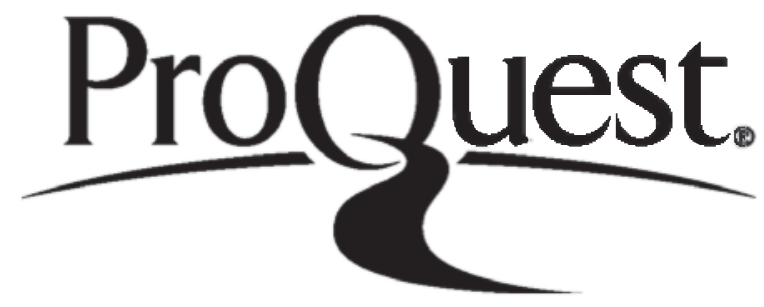

ProQuest 10752724

Published by ProQuest LLC (2018). Copyright of the Dissertation is held by the Author.

All rights reserved.

This work is protected against unauthorized copying under Title 17, United States Code Microform Edition (C) ProQuest LLC.

ProQuest LLC.

789 East Eisenhower Parkway

P.O. Box 1346

Ann Arbor, Ml $48106-1346$ 


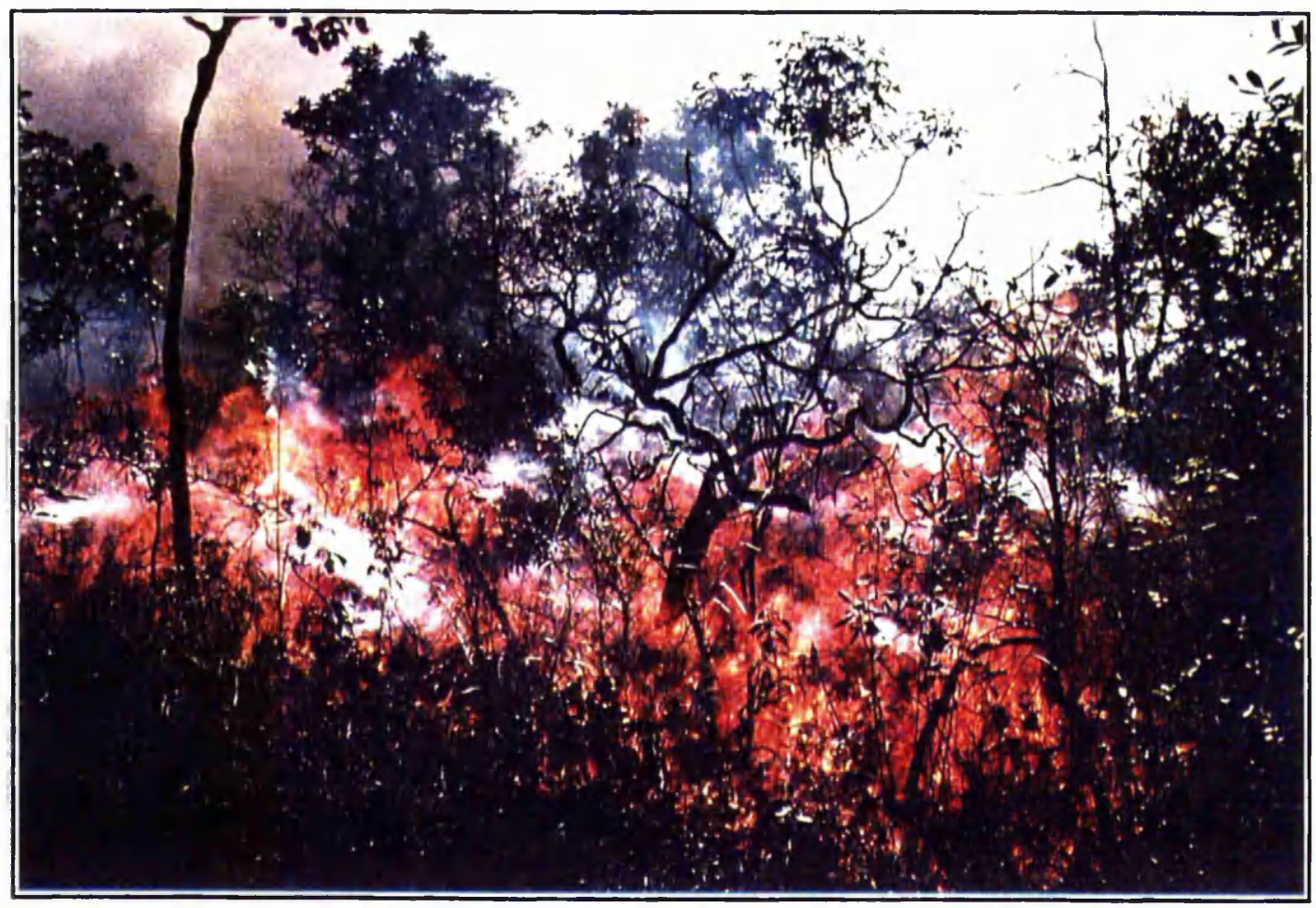

Frontispiece: Fire in the cerrado, Reserva Ecológica do IBGE, Brazil, 24/8/94. 


\begin{abstract}
The aim of this thesis is to investigate the potential use of epiphytic corticolous lichens as indicators of fire history in the cerrado (savannas) of central Brazil. Work was carried out at the Reserva Ecológica do IBGE and the Jardim Botânico de Brasilia, $33 \mathrm{~km}$ outside Brasilia D.F., in plots of cerrado denso within the 'Fire Project' area. Each plot was subjected to a specific prescribed burning regime, with study sites varying from a plot protected from fire for over 20 years to a plot burned every two years.

The research was carried out in three stages:

1) a preliminary survey of plots with different fire histories, measuring variables about the lichen habitat and the lichen communities present in the habitats;

2) lichen sampling in plots with different fire histories, where collection and identification of lichen species took place;

3) sampling of the lichen genus, Bulbothrix, in plots with different fire histories, measuring abundance and size of individual lichens.

Field techniques used included plotless sampling, and identification of lichens was carried out using taxonomic keys, both in the field and in the laboratory.

The results show that fire is a major determinant of epiphytic corticolous lichen communities in cerrado denso vegetation. The abundance, distribution, and recolonisation of lichen communities can clearly be correlated with the frequency and behaviour, in terms of homogeneity and flame heights, of the fires that have occurred in each of the plots surveyed. Particular lichen species show differential sensitivities to fire frequency and behaviour, and as the length of the fire-free period increases, Bulbothrix individuals become greater in size. Using these various responses of lichens, at the community, population and species level, a Lichen Fire History (LFH) Key was constructed for estimating fire frequency, fire behaviour, and the 'time-since-the-last' fire. The LFH Key is then presented as a simple booklet to be used in the field.
\end{abstract}

Key words: savanna, cerrado, Brazil, corticolous lichens, fire history, bioindicators, Lichen Fire History (LFH) Key. 


\section{Acknowledgements}

My greatest thanks goes to my supervisor Professor Philip Stott, for his guidance, patience and limitless enthusiasm throughout the three years. A huge 'Obrigada' also goes to my field supervisor, Dr. Carlos Klink, who not only gave me endless advice and guidance with fieldwork, but also took me into his family, and made my stay in Brazil a wonderful and memorable experience.

Many other friends and colleagues helped me in one way or another, and these include: my Research Committee at SOAS: Dr. Tanya Bowyer-Bower, Dr. Sarah Jewitt and Prof. Tony Allen; the technicians in the Malacologia laboratory; everyone in the UnB Herbarium, especially Carol; the staff at the IBGE Reserve; Heloisa and Antonio Miranda, for help with the fire study; my English students; my friends Adriana, Tomas, Maricy, Daniella, Ivani, Silvani, the Moreira family and June; Kiki, the best flatmate ever; Mercedes and Mauricio, for their kind hospitality; Dr. Marcelo Marcelli, for identifying my lichens and help with cerrado lichen ecology; Victoria Byrne, for her great friendship; Bill Hoffman, for lifts to the field in his car, and for introducing me to Jimmy Buffet; e-mail, for allowing me to have an 'electronic' love-life; Pat Wolseley, for her ideas, advice and constant help; and the crazy Dulce Rocha, for being herself, and her supplements of red wine and gorgonzola!

This thesis was largely supported and funded by my Mum and Dad. Fieldwork was also funded by the Central Research Fund, University of London, and the SOAS Additional Fieldwork Awards.

Finally, I would like to thank Andrea Berardi, who has helped me with everything and more, and whose love and friendship have never failed.

Este tese e pra todos os meus amigos. Obrigada gente!

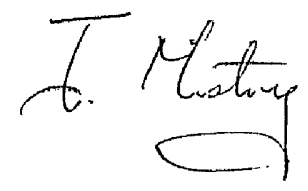

Jayalaxshmi Mistry

January 1996 


\section{Table of Contents}

List of Tables.

List of Figures.

Chapter 1: Fire history in savannas: a problem of measurement ...............................23

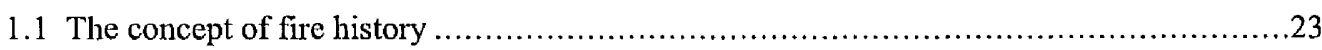

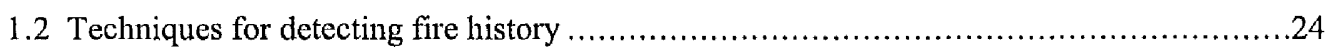

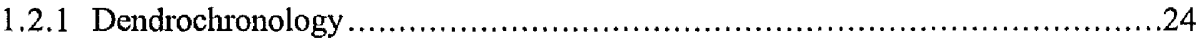

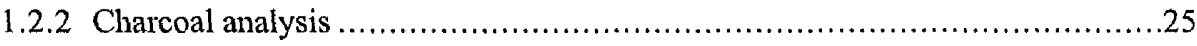

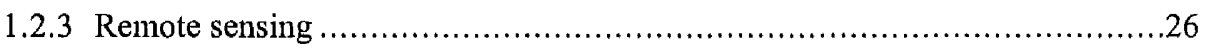

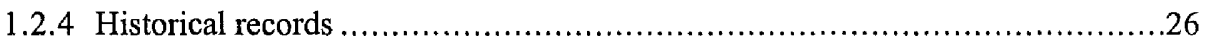

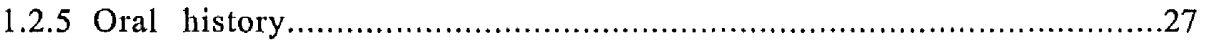

1.3 The aim of this thesis: lichens as potential bioindicators of fire history .................27

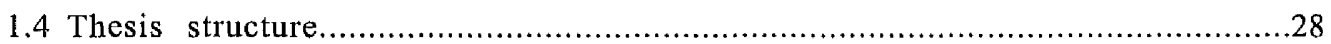

Chapter 2: The ecology of lichens and their role as bioindicators ..............................29

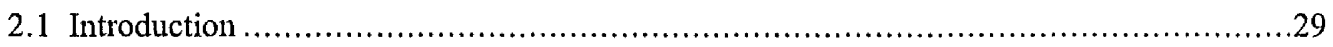

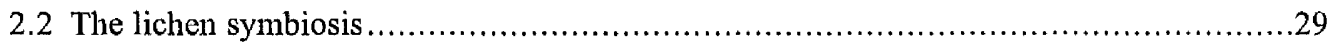

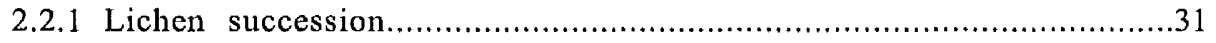

2.2.2 Factors influencing lichen growth........................................... 33

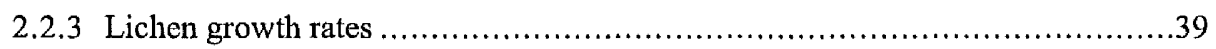

2.3 The concept of biological indicators................................................... 40

2.4 The uses of lichens as bioindicators .................................................40

2.4.1 Environmental pollution...............................................40

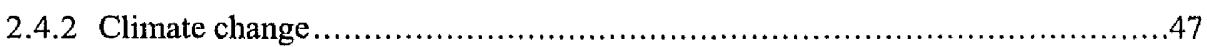

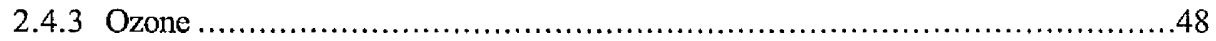

2.4.4 Forest management in temperate regions.....................................48

2.4.5 Forest management in tropical regions ...................................49

2.4.6 Lichen and fire studies in savannas.........................................50

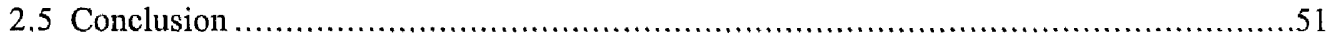

Chapter 3: The Brazilian cerrado: distribution, determinants and ecology of study site............53

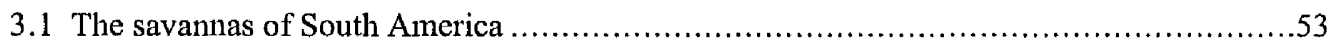

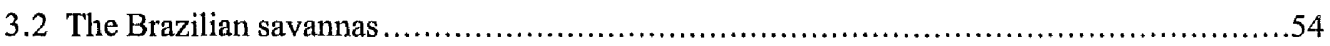

3.3 Determinants and adaptations of cerrado vegetation............................................57 


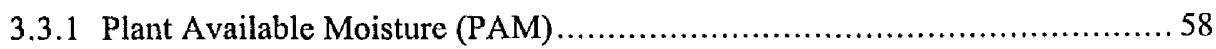

3.3.2 Plant Available Nutrients (PAN) ......................................... 60

3.3.3 Aluminium levels........................................................ 61

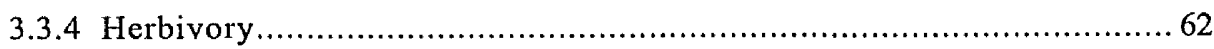

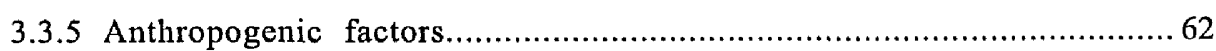

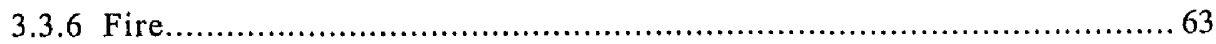

3.4 The role of fire in the Brazilian cerrado............................................. 63

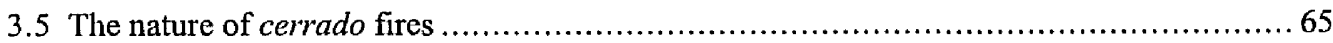

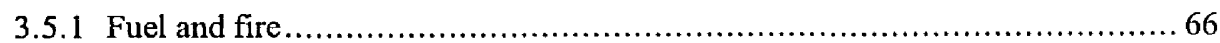

3.5.2 Vertical distribution of temperatures during fires ............................. 67

3.5.3 Fire and mineral nutrient cycling ....................................... 68

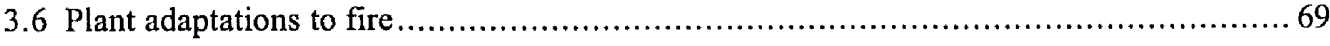

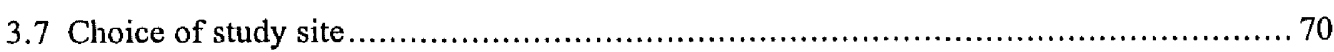

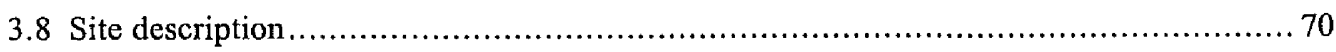

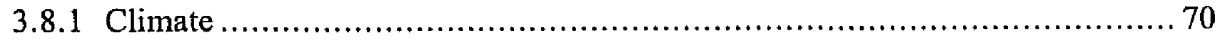

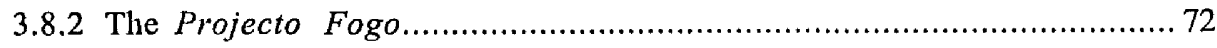

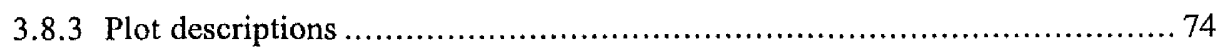

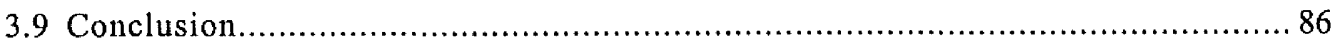

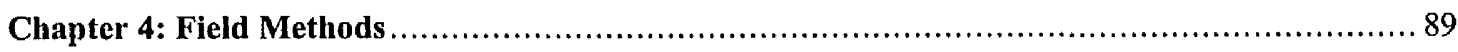

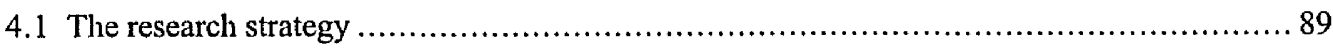

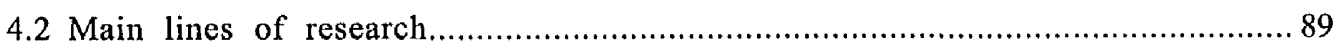

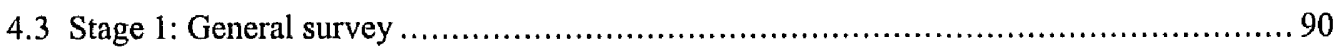

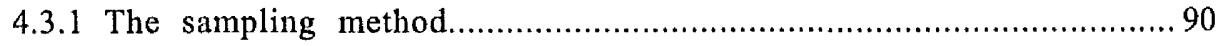

4.3.2 Criteria for phorophyte sampling ......................................... 93

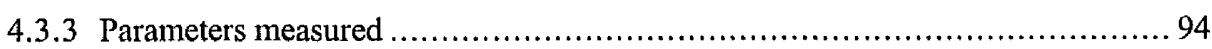

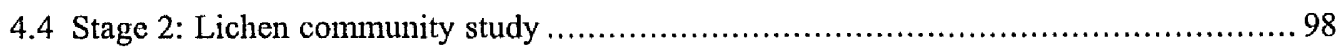

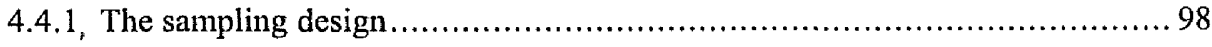

4.4.2 The sampling method..................................................... 99

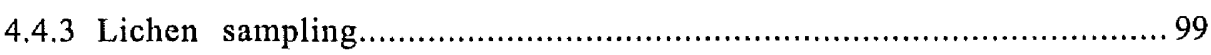

4.4.4 Lichen collection.......................................................... 101

4.4 .5 Lichen identification .................................................... 101

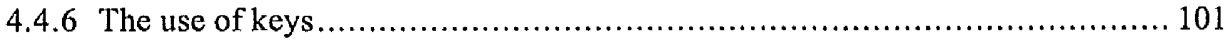

4.4.7 Morphological examination of the specimens................................. 102

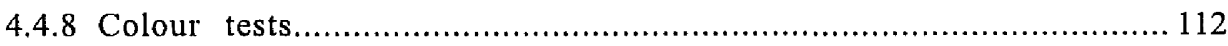

4.4.9 Problems encountered during lichen identification ......................... 113

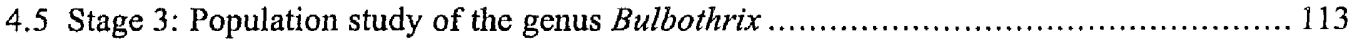




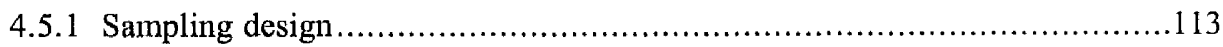

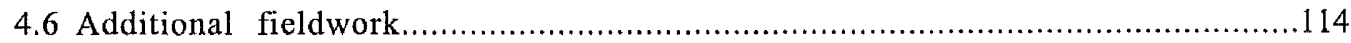

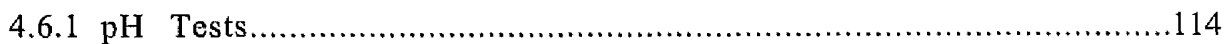

4.6.2 Measurements of fire behaviour......................................................115

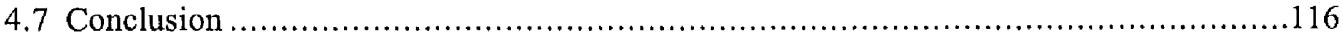

Chapter 5: Results I: Fire history and its relation to lichen abundance, distribution and

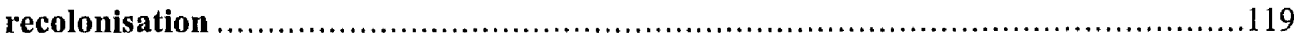

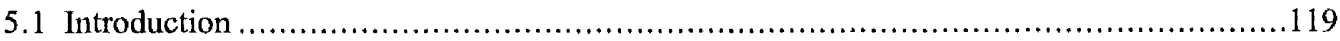

5.2 Fire history and lichen abundance, distribution and recolonisation..............................120

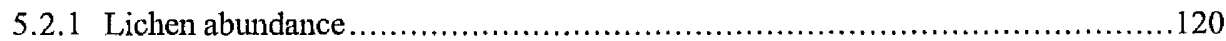

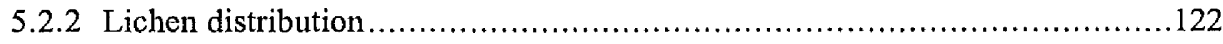

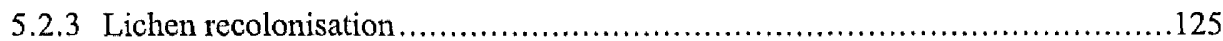

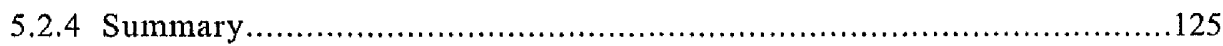

5.3 Phorophyte height and lichen abundance, distribution and recolonisation in plots

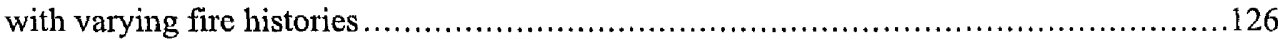

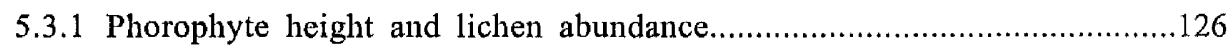

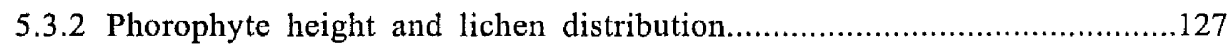

5.3.3 Phorophyte height and lichen recolonisation...........................................129

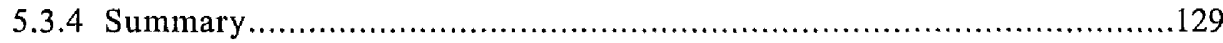

5.4 Phorophyte girth and lichen abundance, distribution and recolonisation in plots with

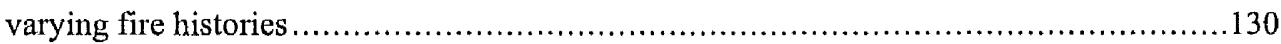

5.4.1 Phorophyte girth and lichen abundance...............................................130

5.4.2 Phorophyte girth and lichen distribution..............................................130

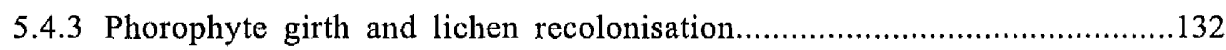

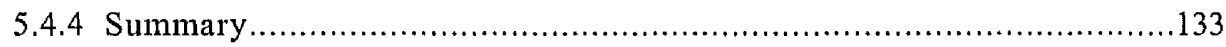

5.5 Phorophyte first branch height and lichen abundance, distribution and recolonisation

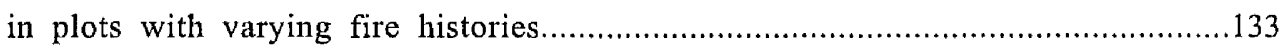

5.5.1 Phorophyte first branch height and lichen abundance...................................133

5.5.2 Phorophyte first branch height and lichen distribution.................................133

5.5.3 Phorophyte first branch height and lichen recolonisation..............................136

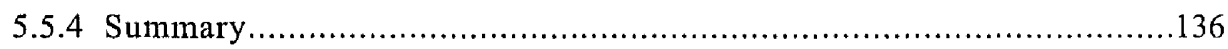

5.6 Phorophyte bark texture and lichen abundance, distribution and recolonisation in

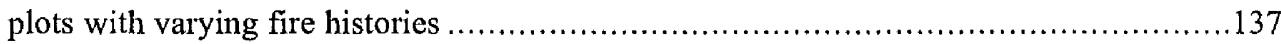

5.6.1 Phorophyte bark texture and lichen abundance …...............................137

5.6.2 Phorophyte bark texture and lichen distribution ....................................138

5.6.3 Phorophyte bark texture and lichen recolonisation ..............................139 


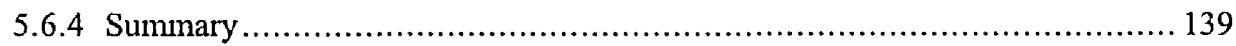

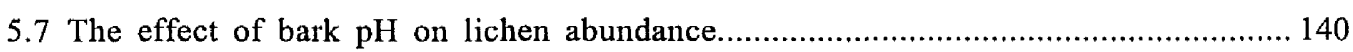

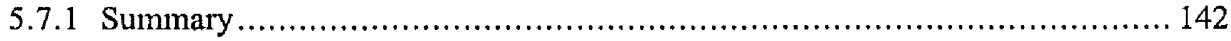

5.8 Scorch height and lichen abundance, distribution and recolonisation in plots with

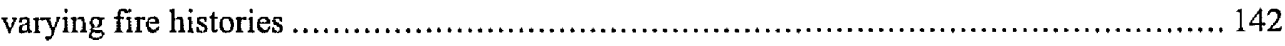

5.8.1 Scorch height and lichen abundance .......................................... 142

5.8.2 Scorch height and lichen distribution ........................................... 142

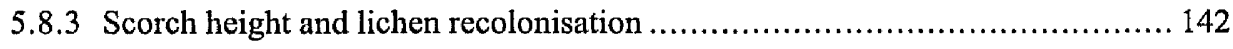

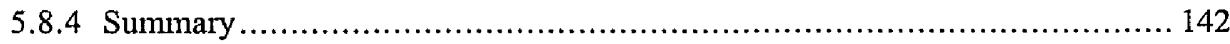

5.9 Phorophyte species and lichen abundance, distribution and recolonisation in plots

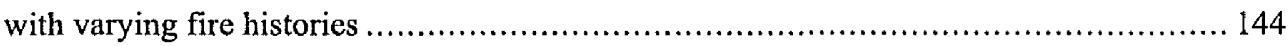

5.9.1 Phorophyte species and lichen abundance....................................... 144

5.9.2 Phorophyte species and lichen distribution.................................... 147

5.9.3 Phorophyte species and lichen recolonisation................................. 149

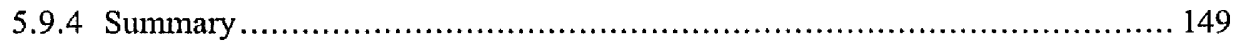

5.10 Choosing the phorophyte species for the Stage 2 data collection.............................. 149

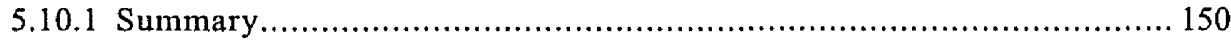

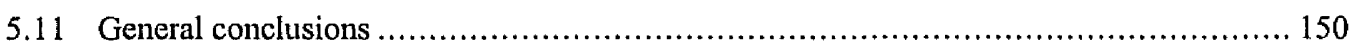

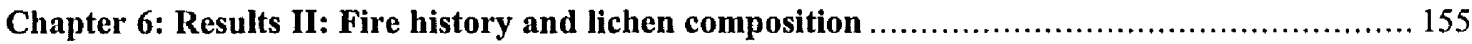

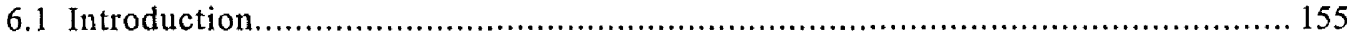

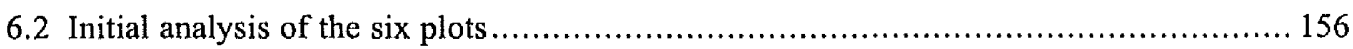

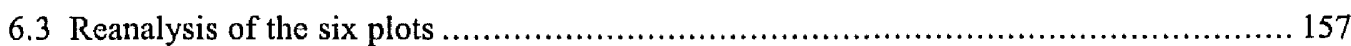

6.3.1 Analysis of Plot 1: factors controlling lichen species composition in the

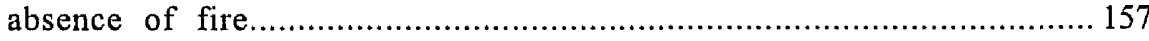

6.3.2 Analyses of Plots 1,2 and 6: fire frequency and behaviour as factors determining lichen species composition.

6.3.3 Analyses of Plots 3, 4 and 5: comparing the effects of early, middle and late season burns on lichen species composition

6.4 The variation in frequency of lichen species between plots with different fire histories 170

6.4.1 Frequency variations in lichen species between Plots 1, 2 and 6 170

6.4.2 Frequency variations in lichen species between Plots 3,4 and 5............... 173

6.5 General conclusions

Chapter 7: Results III: Lichen population dynamics and fire ecology 177

7.1 Introduction. 177 
7.2 The effect of fire history on Bulbothrix lichen populations

7.3 Lichen compositional, morphological and reproductive responses to various fire histories 182

7.3.1 Species richness 182

7.3 .2 Lichen families .......................................................... 182

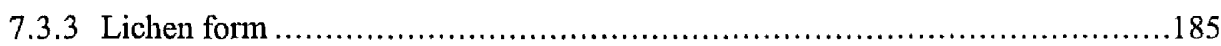

7.3.4 Lichen photobionts................................................... 187

7.3 .5 Lichen reproductive methods ........................................... 188

7.4 Fire patterns on phorophyte trunks .............................................. 191

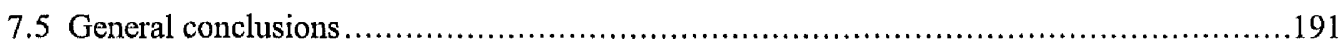

Chapter 8: Theoretical discussion, and development of the Lichen Fire History (LFH) Key.......195

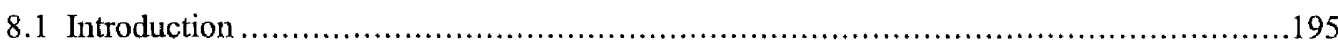

8.2 Towards a LFH Key using general characteristics of lichen abundance, distribution

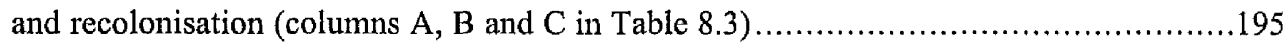

8.2.1 Absence of fire: the importance of other small-scale determinants...............195

8.2 .2 Summary ................................................................... 197

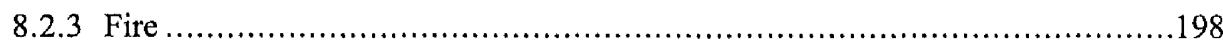

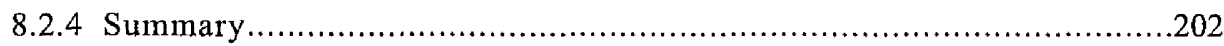

8.3 The LFH Key using lichen abundance, distribution and recolonisation ....................203

8.4 Towards a LFH Key using lichen indicator species (columns D, E and F in Table

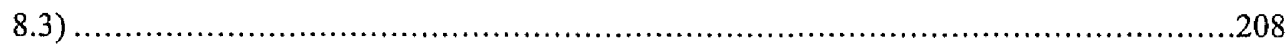

8.4.1 General characteristics of the lichen community in the absence of fire............209

8.4.2 Absence of fire and lichen species composition ...............................210

8.4.3 General characteristics of the lichen community in the presence of fire...........211

8.4.4 Presence of fire and lichen species composition....................................213

8.4 .5 Summary: lichen indicators of fire history ................................... 216

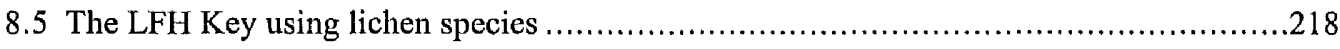

8.6 Towards a LFH Key using the lichen genus Bulbothrix (Table 8.4) ......................220

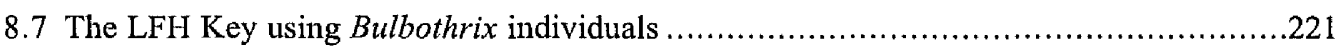

8.8 The Lichen Fire History (LFH) Key...................................................221

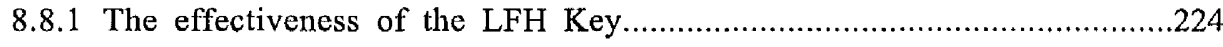

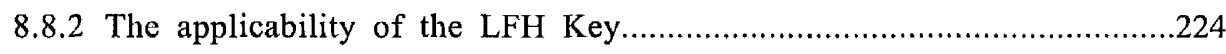

8.8.3 Suggestions for further research................................................225

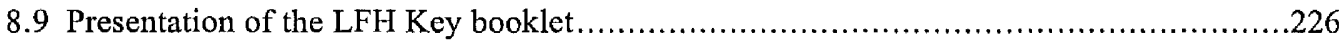

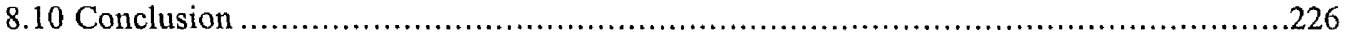


Glossary

Appendix 1: List of phorophyte species found in this study

Appendix 2: List of lichen species found in this study

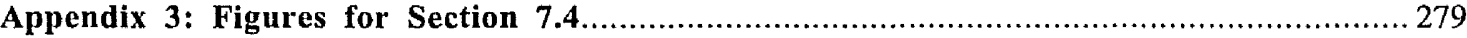

Appendix 4: The fire histories of the ten plots and their codes (in pocket).

285

Appendix 5: The Lichen Fire History (LFH) Key Booklet (in pocket)

286 


\section{List of Tables}

Table 3.1 The fire histories of the ten plots and their codes.

Table 5.1 The percentage frequency of phorophytes in each lichen distribution category within different height classes $(\mathrm{m})$ in an area protected from fire and in areas subjected to fire.

Table 5.2 The percentage frequency of phorophytes in each lichen distribution category within different girth classes (diameter in $\mathrm{cm}$ ) in an area protected from fire and in areas subjected to fire.

Table 5.3 The percentage frequency of phorophytes in each lichen distribution category within different phorophyte first branch height classes $(\mathrm{m})$ in an area protected from fire and in areas subjected to fire.

Table 5.4 The percentage frequency of phorophytes in each lichen distribution category within different bark texture categories in an area protected from fire and in areas subjected to fire

Table 5.5 The percentage frequency of phorophytes in each lichen distribution category within different scorch height classes ( $\mathrm{m}$ ) in areas subjected to fire.

Table 5.6 The Importance Value (IV) and Mean Lichen Abundance (MLA) for the phorophyte species in an area protected from fire and in areas subjected to fire, and the percentage frequency of individuals with lichen recolonisation $(R)$ in areas subjected to fire

Table 5.7 The percentage frequency of individuals within each lichen distribution category for phorophyte species with an Importance Value (IV) above 5 in an area protected from fire and in areas subjected to fire

Table 5.8 The Importance Value (IV), Mean Lichen Abundance (MLA) and Coefficient of Variation (CV) for the phorophyte species with an Importance Value over 10 in the ten plots.

Table 6.1 The average height $(\mathrm{m})$, girth (diameter in $\mathrm{cm}$ ) and first branch height $(\mathrm{m})$ of the five phorophyte species sampled within Plots 1 to 6 . .155

Table 6.2 The percentages of samples taken from each plot to form the TWINSPAN groups ...........164

Table 6.3 The percentages of samples taken from each plot to form the TWINSPAN groups ............169

Table 6.4 The frequency of each lichen species in Plots 1,2 and 6, the total number of occurrences and the Coefficient of Variation (CV).

Table 6.5 The frequency of each lichen species in Plots 3, 4 and 5, the total number of occurrences and the Coefficient of Variation (CV)

Table 8.1 The Mean Lichen Abundance (MLA), Spatial Index of Fire (SIF) and percentage recolonisation for determining the fire history of an area.

Table 8.2 The Fire Influence Index (FII), Fire Frequency Index (FFI) and Spatial Pattern of Fire Index (SPFI) values for Plots 1 to 6 of this study

Table 8.3 The LFH Key .223

Table 8.4 The LFH Key: the 'time-since-last-fire' index 


\section{List of Figures}

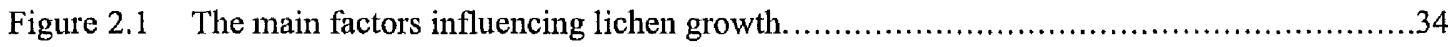

Figure 3.1 Tropical and subtropical savanna regions in South America (modified by the author

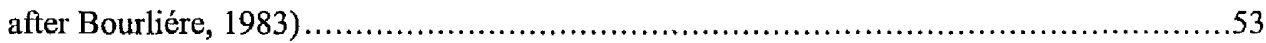

Figure 3.2 The basic structural gradient from campo limpo to cerradão

Figure 3.3 A hierarchy model of cerrado key determinants (modified by the author after Solbrig, 1991)

Figure 3.4 A backfire in cerrado denso vegetation at 2:40 pm in the Reserva Ecológica do IBGE, 24/8/94.

Figure 3.5 Map of the Distrito Federal, showing the locations of the Reserva Ecológica do IBGE and the Jardim Botânico de Brasilia (modified by author after Pereira et al., 1989) .71

Figure 3.6 Climate at the Reserva Ecológica do IBGE meteorological station from October 1993 to September 1994: a) the total monthly precipitation (mm) and the mean monthly relative humidity $(\%)$; b) the mean monthly air temperature $\left({ }^{\circ} \mathrm{C}\right) \ldots \ldots \ldots \ldots \ldots . \ldots 73$

Figure 3.7 Typical cerrado denso vegetation, Reserva Ecológica do IBGE, 30/7/94 ...................74

Figure 3.8 The Projecto Fogo and the ten study plots employed (modified after the Projecto

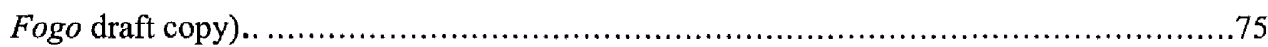

Figure 3.9a The percentage frequency of phorophytes with scorch in each plot .........................77

Figure 3.9b The percentage frequency of phorophytes within different scorch height classes (m

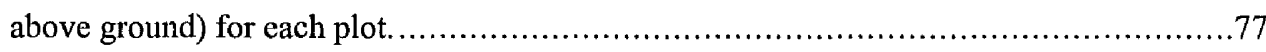

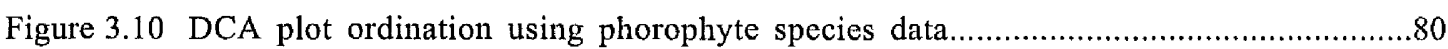

Figure 3.11 Dendrogram of TWINSPAN results showing the separation of plots according to

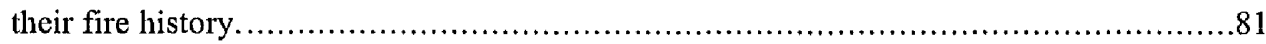

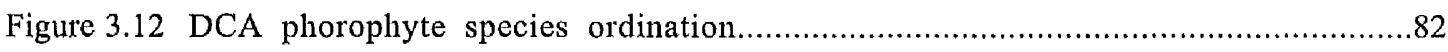

Figure 3.13 DCA phorophyte species ordination with TWINSPAN group (A-D) overlay...................83

Figure 3.14a The percentage frequency of phorophytes in different height classes $(\mathrm{m})$ for each plot.

Figure $3.14 \mathrm{~b}$ The percentage frequency of phorophytes in different girth classes (diameter in $\mathrm{cm}$ ) for each plot.

Figure 3.14c The percentage frequency of phorophytes in different first branch height classes (m)

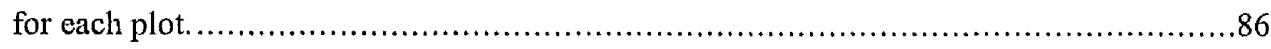

Figure $4.1 \quad$ General research scheme for this thesis. ...................................................... 91

Figure 4.2 The point-centred quarter method of plotless sampling......................................93 
Figure 4.3 Bark textures: a) smooth, Sclerolobium paniculatum; b) rough without marked crevices, Blepharocalyx salicifolius; c) rough with crevices, Dalbergia miscolobium; d) rough with deep crevices, Vochysia thyrsoidea. 96

Figure 4.4 The five selected phorophyte species (not to scale): a) Sclerolobium paniculatum;

b) Blepharocalyx salicifolius; c) Caryocar brasiliense; d) Guapira noxia;

e) Vellozia squamata. 100

Figure 4.5 Thallus forms: a) crustose, Haematomma puniceum (x10); b) squamulose, Cladonia ochroclora (x5); c) foliose, Parmotrema mellissii (x5); and d) fruticose, Usnea sp. 'A' (x5).

Figure 4.6 Cilia: a) simple, Parmotrema mellissii ( $\mathrm{x} 30$ ); and b) bulbate, Bulbothrix coronata (x30) 105

Figure 4.7 A hypothallus, Buellia myriocarpa (x5). 105

Figure 4.8 Rhizines (not to scale): a) simple; b) dichotomous branched; and c) squarrose branching

Figure 4.9 A holdfast, Usnea sp. 'A' (x15)

Figure 4.10 Vegetative structures: a) soredia, Hypotrachyna sp. ' $\mathrm{C}$ ' (x30); b) isidia, Parmotrema tinctorum $(\mathrm{x} 40)$.

Figure 4.11 Positions of vegetative structures on thallus (not to scale): a) laminal; b) terminal; and c) marginal

Figure 4.12 Sexual reproductive fruiting bodies: a) rounded apothecia, Canoparmelia caroliniana (x20); b) lirellae, Graphina sp. (x40); and c) perithecia, Porina sp. (x30). 110

Figure 4.13 The internal structure of a rounded fruiting body (not to scale) 111

Figure 4.14 Spore types (not to scale): a) simple; b) transversely septate; and c) muriform 112

Figure 5.1 The percentage frequency of phorophytes within each lichen abundance category for the ten plots.

Figure 5.2 A table of Czekanowski similarity coefficients for the ten plots based on the lichen abundance categories.

Figure 5.3 The percentage frequency of each lichen distribution category within the ten plots. 122

Figure 5.4a The percentage frequency of phorophytes with lichens on specific parts of the phorophyte within the 'partially restricted lichen distribution' category for the ten plots.

Figure 5.4b The percentage frequency of phorophytes with lichens on specific parts of the phorophyte within the 'restricted lichen distribution' category for the ten plots.

Figure 5.5 The percentage frequency of phorophytes with lichen recolonisation in the ten plots.. 125

Figure 5.6 The Mean Lichen Abundance on phorophytes within different height classes (m) in an area protected from fire 
Figure 5.7 The Mean Lichen Abundance on phorophytes within different height classes (m) in areas subjected to fire.

Figure 5.8 The mean percentage frequency of phorophytes with lichen recolonisation within different height classes $(\mathrm{m})$ in areas subjected to fure.

Figure 5.9 The Mean Lichen Abundance on phorophytes within different girth classes (diameter in $\mathrm{cm}$ ) in an area protected from fire.

Figure 5.10 The Mean Lichen Abundance on phorophytes within different girth classes (diameter in $\mathrm{cm}$ ) in areas subjected to fire.

Figure 5.11 The mean percentage frequency of phorophytes with lichen recolonisation within different girth classes (diameter in $\mathrm{cm}$ ) in areas subjected to fire.

Figure 5.12 The Mean Lichen Abundance on phorophytes within different first branch height classes $(m)$ in an area protected from fire.

Figure 5.13 The Mean Lichen Abundance on phorophytes within different first branch height classes $(\mathrm{m})$ in areas subjected to fire.

Figure 5.14 The mean percentage frequency of phorophytes with lichen recolonisation within different first branch height classes $(\mathrm{m})$ in areas subjected to fire.

Figure 5.15 The Mean Lichen Abundance on phorophytes for each bark texture category in an area protected from fire.

Figure 5.16 The Mean Lichen Abundance on phorophytes for each bark texture category in areas subjected to fire.

Figure 5.17 The mean percentage frequency of phorophytes with lichen recolonisation within different bark texture categories in areas subjected to fire

Figure 5.18 The mean $\mathrm{pH}$ for ten phorophyte species.

Figure 5.19 The Mean Lichen Abundance on phorophytes within different scorch height classes (m) in areas subjected to fire.

Figure 5.20 The mean percentage frequency of phorophytes with lichen recolonisation within different scorch height classes $(\mathrm{m})$ in areas subjected to fire.

Figure 6.1 DCA sample ordination of Plots 1 to 6 using lichen species data.........................156

Figure 6.2 DCA sample ordination of Plot 1 using lichen species data...................................157

Figure 6.3 DCA lichen species ordination of Plot 1

Figure 6.4 DCA sample ordination of Plot 1 overlaid by the groups (A-D) identified by the TWINSPAN classification.

Figure 6.5 DCA lichen species ordination of Plot 1 overlaid by the groups (1-5) identified by the TWINSPAN classification.

Figure 6.6 Dendrogram representing the major divisions of a TWINSPAN classification of the samples from Plot 1.

Figure 6.7 DCA sample ordination of Plots 1,2 and 6 using lichen species data.... 161 
Figure 6.8 DCA lichen species ordination of Plots 1, 2 and 6.

Figure 6.9 DCA sample ordination of Plots 1, 2 and 6 overlaid by the groups (A-E) identified by the TWINSPAN classification.

Figure 6.10 DCA lichen species ordination of Plots 1,2 and 6 overlaid by the groups (1-5)

identified by the TWINSPAN classification.

Figure 6.11 Dendrogram representing the major divisions of a TWINSPAN classification of the samples from Plots 1,2 and 6. 165

Figure 6.12 DCA sample ordination of Plot 3, 4 and 5 using lichen species data. .................. 166

Figure 6.13 DCA lichen species ordination of Plots 3,4 and 5.

Figure 6.14 DCA sample ordination of Plots 3, 4 and 5 overlaid by the groups (A-D) identified by the TWINSPAN classification. 168

Figure 6.15 DCA lichen species ordination of Plots 3, 4 and 5 overlaid by the groups (1-4) identified by the TWINSPAN classification.

Figure 6.16 Dendrogram representing the major divisions of a TWINSPAN classification of the samples from Plots 3, 4 and 5 . 169

Figure 7.1 The mean percentage frequency of Bulbothrix individuals in Plots 1, 2 and 6. 178

Figure 7.2 The percentage frequency of Bulbothrix individuals in different thallus size classes 179

Figure 7.3 The percentage frequency of Bulbothrix individuals within different height classes on the phorophytes.

Figure 7.4a The percentage frequency of different Bulbothrix thallus sizes in Plots 1, 2 and 6 between the base and $0.5 \mathrm{~m}$ on the phorophyte.

Figure 7.4b The percentage frequency of different Bulbothrix thallus sizes in Plots 1, 2 and 6 between $>0.5 \mathrm{~m}$ and $1 \mathrm{~m}$ on the phorophyte

Figure 7.4c The percentage frequency of different Bulbothrix thallus sizes in Plots 1, 2 and 6 between $>1$ and $1.5 \mathrm{~m}$ on the phorophyte.

Figure 7.4d The percentage frequency of different Bulbothrix thallus sizes in Plots 1, 2 and 6 between $>1.5$ and $2 \mathrm{~m}$ on the phorophyte.

Figure 7.5 The total number of lichen species in each plot. 183

Figure 7.6 The total number of lichen individuals in each plot...................................... 183

Figure 7.7a The percentage representation of species by lichen family in each plot ................... 184

Figure $7.7 \mathrm{~b}$ The percentage representation of individuals by lichen family in each plot................... 184

Figure 7.8 The percentage representation of species in relation to lichen form in each plot............. 186

Figure 7.9 The percentage representation of individuals in relation to lichen form in each plot........ 186

Figure 7.10 The percentage representation of lichen species in relation to algal photobiont in each plot.

Figure 7.11 The percentage representation of lichen individuals in relation to algal photobiont in each plot. 
Figure 7.12 The percentage representation of lichen species in relation to reproductive method in each plot....

Figure 7.13 The percentage representation of lichen individuals in relation to reproductive method in each plot.

Figure 7.14 The percentage representation of lichen species in relation to vegetative structure in each plot.

Figure 7.15 The percentage representation of lichen individuals in relation to vegetative structure in each plot.

Figure 8.1 Lichens in cerrado denso: a) and b) rich lichen communities common in undisturbed areas; $c$ ) heterogeneous fires cause lichens to be destroyed on one side of the phorophyte, leaving healthy individuals on the other; d) lichen recolonisers after fire.

Figure 8.2 The Mean Lichen Abundance (MLA) and Spatial Index of Fire (SIF) for the ten plots.

Figure 8.3 The Mean Lichen Abundance (MLA) divided by the Spatial Index of Fire (SIF), plotted against percentage recolonisation for the ten plots .205 


\section{Chapter 1 \\ Fire history in savannas: a problem of measurement}

\subsection{The concept of fire history}

Although reliable evidence on the role of fire during the past several hundred millions of years is scarce, wildfires were probably common ever since the build-up of plant biomass some 350 to 400 million years ago (Schüle, 1990). It has been demonstrated that natural fires have affected and shaped many terrestrial ecosystems since the late Quaternary, and in some vegetation formations, such as the boreal forest regions, they are still an important force (Goldammer and Crutzen, 1993). However, with the first appearance of hominids in African savannas between 1.5 to 2 million years B.P. (Barbetti, 1986; Brain and Sillen, 1988), there began a world-wide shift from a natural to an anthropogenic fire regime. In most regions of the world today, anthropogenic fires are dominant. Human-caused fires influence the formation and maintenance of various vegetation types, including the Australian eucalypt forests, the seasonal tropical forests, and the majority of tropical savannas (Goldammer and Crutzen, 1993).

Depending on whether there has been a single fire event, or successive burns, and on the nature of the fires, the characteristics of fire frequency and behaviour of past fires can be described as the 'fire history' ${ }^{1}$ of an area. Fire behaviour can be measured in terms of characteristics such as flame temperatures and the rate of fire spread. However, in this study, more basic fire behaviour variables are used to describe the fire history. These are the homogeneity of the fire i.e. the evenness of the burn, and the flame heights of the fire i.e. low, various or high.

The importance of determining the fire history of an area lies in the management of the vegetation. It is vital to know what role fire has played in an area of vegetation in order to apply correct and effective burning regimes. For example, van Wilgen et al. (1990) point out that the fire management aims in many national parks and areas of conservation are to maintain the biodiversity of the ecosystems, the scientific value for researchers, and scenic features for tourism. In areas where fire is recognised to be important for the vegetation e.g. savanna regions, attempts are made to recreate 'traditional' or 'natural' fire regimes. However, information on the fire history of the area is often not available or is limited, and consequently fire prescriptions are based on research done elsewhere, as in many South African national parks (van Wilgen et al., 1990). If the fire history of these areas were known, comparisons with the present day status of the vegetation would unravel the importance of fire as a determinant of the vegetation, and reveal to what extent fire has influenced the vegetation. Accordingly, this would allow decisions to be made on how to use fire, whether for maintaining or changing the vegetation, depending on the needs of the manager. In terms of present day management, the significance of recent fire history is thus especially important. For example, if a manager needs to

\footnotetext{
1 Terms appearing in bold are defined in the Glossary (p.267).
} 
burn an area, it is vital to know the fire history of the last ten to twenty years, and information regarding even older fires may be significant where available. In the present study, 'past fires' refers to up to twenty years ago, and so 'fire history' is defined as 'the combination of fire frequency and fire behaviour of recent past fires in an area of vegetation'.

Today, anthropogenic fires are becoming an increasingly important phenomenon in many vegetation formations, but particularly in savanna regions, which cover about $40 \%$ of the tropics (Solbrig, 1991), or nearly a third of the world's land surface (Werner et al., 1990). With over one fifth of the world's population living in or around savanna areas (Frost et al., 1986), land managers and scientists have come to recognise the urgency for research into fire management practices which are sustainable and compatible with the increasingly intense use of savannas by the expanding human population (Solbrig, 1991). Most of these savanna fires are related to agricultural practices, such as improving pastoralism (e.g. Batchelder, 1968; Coutinho, 1990), and in many areas, past fire regimes are uncharted, resulting in inappropriate and damaging prescribed fires being applied. These may result in the destruction of vegetation, the disappearance of soil fertility, and ultimately make the land unproductive, which may be a considerable loss, not only for humans, but also for other species. It is therefore fundamental to develop techniques for establishing fire history within savanna areas.

\subsection{Techniques for detecting fire history}

\subsubsection{Dendrochronology}

Tree growth is affected by variations in the external environment, with favourable conditions resulting in rapid growth. In seasonal environments, the rate of tree growth is reflected in the width of tree rings, whose study, dendrochronology, allows us to investigate past environmental conditions (Fritts, 1976). Dendrochronology involves taking cores from a number of trees and wood fragments in a given area, and matching their ring patterns. Referred to as crossdating, this procedure is necessary in order to identify special cases where rings may be absent, or where two or more apparent rings have been formed during one year. This is most common in the tropics, where many woody species can produce several growth layers, which often vary from tree to tree, and even between opposite sides of one tree (Alvim, 1964). However, some tropical trees do produce distinct annual rings, but, as yet, limited research has been carried out in this field (Fritts, 1976).

In cases where dendrochronology can be applied, variations in tree-ring widths can be used to reconstruct the occurrence of past disturbance in forests, as well as climatic impacts on tree growth (Abrams et al., 1995). For example, where fire has killed part of the cambium, a scar appears on the tree ring, which can then be dated (Fritts, 1976). Based upon the position of the scar within the annual ring, it is also possible to determine which time during the year the fire took place (Brown and Swetnam, 1994). The immediate effects after a fire include the reduction of competition in a stand of trees, the removal of shade, and the release of minerals, so that the rings of some trees become wider 
due to increased growth (Abrams and Nowacki, 1992; Lorimer and Frelich, 1989; Orwig and Abrams, 1994). Together with data on age distribution classes of trees, fire scars have been used to construct chronologies of fire frequencies, and to determine how fire frequency has varied in time (Agee, 1991; Cutter and Guyette, 1994; Dansereau and Bergeron, 1993; Mann et al., 1994; Wills and Stuart, 1994).

To determine the fire history of a site, data from tree rings are used to construct a 'stand origin map' (Heinselman, 1973). This map is the result of a complex pattern of overlapping past burns, and is first outlined using aerial photographs to identify major boundaries (Johnson, 1992). Next, various areas are sampled in the field and assigned dates according to data from fire scars. Information derived from the 'stand origin map' is then applied to models based on tree survivorship and age distributions (van Wagner, 1978). These models can give estimates of a number of fire history variables, including 'time-since-last-fire' and the fire frequency (Johnson and van Wagner, 1985).

The use of fire scars to date past fires is probably the most accurate method for evaluating fire history in temperate regions (Fritts, 1976). In the tropics, however, dating events with tree rings is much more difficult and prone to errors due to the common development of several growth rings during a single year. Also, the mosaic nature of fires means that some trees will have escaped certain fires. Therefore, in order to determine the fire history of a large area, a substantial number of trees would need to be sampled, so that accurate crossdating could take place. In conclusion, not only is this method time consuming, it is also unreliable in the tropics.

\subsubsection{Charcoal analysis}

Analysis of charcoal remnants from lake and swamp deposits have been widely used in temperate regions to reconstruct the fire history of an area (Clark, 1988, 1990; Clark and Royall, 1994). So far, work involving charcoal analysis in tropical areas has been limited to investigating paleoenvironments rather than more recent fire histories (Dcosta and Kershaw, 1995; Heusser, 1994; Hope and Tulip, 1994; Hopkins et al., 1993; Horn and Sanford, 1992; Vernet et al., 1994).

One limitation of charcoal analysis is the problem of finding suitable areas of sedimentation. These areas are infrequent in many vegetation types, and, if found, it may not be possible to discern any stratification within the sediment if local disturbance has taken place e.g. the occurrence of strong currents within a lake. It is also extremely difficult to determine the origin of charcoal particles within sediments. In open areas, charcoal may have been transported to the sediment from a great distance, through the action of wind or in streams, whereas in a closed area, the charcoal may have been deposited from only a few metres away. It is therefore only possible to tell with any certainty the fire frequency of an area that has contributed to the sediment. Information regarding the extent of the fire and its behaviour is highly questionable. Charcoal analysis also requires detailed examination of the sediment, a procedure which involves extraction equipment, carried out within a laboratory. This renders the method time consuming and costly, and with the limited information 
obtained, charcoal analysis is probably the least useful technique for determining the fire history of an area.

\subsubsection{Remote sensing}

Satellite remote sensing can provide important information on a range of fire variables including fire frequency and behaviour. Various satellite systems are able to map successive active fires, as well as burn scars, and discern the fire intensity through interpretation of the spectral reflectance from the resulting ash layer (Justice et al., 1993). This information has enabled the construction of recent fire histories within some areas of vegetation (Chuvieco and Congalton, 1988; Minich, 1983). Different levels of information are available depending on the resolution of the satellites, which can be up to $10 \times 10 \mathrm{~m}$ (Malingreau, 1990), thereby allowing fire monitoring to take place at both a large- and sinall-scale.

Although satellite images have been available since the 1960s, tropical remote sensing is still in its infancy (Malingreau, 1990). There are a wide range of satellite systems in use at present, but many do not have the resolution sufficient for constructing fire histories for small areas of vegetation. More importantly, remote sensing involves computer-based technology, which is not only expensive, but also requires considerable training. Still, as data analysis programs become more user friendly, and the satellite images cheaper and of greater accuracy, remote sensing will probably become one of the most important tools for determining an area's fire history.

\subsubsection{Historical records}

The use of historical records has been a tool for identifying the fire history in areas of vegetation. In some cases, past research detailing the ecology and vegetation of a specific area has proved useful for gathering information about the frequency and behaviour of past fires. For example, Warming (1892) described the savanna vegetation around Lagoa Santa in the state of Minas Gerais, Brazil and outlined the nature of fire in this area. Another more recent example is Goodland and Ferri's (1979) account of the Triângulo Mineiro area in the west of Minais Gerais. The problem with these types of historical records is that they are focused on a certain number of years, and in some instances, relate to the last century. As a result, they do not give a record of continuous fire history over a long period of time, or to the present day.

Other potential sources of historical fire records include government departments, official reserves and non-governmental organisations. For instance, records obtained from the Department of Environmental Affairs in South Africa have documented the history of fires caused by hot, dessicating winds (termed 'bergwinds') in the southern Cape since the last century (Geldenhuys, 1994). Snyder (1991) was able to construct the fire history of the Everglades National Park in Florida using a data set of fire records from the park, which goes back to 1948. Although these kinds of records may be comprehensive and reliable, some are restricted to the public, and where they are 
available for general use, access to them may involve long, and sometimes unsuccessful, beauracratic procedures. This is particularly true in many tropical countries, such as Brazil, where the beauracracy of the government system, and the unwillingness of researchers and officials to part with historical records, especially to foreigners, means that records are very difficult to obtain (Carlos Klink, pers. comm. 22/5/94).

\subsubsection{Oral history}

In many indigenous cultures, the traditional method for determining the fire history of an area has been through 'word of mouth'. For example, the Aborigines living in the eucalypt savanna forests of northern Australia pass on their fire history knowledge to members of their groups, and from one generation to another, through oral means (Haynes, 1984, 1991; Lewis, 1989; Roberts, 1995). This information regarding fire frequency and behaviour in different areas of vegetation ensures sustainable and effective fire management practices at all times.

However, with the arrival of Europeans into many of these indigenous cultures, much traditional knowledge has been lost (Braithwaite, 1991). This means that though information about the fire history of certain areas may have been preserved, this evidence is no longer reliable. For example, in Brazil, the numbers of Kayapó Indians living in the savannas have been greatly reduced since the arrival of the Portuguese. Many of these Indians live on reservations set up in order to protect their land, and with the topic of indigenous peoples being highly sensitive for the government, permission to interview the Indians is nearly impossible to obtain (Carlos Klink, pers. comm. 22/5/94).

Also, in many cases, scientific ideas may come into conflict with traditional views. For example, Kanjanavanit (1992) noted the annual incidence of a lightning-caused fire in West Thailand after interviewing villagers living within or along the forest where the fires were observed to occur. Many members of the Thai Forest Fire Control Unit, however, entirely reject the possibility of such fires caused by lightning strikes in Thailand, on the assumption that there are no dry thunderstorms. These contrasting beliefs may confuse accounts of the fire history of an area, thereby rendering the method of oral history unreliable.

\subsection{The aim of this thesis: lichens as potential bioindicators of fire history}

The majority of fires which take place in the savanna regions of the world are within cultures where information systems and computer technology are not part of everyday life. In these places, methods for detecting fire history, such as dendrochronology, charcoal analysis and remote sensing, remain impractical. Also, in many of these savanna areas, it may be extremely difficult to get access to historical fire records, or to find people who have traditional knowledge about fire history. The use of lichen bioindicators may offer an easy, efficient and economic alternative. Bioindicators are organisms which respond to environmental change, and thereby can provide information on both the change and the extent of change (Kovács, 1992). They have to occur in abundance, react rapidly to 
environmental change, and each species must have a differential sensitivity to the environmental change, thereby providing a unique assemblage of species in any one environmental scenario. Many organisms, such as higher plants, bryophytes and algae, as well as insects and amphibians have been employed as bioindicators, but lichens are particularly good since they fulfil all the above criteria and occur in almost every ecosystem of the world.

So far, studies have demonstrated the effects of fire on lichens (Ahti, 1977; Brodo, 1968), but relatively little research has dealt with the subject of lichens as indicators of fire history. Nevertheless, recent work in North America (Wetmore, 1983) and Thailand (Wolseley and AguirreHudson, 1991, 1996a,b) has shown that epiphytic lichen species respond to different fire regimes, allowing the identification of indicator species. Phorophyte bark surfaces can support an abundant and wide range of lichen species adapted to specific niches (corticolous lichens), and are therefore most likely to show specific sensitivities to variations in fire histories. If corticolous lichens can provide an indication of various fire histories, they may be a quick, cost-effective and accessible substitute to dendrochronology, charcoal analysis, remote sensing, historical records and oral history.

The aim of this study is to investigate the potential use of lichens as bioindicators of fire history. The cerrado of Brazil is an ideal savanna formation for this study, since not only is fire an integral part of the ecology of the ecosystem (Coutinho, 1990), but also the cerrado has the richest woody flora of all the world's savannas (Eiten, 1994). This suggests the establishment of an abundant corticolous lichen flora, from which bioindicators may be identified. Scales to monitor changes in air pollution and woodland management have been constructed using lichen indicators (Hawksworth and Rose, 1970; Rose, 1994). A similar idea is considered in this study, where it is hoped that a Lichen Fire History (LFH) Key can be developed for detecting different fire histories in areas of cerrado. This study is wholly exploratory, with the aim to generate hypotheses regarding lichen bioindicators and fire history, which can later be tested with long-term monitoring studies.

\subsection{Thesis structure}

The thesis begins with an introduction to lichen ecology, an outline of the specific characteristics of lichens which make them ideal bioindicators, and a review of the areas in which they have been applied as bioindicators (Chapter 2). This is followed by a discussion of cerrado ecology, pointing out the main determinants of the cerrado formation and the role of fire within this savanna ecosystem (Chapter 3). This chapter ends with a description of the study site, in terms of its woody flora and fire history. Chapter 4 describes the field methods employed, and Chapters 5, 6 and 7 present the results, in which conclusions are proposed. These conclusions, together with the development of the LFH Key, are discussed in the final chapter (Chapter 8), which ends with the presentation and critical examination of the LFH Key. 


\section{Chapter 2 \\ The ecology of lichens and their role as bioindicators}

\subsection{Introduction}

Lichens have been employed as biological indicators for a wide range of purposes, from detecting changes in levels of atmospheric pollutants to monitoring disturbance in forest ecosystems (Galloway, 1993). However, before these uses of lichens as bioindicators can be described, it is important to understand what a lichen is, and how it functions within the environment.

The first part of this chapter begins with a brief definition of a 'lichen', and a summary of the main lichen characteristics. This is followed by a description of the role of lichens in the process of succession, and how lichens employ various life strategies to build dynamic and competitive communities within their specific environments. The section on lichen ecology ends with a discussion of the environmental factors which influence lichen growth, focusing on physiological and morphological adaptations that enable lichens to be sensitive to changes in their environment.

The second part defines a 'bioindicator', and lists the specific features of lichens which make them ideal as indicators. Finally, examples of the uses of lichens as bioindicators are given, ending with an explanation as to why lichens are likely to prove appropriate indicator organisms for the present study.

\subsection{The lichen symbiosis}

A lichen is a symbiotic association of a fungus (mycobiont) and a photosynthetic partner (photobiont), which may be an alga or a cyanobacterium. Together, the mycobiont and the photobiont contribute to the production of a thallus, or body (Ahmadjian, 1993). Lichenised genera of fungi are found in two groups, Ascomycetes and Basidiomycetes (Hale, 1983). However, in contrast to the thousands of species of lichenised Ascomycetes, there are only ten to twenty species of lichenised Basidiomycetes. About twenty-five genera of lichenised photobionts have been identified, belonging to two classes of algae: the Chlorophyta (green algae) and the cyanobacteria (blue-green algae) (Ahmadjian, 1993). The most common photobionts are the unicellular green algae Trebouxia and the filamentous green algae Trentepohlia (Gärtner, 1992; Poelt, 1973), the latter occurring more frequently in the tropics. Within the cyanobacteria, common photobionts include Nostoc, Scytonema and Stigonema (Büdel, 1992).

There are three major types of lichen thalli: crustose, which closely adheres to the substrate and lacks a lower cortex; foliose, which is leaf-like, attached loosely to the substrate and has both an upper and lower cortex; and fruticose, which may have pendulous strands or hollow, upright stalks, and can resemble a miniature shrub (Hale, 1983). The thallus is composed of a cortex and medulla, both made of fungal tissue, and a photobiont layer, where the algal or cyanobacterial cells are 
enveloped by fungal hyphae (Hale, 1983). This photobiont layer, about $7 \%$ of the total thallus volume (Collins and Farrar, 1978), is sandwiched between the upper cortex and the medulla, so as to obtain the maximum amount of sunlight for photosynthesis. The outer cortex protects the photobiont cells from drying and excessive light, while the inner medulla has a large water-holding capacity and promotes gas exchange (Ahmadjian, 1993).

Lichens occur in virtually every ecosystem, from tidal zones on rocky shores to mountain summits, and within the extreme conditions of hot deserts and tropical forests to the freezing temperatures of the Arctic and Antarctic (Hale, 1983; Kappen, 1973). They are the dominant vegetation on about $8 \%$ of the earth's terrestrial surface (Larson, 1987), such as the tundra, mire, grassland and coastal desert environments (Longton, 1992). Lichens grow on many substrates, including rocks (saxicolous), soil (terricolous), bark (corticolous), wood (lignicolous), bryophytes (muscicolous) and leaves (foliicolous) (Brodo, 1974).

The remarkable success of lichens is the result of unique survival strategies. When water is available, from rain or dew, lichens become metabolically active within a few minutes, although it may take longer for photosynthesis to reach optimal levels (Kershaw, 1985). Under sunny conditions, they quickly dry out, and as their water content drops, first photosynthesis, and then respiration stops, after which they can remain dormant for an unlimited amount of time until remoistened. Lichens have also evolved efficient mechanisms for nutrient uptake from their environment. They can adsorb metal ions such as calcium ${ }^{2+}$ via an ion exchange mechanism, and trap tiny particles of rock, soil or pollutants within their structure which are then broken down, releasing nutrients for uptake (Richardson, 1992). Cyanobacteria, present in about $10 \%$ of all lichen species, are able to fix nitrogen from the air, and a substantial amount of this supplements the fungal partner, in addition to the small quantity found in rain water (Ahmadjian, 1993).

Reproduction in lichens can be both sexual and asexual. Most lichens belong to the fungal group Ascomycetes. They reproduce by ejecting spores from sacs within fruiting bodies that form on the cortex of the lichen thallus. If these spores land on a suitable substrate, they germinate, and entrap algae or cyanobacteria. If these photobionts are compatible with the fungus, a lichen resynthesis will occur, and a thallus will begin to grow. Many spores will not find the correct substrate for germination, or if germination does take place, a compatible photobiont may not be available. Therefore, many lichens have evolved vegetative propagation in which both partners are distributed together from the parent plant. This can take place through small pieces of thallus being broken off, but more commonly through vegetative propagules that form on the thallus surface. These include soredia, small, light-weight granules distributed by wind or rain, and the larger, heavier isidia, fragile fingerlike protuberances that are easily detached and dispersed. These vegetative means of reproduction are particularly important in invasive situations, allowing lichens to colonise and establish quickly.

Rogers (1990) studied the reproductive adaptations of 34 lichen species, and found a range of life strategies, including: stress-tolerant or ruderal species, producing smaller propagules 
(soredia and spores), such as the epilithic crustose Rhizocarpon obscurata (Rogers, 1990); ephemeral colonists e.g. Aspicilia excavata, which reproduces only by soredia (Poelt and Vezda, 1990); perennial competitive species, which occur in more permanent habitats, producing small spores e.g. Cladoniaceae and Lobariaceae (Rogers, 1990); short-lived shuttle species found in seasonally suitable microsites within a community, producing small spores, and dispersed in small clumps over short distances e.g. Aphanopsis coenosa (Poelt and Vezda, 1990; Sipman, 1983); and long-lived shuttle species, found in long-lasting microsites, producing very large spores, and frequent quantities of soredia and isidia e.g. Pertusaria and Ochrolechia species (Rogers, 1990; Sipman, 1983).

\subsubsection{Lichen succession}

Lichens are commonly the primary colonisers on rock surfaces, and the pioneer organisms in a series of communities in vegetation succession (Longton, 1992). Lichen establishment on rocks is brought about through adaptations such as tolerance to desiccation and extreme temperatures, and low growth rates in accord with the slow release of mineral nutrients from the substratum (Topham, 1977). Generally, crustose lichens are the first colonisers, followed by foliose and later fruticose lichens, though this pattern can vary depending on moisture, rock type and other factors specific to the climatic region (Hale, 1983).

Once they are established, lichens promote soil formation by trapping wind-blown organic and inorganic material, by contributing to undecomposed organic matter and by accelerating physical and chemical weathering (Longton, 1992). Physical weathering comes about through the expansion and contraction of endolithic crustose lichens, as their water content varies, and by rhizine penetration into rocks by foliose species (Ascaso, 1985; Viles, 1987). Chemical weathering occurs when lichens release oxalic acid, carbonic acid and other secondary metabolites, which crystallise on the outer surface of hyphae, directly in contact with the rock (Friedmann, 1982). However, it is unclear at what scale lichen-associated weathering occurs, and some authors have suggested that lichens may inhibit weathering by protecting surfaces from erosion (Lindsay, 1978).

Lichens are prominent in succession following the destruction of established vegetation i.e. secondary succession (Longton, 1992). Ahti (1977) recorded the following sequence after recurrent lightning-induced fires in boreal forests:

1. bare soil for 1 to 3 years after fire;

2. crustose lichen stage, 3 to 10 years after fire;

3. cup lichen stage e.g. Cladonia crispata, 10 to 50 years after fire;

4. larger cup lichens e.g. Cladina rangiferina, 30 to 120 years after fire.

Lichens have been shown to modify environmental conditions following a fire. Before colonisation, wide diurnal temperature fluctuations are common at the ground level, whereas after lichen invasion, net radiation on the ground surface is reduced, and by retaining moisture in the thallus, absorbed energy is increasingly dissipated as heat (Longton, 1992). This leads to a decrease in surface temperatures, 
allowing a larger range of lichen species to establish. Once the canopy begins to close, some of these lichens are also lost, primarily due to light restriction inhibiting photosynthesis (Kershaw, 1985).

On many trees, including saplings, lichen invasion occurs at the internodes of terminal branches, where bark texture is rougher, giving purchase to propagules and protection to developing lichens. These first colonisers on twigs are commonly endophloedal species, such as of the crustose family Pyrenocarpaceae. As the bark substrate ages, other crustose and foliose species, with a preference for the conditions on smaller branches, such as high light levels, invade, with fruticose lichens usually colonising the middle-aged branches. The trunk is the oldest part of the phorophyte, and normally holds a community of crustose and foliose lichens, indicators of old age e.g. the Lobarion community of Fagaceous forests (James et al., 1977; Wolseley, 1991; Wolseley and O'Dare, 1990).

Together with the succession of lichens as bark age increases, is the process of lichen succession with changes in phorophyte structure. Young phorophytes may have increased levels of light, and high temperatures on their bark surfaces, due to the lack of canopy cover, thereby influencing the lichen species present. However, as the canopy begins to close, lower parts of the trunk and branches may become shaded, leading to a change in microhabitat along the trunk. In parallel, lichens distribute themselves along the trunk according to their particular environmental needs, whether they be light, water or temperature (Hale, 1952; Harris, 1971; Rose, 1974). For example, in temperate areas, the tree base is usually inhabited by shade-loving species of Cladonia, Leptogium and Peltigera, whereas the canopy is rich in more xeric lichens such as Parmelia and Ramalina (Hale, 1983). In the tropical rain forests, many foliose and fruticose lichens inhabit the tree crowns ('sun epiphytes') rather than living in the sub-canopy ('shade epiphytes') (Richards, 1954).

Once the vegetation cover has established itself, progression to a climax lichen community may take 15 to 20 years in temperate regions, whereas in warmer climates, mature communities may form within 6 to 8 years (Hale, 1983). These processes of succession on the phorophyte are particularly important for this study. In the absence of fire, succession will lead to the presence of old-aged lichens on the phorophyte trunk, and to a community comprised of species characteristic of long-standing, undisturbed bark surfaces. Moreover, as the vegetation structure becomes more complex, there will be an expansion of habitat availability on the trunk, thereby increasing the diversity and abundance of the lichen community. With the occurrence of fire, all the lichens present within the flame zone will be destroyed, and successional processes will begin again as recolonisation takes place from the surviving lichen community (Wolseley and Aguirre-Hudson, 1996b). Therefore, the stage at which lichens are in the process of succession may be indicative of the impact of fire in an area.

Both primary and secondary succession show a marked progressive increase in lichen species diversity with time, although there is a slight decline in the climax community (Filion and Payette, 1989; Magomedova, 1980). The r-selected lichen species predominate in pioneer 
communities, such as on bare, burned bark following a fire, allowing them to occupy a wide range of niches. As succession progresses, both the increase in niche diversity (i.e. increase in phorophyte structural complexity) and the invasion of $\mathbf{K}$-selected species, characterised by a more restricted niche specificity, results in higher lichen diversity e.g. in areas of long-term fire protection. As the plant community reaches climax, there is a reduction in niche heterogeneity, with a consequent reduction in lichen diversity (Rogers, 1988; Topham, 1977).

Competition between lichens in the process of succession is greatest when light becomes a limiting factor (Topham, 1977). Fruticose species are generally the most aggressive competitors, followed by foliose and then crustose lichens (Rogers, 1988, 1990). The larger fruticose and foliose lichens may simply overgrow other adpressed species (John and Dale, 1995), although crustose species may employ allelopathic substances, such as various lichen acids (e.g. barbatic acid), which can diffuse from the thallus and prevent neighbouring lichens from encroaching further (Topham, 1977). Lichens with larger vegetative propagules tend to be more competitive (isidia) than those with smaller propagules (spores and soredia) (Rogers, 1990). Competitive lichen species can therefore be associated with K-selected species, which tend to produce small numbers of large propagules, and ruderal lichen species with r-selected species, which produce large numbers of small propagules (Stearns, 1977).

Since corticolous lichens are the subject of this thesis, the descriptions in the subsequent sections will be restricted to this group of lichens.

\subsubsection{Factors influencing lichen growth}

The main factors controlling corticolous lichen growth are:

1) climate i.e. moisture, light and temperature;

2) bark characteristics, such as texture, $\mathrm{pH}$, and the presence of bark solutes;

3) disturbance, which can be biotic e.g. predation, or abiotic e.g. as in this thesis, fire (Barkman, 1958; James et al., 1977; Sipman and Harris, 1986) (see Figure 2.1).

These factors can determine lichen communities at a large-scale, over whole regions, and at a smallscale, on the phorophyte trunk, and many are associated with one another e.g. light and temperature, or substrate and moisture. Lichens, in turn, have responses to factors influencing their growth, which may be positive, involving adaptations of their physiology, morphology and ecology, or negative, where lichens may disappear from a given environment, or seem strongly damaged (Kappen, 1973). These positive and negative responses are not necessarily of the whole lichen organism, but may be either of the fungal or algal component.

\section{a) Moisture}

According to Paterson et al. (1983), moisture is the most important factor that influences lichen growth. Lichens achieve their highest growth rates during periods of continuous 


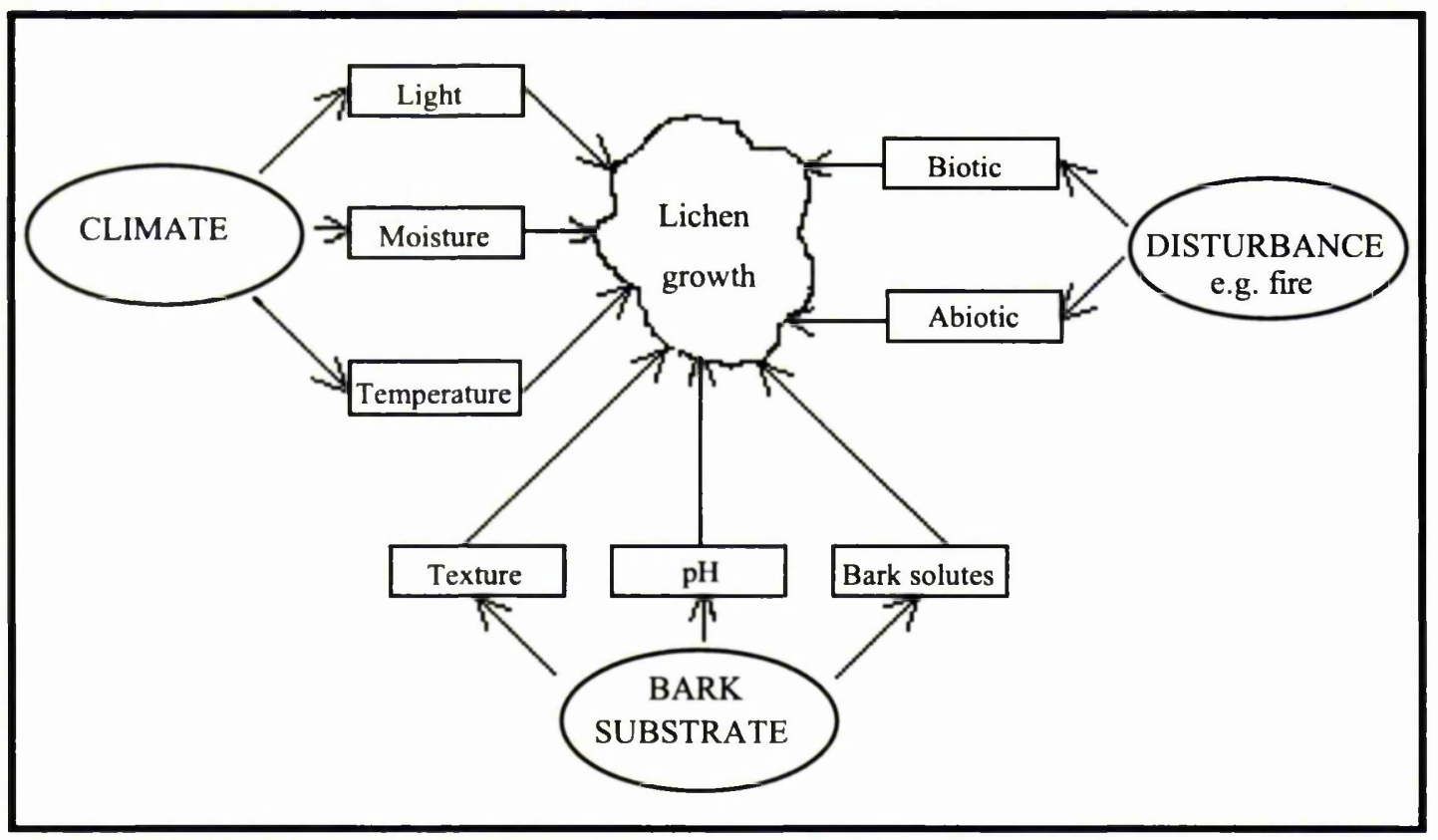

Figure 2.1 The main factors influencing lichen growth. The boxes represent interacting factors.

moisture, such as times of rainfall or cloud cover (Armstrong, 1973; Karenlampi, 1971), and after snowmelt, especially important for lichens in polar and alpine regions (Kappen and Breuer, 1991). In the seasonal tropics, growth mostly occurs during the rainy season (Hale, 1983). In England, the species Pseudoparmelia caperata, grows up to $0.09 \mathrm{~mm}^{-1}{ }^{-1}$ between August and October, corresponding to the main rainy season (Fisher and Proctor, 1978).

The way in which moisture affects lichen growth depends on the degree of thallus saturation and on alternating cycles of wetting and drying. At a low water content (15 to 50\% maximum thallus saturation) in the light, fungal respiration is inhibited more than algal photosynthesis, allowing the photobionts to utilise greater quantities of the photosynthetic products for their own growth. At a high water content, the reverse takes place, and the photobionts receive less photosynthetic products. At maximum thallus saturation in continuous light, the photobiont eventually dies because all of its products are translocated to the fungus (Harris and Kershaw, 1971).

An adaptation of lichens to dry conditions is the ability to assimilate $\mathrm{CO}_{2}$ at nearoptimal levels when their thalli are exposed only to water vapour (Lange et al., 1970a 1970b). For example, in coastal regions of northern Chile, lichens can reach a water content of up to $70 \%$ of their dry weight through water vapour alone (Lange and Redon, 1983). Kappen and Redon (1987) found that all the lichens with green photobionts they studied could absorb water vapour. Cyanolichens, however, can only be metabolically reactivated by liquid water (Lange et al., 1989). Another adaptation to water deficiency is the utilisation of dew. Many lichens in temperate and tropical regions are moistened by 
dew in the evenings after clear, warm days and achieve levels of thallus saturation, allowing them to photosynthesise at maximum rates in the early morning. Studies have shown that desert lichens, such as Ramalina maciformis and Teloschistes capensis, receive sufficient nightly dew to allow them to photosynthesise at high rates for about 3 hours after sunrise (Lange et al., 1970a, 1970b, 1990). Northerly exposed thalli have higher photosynthetic rates due to the longer duration of cool and humid conditions after sunrise (Kappen et al., 1980).

In many lichens, complete water saturation of the thallus impedes $\mathrm{CO}_{2}$ diffusion to the photobiont, lowering the rate of photosynthesis. Only when the thallus begins to dry out $(65-90 \%$ saturation), does photosynthesis peak (Cowan et al, 1992). This is because drying causes air spaces to form in the cortex and medulla, and $\mathrm{CO}_{2}$ can diffuse more easily to the algae. Some subtropical lichens have structural adaptive modifications on their thalli such as soredia and cyphellae that maintain air spaces even in saturated thalli (Snelger et al., 1981). Others, such as species of Stictaceae, have thallus structures which separate the functions of water uptake and storage, and carbon dioxide exchange (Green et al., 1985). This thallus adaptation to maximise gas exchange provides these lichens with a selective advantage in environments where they rarely dry out (Ahmadjian, 1993).

Some lichens undergo frequent drying and wetting in their natural habitats. Adaptations to this phenomenon include the ability to reach peak photosynthesis quickly after a dry thallus is rewetted, and to shut down photosynthesis and respiration when the thallus dries (Ahmadjian, 1993). Another adaptation to frequent drying and wetting can be observed when dry thalli are rewetted. The thalli undergo a period of very intense respiration called resaturation respiration, which is accompanied by a rapid efflux of organic and inorganic solutes from the mycobiont (Farrar and Smith, 1976; Smith and Molesworth, 1973). During this process, a considerable amount of $\mathrm{CO}_{2}$ is released, which occurs only when dry thalli are rewetted quickly with liquid water. Farrar and Smith (1976) have hypothesised that this period of respiration may allow the algae to take up the solutes leaked from the mycobiont. Resaturation respiration varies in duration according to the lichen habitat. For example, desert lichens, such as Chondropsis semiviridis and Ramalina maciformis, elevate their respiration for only a few minutes after rewetting (Rogers, 1971). This may allow them to maximise the brief periods of favourable conditions available for metabolism. However, lichens that undergo long periods of resaturation respiration can only survive in habitats that allow them to achieve a positive growth rate and a photosynthetic gain over the long term. This is because the respiratory carbon losses from frequent periods of rewetting are extremely large and detrimental to the lichen, and may be one reason for the slow growth of most lichens (Lechowicz, 1981).

\section{b) Temperature}

Most lichens grow best during periods of moderate temperatures e.g. 15 to $30^{\circ} \mathrm{C}$ (Ahmadjian, 1993). In temperate zones, this is usually during spring or autumn. For example, the species Pseudoparmelia baltimorensis found in Maryland, U.S.A., grows at a maximum rate of 0.05 
$\mathrm{mm}$ day $^{-1}$ in May/June when temperatures vary between 25 to $30^{\circ} \mathrm{C}$ (Hale, 1983). Low temperature exposure may play an important role in constraining the distribution of tropical lichens, due to their greater sensitivity to photoinhibition and pigment destruction at low temperatures (Coxson, 1987a).

Some lichens are extremely tolerant of thermal stress, adjusting their photosynthetic and respiratory rates with external temperature conditions (Ahmadjian, 1993). Most dry lichens can tolerate adverse high and low temperatures, though there may be some damage to the basic metabolic processes (Larson, 1982; MacFarlane and Kershaw, 1980). Alternatively, photosynthesis in moist lichens is damaged at warmer temperatures $\left(36\right.$ to $45^{\circ} \mathrm{C}$ ) that may be $50^{\circ} \mathrm{C}$ lower than those that cause injury to dry lichens (Ahmadjian, 1993). Cooling of moist lichens can result in severe morphological damage to thalli, including peeling of the upper cortex and algal layer (Benedict, 1990). Therefore, many lichens undergo a period of dry state dormancy in seasonal climates, where extreme temperatures may occur for several months. In cold climates, lichens have adaptations such as dark coloured thalli, to absorb radiation and raise the thallus temperature, and adpressed thalli, to avoid the effects of cold winds (Lindsay, 1977). Adaptations to high temperatures include light coloured thalli, to reflect the light, and a thickened upper cortex, which reduces the intensity of light reaching the photobiont, reduces the evaporative loss, and also permits direct absorption of water vapour from the air (Rogers, 1977).

\section{c) Light}

The amount of light required for optimal lichen growth is not yet known (Ahmadjian, 1993). However, light is essential for photosynthesis by the algal partner, and therefore vital for growth. For example, in the polar zones, growth ceases in the winter months of unbroken darkness (Hale, 1983). Continuous light also harms lichens, which indicates that a period of darkness is important for the overall viability of lichens, probably for the 'dark reaction' i.e. production of carbohydrates, of photosynthesis (Ahmadjian, 1993). Kershaw and MacFarlane (1980) found that variations in the length of a day caused a rapid decline in photosynthesis in air-dried specimens of Peltigera, though there was a full recovery in a few days. Day length also plays a role in triggering seasonal acclimatisation of photosynthetic processes in lichens (Brown and Kershaw, 1984).

In temperate regions, aspect is an important factor affecting lichen growth (Armstrong, 1975, 1977; Rose, 1992). In these regions, the amount of sunlight varies with the direction of exposure, and together with prevailing wind directions, rain directions, inclination of trunks and shading by crowns, causes different sides of tree trunks to have entirely different microclimates (Barkman, 1958). In the tropics, however, aspect plays a relatively small role, since there is not such a great distinction in the amount of light reaching each side of a trunk (Barkman, 1958). Although aspect has been found to be insignificant in lichen communities of Thai tropical forests (Wolseley, pers. comm. 25/1/95), it has been correlated with variations in lichen abundance on different exposures in some mangrove forests of Brazil (Marcelli, 1992). 
The amount of light reaching lichens in different vegetation types is also important. For example, in Alnus-dominated woodlands in northern Norway, the growth of large ferns on the trees limits the amount of light reaching below the canopy, and thereby deterring lichen growth in these areas (Ovstedal, 1980). However, some woodland lichen species of the genus Peltigera can rapidly adjust to fluctuations in light intensity, and photosynthesise optimally in both the presence and absence of the forest leaf canopy (Kershaw and MacFarlane, 1980). In many tropical forests, the structural complexity of the vegetation confines the majority of lichens to the higher levels of trees, where light is able to penetrate the canopy (Gradstein, 1992). For example, Marcelli $(1987,1991)$ found that foliose and fruticose lichens were usually larger, and more abundant in the more illuminated regions of mangrove forests. Within the forest, some lichens are adapted to shade, and in some, such as Stereocaulon virgatum, high light intensities causes the inhibition of net photosynthesis, and eventual death (Coxson, 1987b).

In tropical rain forests, lichens vary morphologically with the light regime of the environment (Kappen, 1988). Shade-adapted thalli have a thinner cortex, are less pigmented (with little need for protection against light), and have a greater degree of ramification of lobes (to capture more sunlight) than when found growing in open habitats e.g. Parmelia perforata, Physcia erythrocardia and Sphaerophorus melanocarpus (Kappen, 1988). Sun-adapted lichens, on the other hand, have deeply pigmented thalli or contain greater quantities of secondary compounds, and have thicker cortical layers for protection against high light intensities (Legaz et al., 1986). Differences in net photosynthesis between sun- and shade-adapted lichens have been directly related to the quantities of chlorophyll in the thalli, with a greater amount of chlorophyll in shade-adapted forms (Kershaw et al., 1983; MacFarlane et al., 1983; Savoye and Leclerc, 1982). Many lichens living at high altitudes have sun and UV+ screening compounds, such as thiol, xanthones and usnic acid in their cortex, which protect the algal symbiont from intense light damage (Guttenberger et al., 1991; Rundel, 1978).

\section{d) Bark substrate}

Although many differences between lichen communities on barks of various textures can bear directly on other aspects of the substrate e.g. relationship of bark hardness to moisture capacity, the ease of colonisation is probably due solely to texture (Brodo, 1974). Lichen propagules can become trapped and develop on rough surfaces more easily than on smooth surfaces. However, it is not known whether this is because of different colonisation abilities on discrete bark textures, or due to survival in moist (rough creviced bark) as opposed to dry (smooth bark) microhabitats (Brodo, 1974). The physical form of deep creviced bark types may also aid lichen survival during disturbances such as fire (Wolseley and Aguirre-Hudson, 1996b).

Water-holding capacity is related to the porosity and texture of bark. Generally, softbarked trees such as Ulmus and Fraxinus, have a higher water capacity and porosity, and give up water more slowly than hard-barked species such as Quercus (Barkman, 1958). Dry bark may also occur 
higher on a tree trunk due to greater windspeeds and higher irradiances, whilst bark at the tree base may retain more water due to the close proximity to moist soil and the lower windspeeds (Bates, 1992). A reduced bark slope favours hygrophilous lichens by prolonging the period of water uptake (Barkman, 1958). Moisture content may also vary with bark substrate age. For example, increasing moisture retention of older bark surfaces was found to correlate with richer lichen communities in the rain forests of Tasmania (Kantvilas and Minchin, 1989).

Many broad-leaved trees have a bark $\mathrm{pH}$ between 4.5 and 7 , while conifers have a lower $\mathrm{pH}$, from 3 to 5 (Hale, 1983). Bark $\mathrm{pH}$ can also vary between individuals of the same tree species and between different parts of the trunk (Barkman, 1958). Some lichen species may prefer or be able to tolerate acidic bark, whereas for other lichens, acidity may deter germination of fungal spores and growth of the algae. In Fagaceous temperate forests, $\mathrm{pH}$ varies with bark age in Quercus petraea, older trees having a higher $\mathrm{pH}$ and a richer lichen community (James et al., 1977).

Inorganic minerals and organic substances formed in, or leached from, substrate surfaces are important factors influencing lichen distribution (Barkman, 1958). Carlisle et al. (1967) found that the concentrations of potassium, calcium, magnesium, and various other soluble carbohydrates in rainwater collected from Quercus petraea stands were higher after having flowed over the bark. Barkman (1958) classified various European trees according to their nutrient content by measuring the ash content of their bark i.e. percent dry weight. Trees such as Acer pseudoplatanus, Sambucus nigra and Prunus avium, with an ash content of 5 to $12 \%$, were categorised as eutrophic; Quercus robur, $Q$. petraea and Fraxinus excelsior, with an ash content of 2 to $5 \%$ were classified mesotrophic trees; and species of Betula, Picea and Abies, with an ash content of 0.4 to $2.7 \%$, were labelled oligotrophic trees. The tree species ash content values were then correlated with their epiphytic vegetation. For example, the Arthonietalia radiatae and Parmelion caperatae communities were associated with mesotrophic trees.

Other bark characteristics which may influence lichens include colour, shedding and the presence of resins or tannins. Bark colour may influence the temperature of lichens. For example, dark coloured trees such as oaks and conifers have a greater heat absorption capacity than light coloured bark e.g. ash, beech and birch (Barkman, 1958). In some tropical trees, such as Terminalia species, regular bark shedding limits the growth of large lichen communities (Wolseley and Aguirre-Hudson, 1996a). The presence of resins or tannins in trees such as Alnus, Betula and conifers, may deter lichen growth (Barkman, 1958). Many tropical tree barks contain compounds such as phenolic acid, or produce resins and latex which contain a variety of substances, which may deter lichen establishment and growth (Wolseley and Aguirre-Hudson, 1996a).

Conifers have a distinctive lichen flora of Cetraria and Usnea species, whereas deciduous hardwoods tend to be dominated by species of Heterodermia, Parmelia, Physcia and Xanthoria (Barkman, 1958). However, although many lichens appear phorophyte specific (Hale, 1983), it is not the identity of the host phorophyte but the ecological conditions prevalent on the phorophyte 
that may produce specific phorophyte-lichen relationships (Wolf, 1994). For example, Cornelissen and Ter Steege (1989) compared two tree species of Eperua in a lowland Guyanan rain forest, and found that lichen communities were host specific, probably due to differences in bark texture and chemistry. Marcelli (1992) working in the southeastern coastal mangroves of Brazil also found host specific lichen communities, attributed to bark qualities such as $\mathrm{pH}$ and roughness.

\section{e) Disturbance}

There are two types of disturbance: biotic and abiotic. A common biotic disturbance is predation. Lichens are an important food source for reindeer and caribou in the tundra and subarctic forests (Richardson and Young, 1977), as well as sheep in the Lybian deserts (Hale, 1983). They are also utilised by birds (Raynor, 1988; Sillett, 1994), snails and slugs (Yom-Tov and Galun, 1971), marine mollusca (Hale, 1983) and a variety of insects (Gerson and Seaward, 1977). A major source of abiotic disturbance is mechanical damage from factors such as wind and rain, which may cause lichens to be removed from their habitat, and subsequent death. Other abiotic factors include pollutants, and forest disturbance through logging or fire, discussed in Section 2.4.

Adaptations to biotic disturbances may include, for example, the presence of allelopathic substances to deter predation, whereas adaptations to abiotic disturbances may be the employment of certain life strategies, or morphological adaptations such as adpressed thalli to avoid wind damage.

\subsubsection{Lichen growth rates}

Lichens are usually the pioneers in plant succession (see Section 2.2.1), and if their environment is stable e.g. in the Arctic, Antarctica or in deserts, they can survive for hundreds or even thousands of years (Ahmadjian, 1993; Kappen, 1988). Their radial growth ranges from an average of 0.5 to $2.5 \mathrm{~mm} \mathrm{yr}^{-1}$ for crustose lichens to 1 to $6 \mathrm{~mm} \mathrm{yr}^{-1}$ for foliose and fruticose lichens (Hale, 1983). Growth rates of lichens vary greatly according to many factors such as season, substrate, and aspect, and may even vary between individual lobes of a single thallus. It is therefore very difficult to compare annual growth rates between different species of lichens.

Lichenometry is the technique of dating substrates of unknown age using lichens

(Beschel, 1973). This method is based on the 'lichen factor', which is defined as the total growth of the particular lichen selected per hundred years, which can be estimated from historical photographs, dated surfaces or direct photography over several years (Hale, 1983). For example, a common crustose lichen of Arctic and alpine regions, Rhizocarpon geographicum, has a lichen factor of 10 to $25 \mathrm{~mm} 100 \mathrm{yr}^{-1}$. Thus, a thallus of $R$. geographicum $150 \mathrm{~mm}$ in diameter on a certain moraine can be extrapolated to be roughly 1000 years old (average factor of 15). It could be stated then, that the moraine was exposed approximately 1000 years ago during a glacial retreat. Similar extrapolations have dated glacial retreats since 9000 B.P. in Swedish Lapland (Denton and Karlen, 1973). This method of dating substrates 
using lichens is important for this study because the measurement of lichen thalli sizes may give an estimate of how long ago a fire occurred in an area. For example, a high frequency of lichens with large thalli may indicate the lack of fire disturbance in an area, whereas an abundance of small sized lichens may suggest a recent fire event. Though lichenometry is widely used, it has been criticised by some workers, especially because the lichen colonisation time and fluctuations in growth rates in response to environmental changes are not known (Jochimsen, 1973). Even so, for this study, the measurement of lichen thalli sizes may be an important method for dating the last fire in an area.

\subsection{The concept of biological indicators}

Biological indicators are organisms (or populations of organisms) whose occurrence and/or vitality change with varying environmental conditions (Kovács, 1992). Each organism may respond to environmental changes on a variable scale, from a sensitive to a resistant way, thereby allowing an estimation of the degree of environmental impact (Kovács, 1992). The main requirements of a biological indicator are that it occurs at a high abundance, and that it possesses specific reactions to the environment (Kovács, 1992). Once indicator organisms have been identified, these can then be used to monitor environments through a system of regular observations, allowing comparisons to be made between past and present states, and/or to survey different sites at the same time in order to compare the spatial differences in the environment (Podani, 1992).

\subsection{The uses of lichens as bioindicators}

Lichens are found in large numbers within many ecosystems, have slow growth rates, and have various tolerances and adaptations, which enable rapid differential species responses to envirommental change. It is for these reasons that they have been employed as bioindicators for a range of factors, from air pollution to forest disturbance (Richardson, 1988a).

To date, a great deal of work has focused on the use of lichens as bioindicators of pollution, most notably for monitoring atmospheric pollution, but also in reference to metal pollution, organic compounds, acid rain and radionuclide emissions. However, it has been realised recently that lichens may play an important role in assessing other types of environmental change. These include climatic change, monitoring levels of ozone in the atmosphere, and for indicating site history and management of forest ecosystems. Most forest management studies carried out on epiphytic lichen communities have, as yet, been concentrated in Europe and North America, and it is only recently that lichens have been recognised as potential bioindicators of forest management in tropical ecosystems.

\subsubsection{Environmental pollution}

There are numerous polluting compounds in the environment, but relatively few have been studied in regards to their effect on lichens. Of these, many originate from industrial combustion, home heating systems and car exhaust emissions, and include sulphur dioxide, hydrogen fluoride, 
ozone, peroxyacetyl nitrate and nitrogen oxides (Ahmadjian, 1993). Others include particulate pollutants, such as metals (e.g. lead, copper and zinc), and various radionuclides, generated from urban and industrial areas, smelters and power stations.

\section{a) Determining the sensitivity of lichens to pollution}

By correlating the relative sensitivities of lichen species to different pollutant levels, it is possible to identify the responses of specific lichen species. The simplest method is to monitor the responses of lichen communities to varying pollutant concentration levels in the field. However, this is time consuming, and it is impossible to eliminate other determinants that may influence the lichen species composition. More reliable methods of determining lichen sensitivity to pollutants are laboratory fumigations (Moser et al., 1980; Nash, 1988; Ronen, 1986). This method can be useful in giving rapid results, but has severe problems (Ahmadjian, 1993). Many studies have used higher pollutant levels than would normally be found naturally, exposure times to pollutants have been short in comparison to natural situations, the form of the pollutant has varied i.e. a gas or in solution, and it has been difficult to maintain the moisture of samples for more than a few hours (Richardson, 1988; Richardson and Puckett, 1973). Despite these criticisms, this method can provide a way of confirming field studies, and increase understanding of how pollutants affect lichen metabolism (Nash, 1988).

Once the relative sensitivities of lichen species have been established, by comparing the lichen composition between areas, it is possible to develop contour maps of pollutant influence. This kind of distribution mapping relies on presence/absence data, so a species must disappear before an effect is registered by the scales. A better way to follow gradual changes in lichen communities is to record both the presence of lichens in different areas and the percentage cover. Though this method is time consuming, the data collected can be used to calculate Indices of Atmospheric Purity (IAPs) (LeBlanc and De Sloover, 1970). Maps can then be drawn with lines joining sites which have numerically similar indices.

As the proportion of pollution-sensitive species recorded in a survey increases, the reliability of the IAP values also increase (Richardson, 1992). If there is a low proportion of these species at a site, more trees have to be surveyed, although this does not fully redress the loss in quality resulting from a low density of pollution-sensitive species. The IAP method is therefore not recommended where the whole study area has an impoverished lichen flora (Herben and Liska, 1986). Also, distribution and IAP studies are useful predictors of current air quality only if the area being studied has static or rising levels of pollution (Richardson, 1992). If, for example, levels of sulphur dioxide pollution have fallen within the last five to ten years, the distribution of recorded lichens may not relate to the measured pollution levels, due to a time lag in lichen reinvasion (see Section b

below). Recently, computer analyses of distribution data for the air quality around La Spezia, northern Italy, have produced three-dimensional IAP maps (Nimis et al., 1990; Will-Wolf, 1988). These maps 
show the difference between elevated areas, which have high IAP values i.e. purer air, and the valley bottom, where IAP values are much lower due to a large coal-fired electricity generating plant.

Transplanting lichens is another widely used method for determining whether an area is polluted, and what effects pollutants have on lichens (Ferry and Coppins, 1979; Holopainen, 1984a; Kauppi, 1976). The zone in the centre of urban or industrial areas where there are little or no lichens is often called a 'lichen desert' (Sernander, 1926). Lichens or bark discs with thalli can be attached to wooden boards or similar supports and placed in these lichen desert zones to assess the current air pollution (Brodo, 1961, 1968). For example, the lichen Hypogymnia physodes has been used in transplant studies around Budapest, Hungary. Thalli were transplanted from rural control areas (attached to pieces of felt) to trees in the city. The lichens transplanted near a sulphuric acid factory soon showed yellow and red marginal lobes, signs of damage. Lichens transplanted close to main roads showed more discolouration than those attached in quiet streets, and when attached on opposite sides of the same tree, the lichens facing the road exhibited greater symptoms of injury (Farkas et al., 1985).

\section{b) Sulphur dioxide pollution}

Sulphur dioxide $\left(\mathrm{SO}_{2}\right)$ is a very soluble gas which can dissolve in rain water or moisture within the cell walls of a wet lichen thallus to form sulphuric acid. The sensitivity of a lichen to $\mathrm{SO}_{2}$ depends therefore on its ability to absorb and retain moisture, as well as on certain morphological features of the thallus that prevent entry of $\mathrm{SO}_{2}$ i.e. a thick, compact cortex (Wirth and Türk, 1974). At a high $\mathrm{pH}$, sulphuric acid remains dissociated, but at acid $\mathrm{pH}$ levels, it is converted into bisulphite and sulphuric acid, which are toxic (Puckett et al., 1973). These compounds alter the permeability and structure of cell membranes (e.g. chloroplasts and mitochondria) and enzyme activity (Sundstrom and Hallgren, 1973), disrupting a wide variety of metabolic processes including photosynthesis, respiration and nitrogen fixation in the photobiont (Lange et al., 1989; Richardson, 1992).

Visible morphological changes common in lichens affected by $\mathrm{SO}_{2}$ are smaller thalli, the reduction or absence of fruiting bodies, and a change in thallus colour e.g. Parmelia sulcata, normally grey/green turns reddish violet when exposed to $\mathrm{SO}_{2}$ (Ahmadjian, 1993). Some lichens turn brown at the lobe ends, or become white and detach from the substrate due to the death of the photobiont (Saunders, 1970), while in others, the thallus becomes fragmented as the biont association is disturbed (Jahns and Neumann, 1981). $\mathrm{SO}_{2}$ can also stimulate the production of vegetative structures such as soredia and isidia (De Sloover and LeBlanc, 1970; Stringer and Stringer, 1974). This could be a response to the breakdown of the thallus (Ahmadjian, 1993).

Different lichens have different sensitivities to $\mathrm{SO}_{2}$ and this will determine the composition and abundance of lichens found in any specific area depending on the level of $\mathrm{SO}_{2}$ pollution present (Kärnefelt et al., 1990; Rassi and Väisänen, 1987; Richardson, 1992; Trass and Randlane, 1987). It has been shown that lichen diversity and abundance increases with distance from an 
urban or industrial centre (Caniglia and Drudi, 1984; Fenton, 1960), and this factor, together with $\mathrm{SO}_{2}$ readings from monitoring stations, has been used to devise scales for $\mathrm{SO}_{2}$ pollution. The most well known and widely used scale in Europe is the 'Hawksworth and Rose scale', which distinguishes ten lichen zones in relation to mean winter sulphur dioxide levels (Hawksworth and Rose, 1976). This scale was established using $\mathrm{SO}_{2}$ readings from England and Wales, and though it has been applied to other countries in Europe, it has been found that the tolerated levels of $\mathrm{SO}_{2}$ pollution between individuals of the same lichen species are different. For example, in the 'Hawksworth and Rose' scale, it is stated that Lecanora conizaeoides can withstand up to $150 \mathrm{mg} \mathrm{m}^{-3}$ of $\mathrm{SO}_{2}$ and Parmelia caperata up to $40 \mathrm{mg} \mathrm{m}^{-3}$ of $\mathrm{SO}_{2}$ without showing any adverse effects (Lerond, 1978). However, studies in Ireland show that the limit for growth of $L$. conizaeoides is about $50 \mathrm{mg} \mathrm{m}^{-3}$ of $\mathrm{SO}_{2}$, while for $P$. caperata it is $30 \mathrm{mg} \mathrm{m}^{-3}$ of $\mathrm{SO}_{2}$ (Ni Lamhna et al., 1988). This may be due to more frequent rain in Ireland, keeping the lichens moister and more metabolically active, and therefore more sensitive (Richardson, 1992). So, though the 'Hawksworth and Rose' scale is a useful technique for establishing pollution zones around cities or industrial sites, the relative sensitivities of lichens should be determined at each site.

Recently, falls in $\mathrm{SO}_{2}$ concentrations, due to reductions in emissions from low-level sources (e.g. oil combustion for heating in domestic properties) and the increasing use of sulphur-free fuels, has seen the reinvasion of lichens (Bates et al., 1990; Gilbert, 1986a, 1992). For example, in the city of London there was an annual mean atmospheric $\mathrm{SO}_{2}$ concentration decrease from $300 \mathrm{mg} \mathrm{m}^{-3}$ in 1964/65 to about 25 to $40 \mathrm{mg} \mathrm{m}^{-3}$ in 1984/85 (Laxen and Thompson, 1987). Surprisingly, this has resulted in the recolonisation of lichens typical of zones 6 and 7 in the Hawksworth and Rose scale, rather than the more tolerant species of zones 4 and 5 (Hawksworth and McManus, 1989). This phenomenon is termed 'zone skipping', and is defined as recolonisation without the return of species progressively lost under conditions of gradually rising ambient air pollution levels (Alexander, 1982; Hawksworth and McManus, 1989). It seems that a new and different lichen flora may be occupying certain areas of lichen deserts (De Bakker, 1989; Seaward and Letrouit-Galinou, 1991; van der Knaap and van Dobben, 1987), with some species recolonising areas more quickly than more tolerant species, perhaps through a more efficient dispersal strategy (De Bakker, 1987).

Most studies have shown that there is a time lag of 5 to 10 years between a decrease in $\mathrm{SO}_{2}$ levels and the reinvasion of lichens (Richardson, 1992). This time lag is partly controlled by dispersal capacity, and studies have shown that lichens can be categorised as 'zone skippers' (rapid colonisers) or 'zone dawdlers' (slow colonisers) (Hawksworth and McManus, 1989). The majority of 'zone skippers', such as Usnea species, which disappeared from an area over 70,000 km² in Britain as a result of increasing air pollution (Seaward, 1987), occur on well-lit mature deciduous trees in sites subject to regular wetting. Usnea subfloridana, for example, has re-established on trees such as ash and willow, which have bark with a high $\mathrm{pH}$, buffering the effects of acidic pollution, and also retaining higher amounts of moisture, which facilitates colonisation (Seaward, 1987). In contrast, many 'zone 
dawdlers' are crustose lichens characteristic of dry bark that rarely gets wetted by the rain, and thus retaining the bark acidity of the past (Grodzinska, 1977, 1979). The input of alkalinity from dust also speeds up reinvasion, observed around buildings, cement factories and quarries (Gilbert, 1976; Hawksworth and McManus, 1988).

It seems, therefore, that habitat, in particular $\mathrm{pH}$, is just as important for recolonisation, as dispersal efficiency (Bates et al., 1990; De Bakker, 1989; Farmer et al., 1991; Henderson-Sellers and Seaward, 1979). What is also apparent is that while lichens can provide a general picture of pollution abatement, they are not ideal monitors for this due to the time-lag phenomenon (Gilbert, 1992).

\section{c) Acid rain}

Acid rain forms when sulphuric acid and nitric acid, derived from dissolved sulphur and nitrogen oxides, fall with rain water. This acidifies the environment, sometimes even in areas at some distance from the source, and results in the leaching of nutrients and a reduction in the buffering capacity of bark and soil (Richardson, 1992). Lichen species composition is governed by natural variations in substrate and water acidity (Barkman, 1958; James et al. 1977), so that increasing acidification brought about by pollution can be expected to favour some species and weaken others (Hawksworth, 1990). Therefore, the lichen species most susceptible to acid rain are those with poor resistance to high concentrations of acid, and occurring in environments with less robust buffering properties e.g. acid bark (Büscher et al., 1990). The effects on these lichens include thallus discolouration, the death of algal cells, and damage to the photosynthetic and respiratory systems (Hutchinson et al., 1986; Lechowicz, 1987; Roy-Arcand et al., 1989; Scott and Hutchinson, 1987).

Cyanolichens are particularly sensitive to the decreased $\mathrm{pH}$ levels caused by acid rain (Gilbert, 1986b; Hallinbäck, 1989). In Great Britain, the Lobarion cyanolichen community has been used to monitor the effects of acid rain. These studies have shown that from 1986 to 1990 phorophyte bark $\mathrm{pH}$ has declined, resulting in the local extinction of a number of Lobaria species and a reduction in their relative growth rates (Looney, 1991; Looney and James, 1990; Wolseley and James, 1991). In Sweden, Lobaria scrobiculata, previously recorded at over 300 localities, has now disappeared from the south and east of the country, and has become rare elsewhere (Hallinbäck, 1989). This has been due to the progressive decrease in bark $\mathrm{pH}$ from the effect of weak acid rain derived from pollution produced in the continent and the U.K. (Nieboer et al., 1984).

Many lichens are resistant to or require low $\mathrm{pH}$, and so while acid-sensitive species may decline, acid-tolerant species would be expected to increase (Day, 1985). Seaward (1989) has noted the expansion in the UK of Parmelinopsis ambigua, from a restricted distribution on debarked conifer wood to widespread growth on acidified bark of deciduous trees in polluted areas. Many other oligotrophic crustose lichens have also expanded in their range, and could be used for monitoring acid rain pollution (Seaward, 1989). 


\section{d) Fluorides}

Fluorides are released into the atmosphere through industrial processes such as aluminium smelting, brick firing, the production of fertilisers, and by volcanic eruptions (Richardson, 1992). Symptoms of damage on the lichens include: the degradation of the chlorophyll in the algal cells, and subsequent death of the thalli; red colouration; weakening of bark attachment; and the swelling and breakdown of chloroplast membranes in the algal cells, followed by the accumulation of small globules and crystalline material, causing mitochondrial (respiratory) degeneration (Holopainen, 1984b; Nash, 1971; Perkins and Millar, 1987a, b).

The effects of fluorides on lichens are more localised than for $\mathrm{SO}_{2}$ or acid rain pollution, providing the opportunity to monitor the impact of fluoride pollution near the source. For example, in 1970, a new aluminium smelter was commissioned near Holyhead, North Wales. Within 6 to 12 weeks, nearby lichens were showing signs of damage, and after five years, fruticose and foliose lichens decreased to less than $1 \%$ and $12 \%$ respectively, of the initial cover. Crustose lichens were least affected, and some species such as the pollutant-tolerant Lecanora expallens, increased markedly. Many fruticose and foliose lichens can accumulate up to $50 \mathrm{mg} \mathrm{g}^{-1}$ of fluoride without being permanently damaged, and some of the fluoride-tolerant species, such as Parmelia loxodes, show little or no injury after taking up to three times this amount (Perkins, 1980).

Recent studies have found that lichens can accumulate high levels of chloride, another halogenic element like fluoride, from wind blown salt particles without damage (Takala et al., 1990). This has led to the conclusion that the damage caused to lichens around aluminium smelters is probably due to the effect of hydrogen fluoride, rather than to particulate fluorides.

Volcanoes release fluorides in gaseous form or as microscopic salt particles within or crystallised onto volcanic ash (Richardson, 1992). During the dormant phase, fluorides form part of the gas plume, and though lichens cannot be used to give absolute measures of fluoride content, they can be used to evaluate dispersion patterns of fluoride fallout. This was carried out for Mount Etna in Sicily, where it was found that different levels of fluoride fallout at different locations around the volcano were due to an interaction between the prevailing winds and the shape of the mountain (Davies and Notcutt, 1988). Lichens could therefore be used to identify fluoride-contaminated areas, in order to prevent animals and people from developing illnesses such as fluoridosis.

\section{e) Metals}

Lichens can accumulate high levels of various metals, and are therefore excellent monitors of atmospheric fallout around smelters, industrial and urban areas, mines and road systems (Richardson, 1992). They accumulate metals either by trapping insoluble particulates (usually oxides, sulphates and sulphides) or by absorbing dissolved metal ions into their cell walls (fungi and algae) through ion exchange mechanism (Richardson and Nieboer, 1981). 
Some lichens have been found to contain high levels of metals e.g. over $5000 \mathrm{mg} \mathrm{g}^{-1}$ dry weight, without resulting in any apparent harm (Nash, 1989; Tyler, 1989). In fact, it is the type of the metal that is important, not necessarily the quantity. Zinc, lead and copper are much more damaging to lichens than iron (Richardson, 1991). Where injury does take place, there are detrimental changes in cell membrane permeability, chlorophyll composition, and enzyme function, affecting photosynthesis, respiration and nitrogen-fixation (Puckett, 1976; Van Assche and Clijsters, 1990). Some lichens, however, secrete compounds such as oxalic acid, which form complexes with excess metal ions, providing a metal tolerance mechanism (Jones, 1988). This includes species such as Lecanora cascadensis and $L$. vinetorum, which can grow on copper-rich rocks or wood sprayed with copper-containing fungicides (Tyler, 1989). Another tolerance mechanism is the regulation of metals reaching the thallus by the rhizinae from metal-contaminated soils as in Peltigera (Goyal and Seaward, 1982).

As monitors of metal pollution, lichens have been used around isolated industrial works e.g. smelters, as well as around large urban and industrial zones (Blyum and Tyutyunnik, 1985; Mukherjee and Nuorteva, 1994; Sloof and Wolterbeek, 1991; Thompson et al., 1987; Walthier et al., 1990). They have also been used to monitor levels of lead emitted from vehicle exhausts (Gordon et al., 1995; Kral et al., 1989; Laarksovirta, 1976) and to define zones of influence of mining activities on the surrounding area (Bargagli et al., 1987; Beckett et al., 1982).

Recently, lichens have been used to detect changes in the levels of metal contamination in rivers. Samples of Parmelia praesorediosa were collected from a remote site in southwestern Louisiana, USA, washed in distilled water and air dried. Five grams of the lichen were then packed in nylon mesh sacks and placed in PVC containers with holes drilled in all sides. These tubes were then submerged at ten sampling locations along a tributary of the Calcasieu River for two weeks. Once retrieved, washed and dried, it was found that levels of zinc, copper, cadmium and chromium increased upstream to a maximum value just inside the outlet of an industrial drainage ditch (Beck and Ramelow, 1990). In another study, currently in progress, lichen material suspended in metalcontaminated waters is being used to evaluate the quantity of metals adsorbed by the lichens, from which the levels of biological available soluble metal ions in rivers can be determined (Connor et al., 1991).

\section{f) Aromatic hydrocarbons}

Aromatic hydrocarbons and polyaromatic hydrocarbons (PAHs) include dioxins and furans (released during the incomplete burning of, for example, fossil fuels or rubbish) and PCBs (polychlorinated biphenyls), which are carcinogenic compounds used in the chemical industry and in electrical transformers (Thomas, 1981; Thomas et al., 1984). PCBs are more volatile than PAHs, and so occur in the atmosphere as gases rather than particulates. Chlorinated hydrocarbons e.g. Lindane and DDT, are found in pesticides and in compounds employed in the paint and plastics industry (Brown, 
1992). High concentrations of these compounds in lichens can inhibit photosynthesis, respiration and nitrogen fixation (Howes, 1986; Kallio and Wilkinson, 1977).

Lichens that can accumulate these aromatic hydrocarbons could provide information on the degree of environmental contamination (Villeneuve et al., 1988). For example, regular sampling in remote areas of northern Sweden of the reindeer lichen Cladonia rangiferina showed that there was a progressive increase in the levels of PCBs over a 10 year period. The mean residence time of the PCBs in the atmosphere was estimated to be 2 to 3 years, and it was suggested that aerial transport was the main dispersal route for the chlorinated hydrocarbons to this isolated site (Villeneuve and Holm, 1984). In winter, reindeer survive mostly on C. rangiferina, and the Lapp people eat the reindeer (Pruit, 1963; Slack, 1988). Studies indicate that the Lapps may ingest up to $12 \mathrm{mg} \mathrm{yr}^{-1}$ of this compound from deer meat (Villeneuve et al., 1985). Thus, sampling lichens could be a rapid and simple technique for monitoring aromatic hydrocarbon pollution levels in the environment.

\section{g) Radioactive elements}

Radioactive contaminants (e.g. ${ }^{137}$ caesium and plutonium) from atmospheric nuclear bomb testing, the crashing of nuclear-powered satellites, and accidents at nuclear-powered stations, such as at Chernobyl, have been successfully monitored using lichens. For example, lichen studies on

${ }^{137}$ caesium concentrations released from nuclear explosions revealed that the Lapps of Scandinavia, and the Inuit people of Canada and Alaska, were part of a food chain that resulted in up to five times more ${ }^{137}$ caesium ingestion than people who did not depend on reindeer or caribou for food (Aberg and Hungate, 1967). The ${ }^{137}$ caesium can be accumulated by lichens either through the radioactive material being adsorbed into small particles (dry deposition), or by the radioactive material dissolving in rain water (wet deposition) (Smith and Ellis, 1990).

After the 1986 Chernobyl nuclear power station explosion in the Ukraine, lichens were used to monitor the radioactive fallout in many countries (Mackenzie, 1986; Papastefanou et al., 1989; Smith and Ellis, 1990; Strandberg, 1994). For example, in Poland, post-Chernobyl samples of the lichen Umbilicaria showed a 165-fold increase in levels of ${ }^{137}$ caesium (Seaward et al., 1988).

\subsubsection{Climate change}

With the present trends of climate warming in both the southern and northern hemispheres, many glaciers and icefields are retreating to create and expose new rock, gravel and soil surfaces, ideal for colonisation by lichens. For example, the San Rafael Glacier in Chile is descending from the North Patagonian Icecap into the sea, at a rate of between 17 to $28 \mathrm{~m} \mathrm{day}^{-1}$. Consequently, the freshly exposed rock surfaces are being rapidly colonised by minute colonies of the alga Trentepohlia, the photobiont partner for the lichen Placopsis, which grows rapidly in this environment (Galloway, 1992). Within 10 to 15 years, rock surfaces 10 to $50 \mathrm{~m}$ above the glacier are completely covered by a mosaic of Placopsis species. 


\subsubsection{Ozone}

A study of mosses over a period of 24 years from the Ross Sea region of Antarctica found that the absolute levels of photoprotective flavonoids correlated directly with measured atmospheric concentrations of ozone (Markham et al., 1990). Lichens in alpine and high altitude environments also produce a number of cortical screening compounds, especially carotenoids and usnic acid, which protect the photobiont from radiation damage, and make lichens potentially useful biomonitors for the long-term effects of ozone thinning (Galloway, 1993).

\subsubsection{Forest management in temperate regions}

Nowadays, there are comparatively few ancient woodlands left in Britain and western Europe, and even fewer still managed in the traditional way (Rose, 1992). The Fagaceous New Forest, England, for example, contains 9000 acres of ancient pasture-woodland (the largest in lowland Europe), and is still managed by grazing of ponies, cattle and deer. It has the largest epiphytic lichen flora known in any comparable area in Europe: 312 species, including two rarities, Catinaria laureri and Parmelia minarum, known nowhere else in the British Isles and rare in western Europe (Rose and James, 1974).

Studies in other little modified forest areas, such as in the montane forests of the mountain massifs of central Europe e.g. the Vosges, Black Forest and Pyrenees, have found communities of lichens which may have remained unchanged since the time before any human disturbance. The alliance Lobarion pulmonariae is the most significant community of undisturbed Fagaceous forests and includes foliose species such as Lobaria pulmonaria, L. virens, L. amplissima and Sticta limbata, as well as crustose species such as Arthonia vinosa and Thelopsis rubella (James et $a l ., 1977$ ). Another ancient forest lichen community specific to oak trees (over 300 years old), is the alliance Lecanactidetum premneae. This persists on the overhung side of trunks, where the bark is extremely dry, and includes Lecanactis premnea, L. lyncea, L. amylacea and Opegrapha prosodea (James et al., 1977).

The occurrence of these 'ancient woodland indicator' lichen epiphytes (Rose, 1974), has led to the formation of the Revised Index of Ecological Continuity (RIEC) (Rose, 1976). This key employs 30 lichens known to be faithful to ancient woodlands. The occurrence of 20 of these species is an indication that a woodland has not been disturbed since early medieval times. The greater the number of RIEC species present, the greater the probability that a site is ancient in origin. Even though some lichen species were more valuable indicators of stability e.g. Lobaria species, an index based on weightings for different species was considered too difficult to devise (Rose, 1992). Also, when using the index, it is important to survey areas which from the point of view of disturbance or replanting, are as homogeneous as possible.

Sensitive lichen species are often local or regional in their distribution, and so indices using these species may provide more reliable results. This concept led to the development of the New 
Index of Ecological Continuity (NIEC) for lowland Britain, which also works from western Norway and western France to the western Pyrenees and into Spanish Navarra (Rose, 1992). Since lichen taxonomic work has advanced in recent years, this new index incorporates 70 species for the calculation of a main index number, to which the number of 'bonus' species occurrences are added. Together, this gives a final index figure ' $T$ '. The RIEC is useful as an indication of disturbance, whereas the NIEC is more effective at sorting out woodlands in terms of their conservation value (sites with ' $\mathrm{T}$ ' values $<20$ are presumed to be of limited conservation importance) (Rose, 1992). Indices incorporating special characteristics of particular areas, such as the communities of acidic oak-birch woods in the very high rainfall areas of upland western Britain, are in preparation (Rose, 1992). An index for forest continuity using crustose lichens as indicators has been designed for the boreal coniferous forests of southern Sweden to Lapland (Tibell, 1992), and in other parts of Europe, lichen indicators of ancient forests are being identified (Camenzind and Wildi, 1991; Dietrich, 1991).

Outside Europe little work has been carried out on lichen indicators of forest management. In the U.S.A., ancient forest lichen indicator species have been used in an index of "ecological continuity (IEC) for northern hardwoods and spruce-fir stands in Maine, New Hampshire, Vermont and western New Brunswick (Selva, 1994). Some macrolichens may provide a rough index of environmental continuity in old-growth inland forests of British Columbia, Canada (Goward, 1994). Kantvilas (1985) and Kantvilas et al. (1985) found lichen communities confined to pristine temperate rain forests in Tasmania, but as yet, no indices have been devised.

\subsubsection{Forest management in tropical regions}

A pioneer work using lichens as bioindicators of environmental stability and change in the tropical forests of Thailand was carried out by Wolseley and Aguirre-Hudson (1991). They worked in three vegetation types: dry deciduous dipterocarp savanna forest (DDF); seasonal evergreen forest (SEF); and montane oak forest (MOF). They found that the DDF, an open, well-lit forest, had high frequencies of light-demanding lichen families, such as Physciaceae, Graphidaceae and Parmeliaceae. In contrast, the SEF, a more closed and moist environment, had a predominance of shade-loving and hydrophilous species of the Bacidiaceae and Arthoniaceae families (Wolseley et al., 1994). These species have Trentepohlia as their photobiont, which prefers shady, moist conditions (Wolseley and Aguirre-Hudson, 1996b). The MOF was characterised by a combination of the previous families, as well as species of Megalosporaceae, Pyrenocarpaceae and Thelotremataceae (Wolseley and Aguirre-Hudson, 1996a). This is probably due to the lower temperatures, and high moisture availability (Gradstein, 1992). Larger foliose species of Lobaria, Sticta and Pseudocyphellaria, indicators of ancient Fagaceous woodlands in Europe (Rose, 1988; Wolseley, 1991), were also found in undisturbed MOF (Wolseley and Aguirre-Hudson, 1996b).

Within the areas of the MOF that had been disturbed (by logging or regular fire damage), crustose lichens such as Lecidopyrenopsis, Gyalecta, Pyrgidium and Tylophoron had

49 bonds.


disappeared, and species such as Relicinopsis rahengensis, Dirinaria sp. and Pyxine consocians, typical of well-lit or disturbed areas had become frequent. Macrolichens, including Physcidia, Lobaria, Sticta and Usnea were absent from the disturbed MOF areas, whereas there were high abundances of Rimelia reticulata, Parmotrema tinctorum and Hypotrachyna sp., species that are able to colonise quickly after disturbance. Together with an isidiate squamulose species of Phyllospora, these species were also frequently present in disturbed SEF plots. The most common form of disturbance in the SEF and DDF plots was fire, and lichen species indicative of different fire regimes were found (see Section 2.4.6 below).

Limited other work has been carried out on using lichens as bioindicators of forest growth and disturbance in the tropics. Marcelli (1992) studying mangrove lichen ecology in the south and southeastern coast of Brazil, found that the heliophilous crust family Thelotremaceae, containing the shade and moisture-loving Trentepohlia photobiont, was a good indicator of undisturbed, oldgrowth mangrove trees.

\subsubsection{Lichens and fire studies in savannas}

Wetmore (1983) studied the effects of fire on lichen communities in a forested oak 'savanna' in east-central Minnesota, USA. The main tree species in this savanna included bur oak (Quercus macrocarpa), northern pin oak (Quercus ellipsoidalis) and green ash (Fraxinus pennsylvanica). To see the effects of different burning regimes, five areas with the following burning histories since 1962 were used: burned every year (BU1); burned three out of four years (BU2); burned two out of four years (BU3); burned once every four years (BU4); protected from fire for at least 50 years (BU5). Lichen sampling took place at three different height bands on twenty trees within each area: base (below $5 \mathrm{~cm}$ ); mid ( 5 to $75 \mathrm{~cm}$ ); top (above $75 \mathrm{~cm}$ ).

The results showed lower lichen frequency and cover values in the more frequently burned plots, and decreasing values of lichen frequency and cover as one moved down the trunk, paralleling an increase in fire damage. Wetmore also found a number of lichen species including Phaeophyscia chloantha, Physcia millegrana and Candelaria concolor that had much higher occurrences in frequently burned areas. It was hypothesised that since these lichens typically grow in the cracks of bark, they are able to escape damage by fire, and are thus able to colonise areas where more competitive, but fire sensitive species, have been displaced. Some lichens appeared to survive at the tree bases in BU3 and BU4, probably having escaped burning because of the direction of the fire, and the variation in fire homogeneity from one burn to another (Brodo, 1968). Some species such as Caloplaca flavorubescens and Phaeophyscia rubropulchra, however, are eliminated by repeated fires and were mostly found in the protected area (BU5). The study also showed that more lichen species were present on bur oak than on the northern pin oak, attributed to differences in bark texture, $\mathrm{pH}$ and moisture holding capacity (Brodo, 1968; Hale, 1955). 
In the same studies described in Section 2.4.5, Wolseley and Aguirre-Hudson $(1996 \mathrm{a}, \mathrm{b})$ found that lichen species had differential sensitivities to the effects of fire in the dry dipterocarp savanna forests (DDF) of Thailand. These forests are dominated by species of Dipterocarpus and Shorea, and many of the phorophytes are adapted to fire e.g. dry thick bark (Stott et al., 1990). Lichen sampling took place on phorophyte species up to a height of $3 \mathrm{~m}$, in plots of varying fire histories, ranging from frequently burned, to protected for over 23 years.

Where fire had occurred, there was a lichen desert that corresponded to the flame height. Above this zone, many lichens species remained undamaged which facilitated rapid recolonisation on the bare bark using vegetative propagules. These recolonisers included species of Pyxine, Dirinaria, Relicinopsis, Bulbothrix, Canoparmelia and Parmelinella. These species are closely attached to the bark surface, so may have survived the fires in bark crevices.

Crusts varied in their sensitivity to fire and colonisation rates following fire. Some species of Pertusaria and Rinodina appeared to be more tolerant of fire, and were found frequently in burned areas, whereas species from the Pyrenocarpaceae and Thelotremataceae, were more readily damaged. 'Time-since-last-fire' could be estimated by the diameters of the recolonisers, and where fires were both very frequent and intense, recolonisation did not occur at all (Wolseley and Aguirre-Hudson, 1996b). Additional findings showed that many less fire-sensitive crustose species occurred strictly in a vegetative state where frequent fires had occurred, but were found fertile above the flame height or in areas not subjected to fires for a long time (Wolseley and Aguirre-Hudson, 1996b).

These authors are hoping to set up projects with local people to assess and monitor the health of their forests using lichens, and to use indicator lichens as a basis of management recommendations, in particular with regards to fire practices (Wolseley, pers, comm. 1995).

\subsection{Conclusion}

Lichens have been successfully used as bioindicators for various types of disturbances within a wide range of ecosystems. Their outstanding attributes of wide ecological amplitude, high abundance, and rapid reactions to fluctuations in the environment make them ideal organisms for bioindicating. It has been shown that lichens are sensitive to changes in fire management, both in $\mathrm{N}$. America and in the seasonal tropics of Thailand. It was therefore hoped that lichens would also indicate differences in past fire management in the savannas of central Brazil. 


\section{Chapter 3 \\ The Brazilian cerrado : distribution, determinants and ecology of study site}

\subsection{The savannas of South America}

Savannas can be defined as 'those tropical and subtropical formations which lie between rain forests and deserts and semi-deserts, where the $\mathbf{C}_{\mathbf{4}}$ grass stratum is continuous and important, occasionally interrupted by trees and shrubs, the main growth patterns are closely associated with alternating wet and dry seasons, and fires occur from time to time' (Bourliére and Hadley, 1983). In the American tropics, savannas are the second largest ecosystem and occupy an area over 2 million $\mathrm{km}^{2}$ (Figure 3.1). In some regions of South America, savannas cover vast stretches of land, such as the

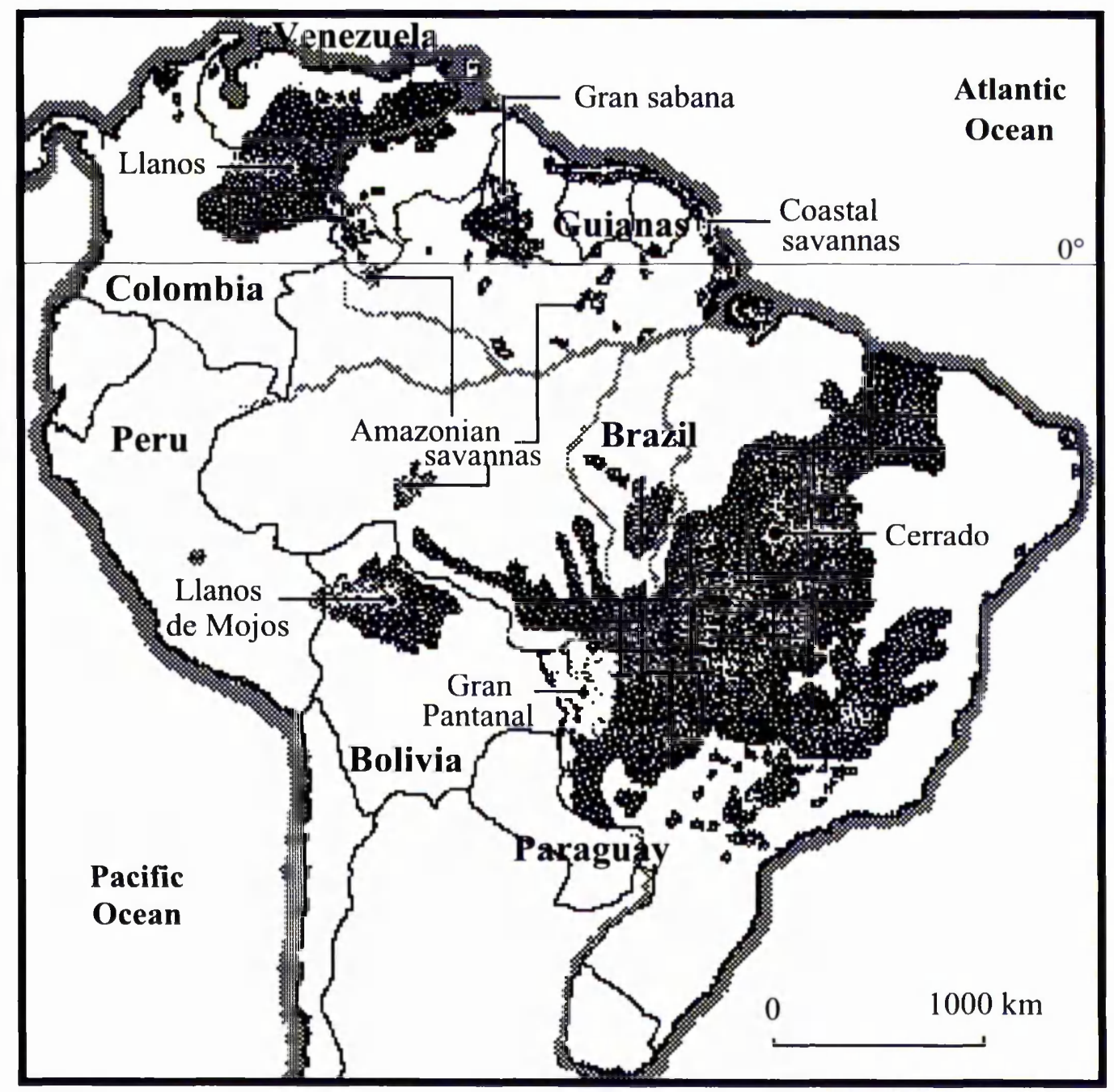

Figure 3.1 Tropical and subtropical savanna regions in South America (modified by the author after Bourliére, 1983). 
Brazilian cerrado and the Colombian and Venezuelan llanos, but they also occur in smaller, isolated patches amid rain forests in Central America and Amazonia (Eden, 1990; Sarmiento, 1983). The open forms of caatingas, concentrated in the Amazonian Rio Negro drainage basins and in north-eastern Brazil are, according to some authors (Cole, 1960; Eiten, 1982), also savannas.

The savannas of tropical America have been classified in two different dimensions, one ecological, the other physiognomic (Sarmiento, 1984). The physiognomic categories, defined by a structural classification, agree with the savanna forms recognised in the Brazilian literature, which will be discussed later (see Section 3.2). From an ecological standpoint, neotropical savannas have been divided into four major categories according to seasonality (Sarmiento, 1978; Sarmiento and Monasterio, 1975).

The first ecological type is the semi-seasonal savanna. It is characterised by weak seasonal water stress of only one or two short dry seasons. These savannas occur as scattered patches within areas of rain forest, such as the Amazonian campos. The second type, and most widespread, is the seasonal savanna. It is determined by long periods of moisture stress, and occurs in large tracts of Brazil, Colombia and Venezuela. A third savanna form, the hyperseasonal savanna, is subjected to alternate periods of water deficiency and waterlogging during each annual cycle. Common in poorly drained sites, it occurs in large regions of Brazil and Bolivia (for example the Gran Pantanal formation). The fourth savanna type, esteros, or marshy savannas, remains under conditions of excessive soil water during a major part of the year and occupies sites in valleys or tableland margins.

These different savanna types show a surprising floristic affinity, with several species prevalent not only in similar formations of adjacent areas, but also throughout their whole geographical range. Among the most widespread species are trees like Bowdichia virgilioides (LeguminosaePapilionoideae), Byrsonima crassifolia (Malpighiaceae) and Curatella americana (Dilleniaceae), as well as several grass species of Andropogon, Axonopus, Paspalum and Trachypogon (Sarmiento, 1983). Within this general scheme of floristic homogeneity, the Brazilian savannas are exceptional, with a diversity of woody elements not matched by any other savanna flora in the world (Eiten, 1972; Filgueiras and Pereira, 1994).

\subsection{The Brazilian savannas}

The Brazilian savanna, commonly called cerrado (meaning 'closed' in Portuguese) is a complex vegetation form, characterised by a mosaic of physiognomies ranging from pure grasslands through open scrubland to dense woodlands (Eiten, 1972, 1978). Situated between latitude $3^{\circ}$ and $24^{\circ}$ $\mathrm{S}$ and longitude $41^{\circ}$ and $63^{\circ} \mathrm{W}$, it occupies over 1.8 million $\mathrm{km}^{2}, 22 \%$ of the Brazilian territory (Coutinho, 1990; Goodland, 1971a) (see Figure 3.1), and in terms of area, is second only to the Amazonian rain forest (Furley and Ratter, 1988). The cerrado is centred on the Brazilian Planalto, characterised by a realm of plateaux and high tablelands (termed chapadas) ranging in altitude from approximately $300 \mathrm{~m}$ to $1000 \mathrm{~m}$ above sea level (Ab'Saber, 1971). From here cerrado descends 
southwards to the lowlands of the Mato Grosso Gran Pantanal, and northwards to the Amazon rain forests. To the east and south, the transition with the humid forest landscapes of the Atlantic region is gradual, while to the north-east a rather steep climatic gradient leads to the large depressions of the dry caatinga region (Eiten, 1994). The tablelands covered in savannas are occasionally dissected by wide valleys penetrated by gallery forest.

The soils of the cerrado are mostly oxisols, and shales are the predominant parent material (Parada and Andrade, 1977). They are characteristically deep ( $>3 \mathrm{~m}$ ), well drained, red or yellow, clay-rich, acidic, structurally strong but nutrient-poor (Furley and Ratter, 1988). Due to the low cation exchange capacities and the high levels of aluminium saturation of the soil, the amounts of exchangeable calcium, magnesium and phosphorous are low, with aluminium reaching toxic levels in many areas (Goedert, 1983). The whole cerrado region has a tropical seasonal climate (Aw type of Köppen, 1931) with average annual rainfall in the order of $1500 \mathrm{~mm}$. The dry season lasts from 3 to 5 consecutive months during the winter of the Southern Hemisphere (May to September) (Ab'Saber, 1983).

The cerrado encompasses several structural types of open vegetation, from grasslands to dense woodlands. With such variation in form, the delimitation of physiognomic types is fairly arbitrary. A generally accepted classification based on the presence of woody elements recognises five structural types of cerrado vegetation (Eiten, 1972) (Figure 3.2):

a. campo limpo ('clean field') - a pure or almost pure grassland;

b. campo sujo ('dirty field') - a tree and shrub savanna, with widely scattered woody species;

c. campo cerrado - a wooded savanna, where the scattered low trees have a total crown cover of about $3 \%$, but the herbaceous species still appear as a conspicuous part of the landscape;

d. cerrado sensu stricto - a savanna woodland where the total woody cover is about $20 \%$;

e. cerradão - a woodland or open low forest, with a tree canopy cover above $50 \%$.

Throughout the cerrado region, these physiognomic forms can be found mixed and intergraded with one another, forming complex vegetation mosaics. The 'forest-ecotone-grassland concept' of Coutinho (1978a) describes this intricacy as a continuum of grassland formations (campos), savanna intermediary formations (cerrado sensu stricto - the most common cerrado formation) and forest formations (cerradão - the rarest cerrado formation). Goodland (1971a) quantitatively analysed 110 stands of cerrado vegetation in a region of Minas Gerais in central Brazil. He found a continuous variation in physiognomy and species composition. For example, from campo sujo to cerradão, canopy cover ranged from 0 to $85 \%$, ground cover from $30 \%$ to $2 \%$, number of tree species from 19 to 72 , and number of herb species from 79 to 21 . This gradual change along a physiognomic gradient suggests the ecotonal nature of the cerrado, especially in the intermediary formations.

Other savanna formations present within the cerrado include hyperseasonal savannas and veredas, generally occurring as treeless grasslands or sometimes as palm savannas with Mauritia vinifera. (Askew et al., 1970; Eiten, 1975). They occupy wet sites on valley sides or tableland margins 


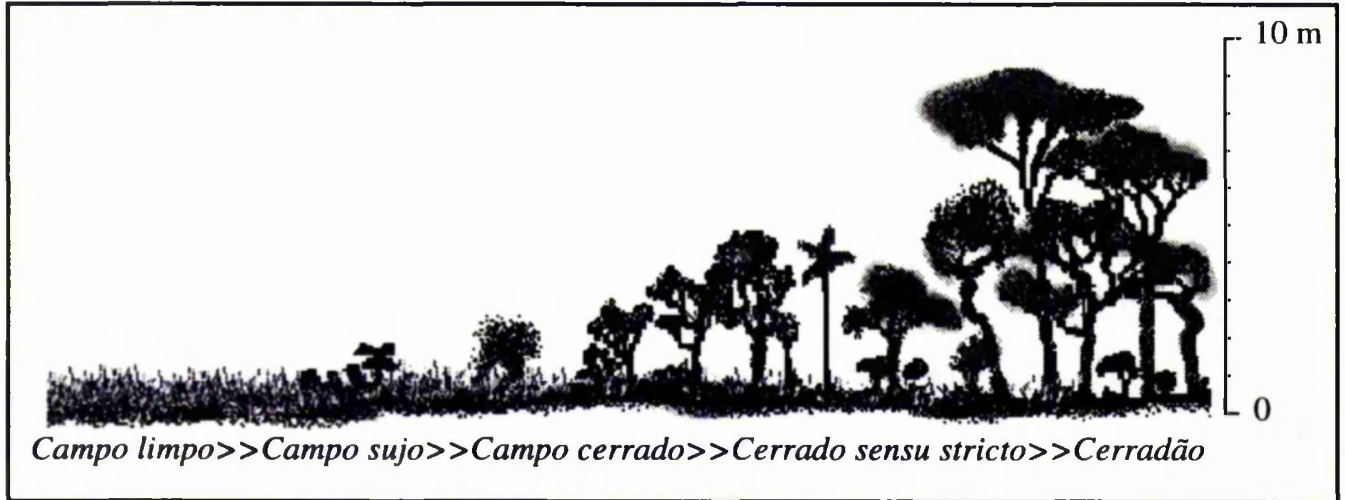

Figure 3.2 The basic structural gradient from campo limpo to cerradão.

throughout the area (Eiten, 1978), though they become more important in Mato Grosso, towards the transition to the Gran Pantanal formation (Eiten, 1975, 1978).

The flora of the cerrado is notably rich and diverse (Sarmiento, 1983; Eiten, 1994). Heringer (1971) recorded more than 300 species in one hectare of protected cerrado near Brasilia. According to Heringer et al. (1977), 774 woody plant species are known, while the herbaceous flora may comprise more than double this number. The total number of plant species in the cerrado is estimated to be around 2400 (Coutinho, 1990).

This high diversity is thought to have originated during the humid conditions of the last interglacial, when the Amazonian forest covered a much greater area of Brazil, with the cerrado having contracted to a few disjunct islands (Ledru, 1993; Prance, 1973, 1982a). It has been suggested that these remnant savannas formed 'refugia' (Haffer, 1969), harbouring species which began to diverge through evolution. The return of xeric conditions during the glacials resulted in the expansion and convergence of these refugia. In these circumstances, if speciation was complete, there would be geographic overlap, but if incomplete, either geographic exclusion of one form by the other or hybridisation would take place. These periodic fluctuations in savanna cover led to a high species diversity. This refugial hypothesis is largely based on biogeographic distributions of endemic species, as well as geomorphological data and paleoecological records (Bush, 1994). Characteristic examples of endemic cerrado flora include the genera Antonia (Loganiaceae), Austroplenckia (Celastraceae), Pterodon (Leguminosae) and Salvertia (Vochysiaceae).

More recent studies, however, emphasise the role of biotic interchange between the Amazonian rain forest, the Atlantic forest, and the cerrado, through successive expansions and contractions during the alternating glacial periods of the Pleistocene (Ab'Saber, 1977; Eiten, 1972; Heringer et al., 1977; Oliveira-Filho and Ratter, 1995; Sarmiento, 1983; Van der Hammen, 1974). These studies have rejected the refugia theory in favour of a more complex evolutionary history (Bush, 1994). In this new model, the endemic centres are not seen as unchanging refugia, but as areas most 
susceptible to climatic change, located primarily at ecotonal boundaries (e.g. cerrado/rain forest) (Brown, 1987). Here, rather than a marked species change, it is more likely that there was coexistence of both forest and savanna flora, forming a novel species assemblage (Bush et al., 1990; Piperno et al., 1990). The different rates of species expansion and contraction created communities of unique floristic composition in space and time. This resulted in hybridisation between related species, and the evolution of an endemic flora (Bush, 1994). Evidence for floristic interchange between different floras comes from the high number of genera, such as Caryocar (Caryocaraceae), that have both rain forest (e.g. Caryocar villosum) and cerrado (e.g. Caryocar brasiliense) species (Heringer et al., 1977; Prance, 1973, 1982b, 1987). This new 'diversity-instability' argument is in contrast to the 'diversitystability' concept of refugia theory, where species evolved in isolation.

Cerrado vegetation has two principal strata of flora: the ground layer; and the woody layer. The ground layer contains almost no annual herbs (Coutinho, 1990). It is composed of three growth forms (Eiten, 1994):

1) perennial herbs, defined as plants with herbaceous aerial stems throughout their existence;

2) 'recurrent sub shrub' which has a basal stem with or without bark, and a purely herbaceous upper stem - the whole stem dying from the base during either the dry or rainy season, and then new aerial stems arising from xylopodia (swollen, woody underground structures) in the following rains;

3) 'recurrent shrub', like 2), but here the whole stem has bark.

The woody layer is made up of trees, together with thick-stemmed 'persistent shrubs', which remain alive for many years producing new branches and increasing in girth (Eiten, 1994). These have rather large, usually stiff leaves, or large compound leaves with tiny to large leaflets; only a few species have soft, hairy or mesomorphic leaves (Eiten, 1982). Generally, cerrado trees have fewer branches for their size than tropical mesophytic forest trees or temperate zone trees, and many have rather open crowns (Eiten, 1982).

Though the study of cerrado phytogeography is still at an early stage, it has been shown that marked differences occur in floristic composition at a large scale between various regions of Brazil (Felfili and Silva Jr, 1988; Gibbs et al., 1983; Oliveira-Filho and Martins, 1991; Oliveira-Filho et al., 1989; Ratter, 1986, 1987; Ratter and Dargie, 1992; Ratter et al., 1973, 1988), and at a smaller scale between areas close to each other, such as the protected areas within the Federal District (Felfili and Silva Jr, 1993).

\subsection{Determinants and adaptations of cerrado vegetation}

The origins and the principal determinants of the cerrado vegetation have been discussed since the last century (Saint-Hilaire, 1824; Warming, 1892). In his classic work Lagoa Santa, Warming considered the cerrado to be a climatic climax determined by dry conditions during the winter months. Other authors, such as Rawitscher (1942a) and Ferri (1944) gave greater relevance to fire, although their work was restricted to the southern cerrado physiognomies. Some, like Goodland 
(1969, 1971a, 1971b), Lopes and Cox (1977) and Queiroz Neto (1982), have emphasised the role of soil dystrophy and aluminium toxicity. However, in the new conceptual framework of savanna modelling (Frost et al., 1986; Goldstein et al., 1988; Medina, 1987), there is no one single cause that governs cerrado formation. An approach employing 'hierarchy theory' (Solbrig, 1991), stresses the relative importance of all savanna determinants, at different spatial and temporal scales. The hierarchy diagram shown in Figure 3.3 hypothesises how the key determinants of the cerrado are related to one another, and within which spatial scales (region, landscape, catena, patch) they might play a significant role.

\subsubsection{Plant Available Moisture (PAM)}

At the regional scale, the limits of cerrado distribution coincide with the seasonal tropical climate predominant there. At a smaller scale the principal influences of relief, rock and soil type regulate the drainage conditions, and ultimately the water available for vegetation (Sarmiento, 1984).

The geomorphology of the cerrado region is one of the determinants of the hydrology at a landscape scale. For example, the Distrito Federal is characterised by relief forms of chapadas, plateaux whose surfaces are level or slightly rolling, and are dissected by elongated valleys (Novaes Pinto, 1994). With $57 \%$ of the chapadas above $1000 \mathrm{~m}$ in altitude, they act as water divides for Araguaia-Tocantins (Amazon), Paranã and São Francisco drainages (fluvial valleys) (Novaes Pinto, 1994).

Geology is the second most important landscape determinant. The chapadas of the Distrito Federal, for example, are covered with metamorphic rocks of very low porosity and permeability, with a heterogeneous distribution of laterite, quartzites, metasiltites and latosols (Barros, 1994). At the subsoil level, the prevalence of metamorphic rocks and various depths of hard laterite limit the replenishment of subterranean water (Barros, 1994; Haridasan, 1994). Characteristics of the latosol soils, which have a high clay content, are their high water holding capacity, low infiltration ability and problems with aeration after intense rains (Haridasan, 1994). Where quartzites predominate, the chapadas are covered in lithosolic soils of a shallow, stony and humus-rich composition, freely-drained and with good aeration (Bridges, 1978).

The mosaic of catenas present within the cerrado landscape determine gradients in ground water levels, closely matched by gradients in vegetation, from cerrado to gallery forest (Askew et al., 1970; Oliveira-Filho and Martins, 1986). Since cerrado species cannot tolerate soil waterlogging, even for a relatively short period (Eiten, 1972, 1975; Joly and Crawford, 1982), the occurrence of woody cerrado vegetation on more elevated, level sites reflects its requirement for soils which are well drained throughout the year (Furley and Ratter, 1988; Ratter et al., 1973). Where the water table is permanently high, swampy gallery forest presides, and in areas where the soil is 


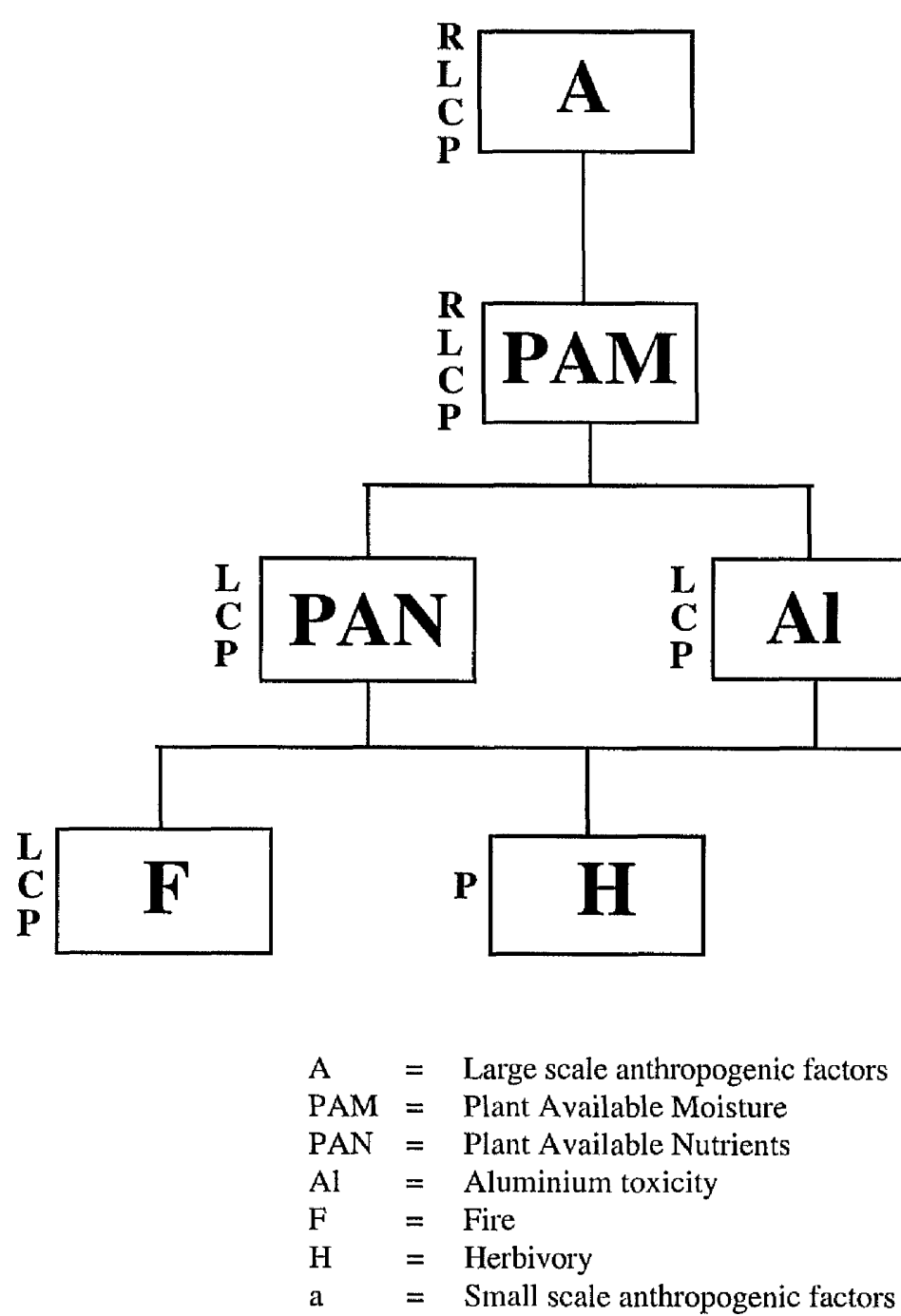

$\mathrm{R}=$ Region, $\mathrm{L}=$ Landscape, $\mathrm{C}=$ Catena, and $\mathrm{P}=$ Patch. These represent a range of scales at which each determinant has a significant role.

Figure 3.3 A hierarchy model of cerrado key determinants (modified by the author after Solbrig, 1991). N.B. Determinants at one level in the hierarchy are constrained by those above. Determinants at the same level of the hierarchy interact frequently and strongly.

inundated for part of the year, but dries up during the dry season, wet campo grassland is prominent (Freire, 1979; Furley, 1985).

Plant Available Moisture (PAM) also plays a role at the patch scale. A distinct community of tree species is formed on raised islands of ground within wet campos (Furley and Ratter, 1988). The island formations, called campos de murundu (Diniz et al., 1986; Eiten, 1982), are 
particularly common in inundated areas such as the Pantanal do Mato Grosso and the Ilha do Bananal. They consist of raised earthmounds bearing shrubs, termitaria, and cerrado trees, most commonly Curatella americana (Dilleniaceae) and Byrsonima crassifolia (Malpighiaceae) (Prance and Schaller, 1982; Ratter et al., 1973), two species which can tolerate periodic inundation of the soil. During this seasonal rise of the water-table, the deeper roots of these species die, causing chlorosis of the leaves, and subsequent annual leaf fall (Foldats and Rutkins, 1975).

The evolutionary significance of PAM is evident in the many examples of adaptations to water stress present in cerrado plant species. Studies of transpiration and water balance in a number of tree, shrub and grass species have shown that deep rooted woody species do not curtail their transpiration during the dry season, and some grasses, such as Echinolaena inflexa, simply dry out completely (Ferri, 1944; Maitelli, 1987; Rachid, 1947). This led to the conclusion that the deep roots of cerrado woody species enable them to reach enough disposable water in the lower levels of the soil during the dry season to survive (Miranda and Miranda, 1992; Rawitscher, 1948; Rawitscher et $a l ., 1943$ ). Many species also use xylopodia to store water (Coutinho et al., 1978). Sclerophylly is a common adaptation to water stress, and many species have leaves with thick cuticles, sunken stomata and greatly lignified tissues (Furley and Ratter, 1988).

\subsubsection{Plant Available Nutrients (PAN)}

Within the cerrado region, soil fertility is considered to be a major factor determining the vegetation (Eiten, 1972; Lopes and Cox, 1977; Queiroz Neto, 1982). As geology, geomorphology and soil characteristics control landscape hydrology, these factors also determine nutrient availability.

Higher levels of the chapadas, steep slopes, and low-lying areas all have different soil types of varying nutrient content and availability (Camargo and Bennema, 1966; Freitas and Silveira, 1977; Ranzani, 1971). For example, the dark red latosols found at higher levels of the Planalto have low nutrient reserves compared to other red latosols found on gently sloping topography. These differences in nutrient levels of the soil are reflected in the vegetation present.

An example is the occurrence of two types of cerradão. One occurs on soils with a high calcium content (between $3.25-7.58 \mathrm{me} / 100 \mathrm{~g}$ soil), and is identified by a number of indicator species such as Magonia pubescens and Callisthene fasciculata, allowing it to be recognised as a mesotrophic facies cerradão (Araújo, 1984; Ratter, 1971; Ratter et al., 1973, 1977). It is widespread in the cerrado region and has been recorded from many localities in Goiás, Minas Gerais, Mato Grosso and Mato Grosso do Sul, some of these more than $1500 \mathrm{~km}$ apart. Often associated with the margins of deciduous or semideciduous forest (the climax vegetation of better soils in the cerrado region), this cerradão indicates an intermediate in soil fertility between the dystrophic forms of cerrado and the deciduous forest (Furley and Ratter, 1988). A floristically different type of cerradão, dystrophic facies cerradão (Araújo, 1984; Ratter et al., 1977), with indicator species such as Hirtella glandulosa and 
Emmotum nitens, is found on dystrophic soils. Here, the soil calcium content falls to a range of 0.08$0.2 \mathrm{me} / 100 \mathrm{~g}$. This cerradão is widespread in central Brazil (in the absence of disturbance), especially in the Distrito Federal.

Changes in floristic composition and physiognomy of cerrado vegetation occurring at a catena scale are frequently hypothesised to be related with differences in soil fertility (Lopes and Cox, 1977). For example, Goodland and Pollard (1973) correlated increased production of woody vegetation (from campo limpo to cerradão) with an increasing soil fertility gradient in the Triângulo Mineiro, south Minas Gerais. However, other workers in the Distrito Federal such as Haridasan (1992) and Ribeiro (1983) failed to demonstrate this relationship, and found well-developed cerradão on no more fertile soils than other less woody forms of cerrado. Though these results could be partly explained by the occurrence of two types of cerradão (discussed above), it seems more probable that other determinants, such as fire, may be important in this area.

Oliveira-Filho et al. (1989) observed small scale variations (patch scale) in soil nutrient status, and suggests they may be due to localised soil patchiness. This patchiness could be accounted for by a number of factors including run-on nutrients from soil erosion, leaf-cutter ants (Atta species), which accumulate nutrients in their chambers (Constantino, 1988; Egler and Haridasan, 1987; Haridasan, 1994), and through the recycling of nutrients after patchy fires (see Section 3.5.3).

Research on physiological adaptations of cerrado species to poor nutrient levels is in its infancy. It is possible that many cerrado species have similar adaptations to other plants of nutrient poor areas, which include mycorrhizal symbiotic associations between plant roots and certain fungi, and storage of nutrients within living tissues (Allen, 1994; Crawford, 1989; Killham, 1994). The examples of plant adaptations to poor nutrient availability in the cerrado that are known are related to fire and include the presence of xylopodia, which absorb mineral nutrients particularly after the occurrence of fire (Coutinho et al., 1978) (see Section 3.5.3).

\subsubsection{Aluminium levels}

Goodland (1971a) described aluminium as an ecological factor with a strong negative influence over cerrado vegetation. At high soil concentrations, this element impedes the growth of roots by inhibiting the mechanisms of phosphorylation in the cells, and thereby interfering with normal growth (Clarkson, 1969). Aluminium also makes the essential plant nutrients phosphorus and calcium insoluble, thus reducing soil fertility (Coleman et al., 1960). The aray of factors associated with high soil aluminium concentrations have also been attributed to characteristics other than growth responses, such as the high degree of scleromorphy. It should be noted though that the more serious toxic effects attributed to aluminium appear to have been overrated, as 40 to $60 \%$ of the Amazon rain forest (non sclerophyllous) has equally high levels of aluminium (Tothill, 1985).

Aluminium levels are directly related to soil type and will therefore vary at the landscape, catena and patch scale. At the landscape scale, for example, Ratter et al. (1977) recorded 
aluminium levels in mesotrophic soils in Mato Grosso and Goiás of 0 and $0.62 \mathrm{me} / 100 \mathrm{~g}$ soil respectively, whereas Ribeiro (1983) found $2.36 \mathrm{me} / 100 \mathrm{~g}$ soil of aluminium in dystrophic soils in the Distrito Federal.

Though aluminium can reach toxic levels harmful to most plants, a taxonomically unrelated group of plants can actually accumulate aluminium in their tissues (Goodland, 1971b). These aluminium-tolerant plants include, most notably, the Vochysiaceae e.g. Qualea grandiflora, Qualea parviflora and Vochysia thyrsoidea (accumulating an extraordinary $14,120 \mathrm{mg} \mathrm{kg}^{-1}$ in its leaves), Palicourea species (Rubiaceae) and Miconia species (Melastomataceae) (Haridasan, 1982; Haridasan and Araújo, 1988; Haridasan et al., 1987). Aluminium-tolerant species are just as abundant amongst the larger trees of the cerradão as they are in the smaller species of more open forms of cerrado, suggesting that this characteristic does not seem to be associated with differences in the stature of the community (Haridasan, 1992). Nevertheless, the amount of aluminium in the soil at a catena and patch scale will determine which species will most successfully establish there, and in turn delimit the composition of the cerrado form present.

\subsubsection{Herbivory}

Herbivory by native fauna, a major determinant of other savanna formations (Solbrig, 1991), appears to play a less significant role in determining the cerrado, principally due to the low abundance of large herbivores present (Moura et al., 1989; Nascimento, 1987; Nascimento and Lewinsohn, 1992; Nascimento et al., 1990; Ojasti, 1978; Prado, 1989). Although the effects of native mammals may be negligible, insects, such as termites, are probably extremely important herbivores in the cerrado, as has been shown for other savanna regions (Andersen, 1995; Andersen and Lonsdale, 1991). However, the lack of research in this area means that the influence of herbivores on cerrado vegetation can only be ascertained at the patch scale.

\subsubsection{Anthropogenic factors}

Since the establishment of Brasilia in 1959/1960, development within the cerrado region has expanded from peripheral areas of the coastal states of Rio de Janeiro and São Paulo, to more western and northen cerrado in Mato Grosso, Mato Grosso do Sul and Tocantins (Alencar, 1979). The principal advance has been in large-scale commercial arable cultivation (wheat, maize, soya, sorghum), followed by extensive low production ranching (Furley and Ratter, 1988). Using liming and fertilisation, the low soil fertility resulting from high aluminium levels has been neutralised (Lobato, 1980; Sanchez, 1976, 1981). This, together with improved plant breeding (which has concentrated on enhancing root growth for obtaining higher water and nutrient extraction from greater soil depths (Goedert, 1983)), is likely to greatly increase crop production. For example, the production of crops such as soyabean has increased from virtually zero in 1960 to 5.8 million tonnes in 1987 (Klink et al., 1993), and sugarcane from 297,000 tonnes in 1970 to 1.3 million tonnes in 1980 (Mesquita, 1989). It 
has been estimated that using modern techniques, at least 50 million hectares of savanna (28\%) could be developed for crop production (Wagner, 1981).

Other major factors increasingly affecting the cerrado region include the growth of urban and industrial land-use, the construction of reservoirs and dams, and the extensive planting of eucalypts and pines for pulp and charcoal production (Dias, 1994).

Anthropogenic factors work at two different leveis. At one level are the factors described above, which determine the cerrado from the landscape (e.g. farming), to the patch scale (e.g. dumping household waste). At another level, anthropogenic factors can influence the vegetation at all scales, including the regional scale. This could be the effect of global warming for instance. It is for this reason that large-scale anthropogenic factors (A) are distinguished from small-scale anthropogenic factors (a), and that the former ' $\mathrm{A}$ ' is placed at the top of the hierarchy diagram.

\subsubsection{Fire}

Fire is undoubtedly extremely important in the cerrado. Frequent fires favour the more open forms, whereas protection from fire allows the woody vegetation to establish, and succession continues to the closed cerradão when other factors are not limiting (Ferri, 1973; Henriques, 1993; Ratter, 1991; Ratter et al., 1973, 1978). Several authors, like Rizzini and Heringer (1962) and Rizzini (1963) have considered the cerradão as the original forest type in the whole cerrado area, the other structural types having been derived by human activities, particularly burning. Though this hypothesis may be applicable to some restricted areas, it is improbable that the whole cerrado region is determined by ancient anthropogenic management (Sarmiento, 1983).

As a determinant of the cerrado, fire acts at the landscape, catena and patch scales. At the landscape scale, geomorphology is the important factor. An example are the relief forms of chapadas in the Distrito Federal, which control the plant available moisture, and in turn, determine the water content of combustible fuels within the cerrado vegetation. The catenas within this landscape are a parallel gradient of soil moisture and vegetation type. Again, at this catena scale, the water content of combustible fuels will vary, as will the quantity of combustible fuel, according to the cerrado physiognomy present (see Section 3.5). The effect of topography on fire behaviour will also be important at this scale. At the patch level, the mosaic distribution of combustible fuels within the vegetation and the microclimatic conditions will determine fire behaviour.

\subsection{The role of fire in the Brazilian cerrado}

Fire as a stress in the cerrado has been discussed ever since the classic works of Saint-Hilaire (1824, 1847), Warming (1892) and Löfgren (1898). Wildfires have been significant in the cerrado since at least the Middle Holocene, some 6,000 years B.P. (Vernet et al., 1994), and even today, natural causes of fire, such as lightning, are reported by farmers and park rangers. However, their 
importance has not been recognised due to the sheer lack of research on the subject (Coutinho, 1990). Even so, humans are unquestionably the principal cause of fire in the cerrado.

People have been using fire for more than 32,000 years in central Brazil (Guidon and Delibrias, 1986). Anthropological research shows that even before the colonisation of Brazil by the Portuguese, Indians were using fire in burning vegetation for hunting and tribal wars (Lukesch, 1969; Villas-Boas and Villas-Boas, 1976). Even today, the Kayapó Indians use fire to limit the growth of certain undesirable species and to stimulate the production of certain native fruit-bearing trees (Anderson and Posey, 1985, 1987). A large number of cerrado species either tolerate or depend on fire, further evidence for the case that fire is an old and major ecological factor in this ecosystem (Coutinho, 1990).

Today, the more open forms of the cerrado are frequently used by cattle ranchers as natural pastures (Klink et al., 1993). During the dry season in central Brazil, the cattle suffer from a lack of palatable, green feed, so firing the cerrado in the second half of the dry season (AugustSeptember) constitutes the cheapest management practice undertaken by the cattle ranchers. In a matter of just a few days or weeks following a fire, the vegetation sprouts, thus providing the cattle with feed, rich in protein, cellulose and salts. This is now the principal cause of fires in the cerrado region (Coutinho, 1990).

To bring in new agricultural land, vast areas of the cerrado are cleared and burned at the end of the dry season (August-September). These sites are then ploughed, fertilised, and sterilised with pesticides, eliminating the majority of native plant and animal species and resulting in the irrevocable loss of cerrado biodiversity (Klink et al., 1993). This is the second major cause of fires in the cerrado at present (Coutinho, 1990).

Other burns arise from various causes, such as the control of shrubs in pastures, pest control, carelessness in fire management in intentionally burned areas (such as during the cutting and burning of vegetation while cleaning the edges of highways and railroads), and the falling of balloons with the wicks still alight during the June religious festivals (Coutinho, 1990). Although carelessness with cigarettes does not seem to be relevant in the cerrado (Coutinho, 1990), arson is common, whether by hunters hoping to catch wild animals escaping from the flames, or local people who burn the vegetation for the aesthetic value fire has (Heloisa Miranda, pers. comm. 14/9/94).

According to Eiten and Goodland (1979), to sustain a cerrado physiognomy, burning should occur at a frequency of every 3 years. This allows enough time for both the herbaceous and woody layers to recover sufficiently. However, population increases and agricultural expansion have led to an increase in burning rates, and large areas still covered in natural vegetation are now burned almost every year (Klink et al., 1993). Though fire frequency is important, the nature of a fire is equally decisive in determining how an area of cerrado may recover from, or degrade due to, fire. Since the cerrado consists of various physiognomies, fire behaviour will vary from one form to another. 


\subsection{The nature of cerrado fires}

Fires in the cerrado are characteristically surface-level (Chandler et al., 1983) and fast-moving (reaching speeds of $30 \mathrm{~m} \mathrm{~min}^{-1}$ (Kauffman et al., 1994)), consuming the herbaceous layer, but rarely igniting the taller woody plants (Miranda and Miranda, 1993) (see Figure 3.4).

They usually begin with the onset of the dry season (May-June), increase in frequency and intensity during June and July, and attain a maximum peak in August (Coutinho, 1990). As the wet season starts (September-October), the occurrence of fires drops markedly, and although prescribed burning does not take place, the vegetation is still susceptible to burning, particularly in areas where there have been no burn-offs for several years, and/or after a sequence of hot days in the absence of rain (veranico) (Cochrane et al., 1988). The period between August to the beginning of September is particularly favourable for the propagation of fire, as relative air humidity during the hottest hours of the day $\left(25-30^{\circ} \mathrm{C}\right)$ can reach below $20 \%$, and the days are very windy (Coutinho, 1982a). In years of frosts, a great part of the epigeous phytomass in the herbaceous/undershrub stratum dies. This, and the accompanying fall of leaves from many trees and shrubs accumulate on the soil as an easily dehydratable and highly combustible material, greatly increasing the risk of fire (Coutinho, 1990).

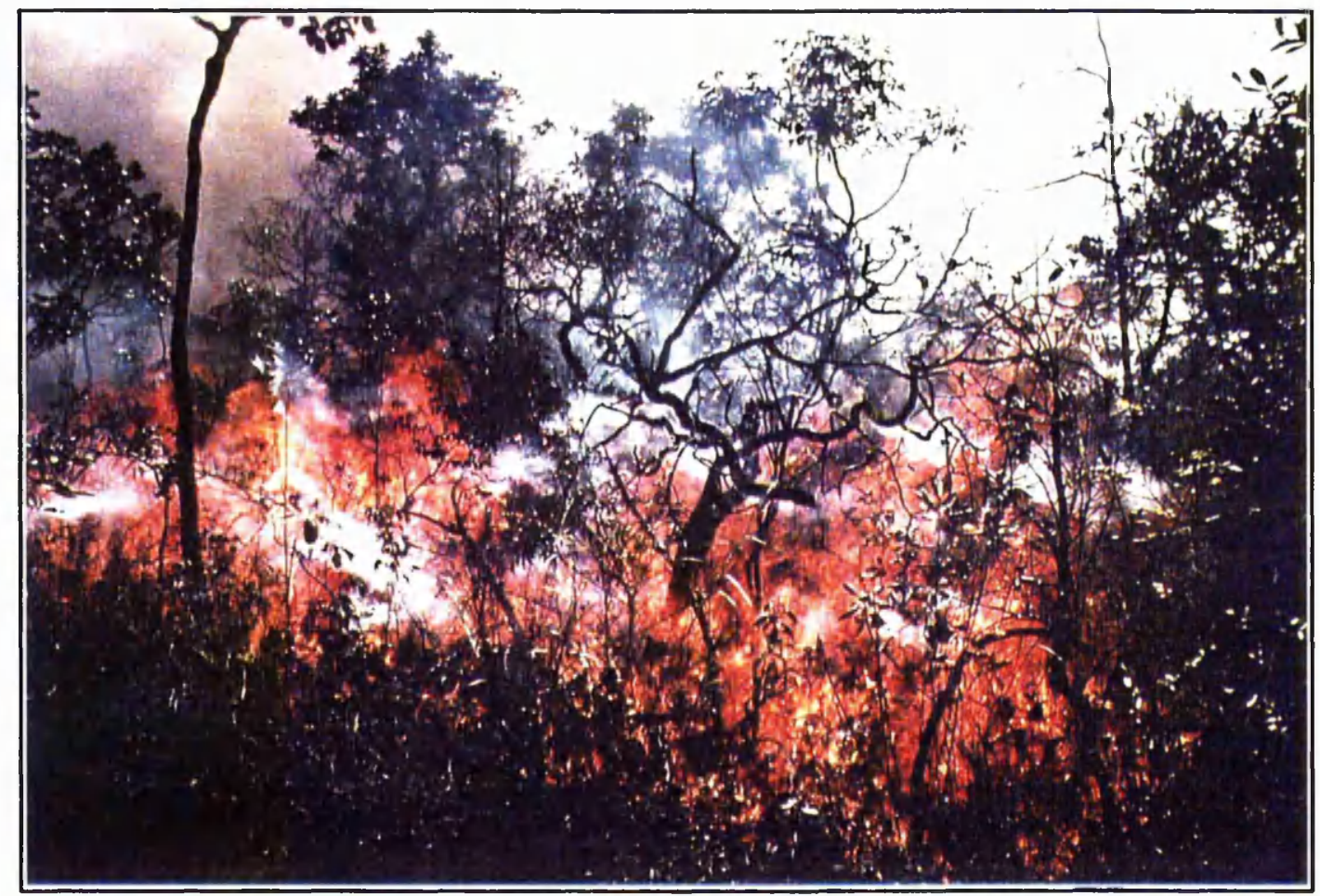

Figure $3.4 \mathrm{~A}$ backfire in cerrado denso vegetation at $2: 40 \mathrm{pm}$ in the Reserva Ecológica do IBGE, 24/8/94. (Photo by the author). 
The cerrado landscape is characterised by gently sloping hills, and in view of this fact, topography probably plays an important role in fire spread, which increases with degree of upslope due to fuel preheating (McArthur, 1971). Unfortunately, research has yet to be carried out on this aspect. of fire behaviour in the cerrado.

The types of fire that occur in the cerrado vary in behaviour most notably in relation to fuels, which is intrinsically related to physiognomy (Kauffman et al., 1994). These fuels also govern the vertical distribution of temperatures, and the amount of nutrients released into the air as part of mineral recycling.

\subsubsection{Fuel and fire}

Although total fuel biomass is significantly greater in cerrado sensu stricto and cerradão, the biomass of grasses is considerably lower than in the campo limpo or campo sujo (Coutinho, 1982a; Kauffman et al., 1994; Pivello and Coutinho, 1992; Miranda and Miranda, 1993; Ward et al., 1992). Because of their high degree of flammability, grasses and other ground-layer vegetation are a major influence on fire behaviour in different cerrado physiognomies. In a campo sujo, for example, where grasses can represent up to $91 \%$ of the combustible fuel (Ward et al., 1992), fires can reach temperatures higher than $800^{\circ} \mathrm{C}$ (Berardi, 1994; Cesar, 1980), whereas cerrado types with prevailing woody elements, e.g. cerrado sensu stricto, yield significantly lower temperatures (Miranda et al., 1993). There is virtually no smouldering combustion following flaming combustion in either campo limpo or campo sujo (due to the low woody biomass), compared to campo cerrado and cerrado sensu stricto, where smouldering combustion is prevalent (Kauffman et al., 1994). This suggests that fire has a greater influence in the open cerrado forms, and that more woody plants will be killed, rather than scorched, in the closed physiognomies.

It is also possible to explain the difference in fire behaviour along the gradient of cerrado physiognomies according to fuel moisture content. Kauffman et al. (1994) found that fuel moisture content was very low in dry, non-green grass (22-29\% dry weight basis), comprising $78 \%$ of the fuel mass in campo limpo and $40 \%$ in campo cerrado. In contrast, fuel moisture content of the woody component ranged from 118 to $140 \%$ (dry weight basis) - $28 \%$ of the fuel mass in campo cerrado yet less than $6 \%$ in campo limpo. Total mass of water in fuels was calculated to be $<3,100 \mathrm{~kg}$ $\mathrm{ha}^{-1}$ in campo limpo and campo sujo, and $\geq 4,600 \mathrm{~kg} \mathrm{ha}^{-1}$ in campo cerrado and cerrado sensu stricto. The differences in moisture content affect the ignitability of fuels, thus possibly contributing to the lower impact of fire on the tree-dominated communities, in comparison to the grasslands.

The different physiognomies of cerrado vegetation, in terms of their densities and corresponding microclimates, also affect fire behaviour. Miranda et al. (1993) recorded a maximum fire temperature of $260^{\circ} \mathrm{C}$ in an area of cerrado sensu stricto which had been protected for 15 years and burned 3 days after rain. Many patches of the vegetation remained unburned. In contrast, campo sujo burned on the same day under the same conditions, left only the woody vegetation unburned, and 
attained temperatures in the region of $650^{\circ} \mathrm{C}$. Shading of the fine fuel on the ground by trees and shrubs affects the rate of fuel moisture loss, causing mosaic-like burns in the more closed cerrado types. In the open campo sujo, most of the dry matter is not in close contact with the wet soil surface, and is well exposed to wind and solar radiation, so moisture is quickly lost to the environment (Luke and McArthur, 1978; Miranda et al., 1993).

The timing of the a burn will affect fire behaviour. Generally, fires during the early dry season (May to June) are patchy and of a low intensity, due to the high moisture still present within the vegetation from the rainy season. The mid-season fires (July to August) are of a higher intensity and more homogeneous, since most of the combustible fuel may be dry, and the climatic conditions may be ideal for fire propagation. In the late dry season, two scenarios are possible: the build-up of dry combustible fuel, and peak air temperatures may cause very intense fires; or, the onset of the rains may result in patchy, low intensity burns (Miranda and Miranda, 1993).

'Time-since-last-fire' also determines the characteristics of cerrado fires. Areas protected from fire for long periods of time will burn at higher temperatures than those areas burned regularly, regardless of their physiognomic type, due to the build up of combustible fuels (Miranda and Miranda, 1993; Miranda et al., 1993).

\subsubsection{Vertical distribution of temperatures during fires}

As fires vary horizontally, they also have a vertical pattern of distribution in terms of temperature. At the soil level, temperature increases during cerrado fires are relatively small e.g. around $50^{\circ} \mathrm{C}$, decreasing exponentially with depth, and becoming more or less negligible at and below $5 \mathrm{~cm}$ depth (Cesar, 1980; Coutinho, 1976, 1978b; Miranda et al., 1993). These insignificant soil temperature changes are irrespective of the physiognomic form being burned, and the maxima observed are unlikely to have any direct effect on soil organic matter, microbial populations, or buried seeds (Miranda et al., 1993).

Miranda et al. (1993) found that regardless of cerrado physiognomy, at $1 \mathrm{~cm}$ above the ground, $60 \mathrm{~cm}$ height and $160 \mathrm{~cm}$ height, maximum temperatures ranged from 85 to $326^{\circ} \mathrm{C}, 180$ to $840^{\circ} \mathrm{C}$ and 107 to $650^{\circ} \mathrm{C}$ respectively. Also, the residence time (duration of temperatures) above $60^{\circ} \mathrm{C}$ varied from 90 to 270 seconds at $1 \mathrm{~cm}$ above the ground, 90 to 200 seconds at a $60 \mathrm{~cm}$ height, and 20 to 70 seconds at a $160 \mathrm{~cm}$ height. Other data confirm these results, which suggest that the highest temperatures occur between 1 to $60 \mathrm{~cm}$ above the ground, and that the residence time above $60^{\circ} \mathrm{C}$ also peaks at this height range (Miranda and Miranda, 1993). This could be related to the height of combustible fuels within the herbaceous layer. Above $60 \mathrm{~cm}$, fire temperatures decrease, with temperatures reaching peaks of up to $700^{\circ} \mathrm{C}$ for short periods of time. These different fire temperatures and residence times at various heights in the vegetation may be extremely important in determining the survival and subsequent recolonisation of lichen communities. Lichens present on higher sections of phorophytes may be exposed to relatively low fire temperatures for only a few seconds, and so many 
with adaptations to high temperatures (see Section $2.2 .2 b$ ) may survive the fire. These, together with the lichens remaining above the flame heights, may then aid recolonisation of the bare bark surfaces.

\subsubsection{Fire and mineral nutrient cycling}

Generally, the soils underlying the cerrado are rather poor in mineral nutrients, distinctly acidic, and with high levels of aluminium (Goodland, 1971b; Lopes, 1975; Lopes and Cox, 1977). Fire is intimately related to this nutritional status since it is involved with the cycling of mineral nutrients (Coutinho, 1990). Through the action of fire, most of the epigeous biomass is rapidly mineralised, with nitrogen, carbon, sulphur and to a lesser extent, phosphorous and potassium, volatilised and lost to the atmosphere, and the remaining material either deposited on the soil surface as ash, or removed as particulate matter in smoke (Frost and Robertson, 1987).

In the cerrado, the immediate effects of burning result in an increment at the soil surface $(0$ to $5 \mathrm{~cm}$ ) in concentrations of calcium, magnesium, phosphorous and potassium, and the complete disappearance of aluminium, which can remain at zero levels for up to 40 days (Cavalcanti, 1978; Coutinho, 1982a). Deeper down in the soil there is no change in these nutrients or in aluminium levels, suggesting that the ash deposited on the top soil is highly beneficial to the growth of herbaceous/undershrub plants with superficial root systems, since they are provided with a large quantity of mineral nutrients and a significant reduction in aluminium toxicity (Coutinho, 1990).

However, for the tree/shrub layer which generally possesses deep root systems (Rawitscher, 1942a, 1942b; Rawitscher et al., 1943), fire is detrimental, since nutrients made available from burned leaves, flowers, fruits and branches, are transferred to the herbaceous layer (Batmanian, 1983; Cavalcanti, 1978). Compensation for this loss of nutrients from the tree/shrub vegetation is brought about through the action of leaf-cutter ants (Atta species), which are frequently encountered in the cerrado (Coutinho, 1982b). Through their foraging activity, nutrients are transported to chambers at depths of 6 to $7 \mathrm{~m}$ in the soil. Although this process is limited to where the ants have their nests, in the long term, nutrients will be absorbed by the deep roots of the tree/shrub stratum, and may determine cerrado vegetation at the patch scale.

Kauffman et al. (1994) looked at the relationship between fire and nutrient dynamics along the physiognomic gradient in the cerrado. They found that though the pool size of nitrogen, carbon and sulphur (within the fuel load) increased along the gradient from campo limpo to cerrado sensu stricto, the percentage of those nutrients lost by fire decreased. For example, along the gradient, total mass of nitrogen increased from 24 to $55 \mathrm{~kg} \mathrm{ha}^{-1}$, but nitrogen lost by fire was greater or equal to $90 \%$ of the pool in the grasslands, in comparison to less than $56 \%$ in the tree-dominated communities. This is probably due to the significantly greater amounts of readily accessible combustible fuel in the grasslands, while nutrients remain locked up in the woody plants, which rarely burn. Other data showed that in cerrado sensu stricto, greater quantities of nutrients were lost as particulates, whereas in campo limpo, most of the nutrients were volatilised during fire. These levels of losses through 
volatilisation are especially important because they are likely to be ecosystem losses (Raison, Khanna and Woods, 1985) in contrast to particulate losses, which may be redistributed within the ecosystem. However, the amount of nutrients lost in the cerrado due to fire represents a minor proportion of the total pool (in roots, soils and above-ground woody vegetation), and is likely to be replaced through natural inputs, particularly through rainfall (Coutinho, 1979; Schiavini, 1984), in one to three years (Kauffman et al., 1994; Pivello-Pompêia, 1985).

\subsection{Plant adaptations to fire}

The closed cerradão is comprised of many species, for example Emmotum nitens and Ocotea pomaderroides, that are extremely fire sensitive (Moreira, 1992). The flora of the open cerrado forms, on the other hand, and especially the herbaceous/undershrub stratum, is typically pyrophytic (Coutinho, 1990). One pyrophytic characteristic of cerrado species is the strong suberisation of the trunk and branches of the trees, permitting thermal isolation of the living internal tissues (Eiten, 1994). Other species maintain the capacity to produce vigorous sprouts from subterranean roots following the total carbonisation of the aerial branches (Rachid-Edwards, 1956). Even the seedlings of certain tree species may present this type of adaptation (Dionello, 1978).

Some trees protect their dormant apical buds using dense, hairy cataphylls e.g. Anemia anthriscifolia (Rachid-Edwards, 1956). Others however, have exposed dormant apical buds, and these frequently die during the fires. A few days later, adventitious buds may sprout from the branches, resulting in sympodial growth of the stems (Eiten, 1982). This imparts the most characteristic feature of the taller shrubs and trees, which enables a cerrado to be recognised on sight its tortuosity.

It is among the herbaceous/undershrub flora that the majority of species highly resistant to fire can be found. Some are annuals, growing and developing during the rainy months, thus escaping the dangers of dry season fires as seeds. Many perennial species possess subterranean organs such as bulbs, underground shoots, rhizomes, and xylopodia, which avoid damage from fire. The densely imbricated sheaths of some grasses provide protection by limiting combustion due to inadequate aeration e.g. Aristida pallens (Rachid-Edwards, 1956). Some woody species present in the herbaceous/undershrub stratum develop their entire system of trunks and branches subterraneously, with only the small vegetative branches or yearly reproductive sprouts protruding above the soil. This example of cryptophytism can be found in trees such as Anacardium pumilum and Andira humilis and among palms such as Acanthococos emensis and Attalea exigua (Lopez-Naranjo, 1975; Rawitscher et al., 1943; Rawitscher and Rachid, 1946).

Burning induces flowering and fruit dehiscence in many cerrado species, and some seeds of the Mimosa genus require a thermal shock in order to germinate (Almeida and Silva, 1989; Coutinho, 1982a; Coutinho and Jurkevics, 1978). Coutinho (1977) postulates that fire has a beneficial 
effect on these species by cleaning out obstructing vegetation, thus facilitating pollination and seed dispersion.

\subsection{Choice of study site}

The Reserva Ecológica do IBGE (IBGE) and the Jardim Botânico de Brasilia (JBB) were chosen as the research sites due to the existence of the 'Projecto Fogo' (Fire Project). This project was set up in 1989 to determine the effects of different burning regimes on the structure and dynamics of cerrado communities in Brasilia (D.F.). This area contains plots with known fire histories, so by assessing the lichen communities in these plots, any relationship between fire and lichen presence could be ascertained and used to form a LFH Key.

Another factor determining the choice of this site was its convenient location, just 33 km outside Brasilia, easily accessible by either bus or car.

\subsection{Site description}

The Reserva Ecológica do IBGE, also known as the Reserva Ecológica do Roncador (RECOR), was created in 1975, and covers an area of 1300 hectares. It is situated $33 \mathrm{~km}$ south of the centre of Brasilia (D.F.), and is adjoined by two other areas of preservation: the Jardim Botânico de Brasilia; and the Fazenda Agua Limpa (University of Brasilia) (Figure 3.5). Together, these form an area more than $7000 \mathrm{ha}$, with an altitude of between $1048-1150 \mathrm{~m}$, and a $3.5 \%$ slope (Pereira et al., 1989). Both reserves reside in a chapada, a high tableland classified within the larger physiognomic unit termed 'Pratinha Surface Highlands' (Cochrane et al., 1985). This physiognomic unit is found in the epicentre of the Brazilian Shield, the elevated and exposed Precambrian shield region of central Brazil, characterised by old, stable plateau surfaces (Ab'Saber, 1971). The earths are mostly covered by detrites-lateritics of the Tertiary, with considerable bands of Quaternary alluvials and the soils are predominantly red-yellow and dark-red latosols (EMBRAPA, 1980, 1987). The vegetation is complex and diverse, represented by the major forms of cerrado, including campo limpo, campo sujo, campo cerrado, cerrado sensu stricto, and cerradão. Gallery forests and swamps are present by the permanent waterways.

\subsubsection{Climate}

The climate of the study site has two well defined seasons. The rainy season begins in September or October and prolongs until April or mid-May. During these months about $75 \%$ of the total annual precipitation falls. The dry season lasts from June through to September. Mean annual temperatures range from a maximum of $29.3^{\circ} \mathrm{C}$ in the summer (September being the hottest month), to a minimum of $15.8^{\circ} \mathrm{C}$ in the winter (July being the coolest month). The average annual temperature is $21.3^{\circ} \mathrm{C}$ (Neto, 1991). Mean annual rainfall is $1,667 \mathrm{~mm}$, peaking in the months of November, December and January, falling in May, with June, July and August having little or no rain (Pereira et 


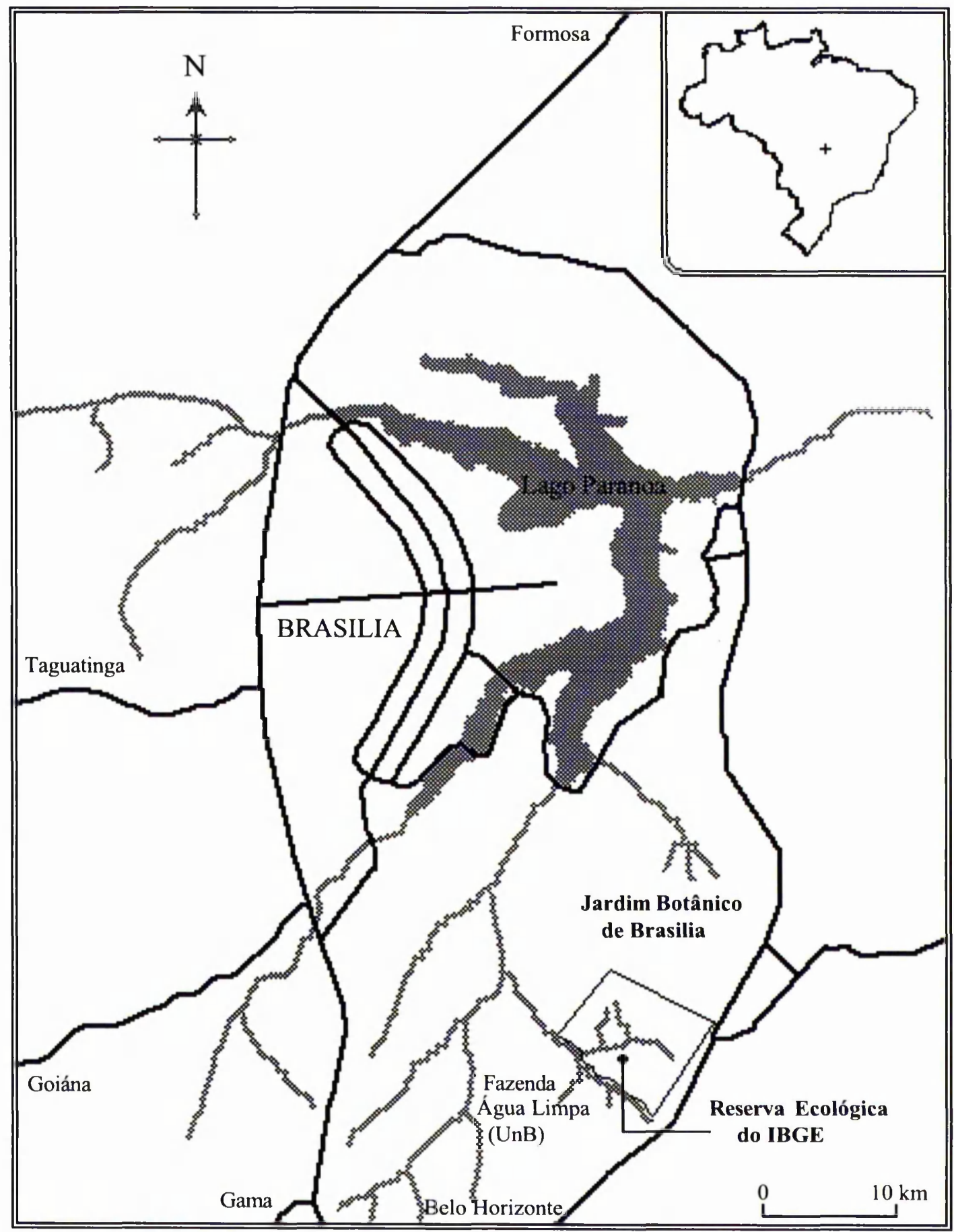

Figure 3.5 Map of the Distrito Federal, showing the locations of the Reserva Ecológica do IBGE and the Jardim Botânico de Brasilia (modified by author after Pereira et al., 1989). Key: black lines, roads; grey lines, water. 
al., 1989). The relative humidity of the air varies throughout the year, registering between 72 and $83 \%$ in the summer and between 58 and $67 \%$ in the winter months, with some days in August and September falling to an average of $20 \%$. Most evaporation occurs between June and October, peaking in August, with average annual evaporation very slightly exceeding annual precipitation. The winds are of a weak to moderate nature, the velocity on average in the order of $2.1 \mathrm{~m} \mathrm{sec}^{-1}$. In the dry season, winds are mostly easterly, while in the rainy season they vary from north-easterly, easterly to north-westerly (Pereira et al., 1989).

Compared to the climate of previous years at IBGE (Pereira et al., 1989), the fieldwork year (October 1993 to September 1994) proved to be notably drier than usual, with no rain and very low humidities recorded in August and September. Relative humidity fell to $11 \%$ on the 15 th of September 1994, the lowest ever recorded for Brasilia ("O Globo", 16/9/94). Figure 3.6 shows the rainfall, air temperatures and relative humidities at the IBGE meteorological station for the period of this study.

\subsubsection{The Projecto Fogo}

The Projecto Fogo is located in both IBGE and JBB, $1555^{\prime}$ '58" S, 47 51' 02 " W. Set up in 1989 , the areas used in the project were initially selected for their homogeneity in topography and edaphic factors (low downward slope and typical latosols, predominant in the cerrado), and to have a gradient of vegetation from campo limpo to cerradão. The experimental area was divided into 3 blocks of 50 hectares, each block relating to a form of cerrado vegetation. These blocks were then subdivided into 5 plots of $200 \mathrm{~m} \times 500 \mathrm{~m}$, to be subjected to a specific experimental treatment. Five treatments, of different times and frequencies of burns, were established for each block:

1) no burning (control) - a regime proposed in the management plans of the National Parks of the cerrado, in favour of succession towards cerradão;

2) early biennial burn (end of June) - an alternative regime to reduce the chance of accidental fires by eliminating excessive combustives, control alien grasses by destroying the flowering structures, and provide food for the fauna during the dry season;

3) middle biennial burn (beginning of August) - the regime dominant in the cerrado;

4) late biennial burn (end of September) - the regime that has probably the biggest impact on the vegetation due to the phenological patterns of peaks in renewal of crowns and reproduction;

5) middle quadrennial burn (beginning of August) - to favour the recruitment of trees.

Before the project was established, both IBGE and JBB had different fire management policies. Within IBGE, fires were not controlled until 1974, after which a fire protection policy was introduced. Thus, the whole Projecto Fogo area within IBGE has not been burned since 1974. The JBB, on the other hand, has a 'let-burn' policy, with patchy burns occurring on average every two years. Here, the plots of the Projecto Fogo have been protected from fire only since 1986. Both reserves are protected from cattle grazing. 


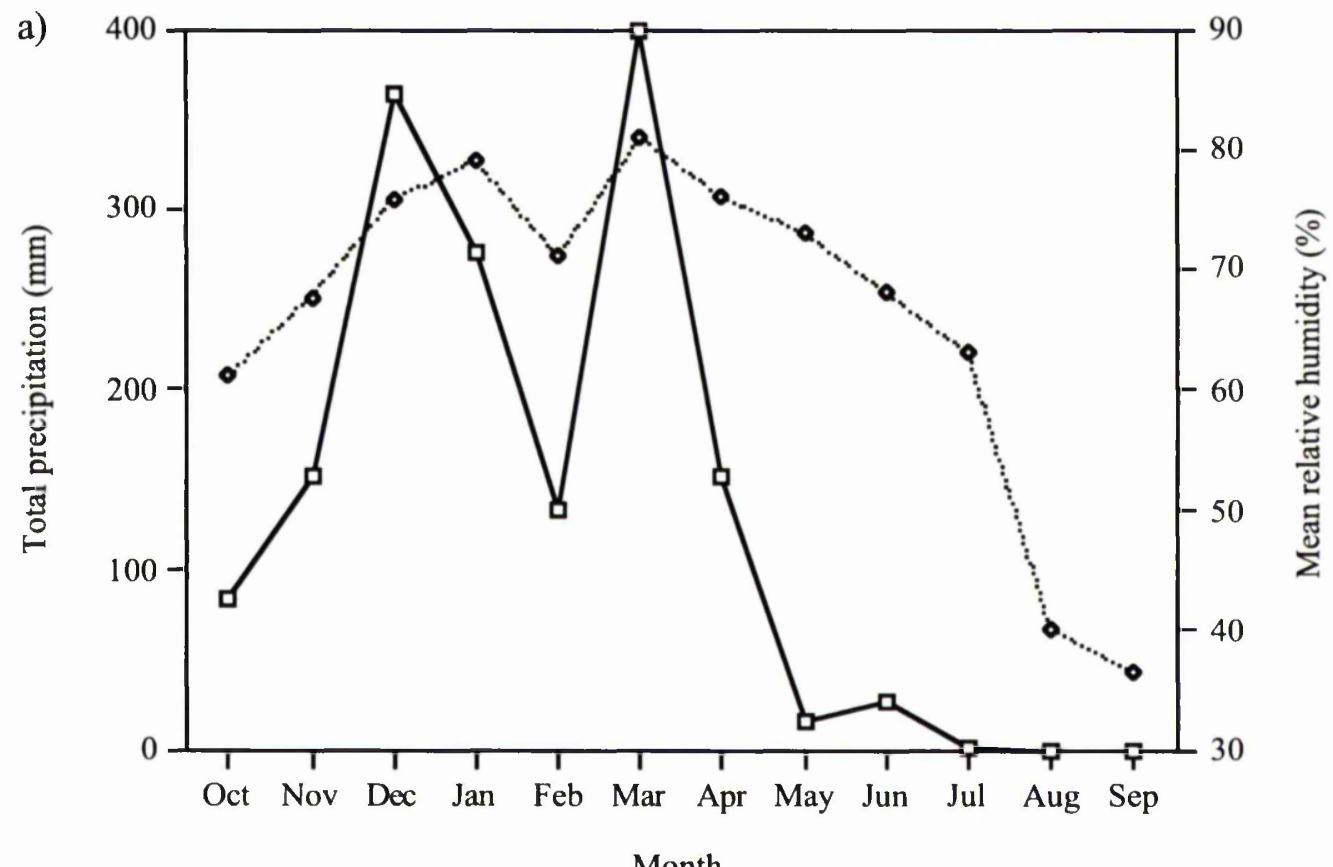

Month
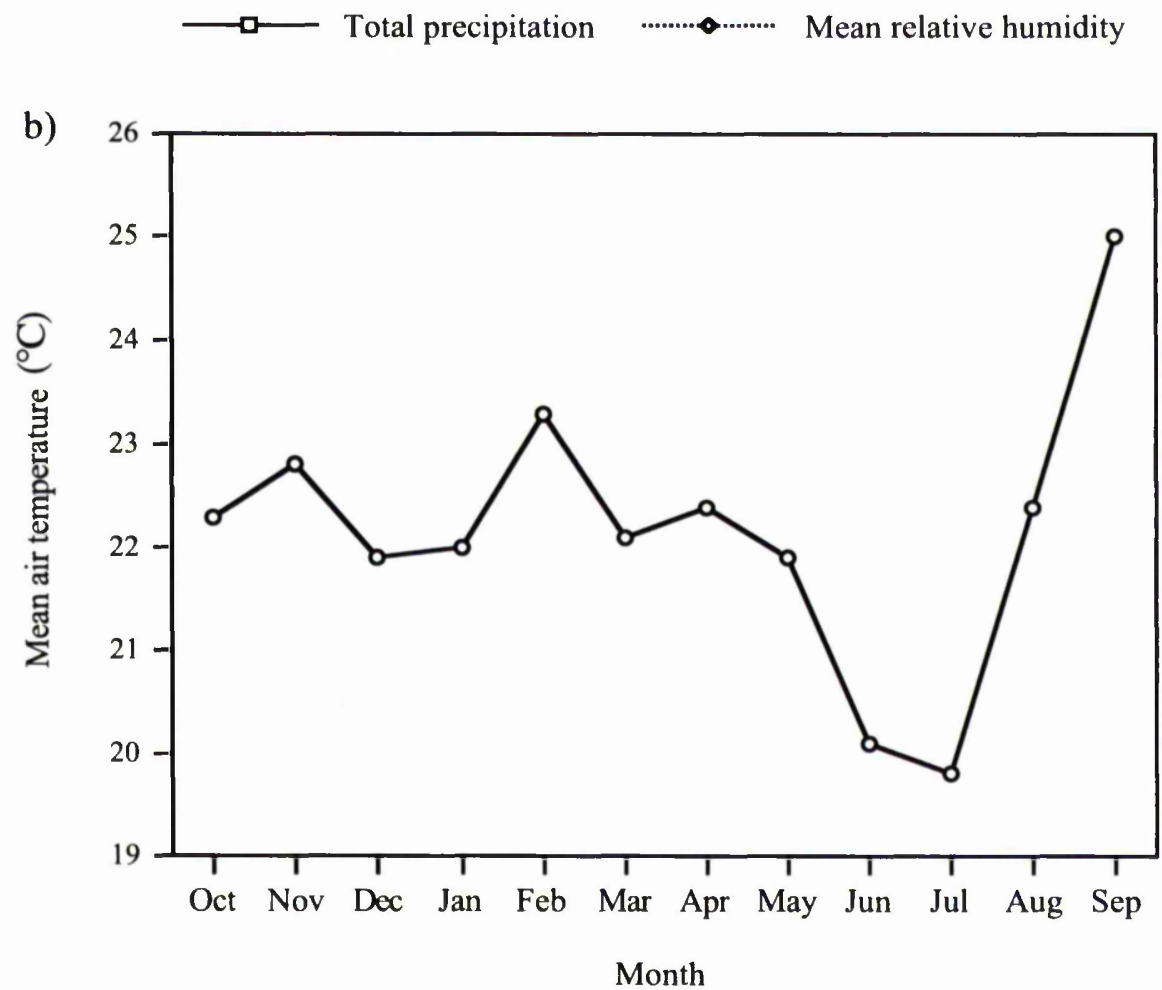

Figure 3.6 Climate at the Reserva Ecológica do IBGE from October 1993 to September 1994: a) the total monthly precipitation $(\mathrm{mm})$ and the mean monthly relative humidity $(\%)$; b) the mean monthly air temperature $\left({ }^{\circ} \mathrm{C}\right)$. (Source: Reserva Ecológica do IBGE meteorological station). 


\subsubsection{Plot descriptions}

The plots of cerrado chosen for this work were classified as campo denso within the Projecto Fogo (Figure 3.7). These were essentially a combination of cerrado sensu stricto and cerradão, with one form presiding over the other in different patches within the plots. Campo denso was used because observations prior to data collecting showed that lichen presence was greatest in this cerrado vegetation type. It also comprises cerrado sensu stricto, the 'typical' and most widespread cerrado vegetation type.

In total, ten plots of campo denso were used for this study, five in IBGE and five in JBB (Figure 3.8), with specific plots used for certain lines of research (see Chapter 4). It is assumed that climate, soil type and topography are consistent between and within all the plots, due to their close proximity to each other. It is therefore presumed that differences in woody species composition and vegetation structure between the plots arises from variations in fire history.

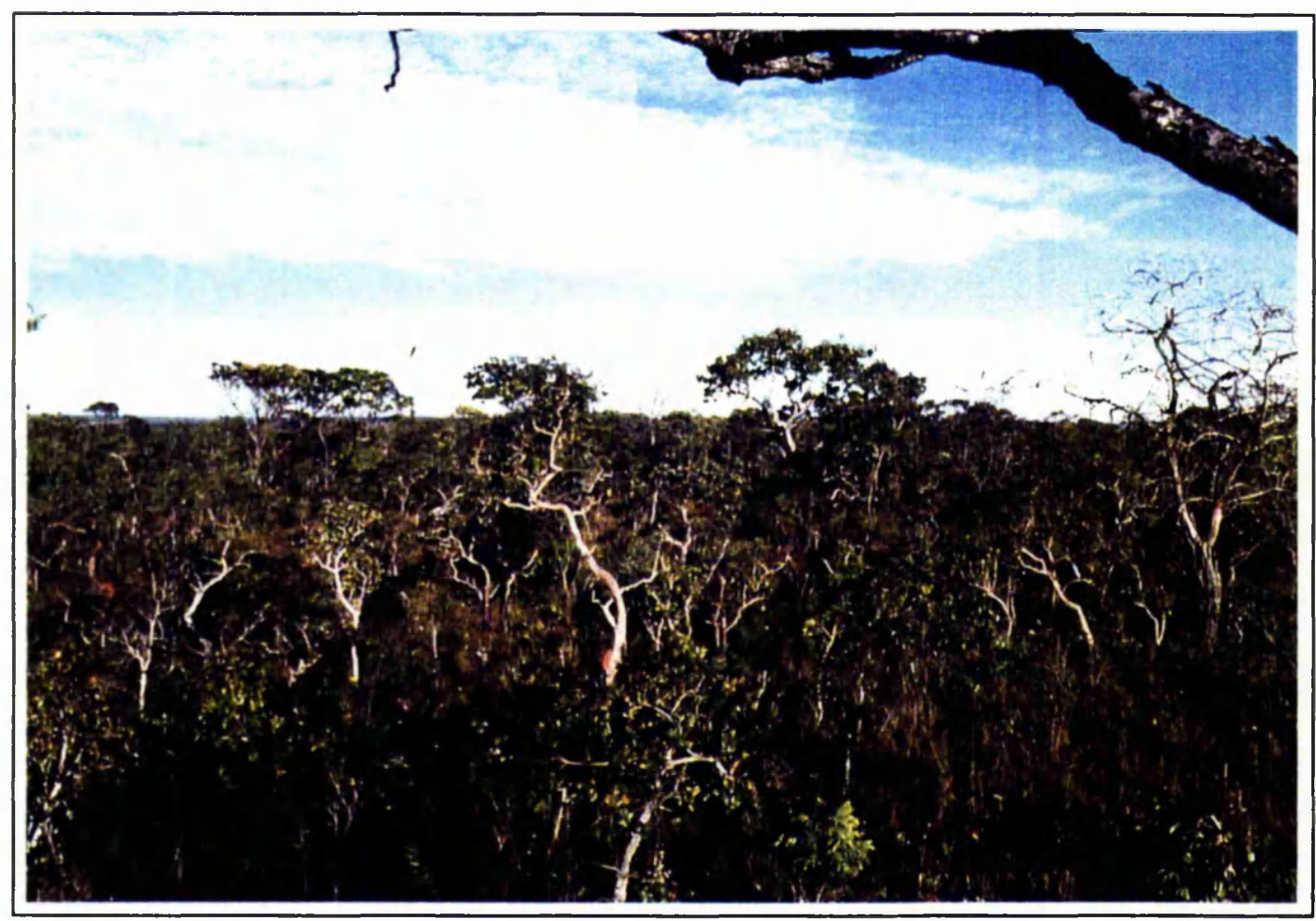

Figure 3.7 Typical cerrado denso vegetation, Reserva Ecológica do IBGE, 30/7/94. (Photo by the author). 


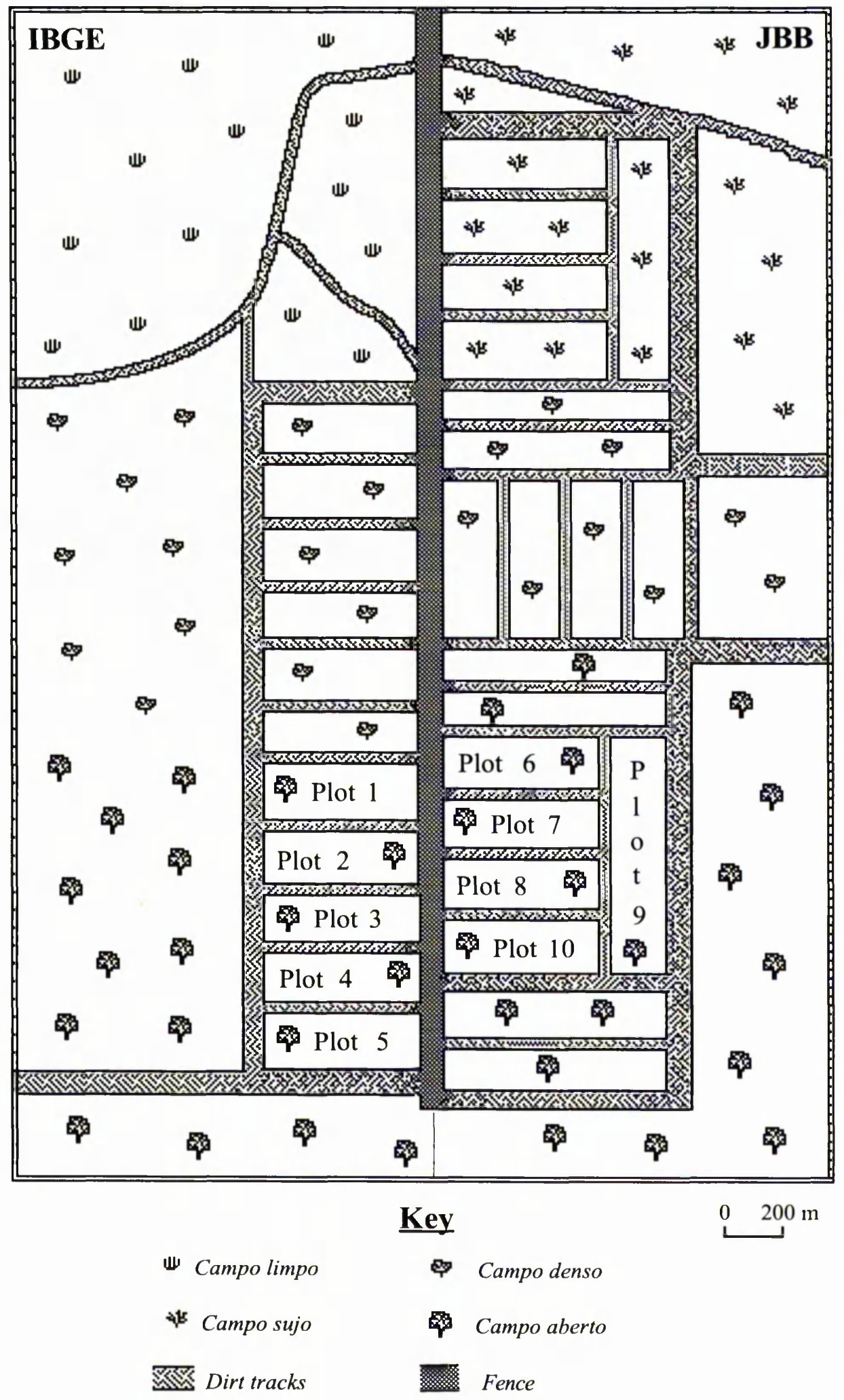

Figure 3.8 The Projecto Fogo and the ten study plots employed (modified after the Projecto Fogo draft copy). 


\section{a) Fire history}

The following is a description of the fire histories of the ten plots combining the observations of Heloisa Miranda, Head of the Projecto Fogo (pers. comm., 20/9/94), and the measurements of presence/absence of scorch and height of scorch, taken during the field research (Figures 3.9a and b) (see Chapter 4):

a) Plots in IBGE ('let-burn' policy until 1974, then fire protection):

i) Plot 1 - controlled from fire for over 20 years. This was the only plot that showed no scorch (see Figure 3.9a);

ii) Plot 2 - burned in August 1991, and is a 'quadrennial' burn plot. The fire in this plot burned evenly throughout the whole area (Figure 3.9a - 100\% of phorophytes with scorch, indicating the homogeneous nature of the burn) and flame heights were high (Figure 3.9b - highest frequency of phorophytes in scorch height class ' $1-2.9 \mathrm{~m}$ ');

iii) Plot 3 - subjected to burning in June 1992 as part of the biennial cycle of burns. This plot had one of the lowest frequencies of phorophytes with scorch (Figure 3.9a), corresponding to the heterogeneous burn in this area. There are high frequencies of phorophytes within scorch height classes ' $<0.5 \mathrm{~m}$ ', ' 0.5 $-0.9 \mathrm{~m}$ ' and ' $1-2.9 \mathrm{~m}$ ' (Figure $3.9 \mathrm{~b}$ ), suggesting that the burn in this area was not only patchy, but was probably with various flame heights.

iv) Plot 4 - burned in August 1992, part of the biennial cycle of burns. This plot burned in the same fashion as Plot 3 (see Figures 3.9a and b);

v) Plot 5 - burned in September 1992, part of the biennial cycle of burns. This plot burned in the same fashion as Plot 3 (see Figures $3.9 \mathrm{a}$ and $\mathrm{b}$ );

b) Plots in JBB ('let-burn' policy until 1986):

i) Plot 6 - controlled from fire for 8 years. It still has many phorophytes with scorch (Figure 3.9a), though less apparent than Plots 7, 8 and 9. Figure 3.8b indicates that the previous burns in this plot may have had high flame heights $(\geq 1 \mathrm{~m})$, with some flames reaching more than $5 \mathrm{~m}$;

ii) Plot 7 - bumed intensely and evenly in August 1991, and is a 'quadrennial' burn plot. There is $100 \%$ scorch (Figure 3.9a), suggesting that fire has been homogenous in this area. This plot may have had fires with high flame heights, shown by the high frequencies of phorophytes within scorch height classes ' $1-2.9 \mathrm{~m}$ ' and ' 3 - $4.9 \mathrm{~m}$ ' (Figure 3.9b);

iii) Plot 8 - burned in June 1991 and 1993 as part of the biennial cycle of burns. It burned in the same manner as Plot 7 (see Figures 3.9a and b);

iv) Plot 9 - burned in August 1991 and 1993 as part of the biennial cycle of burns. It burned with very high flame heights in the same manner as Plots 7 and 8 (see Figures 3.9a and b);

v) Plot 10 - burned in September 1991 and 1993 as part of the biennial cycle of burns. This plot has the lowest frequency of phorophytes with scorch out of all the JBB plots (Figure 3.9a), indicating that fire has been infrequent and heterogeneous in this area. This plot also has higher frequencies of 


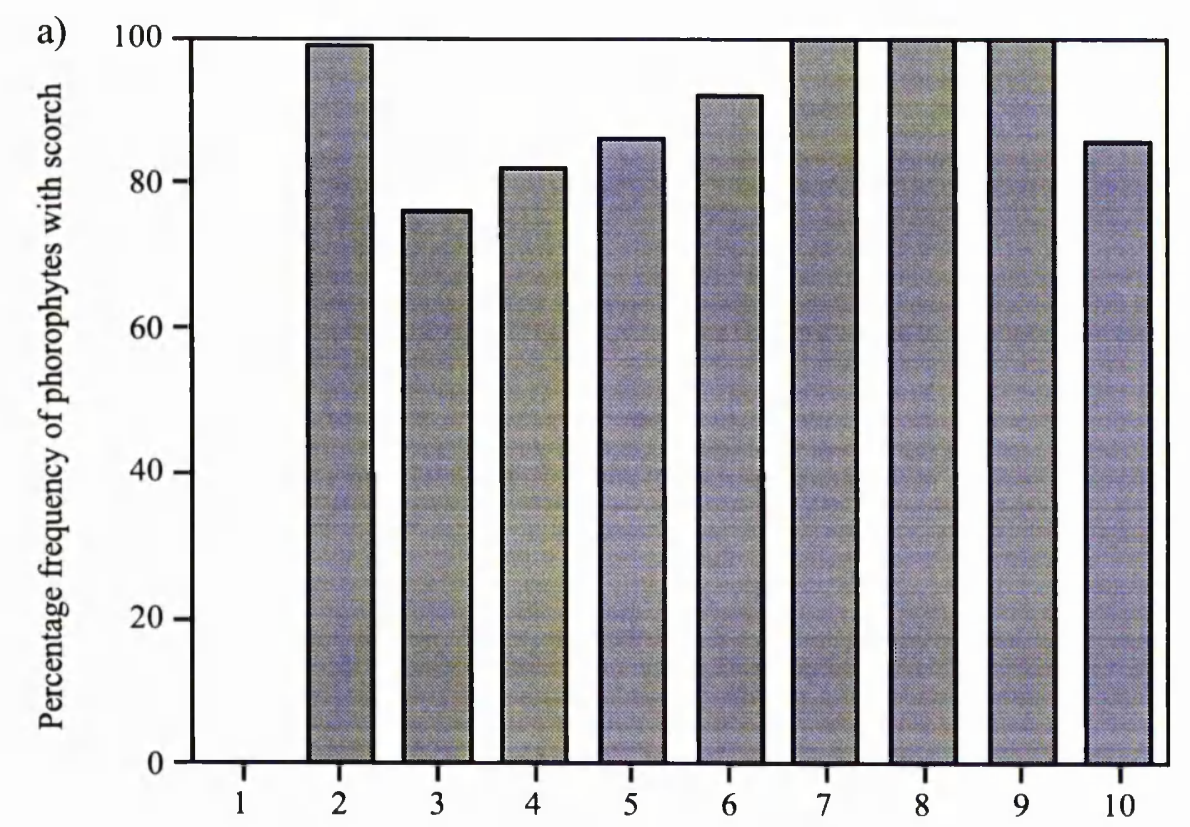

Plot number

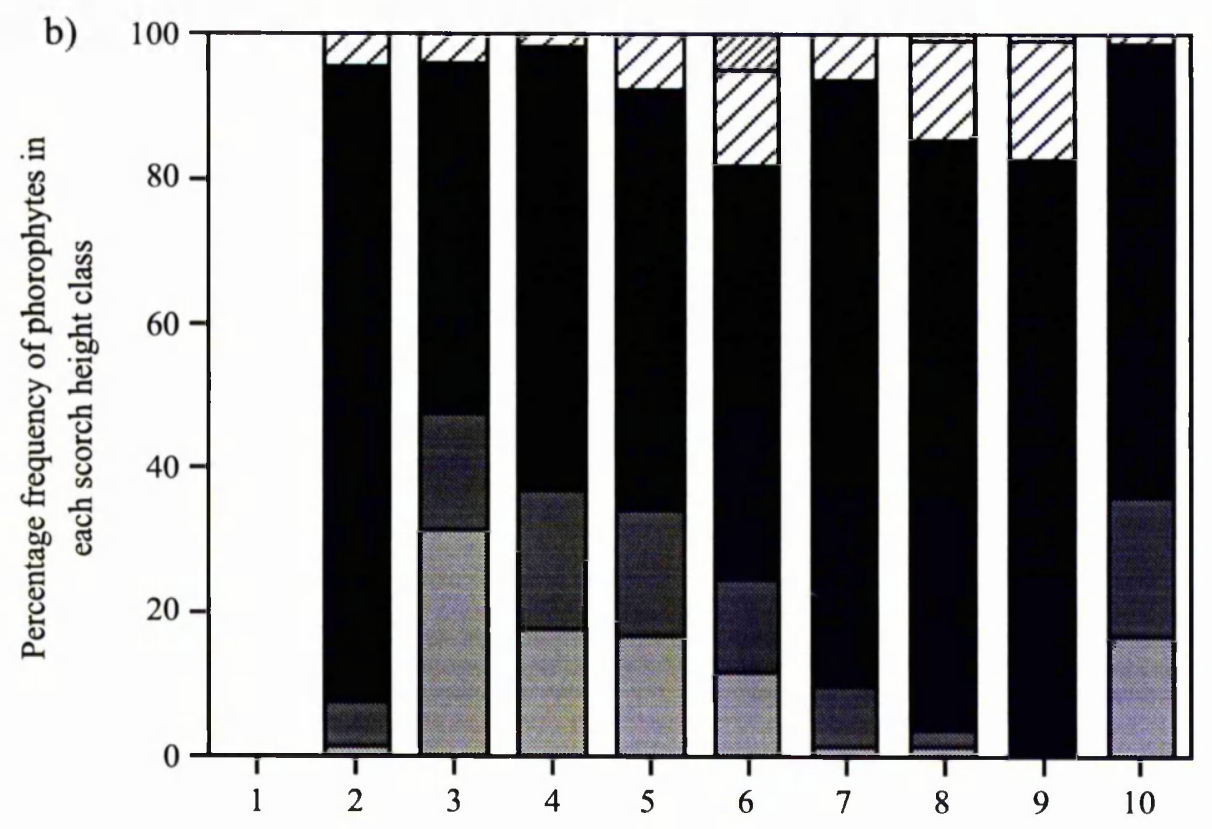

Plot number

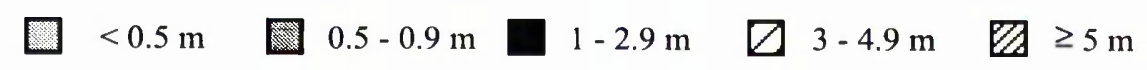

Figure 3.9: a) The percentage frequency of phorophytes with scorch in each plot; b) The percentage frequency of phorophytes within different scorch height classes ( $m$ above ground) for each plot. 
phorophytes within the lower scorch height classes (Figure 3.9b), indicating flames with various heights (as in Plots 3, 4 and 5).

Table 3.1 summarises the fire histories of the plots, and indicates a fire history code for each plot. The code is constructed in the following manner:

Code $=(A-B: C, D, E)$ where,

$A=$ the date up to which there has been a 'let-burn' policy i.e. 1974 or 1986.

$\mathrm{B}=$ the date(s) of last known fire.

$\mathrm{C}=$ whether the burn was homogeneous (Hom) or heterogeneous (Het).

$\mathrm{D}=$ whether there were variable $(\mathrm{V})$ or high $(\mathrm{H})$ flame heights.

$\mathrm{E}=$ whether the fire took place during the early $(\mathrm{E})$, mid $(\mathrm{M})$ or late $(\mathrm{L})$ dry season.

This code is used in the following text as a concise definition of the fire history of each plot. Table 3.1 is replicated in Appendix 4, enclosed at the back of the thesis, as an aid to the reader.

\section{b) Floristics}

In total, 89 woody species were found, belonging to 63 different genera and 37 families. The most diverse family was Leguminosae with 14 species, $16 \%$ of the total. Other diverse families included Vochysiaceae (8\%), Malpighiaceae (8\%), Melastomataceae (5\%), Myrtaceae (5\%) and Rubiaceae (5\%). Within the plots, trees had the highest species diversity, 65 species in total (73\%), followed by shrubs with 21 species (24\%) and sub shrubs with 3 species (3\%).

The phytosociological parameters (density (number of phorophytes $\mathrm{m}^{-1}$ )), dominance (basal area $\left(\mathrm{m}^{2} \mathrm{~m}^{-1}\right)$ ), frequency (percentage occurrence of a species in the plots)) were used to calculate the Importance Value (IV) (Mueller-Dombois and Ellenberg, 1974), defined as the sum of relative density, dominance and frequency, for each species in each plot. The IV places the species in a hierarchical order in the community and as a sum of relative parameters, is useful in comparisons between plots and with other studies. A species has a high IV when their density, basal area and/or frequency are higher than those for the other species in a site (Curtis and McIntosh, 1950, 1951).

Within the study plots, the ten species with the highest overall IV (in descending order) were Blepharocalyx salicifolius ${ }^{2}$, Caryocar brasiliense, Sclerolobium paniculatum, Ouratea hexasperma, Guapira noxia, Qualea grandiflora, Vochysia thyrsoidea, Didymopanax macrocarpum, Vellozia squamata and Qualea parviflora. Among them, C. brasiliense, $Q$. grandiflora and $Q$. parviflora, have been recorded as common by Ratter and Dargie (1992), occurring in 15 or more of the 26 widely scattered cerrado sensu stricto sites compared.

In this study, Caryocar brasiliense, Sclerolobium paniculatum and Vochysia thyrsoidea have greater importance values than other sites around the Distrito Federal (Felfili and Silva Jr, 1993). Though Blepharocalyx salicifolius has a high importance value within the Projecto Fogo (this study; Moreira, 1992) and the neighbouring Fazenda Agua Limpa (Felfili and Silva Jr, 1992), it

${ }^{2}$ Authorities for phoroplyyte species found in this study are given in Appendix 1 (p.271). 
Table 3.1 The fire histories of the ten plots and their codes.

\begin{tabular}{|c|c|c|c|}
\hline Area & Plot & Fire history & Code used in text \\
\hline \multirow{5}{*}{$\begin{array}{l}\text { IBGE - 'let- } \\
\text { burn' policy } \\
\text { until } 1974\end{array}$} & $\overline{1}$ & $\begin{array}{l}\text { Protected since } 1974 \text { (for over } 20 \\
\text { years) }\end{array}$ & (74-control) \\
\hline & 2 & $\begin{array}{l}\text { Protected since } 1974 \text {, but } \\
\text { subjected to a rare middle dry } \\
\text { season homogeneous fire with } \\
\text { high flame heights in } 1991\end{array}$ & (74-91: Hom, $\mathrm{H}, \mathrm{M}$ ) \\
\hline & 3 & $\begin{array}{l}\text { Protected since } 1974 \text {, but } \\
\text { subjected to a rare early dry } \\
\text { season, heterogeneous fire with } \\
\text { various flame heights in } 1992\end{array}$ & (74-92: Het, V, E) \\
\hline & 4 & $\begin{array}{l}\text { Protected since } 1974 \text {, but } \\
\text { subjected to a rare middle dry } \\
\text { season, heterogeneous fire with } \\
\text { various flame heights in } 1992\end{array}$ & (74-92: Het, V, M) \\
\hline & 5 & $\begin{array}{l}\text { Protected since } 1974, \text { but } \\
\text { subjected to a rare late dry season, } \\
\text { heterogeneous fire with various } \\
\text { flame heights in } 1992\end{array}$ & (74-92: Het, V, L) \\
\hline \multirow{5}{*}{$\begin{array}{l}\text { JBB - 'let-burn' } \\
\text { policy until } \\
1986\end{array}$} & $\overline{6}$ & $\begin{array}{l}\text { Frequently burned until } 1986 \text {, but } \\
\text { protected from fire since } 1986\end{array}$ & (86-control) \\
\hline & 7 & $\begin{array}{l}\text { Frequently burned until } 1986, \\
\text { subjected to a middle dry season } \\
\text { homogeneous fire with high } \\
\text { flame heights in } 1991\end{array}$ & (86-91: Hom, H, M) \\
\hline & 8 & $\begin{array}{l}\text { Frequently burned until } 1986, \\
\text { subjected to an early dry season } \\
\text { homogeneous fire with high } \\
\text { flame heights in } 1991 \text { and } 1993\end{array}$ & (86-91,93: Hom, H, E) \\
\hline & 9 & $\begin{array}{l}\text { Frequently burned until } 1986, \\
\text { subjected to a middle dry season } \\
\text { homogeneous fire with high } \\
\text { flame heights in } 1991 \text { and } 1993\end{array}$ & (86-91,93: Hom, H, M) \\
\hline & 10 & $\begin{array}{l}\text { Infrequently burned until } 1986, \\
\text { subjected to a late dry season } \\
\text { heterogeneous fire with various } \\
\text { flame heights in } 1991 \text { and } 1993\end{array}$ & $(86-91,93:$ Het, $V, L)$ \\
\hline
\end{tabular}

is not considered a typical species of the region, being more specific to other areas of the Planalto (Felfili and Silva Jr, 1993). Other species with high importance values comparable to other sites around the Distrito Federal were Didymopanax macrocarpum, Guapira noxia, Ouratea hexasperma and Miconia ferruginata (Felfili and Silva Jr, 1992, 1993).

Multivariate analyses were carried out on the plot phorophyte data in order to identify associations between species and between plots. The matrix of 10 plots by 89 species was ordinated using Detrended Correspondence Analysis (DCA) (Hill and Gauch, 1980) and classified using TwoWay Indicator Species Analysis (TWINSPAN) (Gauch and Whittaker, 1981; Hill, 1979). Although DCA and TWINSPAN have been widely criticised (Gauch, 1982), they still remain one of the most frequently used and effective multivariate analysis techniques (Kent and Coker, 1992), and allow 


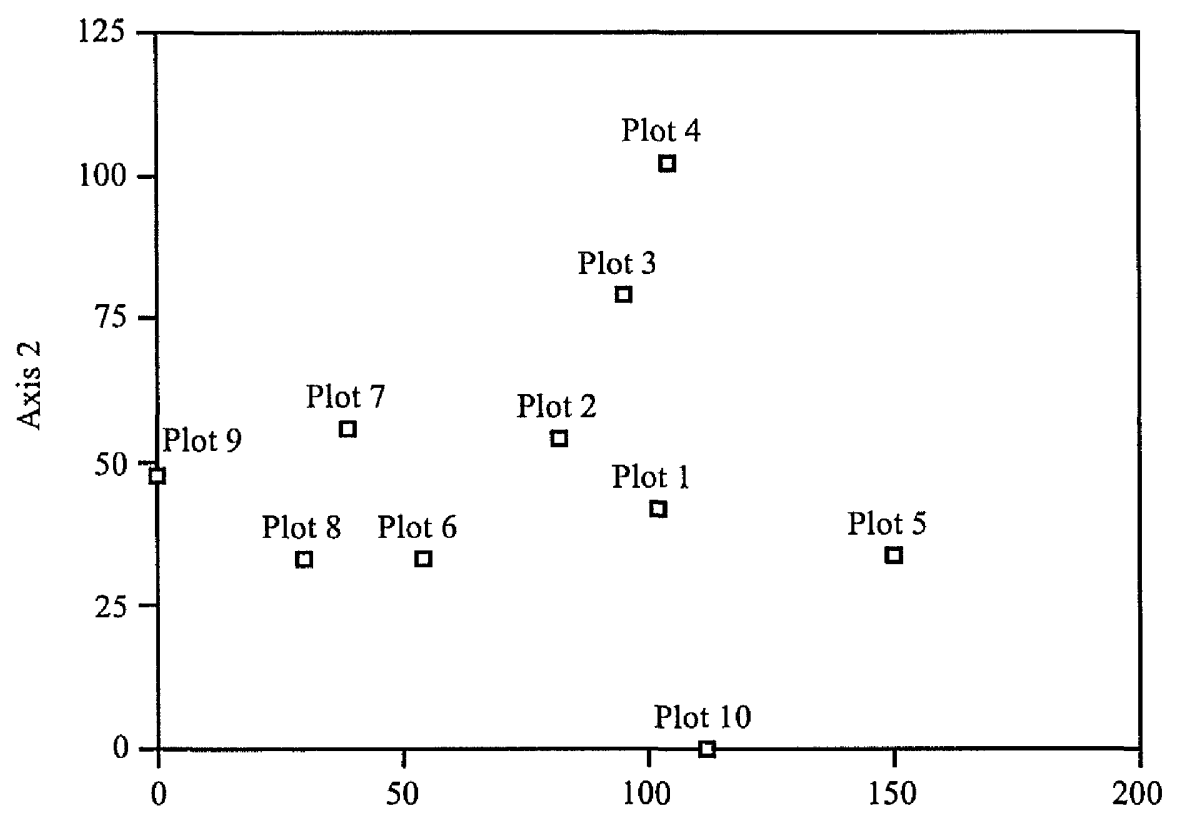

Axis 1

Figure 3.10 DCA plot ordination using phorophyte species data. Note that all the IBGE plots (1-5) are on the right-hand side of the graph, and the JBB plots (6-9) are on the left-hand side. Plot 10 of the JBB is more similar to the IBGE plots, being found on the right-hand side of the graph.

comparisons with other studies. The IV values for species were used in both the ordination and classification since they give good indications of the proportional representation of individual species at a site (Felfili and Silva Jr, 1993).

Because there were many species that occurred only once, it was decided to downweight the rarer species in both the ordination and classification analysis (Kent and Coker, 1992). This helped clarify the patterns determined by the more common species. All other default commands were used for the analyses. The results of the DCA shows that the first component accounts for $73 \%$ of the total variance, and the second for $21 \%$. Together, they account for over $94 \%$ of the total variation, so are therefore regarded as the most significant components (Causton, 1988). Both the plot and species ordinations were plotted using the 1 st component as the $x$-coordinate and the 2 nd component as the $y$ coordinate.

The plot ordination (Figure 3.10) indicates that fire history may account for the polarisation on the Ist axis, with the IBGE plots (1, 2, 3, 4 and 5) on the right-hand side of the graph, and the JBB plots $(6,7,8$ and 9$)$ on the left-hand side. Plot 10 is the only exception to this pattern. The graph shows that the greatest difference on the first axis is between Plots 9 and 5. Plot 5 has been 


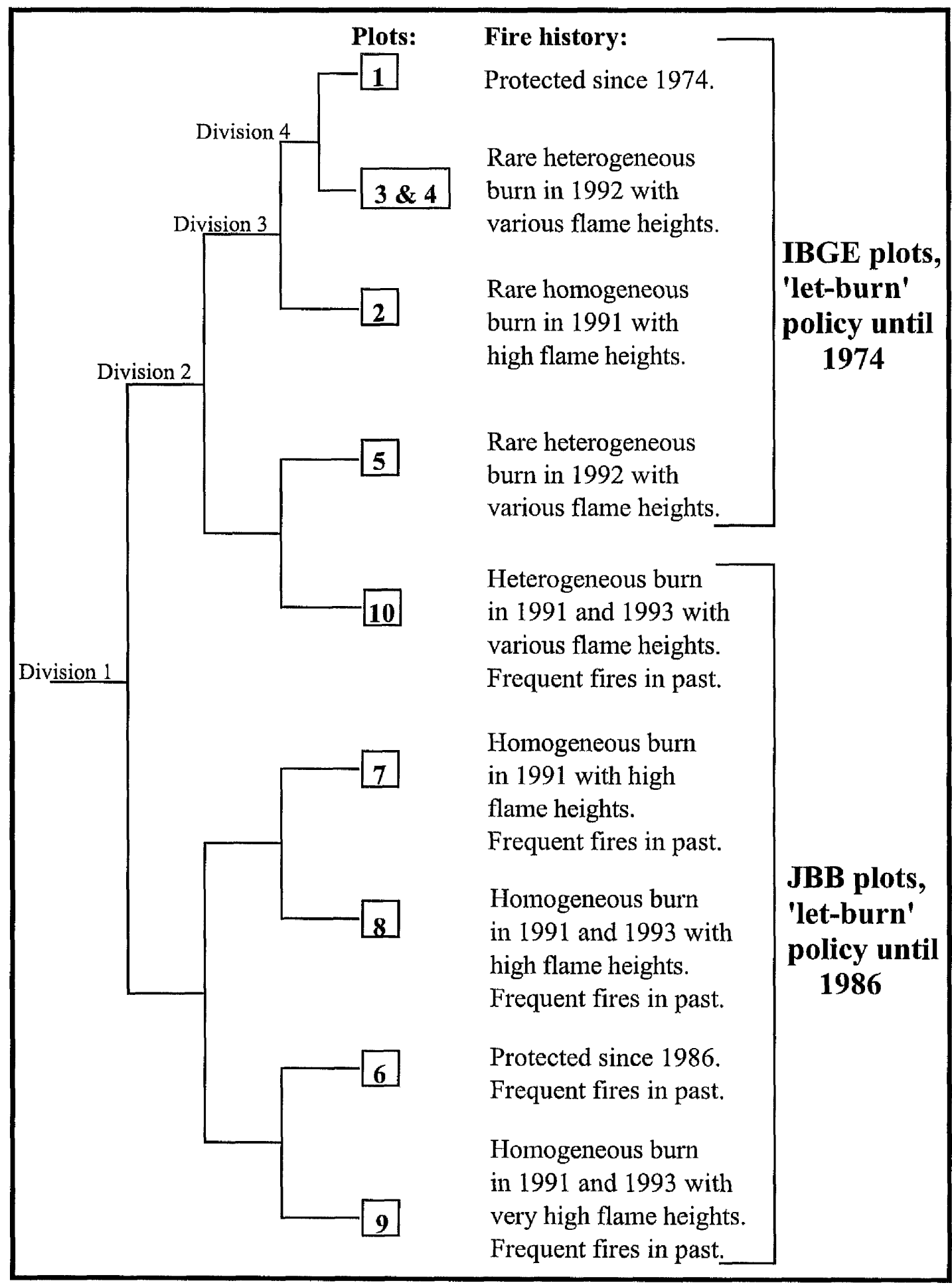

Figure 3.11 Dendrogram of TWINSPAN results showing the separation of plots according to their fire history. 


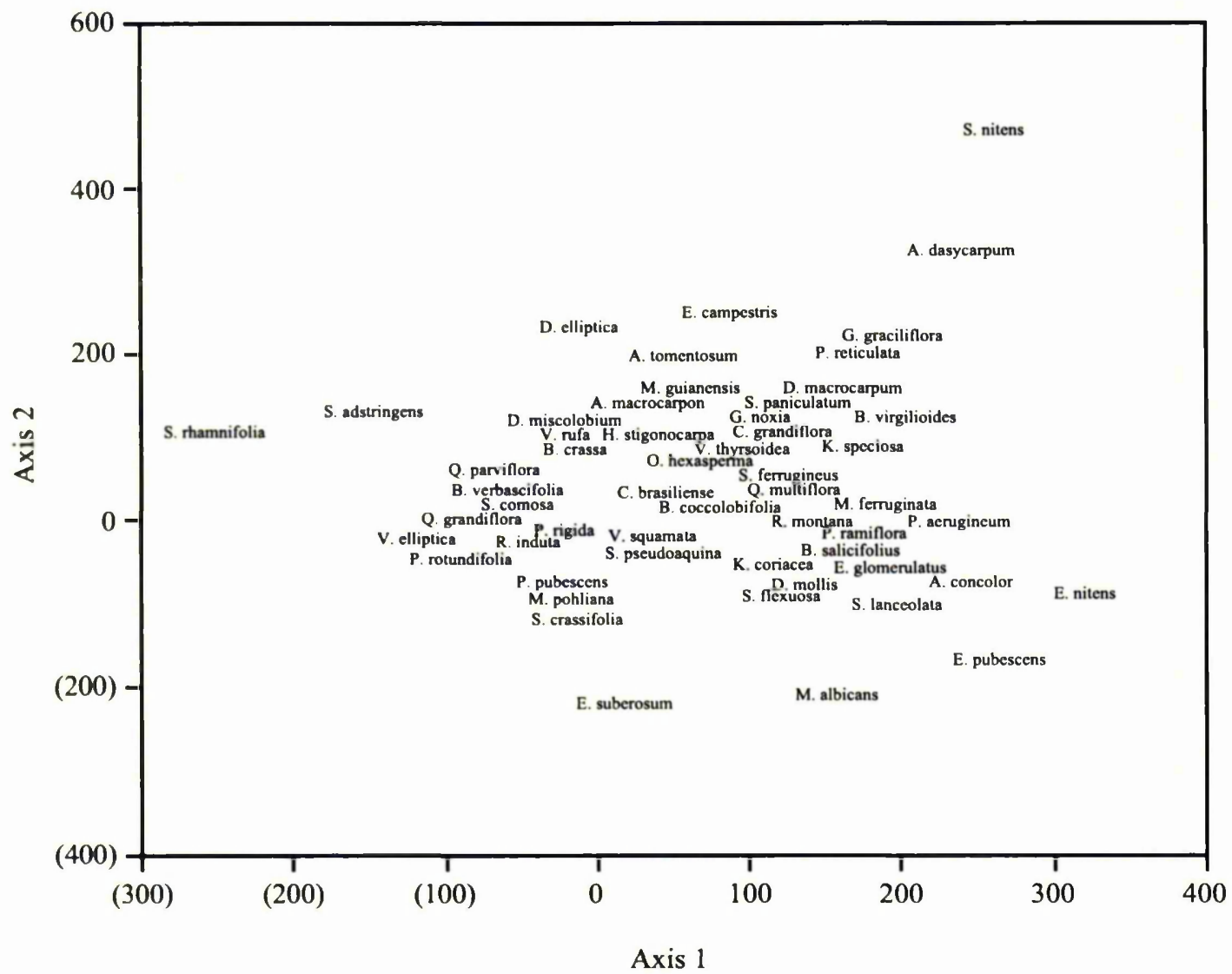

Figure 3.12 DCA phorophyte species ordination.

burned recently and heterogeneously, but was previously protected from fire for over 20 years. Altematively, Plot 9 has been burned frequently in the past, the last burn being of a homogeneous nature with high flame heights. On the graph, Plot 6 occurs between the IBGE plots and the other JBB plots, and this is probably because, though bumed frequently in the past, it has been protected from fire for 8 years. Although Plot 10 is a JBB plot, it seems that fire has not affected this plot in the same fashion as the other JBB plots. This could be because fire in this area was not as frequent and homogeneous compared to the other JBB plots. These results are confirmed by the TWINSPAN classification (Figure 3.11). The first division separates the IBGE plots from the JBB plots, although Plot 10 (a JBB plot) is separated with the IBGE plots. The subsequent divisions separate the plots into a gradient of fire history, with Plot 1 (74-control) at one extreme, and Plot 9 (86-91,93: Hom, H, M) at the other.

Looking at the second axis of the DCA plot ordination, Plot 10 (86-91,93: Het, V, L) is at one pole, Plot 4 (74-92: Het, V, M) at the other. The ordination indicates that this axis accounts for $21 \%$ of the variance, so it is far less important than the first. Since no environmental 
factors were measured, it is impossible to ascertain what could be the reason for the plot distribution on this second axis.

Figure 3.12 shows the phorophyte species ordination and Figure 3.13 is an overlay of the species ordination with the groups (A-D) identified by the TWINSPAN classification (the rarer species i.e. those that occur in two or less plots are excluded from the graph). Although the results of the species ordination are more difficult to interpret than the plot ordination, it does seem that the controlling factor on the first axis may be fire history.

Three fire-sensitive species, Emmotum nitens, Bowdichia virgilioides and Miconia albicans common in protected cerrado denso (Furley and Ratter, 1988; Moreira, 1987; Ratter, 1991; Ribeiro et al., 1985), are present on the right-hand side of Figure 3.11 and in TWINSPAN Group A. However, another fire-sensitive species, Miconia pohliana, is located towards the middle of the ordination graph, thereby not indicating fire-sensitivity. Moreira (1992) suggests that similarities between protected and unprotected cerrado denso may be explained due to the patchy nature of burns in this cerrado form, allowing fire-sensitive species to be protected from fire long enough to enable them to pass through the vulnerable sapling stage, and reach a more fire-resistant mature stage. Other species in TWINSPAN Groups A and B, including Acosmium dasycarpon, Didymopanax macrocarpon, Eremanthus glomerulatus, Guapira graciliflora, Guapira noxia, Blepharocalyx salicifolius and Sclerolobium paniculatum are also common in protected cerrado denso (Moreira, 1992).

In the centre of the graph, typical cerrado denso/cerrado sensu stricto species

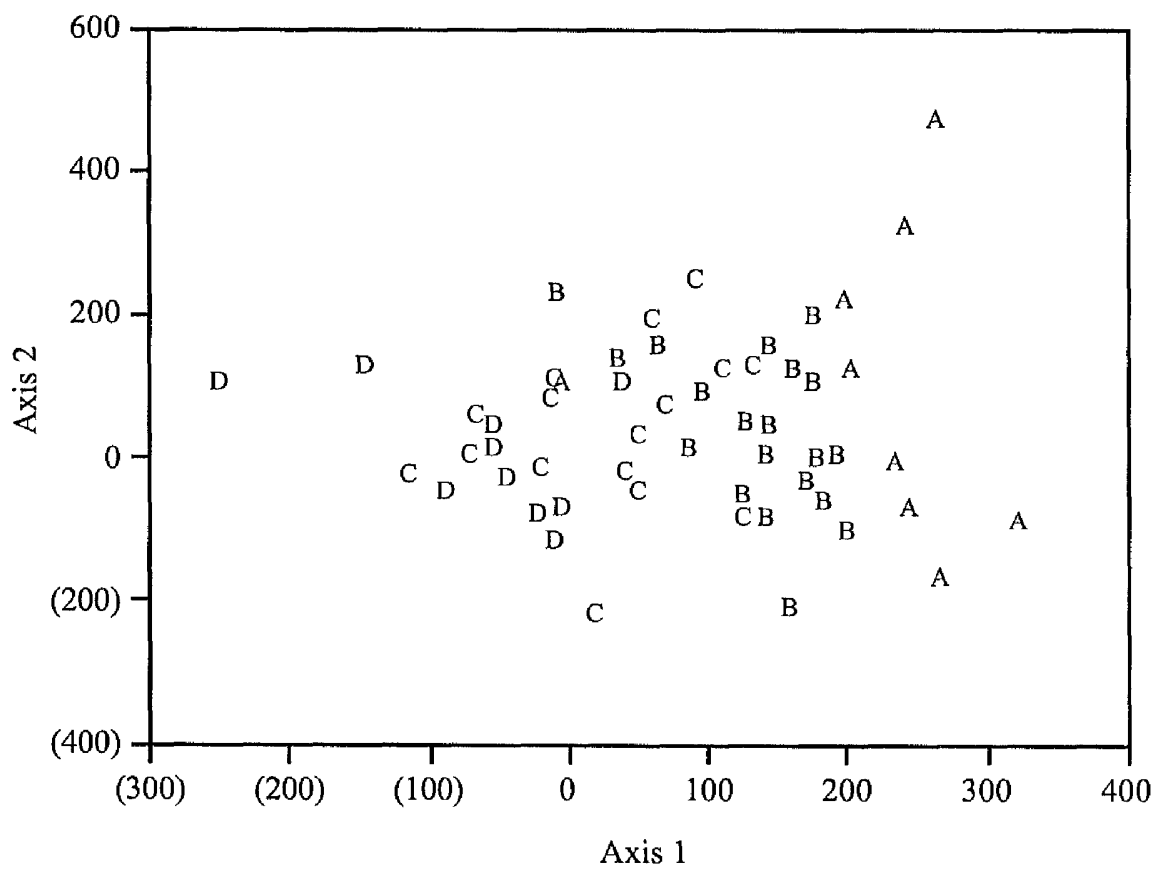

Figure 3.13 DCA phorophyte species ordination with TWINSPAN group (A-D) overlay. 
(Groups B and C) are found. These include Aspidosperma tomentosum, Caryocar brasiliense, Myrsine guianensis, Ouratea hexasperma, Roupala montana, Vellozia squamata and Vochysia thyrsoidea (Moreira, 1992; Ratter, 1991). On the left-hand side of the graph, shrub species such as Rourea induta and Syagrus comosa (Group D) are indicators of more open vegetation (Moreira, 1992). So, from right to left on the first axis, the effect of fire on the vegetation increases, controlling the openness of the vegetation, and in turn, the species present. There are many species that seem to be indicators of open vegetation, such as Symplocos rhamnifolia, Stryphnodendron adstringens, Qualea parviflora and Qualea grandiflora, but they are species typically found in most cerrado types (Ratter, 1991; Ratter and Dargie, 1992), and their importance in this fire gradient may be misleading, since their occurrence is more likely to be due to a clumped distribution (Oliveira et al., 1989; Oliveira-Filho et al., 1989).

The second axis in Figure 3.12 shows the greatest difference between Symplocos nitens and two species, Miconia albicans and Banisteriopsis latifolia. S. nitens is characteristic of the wetter gallery forest (Pereira et al., 1993; Ratter, 1991), and suggests that this gradient could be due to soil hydrology. Even so, there is no evidence to suggest that $M$. albicans or $B$. latifolia are tolerant of drier soils, and so soil hydrology as the determinant on second axis must be considered with caution.

\section{c) Vegetation structure}

Figures $3.14 \mathrm{a}$ to $\mathrm{c}$ show the percentage frequency of phorophytes in different height, girth, and first branch height classes respectively for the ten plots. These graphs indicate that fire protection in the past (Plots 1 to 5) has led to a greater tree height and an increase in those individuals with thicker trunks. Plot 1, protected from fire for over 20 years, has a large proportion of phorophytes with large girths and with low-level branches, suggesting the presence of thick-stemmed phorophytes that are multi-branching near the base (see Section 3.2) and a high structural complexity. In Plots 3, 4 and 5, there is a decrease in the proportion of phorophytes with low branches $(<0.5 \mathrm{~m}$ and $0.5-0.9$ $\mathrm{m}$ ), suggesting that though fire has been rare and heterogeneous in these areas, it has effected the vegetation structure, eliminating many of the lower branches. Plot 2 not only has a low proportion of phorophytes with low branches, but also has fewer phorophytes in the girth class ' $5-7.9 \mathrm{~cm}$ ', a result of the recent homogeneous burn that took place.

Plot 6, protected from fire for 8 years, also has a high proportion of phorophytes with large girths, but otherwise it shows similar structural patterns to Plots 3, 4 and 5. The graphs suggest that frequent burning (Plots 7, 8 and 9) lowers the height of the vegetation, eliminates large-girthed trees and reduces low branch density. The greater number of thin-stemmed phorophytes is probably the result of tree recruitment after fire, and the larger presence of phorophytes with lower branches could be the result of the coppicing effect of fire (Ramos, 1990). Plot 10 shows similar tree height and height of first branch class distribution to Plots 1 to 5 , providing further evidence that it may not have been burned in the same manner as the other JBB plots. However, the lower proportion of phorophytes with large girth classes in Plot 10 compared to Plots 1 to 5 , indicate that fire has effected this area. 


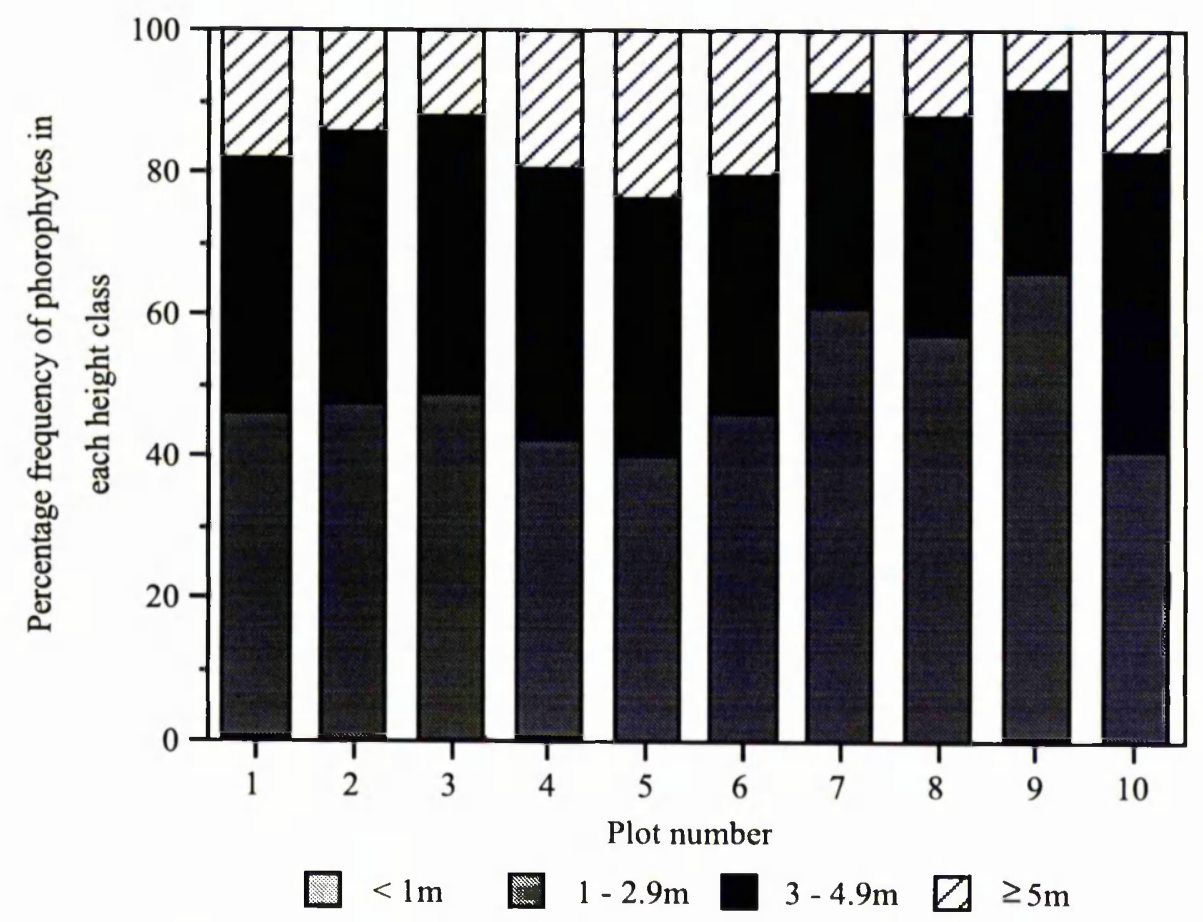

Figure 3.14a The percentage frequency of phorophytes in different height classes (m) for each plot.

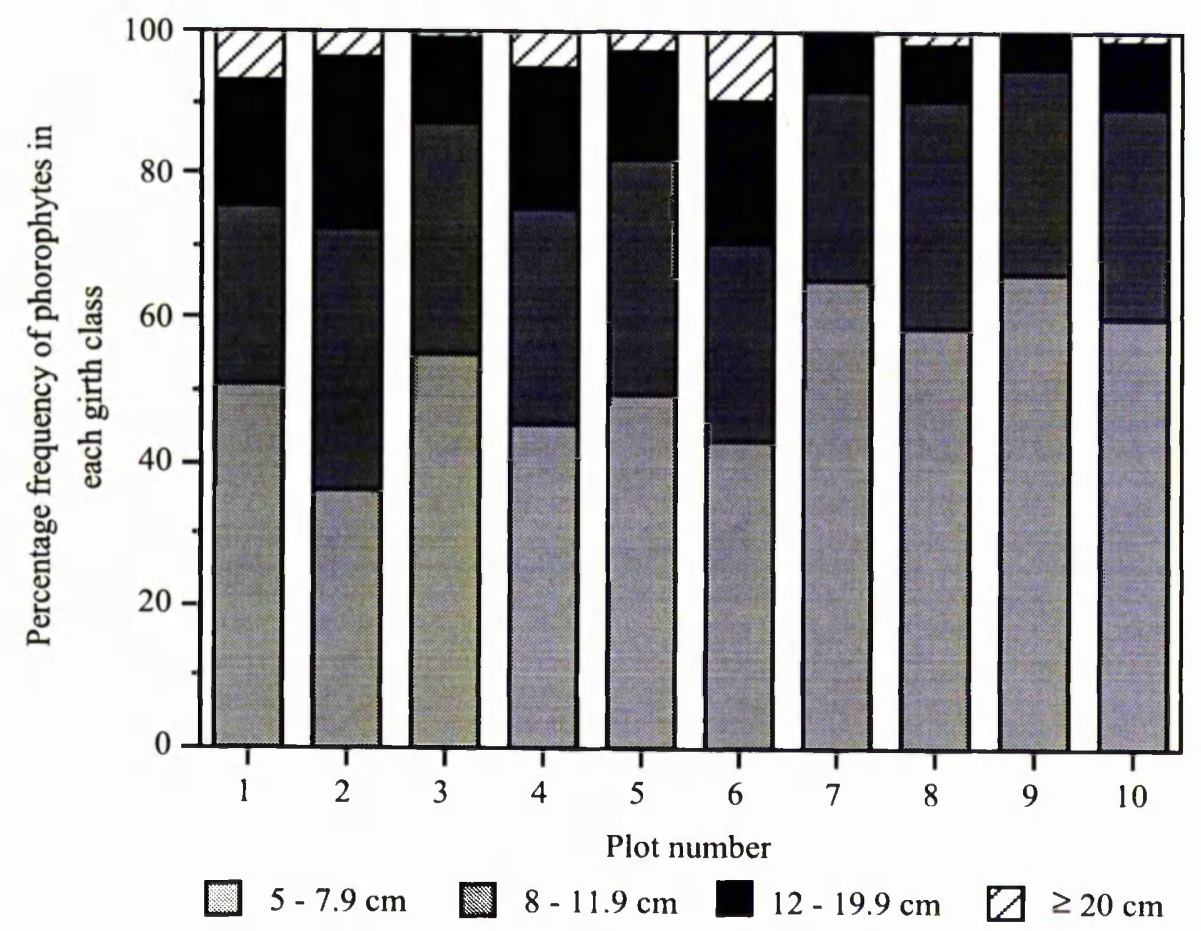

Figure 3.14b The percentage frequency of phorophytes in different girth classes (diameter in $\mathrm{cm}$ ) for each plot. 


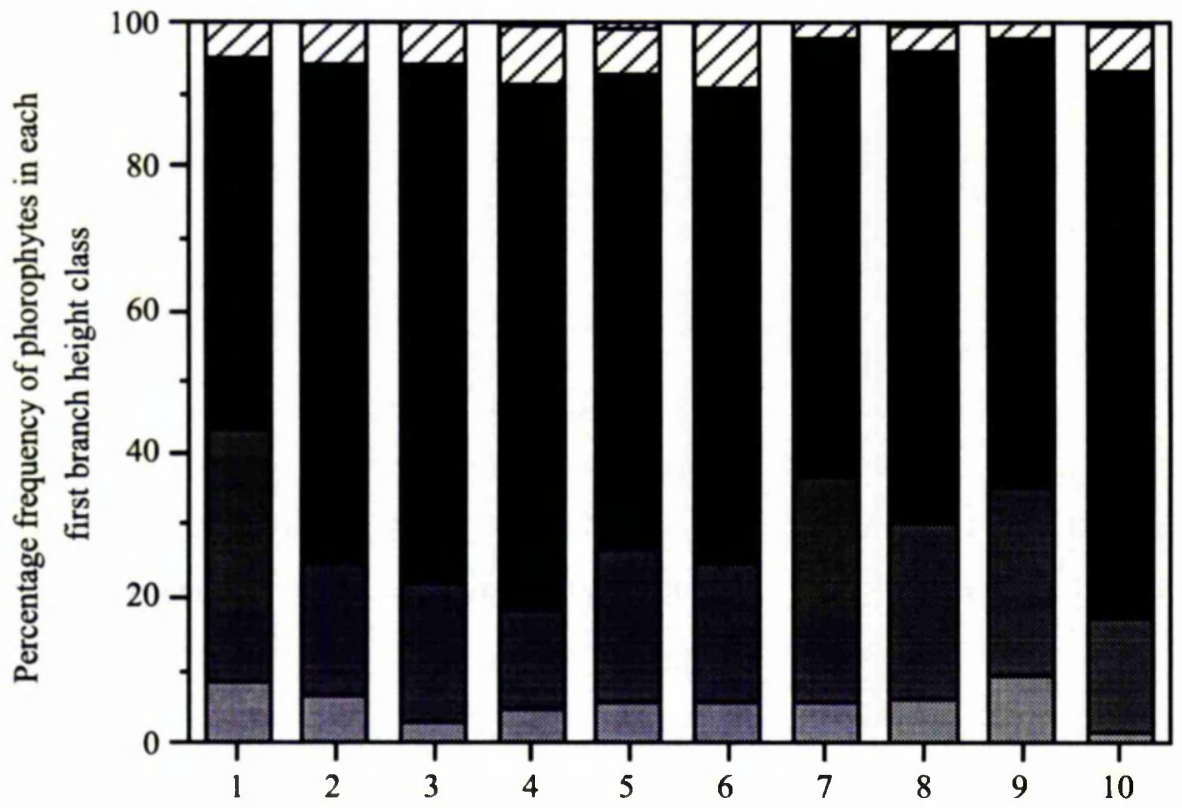

Plot number

$\square<0.5 \mathrm{~m} \square 0.5-0.9 \mathrm{~m} \square 1-2.9 \mathrm{~m} \square 3-4.9 \mathrm{~m} \quad \square \geq 5 \mathrm{~m}$

Figure 3.14c The percentage frequency of phorophytes in different first branch height classes (m) for each plot.

\subsection{Conclusion}

The cerrado of Brazil is unique in having the greatest floristic diversity of all the world's savanna formations. This species rich community forms a mosaic of structural types, ranging from pure grasslands (campo limpo) to closed woodland (cerradão). These physiognomic types are determined at various spatial scales by the following factors: Plant Available Moisture (PAM); Plant Available Nutrients (PAN); aluminium toxicity; anthropogenic disturbance; herbivory; and fire.

Fire is a major factor within cerrado regions, and is at present, the widest used management tool. Little research, however, has been carried out on fire dynamics in the cerrado. Factors associated with the fuel type, e.g. density and moisture content, all intrinsically related to physiognomic type, have been demonstrated to be the most important elements governing fire behaviour. Studies involving the measurement of the vertical distribution of temperatures during fires have shown that the highest temperatures occur between 1 to $60 \mathrm{~cm}$ above the ground and that residence times also peaks at this height range. At higher positions above the ground, fire temperatures are lower, and may last for only a few seconds. These spatial variations in fire temperatures and residence times may be extremely important for the survival and subsequent recolonisation of lichen communities. 
Field research was carried out at the Reserva Ecológica do IBGE and the Jardim Botânico de Brasilia, $33 \mathrm{~km}$ outside Brasilia D.F., in central Brazil. Ten study plots of cerrado denso were chosen within the area of the Projecto Fogo, where prescribed burns of various frequencies take place in order to study their effects on the vegetation. These plots range from controls, e.g. protected from fire for over 20 years, to plots which are burned every two years at different times during the dry season. Using data collected during the present study, each of the ten plots is described in terms of its fire history, floristics and vegetation structure. The analysis indicates the importance of not only fire frequency, but also of fire behaviour, in terms of the homogeneity of the fire and the flame heights of the fire, on the vegetation composition and structure.

The following chapter describes how these plots were employed in the field research and the particular methods used. 


\section{Chapter 4 \\ Field Methods}

\subsection{The research strategy}

The aim of this study is to investigate the potential use of corticolous lichens as bioindicators of fire history in the cerrado, and to generate a Lichen Fire History (LFH) Key. In order to investigate whether corticolous lichens can be useful indicators of fire history, it is necessary to determine how fire history affects corticolous lichens and to what extent fire history affects other factors influencing lichens. The main determinants of corticolous lichens in temperate and tropical forests (Barkman, 1958; James et al., 1977; Sipman and Harris, 1986) are: climatic factors, such as moisture, light and temperature; bark characteristics, including texture, rate of shedding, $\mathrm{pH}$, age, nutrient status, chemical composition, presence of resins, and moisture-absorbing and retaining capacities; and disturbance e.g. predation and fire. These factors do not have an absolute control over lichen communities, but vary in their effect along a spatial scale. For example, climate may determine lichens over whole regions, as in the area of the Distrito Federal of this study, but it can also act at a microscale, restricting particular lichens to certain parts of a phorophyte trunk depending on their specific micro-climatic requirements. Bark characteristics can also act at a large-scale, for example, between different forest types due to their phorophyte composition, and at a small-scale, on different sections of the same trunk. Disturbances, more specifically fire, can cover large areas, thereby influencing lichens at a large-scale, but can also determine whether lichens are present on one phorophyte individual, or even on one side of a trunk.

The aim of this study is not to use lichens for determining the fire history over large tracts of cerrado vegetation, but to allow managers to employ a simple method within small, relatively homogeneous areas. Hence, it is important to investigate the effects of fire history, and other lichen determinants at a small-scale, rather than at the large-scale. However, factors influencing lichen growth are not independent from one another. For example, fire may reduce the canopy cover of the woody vegetation, and therefore indirectly alter the microclimate for lichens. Thus, it is important not only to investigate the direct effects of fire history on lichen communities, but also the effects of fire history on other small-scale lichen determinants. This should provide evidence to show the precise influence that fire history has on lichens, both direct and indirect. Once this is established, other small-scale factors strongly influencing lichen communities may be eliminated from sampling so that fire history becomes the major determinant of lichens. Consequently, lichen indicators of fire history can be isolated.

\subsection{Main lines of research}

The research scheme is outlined in Figure 4.1. Data collecting events are represented by squares, products by circles, and decisions by diamonds. Since no work has been carried out on any 
aspect of lichen ecology, let alone lichen fire ecology, within the cerrado, a thorough investigation of lichen abundance, distribution and recolonisation, and their relationship to factors influencing corticolous lichen growth was necessary. By comparing these lichen small-scale determinants between plots with different fire histories, it could be ascertained whether fire history, directly or indirectly affects lichen communities. The first part of the research (Stage 1), therefore, involved measuring parameters about the lichens e.g. abundance, and their small-scale determinants e.g. phorophyte bark texture, in areas with different fire histories. Data relating to phorophyte structure, species composition and presence of scorch (as an indication of past fires) was also used for constructing descriptions of the ten study plots (see Section 3.8.3).

Once it was established that lichen communities were influenced by fire history, five woody species were selected to carry out a study of the lichen composition in areas with different fire histories (Stage 2). By selecting specific phorophyte species, the influence of factors, other than fire history, could be reduced. The five phorophyte species were chosen on the basis of their high density within the plots, the high abundances of lichens present on them, and the high variation in lichen abundance between plots with different fire histories. It was hoped that from this stage of the study, lichen 'indicator' genera/species for different fire histories could be identified.

From Stage 2 of the research, the genus Bulbothrix ${ }^{3}$ was found to have one of the most dynamic responses to different fire histories. Data about the abundance and size of Bulbothrix individuals from plots with different fire histories was then collected (Stage 3). It was hoped that this would show how fire history affects Bulbothrix populations in terms of their numbers, distribution and growth rates.

A combination of the most significant results from Stages 1,2 and 3 were then used to construct the LFH Key.

The methods employed for each of these stages will now be presented in detail.

\subsection{Stage 1: General survey}

For this part of the study, all 10 cerrado denso plots of the 'Projecto Fogo' were surveyed (see Section 3.8.3). Before vegetation sampling could begin, two important choices had to be made, namely: the sampling method to be used, and the criteria for choosing which phorophytes would be sampled.

\subsubsection{The sampling method}

Sampling methods, like the conventional quadrat, are ideal if the vegetation is truly homogeneous (Kent and Coker, 1992). In contrast, the cerrado has a very heterogeneous structural and floristic composition, both at the regional (Oliveira-Filho et al., 1989; Ratter and Dargie, 1992) and local scale (Felfili and Silva Jr, 1993). To overcome this, and the problem of the distribution pattern

\footnotetext{
${ }^{3}$ Authorities for lichen species found in this study are given in Appendix 2 (p.275).
} 


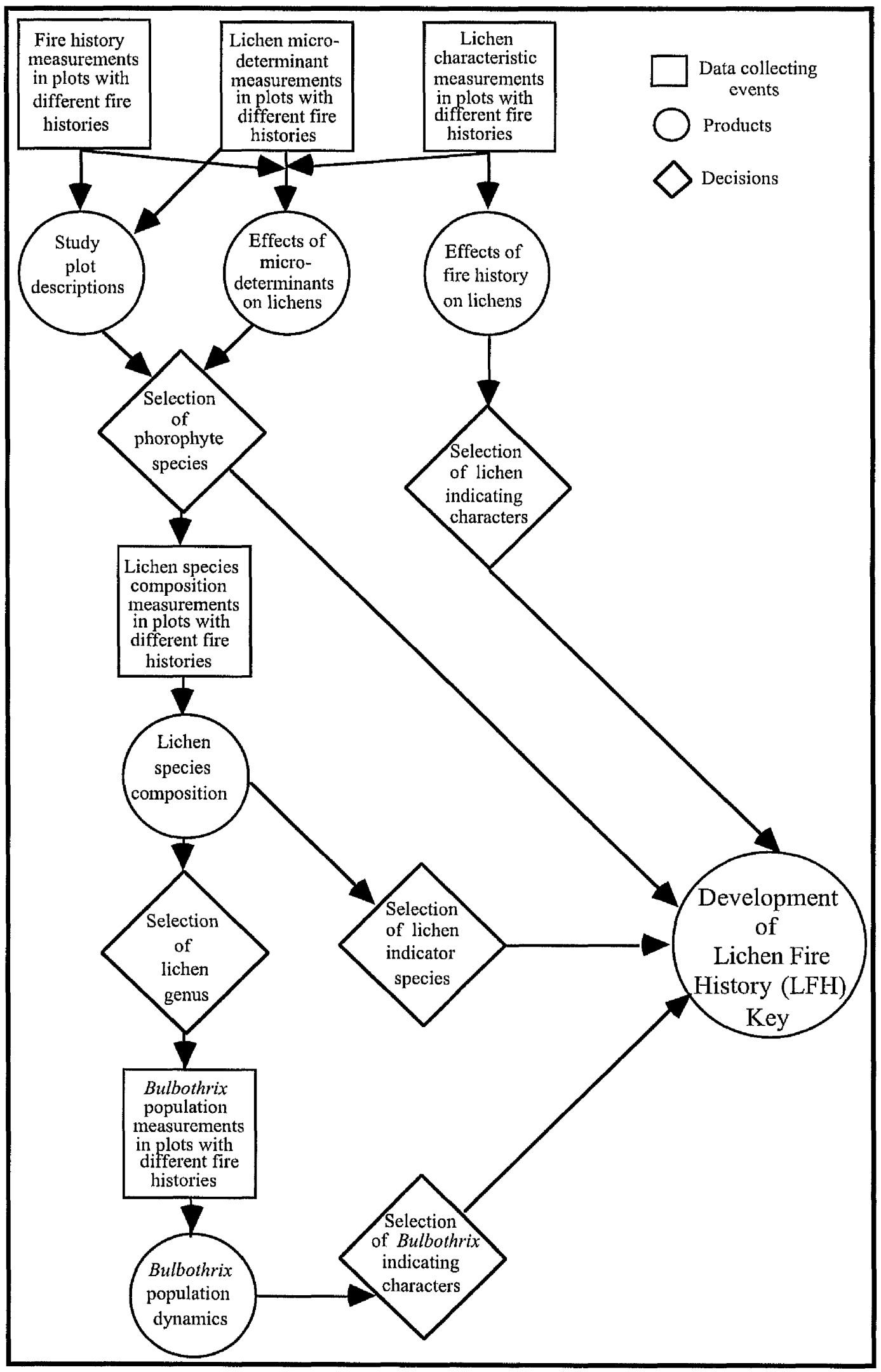

Figure 4.1 General research scheme for this thesis. 
i.e. random, regular, or clumped, it was felt that the largest area possible for each plot $(200 \mathrm{~m} \mathrm{x} 500 \mathrm{~m}$ in size) should be sampled. The other important factor influencing the choice of sampling procedure was the amount of time available. The quantitative measurements necessary for this study meant that surveying all the vegetation within each of the ten plots would have taken too long, and, in the end, this was the deciding factor governing which sampling method was used.

The distance method of plotless sampling was chosen as the sampling technique for this study. Defined as sampling without a two-dimensional reference area (Mueller-Dombois and Ellenberg, 1974), it was first developed for timber surveys, based on the idea that the number of trees per unit area can be calculated from the mean distance between the trees (Curtis, 1959). Since then, a number of distance methods have been proposed and applied to vegetation studies, all of which operate from sampling points that can be established either randomly or systematically.

The 'nearest neighbour method' and the 'random pairs method' involve selecting pairs of individuals near randomly chosen points. A third method, the 'closest individual method' simply measures the distance from a randomly selected point to the nearest tree (Cottam and Curtis, 1949; Cottam and Curtis, 1956; Cottam et al., 1953). The distance method used in this work was the 'pointcentred quarter method' (Cottam and Curtis, 1956). This involves measuring four distances from a sampling point. A random point was located at the edge of each plot, and according to a pre-established compass bearing, sampling took place in a straight line, every 10 metres for a distance of $500 \mathrm{~m}$, i.e. 50 sampling points ${ }^{4}$. Four quarters were established at each sampling point through a cross formed by two lines. One line was the compass direction and the other a line running perpendicular to the compass direction through the sampling point. The distance to the mid-point of the nearest phorophyte from the sampling point was measured in each quarter and the phorophyte was identified to species (see Figure 4.2). These parameters were used to calculate the Importance Value (IV) of phorophyte species within each plot (see Section 3.8.3b).

The important factor for this study was to sample a large number of phorophytes and their lichen communities quickly and easily. In comparison to the other three distance methods described above, it has been shown that the point-centred quarter method does not require a correction factor for calculating the mean distance, and it is the most efficient of all the methods (Cottam and Curtis, 1956). Since there is no requirement for the laying out of plot boundaries, considerable time is saved, and it eliminates, to a certain extent, the personal error from judging whether boundary individuals are inside or outside the quadrat. This technique, however, does have limitations for field applications. An individual must be located within each quarter and must not be measured twice (Newsome and Dix, 1968). This presents a problem in very open stands of vegetation, but was not encountered in the more closed cerrado denso of this study.

\footnotetext{
${ }^{4}$ The accuracy with which the mean distance, and thereafter density, is calculated increases with the number of sampling points, and a minimum of 20 points is recommended (Cottam and Curtis, 1956).
} 


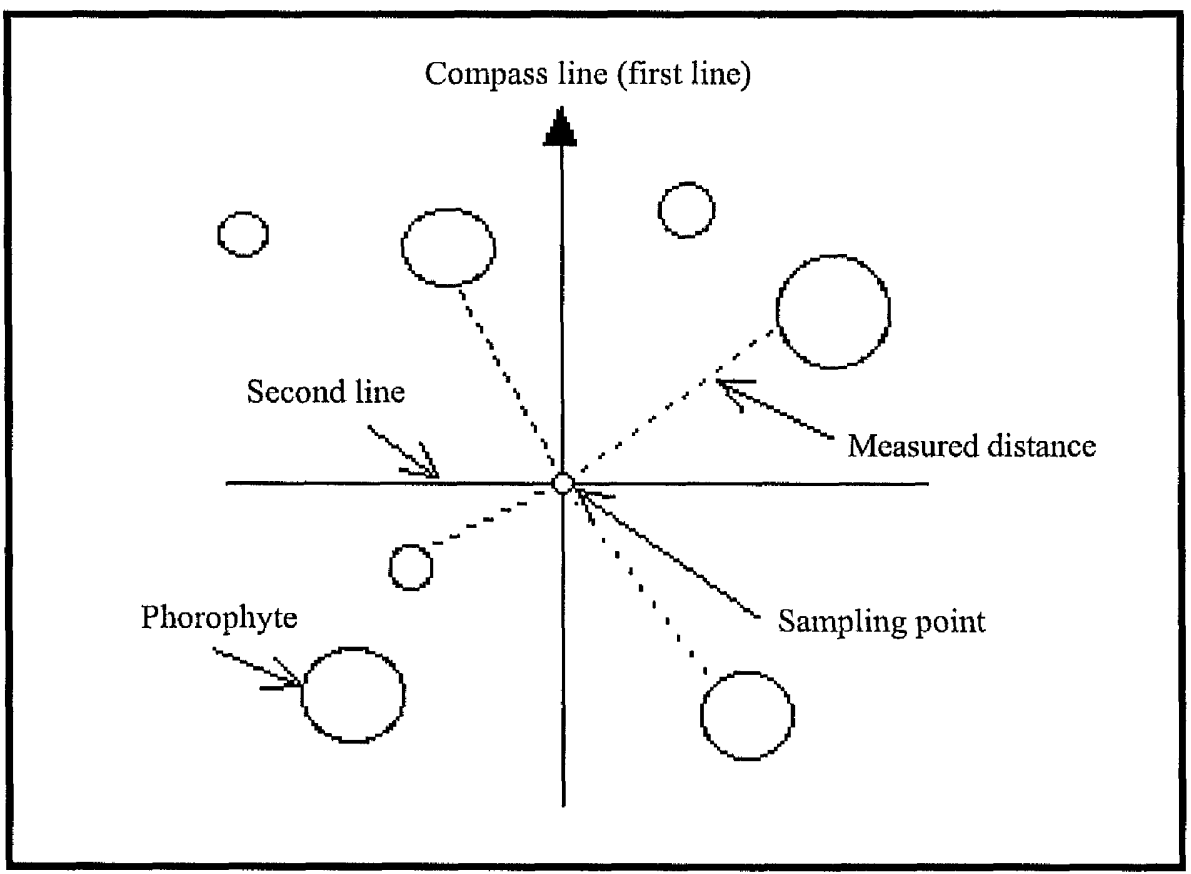

Figure 4.2 The point-centred quarter method of plotless sampling.

\subsubsection{Criteria for phorophyte sampling}

Difficulties arose when choosing criteria for selecting phorophytes to be sampled. It was important to include all phorophytes with lichens that would be affected by fire. The cerrado has a flora characterised by a high structural diversity, and the use of a minimum trunk diameter at breast height - a criterion commonly used in phorophyte sampling - would have excluded some species useful for this study. For example, the thick-stemmed shrubs of the cerrado develop a short, stout trunk, and a number of thinner aerial stems that can remain alive from several to many years (Eiten, 1994). This means that if a limit of a certain diameter at breast-height was used, these shrubs would be excluded from sampling.

There is also no proven correlation between the age of a phorophyte and height or diameter (Oliveira and Silva, 1993). Jatoba (Hymenea stigonocarpa), for example, can continue to have the appearance of a juvenile even after fire or chopping, though being quite old in age (Dulce Rocha, pers. comm. 12/9/94).

Therefore, a certain criterion needed to be established that would avoid saplings, seedlings, and herbaceous species, but which would include the thick-stemmed shrubs that are multibranching near the base, and allow for the tortuosity of the vegetation. Considering all these factors, it was decided to use a minimum diameter of $5 \mathrm{~cm}$, measured at $30 \mathrm{~cm}$ above ground level. 


\subsubsection{Parameters measured}

In this study, two sets of measurements were taken: those of the woody vegetation; and those of the lichen vegetation. For each phorophyte, the following data was collected:

1) distance from sampling point to phorophyte $(\mathrm{m})$;

2) species name;

3) height (m);

4) girth (cm);

5) height of first branch (m);

6) presence/absence of scorch (P/A);

7) if present, the height of scorch (m);

8) bark texture (using a pre-determined scale);

9) degree of lichen abundance (using a pre-determined scale);

10) lichen distribution (using a pre-determined scale);

11) presence/absence of lichens growing on scorched bark (P/A).

Parameter (1) was measured in order to calculate the density of phorophyte species. This was important for choosing the phorophyte species for Stage 2 of the data collection, and essential for the study plot descriptions. Parameters (2) to (8) were measured so the effect of smail-scale determinants on lichens could be analysed. Factors which influence lichen communities include bark texture, moisture, $\mathrm{pH}$, age, nutrient status, chemical composition, presence of resins and tannins, and rate of shedding, as well as microclimatic factors such as light and temperature (James et al., 1977). To measure most of the bark characteristics would have involved time consuming and complicated procedures, beyond the scope of this study. However, bark texture is important in affecting both lichen survival during a fire and subsequent lichen recolonisation (Wolseley and Aguirre-Hudson, 1996b). Bark texture can be recorded quickly and easily, and information about the moisture content of the bark can also be deduced from this, since bark texture is related to bark moisture.

Time available at the end of the study, allowed the measurement of bark $\mathrm{pH}$ on a number of phorophyte species (see Section 4.6.1). It was hoped that the measurement of phorophyte height and girth may give an idea as to how bark age also affects lichens. Microclimatic measurements would have also been too time consuming for this study. However, phorophyte height, girth and first branch height i.e. phorophyte structure, may effect the lichen microclimate, and could be used to analyse its effects on lichens. Aspect is easily recordable and an important factor influencing lichen establishment, although mostly in temperate regions (see Section 2.2.2c). In the cerrado, the woody vegetation has a very tortuous nature. Many phorophytes are twisted, with few sections of a trunk being in a vertical position, making it extremely difficult to ascertain the overall aspect. Aspect was therefore not measured in this study. The variables (2) to (7) were also used in the study plot descriptions.

Lichen variables (9) and (10) were employed to assess the ecology of lichens: the abundance scale showing the degree of lichen cover; and the distribution scale giving an idea of the 
microclimatic conditions on the phorophytes which may determine the location of lichen establishment. Presence/absence of lichens on scorch, parameter (11), was a measure of the degree of recolonisation after fire.

The methods employed for each of the parameters measured will now be discussed in detail.

\section{a) Phorophyte species name}

At the beginning of the survey, samples of leaves (and fruits when possible) were taken from all phorophytes sampled. With time, the more common species did not need to be collected. Samples were tagged and placed in plastic bags. They were later dried, pressed and sterilised at the University of Brasilia Herbarium. Identification took place primarily with help of the Herbarium staff, and then with consultation of identified specimens in the herbarium collection.

\section{b) Distance, height and girth measurements}

Distance from sampling point to phorophyte was measured using a $10 \mathrm{~m}$ length measuring tape. Height of phorophyte, first branch height and height of scorch were measured using a $15 \mathrm{~m}$ extendible measuring pole. Girth of phorophytes (diameter in $\mathrm{cm}$ ) was recorded with a $100 \mathrm{~cm}$ long diameter tape.

\section{c) Presence/absence of scorch}

This was a purely subjective recording, according to whether there was distinctive blackening on the phorophyte bark surface or not. It was sometimes difficult to decipher the presence of scorch, especially since a few of the phorophyte species had naturally dark-coloured bark. In these cases, scorch was recorded as present, but a question mark was added to signify doubt. The same problem arose in the case of height of scorch since, on occasions, the scorch marks became patchy towards the phorophyte canopy, and so the maximum discernible height was recorded.

\section{d) Bark texture}

Through observations prior to data collecting, phorophyte species were found to have varying bark textures. From this, four main bark textures were established and the simple scale below was constructed (see Figure 4.3):

$$
\begin{aligned}
& \text { Texture value } \\
& \text { 1= smooth; } \\
& \text { 2= rough without marked crevices; } \\
& 3=\text { rough with crevices; } \\
& 4=\text { rough with deep crevices. }
\end{aligned}
$$




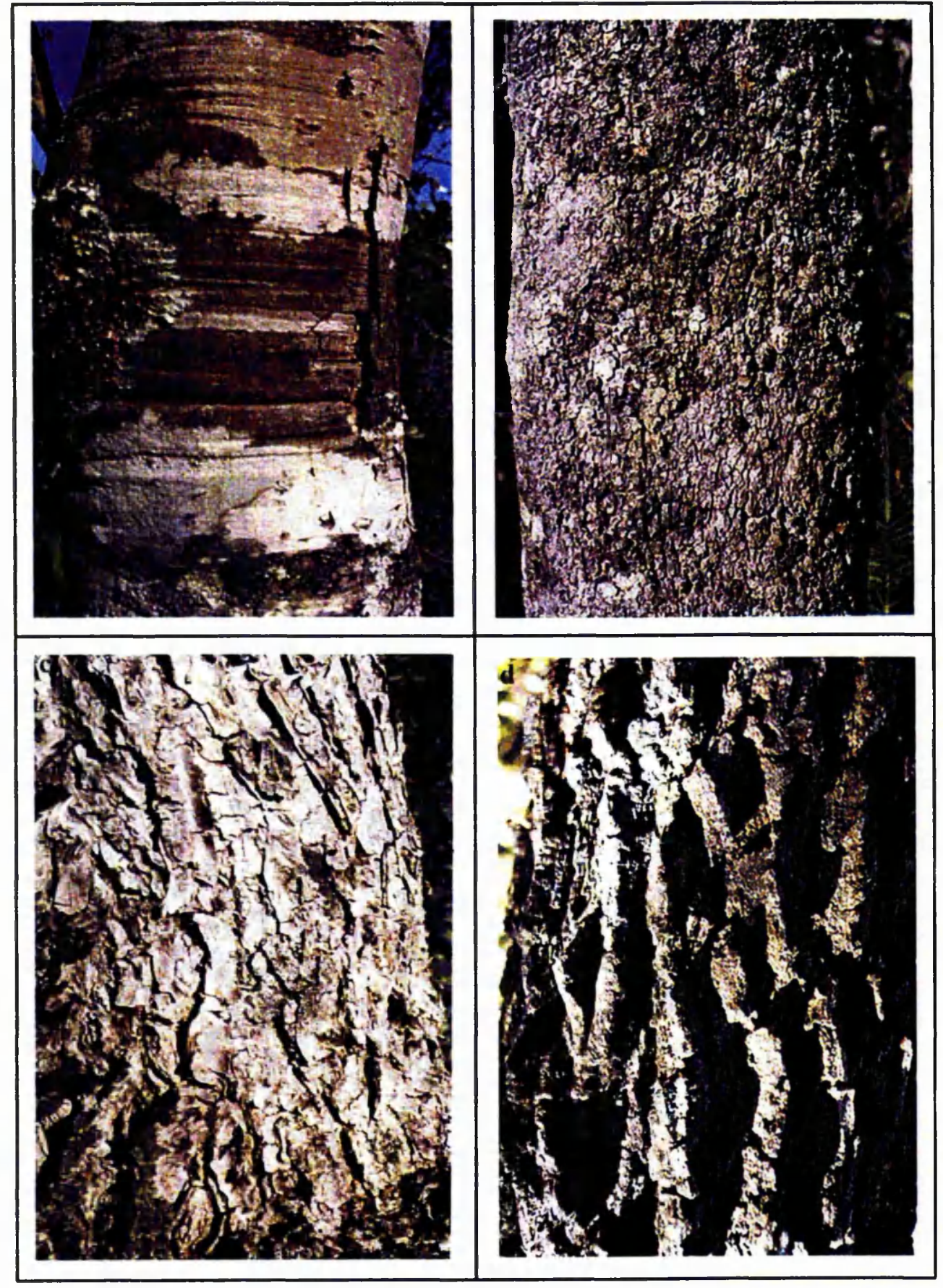

Figure 4.3 Bark textures: a) smooth, Sclerolobium paniculatum; b) rough without marked crevices, Blepharocalyx salicifolius; c) rough with crevices, Dalbergia miscolobium; d) rough with deep crevices, Vochysia thyrsoidea. (Photos by the author). 
For this scale, a crevice was defined as a fissure that occurs between delimited segments of bark, regardless of the type or pattern of the actual segment (see Figures $4.3 \mathrm{c}$ and $4.3 \mathrm{~d}$ ). When a phorophyte did not exactly match any of the scale categories, it was allocated to the one most similar to its bark texture.

\title{
e) Degree of lichen abundance
}

Previous observations showed that there were many phorophytes with absolutely no lichens on them, and in other cases, with just one or two individuals. It was also noted that the richness of lichen cover rarely exceeded more than half of the phorophyte surface. Allowing for these factors, a scale was constructed that had a small number of classes and could be used to take quick and accurate cover estimations easily:

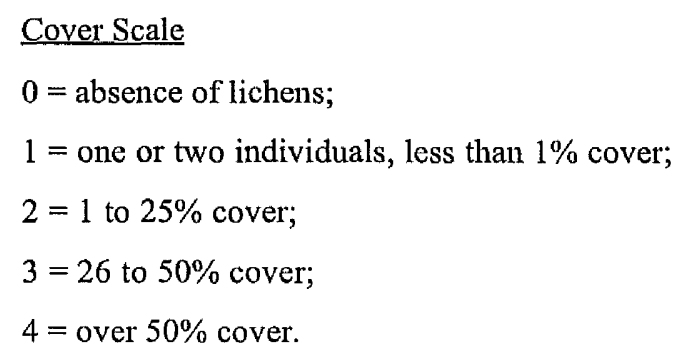

There were difficulties when trying to estimate lichen cover on phorophytes. The main problem was with the taller phorophytes, where lichens may have been growing at heights out of sight of the author. It has to be noted, therefore, that cover values were assigned according to the visibility of the lichens. The cylindrical nature of phorophytes also presented problems, and though systematic recording took place, some errors were likely.

\section{f) Lichen distribution on the phorophyte}

This was estimated using the scales below:

\author{
Distribution scale \\ $0=$ homogeneous lichen distribution; \\ $1=$ partially restricted lichen distribution, to \\ a. base; \\ b. base to $0.9 \mathrm{~m}$; \\ c. 1 to $2 \mathrm{~m}$; \\ d. higher than $2 \mathrm{~m}$; \\ e. on branches \& twigs;
}


Distribution scale continued

$2=$ restricted lichen distribution, to
a. base;
b. base to $0.9 \mathrm{~m}$;
c. 1 to $2 \mathrm{~m}$;
d. higher than $2 \mathrm{~m}$;
e. on branches \& twigs.

\section{g) Presence/absence of lichens growing on scorched bark}

This was a purely nominal measurement, regardless of the amount of coverage of the lichens on the scorch.

\subsection{Stage 2: Lichen community study}

With virtually no previous research on cerrado lichens, except for an occasional taxonomic study (Marcelli, 1993), the aim of this stage in the study was to identify the lichen flora of the cerrado and, by comparing the flora between plots with different fire histories, be able to identify indicator species or genera which might help to generate a LFH Key.

\subsubsection{The sampling design}

Hawksworth and Rose (1976) recommend some procedures of standardisation for surveying phorophytes to be used in developing lichen scales for pollution studies. These include using: phorophytes of the same species or at least similar bark characteristics (supporting similar communities in unaffected areas); phorophytes which are positioned vertically, in comparable situations i.e. exposed and free-standing, rather than in ravines or dense woods; phorophytes of similar size classes (according to girth or height); phorophytes differentiated according to their bark $\mathrm{pH}$ i.e. separating acidic from naturally basic barks. All of these criteria were used by Hawksworth and Rose (1970) to construct a lichen scale for sulphur dioxide air pollution in England and Wales.

Since a level of standardisation was required for this study too, these guidelines served as a basis for choosing which phorophytes would be sampled. The scenario of pollution was replaced with fire, and the vegetation characteristics of the cerrado, as well as the absence of previous lichen studies, had to be taken into consideration.

The heterogeneity and richness of the cerrado woody flora meant that important criteria for choosing which phorophytes to use were: phorophytes commonly found in cerrado denso; and phorophytes most easily recognisable in the field. Using the results of simple analysis on the Stage 1 data, woody species that showed high lichen abundances and differences in lichen abundance between plots of different fire histories, were short-listed as potential candidates (see Section 5.10). Based on these criteria, the following five phorophyte species were chosen on which to study the lichen 
community in more depth (local names in brackets): Blepharocalyx salicifolius (Maria preta), Caryocar brasiliense (Pequizeiro), Guapira noxia (Pau-de-lepra), Sclerolobium paniculatum (Carvoeiro) and Vellozia squamata (Canela-de-ema) (Figure 4.4).

The topography of the plots was reasonably constant, and only free-standing (in contrast to fallen individuals) were sampled. No strict girth diameter was assigned. For example, $V$. squamata is normally a very thin-stemmed species, yet an important one in terms of its constancy and conspicousness in the field, as well as its lichen flora. For each of the five woody species, sampling took place according to the girth criteria discussed in Section 4.3.2, though between individuals of the same species the trunk diameter was kept as constant as possible.

Only Plots 1 to 6 were used for this stage of the research. It was hoped that by comparing the lichen species composition and frequency within Plot 1 (74-control), Plot 2 (74-91: Hom, H, M) and Plot 6 (84-control), certain 'indicators' could be found for fire frequency and behaviour. Although the past burns through Plot 3 (74-92: Het, V, E), Plot 4 (74-92: Het, V, M) and Plot 5 (74-92: Het, V, L) have been very patchy, it was hoped that the lichen composition/frequency data from these would isolate certain lichen species indicative of fire timing during the dry season.

\subsubsection{The sampling method}

A sampling procedure was established that could encompass the area of each plot, and be efficient within the time available. It was, in essence, a belt transect (Kent and Coker, 1992). A random point was located in the plot, and walking in a straight line of a pre-determined compass bearing, those individuals encountered on or within 2 metres to the left or right of this line were sampled. In this way, a large part of each plot was covered, and the chance of encountering an individual of the chosen phorophyte species, greatly increased. Only five individuals of each species were sampled per plot, as lichen identification was a difficult process, and five was seen as a manageable number for the time available, and sufficient to provide statistically significant data. The height, girth and first branch height were measured on each phorophyte individual.

\subsubsection{Lichen sampling}

Branches, twigs and leaves support their own distinctive communities of lichens, usually in the earlier stages of succession (Barkman, 1958; Hale, 1983). The phorophyte trunk, on the other hand, generally possesses the oldest lichen community, reflecting the conditions of the surrounding environment (Wolseley, pers. comm., 19/5/95). The trunk is also the most accessible part of the phorophyte, and so it was decided to limit sampling just to the trunk. The trunk of each phorophyte was divided into 4 sections, every half a metre up to $2 \mathrm{~m}$, and within each of these quarters, samples of all the different lichen species were collected. A limit of $2 \mathrm{~m}$ was chosen because average flame heights range from 1 to $2 \mathrm{~m}$ (see Figure 3.9b), and so the effects of fire on lichens would be most apparent at up to $2 \mathrm{~m}$. Also, in order to make the LFH Key easy to use, it was important to 
Figure 4.4 The five selected phorophyte species (not to scale): a) Sclerolobium paniculatum; b) Blepharocalyx salicifolius; c) Caryocar brasiliense; d) Guapira noxia; e) Vellozia squamata. (Photos by the author).

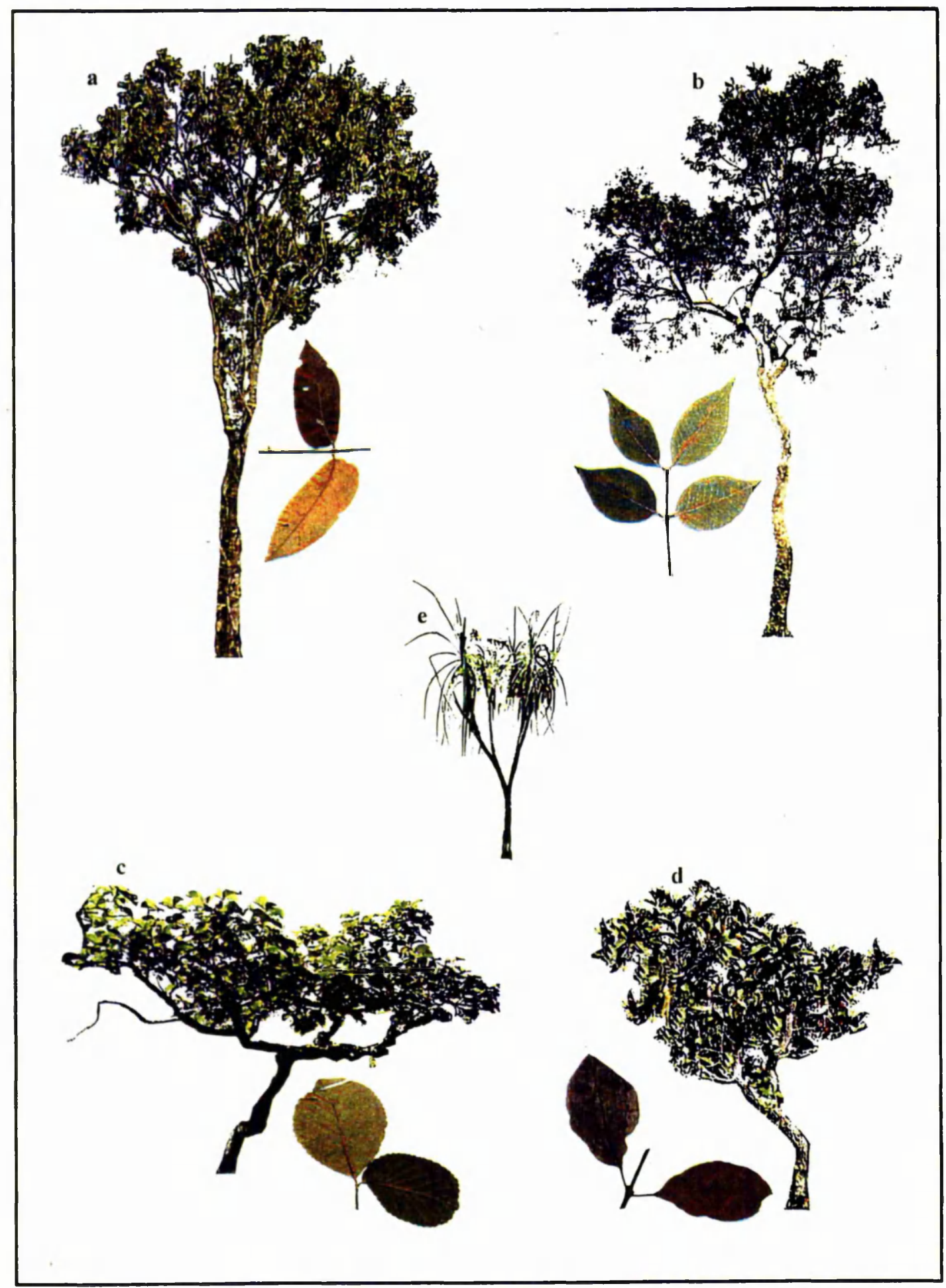


find indicator lichen species on accessible parts of the trunks i.e. below $2 \mathrm{~m}$. By sampling at four different heights on the trunks, it could be ascertained whether certain lichen species had preferences for particular locations on the phorophyte trunk.

\subsubsection{Lichen collection}

Samples of lichen species were collected using a strong pen-knife, and were then wrapped in tissue paper, labelled using a pseudo-name generated by field identification and placed in paper envelopes. Once back in the laboratory, the lichens were laid out to dry in the sun for a day, and then placed back in their envelopes for further identification.

\subsubsection{Lichen identification}

This involved the use of keys, which, by following a series of steps, allowed the identification of lichens to either generic or species level. Methods employed for usage of the keys included recognising morphological features of the lichens, both external and internal, and the use of chemicals for colour tests, which serve as indicators of certain groups of lichen substances.

\subsubsection{The use of keys}

Apart from a very general, out-dated key based on the lichens of north-eastern Brazil (Xavier Filho, 1976), there are no major identification guides for Brazilian lichens. Marcelli (1991, 1992) has contributed greatly to lichenological work in Brazil, but taking into account the vast territory of the country and its diversity of ecosystems, there is plenty of work remaining to be done. After reviewing a number of keys, the following four were chosen for this study:

1) Marcelli, M.P. (1993). Pequenas Parmelia S.L. (Liquens: Ascomycotina) ciliadas dos cerrados brasileiros. Acta bot. bras., 7(2): 25-70;

2) Sipman, H.J.M. (1986). Key to the genera occurring in the Guianas. Unpublished manuscript;

3) Swinscow, T.D.V. and Krog, H. (1988). Macrolichens of East Africa. British Museum (Natural History). London;

4) Wolseley, P.A. and Aguirre-Hudson, B. (1993a). Key to lichen genera in Thailand with special reference to epiphytic communities. Part I Macrolichens. Unpublished, draft copy.

The majority of the identifications were carried out using the key by Wolseley and Aguirre-Hudson. Their work has been concentrated in northern Thailand (Wolseley and AguirreHudson, 1991), and this key has been constructed with students in mind, as an introduction to lichenology. In view of this, it is a very simple and easily usable key, and concentrates on identification through lichen morphology, rather than on the complicated procedures of chemical examination. Here, only fruticose, foliose and squamulose lichens are dealt with, all keyed to the level of the genera. Though Thailand is geographically distant from Brazil, at a generic level, their lichen 
floras are similar (Sipman and Harris, 1989), and since this Thai key included lichens from dry dipterocarp (savanna) forests to montane forest types, it was seen as the most suitable key available.

The Swinscow and Krog (1988) key is a comprehensive account of the fruticose, foliose and squamulose lichens of East Africa, illustrated with photographs and diagrams to aid identification. The main key is to generic level, but under each genera, further classification to species level is given, with detailed explanations describing characteristic features of each species/genera, including their preferred substrate, altitude and geographical location. This key was used in conjunction with the Thai key, for checking identifications and consulting the descriptions (though for some genera, especially Parmelia, it is out-dated: see Elix, 1993). It was considerably more difficult to use, as the key referred to complicated, and very detailed lichen morphology, which at the species level became quite incomprehensible. As in the Thai key, this text dealt with a region quite different to central Brazil, but it was a pioneering work on tropical lichens, and with many genera common to both areas, on the whole, it was an invaluable support aid for identification.

The only key used to identify the crustose lichens was the Sipman (1986) key for the Guianas. This did include foliose and fruticose lichens, but their classification was very simple and excluded a number of recent delimitations of certain genera, such as Parmelia mentioned above. But for the crustose taxa, it provided identification to the generic level, without too much difficulty. More emphasis was placed on the internal morphology of the reproductive structures, in particular identifying the spore type (see Section 4.4.7b), a task that grows easier with practice.

Marcelli's (1993) work with a number of foliose genera of the Parmeliaceae provides the sole lichen key to date for the cerrado. It uses simple colour tests, and the recognition of external morphological structures, which makes it very easy to use. Unfortunately, it deals with only seven genera, although these are delimited to 30 species in total, each fully described, with photographs. Using this key, identifications of those seven genera were made to species level.

The majority of lichens were identified only to genera, but where it seemed possible, some were named as species. Samples of all the different lichens collected were later sent to a specialist in São Paulo, Dr. Marcello P. Marcelli at the Instituto de Botânica, who verified the identifications, and named many to species.

\subsubsection{Morphological examination of the specimens}

To be able to use the keys, it was necessary to have a general knowledge of the terminology involved, and to be familiar with the range of structures that are used as a basis for the description of lichens. Lichen specimens were sorted in the field and in the laboratory, using the following characteristics (in order of undertaking):

A) in the field:

i) the type of thallus present;

ii) general features of the thallus, including: 
a) thallus colour, both on the upper and lower sides;

b) the colour of the medulla;

c) which type of photobiont it contains;

d) the size and branching pattern of the lobes;

e) the characteristics of the upper surface;

f) examination of the lower surface for attachment organs;

iii) presence of reproductive structures on the thallus, vegetative and sexual;

B) in the laboratory:

iv) morphology of the internal organs of the thallus, and the reproductive apparatus.

Lichen characteristics were identified using a hand lens (x10) in the field, and a dissecting or compound microscope in the laboratory. These lichen features will now be described in more detail.

\section{a) Lichen characteristics identified in the field}

i) Thallus form

Lichens were primarily separated into groups according to their thallus form (Figure 4.5):

1) Crustose - closely appressed to the substrate, and attached to it by the hyphae of the medulla. Crustose lichens may grow as a continuous crust, or as rounded or angular areaolae;

2) Squamulose - consisting of numerous small squamules or peltate discs, often on a hypothallus. May appear crust-like or foliose-like;

3) Foliose - leaf-like, with a distinct upper and lower cortex, attached to the substrate by rhizines, hapters or a central holdfast;

4) Fruticose - erect, shrubby, or pendulous, may be attached to substrate by a holdfast, or be unattached. They may be terete or flattened, hollow or solid and with or without a central cord-like axis.

ii) Lichen colour

Lichen colour was recorded for both the upper and lower surface, since in general they are different in colour on each side. The presence or absence of a differentiated border (lighter or darker in colour) on the lower surface of the lichen was also noted. The colour of the medulla is also used in identification, and may be white or coloured. It was examined by scraping away the cortex with a scalpel or razor.

iii) Lichen photobionts

Lichen photobionts were identified by observing colour changes of the thallus when scratched. Thalli that turned yellow-orange when dry contained Trentepohlia. If there was no colour 


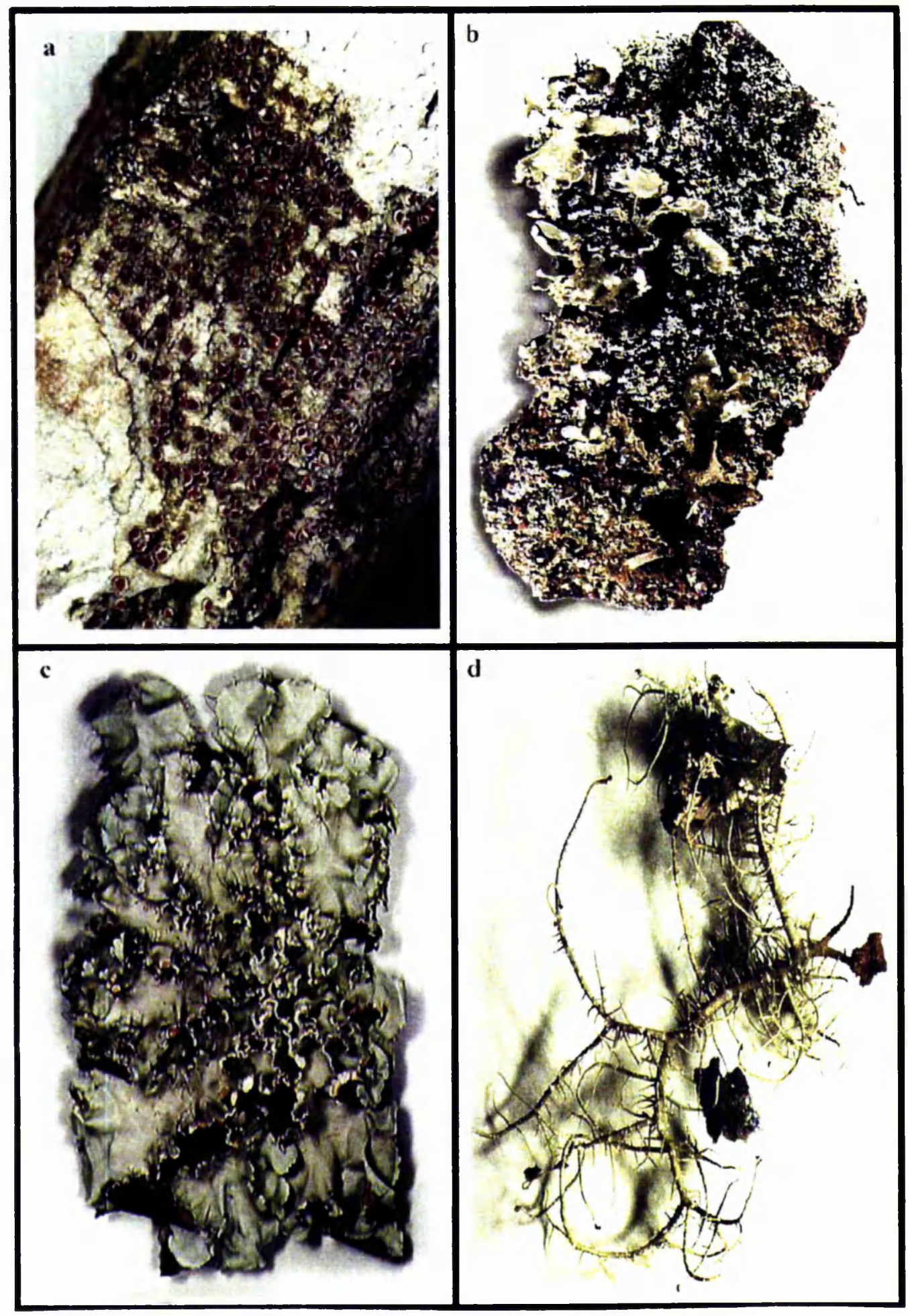

Figure 4.5 Thallus form: a) crustose, Haematomma puniceum (x10); b) squamulose, Cladonia ochroclora (x5); c) foliose, Parmotrema mellissii (x5); and d) fruticose, Usnea sp. 'A' (x5). (Photos by the author). 


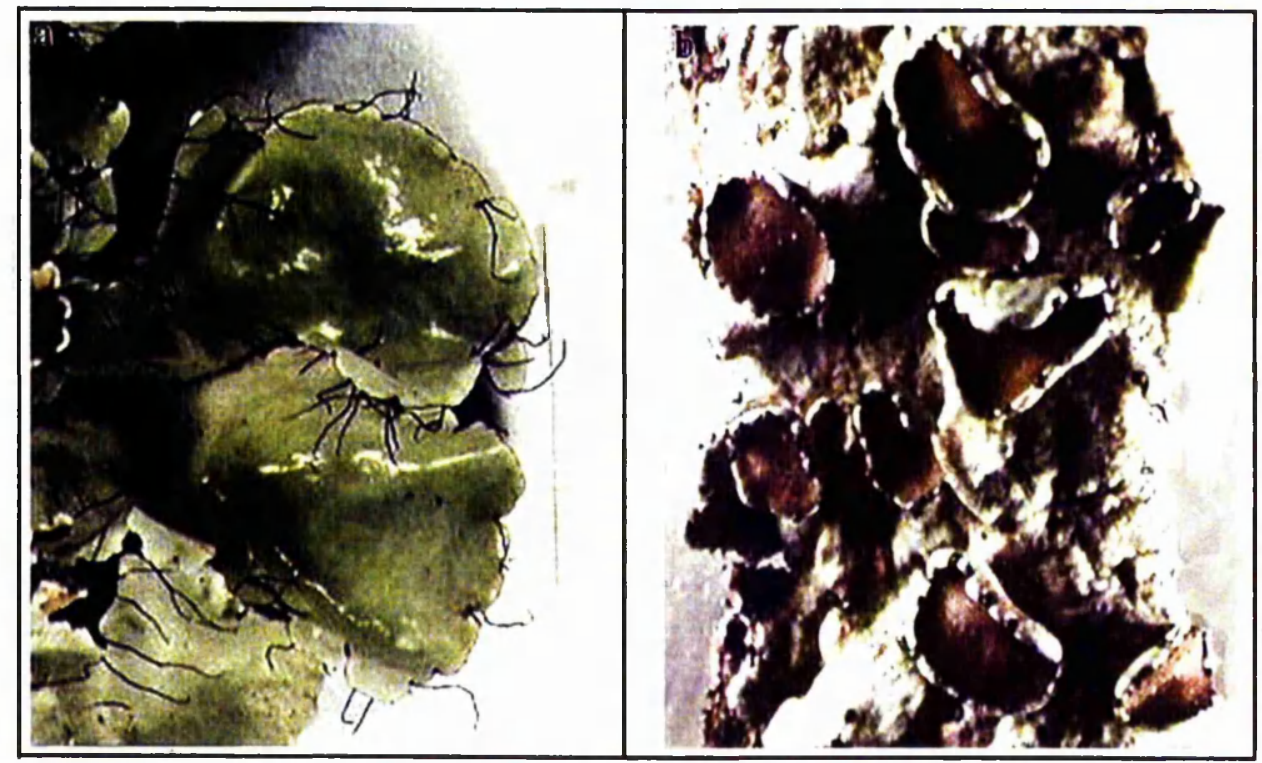

Figure 4.6 Cilia: a) simple, Parmotrema mellissii (x30); and b) bulbate, Bulbothrix coronata (x30). (Photos by the author).

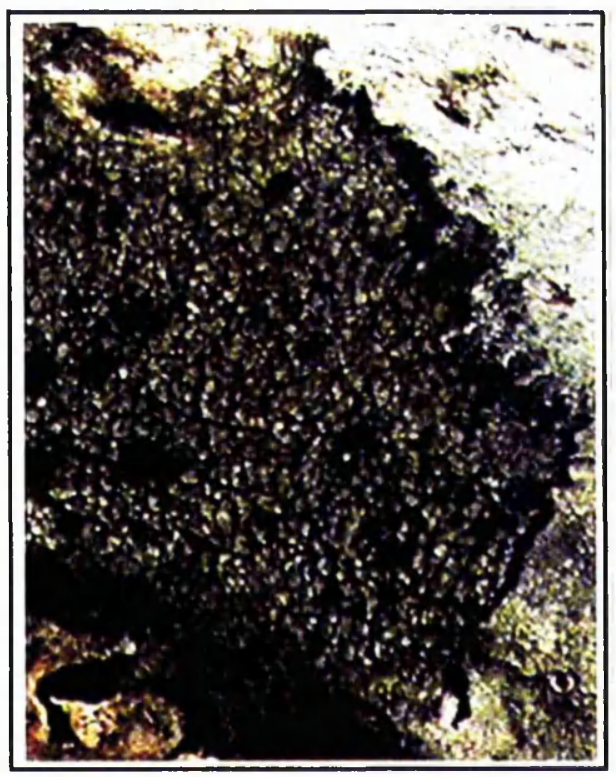

Figure 4.7 A hypothallus, Buellia myriocarpa (x5). (Photo by the author).

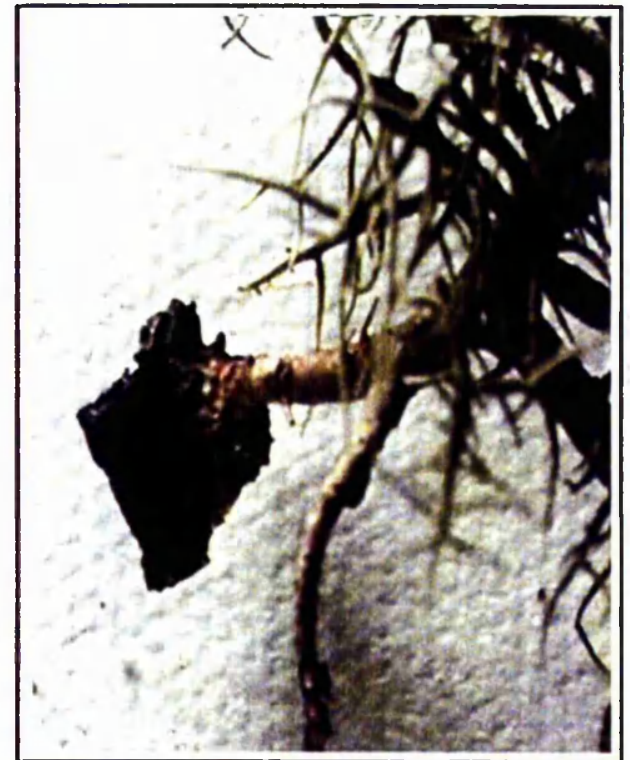

Figure 4.9 A holdfast, Usnea sp. 'A' (x15). (Photo by the author). 
change while the thallus was dry, water was applied to the scratched area. If the thallus turned blue-grey or brown when wet, it contained cyanobacteria, and if it turned bright green it contained Trebouxia algae (Wolseley and Aguirre-Hudson, 1993a).

iv) Thalline features

The upper surface of the thallus was observed for many different characteristics. It can be smooth, wrinkled, cracked or reticulate, and also shiny, pruinose (i.e. frosty looking) or hairy. Due to the irregular distribution of algal cells, a spotted or reticulate pattern of maculae (i.e. paler areas) can occur (Wolseley and Aguirre-Hudson, 1993b). The lobes in foliose and fruticose thalli can be arranged dichotomously or sympodially. The lower surface of the thallus can be corticate or ecorticate.

Cilia are hair-like thalline appendages, decolourised or carbonised strands of hyphae that originate along the lobe margins of the thallus, or on the exciples of apothecia. They can be short, long, bulbate or simple (Figure 4.6).

The hypothallus is a thick, felty layer of hyphae, white to darkly coloured, on the substrate, which precedes the development of the lichen thallus. It can be seen as a dark-coloured rim surrounding crustose thalli (Figure 4.7), or as a woolly or spongy structure surrounding squamulose and some foliose thalli. In some genera, a related tomentum occurs.

Some large foliose lichens produce pores on their surface. Cyphellae are structured pores through the lower cortex, with a raised rim around a cup-like structure, and a distinct membrane bounding the medulla. Pseudocyphellae are simple, undifferentiated perforations in the upper or lower cortex, or on the margins of lobes.

Cephalodia are bodies of cyanobacteria and fungal hyphae, seen as outgrowths growing on the surface or within the thallus of a lichen with a green photobiont.

v) Attachment organs

Rhizines are compacted strands of colourless or blackened hyphae that originate largely from the lower cortex and anchor the thallus to the substrate. They can be simple i.e. unbranched, and where branching does occur, they can take two forms, squarrose or dichotomous (Figure 4.8). They can be distributed uniformly over the lower cortex, or in clumps.

A hapter is a sucker-like attachment organ, present on the underside of the thallus, and distributed like rhizines. A holdfast is an expanded, sometimes disc-like, attachment of the thallus to the substrate (Figure 4.9).

6) Vegetative reproductive structures

Soredia are separable non-corticated clumps of a few algal cells loosely enveloped by fungal hyphae (Figure 4.10a). Sorelia, delimited masses of erupted soredia, can be classified as 


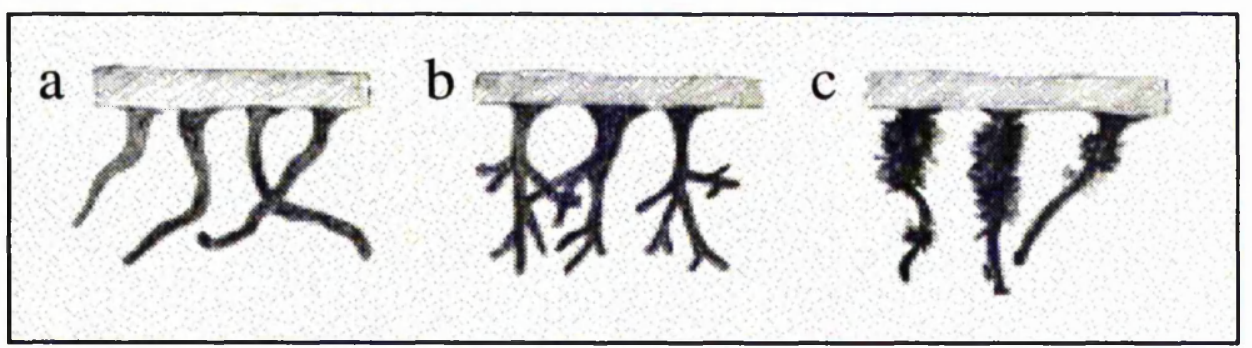

Figure 4.8 Rhizines (not to scale): a) simple; b) dichotomous branched; and c) squarrose branching.

laminal, terminal, and marginal on the upper surface of the thallus (Figure 4.11). They may vary in texture from a fine powder to a granular appearance, but are usually paler in colour than the thallus.

Isidia are protuberances of the upper cortex in which algal and fungal tissues are more or less continuously incorporated. They can be finger-like, globose or flattened, branched, coralloid or simple in appearance, and are often fragile and easily broken off (Figure 4.10b). They may be produced laminally or marginally over the upper side of the thallus, and appear either the same colour or darker than the thalline surface.

Dactyls or pustules are irregularly corticated extensions of the thallus. They appear blister-like and eroded, and may bear isidia or soredia. Phyllidia are small dorsiventral structures, constricted at the base, appearing on the margin or lamina of the lichen thallus. They resemble, in miniature, the parent thallus.

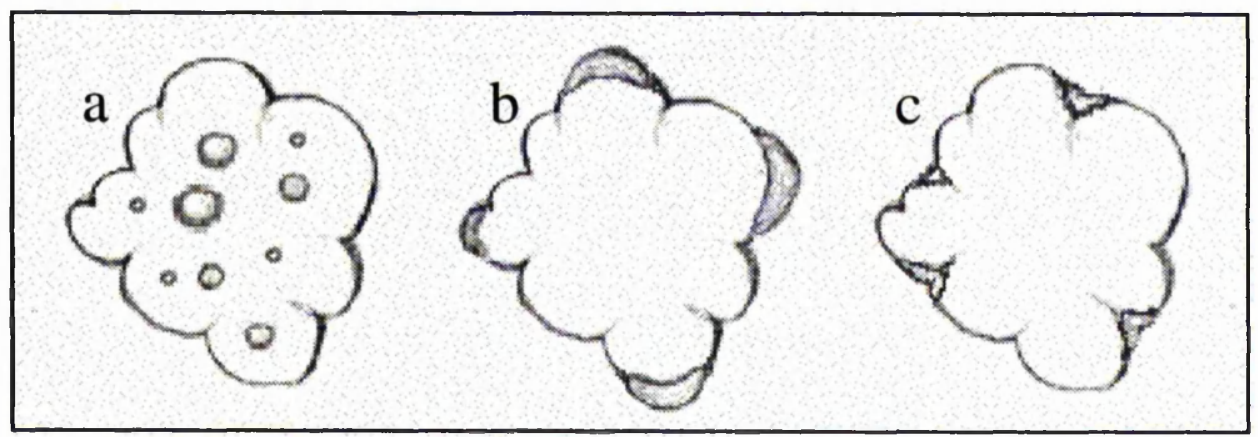

Figure 4.11 Positions of vegetative structures on thallus (not to scale): a) laminal; b) terminal; and c) marginal. 

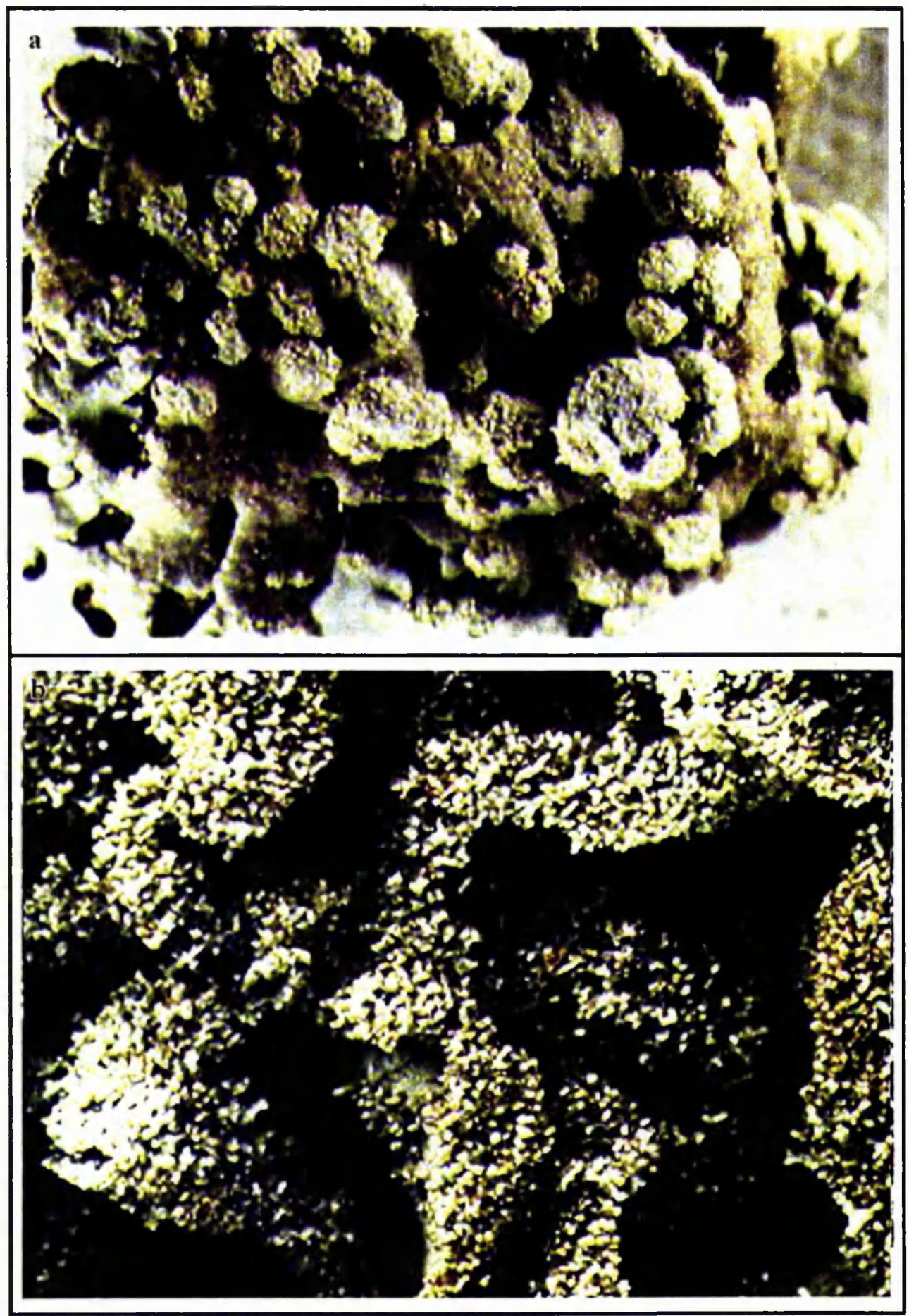

Figure 4.10 Vegetative structures: a) soredia, Hypotrachyna sp 'C' (x30); b) isidia, Parmotrema tinctorum (x40). (Photos by the author). 


\section{7) Sexual reproductive structures}

The most frequently occurring group of lichenised fungi are the Ascomycetes, which produce three kinds of characteristic fruiting bodies:

1) rounded apothecium - a disc-like structure that occurs on the margin or laminal surface of the thallus, and can be immersed, adnate, or stalked (podetia), and with or without a central perforation. In lecideine apothecia the outer edge of the apothecium forms a margin known as the proper exciple, similar in colour to the disc, whereas lecanorine apothecia have a thalline rim (containing algae) visible around the apothecia, which is the same colour as the thallus and different to the disc (Figure 4.12a);

2) lirella apothecium - where the apothecia have become elongated and contorted, and worm-like in appearance. They can occur evenly over the thallus surface, or in clumps (Figure 4.12b);

3) perithecium - are globular or flask-shaped bodies, with a pore-like opening called an ostiole, which itself can be orientated apically or laterally, and free or fused with other ostioles. Perithecia can be found immersed or sessile on the thallus surface, and sometimes occur in compound groups (Figure $4.12 \mathrm{c})$.

Pyenidia are sexual reproductive structures which produce microconidia by budding of simple or branched hyphae within the pycnidium. They strongly resemble perithecia, and may be immersed, sessile, or penicillate on the thallus.

\section{b) Lichen characteristics identified in the laboratory}

i) Preparation of microscope slides

In taking a fragment of an apothecium or the thallus for a squash preparation, the area was first moistened for a few minutes to soften the structures. A cut was then made vertically down with a razor blade, through the structure a little in from the edge. This section was discarded, and from the remaining material several thin slices were obtained. The material was then placed in a drop of water in the middle of the slide, and the coverslip placed on it. The slide was then examined for fruiting structures, or thallus organisation. In some cases, if there was difficulty in observing these structures, especially the spores, with gently pressure on the coverslip, the material was squashed, the surplus fluid being moped away, and followed by re-examination of the slide.

Sometimes, if the slides were particularly good, for example, for showing the spore type present, they were made semipermanent (Swinscow and Krog, 1988). This was done by spreading a large drop of lactophenol cotton blue along one edge of the coverslip and withdrawing the water at the opposite end by means of absorbent paper. In this way, one reagent is suppose to replace the other without disturbance of the sections, though some clarity of the specimen is lost. After cleaning the glass, the margins of the coverslip were sealed with two coats of ordinary cosmetic nail varnish. Treated in this way, the slide is suppose to remain in a fit state to be examined for some months, though it was found that since the author did not have much experience with these techniques, many of 
Figure 4.12 Sexual reproductive fruiting bodies: a) rounded apothecia, Canoparmelia caroliniana (x20); b) lirellae, Graphina sp. (x40); and c) perithecia, Porina sp. (x30). (Photos by the author).
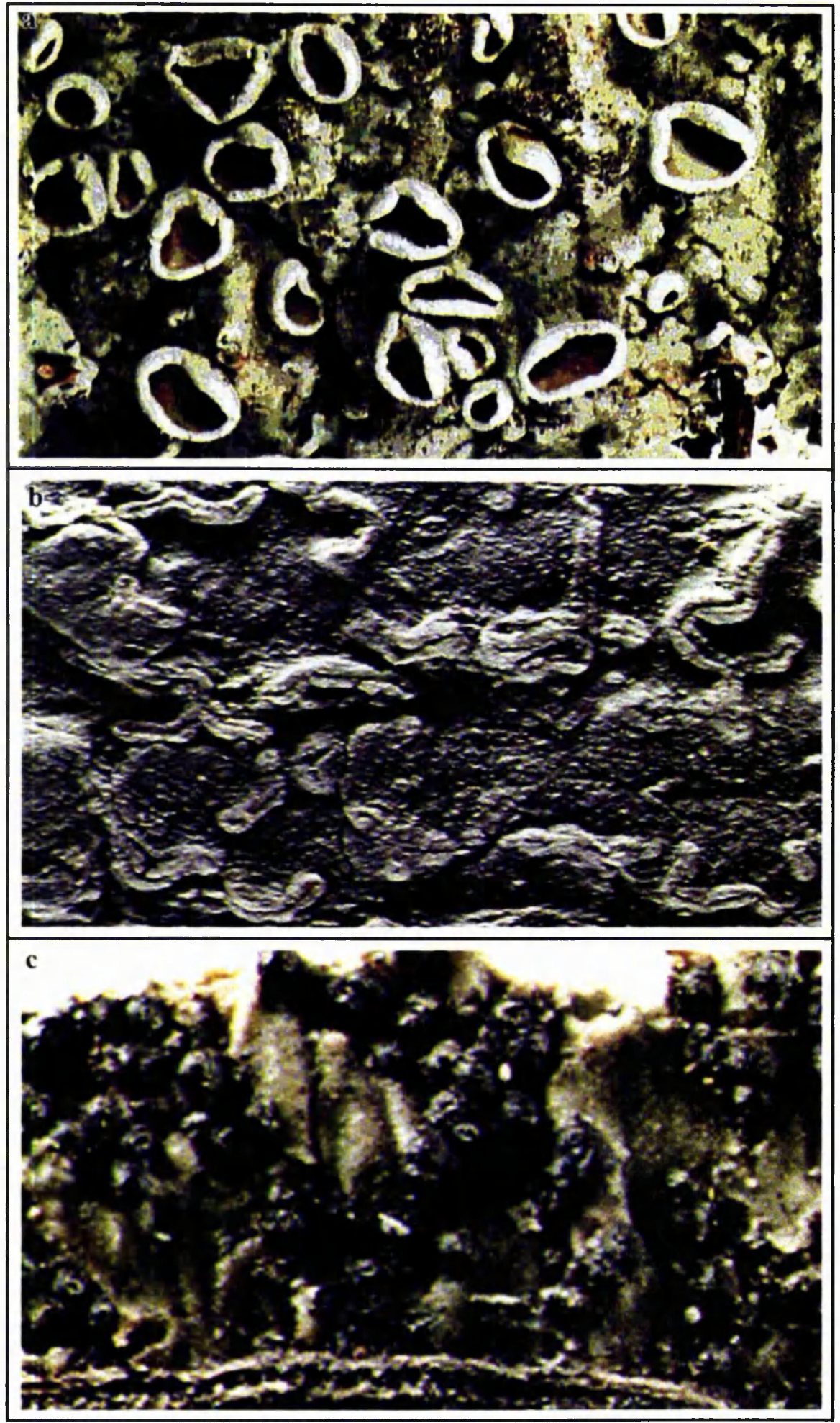
the specimens turned too densely blue to be examined within a couple of weeks. In any case, the slides were useful for checking against recent identifications.

ii) Thallus structure

Thalli can have stratified layers, where the photobiont is restricted to the upper cortex, called heteromerous, or can have the fungal and algal partners occurring together throughout the thallus, which is termed homoiomerous. The first is identified by the upper and lower surfaces being different in colour, and the second, by both surfaces being similar in colour.

The cortex of a heteromerous thallus is composed of hyphae which become orientated in various directions and compressed so as to give the appearance of cellular organisation. There are two different kinds of orientation: irregularly organised paraplectenchyma, where the hyphae grow from the inner part of the thallus at right angles to the surface, giving the cortex a cellular appearance in both cross and longitudinal section; and periclinally prosoplectenchyma, where the cortical hyphae is seen parallel to the surface. In contrast to this, the medulla is always composed of loosely interwoven hyphae with clear gaps.

iii) Internal morphology of sexual reproductive structures

The spores are contained in asci, sac-like bodies within the hymenium. The hymenium is made up of filaments called paraphyses, free at the tips, which are usually simple, or more rarely branched (Figure 4.13). In some lichens the asci degenerate at maturity leaving the spores in a powdery mass termed a mazaedium.

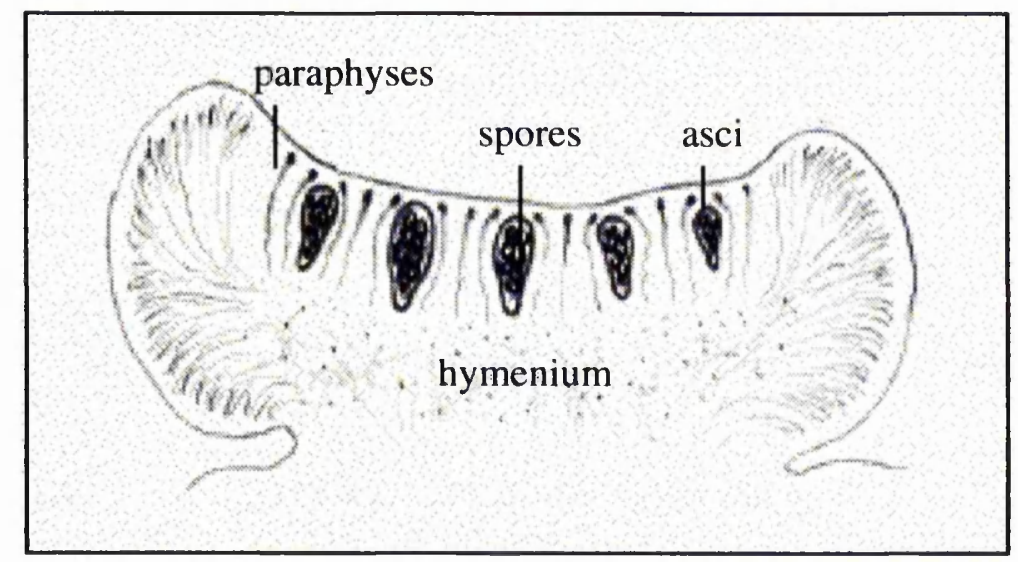

Figure 4.13 The internal structure of a rounded fruiting body (not to scale). 


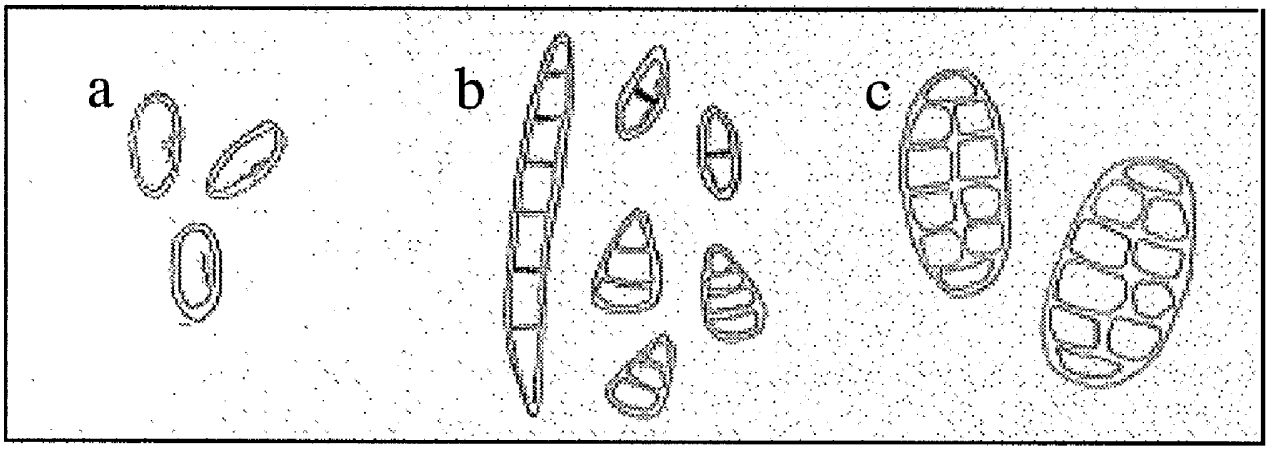

Figure 4.14 Spore types (not to scale): a) simple; b) transversely septate; and c) muriform.

There are usually eight spores in each ascus, though this number can vary. They can be either colourless or brown. Septation is one of the most useful features separating spores. They were identified according to the following classification (Wolseley and Aguirre-Hudson, 1993a) (Figure 4.14):

1) Simple - unicellular and nonseptate, often small and thin walled, more rarely very large and thickwalled;

2) Transversely septate - elongate and multicellular, with one to as many as 30 to 40 transverse cross walls. The spore can have thin septa with a cubic lumina or thick septa with a lumina either rounded or diamond shaped;

3) Muriform - multicellular with both transverse and longitudinal walls (a shattered glass appearance), often quite large. The spore can have thin septa with a cubic lumina or thick septa with a lumina either rounded.

If it was necessary to measure the size of a spore, a micrometer eyepiece, with a corresponding table showing what the large and small divisions of the micrometer with each of the microscope's objectives were in actual lengths (micrometres), was used.

\subsubsection{Colour tests}

Lichens contain a great variety of unique compounds which are associated with metabolic pathways, and have been used in chemotaxonomy to define groups of related species (Hawksworth, 1976). Simple, readily-obtained chemicals that undergo colour reactions are used.

Colour tests were carried out in the laboratory and only where required, for example, in many genera of Parmeliaceae, and for certain lichens at the species level. The following common reagents were used (Swinscow and Krog, 1988):

K................... $5 \% \mathrm{KOH}$ in water;

C.

a solution of calcium hypochlorite in water, for example a commercial brand of household bleach; 
$\mathrm{KC}$

PD

reagent $\mathrm{K}$ quickly followed by reagent $\mathrm{C}$;

a saturated solution of paraphenylenediamine in $96 \%$ alcohol (ethanol) (must be freshly prepared every 3-4 hours). There was difficulty in obtaining a sufficient quantity of this chemical, so this test was used only rarely.

The tests were carried out under the dissecting microscope, and applied using a thin glass rod. A small drop of the reagent was tested either directly onto the surface of the thallus, or on the medulla, in which case, the cortex was removed with a scalpel from an area large enough to prevent the reagent from coming into contact with the cortex. Positive reactions are usually yellow, orange, pink, red or reddish brown (Swinscow and Krog, 1988). The chemicals cause discolouration of the thallus, so the test area was cut away from the specimen and discarded once the reaction had been noted. See White and James (1985) for more details about these chemicals.

\subsubsection{Problems encountered during lichen identification}

Lack of experience was really the only problem when carrying out lichen identifications, though with time, and plenty of practice, it became considerably easier. A number of lichens, especially among the crustose species were sterile i.e. they lacked fruiting bodies, and in these cases, they were given pseudo-names until they could be referred to the specialist. Even the specialist could not identify a few of those lichens, so they were labelled by their pseudo-names.

\subsection{Stage 3: Population study of the genus Bulbothrix}

This section of the research was aimed at analysing in detail how abundances and thallus sizes of lichen populations varied between plots with different fire histories, the results of which could then be built into the LFH Key. The measurement of thallus size was particularly important because the radial growth of lichens meant that thallus size could be used to date fires i.e. determine the 'time-since-last-fire' (see Section 2.2.3). Since this stage of the research involved measuring variables about the lichens in the field, it was decided to do this quantitative work on just one genera of lichen.

The genus Bulbothrix was chosen, principally because it appeared to be one of the first colonisers after fire, and also because it is a genera easily identified in the field, a factor making an in situ study an easier task. It has very characteristic cilia, with nodule, 'bulb-like' features (see Figure $4.6 \mathrm{~b}$ ), sometimes visible to the naked eye, but quite easily seen under a $\times 10$ hand lens.

\subsubsection{Sampling design}

For this part of the study, it was decided to investigate Bulbothrix individuals only on the woody species Guapira noxia, Vellozia squamata and Caryocar brasiliense. These phorophytes were observed to have high occurrences of Bulbothrix. Sampling of the Bulbothrix populations took place in Plot 1 (74-control), Plot 2 (74-91: Hom, H, M) and Plot 6 (86-control). The sampling procedure was the same as in Stage 2 (see Section 4.4.2), and again 5 individuals of each species were 
used. Standard measurements of phorophyte height, girth, and height of first branch for each woody individual were taken.

For each individual of Bulbothrix, measurements of the longest and shortest thallus diameter were taken using a ruler. An average of these two values was then used to calculate the thallus area. Only Bulbothrix lichens with a complete thallus were considered 'individuals'. Where the individuals were too numerous and small, a rough estimate of the abundance, and size was taken. To see if there was a pattern of vertical distribution, the height of each Bulbothrix individual on the phorophyte trunk was also measured, using a measuring tape.

\subsection{Additional fieldwork}

After the three main studies had been completed, two additional experiments were carried out. The first was to test the $\mathrm{pH}$ of bark, to see if it acts as a limiting factor on lichen growth, as has been shown in other studies (Barkman, 1958; Wolseley and Aguirre-Hudson, 1996a), and the second was the measurement of fire temperatures on bark surfaces, to see how they could be related to lichen abundance and distribution patterns.

\subsection{1 pH Tests}

pH was tested using bark from five randomly chosen individuals of the ten phorophyte species Blepharocalyx salicifolius, Caryocar brasiliense, Guapira noxia, Sclerolobium paniculatum, Vellozia squamata, Miconia ferruginata, Palicourea rigida, Qualea grandiflora, Qualea parviflora and Vochysia thyrsoidea. The first five phorophyte species were found to hold abundant lichen populations, whereas the latter five phorophyte species had little or no lichen presence (see Section 5.9.1). Samples were collected from phorophytes in Plot 1 (74-control) which all had similar trunk diameters and heights. These were taken at breast-height for all individuals, except in $V$. squamata, where bark was collected at a $1 \mathrm{~m}$ level because $V$. squamata were generally found to be shorter in height than other phorophyte species.

The method used to measure bark $\mathrm{pH}$ had to be carried out in the laboratory. $\mathrm{pH}$ clectrodes that can be used directly in the field have proved to be valid (Farmer et al., 1990), and would allow a greater number of measurements, but were not available. The following procedures, according to Haertel and Grill (1972) were carried out:

1) The bark samples were dried in an oven at $70^{\circ} \mathrm{C}$ for at least 24 hours;

2) Debris was removed from the bark surface, and then the samples were ground into powder using an electrical grinder;

3) The powder samples were then weighed into portions of $4 \mathrm{~g}$ or $2 \mathrm{~g}$ (depending on the amount there was), and added to either $30 \mathrm{ml}$ or $15 \mathrm{ml}$ of distilled water respectively; 
4) The samples were then placed in a shaker for approximately 2 hours, after which they were tested for $\mathrm{pH}$, using a pH electrode meter.

\subsubsection{Measurements of fire behaviour}

The aspects of cerrado fires that were important for the current work were the fire temperatures attained on the bark surfaces at different heights on the phorophyte trunk, and their residence times i.e. duration of the temperatures. These aspects of fire affect the survival and recolonisation of lichens, and though recovery experiments were not undertaken (which would have to be carried out over a number of years, and therefore beyond the scope of this work), it was hoped that this information about the nature of fire along phorophyte trunks would contribute to the understanding of general lichen fire ecology.

\section{a) Fire temperature measurements}

Fire temperature and duration of temperature have been measured in a number of ways. These include using a heavy duty, non-contact, infra-red digital pyrometer (Kanjanavanit, 1992), heat-sensitive paints (Hobbs et al., 1984; Kanjanavanit, 1992; Stott, 1986), and thermocouples (Miranda, 1988). For this study, both a pyrometer and thermocouples were available. Pyrometer readings have to be taken manually, and as the instrument response is too fast to follow by hand with accuracy, measurements have to be taken at time intervals, such as every 5 seconds (Kanjanavanit, 1992). In the field, it was impossible to get within 2 to 3 metres of the flames, the heat radiating from them being so strong. These factors, together with the requirement of taking measurements at different heights on the phorophytes simultaneously, rendered the pyrometer an unsatisfactory tool for this experiment.

Thermocouples were used in this experiment partly due to their availability and also because a number of fire temperature measurements could be taken simultaneously (Daubenmire, 1968). They can be prone to large errors if not used with caution, and need to be connected to recording equipment that has to be installed and protected from the fire (Vines, 1981; Hobbs et al., 1984). Since they have been used extensively by researchers of the Ecology Department, University of Brasilia, for cerrado fire experiments (Miranda and Miranda, 1993; Miranda et al., 1993), it was hoped that through their help and expertise with the thermocouples, these problems could be overcome.

Heat-sensitive paints may have been a better choice. The benefits of this method would have been the ease of installation and the greater number of phorophytes and heights which could have been measured, and statistically tested. However, the paints do have a problem in that, for interpretation, they need to be recalibrated, since the manufacturer's calibration is for industrial use, and this, in turn, can effect their working ability, with some colour changes not occurring very well (Kanjanavanit, 1992). Also questionable is the accuracy of the fire temperature measurements, since 
more than usual, range rather than point temperatures are attained. Still, for the kind of information wanted for this study, range temperatures would have sufficed.

\section{b) The set-up of the equipment}

The temperature sensors were made of bare thermocouple wires (type $\mathrm{k}$ : chromelalumel, $30 \mathrm{swg}$ ) placed within small ceramic tubes, and wrapped in aluminium foil to reduce heat absorption and conduction along the wires (Miranda et al., 1993). The thermocouple junctions were arc-welded to withstand flame temperatures. The sensors were placed at $0.5,1$ and $2 \mathrm{~m}$ above the ground, fixed against the phorophyte bark by aluminium wire, with about $2 \mathrm{~cm}$ of bare wire exposed to the air.

The temperature readings were obtained from a thermocouple amplifier (AD595AD) buried in a shallow trench near the sensors (Miranda et al., 1993). The amplified signals of the thermocouples were conducted away from the burning area through buried cables to a Campbell $21 \mathrm{X}$ data logger, $2 \mathrm{~m}$ away which selected and recorded the temperatures on each of its 8 channels with $97 \%$ precision and $1^{\circ} \mathrm{C}$ resolution.

Four phorophytes were used: Caryocar brasiliense; Guapira noxia; Sclerolobium paniculatum; and Vellozia squamata. These phorophytes were chosen because they were the species used in the lichen survey, and also because they were located conveniently close enough to each other to be connected to the datalogger by the limited amount of wire present. S. paniculatum (channels 1,2 and 3 ) and G. noxia. (channels 4,5 and 6) were connected to the first datalogger (1D) and V. squamata (channels 1,2 and 3) and C.brasiliense (channels 4,5 and 6) were connected to the second datalogger (2D). All the phorophytes were approximately $2 \mathrm{~m}$ into Plot 4, the IBGE middle season biennial burning plot.

The thermocouples were put in two days before the burn, and programmed to take readings every 10 minutes. On the day of the burn, 10 minutes before the setting of fire, the datalogger readings were set to record every 1 second once a temperature of $50^{\circ} \mathrm{C}$ was reached. 20 minutes after the fire had passed, the datalogger was set back to record every 10 minutes, and continued reading for the following four complete days.

\subsection{Conclusion}

The field methods employed in this study were largely chosen in respect to the time available and the area of the study plots. Research took place in three stages. The first stage involved a general survey of both the phorophyte and lichen communities in plots with different fire histories. The parameters measured here were used to describe the lichen and phorophyte habitats, and to compare the effects of different fire histories on these communities. In the second stage of the research, detailed sampling took place on five woody species to determine the differences in lichen composition in plots with varying fire histories. The third part of the research dealt specifically with one genus of lichen, 
Bulbothrix. Differences in the number of individuals and their sizes were recorded in plots with different fire histories. The results from these three stages of the research were then used to develop the Lichen Fire History (LFH) Key.

Additional work included: $\mathrm{pH}$ tests on phorophyte bark to see whether this is a limiting factor on lichen growth; and the measurement of fire temperatures at different heights on phorophytes to examine their relationship to lichen abundance and distribution. The following three chapters present the analyses and the results of the data collected. 
118 


\section{Chapter 5 \\ Results I: Fire history and its relation to lichen abundance, distribution and recolonisation}

\subsection{Introduction}

The aims of this chapter are:

1) to investigate whether fire history affects the abundance, distribution and recolonisation of lichen communities;

2) to investigate whether changes in other small-scale determinants between areas with different fire histories influence lichen abundance, distribution and recolonisation;

3) to identify a number of phorophyte species for investigating changes in the lichen species composition between areas with different fire histories (Stage 2 of data collection - see Section 4.4).

If fire history does affect the lichen population, the specific changes in lichen abundance, distribution and recolonisation can then be incorporated into the Lichen Fire History (LFH) Key. However, it is necessary to know which other factors influence lichen populations in an area protected from fire, and whether these determinants change in their effect, and to what degree, once fire is introduced. The influence of these factors on lichen populations may affect the LFH Key. Since Plot 1 (74-control) has been protected from fire for over 20 years, it is considered the 'control' plot, and is compared to the plots subjected to fire i.e. Plots 2 to 10.

To compare lichen abundance between data such as height classes, results are presented as an index of Mean Lichen Abundance (MLA). This is the mean frequency distribution of the lichen abundance categories 0 to 4 constructed for this study (see Section 4.3.3e). Where data is presented as mean values, the standard error (S.E.) is used to show the confidence intervals (at 95\%). Where the sample size is small i.e. less than 30 , the correction factor $\mathrm{t}$ is used in the calculation, again at a $95 \%$ confidence. Both are represented by 'mean \pm S.E.'. Data analysis of less than ten samples is deemed to be statistically insignificant, and so where the total number of samples are lower than this limit, a sign of non-significance (N.S.) is shown.

For the categorical data, tests for significance were calculated using the Chi-squared test, where the expected values were the Plot 1 (74-control) frequencies. The degrees of freedom are indicated as a subscript on the Chi-squared sign, and any non-significant results are represented by 'N.S.'. The level of significance used in each calculation is shown as $\mathrm{P}<0.01$ for $99 \%$ confidence, and $\mathrm{P}<0.05$, for $95 \%$ confidence. 


\subsection{Fire history and lichen abundance, distribution and recolonisation}

\subsubsection{Lichen abundance}

Figure 5.1 shows the percentage frequency of phorophytes within each lichen abundance category in the ten plots. In Plot 1 (74-control), lichens are absent on only a few phorophytes, with most phorophytes having 26 to $50 \%$ or over $50 \%$ lichen cover. However, except for Plot 3 (74-92: Het, V, E) $\left(\chi^{2}{ }_{4}=1.58\right.$ (N.S.)), all the other plots have significantly different distributions of phorophyte frequencies compared to Plot 1 (Plot $2 \chi^{2}{ }_{4}=261, \mathrm{P}<0.01$; Plot $4 \chi^{2}{ }_{4}=11.7, \mathrm{P}<0.05$; Plot 5 $\chi_{4}^{2}=34.4, \mathrm{P}<0.01$; Plot $6 \chi^{2}{ }_{4}=70.8$, P $<0.01$; Plot $7 \chi^{2}{ }_{4}=553$, P $<0.01$; Plot $8 \chi^{2}{ }_{4}=794, \mathrm{P}<0.01$; Plot $9 \chi^{2}{ }_{4}$ $=3192, \mathrm{P}<0.01 ;$ Plot $10 \chi^{2}{ }_{4}=19.4, \mathrm{P}<0.01$ ).

On the IBGE side, within Plot 2 (74-91: Hom, H, M), the majority of the phorophytes have less than $1 \%$ lichen cover, with only a small proportion of phorophytes having no lichens or over $50 \%$ lichen cover. Plot 3 (74-92: Het, V, E) has an identical distribution of phorophyte percentages as Plot 1 (74-control), with most phorophytes having 26 to $50 \%$ or over 50\% lichen cover. On the other hand, Plot 4 (74-92: Het, V, M) and Plot 5 (74-92: Het, V, L) show a pattern in lichen abundance slightly different from Plot 1, with major differences being in the '26 to 50\%' category, where lower values are apparent.

The JBB plots present a different picture. In Plot 6 (86-control), although a low proportion of phorophytes have no lichens, as in Plot 1 (74-control), many more phorophytes have less than $1 \%$ and 1 to $26 \%$ lichen cover, and fewer have 26 to $50 \%$ or over $50 \%$ lichen cover. Plot 7 (86-91:

Hom, H, M) and Plot $8(86-91,93$ : Hom, H, E) have few phorophytes in all the lichen abundance

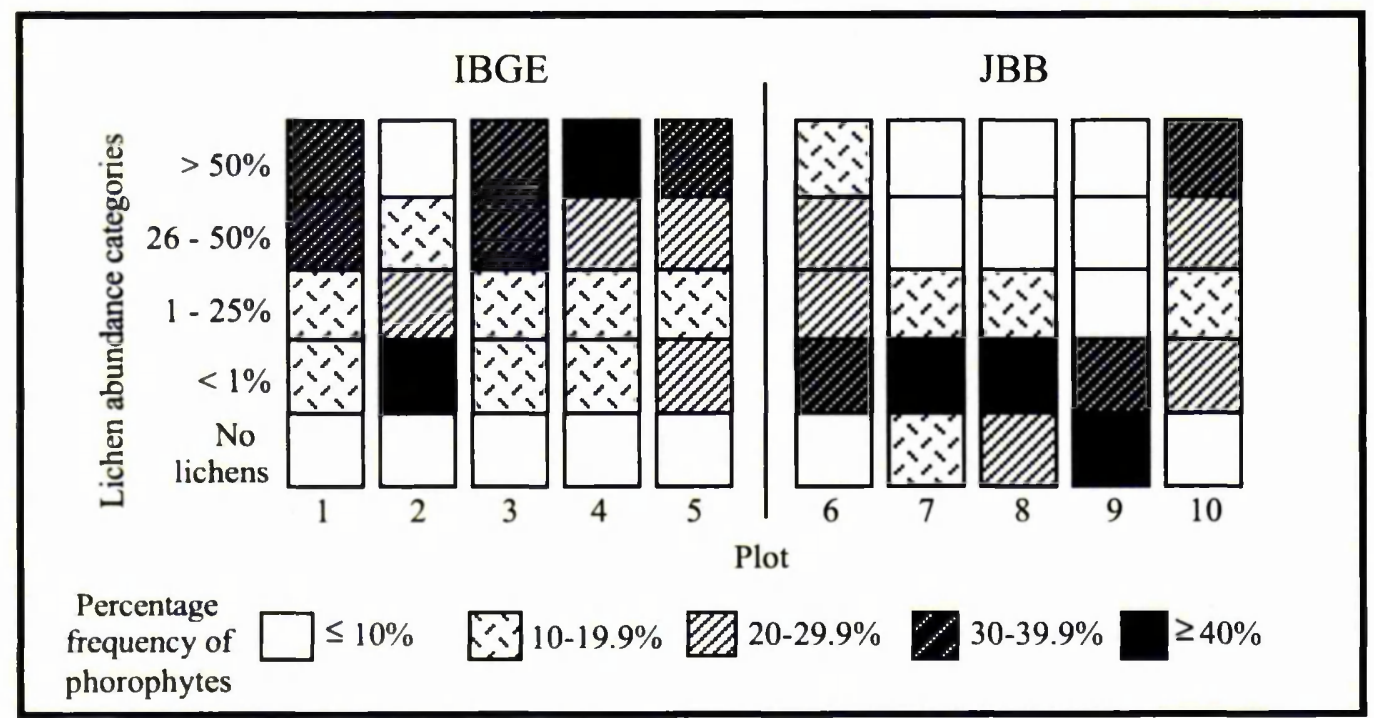

Figure 5.1 The percentage frequency of phorophytes within each lichen abundance category in the ten plots. 


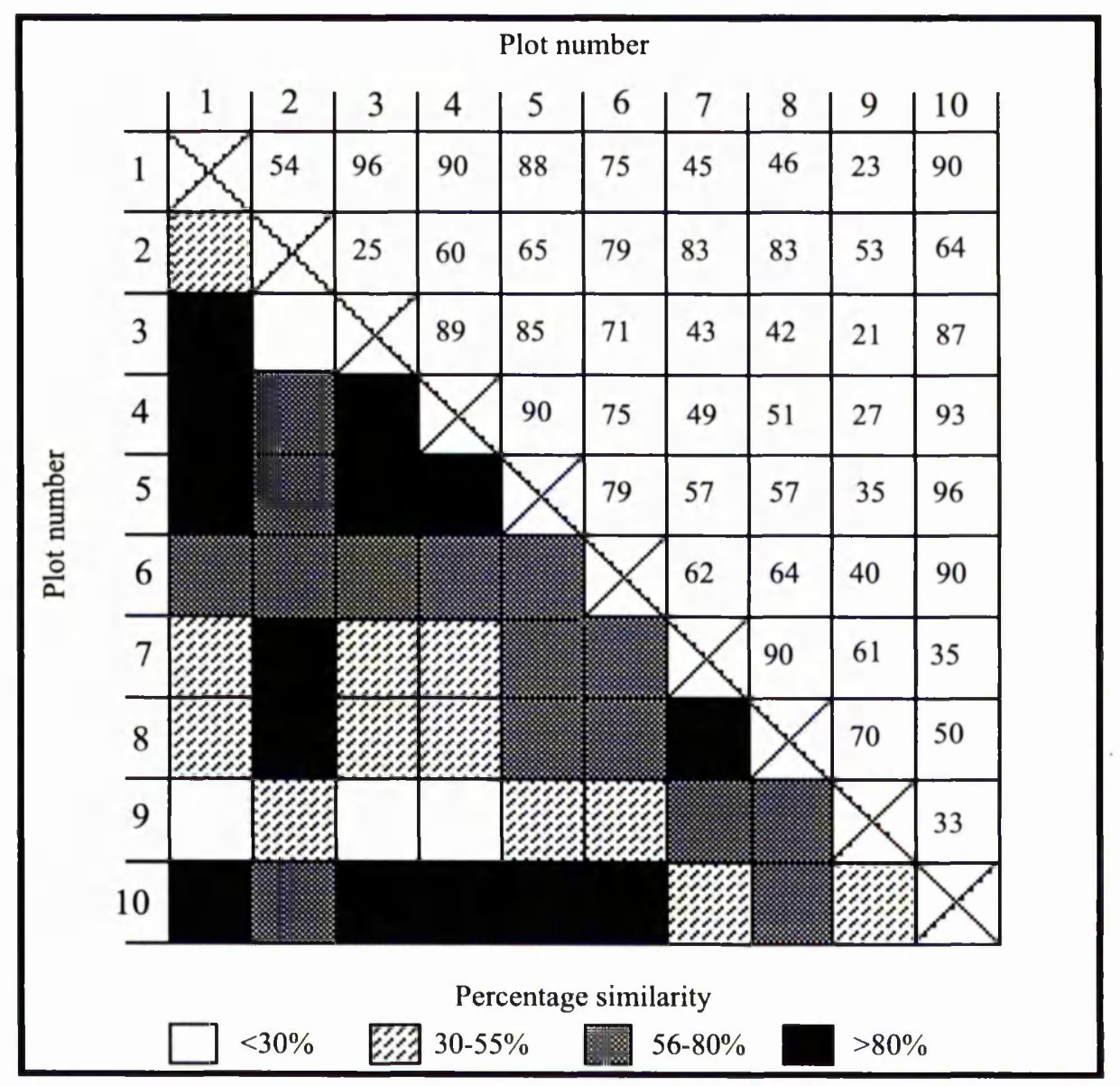

Figure 5.2 A table of Czekanowski similarity coefficients for the ten plots based on the lichen abundance categories.

categories except in the ' $<1 \%$ ' cover category, where values are considerably greater than in Plot 1 . Plot $9(86-91,93:$ Hom, H, M) is different from all the other plots, in that it has a very high proportion of phorophytes with no lichens, and few phorophytes with over $25 \%$ lichen cover. Compared to Plot 1 , Plot 10 (86-91,93: Het, V, L) has a greater proportion of phorophytes with less than $1 \%$ lichen cover and fewer phorophytes with 26 to $50 \%$ lichen cover, similar to the distribution of frequencies found in Plot 5 (74-92: Het, V, L).

Figure 5.2 is a table of Czekanowski similarity coefficients for the ten plots based on the lichen abundance categories. It shows two groups of most similar plots. The largest group, composed of Plot 1 (74-control), Plot 3 (74-92: Het, V, E), Plot 4 (74-92: Het, V, M), Plot 5 (74-92: Het, V, L) and Plot $10(86-91,93$ : Het, V, L), parallels the results found from the phorophyte data analysis, where the DCA ordination, based on the frequency of each phorophyte species in each plot, placed Plots 1, 3, 4, 5 and 10 close together (see Section 3.8.3b). The second group, comprised of Plot 2 (74-91: Hom, H, M), Plot 7 (86-91: Hom, H, M) and Plot 8 (86-91,93: Hom, H, E), show over 
80\% similarity. Plot 6 (86-control) and Plot 9 (86-91,93: Hom, H, M) are not within these groups: Plot 6 has a high degree of similarity (56 to 80\%) with all the plots except Plot 9; and Plot 9 has a low degree of similarity with all the plots except Plots 7 and 8 .

\subsubsection{Lichen distribution}

Figure 5.3 shows the percentage frequency of phorophytes within each lichen distribution category in the ten plots. In Plot 1 (74-control), the largest proportion of phorophytes have a homogeneous lichen distribution, followed by a lower proportion with a partially restricted lichen distribution, and the lowest proportion with a restricted lichen distribution. All the other plots have significantly different patterns of phorophyte frequencies to Plot 1 (Plot $2 \chi^{2}{ }_{2}=21.8, \mathrm{P}<0.01$; Plot $3 \chi^{2}{ }_{2}$ $=26.3, \mathrm{P}<0.01$; Plot $4 \chi^{2}{ }_{2}=12.6, \mathrm{P}<0.01$; Plot $5 \chi^{2}{ }_{2}=30.4, \mathrm{P}<0.01$; Plot $6 \chi^{2}{ }_{2}=11.1, \mathrm{P}<0.05$; Plot $7 \chi^{2}{ }_{2}=33.4$, $\mathrm{P}<0.01$; Plot $8 \chi^{2}{ }_{2}=31.3$, P $<0.01$; Plot $9 \chi^{2}{ }_{2}=52.2$, P $<0.01$; Plot $10 \chi^{2}{ }_{2}=41.5, \mathrm{P}<0.01$ ).

Plot 6 (86-control) has a higher frequency of phorophytes with a homogeneous lichen distribution, and a lower frequency of phorophytes with a partially restricted lichen distribution compared to Plot 1 (74-control). However, in contrast to the other plots, Plot 6 shows the most similar pattern of lichen distribution to Plot 1. Plot 2 (74-91: Hom, H, M), Plot 3 (74-92: Het, V, E), Plot 4

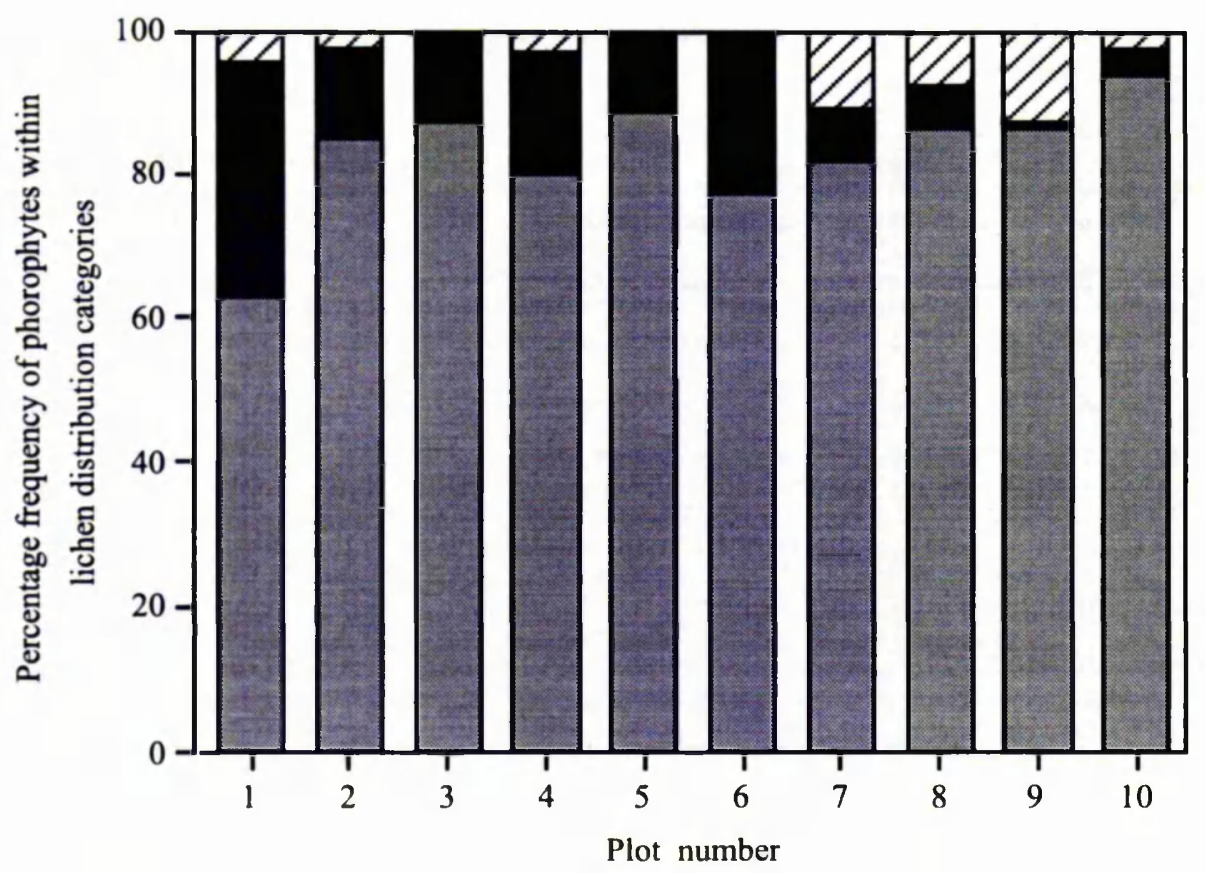

Homogeneous lichen distribution Partially restricted lichen distribution

Restricted lichen distribution

Figure 5.3 The percentage frequency of phorophytes within each lichen distribution category in the ten plots. 
(74-92: Het, V, M), Plot 5 (74-92: Het, V, L) and Plot 10 (86-91,93: Het, V, L) all have much higher frequencies of phorophytes with a homogeneous lichen distribution and lower frequencies of phorophytes with a partially restricted and restricted lichen distribution when compared to Plot 1. Plot 7 (86-91: Hom, H, M), Plot 8 (86-91,93: Hom, H, E) and Plot 9 (86-91,93: Hom, H, M) have high frequencies of phorophytes with a homogeneous lichen distribution, very low frequencies of phorophytes with a partially restricted lichen distribution, but the highest frequencies of phorophytes with a restricted lichen distribution.

Figures $5.4 \mathrm{a}$ and $5.4 \mathrm{~b}$ show the percentage frequency of phorophytes with lichens on specific parts of the phorophyte within the 'partially restricted lichen distribution' category, and the 'restricted lichen distribution' category respectively, in the ten plots. Throughout all the plots there are no occurrences of lichens partially restricted, or restricted to the branches and twigs.

First looking at the different categories among the phorophytes with a partially restricted lichen distribution (Figure 5.4a), Plot 1 (74-control) has the highest proportion of phorophytes with lichens from the base to $0.9 \mathrm{~m}$ and between 1 to $2 \mathrm{~m}$. Plot 6 (86-control) has a pattern of distribution similar to Plot 1 , but with a higher proportion of phorophytes with lichens

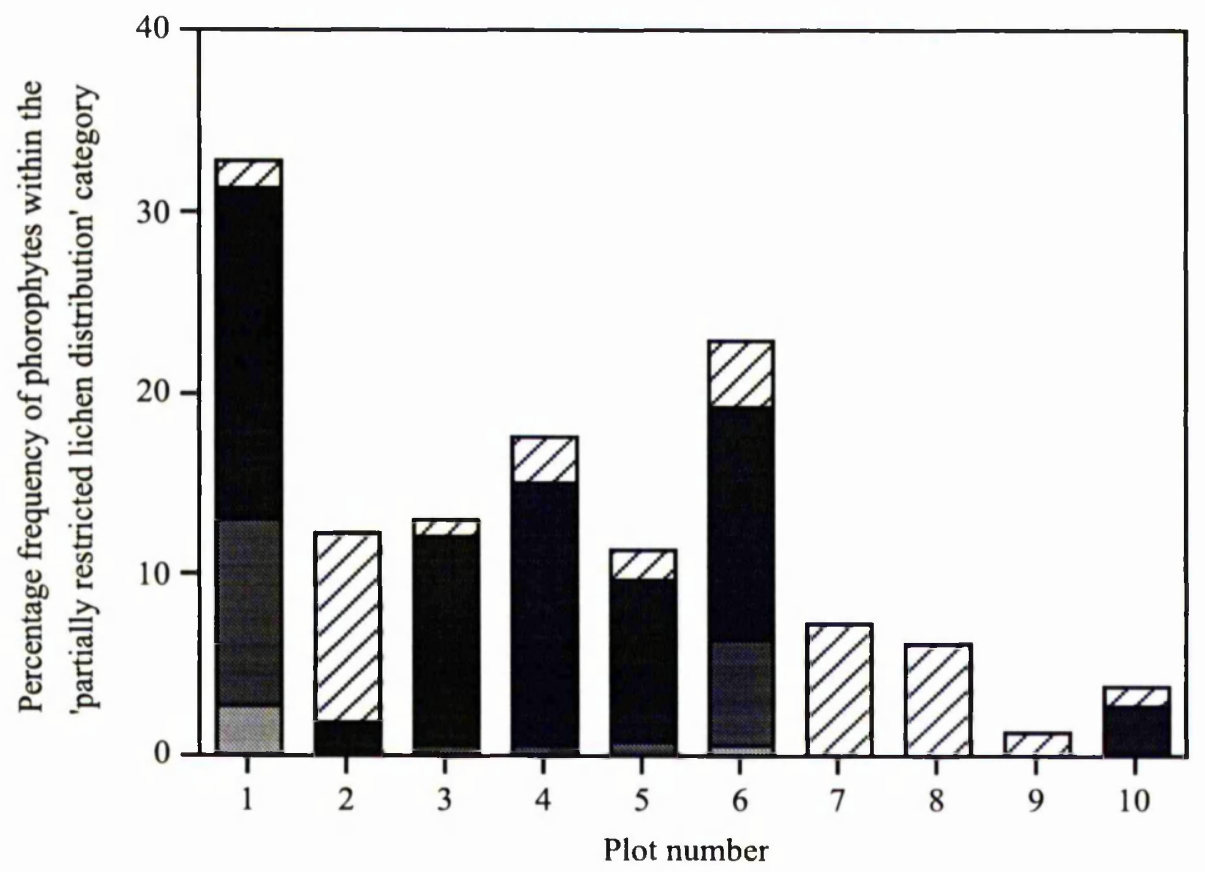

Base Base to $0.9 \mathrm{~m} \square 1$ to $2 \mathrm{~m}$

Đigher than $2 \mathrm{~m} \square$ On branches and twigs

Figure 5.4a The percentage frequency of phorophytes with lichens on specific parts of the phorophyte within the 'partially restricted lichen distribution' category in the ten plots. 
above $2 \mathrm{~m}$. As in Plot 1, Plot 3 (74-92: Het, V, E), Plot 4 (74-92: Het, V, M) and Plot 5 (74-92: Het, $\mathrm{V}, \mathrm{E})$ have the highest frequencies of phorophytes with lichens at 1 to $2 \mathrm{~m}$, although there are few phorophytes with lichens concentrated below $1 \mathrm{~m}$. Plot 2 (74-91: Hom, H, M), Plot 7 (86-91: Hom, $\mathrm{H}, \mathrm{M})$ and Plot 8 (86-91,93: Hom, $\mathrm{H}, \mathrm{E})$ have the highest value in the 'higher than $2 \mathrm{~m}$ ' category, with few phorophytes having lichens concentrated below $2 \mathrm{~m}$. Although most phorophytes in Plot 9 (8691,93: Hom, H, M) have lichens above $2 \mathrm{~m}$, and between 1 to $2 \mathrm{~m}$ in Plot 10 (86-91,93: Het, V, L), the values are too low to be significant.

In the group of phorophytes with a restricted lichen distribution (Figure 5.4b), Plot 1 (74-control) has the highest proportion of phorophytes with lichens from the base to $0.9 \mathrm{~m}$, with all the other plots having no lichens between this height range. Phorophytes with a restricted lichen distribution were not found in Plot 3 (74-92: Het, V, E), Plot 5 (74-92: Het, V, L) and Plot 6 (86control). However, Plot 2 (74-91: Hom, H, M), Plot 4 (74-92: Het, V, M), Plot 10 (86-91,93: Het, V, L), and especially Plot 7 (86-91: Hom, H, M), Plot 8 (86-91,93: Hom, H, E) and Plot 9 (86-91,93: Hom, $\mathrm{H}, \mathrm{M}$ ) show considerably higher values in the 'higher than $2 \mathrm{~m}$ ' category when compared to Plot 1 .

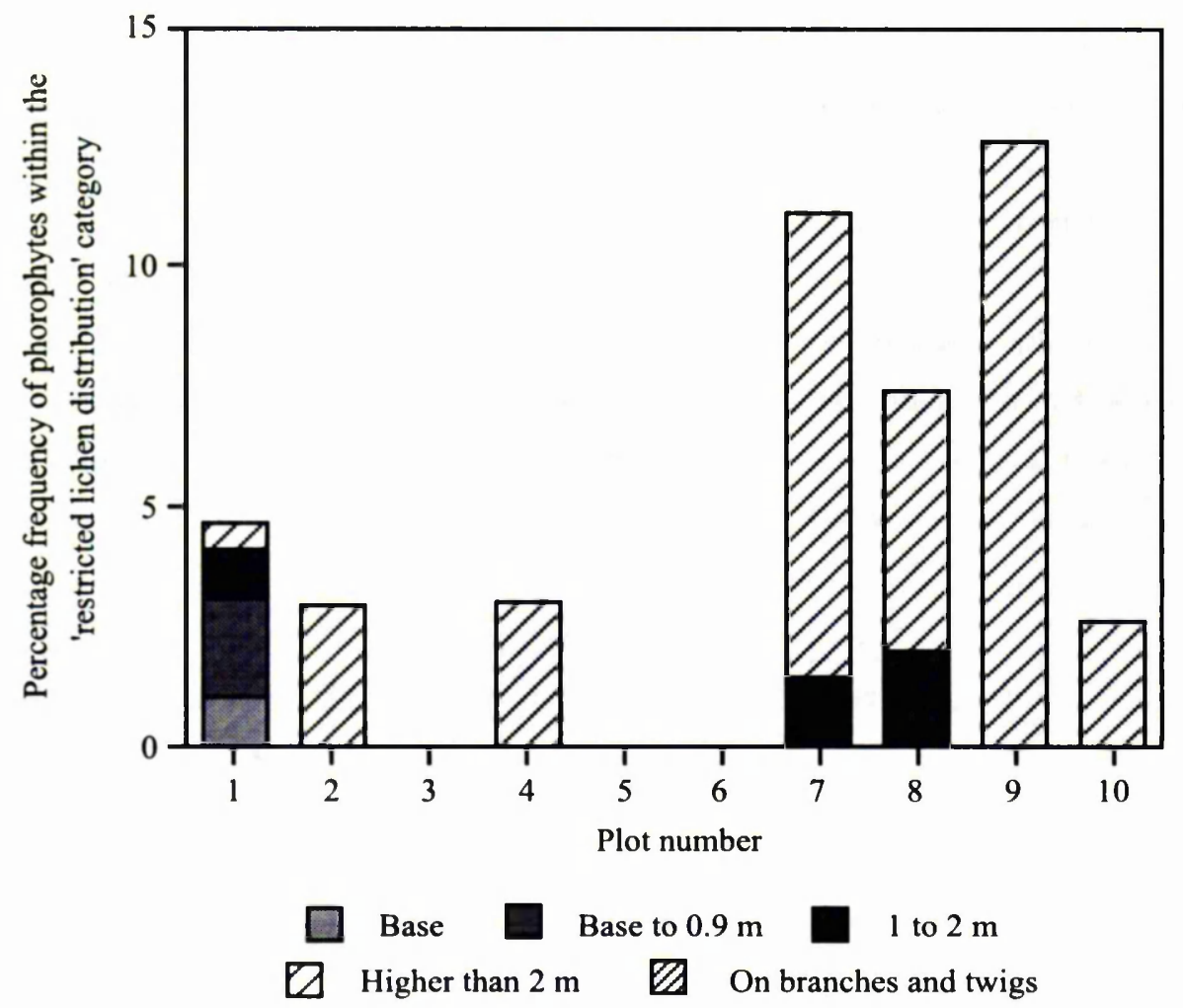

Figure 5.4b The percentage frequency of phorophytes with lichens on specific parts of the phorophyte within the 'restricted lichen distribution' category in the ten plots. 


\subsubsection{Lichen recolonisation}

Figure 5.5 shows the percentage frequency of phorophytes with lichens present on scorch i.e. lichen recolonisation, in the ten plots. Since Plot 1 (74-control) has been protected from fire for over 20 years, scorch was absent (see Section 3.8.3a). Statistical analysis indicates that there is a significant difference in lichen recolonisation between the plots $\left(\chi^{2}{ }_{8}=353.3, \mathrm{P}<0.01\right)$. Plot 2 (74-91: Hom, H, M) has just over $50 \%$ of phorophytes with lichen recolonisation. Plot 3 (74-92: Het, V, E) and Plot 4 (74-92: Het, V, M) both have high frequencies of phorophytes with lichen recolonisation, $71 \%$ and $68 \%$ respectively, while Plot 5 (74-92: Het, V, L) and Plot 10 (86-91,93: Het, V, L) have much lower values: $46 \%$ and 39\% respectively. Plot 6 (86-control) has the highest proportion of phorophytes with lichen recolonisation (86\%) of all the plots. Few phorophytes in Plot 7 (86-91: Hom, H, M) and Plot 8 (86-91,93: Hom, H, E) have lichen recolonisation (20 and 17\% respectively), while Plot 9 (86-91,93: Hom, H, M) has the lowest proportion of lichen recolonisation of all the plots, only $1 \%$.

\subsubsection{Summary}

These results show that there is variation in lichen abundance between plots with different fire histories. Most phorophytes in Plot 1 (74-control) have 26 to $50 \%$ or over $50 \%$ lichen cover. In comparison, all the other plots have varying degrees of differentiation in lichen abundance to Plot 1, with Plot 3 (74-92: Het, V, E) being the most identical, followed by Plot 4 (74-92: Het, V,

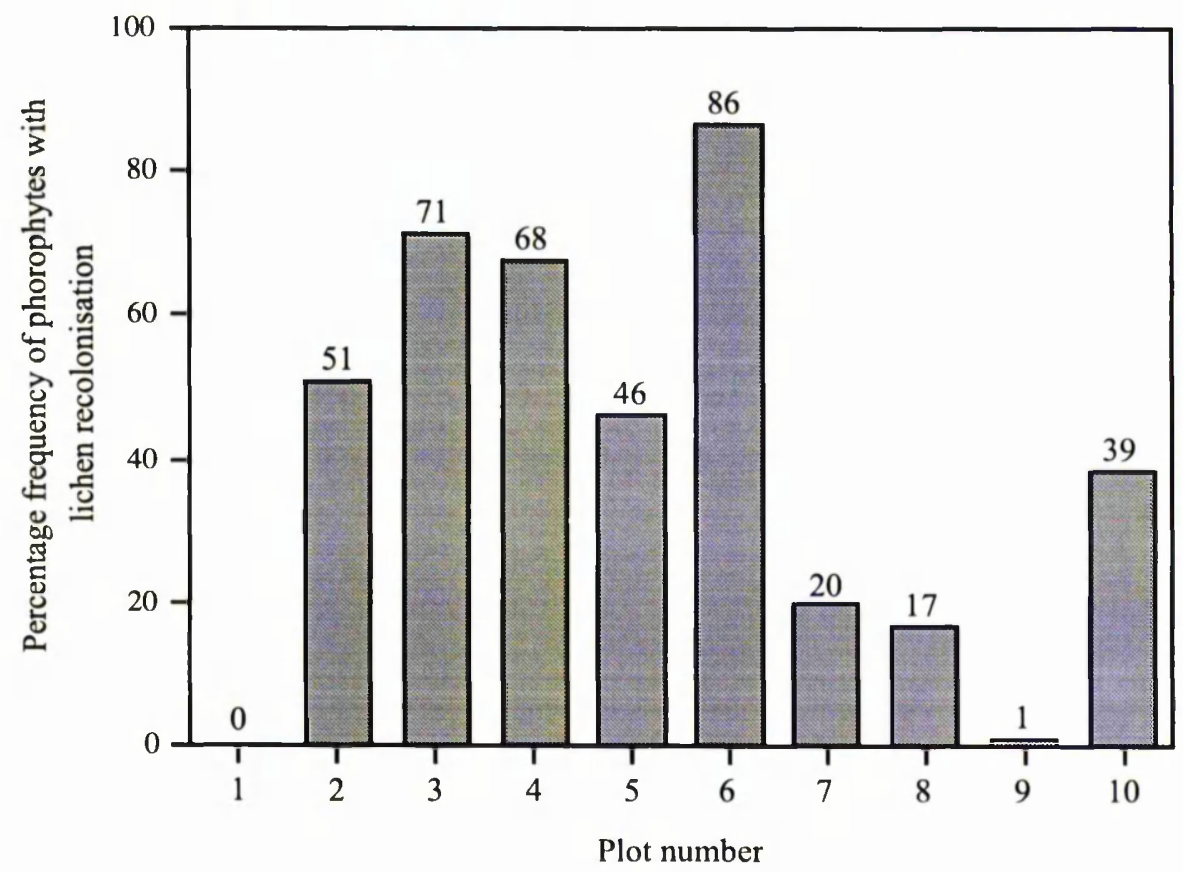

Figure 5.5 The percentage frequency of phorophytes with lichen recolonisation in the ten plots. 
M), Plot 5 (74-92: Het, V, L) and Plot 10 (86-91,93: Het, V, L). Although most phorophytes in Plot 2 (74-91: Hom, H, M) have less than 1\% lichen cover, there are still some phorophytes with between 1 to $50 \%$ lichen cover. Many phorophytes in Plot 6 (86-control) also have a low lichen cover, and in this plot there are few phorophytes with high lichen abundances. Most phorophytes in Plot 7 (86-91: Hom, H, M) and Plot 8 (86-91,93: Hom, H, E) have a low lichen cover, and in the case of Plot 9 (86-91,93: Hom, $\mathrm{H}, \mathrm{M}$ ), few phorophytes have any lichens at all.

Lichen distribution was also found to vary between plots with different fire histories. In Plot 1 (74-control) most phorophytes have a homogeneous lichen distribution, or are partially restricted from the base to $2 \mathrm{~m}$. This is also true for Plot 6 (86-control), although more phorophytes in this plot have lichens above $2 \mathrm{~m}$ compared to Plot 1 . Among the phorophytes showing a significant partially restricted lichen distribution, Plot 3 (74-92: Het, V, E), Plot 4 (74-92: Het, V, M), Plot 5 (74-92: Het, V, L) and Plot 10 (86-91,93: Het, V, L) have much higher frequencies of phorophytes with lichens between 1 to $2 \mathrm{~m}$, and in Plot 2 (74-91: Hom, H, M), above $2 \mathrm{~m}$. In Plot 7 (86-91: Hom, H, M), Plot 8 (86-91,93: Hom, H, E) and Plot 9 (86-91,93: Hom, H, M), where there is the highest proportion of phorophytes with a restricted lichen distribution, notably more phorophytes have lichens above $2 \mathrm{~m}$.

The results showed that lichen recolonisation varied between plots with different fire histories. Plot 6 (86-control) has the highest degree of lichen recolonisation, followed by Plot 3 (74-92: Het, V, E) and Plot 4 (74-92: Het, V, M). Plot 2 (74-91: Hom, H, M), Plot 5 (74-92: Het, V, L) and Plot 10 (86-91,93: Het, V, L) have lower values, and lichen recolonisation decreases further in Plot 7 (86-91: Hom, H, M) and Plot 8 (86-91,93: Hom, H, E), with Plot 9 (86-91,93: Hom, H, M) having the lowest value.

These results, indicating that lichen abundance, distribution and recolonisation are affected by fire history, are highly relevant to the LFH Key. They show that variations in these lichen variables may be used to help determine the fire history of an area.

\subsection{Phorophyte height and lichen abundance, distribution and recolonisation in plots with varying fire histories}

\subsubsection{Phorophyte height and lichen abundance}

Figures 5.6 and 5.7 show the Mean Lichen Abundance (MLA) on phorophytes within different height classes for an area protected from fire and in areas subjected to fire, respectively. Results for phorophytes within the ' $<1 \mathrm{~m}$ ' classes are insignificant since the minimum limit of ten individuals was not passed in this group.

There is no significant difference in MLA on phorophytes between different height classes in an area protected from fire (mean \pm S.E. $=$ NS). Although there is a significant difference in MLA on phorophytes between different height classes in areas subjected to fire (mean \pm S.E.), the high 


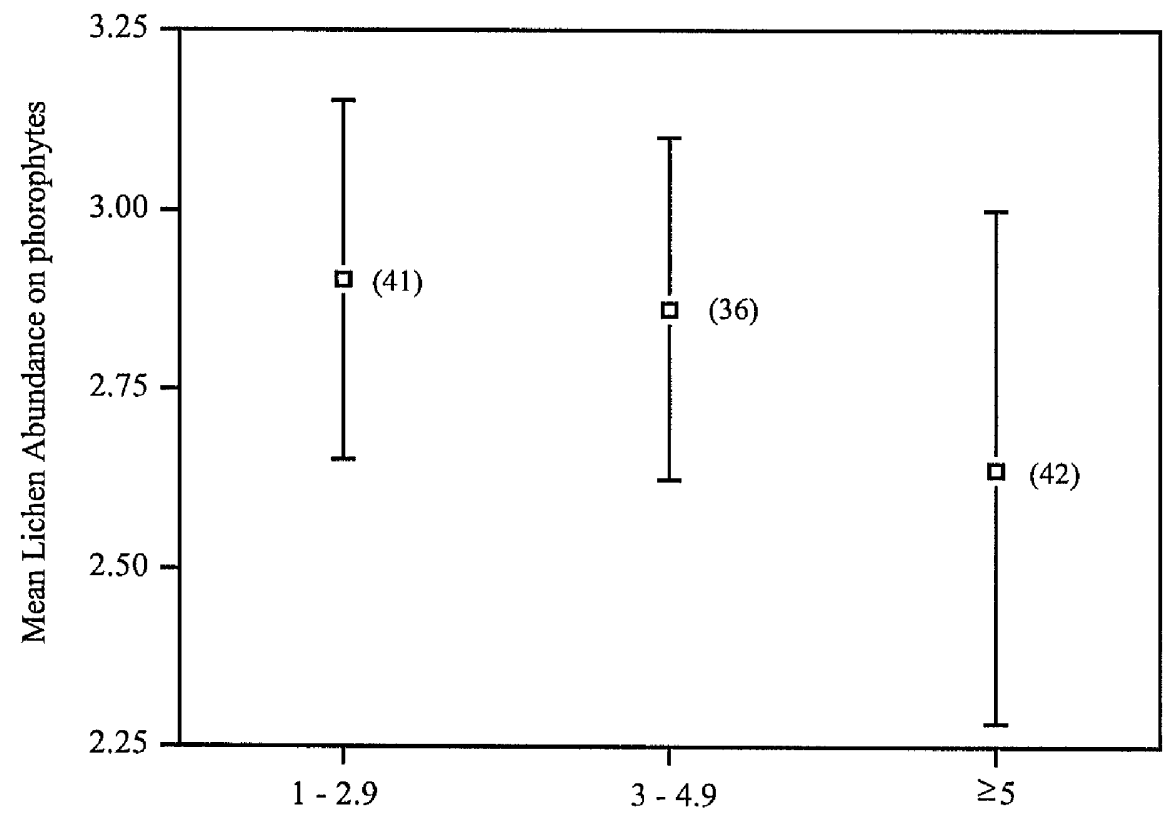

Phorophyte height classes (m)

Figure 5.6 The Mean Lichen Abundance on phorophytes within different height classes (m) in an area protected from fire. The Coefficient of Variation (CV) for each class is shown in brackets, and the vertical bars represent the standard error of the mean.

relative variability in MLA values within the height classes (see CV values) limits the significance of the results.

\subsubsection{Phorophyte height and lichen distribution}

Table 5.1 shows the percentage frequency of phorophytes in each lichen distribution category within different height classes in an area protected from fire and in areas subjected to fire, respectively. Results for phorophytes within the ' $<1 \mathrm{~m}$ ' height class are insignificant since the minimum limit of ten individuals was not passed in this group.

In both an area protected from fire, and areas subjected to fire, the height class ' $1-2.9$ $\mathrm{m}$ ' shows a significantly higher proportion of phorophytes with a homogeneous lichen distribution and a lower proportion of phorophytes with a partially restricted lichen distribution when compared to the '3 - $4.9 \mathrm{~m}$ ' and ' $\geq 5 \mathrm{~m}$ ' height classes. There is an insignificant difference in the frequency of phorophytes between height classes within the 'restricted lichen distribution' category in both the fire protected area and fire subjected areas. 


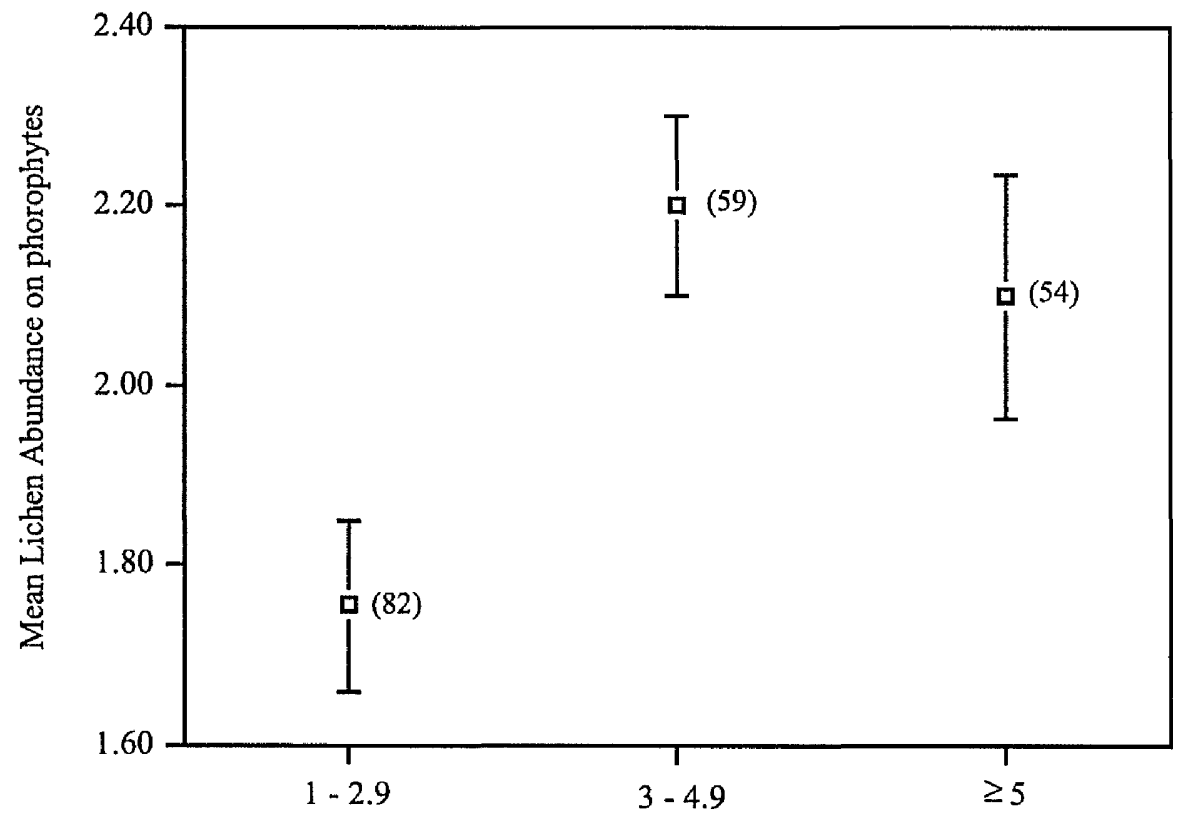

Phorophyte height classes (m)

Figure 5.7 The Mean Lichen Abundance on phorophytes within different height classes (m) in areas subjected to fire. The Coefficient of Variation (CV) for each class is shown in brackets, and the vertical bars represent the standard error of the mean.

Table 5.1 The percentage frequency of phorophytes in each lichen distribution category within different height classes $(\mathrm{m})$ in an area protected from fire and in areas subjected to fire, where 0 $=$ homogeneous lichen distribution, $1=$ partially restricted lichen distribution and $2=$ restricted lichen distribution.

\begin{tabular}{|c|c|c|c|c|c|c|}
\hline \multirow{3}{*}{$\begin{array}{l}\text { Height classes } \\
\text { (m) }\end{array}$} & \multirow{2}{*}{\multicolumn{3}{|c|}{$\begin{array}{c}\text { Area protected from } \\
\text { fire }\end{array}$}} & \multicolumn{3}{|c|}{ Areas subjected to fire } \\
\hline & & & & & $\begin{array}{l}\text { dis } \\
\text { eg }\end{array}$ & \\
\hline & 0 & 1 & 2 & 0 & 1 & 2 \\
\hline$<1=\mathrm{NS}$ & 0 & 0 & 100 & 100 & 0 & $\overline{0}$ \\
\hline $1-2.9$ & 71 & 23 & 6 & 92 & 6 & 2 \\
\hline $3-4.9$ & 58 & 40 & 2 & 83 & 13 & 4 \\
\hline$\geq 5$ & 53 & 44 & 3 & 72 & 22 & 6 \\
\hline
\end{tabular}




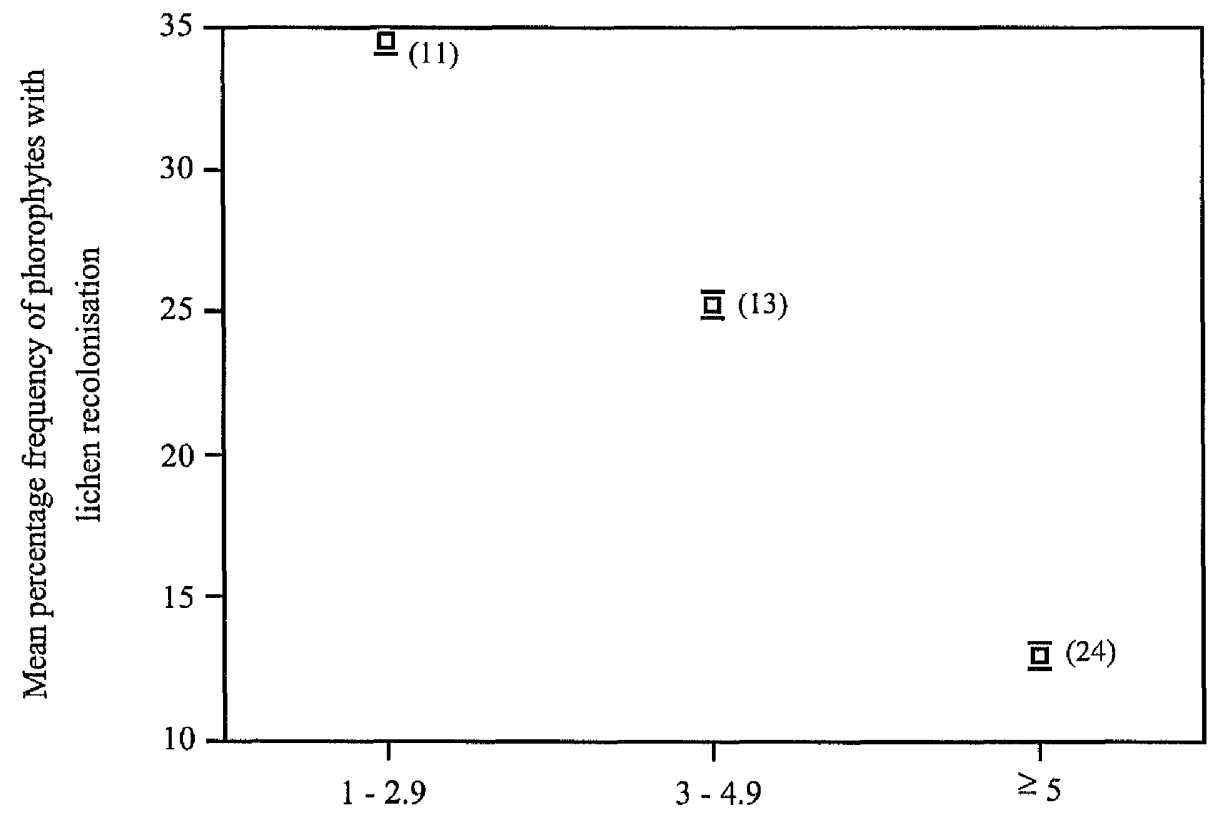

Phorophyte height classes (m)

Figure 5.8 The mean percentage frequency of phorophytes with lichen recolonisation within different height classes (m) in areas subjected to fire. The Coefficient of Variation (CV) for each class is shown in brackets, and the vertical bars represent the standard error of the mean.

\subsubsection{Phorophyte height and lichen recolonisation}

Figure 5.8 shows the mean percentage frequency of phorophytes with lichens on scorch i.e. lichen recolonisation, within different height classes in areas subjected to fire. Class ' $1-2.9$ $\mathrm{m}^{\prime}$ has a significantly higher mean frequency of phorophytes with lichen recolonisation than the other classes, and class ' $3-4.9 \mathrm{~m}$ ' has a significantly higher value than class ' $\geq 5 \mathrm{~m}$ ' (mean \pm S.E.). The relative variability is fairly low in all classes, increasing from $11 \%$ in class ' $1-2.9 \mathrm{~m}$ ' to $24 \%$ in class ' $\geq 5 \mathrm{~m}$ '.

\subsubsection{Summary}

These results indicate that there is no significant difference in lichen abundance and distribution between different phorophyte height classes, both within an area protected from fire and in areas subjected to fire. However, the results significantly indicate that most lichen recolonisation is occurring at a phorophyte height class of ' $1-2.9 \mathrm{~m}$ '. This suggests that phorophyte height may be a determinant of lichen recolonisation after fire. 


\subsection{Phorophyte girth and lichen abundance, distribution and recolonisation in plots with varying fire histories}

\subsubsection{Phorophyte girth and lichen abundance}

Figure 5.9 shows the Mean Lichen Abundance (MLA) on phorophytes within different girth classes in an area protected from fire. Classes ' $5-7.9 \mathrm{~cm}$ ' and ' $12-19.9 \mathrm{~cm}$ ' have significantly higher MLA values when compared to class ' $\geq 20 \mathrm{~cm}$ ' (mean \pm S.E.), although there is a high variability in values.

Figure 5.10 shows the MLA on phorophytes within different girth classes in areas subjected to fire. In these plots, a high relative variability in MLA values within the girth classes (see $\mathrm{CV}$ values) limits the significance of these results.

\subsubsection{Phorophyte girth and lichen distribution}

Table 5.2 shows the percentage frequencyof phorophytes in each lichen distribution category within different girth classes in an area protected from fire and in areas subjected to fire. In the area protected from fire, classes ' $12-19.9 \mathrm{~cm}$ ' and ' $\geq 20 \mathrm{~cm}$ ' have the highest percentages of

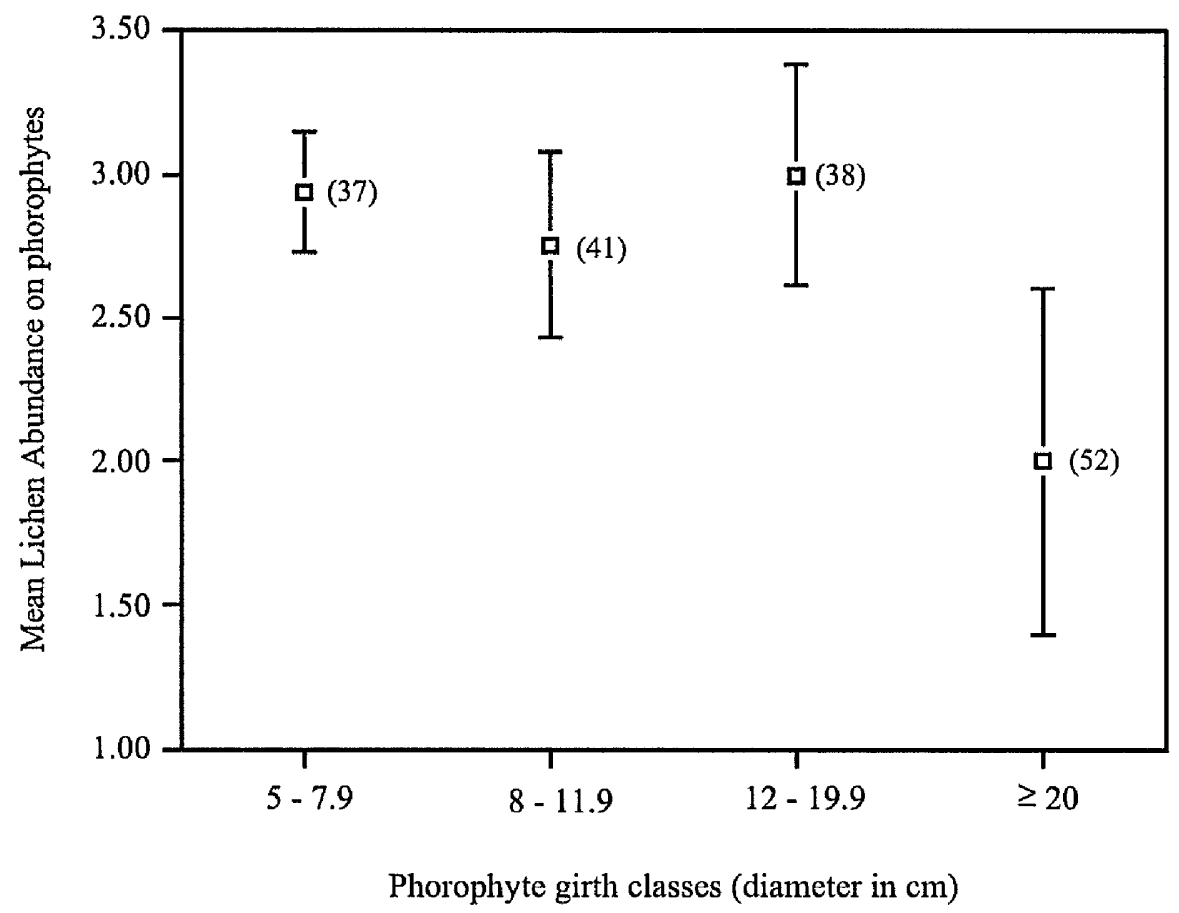

Figure 5.9 The Mean Lichen Abundance on phorophytes within different girth classes (diameter in $\mathrm{cm}$ ) in an area protected from fire. The Coefficient of Variation (CV) for each class is shown in brackets, and the vertical bars represent the standard error of the mean. 


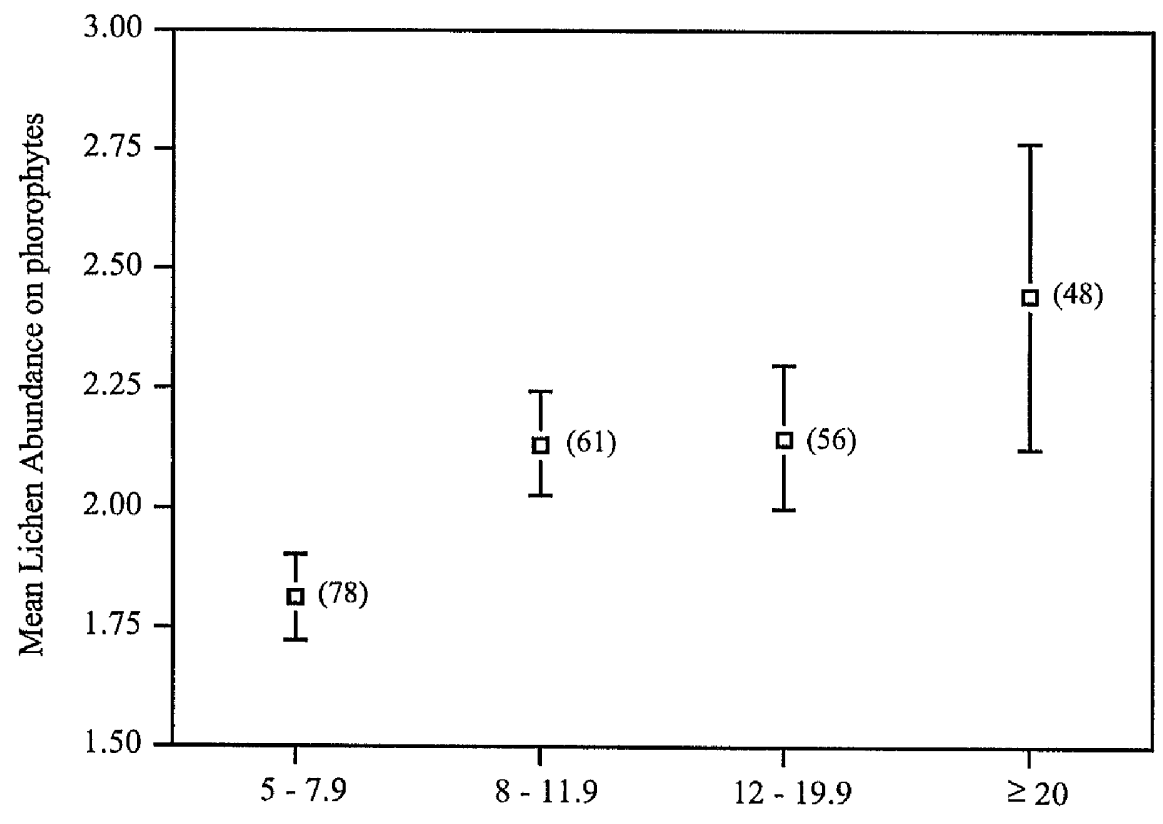

Phorophyte girth classes (diameter in $\mathrm{cm}$ )

Figure 5.10 The Mean Lichen Abundance on phorophytes within different girth classes (diameter in $\mathrm{cm}$ ) in areas subjected to fire. The Coefficient of Variation (CV) for each class is shown in brackets, and the vertical bars represent the standard error of the mean.

Table 5.2 The percentage frequency of phorophytes in each lichen distribution category within different girth classes (diameter in $\mathbf{~ c m}$ ) in an area protected from fire and in areas subjected to fire, where $0=$ homogeneous lichen distribution, $1=$ partially restricted lichen distribution and $2=$ restricted lichen distribution.

\begin{tabular}{|c||c|c|c||c|c|c|}
\hline \multirow{2}{*}{$\begin{array}{c}\text { Girth classes } \\
\text { (cm) }\end{array}$} & \multicolumn{3}{c||}{$\begin{array}{c}\text { Area protected from } \\
\text { fire }\end{array}$} & \multicolumn{3}{c|}{ Areas subjected to fire } \\
\cline { 2 - 7 } & \multicolumn{2}{c||}{$\begin{array}{c}\text { Lichen distribution } \\
\text { category }\end{array}$} & \multicolumn{3}{c|}{$\begin{array}{c}\text { Lichen distribution } \\
\text { category }\end{array}$} \\
\cline { 2 - 7 } & 0 & 1 & 2 & 0 & 1 & 2 \\
\hline \hline $5-7.9$ & 59 & 35 & 6 & 87 & 9 & 4 \\
$8-11.9$ & 58 & 36 & 6 & 84 & 12 & 4 \\
$12-19.9$ & 76 & 24 & 0 & 82 & 15 & 4 \\
$\geq 20$ & 71 & 29 & 0 & 80 & 16 & 4 \\
\hline
\end{tabular}


phorophytes with a homogeneous lichen distribution and the lowest frequencies with a partially restricted lichen distribution. Only classes ' $5-7.9 \mathrm{~cm}$ ' and ' $8-11.9 \mathrm{~cm}$ ' have phorophytes with a restricted lichen distribution, but at low values.

In areas subjected to fire, the highest frequencies of phorophytes with a homogeneous lichen distribution are in the smaller girth classes of ' $5-7.9 \mathrm{~cm}$ ' and ' $8-11.9 \mathrm{~cm}$ '. Of the phorophytes with a partially restricted lichen distribution, the areas subjected to fire have the highest frequencies in the ' $8-11.9 \mathrm{~cm}$ ' and ' $12-19.9 \mathrm{~cm}$ ' classes. All the girth classes have low frequencies of phorophytes within the 'restricted lichen distribution' category.

\subsubsection{Phorophyte girth and lichen recolonisation}

Figure 5.11 shows the mean percentage frequency of phorophytes with lichens on scorch i.e. lichen recolonisation, within different girth classes in areas subjected to fire. There is a significant decrease in the mean frequency of phorophytes with lichen recolonisation from class ' 5 - 7.9 $\mathrm{cm}^{\prime}$ to ' $\geq 20 \mathrm{~cm}$ ' (mean \pm S.E.), and the CV values in the classes are low, except in class ' $\geq 20 \mathrm{~cm}$ '.

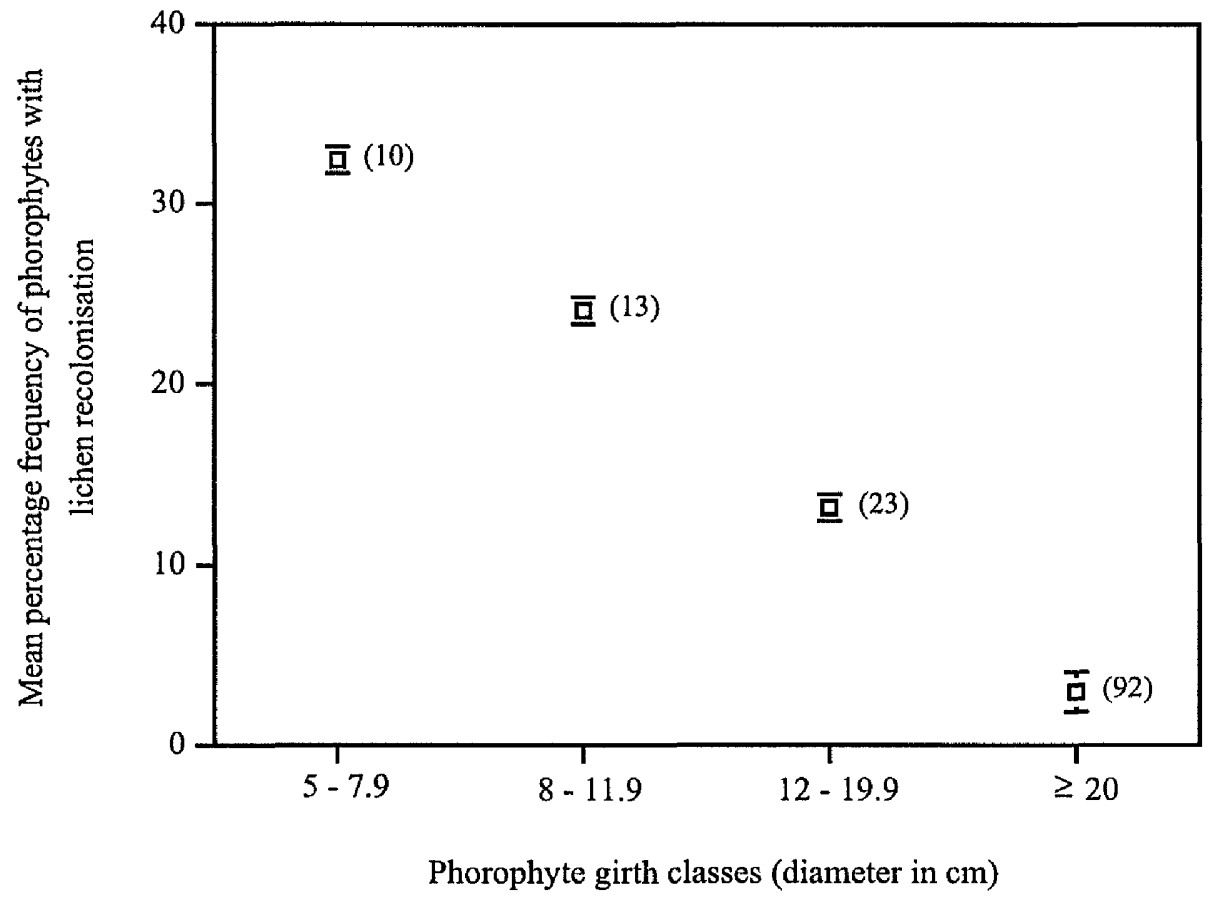

Figure 5.11 The mean percentage frequency of phorophytes with lichen recolonisation within different girth classes (diameter in $\mathrm{cm}$ ) in areas subjected to fire. The Coefficient of Variation (CV) for each class is shown in brackets, and the vertical bars represent the standard error of the mean. 


\subsubsection{Summary}

These results show that in an area protected from fire, phorophytes within girth classes ' $5-7.9 \mathrm{~cm}^{\prime}$ and ' $12-19.9 \mathrm{~cm}$ ' have the highest lichen abundance. However, in areas subjected to fire, there is no significant difference in lichen abundance between different phorophyte girth classes.

In an area protected from fire, most of the phorophytes with a homogeneous lichen distribution have a large girth (between 12 to $\geq 20 \mathrm{~cm}$ ), and the majority of phorophytes with a partially restricted lichen distribution have a small girth (between 5 to $11.9 \mathrm{~cm}$ ). The opposite is seen in areas subjected to fire. Here, most of the phorophytes with a homogeneous lichen distribution have a small girth and the majority of phorophytes with a partially restricted lichen distribution have a large girth. Whereas in fire protected area, only the smaller girth classes had a restricted lichen distribution, in areas subjected to fire, all the classes have values in this distribution category.

The results also significantly indicate that most lichen recolonisation is occurring at phorophyte girth classes of ' $5-7.9 \mathrm{~cm}$ ' and ' $8-11.9 \mathrm{~cm}$ '.

Overall, these results suggest that phorophyte girth may determine lichen abundance, distribution and recolonisation. Although phorophyte girth only affects lichen abundance where fire is absent, it influences lichen distribution both in the absence and presence of fire. This, and the significant affect on lichen recolonisation, expresses the importance of phorophyte girth for the development of the LFH Key.

\subsection{Phorophyte first branch height and lichen abundance, distribution and recolonisation in plots with varying fire histories}

\subsubsection{Phorophyte first branch height and lichen abundance}

Figures 5.12 and 5.13 show the Mean Lichen Abundance (MLA) on phorophytes within different first branch height classes in an area protected from fire and in areas subjected to fire, respectively. Results for phorophytes within the ' $\geq 5 \mathrm{~m}$ ' first branch height class in areas subjected to fire are insignificant since the minimum limit of ten individuals was not passed in this group.

There is no significant difference in MLA on phorophytes between different first branch height classes in an area protected from fire (mean \pm S.E. $=$ NS). Although phorophytes within the first branch height class of ' $1-2.9 \mathrm{~m}$ ' have a significantly higher MLA than those in classes ' $<0.5 \mathrm{~m}$ ' and '0.5 $0.9 \mathrm{~m}$ ' in areas subjected to fire (mean \pm S.E.), the high relative variability in MLA values within the first branch height classes (see CV values) limits the significance of the results.

\subsubsection{Phorophyte first branch height and lichen distribution}

Table 5.3 shows the percentage frequency of phorophytes in each lichen distribution category within different first branch height classes in an area protected from fire and in areas subjected to fire. In an area protected from fire, the highest proportion of phorophytes with a homogeneous lichen 


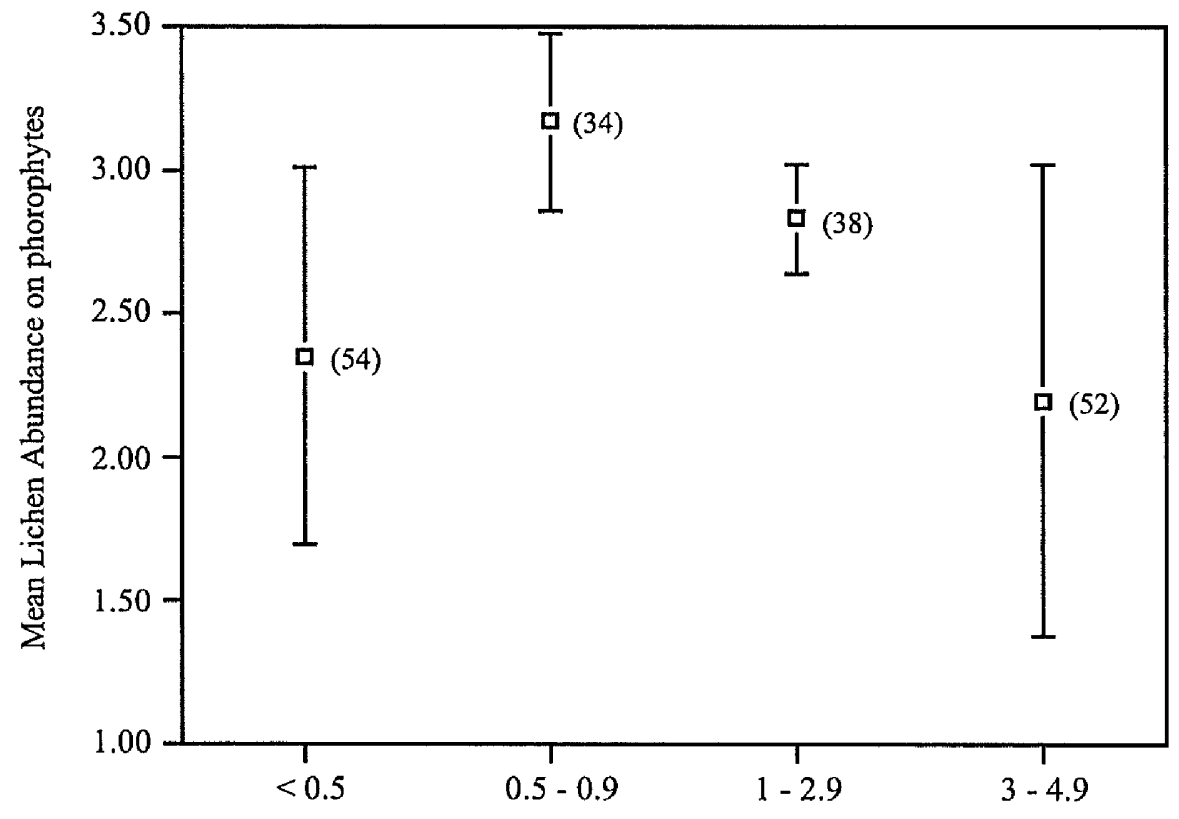

Phorophyte first branch height classes (m)

Figure 5.12 The Mean Lichen Abundance on phorophytes within different first branch height classes (m) in an area protected from fire. The Coefficient of Variation (CV) for each class is shown in brackets, and the vertical bars represent the standard error of the mean.

distribution are within the first branch height classes ' $0.5-0.9 \mathrm{~m}$ ' and ' $3-4.9 \mathrm{~m}$ ' and lowest proportion within classes ' $1-2.9 \mathrm{~m}$ ' and '< $0.5 \mathrm{~m}$ '. Inversely, the highest proportion of phorophytes with a partially restricted lichen distribution are within first branch height classes '1 $-2.9 \mathrm{~m}$ ' and '< $0.5 \mathrm{~m}$ ' and lowest proportion within classes ' $0.5-0.9 \mathrm{~m}$ ' and ' $3-4.9 \mathrm{~m}$ '. All the classes have comparable values for the 'restricted lichen distribution' category.

In areas subjected to fire, results for phorophytes within the ' $\geq 5 \mathrm{~m}$ ' first branch height class are insignificant since the minimum limit of ten individuals was not passed in this group. The highest frequencies of phorophytes with a homogeneous lichen distribution are within the first branch height classes ' $<0.5 \mathrm{~m}$ ' and ' $0.5-0.9 \mathrm{~m}$ ' and lowest frequencies within classes '1 $-2.9 \mathrm{~m}$ ' and '3 - $4.9 \mathrm{~m}$ '. On the other hand, the highest frequencies of phorophytes with a partially restricted lichen distribution are within first branch height classes ' $1-2.9 \mathrm{~m}$ ' and ' $3-4.9 \mathrm{~m}$ ' and lowest frequencies within classes ' $<0.5 \mathrm{~m}$ ' and '0.5 - $0.9 \mathrm{~m}$ '. All the classes have comparable values for the 'restricted lichen distribution' category. 


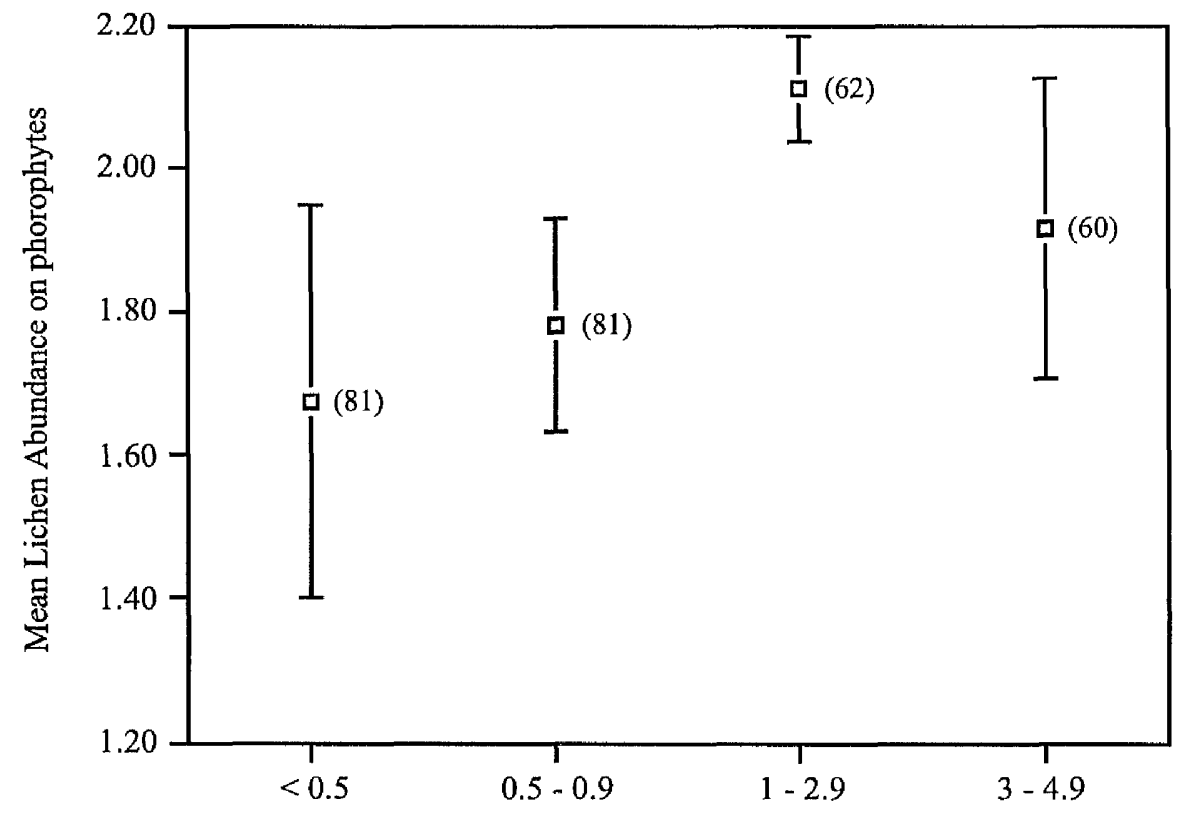

Phorophyte first branch height classes (m)

Figure 5.13 The Mean Lichen Abundance on phorophytes within different first branch height classes (m) in areas subjected to fire. The Coefficient of Variation (CV) for each class is shown in brackets, and the vertical bars represent the standard error of the mean.

Table 5.3 The percentage frequency of phorophytes in each lichen distribution category within different first branch height classes $(\mathrm{m})$ in an area protected from fire and in areas subjected to fire, where $0=$ homogeneous lichen distribution, $1=$ partially restricted lichen distribution and 2 = restricted lichen distribution. Note that the height of first branch class $\geq 5 \mathrm{~m}$ has been excluded from the table because there were no occurrences in an area protected from fire.

\begin{tabular}{|c||c|c|c||c|c|c|}
\hline \multicolumn{1}{|c||}{} & \multicolumn{3}{c||}{$\begin{array}{c}\text { Area protected from } \\
\text { fire }\end{array}$} & \multicolumn{3}{c|}{ Areas subjected to fire } \\
\cline { 2 - 7 } $\begin{array}{c}\text { Height of first } \\
\text { branch } \\
\text { classes (m) }\end{array}$ & \multicolumn{3}{c|}{$\begin{array}{c}\text { Lichen distribution } \\
\text { category }\end{array}$} & \multicolumn{3}{c|}{$\begin{array}{c}\text { Lichen distribution } \\
\text { category }\end{array}$} \\
\cline { 2 - 7 } & 0 & 1 & 2 & 0 & 1 & 2 \\
\hline \hline$<0.5$ & 63 & 31 & 6 & 91 & 5 & 4 \\
$0.5-0.9$ & 75 & 21 & 4 & 90 & 8 & 2 \\
$1-2.9$ & 57 & 38 & 5 & 84 & 12 & 4 \\
$3-4.9$ & 70 & 30 & 0 & 80 & 16 & 4 \\
$\geq 5=$ NS & - & - & - & 100 & 0 & 0 \\
\hline
\end{tabular}




\subsubsection{Phorophyte first branch height and lichen recolonisation}

Figure 5.14 shows the mean percentage frequency of phorophytes with lichens on scorch i.e. lichen recolonisation, within different first branch height classes in areas subjected to fire. Class ' $1-2.9 \mathrm{~m}$ ' has a significantly higher mean frequency of phorophytes with lichen recolonisation than all the other classes (mean \pm S.E.).

\subsubsection{Summary}

These results show that there is no significant difference in lichen abundance between different phorophyte first branch height classes, both in an area protected from fire and in areas subjected to fire.

In an area protected from fire, most phorophytes with a homogeneous lichen distribution are within the first branch height classes '0.5 $-0.9 \mathrm{~m}$ ' and ' $3-4.9 \mathrm{~m}$ '. The majority of phorophytes with a partially restricted lichen distribution are within the first branch height classes '< $0.5 \mathrm{~m}$ ' and ' $1-2.9 \mathrm{~m}$ '. However, in areas subjected to fire, most phorophytes with a homogeneous lichen distribution are within the lower first branch height classes (between $<0.5 \mathrm{~m}$ to $0.9 \mathrm{~m}$ ), and the majority of phorophytes with a partially restricted lichen distribution are within the higher first branch height classes (between $1 \mathrm{~m}$ to $4.9 \mathrm{~m}$ ).

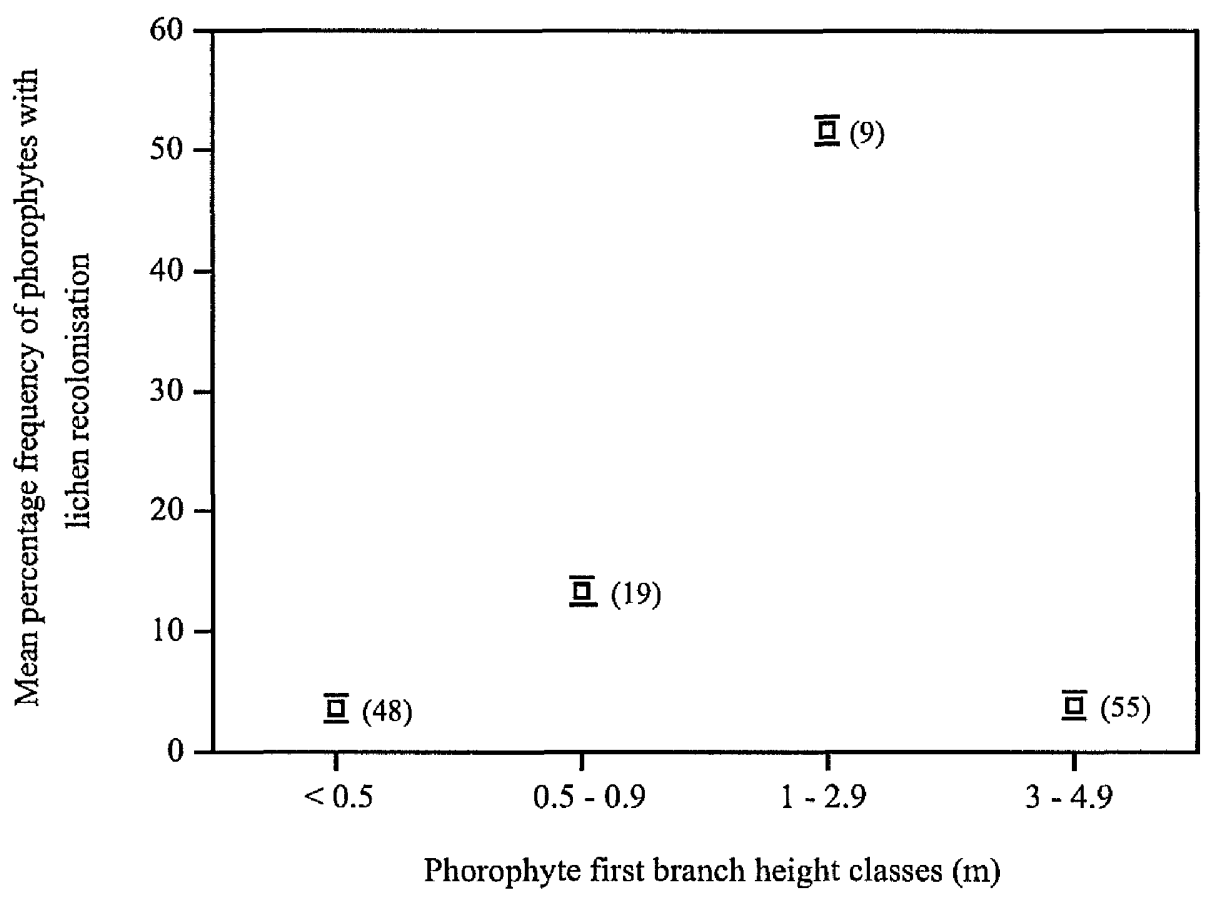

Figure 5.14 The mean percentage frequency of phorophytes with lichen recolonisation within different first branch height classes $(m)$ in areas subjected to fire. The Coefficient of Variation (CV) for each class is shown in brackets, and the vertical bars represent the standard error of the mean. 
The results also significantly indicate that most lichen recolonisation is occurring at a phorophyte first branch height class of ' $1-2.9 \mathrm{~m}$ '.

Overall, these results suggest that phorophyte first branch height may determine lichen distribution, both in the absence and presence of fire, and also affect lichen recolonisation after fire. Phorophyte first branch height may therefore be important for the development of the LFH Key.

\subsection{Phorophyte bark texture and lichen abundance, distribution and recolonisation in plots with varying fire histories}

\subsubsection{Phorophyte bark texture and lichen abundance}

Figure 5.15 shows the Mean Lichen Abundance (MLA) on phorophytes within each bark texture category in an area protected from fire. Phorophytes with both 'smooth' and 'rough without marked crevices' bark textures, have significantly higher MLA values than phorophytes with 'rough with deep crevices' bark texture (mean \pm S.E.). All the bark texture categories, except 'rough with deep crevices', have a low relative variability in MLA.

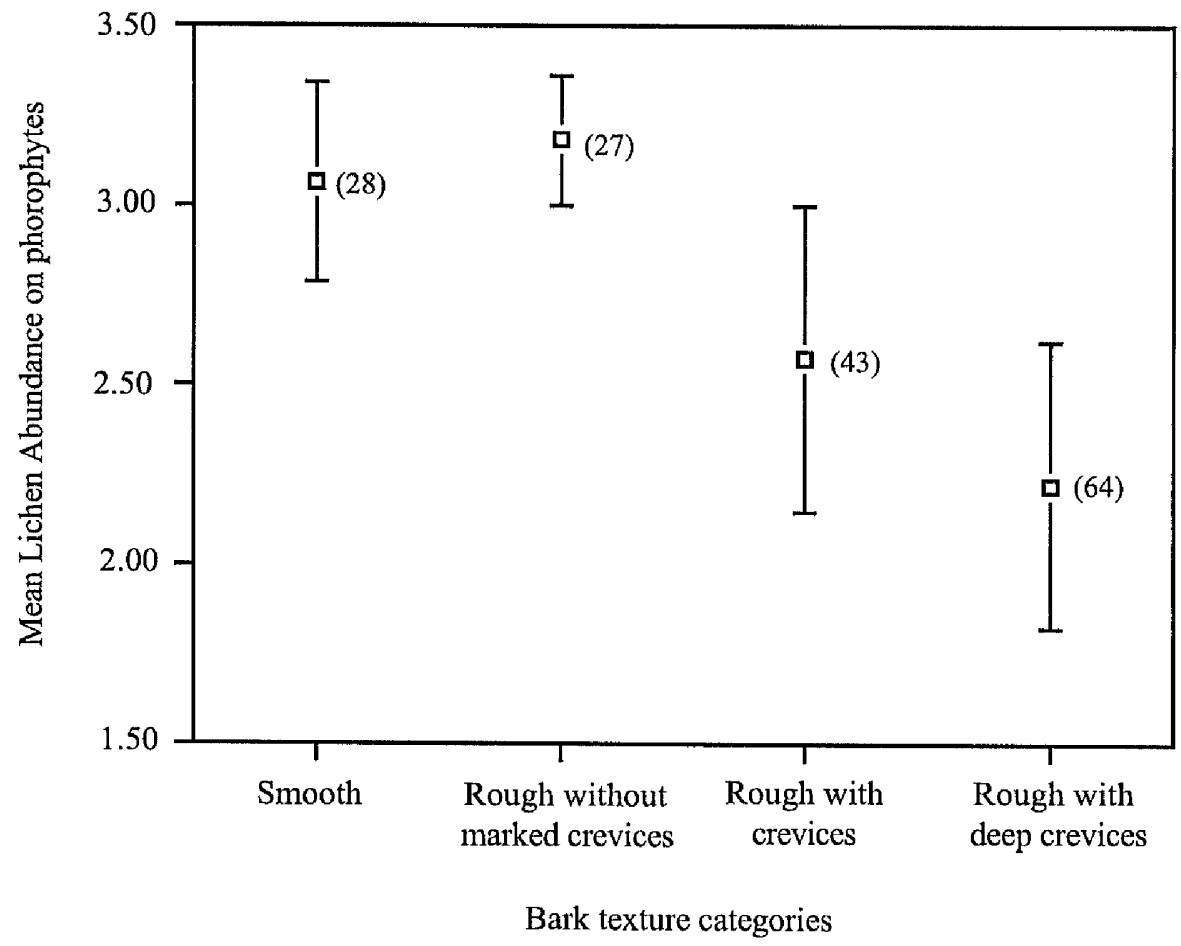

Figure 5.15 The Mean Lichen Abundance on phorophytes within each bark texture category in an area protected from fire. The Coefficient of Variation (CV) for each category is shown in brackets, and the vertical bars represent the standard error of the mean. 
Figure 5.16 shows the MLA on phorophytes within each bark texture category in areas subjected to fire. Here, the 'smooth' bark texture category has a significantly higher MLA than all the other bark textures (mean \pm S.E.). However, all the bark texture categories have a high relative variability in MLA, which limits the significance of the results.

\subsubsection{Phorophyte bark texture and lichen distribution}

Table 5.4 shows the percentage frequency of phorophytes in each lichen distribution category within different bark texture categories in an area protected from fire and in areas subjected to fire. In an area protected from fire, 'rough with crevices' and 'rough with deep crevices' bark texture categories have the highest frequencies of phorophytes within the "homogeneous lichen distribution" category, and the lowest within the 'partially restricted lichen distribution' category. Conversely, 'smooth' and 'rough without marked crevices' bark texture categories have the highest frequencies of phorophytes within the 'partially restricted lichen distribution' category, and the lowest within the 'homogeneous lichen distribution' category. The 'rough with crevices' bark texture category has the highest proportion of phorophytes with a restricted lichen distribution. All the other bark texture categories have low, comparable values.

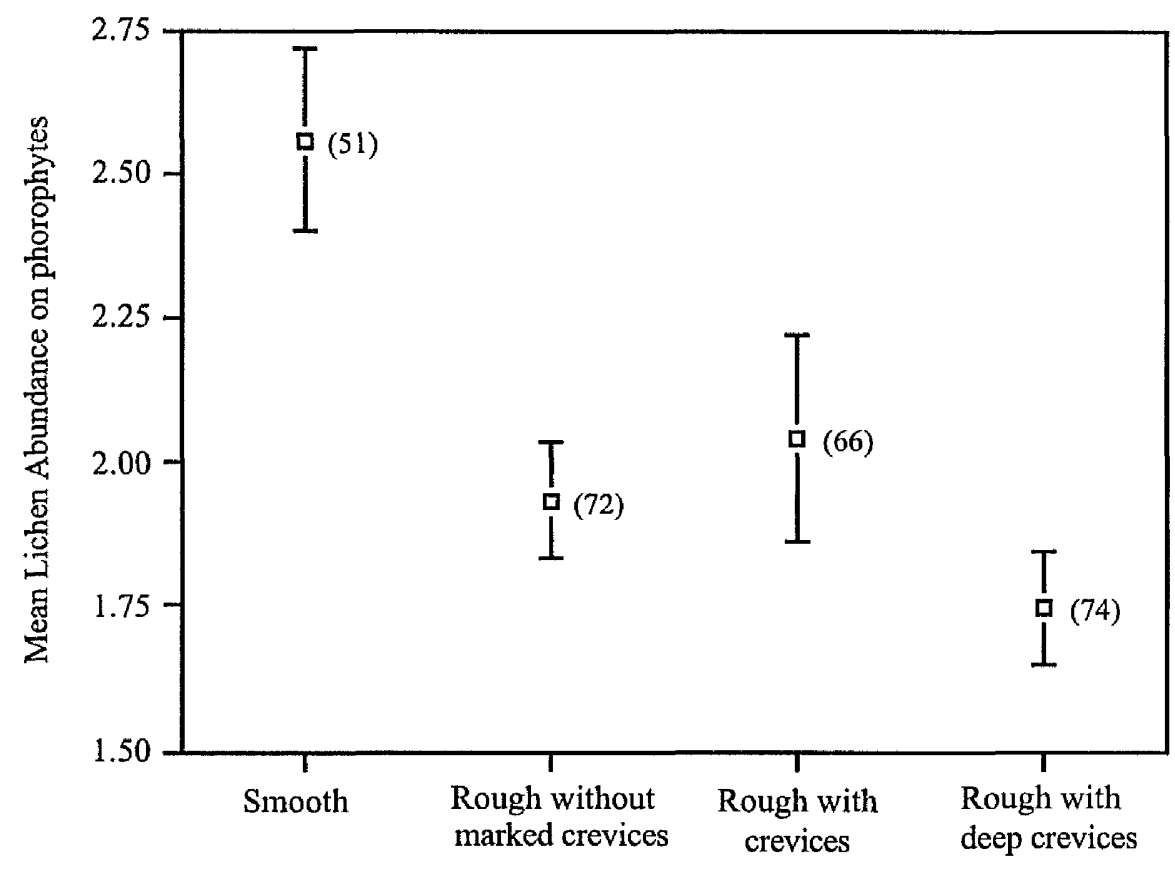

Bark texture categories

Figure 5.16 The Mean Lichen Abundance on phorophytes within each bark texture category in areas subjected to fire. The Coefficient of Variation (CV) for each category is shown in brackets, and the vertical bars represent the standard error of the mean. 
Table 5.4 The percentage frequency of phorophytes in each lichen distribution category within different bark texture categories in an area protected from fire and in areas subjected to fire, where $0=$ homogeneous lichen distribution, $1=$ partially restricted lichen distribution and $2=$ restricted lichen distribution.

\begin{tabular}{|c|c|c|c|c|c|c|}
\hline \multirow{3}{*}{ Bark texture category } & \multirow{2}{*}{\multicolumn{3}{|c|}{$\begin{array}{c}\text { Area protected from } \\
\text { fire }\end{array}$}} & \multicolumn{3}{|c|}{ Areas subjected to fire } \\
\hline & & & & \multicolumn{3}{|c|}{$\begin{array}{c}\text { Lichen distribution } \\
\text { category }\end{array}$} \\
\hline & 0 & 1 & 2 & 0 & 1 & 2 \\
\hline smooth & 51 & 49 & 0 & 73 & 24 & 3 \\
\hline $\begin{array}{l}\text { rough, without marked } \\
\text { crevices }\end{array}$ & 60 & 37 & 3 & 88 & 9 & 3 \\
\hline rough, with crevices & 71 & 18 & 11 & 88 & 8 & 4 \\
\hline rough, with deep crevices & 74 & 22 & 4 & 86 & 10 & 4 \\
\hline
\end{tabular}

In areas subjected to fire, the 'smooth' bark texture category has the lowest proportion of phorophytes with a homogeneous lichen distribution, and the highest with a partially restricted lichen distribution. All the other bark texture categories have comparable values in the two lichen distribution categories. The frequencies of phorophytes within the 'restricted lichen distribution' category are nearly equal between bark texture categories.

\subsubsection{Phorophyte bark texture and lichen recolonisation}

Figure 5.17 shows the mean percentage frequency of phorophytes with lichens on scorch i.e. lichen recolonisation, within different bark texture categories in areas subjected to fire. 'Smooth' and 'rough without crevices' bark texture categories have significantly higher mean frequencies of phorophytes with lichen recolonisation than 'rough with crevices' and 'rough with deep crevices' bark texture categories (mean \pm S.E.). The low $\mathrm{CV}$ values indicate little relative variability of the mean within each bark texture category.

\subsubsection{Summary}

These results indicate that in an area protected from fire, phorophytes with 'smooth' and 'rough without marked crevices' bark textures have significantly greater abundances of lichens than phorophytes with 'rough with crevices' and more significantly, 'rough with deep crevices' bark textures. However, in areas subjected to fire, there is no significant difference in lichen abundance between different phorophyte bark texture categories.

In an area protected from fire, most phorophytes with a homogeneous lichen distribution have 'rough with crevices' and 'rough with deep crevices' bark textures. The majority of phorophytes with a partially restricted lichen distribution have 'smooth' and 'rough without marked crevices' bark textures. A similar pattern of lichen distribution within different bark texture categories is 


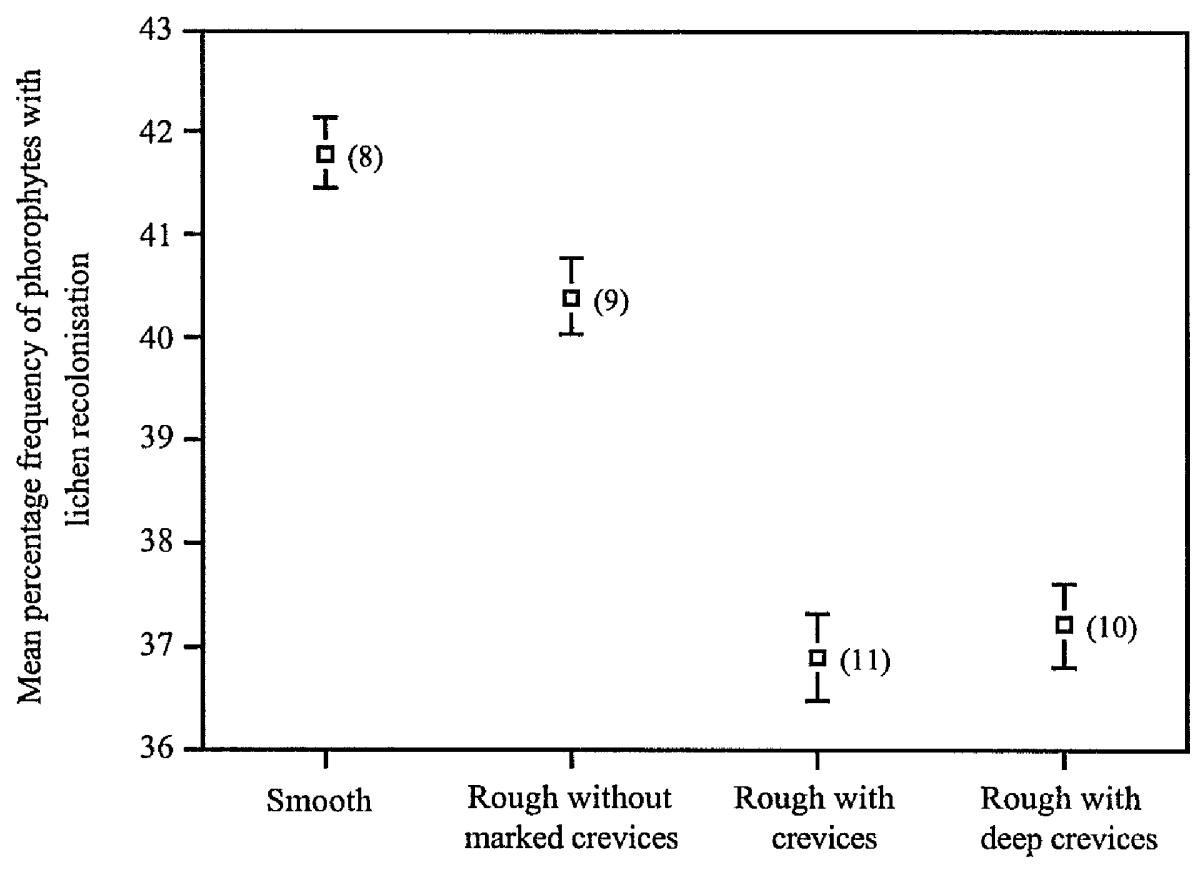

Bark texture categories

Figure 5.17 The mean percentage frequency of phorophytes with lichen recolonisation within different bark texture categories in areas subjected to fire. The Coefficient of Variation (CV) for each category is shown in brackets, and the vertical bars represent the standard error of the mean.

seen in areas subjected to fire, but here, only phorophytes with a 'smooth' bark texture have a high value within the 'partially restricted lichen distribution' category.

The results also significantly indicate that the highest lichen recolonisation is occurring on phorophytes with 'smooth' (highest value) and 'rough without crevices' bark textures.

Overall, these results suggest that phorophyte bark texture may determine lichen abundance, distribution and recolonisation. Although bark texture only affects lichen abundance where fire is absent, it influences lichen distribution both in the absence and presence of fire. This, and the significant affect on lichen recolonisation, expresses the importance of phorophyte bark texture for the development of the LFH Key.

\subsection{The effect of bark pH on lichen abundance}

The measurement of bark $\mathrm{pH}$ was only carried out on ten phorophyte species in Plot 1 (74-control) (see Section 4.6.1). Five of these species have a high Mean Lichen Abundance (MLA) 
and the other five have a low MLA within the ten plots (see Section 5.9.1). Figure 5.18 shows that all the species have acidic barks, ranging from $\mathrm{pH} 3.8$ to $\mathrm{pH} 4.7$.

Overall, the species with a high MLA seem to have a more acidic bark (below pH 4.2) with $V$. squamata the only exception (a mean $\mathrm{pH} 4.6$ and a higher relative variability of $3.4 \%$ ). Within this group of species, $V$. squamata has a significantly higher mean $\mathrm{pH}$ than the other species, and $G$. noxia has a significantly higher mean $\mathrm{pH}$ than $B$. salicifolius, $C$. brasiliense and $S$. paniculatum (mean \pm S.E.).

Except for $Q$. grandiflora, most of the species with a low MLA have less acidic bark (above $\mathrm{pH} 4.2$ ). The relative variability in $\mathrm{pH}$ values for these species is low, the highest being at $6.1 \%$ for $Q$. parviflora. In this group of species, $V$. thyrsoidea, $Q$. parviflora, $P$. rigida and $M$. ferruginata have a significantly higher mean $\mathrm{pH}$ than $Q$. grandiflora (mean \pm S.E.).

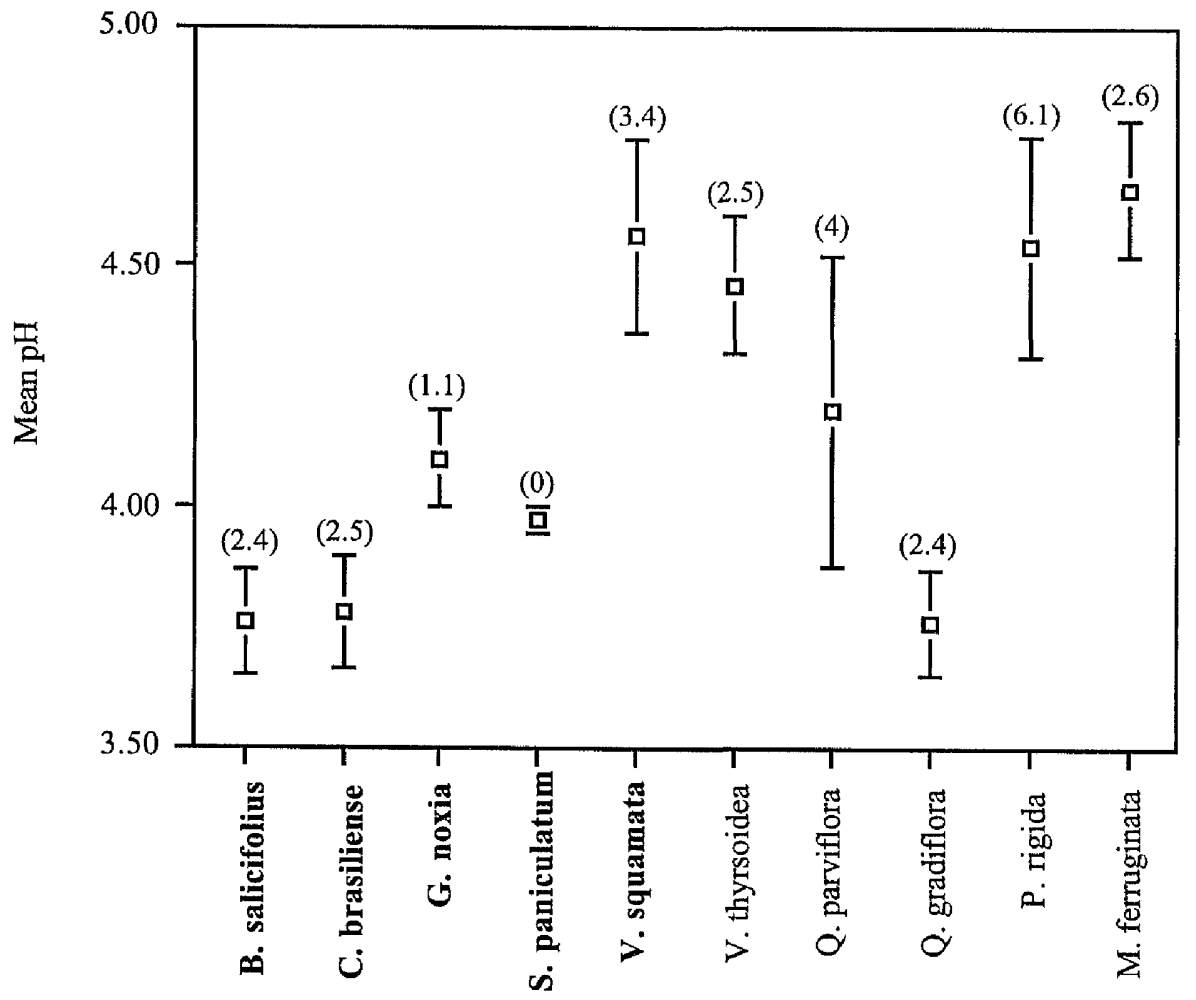

Phorophyte species

Figure 5.18 The mean pH for ten phorophyte species. The species in bold have a high MLA. The Coefficient of Variation (CV) for each species is shown in brackets, and the vertical bars represent the standard error of the mean. 


\subsubsection{Summary}

These results suggest that overall, phorophyte species with a high lichen abundance have more acidic barks than the species with a low lichen abundance. This is therefore an important factor to take into consideration when developing the LFH Key.

\subsection{Scorch height and lichen abundance, distribution and recolonisation in plots with varying fire histories}

\subsubsection{Scorch height and lichen abundance}

Figure 5.19 shows the Mean Lichen Abundance (MLA) on phorophytes within different scorch height classes in areas subjected to fire. Scorch height classes ' $<0.5 \mathrm{~m}$ ' and '0.5 - 0.9 $m$ ' have significantly higher MLA values than classes ' $1-2.9 \mathrm{~m}$ ', ' $3-4.9 \mathrm{~m}$ ' and ' $\geq 5 \mathrm{~m}$ ' (mean \pm S.E.). However, the high relative variability in MLA within these latter classes (over 70\%), limits the significance of the results.

\subsubsection{Scorch height and lichen distribution}

Table 5.5 shows the percentage frequency of phorophytes in each lichen distribution category within different scorch height classes in areas subjected to fire. The frequencies in the different distribution categories are consistent between classes, except in the case of scorch height class ' $\geq 5 \mathrm{~m}$ '. Compared to the other classes, class ' $\geq 5 \mathrm{~m}$ ' has a much lower frequency of phorophytes in the 'homogeneous lichen distribution' category, and a higher value in the 'partially restricted lichen distribution' category.

\subsubsection{Scorch height and lichen recolonisation}

Figure 5.20 shows the mean percentage frequency of phorophytes with lichens on scorch i.e. lichen recolonisation, within different scorch height classes in areas subjected to fire. Results for phorophytes within the ' $\geq 5 \mathrm{~m}$ ' class are insignificant since the minimum limit of ten individuals was not passed in this group. Class ' $1-2.9 \mathrm{~m}$ ' has a significantly higher mean frequency of phorophytes with lichen recolonisation (and the lowest $\mathrm{CV}$ ), than classes '<0.5 $\mathrm{m}$ ', '0.5 - $0.9 \mathrm{~m}$ ' and '3 $-4.9 \mathrm{~m}^{\prime}($ mean \pm S.E. $)$.

\subsubsection{Summary}

These results indicate that there are no significant differences in lichen abundance between scorch height classes in areas subjected to fire. Within these fire subjected areas, most phorophytes with a homogeneous lichen distribution have a scorch height between $<0.5 \mathrm{~m}$ to $4.9 \mathrm{~m}$, whereas the majority of phorophytes with a partially restricted lichen distribution have a scorch height 


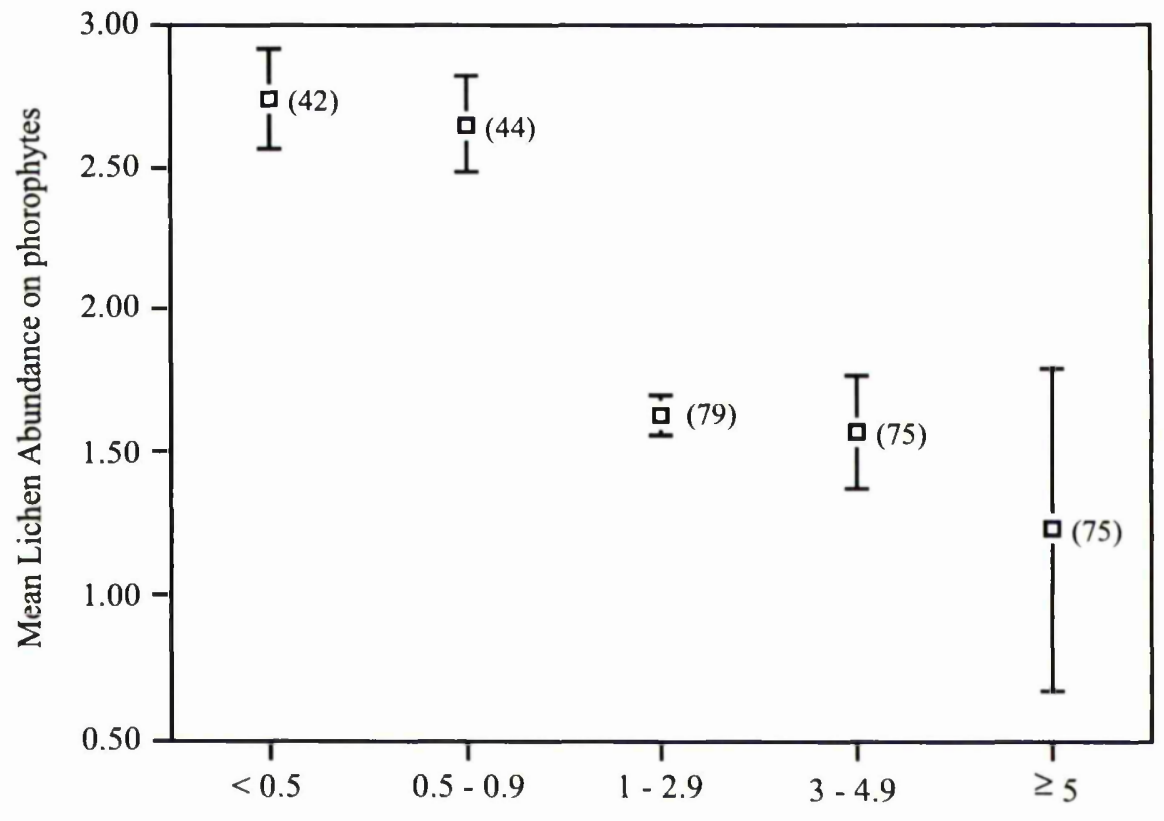

Phorophyte scorch height classes (m)

Figure 5.19 The Mean Lichen Abundance on phorophytes within different scorch height classes $(m)$ in areas subjected to fire. The Coefficient of Variation (CV) for each class is shown in brackets, and the vertical bars represent the standard error of the mean.

Table 5.5 The percentage frequency of phorophytes in each lichen distribution category within different scorch height classes $(m)$ in areas subjected to fire, where $0=$ homogeneous lichen distribution, 1 = partially restricted lichen distribution and 2 = restricted lichen distribution.

\begin{tabular}{|c||c|c|c|}
\hline \multicolumn{1}{|c||}{\multirow{2}{*}{$\begin{array}{c}\text { Scorch height } \\
\text { classes (m) }\end{array}$}} & \multicolumn{3}{c|}{$\begin{array}{c}\text { Lichen distribution } \\
\text { category }\end{array}$} \\
\cline { 2 - 4 } & 0 & 1 & 2 \\
\hline \hline 0.5 & 87 & 13 & 0 \\
$0.5-0.9$ & 87 & 13 & 0 \\
$1-2.9$ & 85 & 10 & 5 \\
$3-4.9$ & 87 & 8 & 5 \\
$\geq 5$ & 64 & 36 & 0 \\
\hline
\end{tabular}




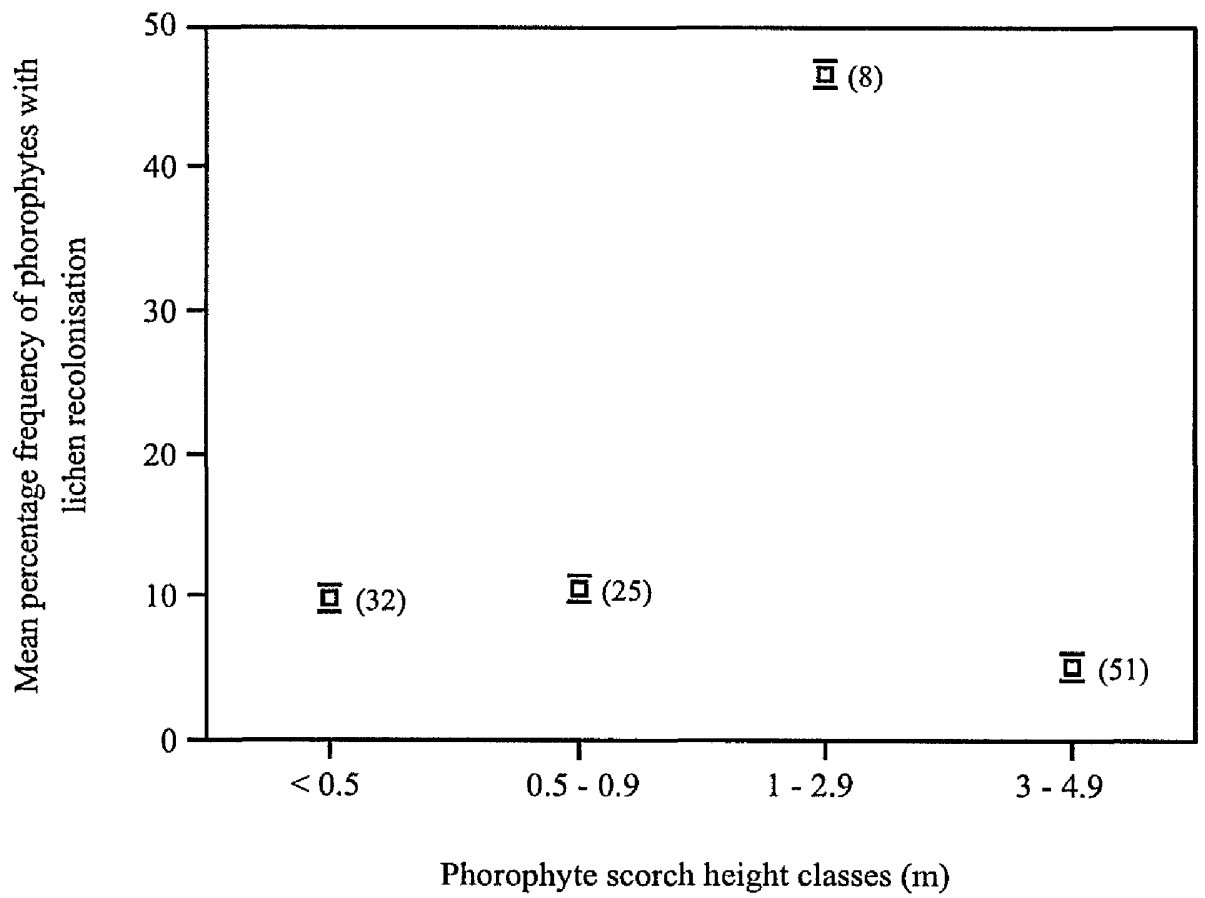

Figure 5.20 The mean percentage frequency of phorophytes with lichen recolonisation within different scorch height classes (m) in areas subjected to fire. The Coefficient of Variation (CV) for each class is shown in brackets, and the vertical bars represent the standard error of the mean.

$\geq 5 \mathrm{~m}$. The results also significantly indicate that most lichen recolonisation is occurring at a phorophyte scorch height class of ' $1-2.9 \mathrm{~m}$ '.

Overall, the results suggest that the scorch height of fire may determine lichen distribution and lichen recolonisation after fire. This is therefore an important factor to take into consideration when developing the LFH Key.

\subsection{Phorophyte species and lichen abundance, distribution and recolonisation in plots with varying fire histories}

\subsubsection{Phorophyte species and lichen abundance}

To investigate the relationship between phorophyte species and lichen abundance in an area protected from fire and in areas subjected to fire, the Importance Value (see Section 3.8.3b) for full definition) of each phorophyte species and the Mean Lichen Abundance (MLA) on each phorophyte species are examined. These values are presented in Table 5.6. In both fire protected and fire subjected areas, most of the phorophyte species ( 25 and 45 respectively) have a very low Importance Value. In an 
Table 5.6 The Importance Value (IV) and Mean Lichen Abundance (MLA) for the phorophyte species in an area protected from fire and in areas subjected to fire, and the percentage frequency of individuals with lichen recolonisation $(R)$ in areas subjected to fire. Note: a '-' represents a non-occurrence.

\begin{tabular}{|c|c|c|c|c|c|}
\hline \multirow[b]{2}{*}{ Phorophyte species } & \multicolumn{2}{|c|}{$\begin{array}{l}\text { Area protected } \\
\text { from fire }\end{array}$} & \multicolumn{3}{|c|}{ Areas subjected to fire } \\
\hline & IV & MLA & $\overline{\text { IV }}$ & MLA & $\mathrm{R}$ \\
\hline Machaerium opacum & $\overline{-}$ & $\overline{-}$ & 0.27 & 3.00 & 50 \\
\hline Banisteriopsis latifolia & - & - & 0.29 & 3.50 & 50 \\
\hline Pera glabrata & - & - & 0.30 & 3.00 & 0 \\
\hline Annona coriacea & - & - & 0.32 & 0.00 & 0 \\
\hline Miconia stenoscrachys & - & - & 0.34 & 1.50 & 100 \\
\hline Diosypros hispida & - & - & 0.35 & 1.33 & 100 \\
\hline Copaifera langsdorfii & - & - & 0.38 & 3.00 & 50 \\
\hline Ocotea sp. & - & - & 0.56 & 3.67 & 33 \\
\hline Bowdichia virgilioides & - & - & 0.63 & 3.33 & 67 \\
\hline Vochysia elliptica & - & - & 0.68 & 1.00 & 75 \\
\hline Enterolobium gummiferum & - & - & 0.72 & 1.00 & 100 \\
\hline Davila elliptica & - & - & 0.81 & 2.20 & 60 \\
\hline Eriotheca pubescens & - & - & 0.84 & 3.20 & 40 \\
\hline Hymenaea stigonocarpa & - & - & 0.89 & 1.20 & 25 \\
\hline Erythroxylum campestris & - & - & 0.97 & 2.17 & 40 \\
\hline Ocotea pomaderroides & - & - & 1.15 & 3.00 & 67 \\
\hline Vochysia rufa & 1.15 & 3.00 & 0.52 & 1.00 & 0 \\
\hline Erythroxylum suberosum & 1.15 & 4.00 & 0.65 & 1.80 & 50 \\
\hline Symplocos nitens & 1.15 & 2.00 & 1.93 & 2.17 & 33 \\
\hline Stryphnodendron adstringens & 1.15 & 3.00 & 6.63 & 1.60 & 50 \\
\hline Miconia pohliana & 1.17 & 1.00 & 2.12 & 0.77 & 20 \\
\hline Salacia crassifolia & 1.19 & 4.00 & 1.69 & 2.09 & 63 \\
\hline Acosmium dasycarpum & - & - & 1.19 & 3.43 & 71 \\
\hline Protium ovatum & 1.21 & 4.00 & - & - & - \\
\hline Alibertia concolor & 1.21 & 4.00 & 0.43 & 3.67 & 67 \\
\hline Psidium aerugineum & 1.24 & 4.00 & 0.62 & 2.50 & 67 \\
\hline Lafoensia pacari & 1.31 & 4.00 & - & - & - \\
\hline Pouteria torta & 1.40 & 4.00 & - & - & - \\
\hline Terminalia brasiliensis & - & - & 1.53 & 4.00 & 50 \\
\hline Syagrus comosa & 1.54 & 3.00 & 3.48 & 0.86 & 78 \\
\hline Aspidosperma tomentosum & 1.59 & 4.00 & 5.71 & 1.86 & 47 \\
\hline Lamanonia tunata & - & - & 1.64 & 4.00 & 0 \\
\hline Byrsonima verbascifolia & - & - & 1.67 & 2.50 & 78 \\
\hline Strychnus pseudoaquina & - & - & 2.01 & 2.30 & 60 \\
\hline Symplocos lanceolata & 2.19 & 0 & 0.31 & 1.00 & 0 \\
\hline Neea theifera & 2.29 & 4.00 & 0.26 & 2.50 & 100 \\
\hline Plathymenia reticulata & 2.32 & 4.00 & 1.24 & 1.80 & 40 \\
\hline Couepia grandiflora & - & - & 2.43 & 2.50 & 64 \\
\hline
\end{tabular}


Table 5.7 continued.

\begin{tabular}{|l||c|c||c|c|c|}
\hline \multicolumn{1}{|c||}{} & \multicolumn{3}{c|}{$\begin{array}{c}\text { Area protected } \\
\text { Phom fire }\end{array}$} & \multicolumn{3}{|c|}{ Areas subjected to fire } \\
\cline { 2 - 6 } & IV & MLA & IV & MLA & R \\
\hline \hline Aspidosperma macrocarpon & 2.50 & 1.50 & 2.90 & 1.39 & 62 \\
\hline Miconia albicans & 2.54 & 1.00 & 0.32 & 2.00 & 0 \\
\hline Emmotum nitens & 2.63 & 3.00 & 6.36 & 3.29 & 36 \\
\hline Symplocos rhamnifolia & - & - & 3.02 & 0.41 & 33 \\
\hline Byrsonima coccolobifolia & - & - & 3.08 & 2.79 & 32 \\
\hline Hirtella grandulosa & 3.14 & 3.00 & - & - & - \\
\hline Pouteria ramiflora & - & - & 3.23 & 2.89 & 47 \\
\hline Pterodon pubescens & - & - & 3.33 & 1.46 & 18 \\
\hline Qualea grandiflora & 3.41 & 3.00 & 15.34 & 1.28 & 27 \\
\hline Palicourea rigida & 3.74 & 0.33 & 4.22 & 0.78 & 5 \\
\hline Dimorphrandra mollis & 4.59 & 1.67 & 1.92 & 1.15 & 30 \\
\hline Rourea induta & - & - & 4.60 & 2.16 & 52 \\
\hline Kielmeyera coriacea & 4.61 & 1.00 & 1.04 & 2.00 & 86 \\
\hline Qualea multiflora & 4.82 & 3.00 & 3.74 & 2.00 & 57 \\
\hline Guapira graciliflora & 5.94 & 2.80 & 6.20 & 3.84 & 20 \\
\hline Eremanthus glomerulatus & 5.95 & 3.50 & 5.26 & 2.03 & 45 \\
\hline Piptocarpha rotundifolia & 6.18 & 3.00 & 5.65 & 1.23 & 50 \\
\hline Qualea parviflora & 6.22 & 1.50 & 13.00 & 1.19 & 25 \\
\hline Byrsonima crassa & 6.29 & 3.80 & 9.39 & 2.43 & 44 \\
\hline Syagrus flexuosa & 6.31 & 2.67 & 6.18 & 1.08 & 77 \\
\hline Myrsine guianensis & 8.37 & 2.57 & 8.49 & 2.08 & 24 \\
\hline Styrax ferrugineus & 8.85 & 3.25 & 6.40 & 2.44 & 49 \\
\hline Guapira noxia & 10.16 & 3.86 & 14.72 & 2.69 & 59 \\
\hline Dalbergia miscolobium & 10.86 & 2.83 & 12.26 & 2.00 & 28 \\
\hline Kielmeyera speciosa & 10.93 & 3.00 & 2.38 & 1.81 & 20 \\
\hline Didymopanax macrocarpum & 11.54 & 2.83 & 13.91 & 1.72 & 22 \\
\hline Roupala montana & 11.78 & 2.45 & 7.47 & 2.52 & 40 \\
\hline Ouratea hexasperma & 12.27 & 3.50 & 17.58 & 2.20 & 52 \\
\hline Miconia ferruginata & 12.77 & 1.22 & 8.81 & 1.44 & 38 \\
\hline Vellozia squamata & 16.16 & 3.71 & 11.92 & 1.75 & 70 \\
\hline Vochysia thyrsoidea & 19.15 & 1.00 & 13.20 & 0.98 & 11 \\
\hline Caryocar brasiliense & 20.23 & 3.00 & 17.72 & 2.28 & 43 \\
\hline Blepharocalyx salicifolius & 24.01 & 3.47 & 19.81 & 2.41 & 46 \\
\hline Sclerolobium paniculatum & 30.80 & 2.83 & 16.38 & 2.15 & 64 \\
\hline
\end{tabular}

area protected from fire, many of these species have an MLA above 2, whereas in areas subjected to fire, the MLA values are lower, with only two species, Terminalia brasiliensis and Lamanonia tunata, having a MLA of 4 . However, the rarity of these species (Importance Value below 5) limits the significance of the results, and will therefore not be discussed further. 
Of the species with an Importance Value between 5 and 10 in an area protected from fire, the majority, including Byrsonima crassa, Eremanthus glomerulatus and Styrax ferrugineus have high MLA values, with Qualea parviflora being the only species with an MLA below 2 . Most of the species with an Importance Value between 5 and 10 in an area protected from fire, are also present in this range of Importance Values within areas subjected to fire. However, except for Guapira graciliflora, most of the species have much lower MLA values in areas subjected to fire. Only Guapira graciliflora and Emmotum nitens have an MLA over 3, with over half of the species having MLA values around 2 or below.

Above an Importance Value of $10 \mathrm{in}$ an area protected from fire, two species, Miconia ferruginata and Vochysia thyrsoidea, have very low MLAs (around 1), whilst the others have MLAs of 2.5 or above and include (in descending order from highest MLA value), Guapira noxia, Vellozia squamata, Ouratea hexasperma, Blepharocalyx salicifolius, Kielmeyera speciosa, Caryocar brasiliense, Dalbergia miscolobium, Didymopanax macrocarpum, Sclerolobium paniculatum and Roupala montana.

Many phorophyte species with an Importance Value over 10 in an area protected from fire are also common to areas subjected to fire. However, these species have much lower MLA values in areas subjected to fire compared to an area protected fro fire. Only Guapira noxia, Sclerolobium paniculatum, Ouratea hexasperma, Caryocar brasiliense and Blepharocalyx salicifolius have MLA values over 2 (no species has an MLA over 3), with the other species having an MLA of 2 or below. Vochysia thyrsoidea has the lowest MLA of 0.98 .

\subsubsection{Phorophyte species and lichen distribution}

Table 5.7 lists the Importance Value (IV) and the percentage frequency of individuals within each lichen distribution category for phorophyte species with an IV above 5, in an area protected from fire and in areas subjected to fire.

Most of the species with an Importance Value between 5 and 10 in an area protected from fire have the highest proportion of individuals with a homogeneous lichen distribution, although Eremanthus glomerulatus, Piptocarpha rotundifolia and Qualea parviflora have comparable values in this category and the 'partially restricted lichen distribution' category. Only Piptocarpha rotundifolia and Syagrus flexuosa have individuals with a restricted lichen distribution.

In areas subjected to fire, all the species with an Importance Value between 5 and 10 have the highest proportion of individuals with a homogeneous lichen distribution. Although the values are small, many more species in areas subjected to fire have a restricted lichen distribution compared to an area protected from fire.

Most of the species with an Importance Value above 10 in an area protected from fire have the highest proportion of individuals with a homogeneous lichen distribution. The exceptions are Kielmeyera speciosa, which has comparable values in the 'homogeneous lichen distribution' and 
Table 5.7 The percentage frequency of individuals within each lichen distribution category for phorophyte species with an Importance Value (IV) above 5 in an area protected from fire and in areas subjected to fire, where $0=$ homogeneous lichen distribution, $1=$ partially restricted lichen distribution and $2=$ restricted lichen distribution. Note: a '-' represents a non-occurrence.

\begin{tabular}{|l||c|c|c|c||c|c|c|c|}
\hline \multicolumn{1}{|c||}{} & \multicolumn{3}{c||}{ Area protected from } & \multicolumn{3}{|c|}{ Areas subjected to fire } \\
\cline { 2 - 10 } \multicolumn{1}{|c||}{ Phorophyte Species } & IV & 0 & 1 & 2 & IV & 0 & 1 & 2 \\
\hline \hline Aspidosperma tomentosum & - & - & - & - & 5.71 & 80 & 10 & 10 \\
\hline Guapira graciliflora & 5.94 & 60 & 40 & 0 & 6.20 & 84 & 16 & 0 \\
\hline Eremanthus glomerulatus & 5.95 & 50 & 50 & 0 & 5.26 & 72 & 24 & 4 \\
\hline Piptocarpha rotundifolia & 6.18 & 40 & 40 & 20 & 5.65 & 78 & 17 & 5 \\
\hline Qualea parviflora & 6.22 & 50 & 50 & 0 & 13.00 & 94 & 4 & 2 \\
\hline Byrsonima crassa & 6.29 & 100 & 0 & 0 & 9.39 & 100 & 0 & 0 \\
\hline Emmotum nitens & - & - & - & - & 6.36 & 86 & 7 & 7 \\
\hline Syagrus flexuosa & 6.31 & 50 & 25 & 25 & 6.18 & 100 & 0 & 0 \\
\hline Stryphnodendron adstringens & - & - & - & - & 6.63 & 75 & 25 & 0 \\
\hline Myrsine guianensis & 8.37 & 57 & 43 & 0 & 8.49 & 84 & 14 & 2 \\
\hline Styrax ferrugineus & 8.85 & 75 & 25 & 0 & 6.40 & 73 & 21 & 6 \\
\hline Guapira noxia & 10.16 & 86 & 14 & 0 & 14.72 & 79 & 19 & 2 \\
\hline Dalbergia miscolobium & 10.86 & 83 & 17 & 0 & 12.26 & 88 & 9 & 3 \\
\hline Kielmeyera speciosa & 10.93 & 44 & 44 & 12 & - & - & - & - \\
\hline Didymopanax macrocarpum & 11.54 & 83 & 17 & 0 & 13.91 & 83 & 9 & 8 \\
\hline Roupala montana & 11.78 & 55 & 27 & 18 & 7.47 & 95 & 3 & 2 \\
\hline Ouratea hexasperma & 12.27 & 80 & 20 & 0 & 17.58 & 91 & 5 & 4 \\
\hline Miconia ferruginata & 12.77 & 78 & 22 & 0 & 8.81 & 98 & 2 & 0 \\
\hline Qualea grandiflora & - & - & - & - & 15.34 & 90 & 5 & 5 \\
\hline Vellozia squamata & 16.16 & 64 & 36 & 0 & 11.92 & 95 & 2 & 3 \\
\hline Vochysia thyrsoidea & 19.15 & 100 & 0 & 0 & 13.20 & 94 & 4 & 2 \\
\hline Caryocar brasiliense & 20.23 & 62 & 38 & 0 & 17.72 & 86 & 12 & 2 \\
\hline Blepharocalyx salicifolius & 24.01 & 53 & 47 & 0 & 19.81 & 89 & 11 & 0 \\
\hline Sclerolobium paniculatum & 30.80 & 28 & 72 & 0 & 16.38 & 39 & 53 & 8 \\
\hline
\end{tabular}

'partially restricted lichen distribution' categories, and Sclerolobium paniculatum, which has the greatest proportion of individuals with a partially restricted lichen distribution. Only Kielmeyera speciosa and Roupala montana have individuals with a restricted lichen distribution.

All the species in areas subjected to fire with an Importance Value over 10 have the highest proportion of individuals with a homogeneous lichen distribution. The only exception to this pattern is found in S. paniculatum, which, as in an area protected from fire, has the greatest proportion of individuals with a partially restricted lichen distribution. Although the values are small, many more species in areas subjected to fire have a restricted lichen distribution compared to an area protected from fire. 


\subsubsection{Phorophyte species and lichen recolonisation}

The percentage frequency of individuals of each phorophyte species with lichens on scorch i.e. lichen recolonisation, in areas subjected to fire are shown in Table 5.6. Among the species with an Importance Value between 5 and 10, most have 50\% lichen recolonisation or below, the only exception being Syagrus flexuosa with $77 \%$ lichen recolonisation. Of the species with an Importance Value over 10, the highest lichen recolonisation (over $40 \%$ ) is found in V. squamata, S. paniculatum, G. noxia, $O$. hexasperma, $B$. salicifolius and $C$. brasiliense, and the lowest in $V$. thyrsoidea (only $11 \%)$.

\subsubsection{Summary}

These results show that in both the area protected from fire and in the areas subjected to fire, of the species with an Importance Value of over 10, Guapira noxia, Vellozia squamata, Ouratea hexasperma, Blepharocalyx salicifolitus, Kielmeyera speciosa, Caryocar brasiliense, Dalbergia miscolobium, Didymopanax macrocarpum, Sclerolobium paniculatum and Roupala montana have a high lichen abundance, and Vochysia thyrsoidea, Qualea grandiflora, Q. parviflora and Miconia ferruginata have a low lichen abundance.

Most of the phorophyte species in the area protected from fire and in the areas subjected to fire, have individuals with a homogeneous lichen distribution. S. paniculatum is the only species that has higher frequencies of individuals with a partially restricted lichen distribution.

The results also show that most phorophyte species with an Importance Value above 5 have under 50\% lichen recolonisation after fire, and of the species with an Importance Value over 10, the highest lichen recolonisation is found on $V$. squamata, S. paniculatum, G. noxia, O. hexasperma, B. salicifolius and C. brasiliense.

Overall, these results suggest that factors specific to different phorophyte species may determine lichen abundance and distribution, both in the presence and absence of fire, and lichen recolonisation after fire. Phorophyte specificity may therefore be extremely important for the development of the LFH Key.

\subsection{Choosing the phorophyte species for the Stage 2 data collection}

After the preliminary survey of the phorophyte and lichen communities in the ten plots was carried out (Stage 1), a number of phorophyte species were selected for the next stage in the research, which involved sampling the lichen composition in plots with different fire histories (see Section 4.4). The criteria for choosing these phorophytes were:

1) they are commonly found in the ten plots;

2) they have a high abundance of lichens on them;

3) they show a variation in lichen abundance between plots with different fire histories. 
Table 5.8 The Importance Value (IV), Mean Lichen Abundance (MLA) and Coefficient of Variation (CV) for the phorophyte species with an Importance Value over 10 in the ten plots.

\begin{tabular}{|c|c|c|c|}
\hline Phorophyte species & IV & MLA & $\mathrm{CV}$ \\
\hline Dalbergia miscolobium & 12.12 & 2.07 & $\overline{57}$ \\
\hline Qualea parviflora & 12.33 & 1.21 & 84 \\
\hline Vellozia squamata & 12.34 & 2.02 & 82 \\
\hline Didymopanax macrocarpum & 13.67 & 1.79 & 52 \\
\hline Vochysia thyrsoidea & 13.79 & 0.98 & 22 \\
\hline Qualea grandiflora & 14.15 & 1.31 & 75 \\
\hline Guapira noxia & 14.26 & 2.77 & 48 \\
\hline Ouratea hexasperma & 17.05 & 2.30 & 64 \\
\hline Sclerolobium paniculatum & 17.82 & 2.28 & 50 \\
\hline Caryocar brasiliense & 17.97 & 2.38 & 47 \\
\hline Blepharocalyx salicifolius & 20.23 & 2.58 & 49 \\
\hline
\end{tabular}

Table 5.8 shows the Mean Lichen Abundance (MLA) and the Coefficient of Variation (CV) for the phorophyte species within the ten plots which have an Importance Value above 10 i.e. the most common species. Of these, three, Vochysia thyrsoidea, Qualea parviflora and Q. grandiflora have MLA values under 1.5. The other eight species have MLA values over 2, and include Dalbergia miscolobium, Didymopanax macrocarpum, Vellozia squamata, Guapira noxia, Caryocar brasiliense, Ouratea hexasperma, Sclerolobium paniculatum and Blepharocalyx salicifolius. The species that have the highest variability in MLA values between plots are $Q$. parviflora (84\%), V. squamata $(82 \%), Q$. grandiflora (75\%), O. hexasperma (64\%), D. miscolobium (57\%), D. macrocarpum (52\%) and $S$. paniculatum (50\%), with B. salicifolius, G. noxia and C. brasiliense having CV values just below $50 \%$.

\subsubsection{Summary}

These results show that the phorophyte species which fulfil the criteria of prevalence in the ten plots, a high lichen abundance, and a variation in lichen abundance between different fire histories are Dalbergia miscolobium, Didymopanax macrocarpum, Vellozia squamata, Guapira noxia, Caryocar brasiliense, Ouratea hexasperma, Sclerolobium paniculatum and Blepharocalyx salicifolius. These phorophytes may be extremely important in the development of the LFH Key.

\subsection{General conclusions}

Analysis of the data from Stage 1 of the research showed the following results:

1) lichen abundance varies between plots with different fire histories. Areas which have been protected from fire in the past, or have had a recent rare heterogeneous fire, have the greatest abundances of lichens. A lower lichen abundance is present in an area which may have had frequent fires in the past, 
but has been recently protected. Where there has been a recent rare, but homogeneous fire, there is a low abundance of lichens, and in areas subjected to frequent, homogeneous fires, lichen abundances are extremely low. If fires are very frequent, little or no lichens are apparent;

2) lichen distribution varies between plots with different fire histories. In areas where there has been no fire for a long period of time or recent fire protection, most phorophytes have either a homogeneous lichen distribution or a partially restricted lichen distribution. Here, lichens are common between the base and $0.9 \mathrm{~m}$. Where there has been a recent, rare fire, phorophytes frequently have a homogeneous lichen distribution, and if some have a partially restricted lichen distribution, it is above $2 \mathrm{~m}$, particularly if the rare fire was homogeneous. In contrast, areas with frequent, homogeneous fires have more occurrences of a restricted lichen distribution, especially above $2 \mathrm{~m}$;

3) lichen recolonisation after fire varies between plots with different fire histories. A recently protected area has the highest degree of recolonisation, followed by areas which were subjected to recent, rare fires, with areas where fire is frequent and homogeneous having the lowest amount of lichen recolonisation;

4) there is no significant difference in lichen abundance and distribution within different phorophyte height classes in an area protected from fire and in areas subjected to fire. However, a significantly greater amount of lichen recolonisation after fire is occurring at a phorophyte height class of ' $1-2.9 \mathrm{~m}$ '; 5) in an area protected from fire, phorophytes within girth classes ' $5-7.9 \mathrm{~cm}$ ' and '12 - $19.9 \mathrm{~cm}$ ' have a significantly higher lichen abundance. However, in areas subjected to fire, there is no significant difference in lichen abundance between different phorophyte girth classes. In contrast to an area protected from fire, most phorophytes with a homogeneous lichen distribution in areas subjected to fire have a small girth and the majority with a partially restricted lichen distribution have a large girth. A significantly greater amount of lichen recolonisation after fire is occurring at phorophyte girth classes of '5 - $7.9 \mathrm{~cm}$ ' and ' 8 - $11.9 \mathrm{~cm}$ ';

6) there is no significant difference in lichen abundance between different phorophyte first branch height classes in an area protected from fire and in areas subjected to fire. Compared to an area protected from fire, most phorophytes in areas subjected to fire with a homogeneous lichen distribution have a low first branch height (between $<0.5 \mathrm{~m}$ to $0.9 \mathrm{~m}$ ), and the majority of phorophytes with a partially restricted lichen distribution have a high first branch height (between $1 \mathrm{~m}$ to $4.9 \mathrm{~m}$ ). A significantly greater amount of lichen recolonisation is occurring at a phorophyte first branch height class of '1 - 2.9 $\mathrm{m}^{\prime}$;

7) in an area protected from fire, phorophytes with 'smooth' and 'rough without marked crevices' bark textures have the highest lichen abundances. However, in areas subjected to fire, there is no significant difference in lichen abundance between phorophytes of different bark textures. In both an area protected from fire and in areas subjected to fire, most phorophytes with a homogeneous lichen distribution have 'rough with crevices' and 'rough with deep crevices' bark textures. In an area protected from fire, the majority of phorophytes with a partially restricted lichen distribution have 'smooth' and 'rough without 
marked crevices' bark textures, but in areas subjected to fire, only phorophytes with a 'smooth' bark texture have a partially restricted lichen distribution. There is a significantly greater amount of lichen recolonisation after fire occurring on phorophytes with 'smooth' (highest value) and 'rough without crevices' bark textures;

8) phorophyte species with a high lichen abundance have more acidic barks than the species with a low lichen abundance;

9) there is no significant difference in lichen abundance within different scorch height classes in areas subjected to fire. In these areas, most phorophytes with a homogeneous lichen distribution have a scorch height between $<0.5 \mathrm{~m}$ to $4.9 \mathrm{~m}$, whereas the majority of phorophytes with a partially restricted lichen distribution have a scorch height $\geq 5 \mathrm{~m}$. A significantly greater amount of lichen recolonisation after fire is occurring at a scorch height class of ' $1-2.9 \mathrm{~m}$ ';

10) in both an area protected from fire and in areas subjected to fire, of the most common phorophyte species, Guapira noxia, Vellozia squamata, Ouratea hexasperma, Blepharocalyx salicifolius, Kielmeyera speciosa, Caryocar brasiliense, Dalbergia miscolobium, Didymopanax macrocarpum, Sclerolobium paniculatum and Roupala montana have high lichen abundances, and Vochysia thyrsoidea, Qualea grandiflora, Q. parviflora and Miconia ferruginata have low lichen abundances. Most of the phorophyte species in an area protected from fire and in areas subjected to fire have individuals with a homogeneous lichen distribution. The highest lichen recolonisation is found on the phorophyte species $V$. squamata, $S$. paniculatum, $G$. noxia, $O$. hexasperma, B. salicifolius and $C$. brasiliense;

11) eight phorophyte species, Dalbergia miscolobium, Didymopanax macrocarpum, Vellozia squamata, Guapira noxia, Caryocar brasiliense, Ouratea hexasperma, Sclerolobium paniculatum and Blepharocalyx salicifolius are possible candidates for the Stage 2 data collection.

From these results, a number of conclusions, which may be important for the development of the LFH Key, are proposed:

a) lichen abundance, distribution and recolonisation after fire are affected by fire history;

b) phorophyte height may determine lichen recolonisation after fire;

c) phorophyte girth may determine lichen abundance where fire is absent, and influence lichen distribution both in the absence and presence of fire. Girth may also determine lichen recolonisation after fire;

d) phorophyte first branch height may determine lichen distribution, both in the absence and presence of fire, and also affect lichen recolonisation after fire;

e) phorophyte bark texture may determine lichen abundance where fire is absent, and influence lichen distribution both in the absence and presence of fire. Bark texture may also determine lichen recolonisation after fire;

f) phorophyte bark $\mathrm{pH}$ may determine lichen abundance;

g) scorch height of fire may determine lichen distribution and lichen recolonisation after fire; 
h) factors specific to different phorophyte species i.e. phorophyte specificity, may determine lichen abundance and distribution, both in the presence and absence of fire, and lichen recolonisation after fire. 
154 


\section{Chapter 6 \\ Results II: Fire history and lichen composition}

\subsection{Introduction}

Having established that the various fire histories directly influence lichen abundance, distribution and recolonisation in the ten plots, detailed work on the composition of these communities was carried out. As a process of standardisation for this stage of the research, sampling was confined to specific phorophyte species. Previous results identified eight phorophyte species as potential candidates, which are all commonly found in cerrado denso, have high abundances of lichens, and show variation in lichen abundance between plots with different fire histories. For the scope of this study, it was only possible to sample five phorophyte species. Taking into account the aforementioned criteria, as well as the easy identification of the phorophytes in the field, and the degree of lichen recolonisation on the phorophytes after fire, Blepharocalyx salicifolius, Caryocar brasiliense, Guapira noxia, Sclerolobium paniculatum and Vellozia squamata were chosen.

Six plots were employed for this part of the research: Plot 1 (74-control); Plot 2 (7491: Hom, H, M); Plot 3 (74-92: Het, V, E); Plot 4 (74-92: Het, V, M); Plot 5 (74-92: Het, V, L); and Plot 6 (86-control). Five individuals of each species were sampled for their lichen flora at four heights on the trunk: base to $0.5 \mathrm{~m}$ (Quarter 1 ); $>0.5$ to $1 \mathrm{~m}$ (Quarter 2); $>1$ to $1.5 \mathrm{~m}$ (Quarter 3); and $>1.5$ to $2 \mathrm{~m}$ (Quarter 4). Table 6.1 shows the average height, girth and first branch height within the six plots for these species.

To investigate the factors determining lichen composition between the different plots, multivariate analyses were carried out using Detrended Correspondence Analysis (DCA) for ordination and Two-Way Indicator Species Analysis (TWINSPAN) for classification (see Section 3.8.3b). The matrix values were composed of lichen species frequencies at each height class for the five phorophyte species sampled in every plot. Downweighting was applied in the ordination to reduce noise generated

Table 6.1 The average height $(\mathrm{m})$, girth (diameter in $\mathrm{cm}$ ) and first branch height $(\mathrm{m})$ of the five phorophyte species sampled within Plots 1 to 6.

\begin{tabular}{|l|c|c|c|}
\hline \multicolumn{1}{|c|}{ Phorophyte species } & Height (m) & $\begin{array}{c}\text { Girth } \\
\text { (diameter } \\
\text { in cm) }\end{array}$ & $\begin{array}{c}\text { First branch } \\
\text { height (m) }\end{array}$ \\
\hline \hline Blepharocalyx salicifolius & 5.2 & 12.8 & 1.9 \\
\hline Caryocar brasiliense & 4 & 11.3 & 1.5 \\
\hline Guapira noxia & 3.5 & 7.4 & 1.4 \\
\hline Sclerolobium paniculatum & 6.1 & 10.8 & 1.7 \\
\hline Vellozia squamata & 2.5 & 6.6 & 1 \\
\hline
\end{tabular}


by uncommon species. All other default commands were used. In the ordination graphs, the plots are represented by a "P" followed by the plot number, the phorophyte species by their genus initial, and the quarters on the trunk as "Q1-4".

\subsection{Initial analysis of the six plots}

The sample ordination for all the plots is shown in Figure 6.1 The first component accounts for $37 \%$ of the total variance (axis 1), and the second for $26 \%$ (axis 2). The graph shows that the samples are widely scattered on both axes. The most apparent feature on axis 1 is that all the Blepharocalyx salicifolius (B) samples are congregated on the right-hand side. Among the other samples, there is no apparent pattern in distribution along this axis. Similarly along axis 2 , samples have no clear sequence of distribution.

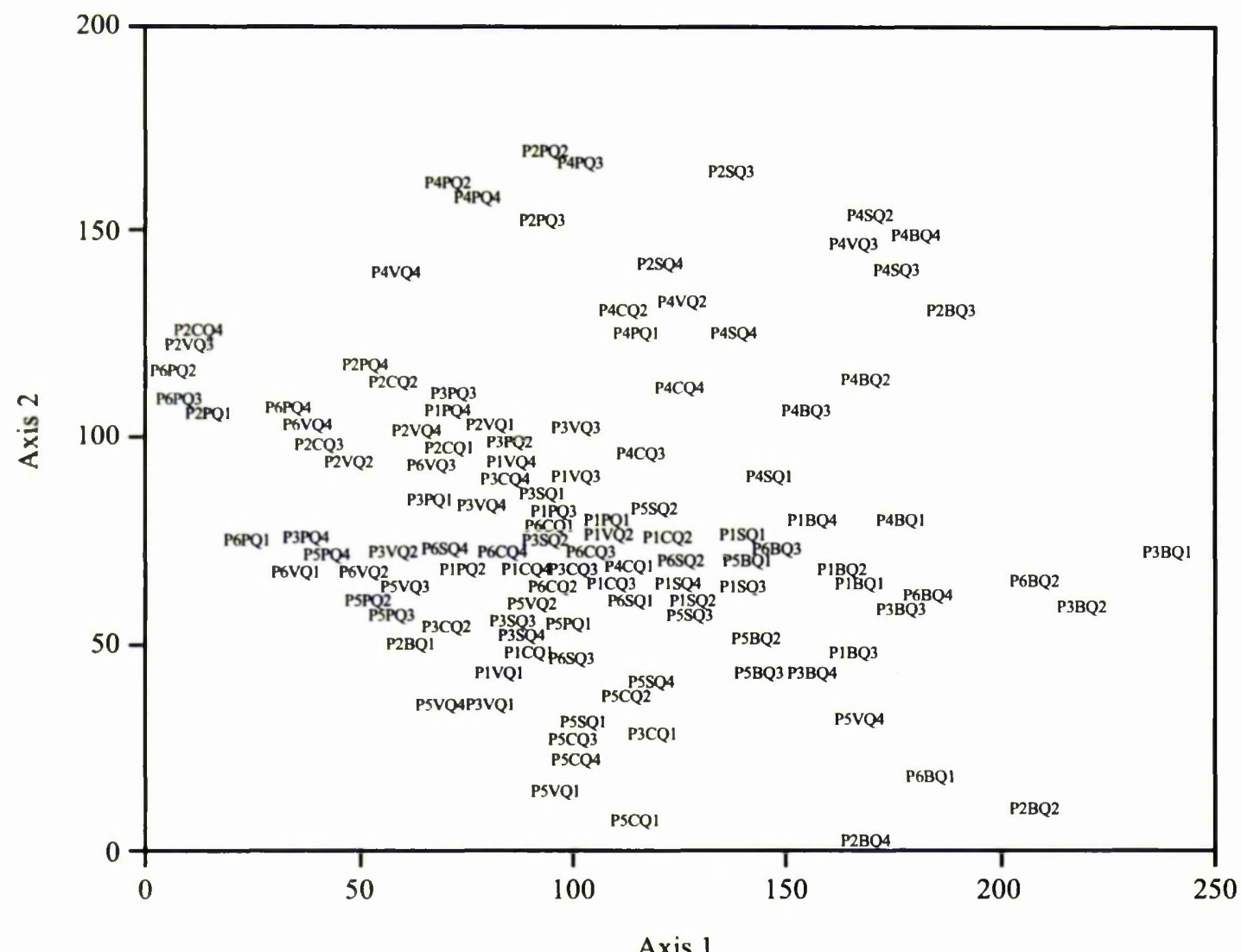

Figure 6.1 DCA sample ordination of Plots 1 to 6 using lichen species data. Note that all the Blepharocalyx salicifolius samples are grouped on the right-hand side of the ordination. Abbreviations: Plot, P; Blepharocalyx salicifolius, B; Caryocar brasiliense, C; Guapira noxia, G; Sclerolobium paniculatum, S; Vellozia squamata, V; Quarter on phorophyte, $\mathbf{Q}$. 
From this ordination result, it was decided to eliminate $B$. salicifolius samples from further analysis, since they seem to be obscuring the effects of fire in the results. It was also resolved to reanalyse the data in the following combinations: 1) Plot 1 (74-control) alone, to determine which factors control lichen composition where fire is absent, and therefore including B. salicifolius samples; 2) Plot 1 (74-control), Plot 2 (74-91: Hom, V, M) and Plot 6 (86-control), to analyse differences in lichen composition due to fire frequency and behaviour; 3) Plot 3 (74-92: Het, V, E), Plot 4 (74-92: Het, V, M) and Plot 5 (74-92: Het, V, L), to detect possible lichen compositional changes in response to burning time during the dry season.

\subsection{Reanalysis of the six plots}

\subsubsection{Analysis of Plot 1: factors controlling lichen species composition in the} absence of fire

The results of the DCA show that the first axis accounts for $50 \%$ of the total variance, and the second axis for $28 \%$. The sample ordination graph (Figure 6.2) shows two clusters of samples: the right-hand cluster has the Vellozia squamata samples with the highest axis values, followed by samples of Caryocar brasiliense and Guapira noxia; the left-hand cluster is composed of

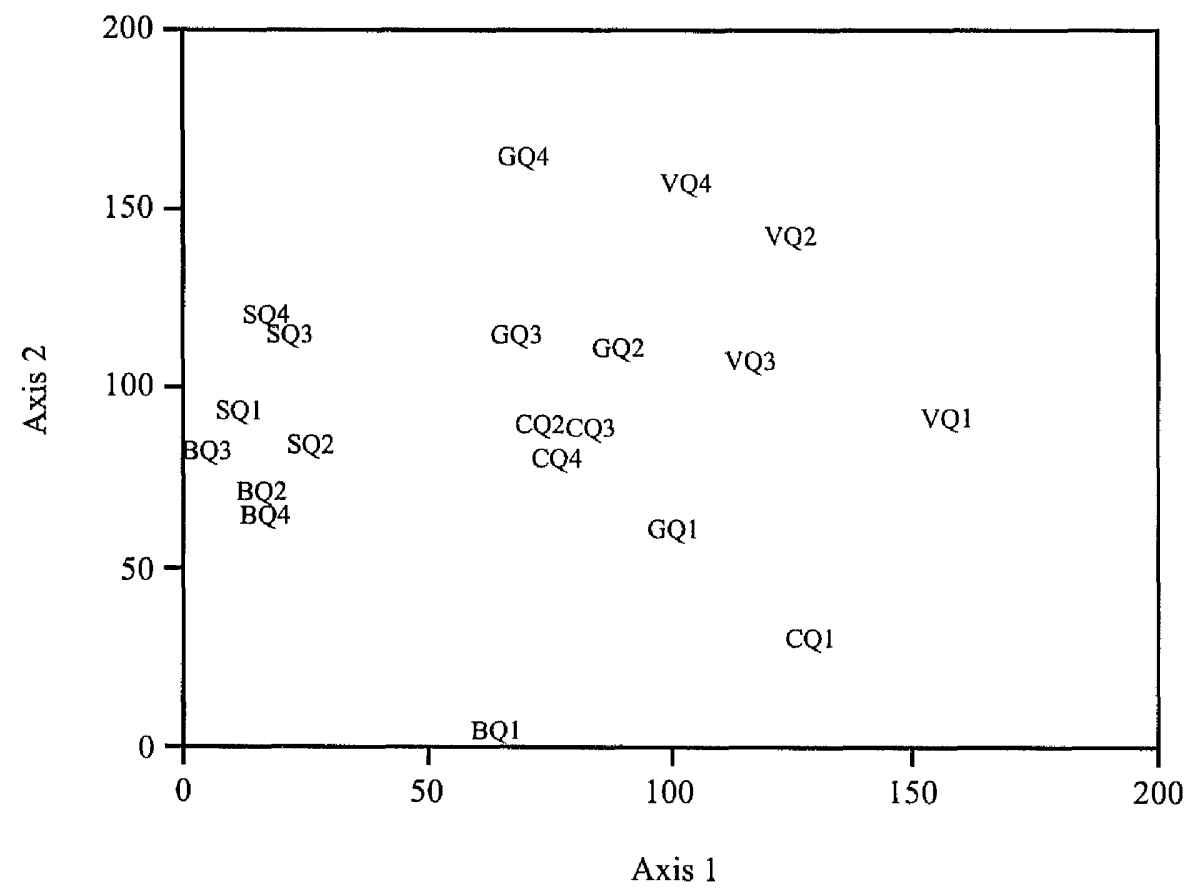

Figure 6.2 DCA sample ordination of Plot 1 using lichen species data. Abbreviations: Blepharocalyx salicifolius, B; Caryocar brasiliense, C; Guapira noxia, G; Sclerolobium paniculatum, S; Vellozia squamata, V; Quarter on phorophyte, Q. 
Sclerolobium paniculatum and Blepharocalyx salicifolius samples. The samples are widely scattered on axis 2, and though there are some Quarter 4 (Q4) samples at the top of the graph, and Quarter 1 (Q1) samples at the bottom (seen most strongly for G. noxia and $V$. squamata), this pattern is not consistent for all the phorophyte species. These results suggest that axis 1 of the DCA ordination graph may express phorophyte specificity, and axis 2 may represent vertical zonation, although this is less certain.

The lichen species ordination is shown in Figure 6.3 It shows species such as Coccocarpia dominguensis, C. imbricascens, Parmotrema jamesii and $P$. mellissii on the right-hand side of the graph, and lichens including 'Sterile White Crust' sp. '4', Lecanora sp. and Arthopyrenia sp. ' 2 ' on the left-hand side. This suggests that the former group of lichens may be specific to $V$. squamata, whereas the latter group of lichens may be more commonly found on B. salicifolius and $S$. paniculatum. The lichen species with intermediate values on axis 1 may prefer $C$. brasiliense and $G$. noxia. This ordination also indicates that the lichen species, Hypotrachyna velloziae, Lepraria sp., Parmotrema nylanderi and P. dilatatum may prefer habitats higher on the phorophyte (top of graph),

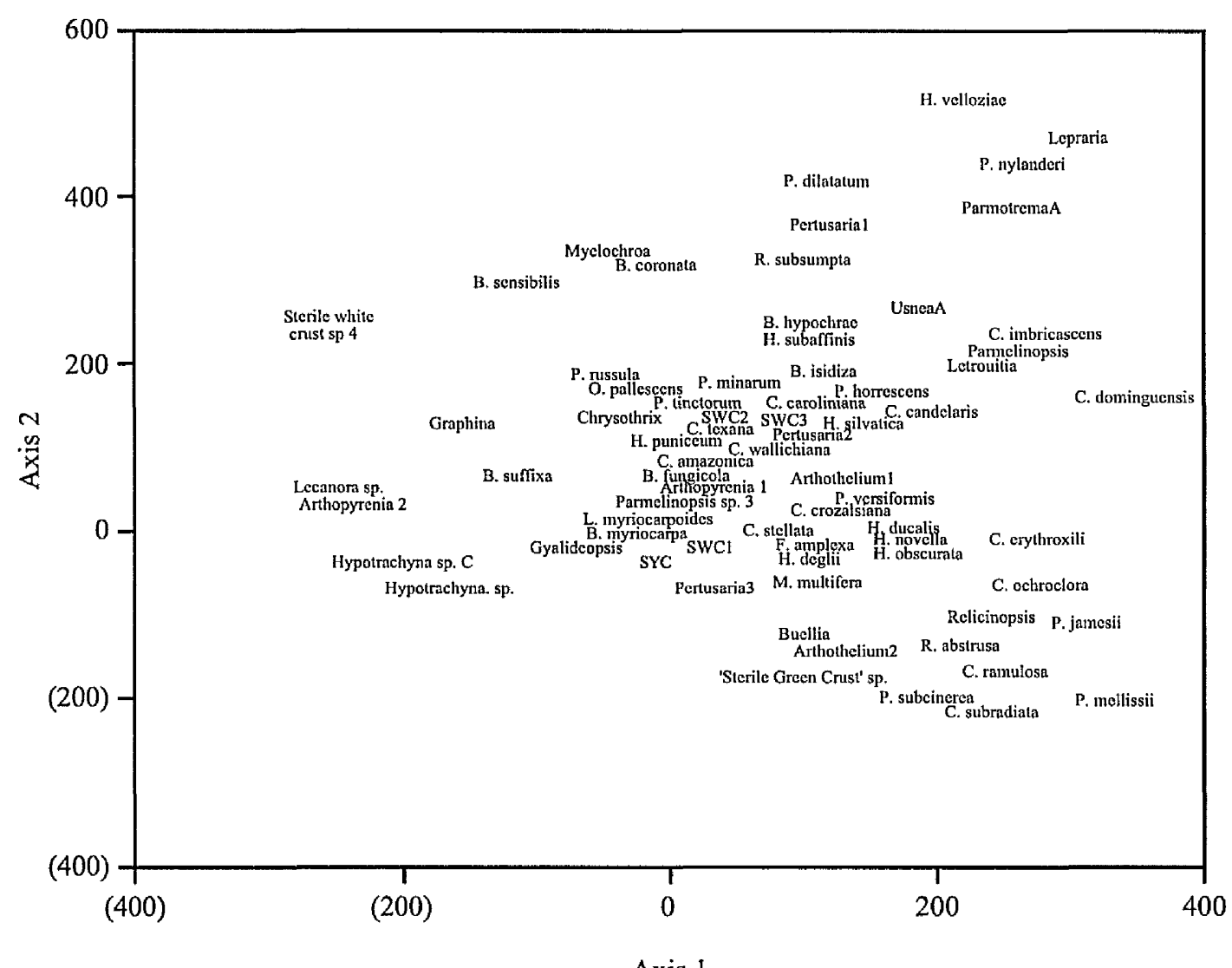

Axis 1

Figure 6.3 DCA lichen species ordination of Plot 1. 


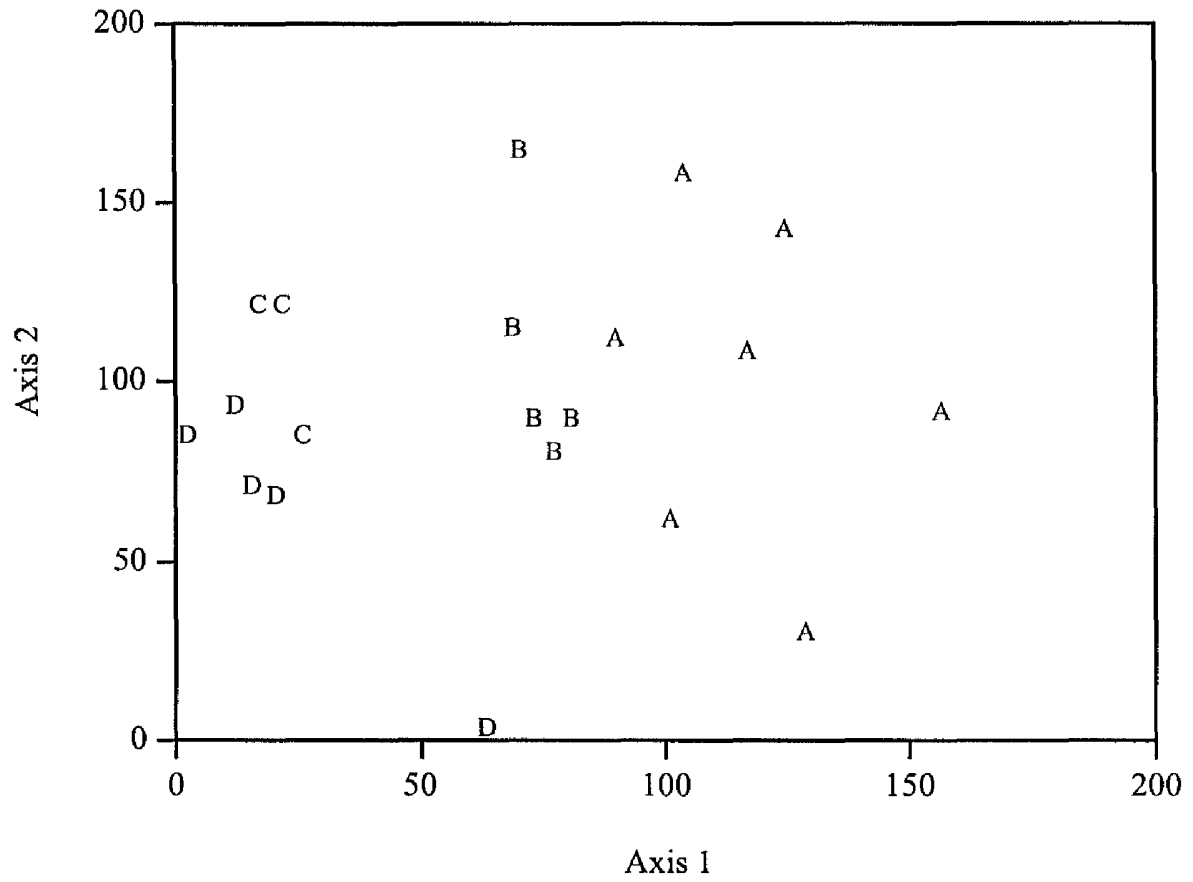

Figure 6.4 DCA sample ordination of Plot 1 overlaid by the groups (A-D) identified by the TWINSPAN classification.

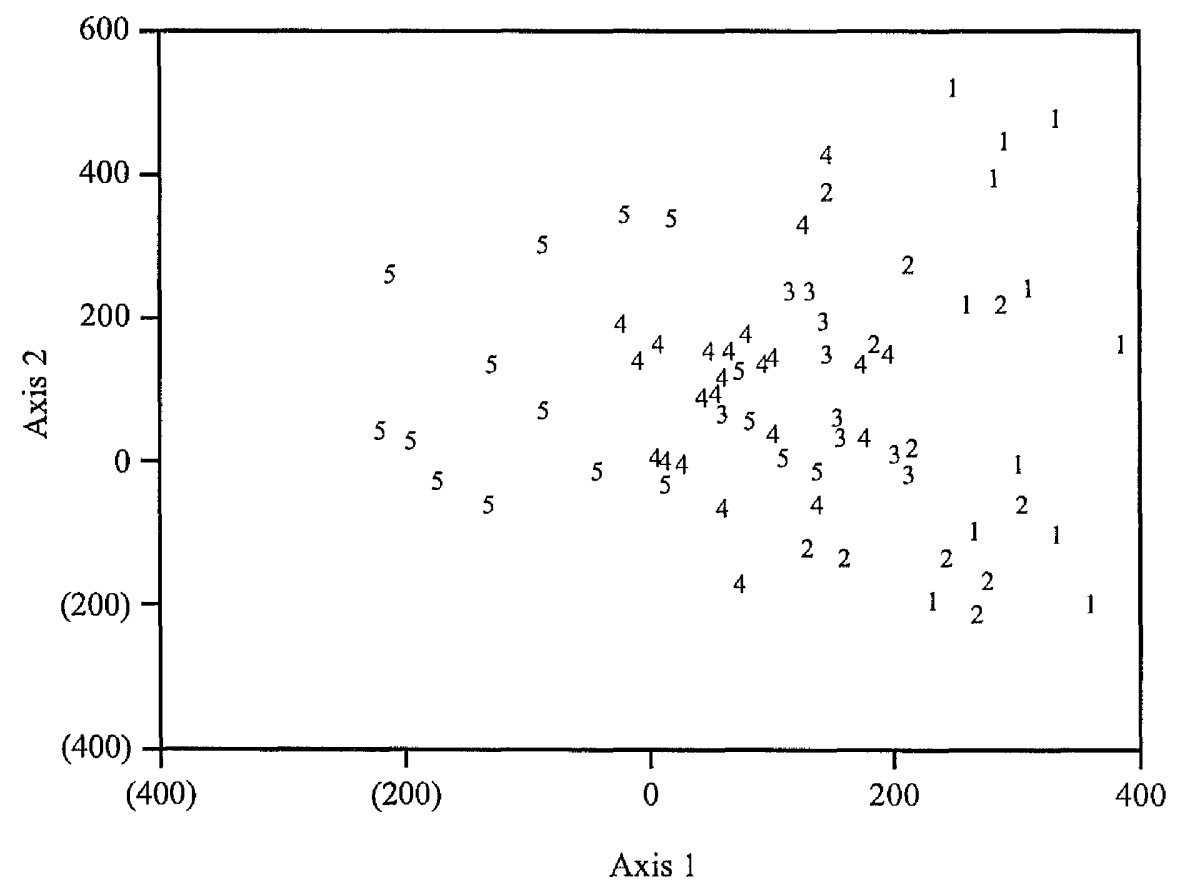

Figure 6.5 DCA lichen species ordination of Plot 1 overlaid by the groups (1-5) identified by the TWINSPAN classification. 
and that Cladonia subradiata, C. ramulosa, Pyxine subcinerea and P. mellissii may be more typically of phorophyte bases (bottom of graph).

The TWINSPAN classification identified four phorophyte specific groups of samples (see Figure 6.4 from right to left): Group A contains all the Vellozia squamata samples; Group B is comprised of all the Caryocar brasiliense and Guapira noxia samples; Group C has just Sclerolobium paniculatum samples; and Group D contains all the Blepharocalyx salicifolius samples and one $S$. paniculatum sample. The groups of lichen species recognised from the classification (see Figure 6.5) suggest that Group 1 is specific to $V$. squamata, Groups 2 and 3 to $C$. brasiliense and $G$. noxia, and Groups 4 and 5 to $B$. salicifolius and $S$. paniculatum.

A dendrogram of the TWINSPAN classification (Figure 6.6) presents the lichen indicator species for each group of phorophyte samples. At the first division, low frequencies of Coccocarpia imbricascens and Parmelinopsis horrescens separate the Vellozia squamata samples (Group A) from the other groups. Low frequencies of Bulbothrix suffixa, Graphina sp., Buellia myriocarpa and a higher frequency of Pyrrhospora russula are indicators of the other phorophytes (Groups B, C and D).

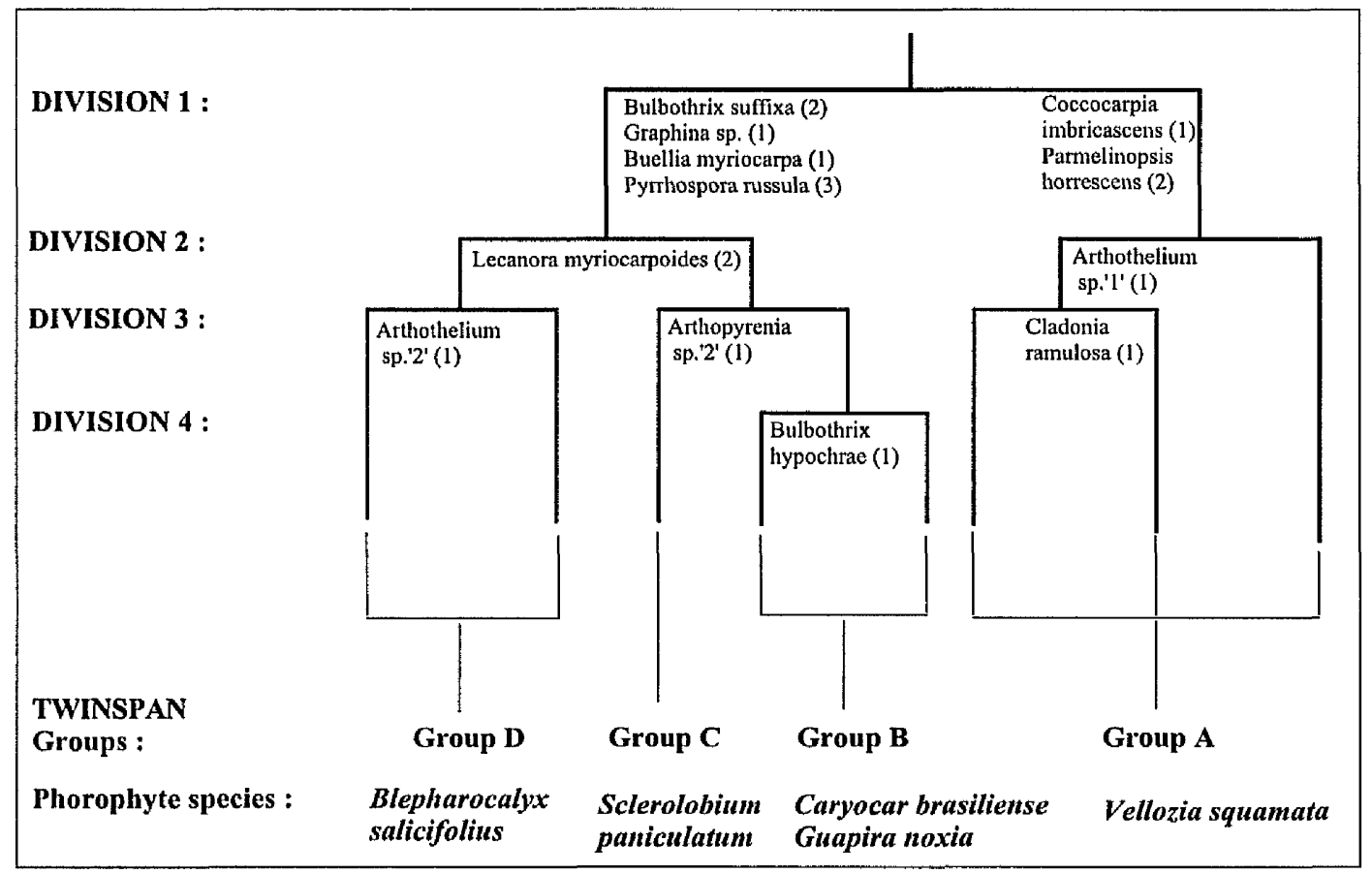

Figure 6.6 Dendrogram representing the major divisions of a TWINSPAN classification of the samples from Plot 1. Negative lichen indicator species appear on the left of each division and positive lichen indicator species on the right. The number in parentheses after each lichen indicator name is a 'pseudospecies' abundance class: classes 1-5, respectively, represent lower cut values for percentage frequencies of $20,40,60,80$ and $100 \%$. 
More specifically, Bulbothrix hypochrae is indicative of Caryocar brasiliense and Guapira noxia samples, Arthopyrenia sp. '2' to Sclerolobium paniculatum samples, and Lecanora myriocarpoides and Arthothelium sp. '2' to Blepharocalyx salicifolius samples.

6.3.2 Analyses of Plots 1,2 and 6: fire frequency and behaviour as factors determining lichen species composition

The results of the DCA show that the first component (1st axis) accounts for $43 \%$ of the total variance, and the second (2nd axis) for $26 \%$. The sample ordination (Figure 6.7) shows that there are three predominant sample assemblages along the 1st axis: on the left-hand side, the samples are chiefly represented by Plot 1 (74-control); in the middle, Plot 6 (86-control) samples are prevalent; and on the right-hand side, Plot 2 (74-91: Hom, H, M) samples are dominant. The second axis of Figure 6.7 shows a wide scattering of Plot 1 samples, less so in Plot 6 samples, and hardly any spread of Plot 2 samples. Within Plot 1 samples, and to a lesser extent in Plot 6, the Vellozia squamata samples have higher values on axis 2 (at the top of the graph), Caryocar brasiliense and Guapira noxia have intermediate values, and Sclerolobium paniculatum have the lowest values (at the bottom of the graph).

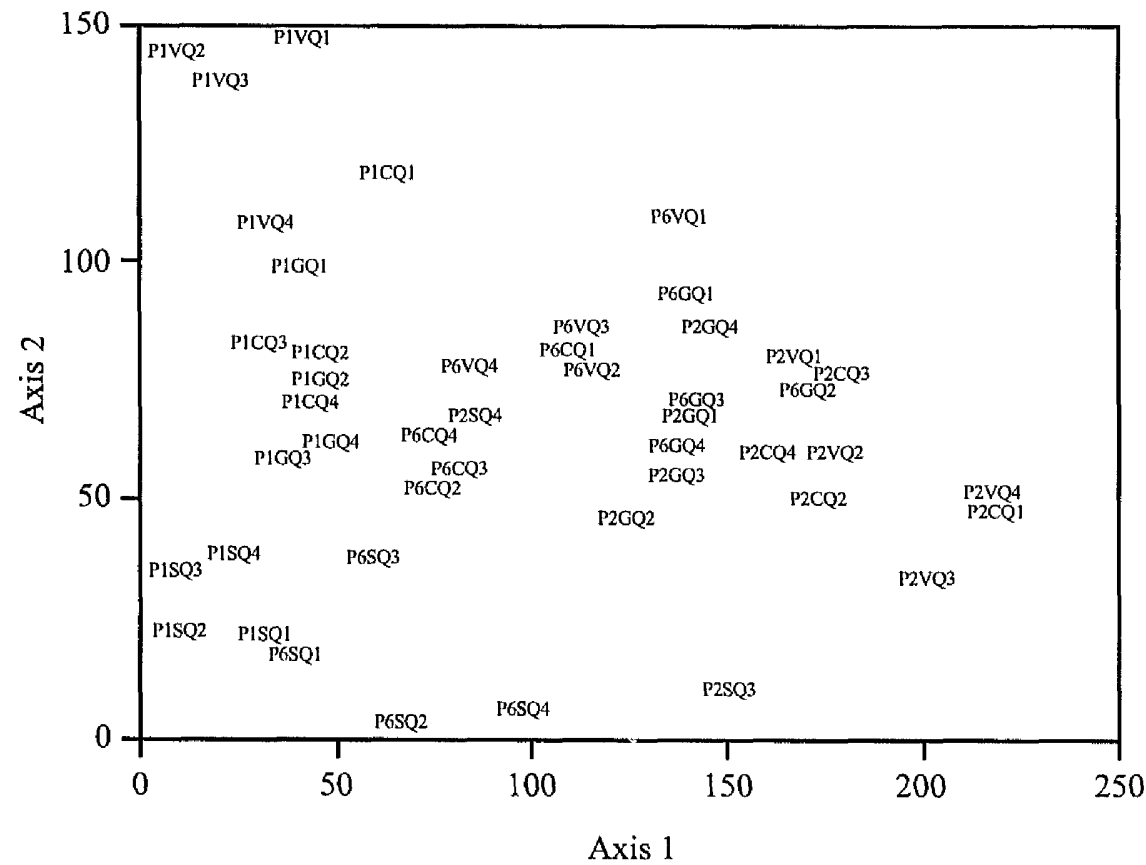

Figure 6.7 DCA sample ordination of Plots 1, 2 and 6 using lichen species data. Abbreviations: Plot, P; Caryocar brasiliense, C; Guapira noxia, G; Sclerolobium paniculatum, S; Vellozia squamata, V; Quarter on phorophyte, $\mathbf{Q}$. 
The lichen species ordination is shown in Figure 6.8, and it largely corresponds with the sample ordination. There is a diffusion of species along both the first and second axes, with a wide spread of points on the left-hand side of the graph that gradually narrows as one moves towards the right-hand side of the graph.

Axis 1 of the DCA may express fire history, low axis values corresponding to fire protection (Plot 1 samples), and the highest axis values indicating a recent, homogeneous burn (Plot 2 samples). Lichen species with low loadings on the first axis include Coccocarpia dominguensis, $C$. imbricascens, Parmotrema nylanderi, Pertusaria sp. '1' and Canoparmelia wallichiana. Lichens with high values on this axis are Flavoparmelia amplexa, Rimelia reticulata, 'Sterile Green Crust' sp., Canoparmelia amazonica and Bulbothrix fungicola. By having intermediate values, Plot 6 (86-control) shows that though it has been recently protected from fire (analogous to Plot 1), there have been frequent fires in the past (i.e. a degree of buming as in Plot 2). This combination of factors make Plot 6 samples a unique group of their own, indicating past frequent fires. Many lichen species have intermediate values on axis 1 and include Bulbothrix isidiza, B. suffixa, Canoparmelia caroliniana, Parmelinopsis sp. '3', and Chrysothrix sp..

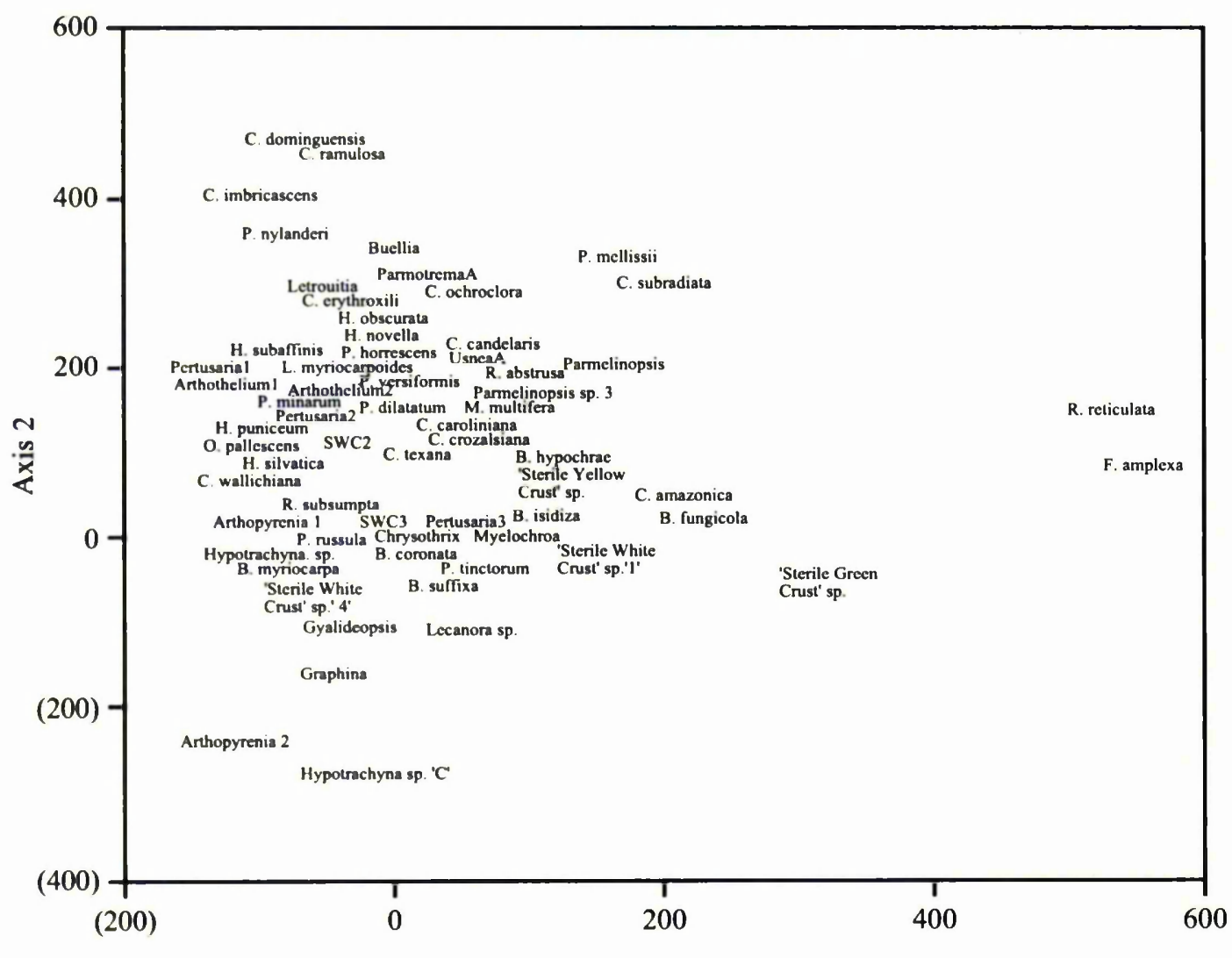

Axis 1

Figure 6.8 DCA lichen species ordination of Plots 1, 2 and 6. 
The second DCA axis may reflect phorophyte specificity, which is highly influential in Plot 1 (74-control), but becomes less relevant in Plot 6 (86-control), and is insignificant in Plot 2 (74-91: Hom, V, M). The ordering of the lichen species along axis 2 agrees with the previous DCA results of Plot 1 alone, where phorophyte specificity was found to be the first axis. Coccocarpia dominguensis, C. imbricascens, Cladonia ramulosa and Parmotrema nylanderi, considered to favour Vellozia squamata, have high axis values, and the lichen taxa Graphina sp., Arthopyrenia sp. '2' and Hypotrachyna $\mathrm{sp}$. 'C' which may prefer Sclerolobium paniculatum have low axis values. The lichen species with intermediate values are probably partial to Caryocar brasiliense and Guapira noxia.

Overlays of the sample and species ordinations with groups identified by the TWINSPAN classification are shown in Figures 6.9 and 6.10 respectively. These groups are aligned along the first axis, suggested to be a variation in fire history. Table 6.2 shows that the highest proportion of samples taken to form Groups A and B are from Plot 2 (74-91: Hom, H, M), to form Group C are from Plot 6 (86-control), and to form Groups D and E are from Plot 1 (74-control). Group 5 is probably an indication of phorophyte specificity becoming an important factor within the classification. The groups of lichen species recognised from the classification (see Figure 6.10) suggest that Group 1 is specific to Plot 2, Groups 2 and 3 to Plot 6, and Groups 4 and 5 to Plot 1.

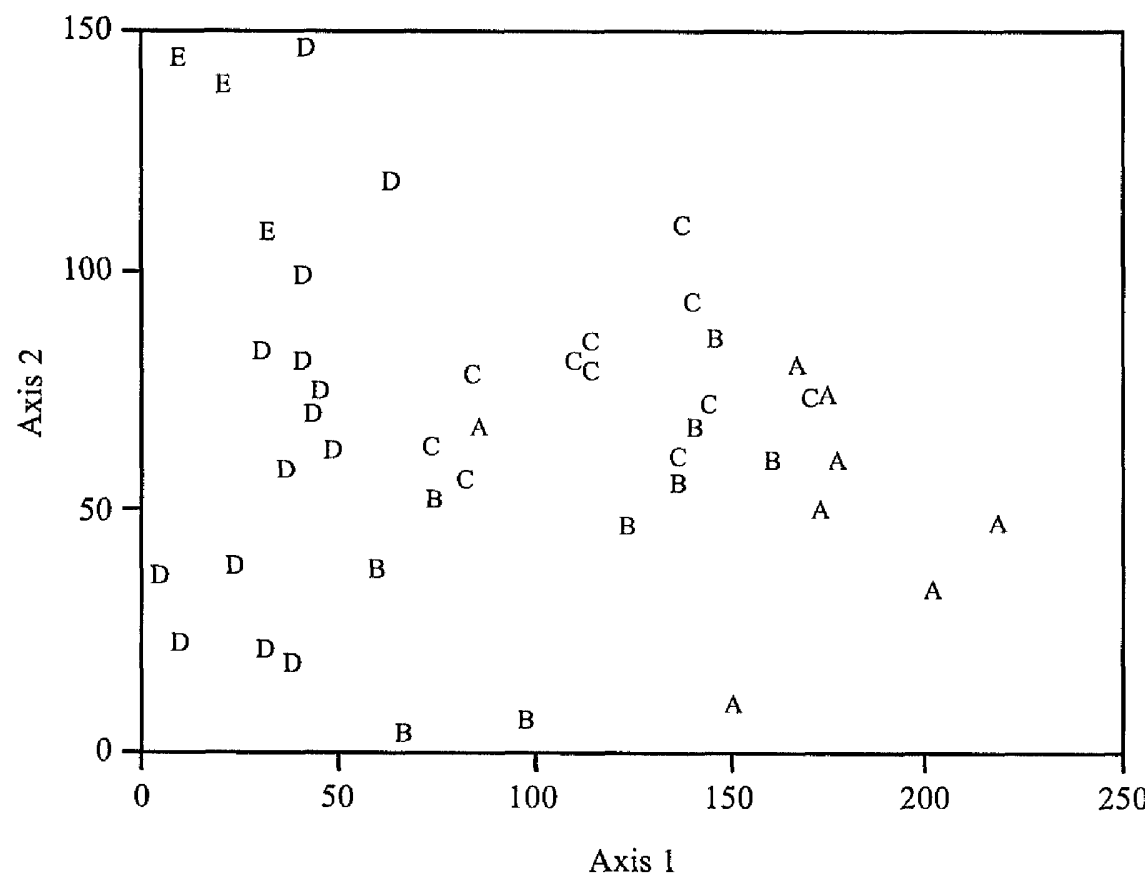

Figure 6.9 DCA sample ordination of Plots 1,2 and 6 overlaid by the groups (A-E) identified by the TWINSPAN classification. 


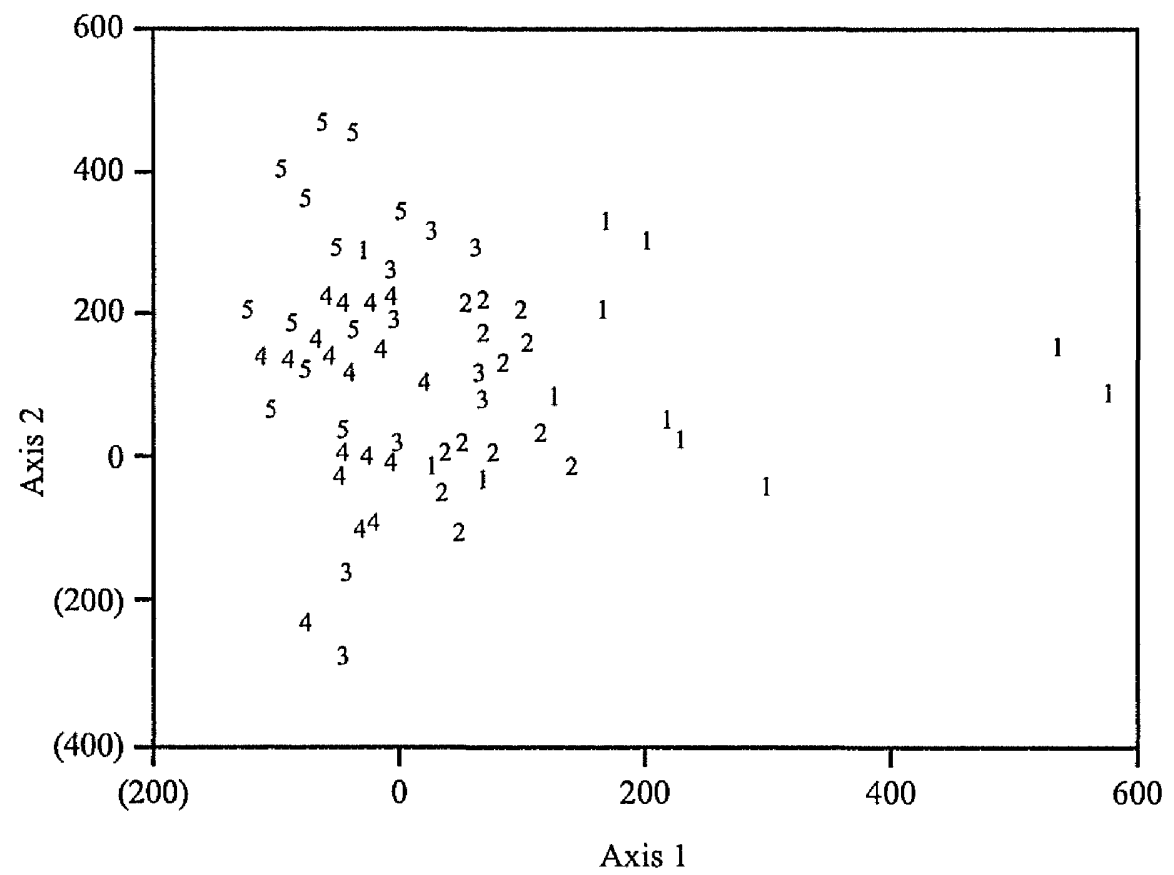

Figure 6.10 DCA lichen species ordination of Plots 1, 2 and 6 overlaid by the groups (1-5) identified by the TWINSPAN classification.

Table 6.2 The percentages of samples taken from each plot to form the TWINSPAN groups.

\begin{tabular}{|c||c|c|c|c|c|}
\hline \multicolumn{1}{|c||}{ Plot } & \multicolumn{5}{c|}{ TWINSPAN group } \\
\cline { 2 - 6 } & A & B & C & D & E \\
\hline 1 & 0 & 0 & 0 & 81 & 19 \\
2 & 64 & 36 & 0 & 0 & 0 \\
6 & 0 & 25 & 69 & 6 & 0 \\
\hline
\end{tabular}

A dendrogram representing the first three divisions in the TWINSPAN classification, and their indicator species are shown in Figure 6.11. A low frequency of Ochrolechia pallescens, 'Sterile White Crust' sp. '2' and Buellia myriocarpa, and an intermediate frequency of Pyrrhospora russula, distinguishes Plot 2 (74-91: Hom, H, M) and Plot 6 (86-control) from Plot 1 (74-control). A high frequency of Canoparmelia amazonica is indicative of Plot 2. Plot 6 is marked by a high frequency of Bulbothrix fungicola and Canoparmelia caroliniana, and a low frequency of Chrysothrix sp.. Within Plot 1, Group D is differentiated from Group E by a low frequency of Coccocarpia imbricascens and an intermediate frequency of Lecanora myriocarpoides. 


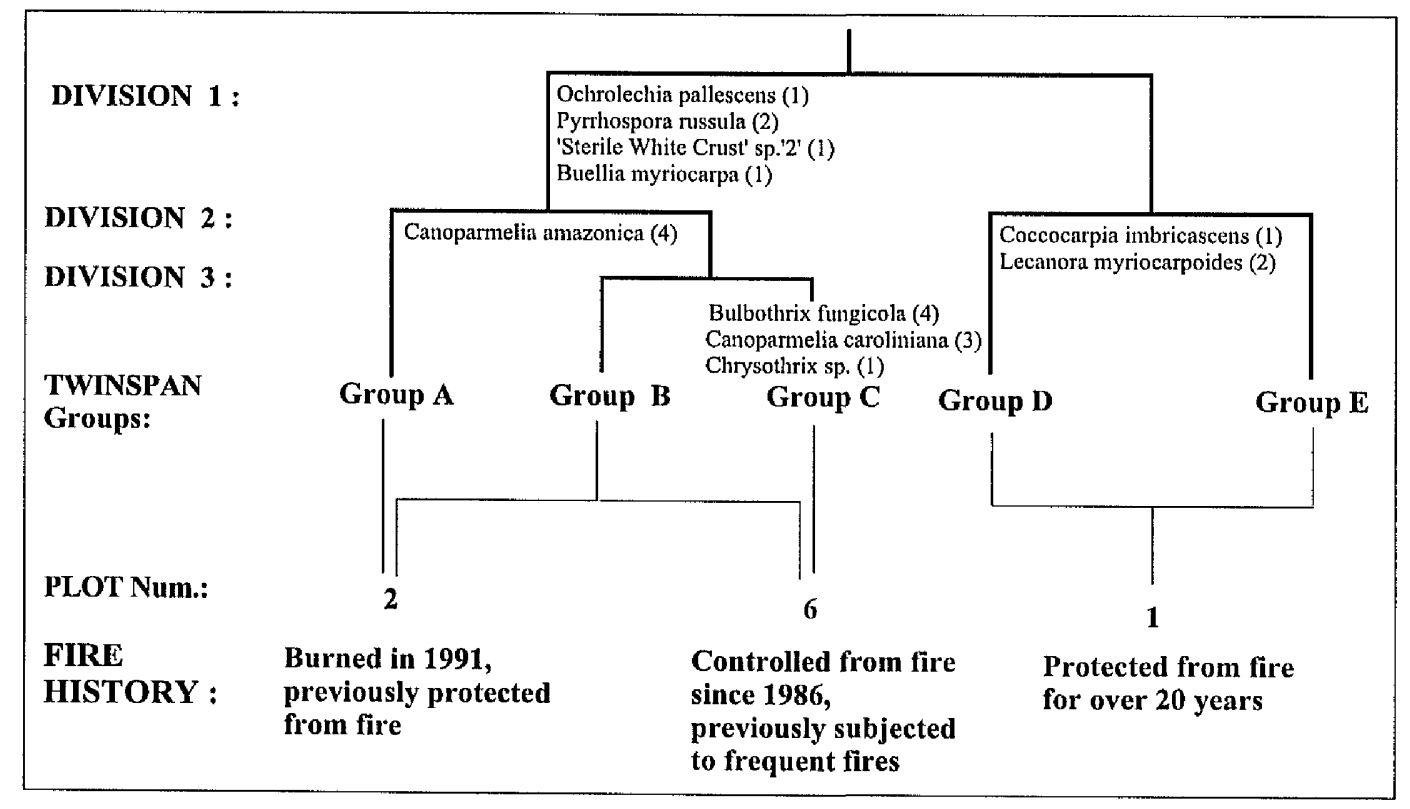

Figure 6.11 Dendrogram representing the major divisions of a TWINSPAN classification of the samples from Plots 1, 2 and 6. Negative lichen indicator species appear on the left of each division and positive lichen indicator species on the right. The number in parentheses after each lichen indicator name is a 'pseudospecies' abundance class: classes 1-5, respectively, represent lower cut values for percentage frequencies of $20,40,60,80$ and $100 \%$.

6.3.3 Analyses of Plots 3, 4 and 5: comparing the effects of early, middle and late season burns on lichen species composition

The results of the DCA shows that the first component (1st axis) accounts for $37 \%$ of the total variance, and the second ( 2 nd axis) for $28 \%$. The sample ordination shows three groups along the 1st axis (Figure 6.12). The first group on the right-hand side of the graph is dominated by Plot 4 (74-92: Het, V, M) samples. The group of samples on the left-hand side of the ordination are principally of Plot 5 (74-92: Het, V, L). In between these two extremes is another group, where Plot 3 (74-92: Het, V, E) samples are predominant, although a handful of Plot 4 and Plot 5 samples are present. Figure 6.12 also shows that samples are widely scattered on axis 2 . However, this spread of samples is most apparent on the right-hand side of the graph among the Plot 4 (74-92: Het, V, M) samples. This is slightly less evident in the Plot 3 (74-92: Het, V, E) samples, and becomes negligible on the left-hand side of the graph within the Plot 5 (74-92: Het, V, L) samples. Where there is this dispersion of samples on the second axis, Sclerolobium paniculatum samples have the highest axis values (at the top of the graph), Caryocar brasiliense and Guapira noxia have lower, intermediate values, and Vellozia squamata samples are at the bottom of the graph, with the lowest values. 


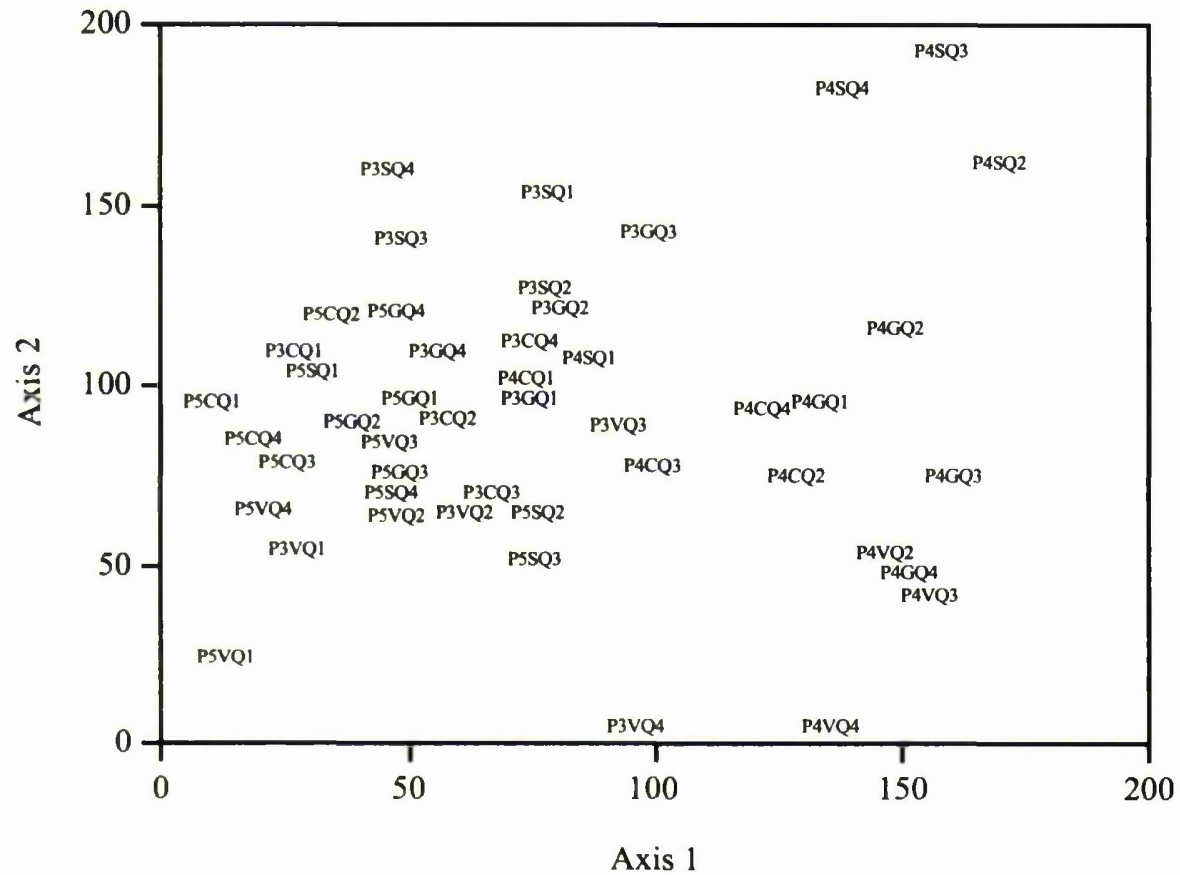

Figure 6.12 DCA sample ordination of Plot 3, 4 and 5 using lichen species data. Abbreviations: Plot, P; Caryocar brasiliense, C; Guapira noxia, G; Sclerolobium paniculatum, S; Vellozia squamata, V; Quarter on phorophyte, $\mathbf{Q}$.

The species ordination is shown in Figure 6.13. Lichen taxa are widely distributed over the first and second axis, though along axis 2, there is greater clumping of species on the left-hand side of the graph, than on the right.

Axis 1 of the DCA ordination may reflect fire history, low axis values correlating with a high density of fire patchiness, and high axis values to a low density of fire patchiness. This suggests that the lichen composition is least affected by fire in a middle season burn (Plot 4), and most affected in a late season burn (Plot 5). Lichen species with high axis values include Chrysothrix candelaris, Laurera sp., Bulbothrix sensibilis and Arthothelium sp. '1', and those with low axis values comprise Cladonia ochroclora, C. ramulosa, Parmelinopsis jamesii and Hypotrachyna sp. 'C'. There is an intermediate density of fire patchiness in the early season burn (Plot 3). Many lichen species intermediate axis values, and include Canoparmelia amazonica, C. caroliniana, Bulbothrix fungicola and Pyrrhospora russula.

The second DCA axis may express phorophyte specificity. However, the influence of this factor may vary according to the degree of fire impact (axis 1). Phorophyte specificity is most notable within Plot 4 samples i.e. least affected by fire, and its importance decreases as the impact of fire increases (also found in the Plot 1, 2 and 6 ordination - see Section 6.3.2 above). Lichen species with high values on axis 2 , such as Parmelinopsis minarum, Arthopyrenia sp. '2' and Chrysothrix 


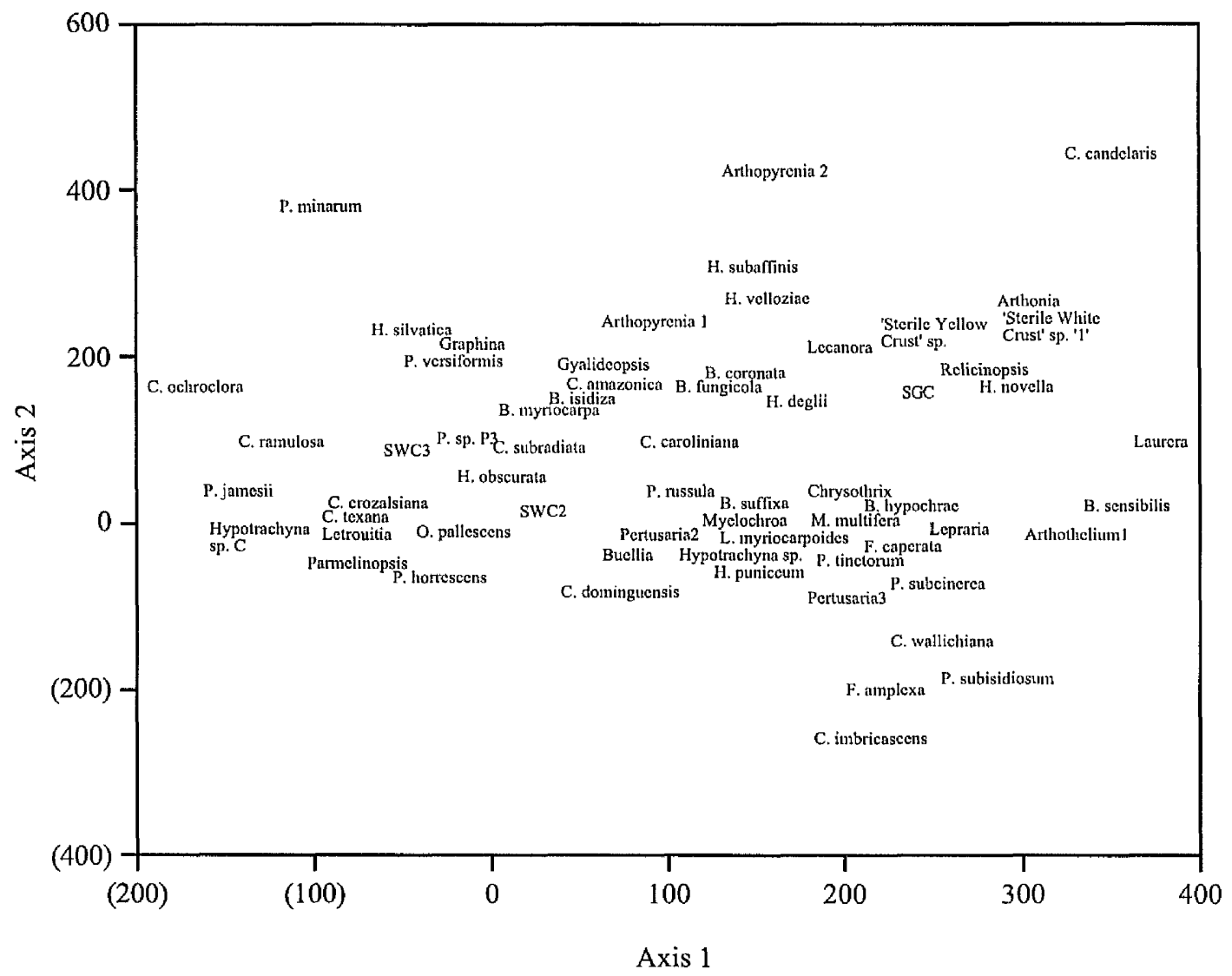

Figure 6.13 DCA lichen species ordination of Plots 3, 4 and 5.

candelaris may prefer Sclerolobium paniculatum, and Coccocarpia imbricascens and Flavoparmelia amplexa may favour Vellozia squamata. Arthopyrenia sp. '2' and C. imbricascens were also found to relate to the same phorophyte species in the ordination of Plot 1 alone, and Plots 1, 2 and 6 (see Sections 6.3.1 and 6.3.2 above). Lichen species with intermediate axis values, such as Bulbothrix fungicola and Canoparmelia amazonica, are most typical of Caryocar brasiliense and Guapira noxia.

Overlays of the sample and species ordination graphs with groups identified by the TWINSPAN classification are shown in Figure 6.14 and 6.15 respectively. These groups are arranged from right to left along the first axis, suggested to be a variation in fire history. Table 6.3 shows that the highest proportion of samples taken to form Group A are from Plot 4 (74-92: Het, V, M), to form Group B are from Plot 3 (74-92: Het, V, E), and to form Groups C and D are from Plot 5 (74-92: Het, $\mathrm{V}, \mathrm{L}$ ). The groups of lichen species recognised from the classification (see Figure 6.15) suggest that Group 1 is specific to Plot 4, Groups 2 and 3 to Plot 3, and Group 4 to Plot 5. 


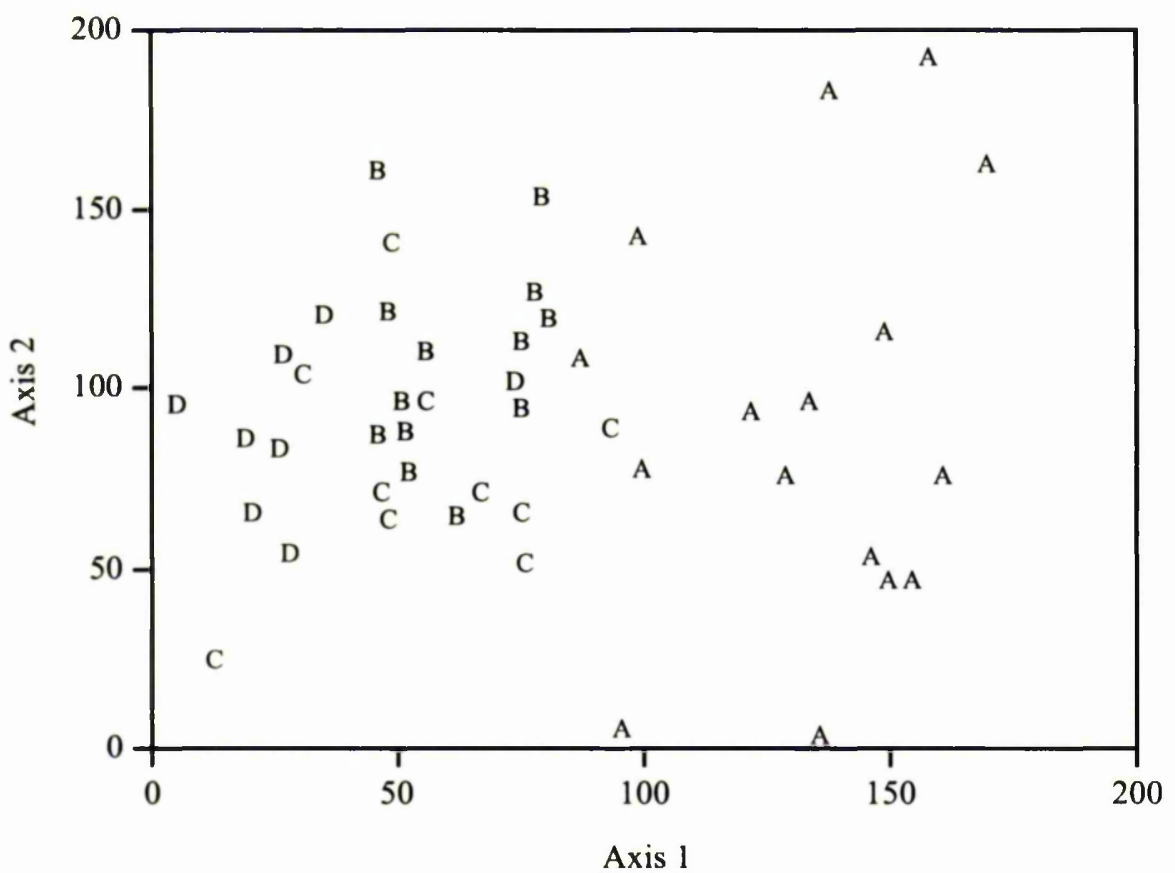

Figure 6.14 DCA sample ordination of Plots 3, 4 and 5 overlaid by the groups (A-D) identified by the TWINSPAN classification.

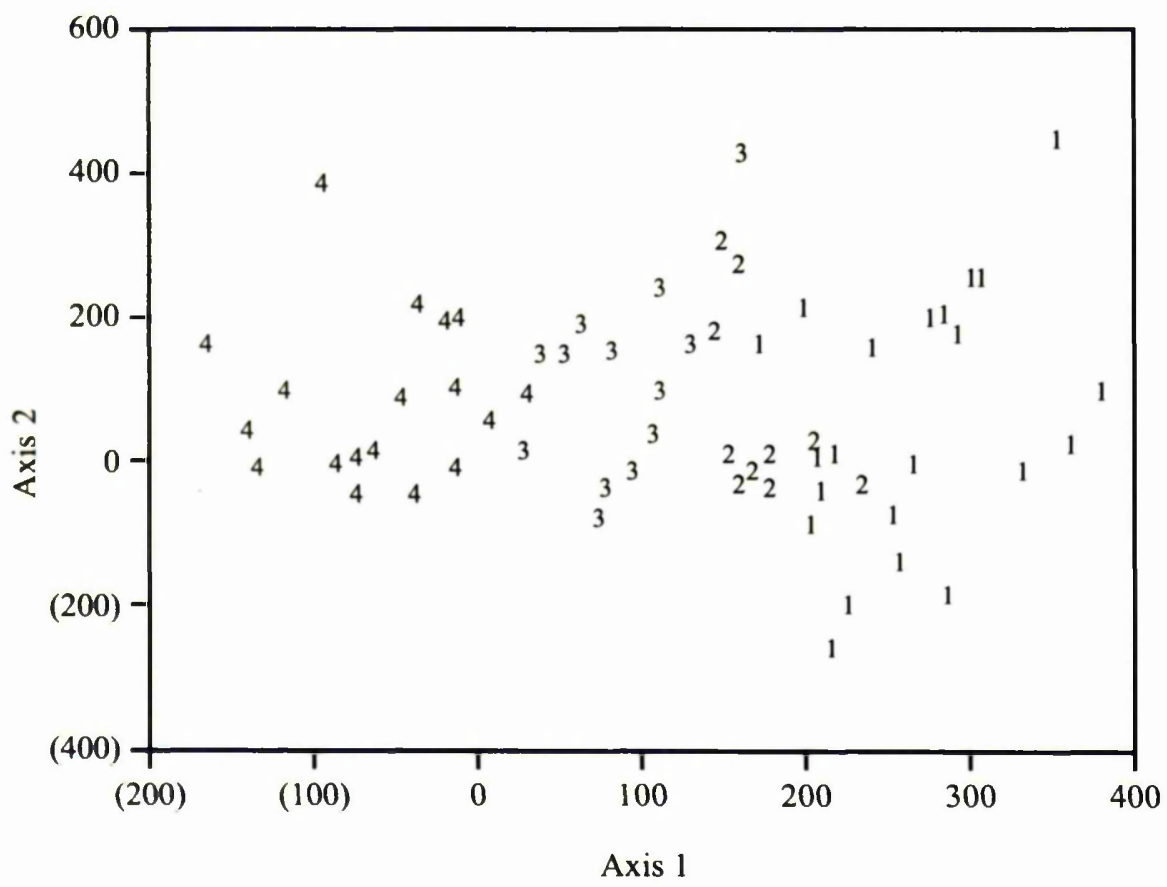

Figure 6.15 DCA lichen species ordination of Plots 3, 4 and 5 overlaid by the groups (1-4) identified by the TWINSPAN classification. 
Table 6.3 The percentages of samples taken from each plot to form the TWINSPAN groups.

\begin{tabular}{|c||c|c|c|c|}
\hline \multicolumn{1}{|c||}{} & \multicolumn{4}{c|}{ TWINSPAN group } \\
\cline { 2 - 5 } Plot & A & B & C & D \\
\hline 3 & 12 & 50 & 25 & 13 \\
4 & 93 & 0 & 0 & 7 \\
5 & 0 & 31 & 38 & 31 \\
\hline
\end{tabular}

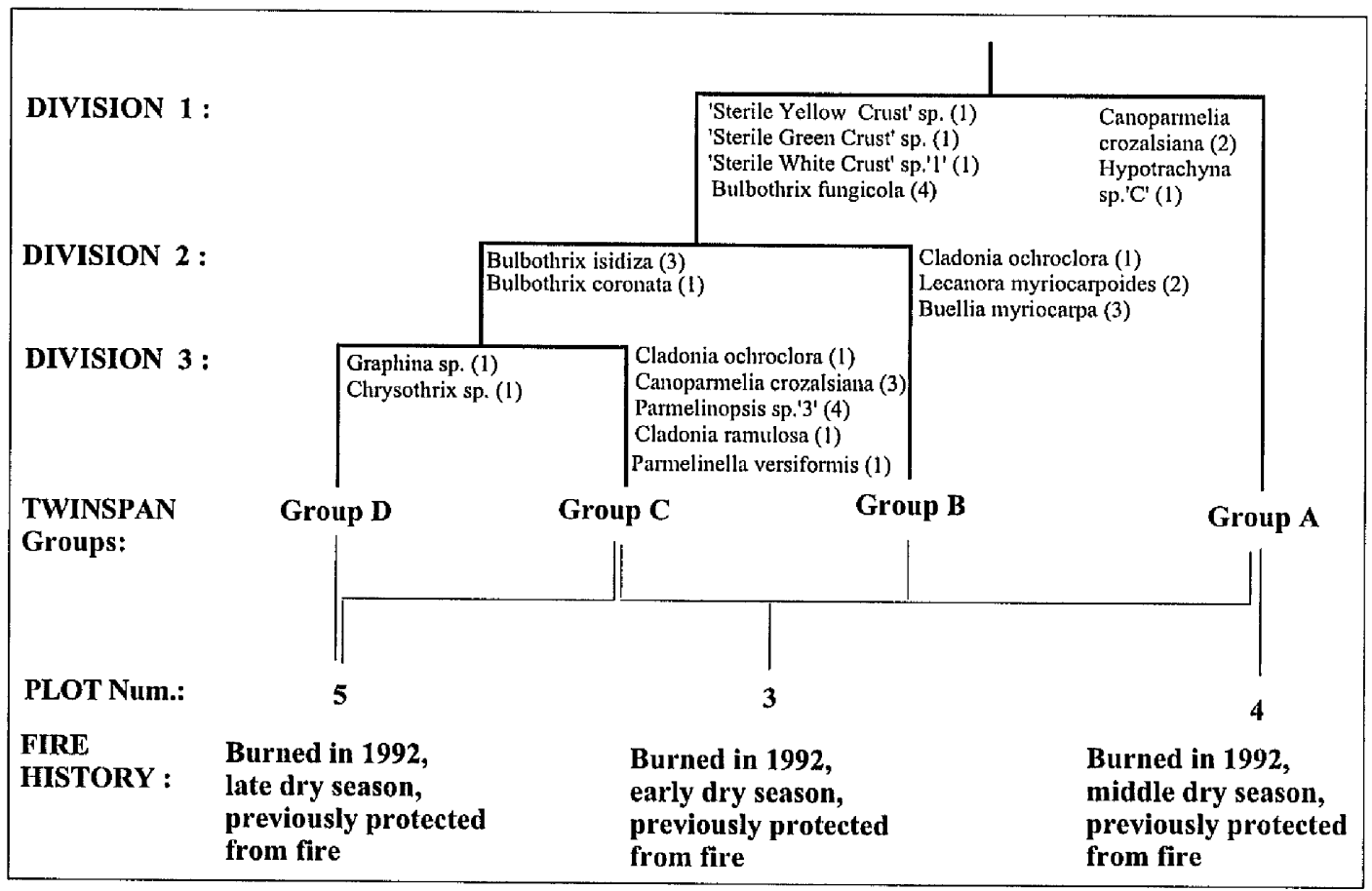

Figure 6.16 Dendrogram representing the major divisions of a TWINSPAN classification of the samples from Plots 3, 4 and 5. Negative lichen indicator species appear on the left of each division and positive lichen indicator species on the right. The number in parentheses after each lichen indicator name is a 'pseudospecies' abundance class: classes 1-5, respectively, represent lower cut values for percentage frequencies of $20,40,60,80$ and $100 \%$.

The first three divisions in the TWINSPAN classification, and their indicator species are shown as a dendrogram in Figure 6.16. At the first division, an intermediate frequency of Canoparmelia crozalsiana and a low frequency of Hypotrachyna sp. 'C' separate Plot 4 (74-92: Het, V, M) samples from Plot 3 (74-92: Het, V, E) and Plot 5 (74-92: Het, V, L) samples. These two latter 
plots are distinguished by low frequencies of 'Sterile Yellow Crust' sp., 'Sterile Green Crust' sp. and 'Sterile White Crust' sp. ' 1 ', and a high frequency of Bulbothrix fungicola. Further divisions show that some Plot 3 samples are distinct, with, for example, a high frequency of Buellia myriocarpa (at division 2), whereas other samples are related to Plot 5 samples, but later differentiated from them by, for example, a high frequency of Canoparmelia crozalsiana and Parmelinopsis sp. '3' (at division 3). Characteristic of Plot 5 samples is a high frequency of Bulbothrix isidiza, and low frequencies of $B$. coronata, Graphina sp. and Chrysothrix sp..

\subsection{The variation in frequency of lichen species between plots with different fire histories}

\subsubsection{Frequency variations in lichen species between Plots 1, 2 and 6}

Table 6.4 shows the frequency of each lichen species in Plot 1 (74-control), Plot 2 (74-91: Hom, H, M) and Plot 6 (86-control), the total number of occurrences within all three plots and the Coefficient of Variation (CV) for each species. In each plot, the frequency is out of 80 samples. Sixteen of the 89 species recorded in these plots were only encountered once, and 67 species have under 20 occurrences. The rarity of these species limits the significance of frequency differences between plots, although it should be noted that there are far greater numbers of rare species in Plot 1 than in Plots 2 or 6.

Of the species with between 20 and 50 total occurrences, Parmelinella versiformis, Lecanora myriocarpoides, Ochrolechia pallescens, Arthopyrenia sp. '1', 'Sterile White Crust' sp. '2', Pertusaria sp. '2' and Buellia myriocarpa have the highest CV values (over 100\%), with the highest frequency in Plot 1 (74-control), a much lower value in Plot 6 (86-control), and a negligible or zero value in Plot 2 (74-91: Hom, H, M). The species with total occurrences between 50 and 100 also show the same frequency distribution between plots, and include Pyrrhospora russula, Canoparmelia crozalsiana and Parmelinopsis sp. '3'. These species have over 70\% relative variability between plots. Bulbothrix isidiza is the only exception, with equal frequencies in Plots 1 and 6, a lower value in Plot 2 and a CV of only $39 \%$.

Only three species, Canoparmelia caroliniana, Bulbothrix fungicola and Canoparmelia amazonica, have over 100 total occurrences. C. caroliniana has the highest $\mathrm{CV}$, with the highest frequency in Plot 1 (74-control), followed by Plot 6 (86-control) and the lowest value in Plot 2 (74-91: Hom, H, M). B. fungicola and C. amazonica, on the other hand, have lower CV values, and show their highest frequencies in Plot 6, and lowest in Plot 2.

These results suggest that many of the lichen species that occur in high numbers show a high sensitivity to differences in fire history between Plot 1 (74-control), Plot 2 (74-91: Hom, H, M) and Plot 6 (86-control). This may be due to lichen species-specific adaptations to conditions prevalent in areas of different fire histories. 
Table 6.4 The frequency of each lichen species in Plots 1,2 and 6, the total number of occurrences and the Coefficient of Variation (CV).

\begin{tabular}{|c|c|c|c|c|c|}
\hline Lichen species & Plot 1 & Plot 2 & Plot 6 & Total & $\mathrm{CV}$ \\
\hline Arthothelium sp. '2' & 1.25 & $\overline{0}$ & $\overline{0}$ & $\overline{1}$ & 173 \\
\hline Bacidia sp. & 1.25 & 0 & 0 & 1 & 173 \\
\hline Bulbothrix apophysata & 1.25 & 0 & 0 & 1 & 173 \\
\hline Bulbothrix sensibilis & 1.25 & 0 & 0 & 1 & 173 \\
\hline Chiodecton sp. & 1.25 & 0 & 0 & 1 & 173 \\
\hline Dimerella $\mathrm{sp}$. & 1.25 & 0 & 0 & 1 & 173 \\
\hline Flavoparmelia caperata & 0 & 0 & 1.25 & 1 & 173 \\
\hline Hypotrachyna velloziae & 1.25 & 0 & 0 & 1 & 173 \\
\hline Lepraria sp. & 1.25 & 0 & 0 & 1 & 173 \\
\hline Medusulina sp. & 0 & 0 & 1.25 & 1 & 173 \\
\hline Physcia albicans & 0 & 0 & 1.25 & 1 & 173 \\
\hline Pyxine daedalea & 1.25 & 0 & 0 & 1 & 173 \\
\hline Pyxine subcinerea & 1.25 & 0 & 0 & 1 & 173 \\
\hline Pyxine sp. & 1.25 & 0 & 0 & 1 & 173 \\
\hline 'Sterile White Crust' sp. '5' & 1.25 & 0 & 0 & 1 & 173 \\
\hline Trypethelium $\mathrm{sp}$. & 1.25 & 0 & 0 & 1 & 173 \\
\hline Buellia sp. & 2.5 & 0 & 0 & 2 & 173 \\
\hline Coccocarpia erythroxili & 1.25 & 0 & 1.25 & 2 & 87 \\
\hline Coccocarpia stellata & 2.5 & 0 & 0 & 2 & 173 \\
\hline Hypotrachyna deglii & 1.25 & 0 & 1.25 & 2 & 87 \\
\hline Hypotrachyna ducalis & 2.5 & 0 & 0 & 2 & 173 \\
\hline Parmotrema gardneri & 2.5 & 0 & 0 & 2 & 173 \\
\hline Parmotrema subisidiosum & 0 & 0 & 2.5 & 2 & 173 \\
\hline Phaeographis sp. & 2.5 & 0 & 0 & 2 & 173 \\
\hline Pyxine physciaeformis & 1.25 & 1.25 & 0 & 2 & 87 \\
\hline Relicinopsis sp. & 2.5 & 0 & 0 & 2 & 173 \\
\hline Usnea sp. 'B' & 2.5 & 0 & 0 & 2 & 173 \\
\hline Cladonia ramulosa & 3.75 & 0 & 0 & 3 & 173 \\
\hline Heterodermia obscurata & 2.5 & 0 & 1.25 & 3 & 100 \\
\hline Lecanora sp. & 1.25 & 0 & 2.5 & 3 & 100 \\
\hline Parmelinopsis jamesii & 2.5 & 1.25 & 0 & 3 & 100 \\
\hline Pertusaria sp. '1' & 3.75 & 0 & 0 & 3 & 173 \\
\hline Rimeliella subsumpta & 3.75 & 0 & 0 & 3 & 173 \\
\hline Parmotrema dilatatum & 3.75 & 0 & 1.25 & 4 & 115 \\
\hline Parmotrema nylanderi & 5 & 0 & 0 & 4 & 173 \\
\hline Rimelia reticulata & 0 & 0 & 5 & 4 & 173 \\
\hline 'Sterile White Crust' sp. '4' & 3.75 & 0 & 1.25 & 4 & 115 \\
\hline Flavoparmelia amplexa & 1.25 & 1.25 & 3.75 & 5 & 69 \\
\hline Letrouitia $\mathrm{sp}$. & 5 & 0 & 1.25 & 5 & 125 \\
\hline Parmotrema mellissii & 2.5 & 0 & 3.75 & 5 & 92 \\
\hline Relicina abstrusa & 3.75 & 0 & 2.5 & 5 & 92 \\
\hline Chrysothrix candelaris & 3.75 & 1.25 & 2.5 & 6 & 50 \\
\hline Coccocarpia dominguensis & 6.25 & 0 & 1.25 & 6 & 132 \\
\hline
\end{tabular}


Table 6.4 continued

\begin{tabular}{|c|c|c|c|c|c|}
\hline Lichen species & Plot 1 & Plot 2 & Plot 6 & Total & $\mathrm{CV}$ \\
\hline Coccocarpia imbricascens & 7.5 & 0 & 0 & 6 & 173 \\
\hline Parmotrema sp. 'A' & 5 & 0 & 2.5 & 6 & 100 \\
\hline 'Sterile Green Crust' sp. & 3.75 & 3.75 & 0 & 6 & 87 \\
\hline Hypotrachyna novella & 7.5 & 1.25 & 0 & 7 & 138 \\
\hline Pertusaria sp. '3' & 3.75 & 1.25 & 3.75 & 7 & 49 \\
\hline Canoparmelia wallichiana & 10 & 0 & 0 & 8 & 173 \\
\hline Hypotrachyna sp. & 3.75 & 0 & 6.25 & 8 & 94 \\
\hline Parmelinopsis sp. & 3.75 & 0 & 6.25 & 8 & 94 \\
\hline Hypotrachyna silvatica & 10 & 0 & 1.25 & 9 & 145 \\
\hline Hypotrachyna sp. 'C' & 6.25 & 0 & 5 & 9 & 88 \\
\hline Canoparmelia texana & 10 & 0 & 2.5 & 10 & 125 \\
\hline Arthothelium sp. '1' & 11.25 & 0 & 2.5 & 11 & 129 \\
\hline Myelochroa sp. & 6.25 & 2.5 & 5 & 11 & 42 \\
\hline Parmotrema tinctorum & 6.25 & 1.25 & 6.25 & 11 & 63 \\
\hline Usnea sp. 'A' & 7.5 & 0 & 7.5 & 12 & 87 \\
\hline Bulbothrix coronata & 11.25 & 0 & 5 & 13 & 104 \\
\hline 'Sterile Yellow Crust' sp. & 10 & 3.75 & 2.5 & 13 & 74 \\
\hline Cladonia subradiata & 7.5 & 0 & 10 & 14 & 89 \\
\hline Maronina multifera & 7.5 & 3.75 & 6.25 & 14 & 33 \\
\hline 'Sterile White Crust' sp. '3' & 10 & 0 & 7.5 & 14 & 89 \\
\hline Haematomma puniceum & 16.25 & 0 & 3.75 & 16 & 128 \\
\hline Hypotrachyna subaffinis & 17.5 & 3.75 & 0 & 17 & 130 \\
\hline Parmelinopsis minarum & 18.75 & 0 & 2.5 & 17 & 144 \\
\hline Arthopyrenia sp. '2' & 12.5 & 0 & 11.25 & 19 & 87 \\
\hline Parmelinella versiformis & 21.25 & 1.25 & 2.5 & 20 & 134 \\
\hline 'Sterile White Crust' sp. '1' & 11.25 & 8.75 & 6.25 & 21 & 29 \\
\hline Bulbothrix hypochrae & 11.25 & 2.5 & 13.75 & 22 & 64 \\
\hline Lecanora myriocarpoides & 22.5 & 3.75 & 2.5 & 23 & 117 \\
\hline Graphina sp. & 17.5 & 0 & 15 & 26 & 87 \\
\hline Chrysothrix sp. & 16.25 & 0 & 17.5 & 27 & 87 \\
\hline Cladonia ochroclora & 21.25 & 1.25 & 11.25 & 27 & 89 \\
\hline Ochrolechia pallescens & 31.25 & 0 & 5 & 29 & 139 \\
\hline Gyalideopsis sp. & 25 & 1.25 & 11.25 & 30 & 95 \\
\hline Parmelinopsis horrescens & 26.25 & 0 & 16.25 & 34 & 94 \\
\hline Arthopyrenia sp. '1' & 36.25 & 2.5 & 8.75 & 38 & 113 \\
\hline Bulbothrix suffixa & 23.75 & 1.25 & 25 & 40 & 80 \\
\hline 'Sterile White Crust' sp. '2' & 40 & 0 & 10 & 40 & 125 \\
\hline Pertusaria sp. '2' & 38.75 & 1.25 & 12.5 & 42 & 110 \\
\hline Buellia myriocarpa & 43.75 & 1.25 & 11.25 & 45 & 119 \\
\hline Pyrrhospora russula & 53.75 & 2.5 & 16.25 & 58 & 110 \\
\hline Canoparmelia crozalsiana & 40 & 2.5 & 31.25 & 59 & 80 \\
\hline Parmelinopsis sp. '3' & 56.25 & 10 & 31.25 & 78 & 71 \\
\hline Bulbothrix isidiza & 45 & 20 & 45 & 88 & 39 \\
\hline Canoparmelia caroliniana & 70 & 12.5 & 51.25 & 107 & 66 \\
\hline
\end{tabular}


Table 6.4 continued.

\begin{tabular}{|l|c|c|c||c||c|}
\hline \multicolumn{1}{|c|}{ Lichen species } & Plot 1 & Plot 2 & Plot 6 & Total & CV \\
\hline \hline Bulbothrix fungicola & 48.75 & 35 & 82.5 & 133 & 44 \\
\hline Canoparmelia amazonica & 68.75 & 55 & 97.5 & 177 & 29 \\
\hline
\end{tabular}

\subsubsection{Frequency variations in lichen species between Plots 3, 4 and 5}

Table 6.5 shows the frequency of each lichen species in Plot 3 (74-92: Het, V, E), Plot 4 (74-92: Het, V, M) and Plot 5 (74-92: Het, V, L), the total number of occurrences within all three plots and the Coefficient of Variation (CV) for each species. Out of the 83 species found within these plots, 10 are found only once, and 57 have under 20 occurrences. Most of these rare species occur in Plot 4.

Among the species with total occurrences between 20 and 50, many have low $\mathrm{CV}$ values around $50 \%$ or below, with only Chrysothrix sp., 'Sterile Green Crust' sp., Hypotrachyna sp. ' $\mathrm{C}$ ' and 'Sterile White Crust' sp. ' $1^{\dagger}$ having a CV value above $80 \%$. Chrysothrix sp., 'Sterile Green Crust' sp. and 'Sterile White Crust' sp. '1' have their highest frequencies in Plot 4 (74-92: Het, V, M), and low comparable values in Plot 3 (74-92: Het, V, E) and Plot 5 (74-92: Het, V, L). Hypotrachyna sp. ' $\mathrm{C}$ ' has its highest frequency in Plot 5, a lower value in Plot 3, and an absence in Plot 4.

Of those with between 50 and 100 total occurrences, the species Lecanora myriocarpoides and Canoparmelia crozalsiana have the highest CV values of $53 \%$ and $71 \%$ respectively. In L. myriocarpoides, the highest frequency is in Plot 4 (74-92: Het, V, M), followed by lower values in Plot 5 (74-92: Het, V, L) and Plot 3 (74-92: Het, V, E) respectively. C. crozalsiana, on the other hand, has its highest frequency in Plot 5, and comparable values in Plots 3 and 5. Canoparmelia amazonica is the sole species with over 100 total occurrences, and although it has a low $\mathrm{CV}$, its highest frequency is in Plot 3, with lower values recorded in Plots 5 and 4 respectively.

These results suggest that many of the lichen species that occur in high numbers do not show a significantly high sensitivity to differences in fire history between Plot 3 (74-92: Het, V, E), Plot 4 (74-92: Het, V, M) and Plot 5 (74-92: Het, V, L). This suggests that it may be difficult to differentiate between areas burned at different times during the dry season using lichens.

\subsection{General conclusions}

From these results, a number of conclusions are proposed:

1) in the absence of fire, the most important determinant of lichen species composition is phorophyte specificity, followed to a lesser extent by vertical zonation on the trunk. The lichen indicators of Vellozia squamata are Coccocarpia dominguensis, $C$. imbricascens, Parmotrema jamesii and $P$. mellissii. For Caryocar brasiliense and Guapira noxia they include Bulbothrix isidiza, Canoparmelia caroliniana, Bulbothrix fungicola, Pyrrhospora russula and Canoparmelia amazonica; and for Blepharocalyx salicifolius and Sclerolobium paniculatum they are Arthopyrenia sp. '2', Graphina 
Table 6.5 The frequency of each lichen species in Plots 3, 4 and 5, the total number of occurrences and the Coefficient of Variation (CV).

\begin{tabular}{|c|c|c|c|c|c|}
\hline Lichen species & Plot 3 & Plot 4 & Plot 5 & Total & $\mathrm{CV}$ \\
\hline Arthonia sp. & 0 & 1.25 & 0 & 1 & 173 \\
\hline Arthothelium sp. '2' & 0 & 1.25 & 0 & 1 & 173 \\
\hline Coccocarpia erythroxili & 0 & 1.25 & 0 & 1 & 173 \\
\hline Coccocarpia stellata & 0 & 0 & 1.25 & 1 & 173 \\
\hline Parmotrema mellissii & 1.25 & 0 & 0 & 1 & 173 \\
\hline Pertusaria sp. '1' & 1.25 & 0 & 0 & 1 & 173 \\
\hline Porina sp. & 0 & 1.25 & 0 & 1 & 173 \\
\hline Pyxine pungens & 0 & 1.25 & 0 & 1 & 173 \\
\hline Pyxine sp. & 0 & 1.25 & 0 & 1 & 173 \\
\hline Rimeliella subsumpta & 0 & 1.25 & 0 & 1 & 173 \\
\hline Bulbothrix bulbochraeta & 2.5 & 0 & 0 & 2 & 173 \\
\hline Bulbothrix linteolocarpa & 0 & 2.5 & 0 & 2 & 173 \\
\hline Canoparmelia texana & 1.25 & 0 & 1.25 & 2 & 87 \\
\hline Chrysothrix candelaris & 0 & 2.5 & 0 & 2 & 173 \\
\hline Hypotrachyna ducalis & 1.25 & 0 & 1.25 & 2 & 87 \\
\hline Hypotrachyna sp. & 0 & 1.25 & 1.25 & 2 & 87 \\
\hline Laurera sp. & 0 & 2.5 & 0 & 2 & 173 \\
\hline Parmotrema dilatatum & 0 & 2.5 & 0 & 2 & 173 \\
\hline Parmotrema nylanderi & 0 & 2.5 & 0 & 2 & 173 \\
\hline Parmotrema sp. 'A' & 1.25 & 1.25 & 0 & 2 & 87 \\
\hline Pyxine daedalea & 0 & 2.5 & 0 & 2 & 173 \\
\hline Relicina abstrusa & 0 & 1.25 & 1.25 & 2 & 87 \\
\hline Usnea sp. 'A' & 1.25 & 0 & 1.25 & 2 & 87 \\
\hline Dirinaria picta & 0 & 3.75 & 0 & 3 & 173 \\
\hline Heterodermia obscurata & 3.75 & 0 & 0 & 3 & 173 \\
\hline Hypotrachyna deglii & 1.25 & 2.5 & 0 & 3 & 100 \\
\hline Hypotrachyna velloziae & 1.25 & 2.5 & 0 & 3 & 100 \\
\hline Lecanora sp. & 1.25 & 2.5 & 0 & 3 & 100 \\
\hline Parmelinopsis jamesii & 0 & 0 & 3.75 & 3 & 173 \\
\hline Parmelinopsis minarum & 3.75 & 0 & 0 & 3 & 173 \\
\hline Relicinopsis sp. & 0 & 3.75 & 0 & 3 & 173 \\
\hline Buellia sp. & 0 & 1.25 & 3.75 & 4 & 115 \\
\hline Flavoparmelia caperata & 1.25 & 2.5 & 1.25 & 4 & 43 \\
\hline Parmotrema subisidiosum & 1.25 & 3.75 & 0 & 4 & 115 \\
\hline Letrouitia sp. & 3.75 & 0 & 2.5 & 5 & 92 \\
\hline 'Sterile White Crust' sp. '3' & 0 & 1.25 & 5 & 5 & 125 \\
\hline Bulbothrix sensibilis & 0 & 7.5 & 0 & 6 & 173 \\
\hline Hypotrachyna novella & 0 & 7.5 & 0 & 6 & 173 \\
\hline Lepraria sp. & 0 & 7.5 & 0 & 6 & 173 \\
\hline Coccocarpia dominguensis & 1.25 & 2.5 & 5 & 7 & 65 \\
\hline Coccocarpia imbricascens & 3.75 & 5 & 0 & 7 & 89 \\
\hline Canoparmelia wallichiana & 2.5 & 6.25 & 1.25 & 8 & 78 \\
\hline
\end{tabular}


Table 6.5 continued.

\begin{tabular}{|l|c|c|c||c||c|}
\hline \multicolumn{1}{|c|}{ Lichen species } & Plot 3 & Plot 4 & Plot 5 & Total & CV \\
\hline \hline Cladonia ramulosa & 1.25 & 5 & 3.75 & 8 & 57 \\
\hline Pyxine subcinerea & 2.5 & 7.5 & 1.25 & 9 & 88 \\
\hline Arthothelium sp. '1' & 0 & 11.25 & 1.25 & 10 & 148 \\
\hline Arthopyrenia sp. '2' & 7.5 & 3.75 & 1.25 & 10 & 75 \\
\hline Hypotrachyna subaffinis & 8.75 & 3.75 & 0 & 10 & 105 \\
\hline Flavoparmelia amplexa & 2.5 & 8.75 & 2.5 & 11 & 79 \\
\hline Parmelinopsis sp. & 3.75 & 1.25 & 10 & 12 & 90 \\
\hline Cladonia subradiata & 5 & 10 & 1.25 & 13 & 81 \\
\hline Pertusaria sp. '3' & 1.25 & 10 & 5 & 13 & 81 \\
\hline Bulbothrix hypochrae & 3.75 & 12.5 & 2.5 & 15 & 87 \\
\hline Myelochroa sp. & 5 & 11.25 & 2.5 & 15 & 72 \\
\hline Parmotrema tinctorum & 5 & 11.25 & 2.5 & 15 & 72 \\
\hline Bulbothrix suffixa & 1.25 & 10 & 8.75 & 16 & 71 \\
\hline Maronina multifera & 3.75 & 15 & 3.75 & 18 & 87 \\
\hline 'Sterile Yellow Crust' sp. & 0 & 21.25 & 2.5 & 19 & 147 \\
\hline Bulbothrix coronata & 11.25 & 8.75 & 5 & 20 & 38 \\
\hline Parmelinella versiformis & 12.5 & 5 & 7.5 & 20 & 46 \\
\hline Graphina sp. & 12.5 & 2.5 & 11.25 & 21 & 62 \\
\hline Chrysothrix sp. & 3.75 & 18.75 & 5 & 22 & 91 \\
\hline 'Sterile Green Crust' sp. & 6.25 & 20 & 3.75 & 24 & 88 \\
\hline Parmelinopsis horrescens & 10 & 6.25 & 17.5 & 27 & 51 \\
\hline Gyalideopsis sp. & 6.25 & 12.5 & 16.25 & 28 & 43 \\
\hline Hypotrachyna silvatica & 12.5 & 6.25 & 18.75 & 30 & 50 \\
\hline Haematomma puniceum & 7.5 & 17.5 & 13.75 & 31 & 39 \\
\hline Ochrolechia pallescens & 12.5 & 8.75 & 20 & 33 & 42 \\
\hline Hypotrachyna sp. 'C' & 15 & 0 & 27.5 & 34 & 97 \\
\hline Arthopyrenia sp. '1' & 13.75 & 18.75 & 11.25 & 35 & 26 \\
\hline Cladonia ochroclora & 11.25 & 8.75 & 23.75 & 35 & 55 \\
\hline 'Sterile White Crust' sp. '1' & 3.75 & 40 & 2.5 & 37 & 138 \\
\hline 'Sterile White Crust' sp. '2' & 17.5 & 15 & 25 & 46 & 27 \\
\hline Lecanora myriocarpoides & 10 & 33.75 & 23.75 & 54 & 53 \\
\hline Pertusaria sp. '2' & 15 & 30 & 32.5 & 62 & 37 \\
\hline Buellia myriocarpa & 20 & 22.5 & 37.5 & 64 & 35 \\
\hline Canoparmelia crozalsiana & 21.25 & 15 & 55 & 73 & 71 \\
\hline Pyrrhospora russula & 35 & 31.25 & 25 & 73 & 17 \\
\hline Canoparmelia caroliniana & 38.75 & 32.5 & 31.25 & 82 & 12 \\
\hline Parmelinopsis sp. '3' & 35 & 23.75 & 51.25 & 88 & 38 \\
\hline Bulbothrix fungicola & 42.5 & 31.25 & 89 & 15 \\
\hline Bulbothrix isidiza & 28.75 & 42.5 & 96 & 26 \\
\hline Canoparmelia amazonica & 60 & 72.5 & 170 & 14 \\
\hline
\end{tabular}


sp., Bulbothrix suffixa and Gyalideopsis sp.. Lichen species typical of phorophyte bases are Cladonia subradiata, $C$. ramulosa and C. ochroclora, and for the higher parts of phorophytes include Hypotrachyna velloziae, Lepraria sp., Parmotrema nylanderi and $P$. dilatatum;

2) once fire is present in the vegetation, fire history becomes the primary determinant of the lichen species composition. The lichen indicator species (i.e. those species that show a distinct grouping within plots of different fire histories) are:

a) for fire protection, Coccocarpia species, Pyrrhospora russula, Buellia myriocarpa, Lecanora myriocarpoides, Parmelinella versiformis, Parmelinopsis horrescens, 'Sterile White Crust' sp. '2', Ochrolechia pallescens, Cladonia species and Pertusaria sp. '2';

b) for a rare, but recent, homogeneous fire, Flavoparmelia amplexa, Rimelia reticulata, 'Sterile Green Crust' sp., Canoparmelia amazonica and Bulbothrix fungicola;

c) for past frequent fires, but recent protection, Bulbothrix isidiza, B. suffixa, Canoparmelia caroliniana, Parmelinopsis sp. '3' and Chrysothrix sp.;

d) for a low density of fire patchiness, Coccocarpia imbricascens, Laurera sp., Chrysothrix candelaris and Bulbothrix sensibilis;

e) for an intermediate density of fire patchiness, Haematomma puniceum, Lecanora myriocarpoides and Chrysothrix sp.;

f) for a high density of fire patchiness, Canoparmelia amazonica, C. caroliniana, Bulbothrix fungicola and B. isidiza;

3) many common lichen species show a high sensitivity to differences in fire history between Plot 1 (74-control), Plot 2 (74-91: Hom, H, M) and Plot 6 (86-control). This may be due to particular lichen species having adaptations to conditions prevalent in areas of different fire histories. These species include Parmelinella versiformis, Lecanora myriocarpoides, Ochrolechia pallescens, Arthopyrenia sp. '1', 'Sterile White Crust' sp. '2', Pertusaria sp. '2', Buellia myriocarpa, Pyrrhospora russula, Canoparmelia crozalsiana, C. caroliniana, C. amazonica, Parmelinopsis sp. '3' and Bulbothrix fungicola;

4) many common lichen species do not show a significantly high sensitivity to differences in fire history between Plot 3 (74-92: Het, V, E), Plot 4 (74-92: Het, V, M) and Plot 5 (74-92: Het, V, L). This suggests that it may be difficult to differentiate between areas burned at different times during the dry season using lichens. 


\section{Chapter 7 \\ Results III: Lichen population dynamics and fire ecology}

\subsection{Introduction}

The results presented in the previous chapter clearly demonstrate that species of the lichen genus Bulbothrix are commonly found in high abundances, and that they show a variation in frequency between plots with different fire histories. This taxon is also one of the primary colonisers after fire, and can easily be identified in the field due to the presence of 'bulb-like' nodules on the thallus. These characteristics made it an ideal genus to study in depth, and therefore a population study, measuring the numbers and sizes of individuals, was carried out (see Section 4.5). It was hoped that any changes in Bulbothrix populations due to fire history could be incorporated into the LFH Key. Measurements took place in Plot 1 (74-control), Plot 2 (74-91: Hom, H, M) and Plot 6 (86-control). These plots were chosen because they showed the greatest differences in lichen composition, as outlined in the previous chapter. The results of this study are presented in the first part of the chapter.

In the second section of the chapter, various lichen characteristics, such as form and reproductive methods, are compared between Plots 1 to 6 . This data was extrapolated from the lichen composition study. Finally, the results of the fire behaviour study are presented (see Section 4.6.2). This was undertaken in order to reveal how fire temperature and duration, at different heights on the phorophyte trunk, affect lichen survival, and subsequent recolonisation.

Where a mean value is presented, the standard error (S.E.) is used to show a $95 \%$ confidence interval, and is denoted by 'mean \pm S.E.'.

\subsection{The effect of fire history on Bulbothrix lichen populations}

Figure 7.1 shows that the mean percentage frequency of Bulbothrix individuals in Plot 1 (74-control) is significantly higher than in Plot 2 (74-91: Hom, H, M) and Plot 6 (86-control) (mean \pm S.E.). These latter two plots have almost identical mean frequencies of individuals. They also have a higher relative variability of the mean values, particularly Plot 2.

Figure 7.2 shows the percentage frequency of Bulbothrix individuals in different thallus size classes. Here, Plot 1 (74-control) and Plot 6 (86-control) have a similar pattern of individuals present in all the classes, having the highest frequencies in the smaller ' $\leq 49 \mathrm{~mm}^{2 \prime}$ and '50 $149 \mathrm{~mm}^{21}$ thallus size classes. Plot 1, however, has slightly more Bulbothrix individuals within the largest class of ' $\geq 350 \mathrm{~mm}^{2}$. In comparison to Plots 1 and 6, Plot 2 (74-91: Hom, H, M) has higher values in the smaller two thallus size classes, but scarcely any Bulbothrix individuals in the larger size classes. 


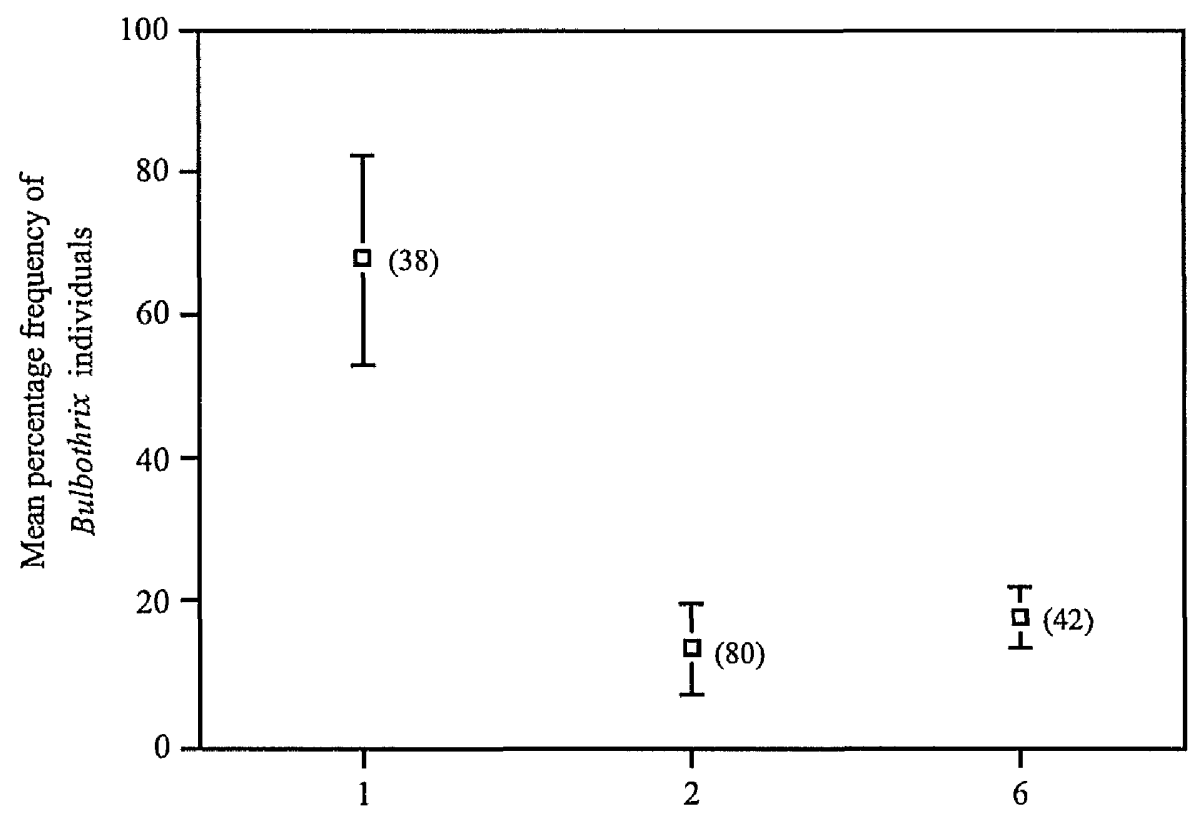

Plot number

Figure 7.1 The mean percentage frequency of Bulbothrix individuals in Plots 1, 2 and 6. The Coefficient of Variation (CV) for each plot is shown in brackets, and the vertical bars represent the standard error of the mean.

The percentage frequency of Bulbothrix individuals within different phorophyte height classes is shown in Figure 7.3. In Plot 1 (74-control) the highest frequencies of individuals are between the base and $0.5 \mathrm{~m}$, and from $>0.5 \mathrm{~m}$ to $1 \mathrm{~m}$. In comparison to Plot 1, Plot 2 (74-91: Hom, $\mathrm{H}, \mathrm{M}$ ) and Plot 6 (86-control) have the highest proportion of Bulbothrix individuals from $>1.5$ to 2 m. However, Plot 6 shows higher values in the lower height classes than Plot 2 (except in class ' $>0.5$ $\left.-1 m^{\prime}\right)$.

The percentage frequencies of different Bulbothrix thallus sizes in Plot 1 (74-control), Plot 2 (74-91: Hom, H, M) and Plot 6 (86-control), within various height classes on the phorophytes, are displayed in Figures 7.4a-d. From the base to $0.5 \mathrm{~m}$ (see Figure 7.4a), the majority of Bulbothrix individuals in all the plots, particularly in Plot 2 and Plot 6 , have small sized thalli $\left(\leq 49 \mathrm{~mm}^{2}\right)$. However, aithough Plot 2 and Plot 6 have some medium sized Bulbothrix individuals (50-249 mm $\mathrm{m}^{2}$ ), only Plot 1 has individuals with thalli $\geq 250 \mathrm{~mm}^{2}$. Between $>0.5$ and $1 \mathrm{~m}$ on the phorophyte (see Figure 7.4b), the majority of Bulbothrix individuals in all the plots, particularly in Plot 2, have small sized thalli ( $\leq 49 \mathrm{~mm}^{2}$ ). Here, Plot 2 has Bulbothrix individuals with thalli only up to $149 \mathrm{~mm}^{2}$, but both Plot 1 and Plot 6 have medium to large sized thalli $\left(\geq 250 \mathrm{~mm}^{2}\right)$. 


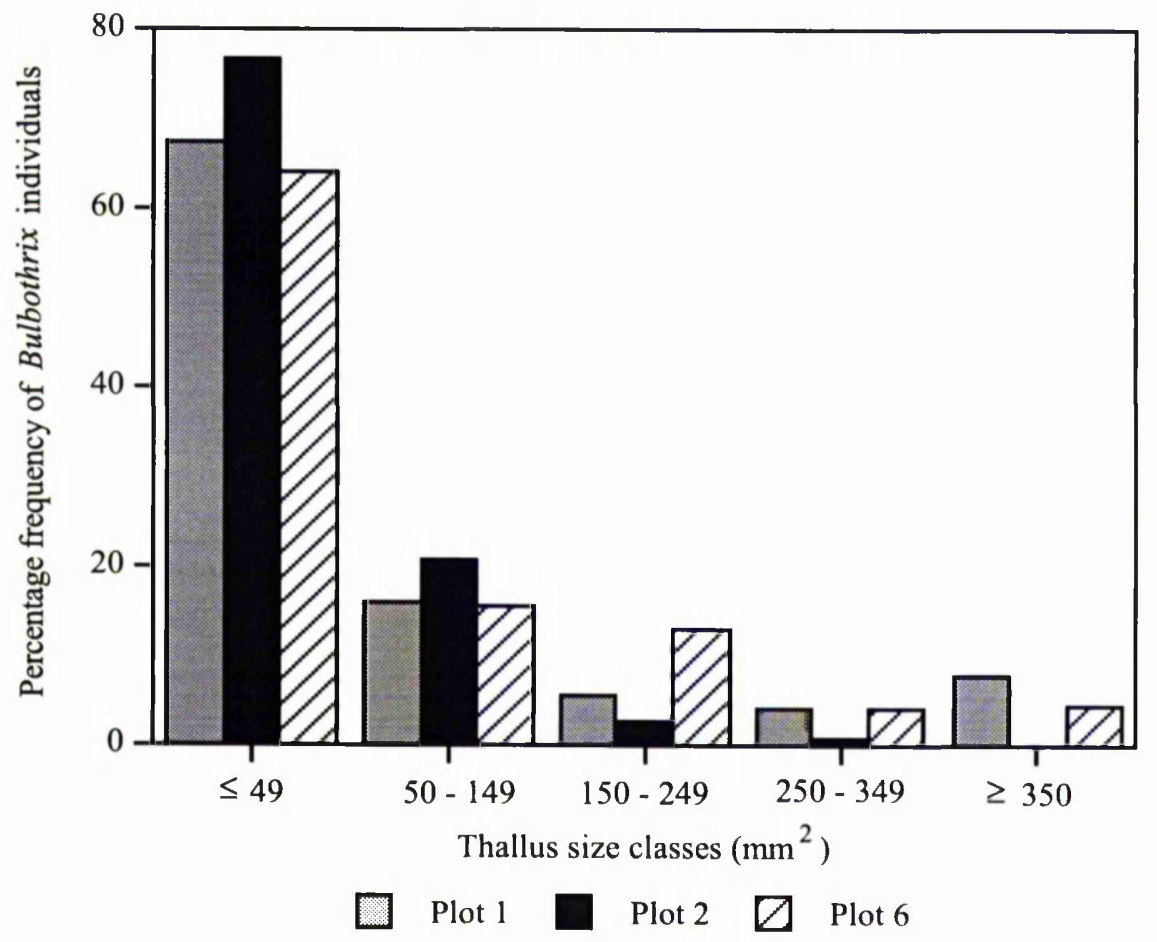

Figure 7.2 The percentage frequency of Bulbothrix individuals in different thallus size classes $\left(\mathbf{m m}^{2}\right)$.

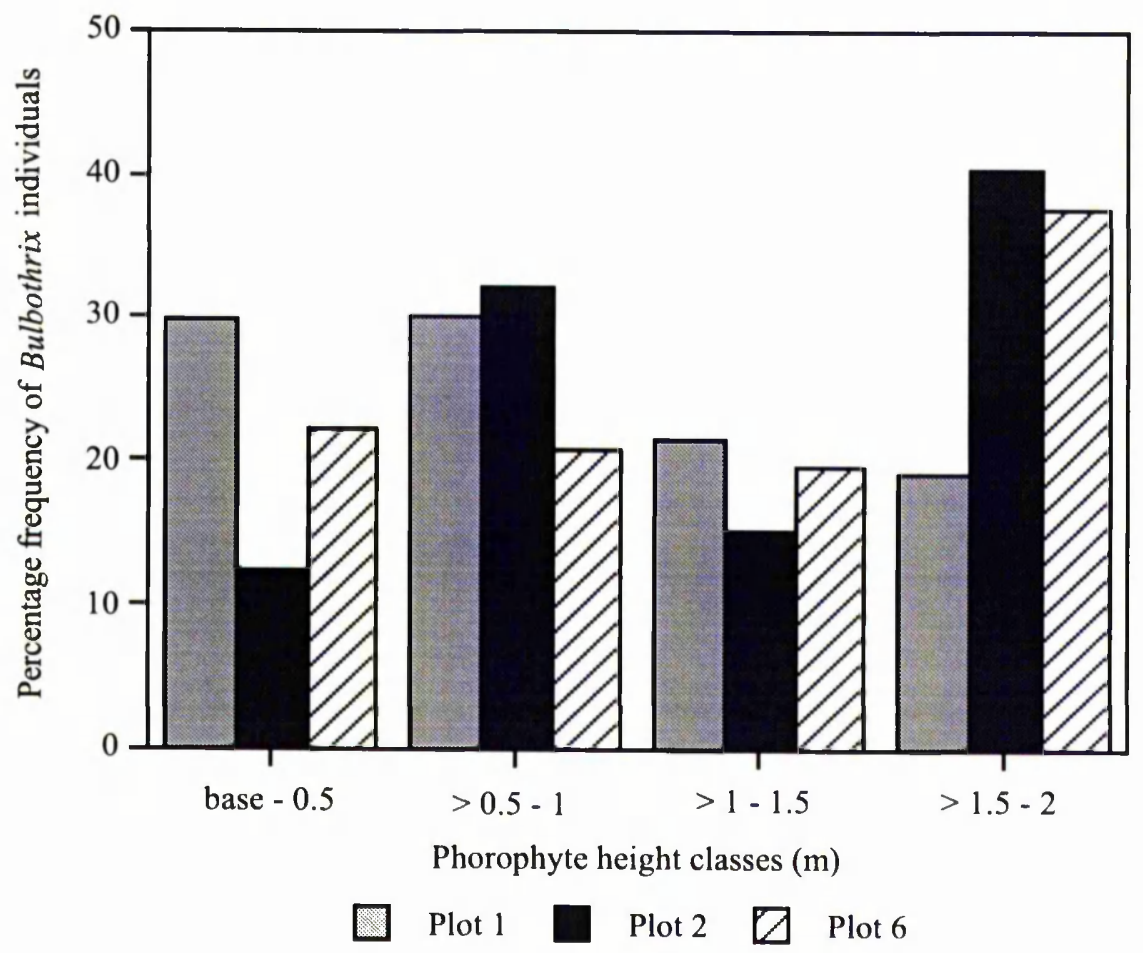

Figure 7.3 The percentage frequency of Bulbothrix individuals within different height classes (m) on the phorophytes. 


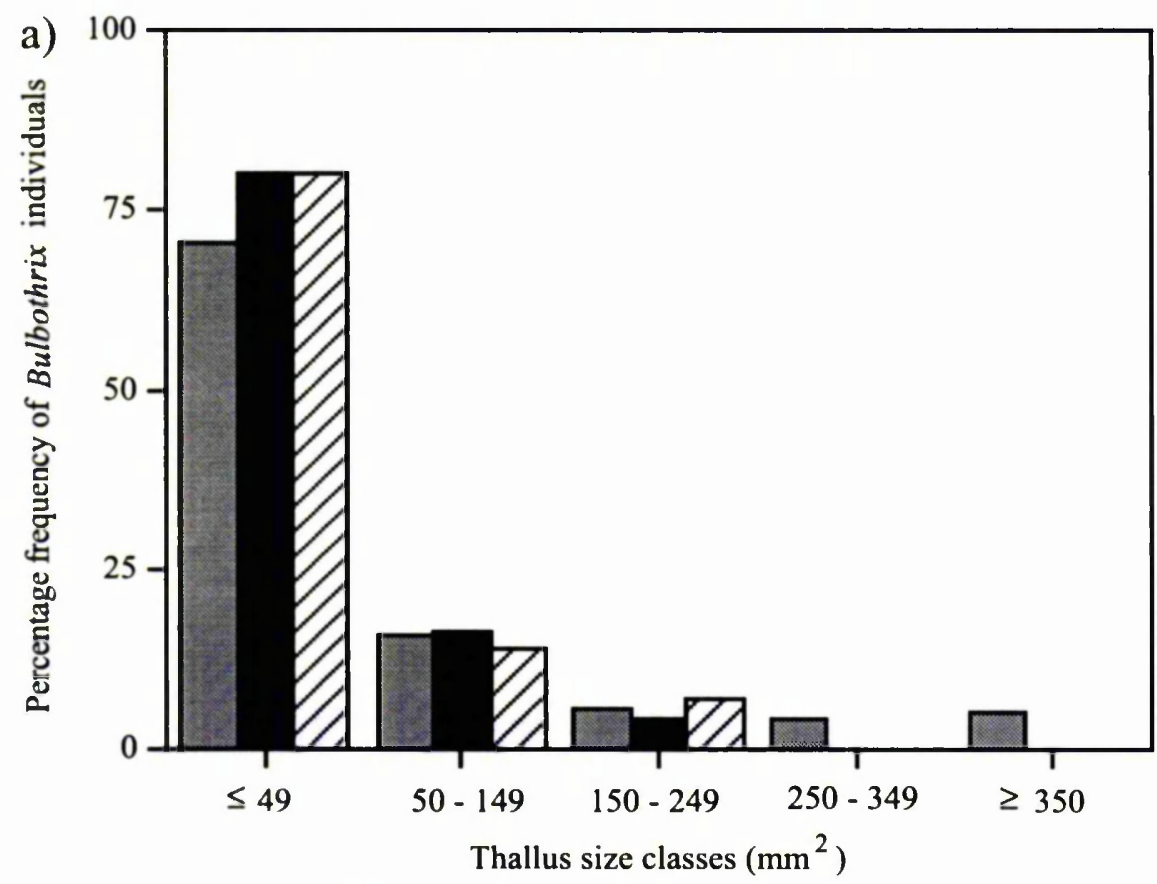

Plot $1 \square$ Plot $2 \square$ Plot 6

Figure 7.4a The percentage frequency of different Bulbothrix thallus sizes in Plots 1, 2 and 6 between the base and $0.5 \mathrm{~m}$ on the phorophyte.

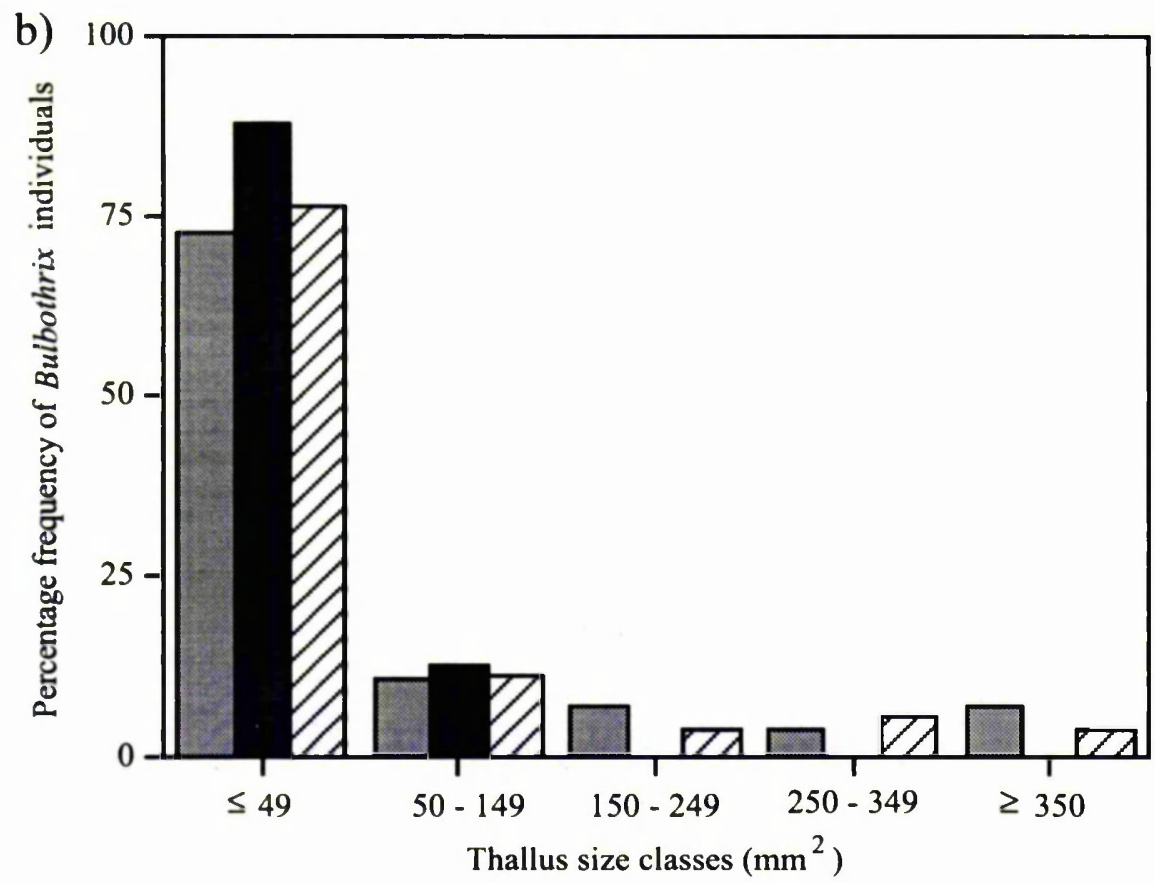

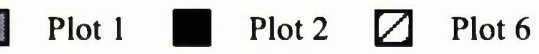

Figure 7.4b The percentage frequency of different Bulbothrix thallus sizes in Plots 1, 2 and 6 between $>0.5 \mathrm{~m}$ and $1 \mathrm{~m}$ on the phorophyte. 


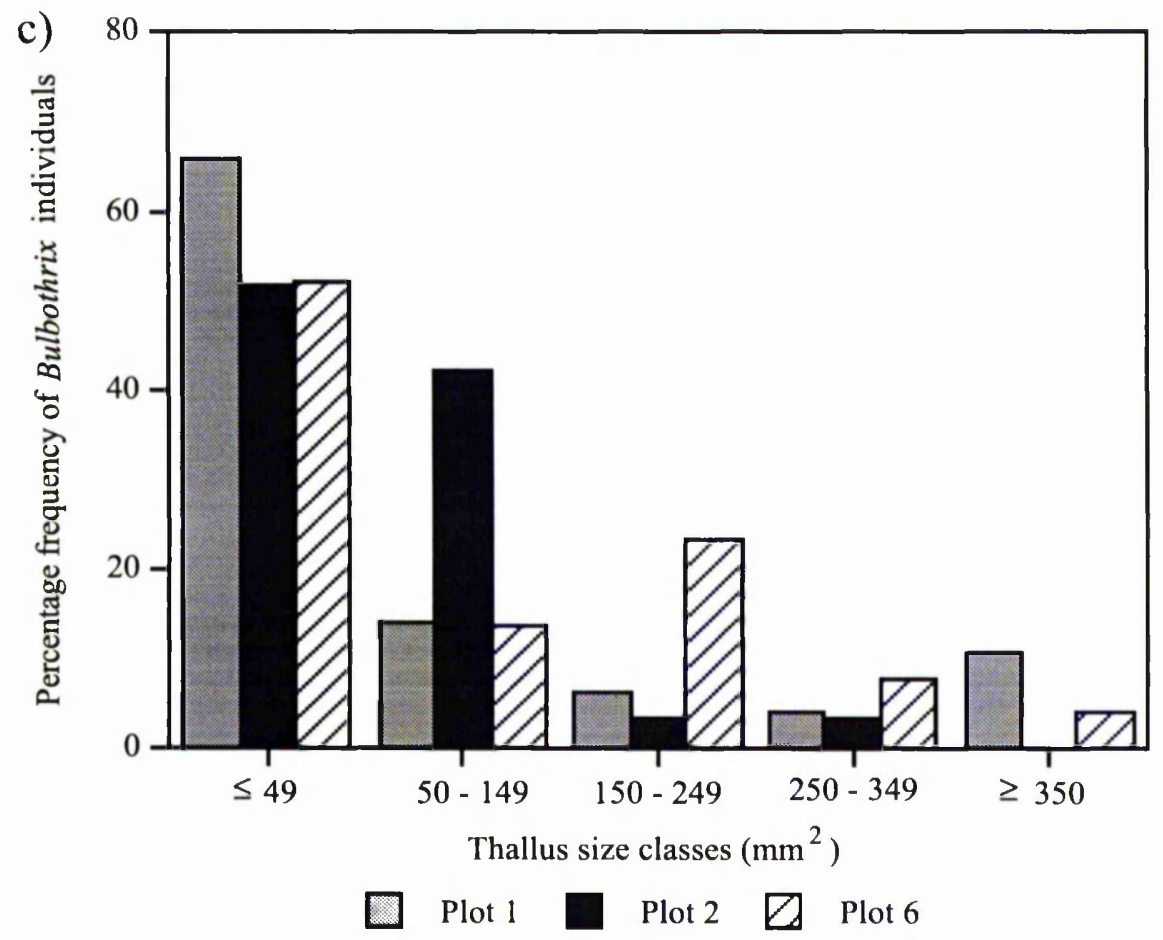

Figure 7.4c The percentage frequency of different Bulbothrix thallus sizes in Plots 1, 2 and 6 between $>1$ and $1.5 \mathrm{~m}$ on the phorophyte.

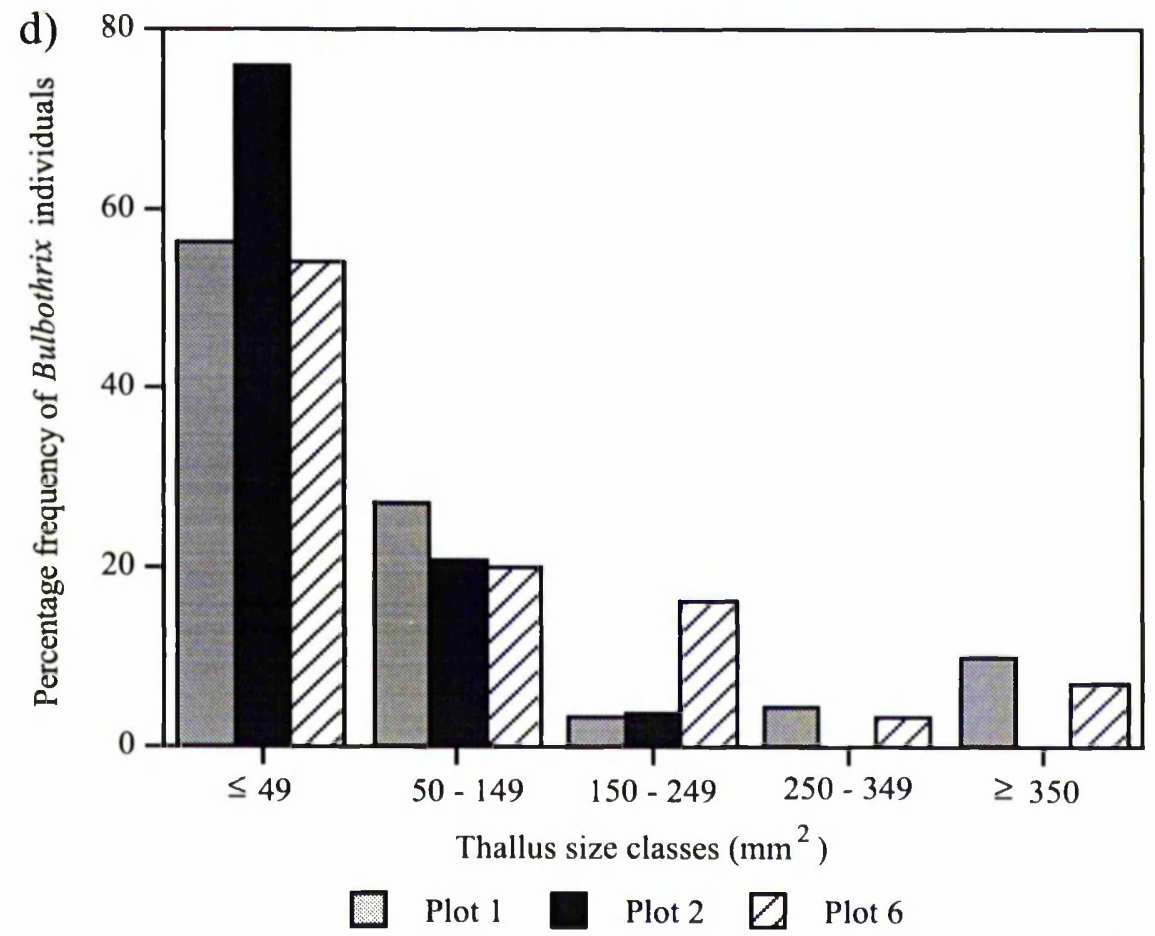

Figure 7.4d The percentage frequency of different Bulbothrix thallus sizes in Plots 1, 2 and 6 between $>1.5$ and $2 \mathrm{~m}$ on the phorophyte. 
From $>1$ to $1.5 \mathrm{~m}$ on the phorophyte (see Figure $7.4 \mathrm{c}$ ), a high proportion of Bulbothrix individuals in all the plots, particularly in Plot 1 (74-control), have small sized thalli ( $\leq 49$ $\mathrm{mm}^{2}$ ). Plot 1 and Plot 6 (86-control) have Bulbothrix individuals present in all the higher thallus size classes, and in Plot 6, these are at higher frequencies than was found on the lower sections of the phorophyte. Although Plot 2 (74-91: Hom, H, M) has a high proportion of Bulbothrix individuals with medium sized thalli $\left(50-149 \mathrm{~mm}^{2}\right)$, at this height range on the phorophyte, there are some individuals with thalli up to $349 \mathrm{~mm}^{2}$.

From $>1.5$ and $2 \mathrm{~m}$ on the phorophyte (see Figure 7.4d), the majority of Bulbothrix individuals in all the plots, particularly Plot 2 (74-91: Hom, H, M), have small sized thalli ( $\leq 49$ $\mathrm{mm}^{2}$ ). Medium to large sized Bulbothrix individuals $\left(\geq 50 \mathrm{~mm}^{2}\right)$ are present in both Plot 1 (74control) and Plot 6 (86-control). At this height range on the phorophyte, Plot 6 has a higher representation of these larger thalli than at lower sections of the phorophyte. Plot 2 only has individuals with thalli up to $249 \mathrm{~mm}^{2}$.

\subsection{Lichen compositional, morphological and reproductive responses to various fire histories}

\subsubsection{Species richness}

In total, 103 lichen species were recorded from the six plots. Figure 7.5 shows the numbers of species in Plots 1 to 6. Plot 1 (74-control) has the highest number of species (84), followed by Plot 4 (74-92: Het, V, M) with 76 and Plot 6 (86-control) with 61. Plot 3 (74-92: Het, V, E) and Plot 5 (74-92: Het, V, L) have comparable totals of 59 and 53 respectively, and Plot 2 (74-91: Hom, $H, M$ ) has the lowest value of only 33 . If the total number of lichen individuals are compared between the plots (Figure 7.6), they show a similar pattern. Plot 1 has the greatest total value of 858 individuals, followed by Plot 4 with a much lower value of 591, and Plots 5 and 6 with 591 and 525 respectively. Plot 3 has 467 individuals in total, and Plot 2 has the lowest value of 151.

\subsubsection{Lichen families}

Figure 7.7a shows the percentage representation of species in relation to lichen family in Plots 1 to 6. Plot 1 (74-control) and Plot 4 (74-92: Het, V, M) have the greatest frequency of families (18 and 17 respectively), Plot 5 (74-92: Het, V, L) and Plot 6 (86-control) have 14, Plot 3 (74-92: Het, V, E) has 13, and Plot 2 (74-91: Hom, H, M) only 9. In all the plots, Parmeliaceae is the most diverse family. Although it contains over $45 \%$ of the species in Plots 1 and 4, other families including Physciaceae, Unknown (which includes all the sterile crust species), Pertusariaceae, Coccocarpiaceae and Lecanoraceae, are all well represented. In Plot 2, Parmeliaceae comprises over $50 \%$ of the total species. Other important families include Unknown, Lecanoraceae and Pertusariaceae, which have greater 


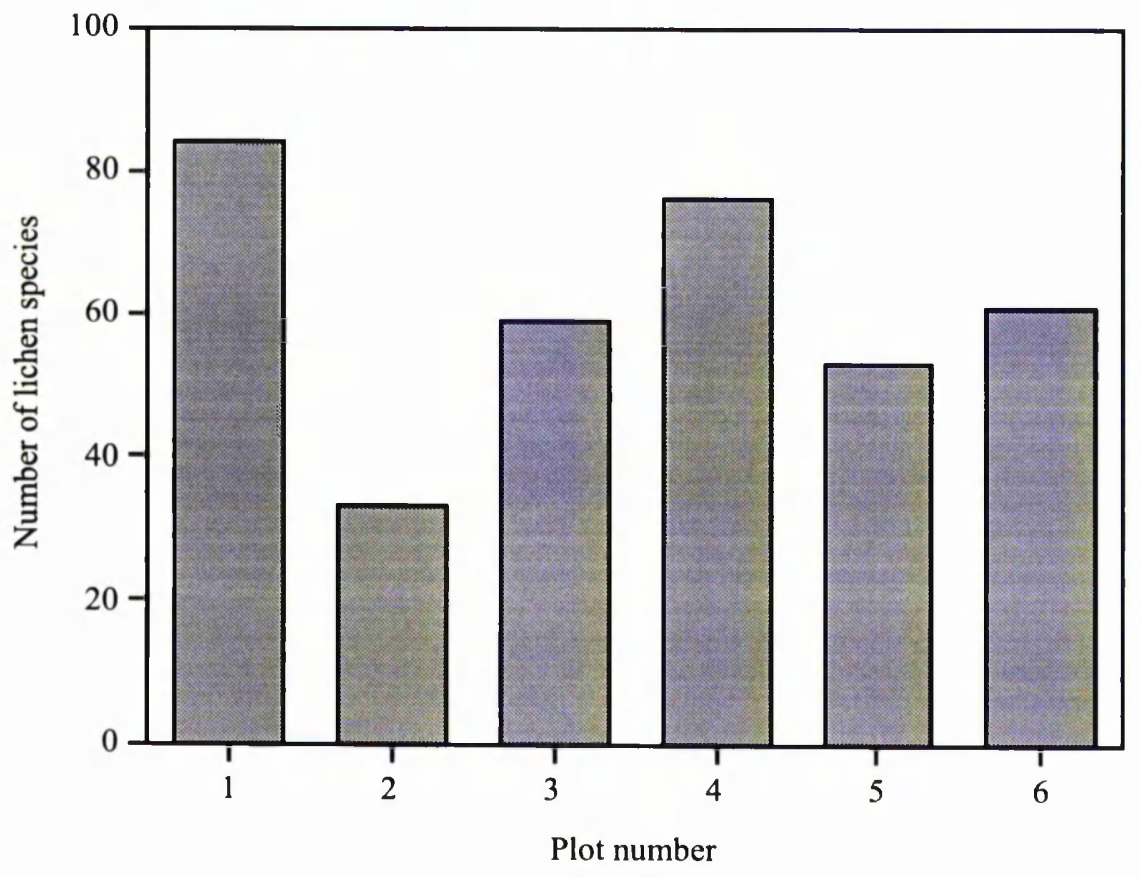

Figure 7.5 The total number of lichen species in each plot.

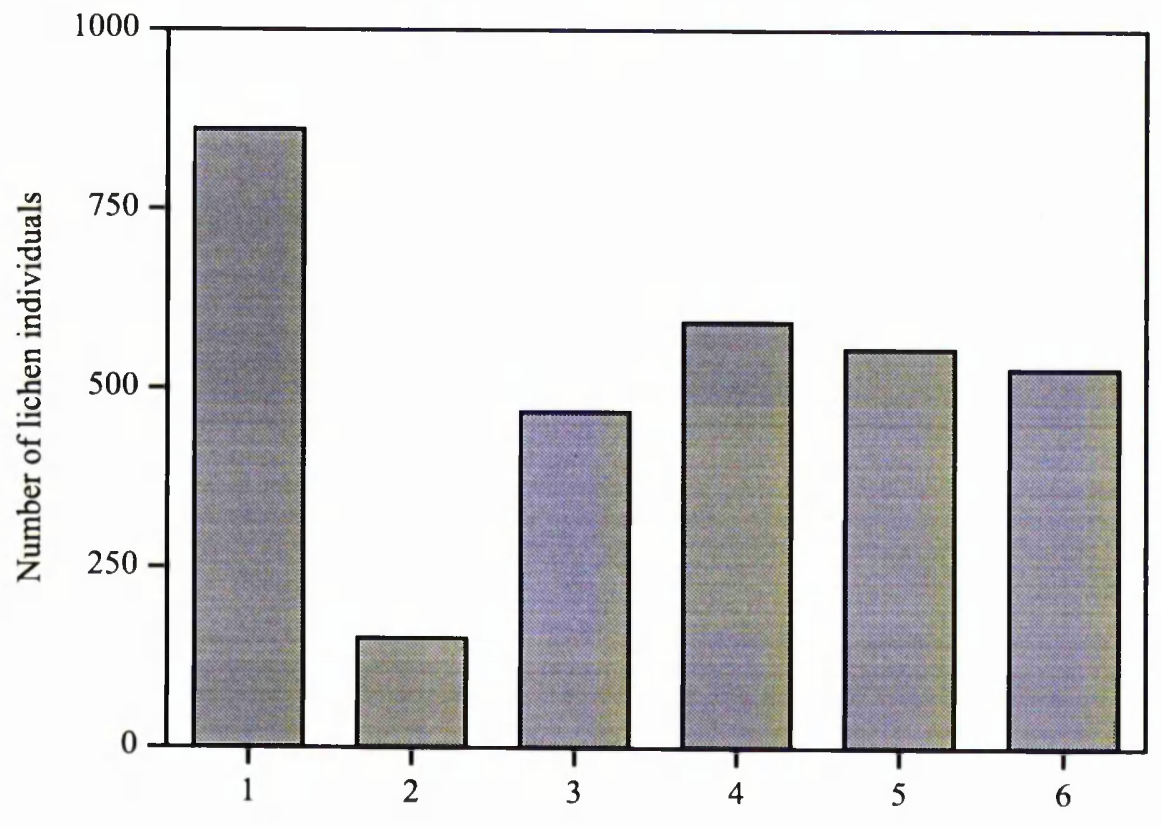

Plot number

Figure 7.6 The total number of lichen individuals in each plot. 


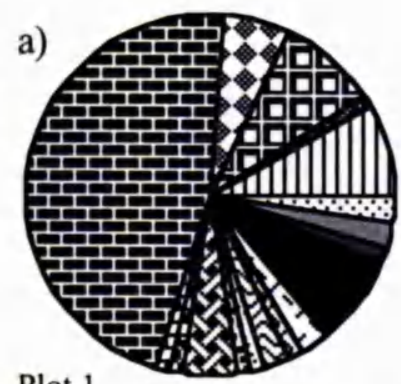

Plot 1

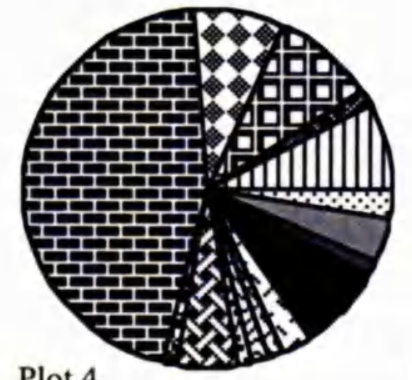

Plot 4

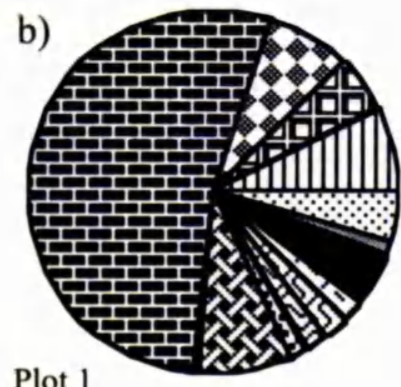

Plot 1

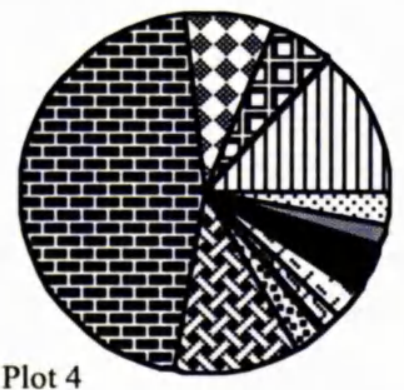

Plot 4

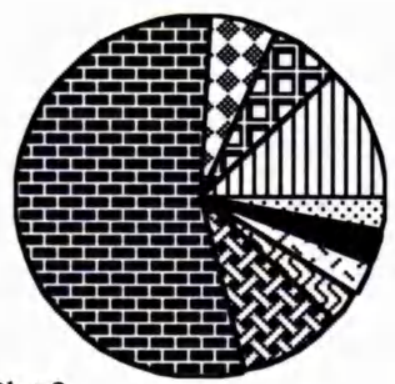

Plot 2

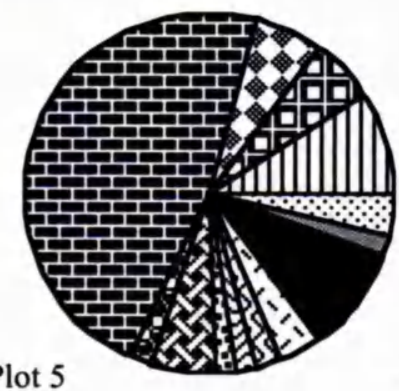

Plot 3
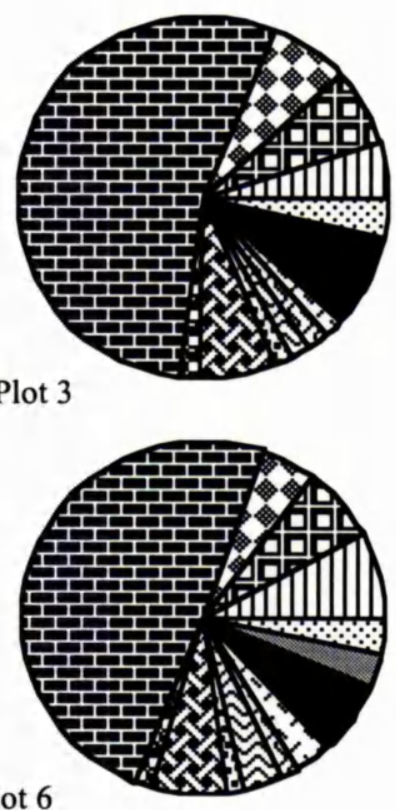

Plot 6
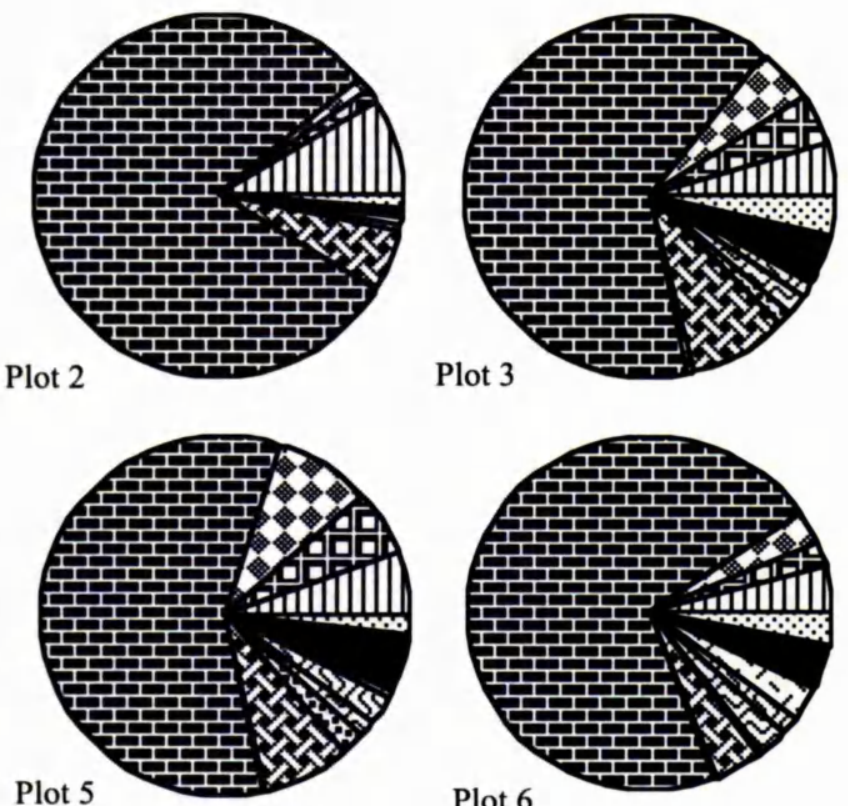

Plot 6

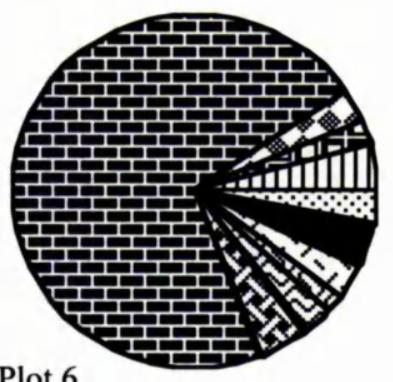
Arthoniaceae
$\square$ Arthopyreniaceae
Bacidiaceae
Candelariaceae
Cladoniaceae
Coccocarpiaceae
E] Chrysotrichaceae
DS Gomphillaceae
Graphidaceae
$\because$ Gyalectaceae
H. Haematommataceae $\mathrm{D}$ Lecanoraceae
8 Letrouitiaceae
동 Opegraphaceae
I Parmeliaceae
Pertusariaceae
$\$$ Pyrenulaceae
I] Physciaceae
Q Trypetheliaceae
II Unknown

Figure 7.7: a) The percentage representation of species by lichen family in each plot; and b) the percentage representation of individuals by lichen family in each plot. 
numbers of species than in Plot 1. Just under 50\% of the species in Plots 5 and 6 are of the Parmeliaceae. In both these plots, as in Plot 1, the families Unknown and Lecanoraceae have high frequencies of species. However, compared to Plot 1, Plot 5 has greater frequencies of Cladoniaceae and Chrysothrichaceae species, whereas in Plot 6, Arthopyreniaceae is more important. Plot 3 has just over $50 \%$ of species of the Parmeliaceae, and a greater proportion of Cladoniaceae species, than in Plot 1.

Figure $7.7 \mathrm{~b}$ shows the percentage representation of individuals in relation to lichen family in Plots 1 to 6 . Throughout all the plots, Parmeliaceae has the greatest proportion of lichen individuals. In Plot 1 (74-control), it has a 50\% occurrence, with Lecanoraceae, Unknown, Pertusariaceae and Physciaceae having lower, but significant values. In comparison to Plot 1, Plot 2 (74-91: Hom, H, M) has over $80 \%$ of individuals in the Parmeliaceae family. However, although the other families have lower frequencies, Lecanoraceae has a comparable value to Plot $1.64 \%$ of the individuals in Plot 3 (74-92: Het, V, E) are of the Parmeliaceac. Here, Lecanoraceae has a similar value to Plot 1, but all the other families have lower values. $45 \%$ of individuals in Plot 4 (74-92: Het, V, M) are of the Parmeliaceae, and there are much higher occurrences in the Lecanoraceae and Unknown families compared to Plot 1. In Plot 5 (74-92: Het, V, L), $45 \%$ of the individuals are of the Parmeliaceae. All the other families have lower values than in Plot 1, but among them, the Pertusariaceae and Lecanoraceae have higher values. $71 \%$ of the individuals in Plot 6 (86-control) are of the Parmeliaceae, and all the other families have lower values in comparison to Plot 1 . Out of these, Lecanoraceae and Unknown have the highest frequencies.

\subsubsection{Lichen form}

Figure 7.8 shows the percentage representation of species in relation to different lichen forms in Plots 1 to 6 . There is a consistent pattern in all the plots of higher foliose than crustose species, and very few squamulose species, which are absent in Plot 2 (74-91: Hom, H, M). Fruticose species are the rarest, with only two species found in total, and these are only present in Plot 1 (74control), Plot 3 (74-92: Het, V, E), Plot 4 (74-92: Het, V, M) and Plot 6 (86-control). The percentage representation of individuals in relation to different lichen forms in Plots 1 to 6 is shown in Figure 7.9. Here, Plot 1 and Plot 4 have the highest frequencies of crustose lichens, Plot 3, Plot 5 (74-92: Het, V, L) and Plot 6 have lower values, and Plot 2 has the lowest value. Foliose lichens are most frequent in Plot 2, less so in Plot 3, Plot 5 and Plot 6, and have the lowest values in Plot 1 and Plot 4. Squamulose lichens have frequencies comparable between plots, except Plot 2 where they are absent, and the fruticose lichens are mostly found in Plot 1 and Plot 6. 


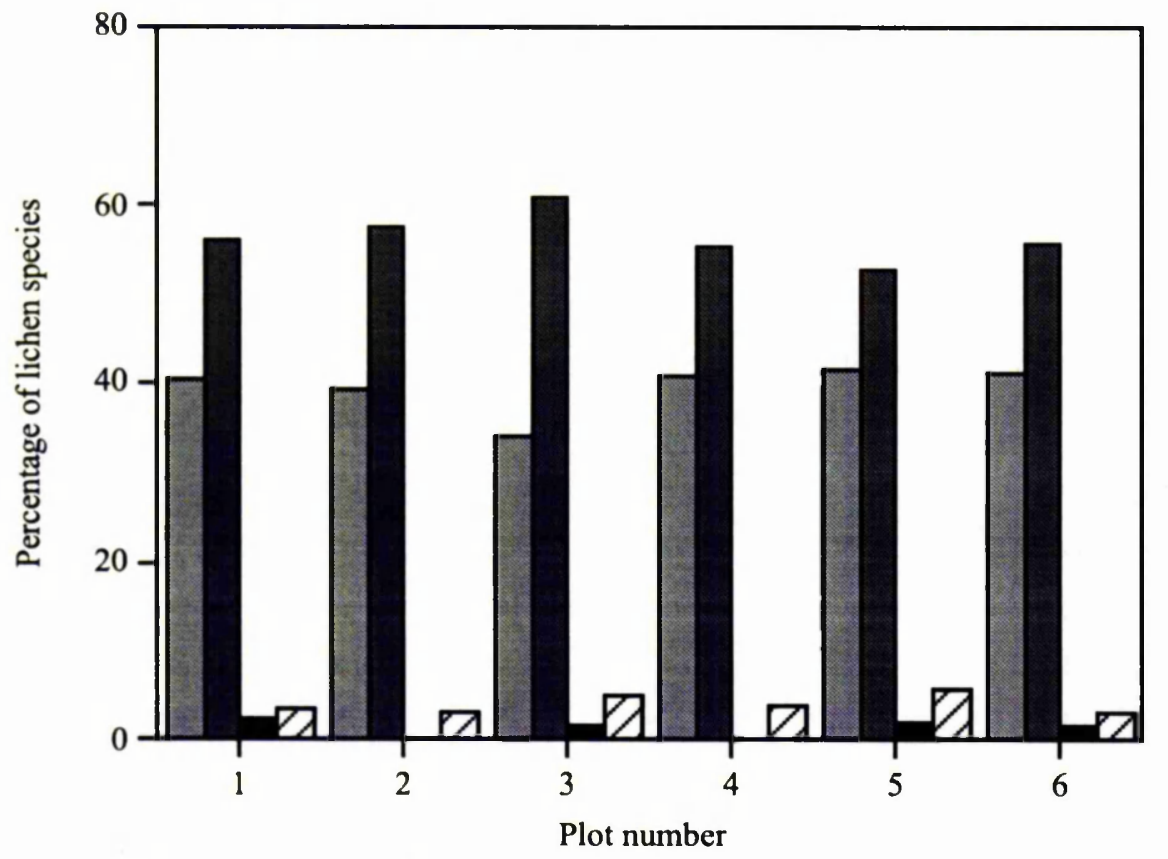

$\square$ Crustose $\square$ Foliose $\square$ Fruticose $\square$ Squamulose

Figure 7.8 The percentage representation of species in relation to lichen form in each plot.

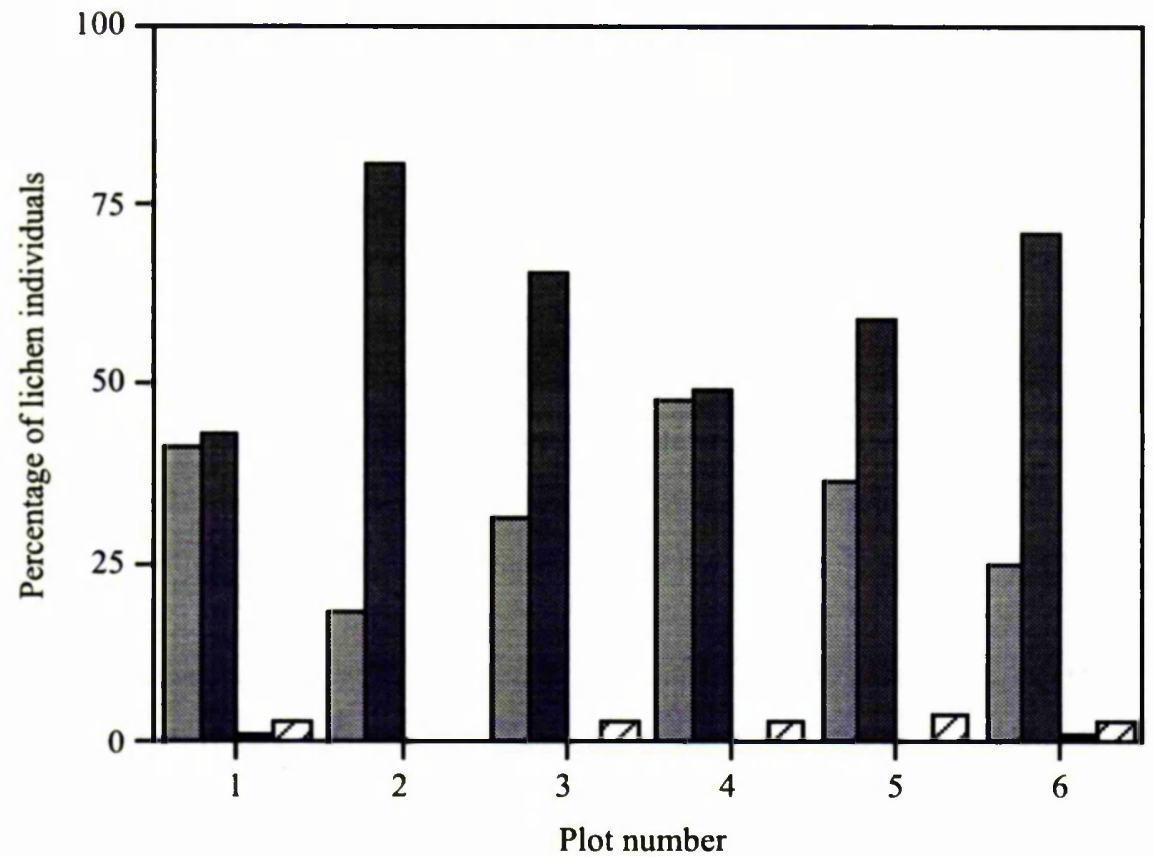

Plot number

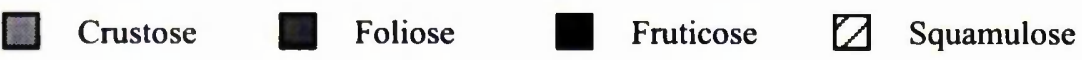

Figure 7.9 The percentage representation of individuals in relation to lichen form in each plot. 


\subsubsection{Lichen photobionts}

The percentage representation of species in relation to different algal photobionts in Plots 1 to 6 is shown in Figure 7.10. Cyanobacterial lichen species are rare but present in all the plots except Plot 2 (74-91: Hom, H, M). Most of the lichen species found have Trebouxia algae, and have equal values in all the plots. Species with Trentepohlia algae are less frequent, and are slightly less represented in Plot 2, Plot 3 (74-92: Het, V, E) and Plot 5 (74-92: Het, V, L) compared to the other plots.

The percentage representation of individuals in relation to different algal photobionts in Plots 1 to 6 is shown in Figure 7.11. Lichen individuals with Trebouxia algae occur most often and have a higher value in Plot 2 (74-91: Hom, H, M) compared to the other plots. Plot 3 (74-92: Het, V, E), Plot 5 (74-92: Het, V, L) and Plot 6 (86-control) have comparable values, and Plot 1 (86-control) and Plot 4 (74-92: Het, V, M) have the lowest frequencies. Very low frequencies of lichen individuals with cyanobacteria are recorded in all the plots, with Plot 1 having the highest value. Lichen individuals with Trentepohlia occur most often in Plot 1 and Plot 4, have similar values in Plot 3, Plot 5 and Plot 6, and the lowest value in Plot 2.

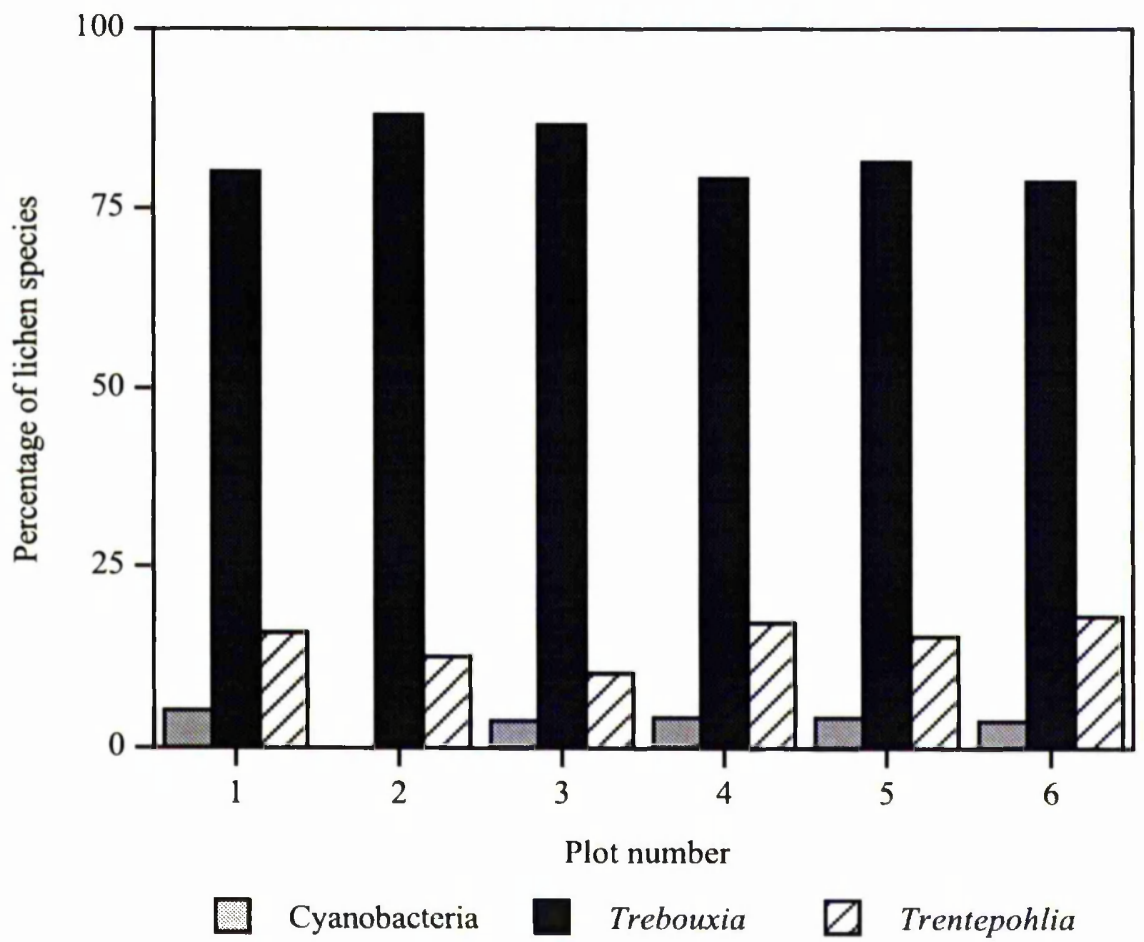

Figure 7.10 The percentage representation of lichen species in relation to algal photobiont in each plot. 


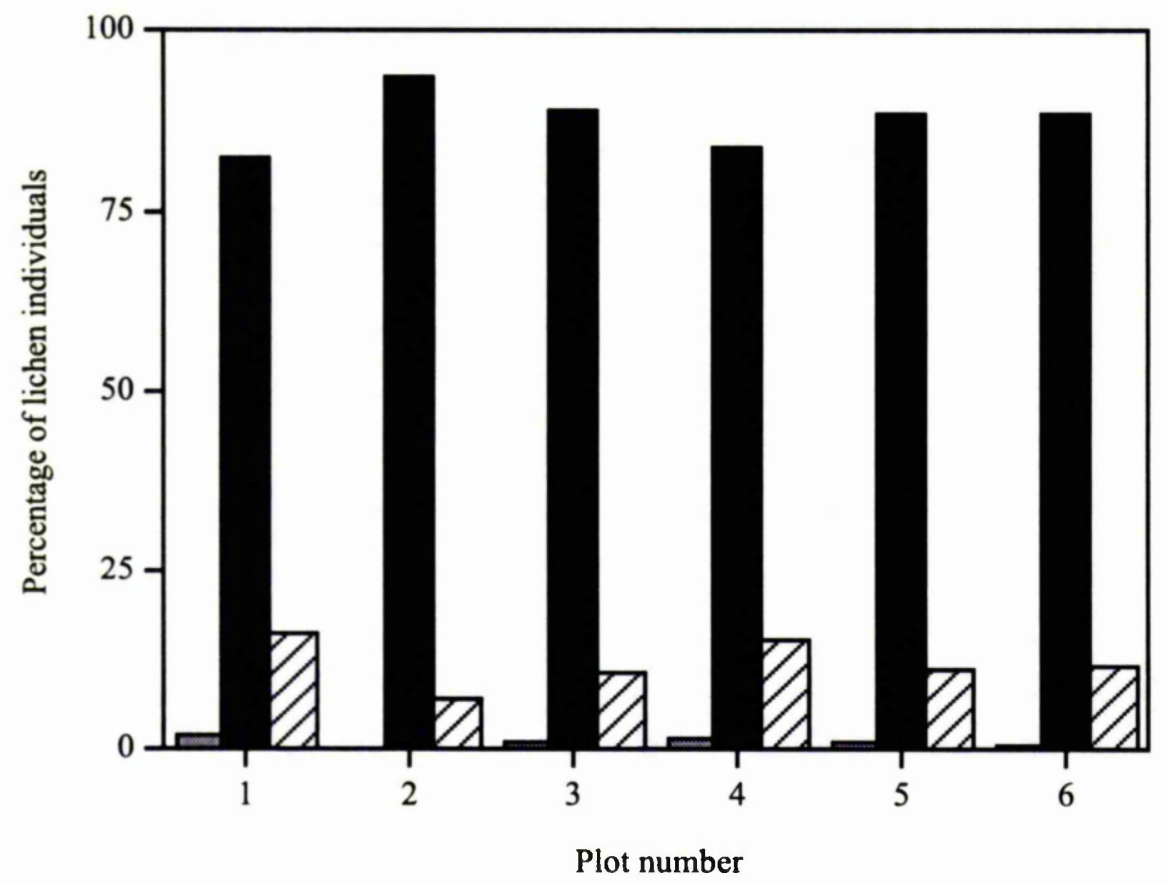

Cyanobacteria

Trebouxia

¿ Trentepohlia

Figure 7.11 The percentage representation of lichen individuals in relation to algal photobiont in each plot.

\subsubsection{Lichen reproductive methods}

Figure 7.12 shows that in all the plots, there are higher frequencies of species reproducing sexually through fruiting bodies, than asexually using vegetative structures. However, although the proportion of lichen individuals using sexual reproduction are more or less equal between plots, the frequency of individuals employing asexual reproduction is much higher in Plot 2 (74-91: Hom, H, M) and Plot 6 (86-control) than in the other plots (Figure 7.13). Both plots also show greater frequencies of individuals employing asexual compared to sexual reproduction. Plot 1 (74-control) and Plot 4 (74-92: Het, V, M) show the lowest values with asexual reproduction.

\section{a) Lichen vegetative structures}

In most of the plots, there are equal or slightly greater frequencies of species with soredia than isidia (Figure 7.14). Plot 2 (74-91: Hom, H, M) and Plot 5 (74-92: Het, V, L) are the exception, having slightly more species with isidia than soredia. However, although the frequencies of individuals with isidia are greater than those with soredia in all the plots (Figure 7.15). Plot 2, followed by Plot 3 (74-92: Het, V, E) and Plot 6 (86-control), have far greater frequencies of lichens 


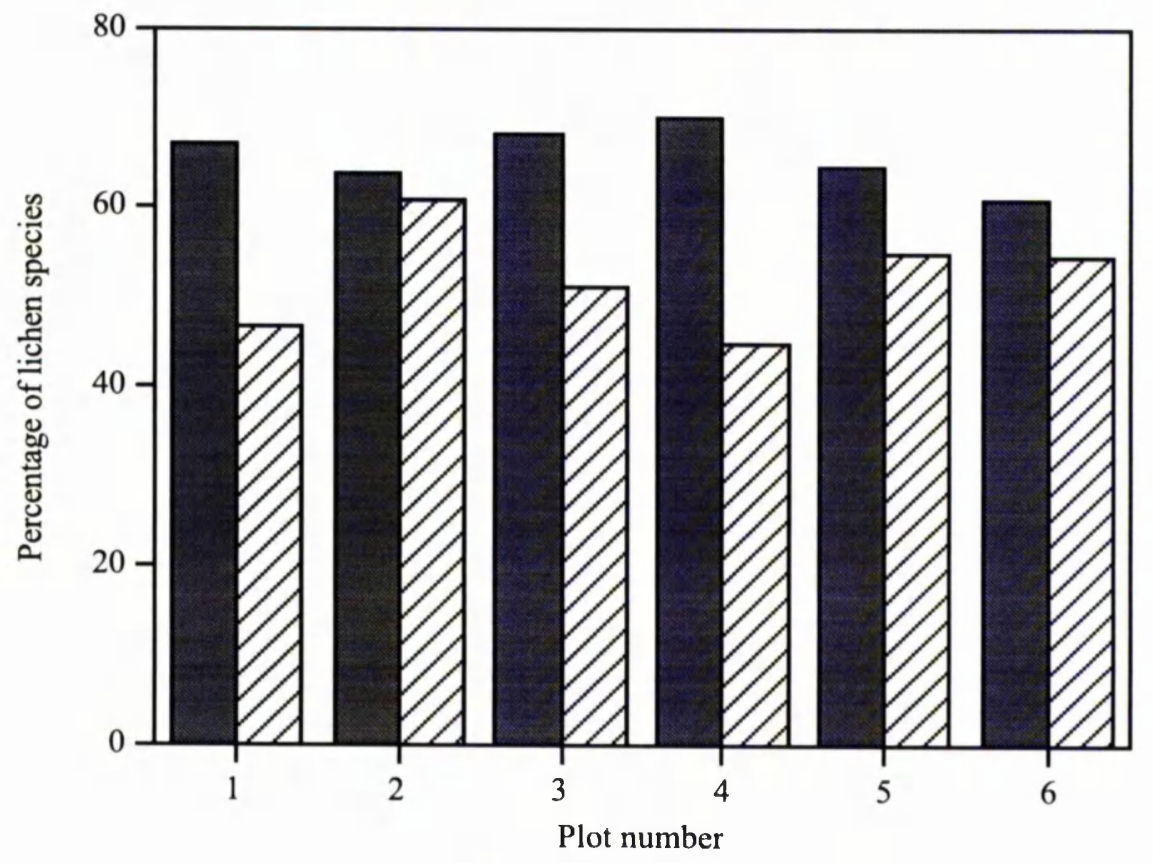

Sexual reproduction $\square$ Asexual reproduction

Figure 7.12 The percentage representation of lichen species in relation to reproductive method in each plot.

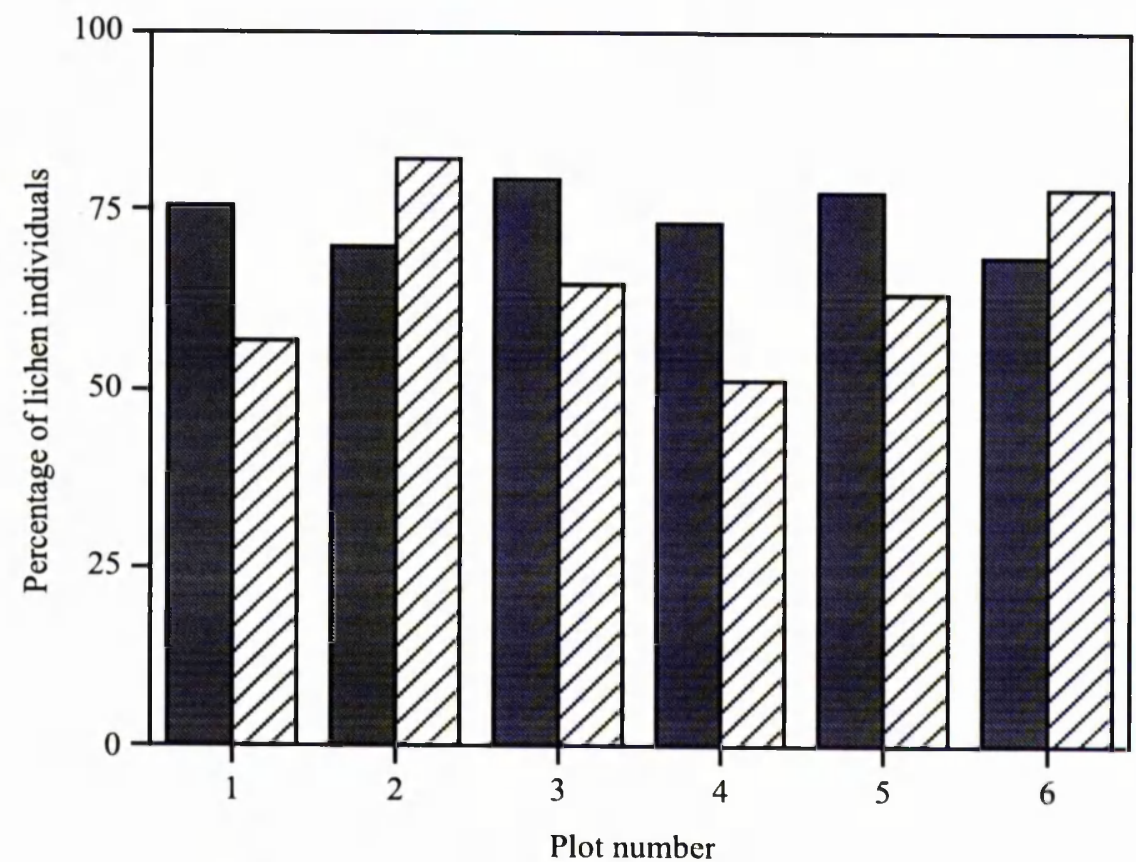

Sexual reproduction $\square$ Asexual reproduction

Figure 7.13 The percentage representation of lichen individuals in relation to reproductive method in each plot. 


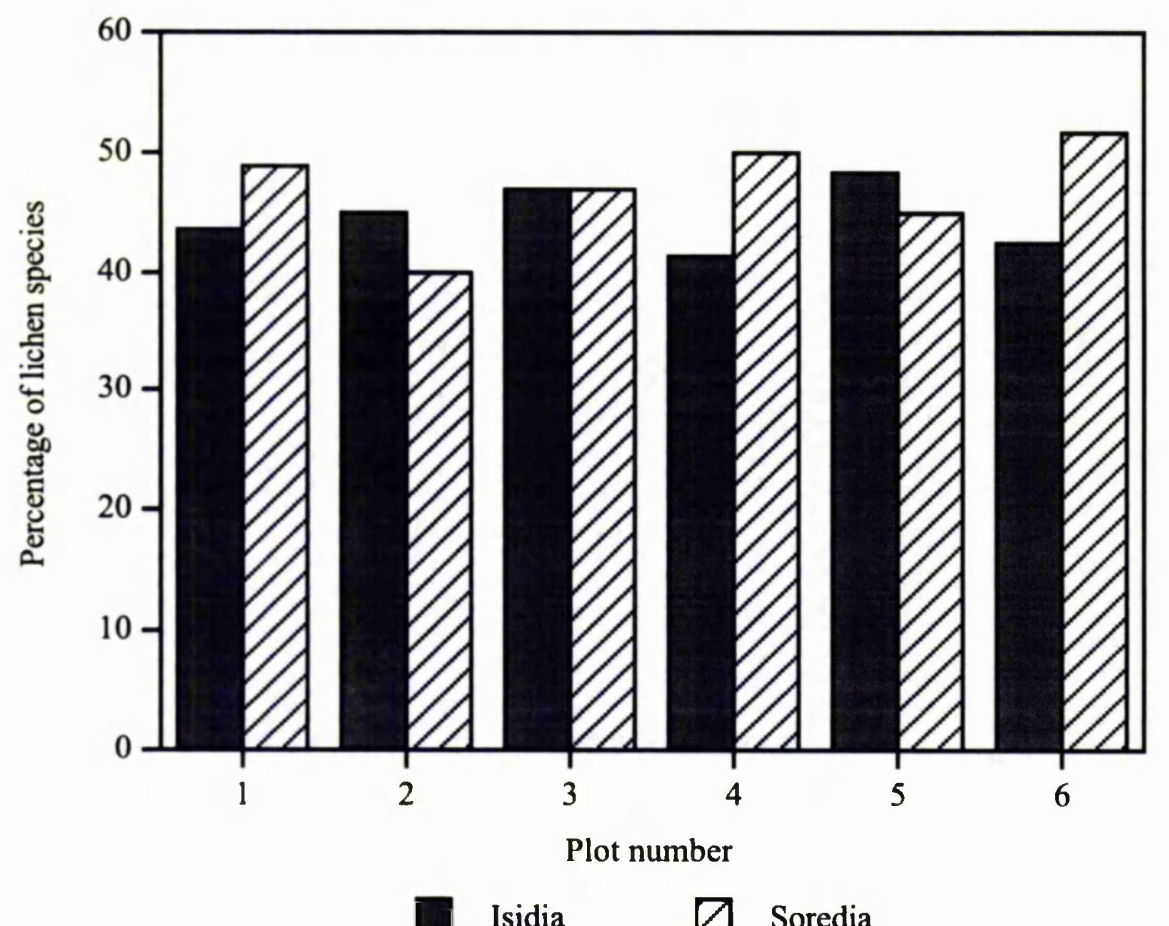

Figure 7.14 The percentage representation of lichen species in relation to vegetative structure in each plot.

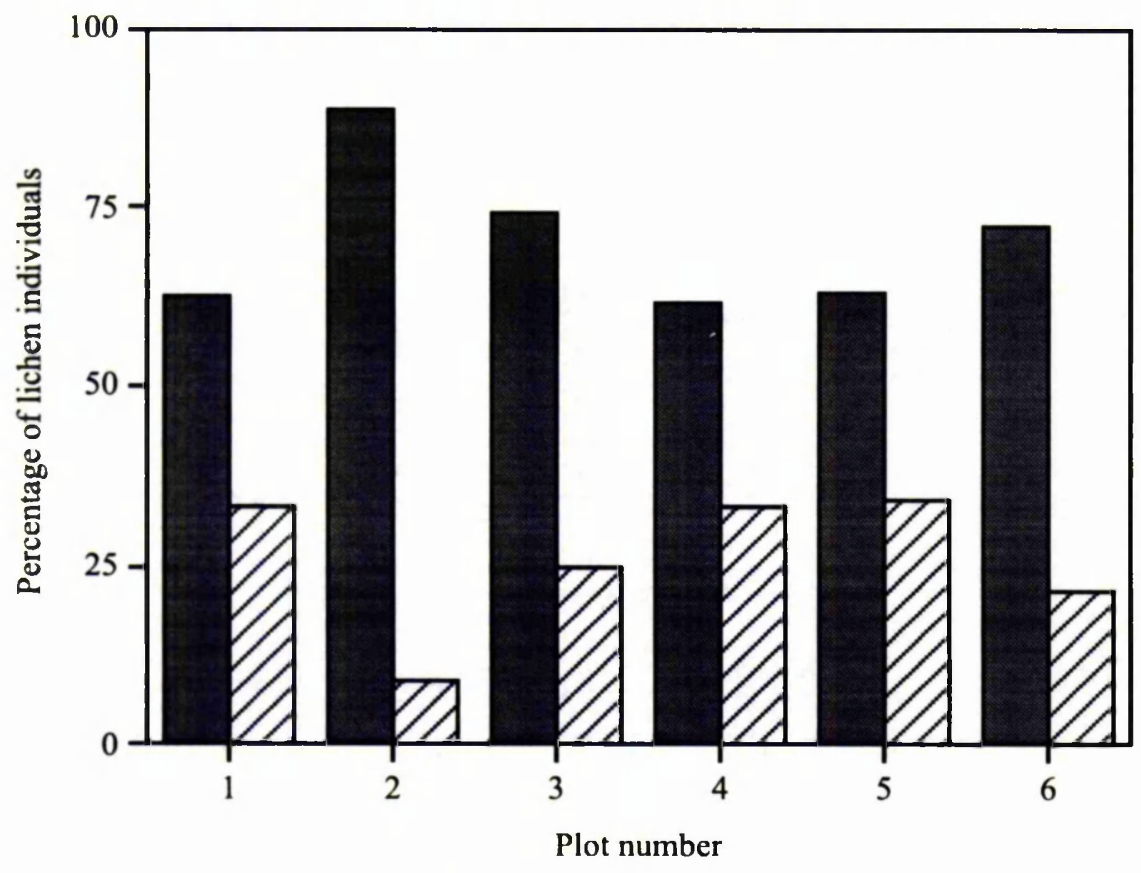

Isidia $\square$ Soredia

Figure 7.15 The percentage representation of lichen individuals in relation to vegetative structure in each plot. 
with isidia than the other plots. Plot 1 (74-control), Plot 4 (74-92: Het, V, M) and Plot 5 have high and equivalent values with soredia.

\subsection{Fire patterns on phorophyte trunks}

Information about fire behaviour was collected from four individual phorophytes of the species Caryocar brasiliense, Guapira noxia, Sclerolobium paniculatum and Vellozia squamata. $S$. paniculatum and G. noxia were located at one end of the plot, and $C$. brasiliense and $V$. squamata at the other. Thermocouples were placed at $0.5 \mathrm{~m}, 1 \mathrm{~m}$ and $2 \mathrm{~m}$ heights on the phorophyte individuals, and 10 minute interval readings began one day before the burn. Ten minutes before the fire, the datalogger was set to record every second once a temperature of $50^{\circ} \mathrm{C}$ was reached, and twenty minutes after the fire had passed, the datalogger was set back to record every 10 minutes and continued for the following four full days.

Figures 7.16a-c, presented in Appendix 3, show the temperatures attained at the different heights on each phorophyte before, during and after the fire. The $2 \mathrm{~m}$ thermocouple on $C$. brasiliense failed a few hours before the burn (see Figure 7.16a(i)), but was repaired before the burn. The graphs show that there is a diurnal variation of temperatures on phorophyte trunks, with the lowest temperatures of between 5 to $10^{\circ} \mathrm{C}$ during the early morning and peak temperatures of between 30 to $50^{\circ} \mathrm{C}$ around midday (see Figures 7.16a(i)-(iv)). These temperatures quickly rise with the onset of the fire (see Figures $7.16 \mathrm{~b}(\mathrm{i})$-(iv)), and the highest temperatures recorded were $542^{\circ} \mathrm{C}$ (on $V$. squamata), and $555^{\circ} \mathrm{C}$ (on G. noxia). As the fire passes, the temperatures fall to the normal air temperature, and continue to show a typical diurnal pattern of temperatures four days after the fire (see Figures $7.16 \mathrm{c}$ (i)(iv)).

The temperatures recorded at the different heights on the phorophytes are roughly the same during the normal diurnal variation in temperatures. However, during the fire, the difference between the various heights become pronounced. In some cases, the highest temperatures are at $0.5 \mathrm{~m}$ on the phorophyte (C. brasiliense and $V$. squamata), whereas in others, the highest temperatures are recorded at $1 \mathrm{~m}$ ( $S$. paniculatum) and $2 \mathrm{~m}$ (G. noxia). Although these extreme temperatures only last for a few seconds, high temperatures of between 50 to $100^{\circ} \mathrm{C}$ at all the heights on the phorophytes last for a couple of minutes. Also worth mentioning is the fact that although $S$. paniculatum was approximately $2 \mathrm{~m}$ away from G. noxia (and the same for the other pair of phorophytes), both individuals registered completely different fire temperatures along the trunk.

\subsection{General conclusions}

These results showed the following:

1) Bulbothrix populations are greater in numbers within fire protected areas compared to plots which have been burned; 
2) Bulbothrix individuals have larger thallus sizes within fire protected areas compared to plots which have been burned;

3) in a fire protected area, Bulbothrix individuals are mostly present between the base and $1 \mathrm{~m}$ on the phorophyte, and these individuals have a wide range in thallus sizes. In an area frequently burned in the past, but recently protected, the majority of Bulbothrix individuals are present between 1.5 to $2 \mathrm{~m}$ on the phorophyte, and include many of the larger thallus-sized individuals. In an area subjected to a recent rare homogeneous fire, the highest frequency of Bulbothrix individuals are also present between 1.5 to $2 \mathrm{~m}$ on the phorophyte, most of which have small thallus sizes;

4) the fire protected area has the highest number of lichen species, families and individuals. Crustose lichens are common here, and fruticose lichens are present. Cyanobacterial lichens, and those with the Trentepohlia photobiont, are most abundant in this area, and the majority of lichens have sexual reproductive methods;

5) in an area frequently burned in the past but recently protected, there are lower numbers of species, families and individuals compared to an area protected from fire, and although foliose lichens are dominant, some fruticose individuals are present. Trebouxia is the most abundant photobiont, and vegetative reproduction is prevalent, chiefly through isidia;

6) in an area subjected to a recent rare homogeneous fire, there is a very low species richness, mostly confined to the Parmeliaceae family. Foliose lichens, and those with the photobiont Trebouxia, are predominant, whilst squamulose and fruticose forms are absent. Lichens employing vegetative reproduction are very abundant, and this is mostly through isidia;

7) in an area subjected to a recent rare heterogeneous fire there are high species numbers, individuals and families, comparable to a fire protected area. Crustose and foliose lichens are dominant, and fruticose forms are also present. However, there may be fewer lichen species with cyanobacteria and Trentepohlia. Sexual reproduction occurs in most lichens and vegetative reproduction with soredia is common;

8) fire temperatures along a phorophyte trunk are commonly around $200^{\circ} \mathrm{C}$ and can reach beyond $500^{\circ} \mathrm{C}$ in some cases. These peak temperatures may only last for a few seconds, but readings of between 50 to $100^{\circ} \mathrm{C}$ may persist for a couple of minutes. Temperatures during fires vary at different heights on the trunk of an individual phorophyte, vary between similar heights on the trunks of various phorophytes, and are different even between two adjacent individuals.

From these results, a number of conclusions, which may be important for the development of the LFH Key, are proposed:

a) Bulbothrix populations, in terms of numbers and distribution on the phorophyte, are affected by fire history. Thallus sizes of Bulbothrix populations also vary with fire history, suggesting that they could be used to date fires;

b) lichens have various compositional, morphological and reproductive responses to different fire histories; 
c) the heterogeneity of fire temperatures along a phorophyte trunk may affect the survival and recolonisation of lichens. 
194 


\section{Chapter 8 \\ Theoretical discussion, and development of the Lichen Fire History (LFH) Key}

\subsection{Introduction}

The aim of this thesis is to investigate whether corticolous lichens can be used as bioindicators of fire history in the cerrado, and to generate a preliminary Lichen Fire History (LFH) Key.

This chapter is divided into four main sections. The first discusses the role of various small-scale determinants on lichen abundance, distribution and recolonisation. Here, the effect of fire on lichens, both directly and indirectly, is analysed in detail. From this, a LFH Key, using lichen abundance, distribution and recolonisation is proposed. The second section deals with the effect of different determinants on lichen species composition, and outlines the importance of fire. Indicator species for different fire histories are discussed in terms of their fire ecology, and from these, a select number of lichen species are chosen for the LFH Key. The third section considers the population dynamics of the genus Bulbothrix in areas of different fire histories. A LFH Key using the thallus sizes of Bulbothrix individuals is presented.

The final version of the LFH Key, incorporating the general characteristics of lichen abundance, distribution and recolonisation, the specific indicator species, and Bulbothrix population responses, are presented in the fourth, and final section of this chapter. Within this section is an appraisal of the LFH Key, summarising its effectiveness and applicability. This section concludes with the presentation of the LFH Key in it's practical form as a working booklet.

\subsection{Towards a LFH Key using general characteristics of lichen abundance, distribution and recolonisation (columns $\mathrm{A}, \mathrm{B}$ and $\mathrm{C}$ in Table 8.3)}

Although fire may directly influence lichens, it can also indirectly cause a change in other small-scale determinants, which in turn will affect lichen populations. Small-scale lichen determinants investigated in the present study include: bark substrate characteristics, using bark texture and $\mathrm{pH}$; bark age, using phorophyte girth and height; and microclimate, using phorophyte structure i.e. height and first branch height.

\subsubsection{Absence of fire: the importance of other small-scale determinants}

The present study reveals that most phorophytes in a plot protected from fire for over 20 years has 26 to $50 \%$ or over $50 \%$ lichen cover (see Figures 8.1 a and $8.1 \mathrm{~b}$ ). A large majority of these lichens are partially restricted to various parts of the phorophyte, particularly below $1 \mathrm{~m}$, as opposed to having a homogeneous distribution. These features of a high lichen abundance, and a degree of vertical 
zonation on the phorophyte trunk i.e. habitat specialisation, are characteristic of the older stages in lichen succession (James et al., 1977), and indicate the long-term fire protection of the area.

In this study, a number of phorophyte species commonly encountered in cerrado denso, including Miconia ferruginata, Palicourea rigida, Qualea species, and Vochysia thyrsoidea, are found to possess very low lichen abundances compared to other common phorophytes such as Sclerolobitm paniculatum and Vellozia squamata. This 'phorophyte specificity' of lichens is most significantly associated with the small-scale determinant bark substrate, which is a combination of the level of aluminium, the $\mathrm{pH}$, the texture, the water-absorbing and holding capacity, the age, and the availability of habitats on the bark.

Many of the phorophyte species with low lichen abundances accumulate high levels of aluminium in their bark. Da Silva (1990) found that $M$. ferruginata contained $12,510 \mathrm{mg} \mathrm{kg}^{-1}, P$. rigida $8,924 \mathrm{mg} \mathrm{kg}^{-1}$ and $Q$. grandiflora $9,768 \mathrm{mg} \mathrm{kg}^{-1}$ of aluminium in their bark compared to $S$. paniculatum with only $640 \mathrm{mg} \mathrm{kg}^{-1}$. Aluminium toxicity in the bark of some phorophyte species may deter lichen establishment by inhibiting growth and reducing available nutrients, with only those lichen species with a tolerance/resistance mechanism being able to survive.

In this study, phorophyte species with a high lichen abundance (Blepharocalyx salicifolius, Caryocar brasiliense, Guapira noxia, Sclerolobium paniculatum and Vellozia squamata) have a more acidic bark than species with a low lichen abundance (Miconia ferruginata, Palicourea rigida, Qualea grandiflora, $Q$. parviflora and Vochysia thyrsoidea). This finding disagrees with previous work in both temperate and tropical regions where lichen abundance increases with $\mathrm{pH}$ (James et al., 1977; Marcelli, 1992; Wolseley and Aguirre-Hudson, 1996a). Gradstein (1992), on the other hand, stated that there was no significant correlation between epiphytic lichens and bark $\mathrm{pH}$ in a wet tropical forest on Mount Kinabalu, Borneo. The reason why cerrado denso phorophytes with a high lichen abundance have a higher bark acidity may be due to the inter-relationship between $\mathrm{pH}$ and aluminium levels. A high acidity increases the solubility of aluminium allowing this metal to be leached away. A lower acidity has the opposite effect, resulting in higher aluminium concentrations (Killham, 1994). However, evidence for this $\mathrm{pH}$-aluminium relationship comes from soil studies, and the presence of a similar relationship in bark is only a hypothesis.

Phorophyte species with 'smooth' and 'rough without crevices' bark textures are shown to have higher lichen abundances and a higher proportion of individuals with partially restricted lichen distributions when compared to species with 'rough with crevices' and 'rough with deep crevices' bark textures. This may be due to the intimate relationship between bark texture and its moistureabsorbing and holding capacity (Brodo, 1974). The 'smooth' bark texture of cerrado denso species is characteristically tough and thin-layered. In contrast, the 'rough with deep crevices' bark texture is thick and brittle. Therefore, phorophytes with a 'smooth' bark in cerrado denso may retain higher levels of water, due to the impervious nature of the bark, and thereby sustain a larger lichen population than the soft, thick-barked species, which have a greater bark porosity (Wolseley and Aguirre-Hudson, 1996a). 
The higher moisture levels in smooth-barked phorophytes may also allow a greater diversity of lichens to establish along the trunk since water will not be the only limiting factor, and could explain the higher proportions of smooth-barked phorophytes with a partially restricted lichen distribution on the trunk i.e. greater habitat specialisation.

Significantly higher lichen abundances are found on small-girthed phorophytes in this study, compared to large-girthed phorophytes. This may be explained by the occurrence of many phorophyte species, such as Hymenea stigonocarpa, Didymopanax macrocarpum, Guapira noxia, Ouratea hexasperma and Vellozia squamata, which are thin-stemmed even though they may be great in age (Dulce Rocha, pers. comm., 12/9/94), and may reflect some long-standing bark surfaces. These species make up nearly $50 \%$ of the phorophyte species in an area protected from fire. In temperate forests, the increasing age of a bark substrate is accompanied by an increase in bark $\mathrm{pH}$, favourable for the establishment of richer lichen communities (James et al., 1977), and in the tropical savanna forests of Thailand, an elevated $\mathrm{pH}$, as well as the ability to retain higher levels of moisture in older bark surfaces, were considered the reasons for a high lichen abundance (Wolseley and Aguirre-Hudson, 1996a). These factors may also be relevant to cerrado denso lichens. It is also possible that aluminium levels fall as bark becomes older as a result of leaching. Older bark surfaces may also explain the significantly higher proportions of small-girthed phorophytes found to have lichens with a partially restricted and restricted distribution. This confinement of groups of lichens to certain parts of the phorophyte suggests a habitat preference for a particular microclimatic condition on the trunk as the bark ages. However, some of the small-girthed phorophytes with high lichen abundances may be young individuals. Wolseley (pers. comm. 21/8/95) suggests that, regardless of species, the bark of many young individuals is relatively thin, which may allow greater water availability from the transpiration stream, thereby increasing the abundance of lichens. The larger proportion of partially restricted and restricted lichen distributions found on young, small-girthed phorophytes may also be due to greater available bark moisture, allowing a more diverse population of lichens to invade and establish.

Phorophytes with lower first branches $(<0.5$ to $0.9 \mathrm{~m}$ ) are shown to have higher proportions of individuals with partially restricted lichen distributions compared to phorophytes with higher first branches (1 to $4.9 \mathrm{~m}$ ), which had higher proportions of individuals with homogeneous lichen distributions. This suggests that the structural complexity of phorophytes may provide a greater range of available habitats for lichens. According to microclimate, lichens can inhabit specific niches on the phorophytes, thereby showing a partially restricted distribution. The phorophytes with a lower structural complexity may have fewer habitats present throughout the phorophyte, thereby showing a homogeneous lichen distribution.

\subsubsection{Summary}

Cerrado denso lichen communities are highly influenced by the bark substrate in firecontrolled areas. Results from this study indicate that the most important factor controlling lichen 
communities is the level of aluminium present in bark, although moisture status within various bark types and the age of the bark substrate may also be significant lichen determinants. These factors are phorophyte specific, as each phorophyte species will have a unique combination of bark characteristics. This suggests that, as in many other ecosystems, lichens in cerrado denso are commonly phorophyte specific as a result of the conditions prevalent on the phorophyte (Hale, 1983). This phorophyte-lichen specificity factor is of utmost importance for the development of a LFH Key. So as to eliminate changes in lichen abundance and distribution determined by factors other than fire, it is necessary to select a few specific phorophyte species for the LFH key. The phorophyte species chosen for the LFH Key were Blepharocalyx salicifolius, Caryocar brasiliense, Guapira noxia, Sclerolobium paniculatum and Vellozia squamata. These species are common in cerrado denso, have a high lichen abundance, and show a variation in lichen abundance between different fire histories. Since the small-girthed phorophyte individuals have the greatest lichen abundance, it may be necessary to select only individuals of this size range to be used in the LFH Key.

\subsubsection{Fire}

The results of this study show that once fire is introduced into cerrado denso vegetation, it is overwhelmingly the major factor influencing lichens, with the effect of other smallscale determinants becoming insignificant. No factor other than fire can account for the differences found in lichen communities between an area protected from and those subjected to burning. Fire acts on lichens in two ways: the heat causes the destruction of the algae and the flames physically destroy the fungal body of the lichen. It is suggested that fire has both a direct and an indirect effect on lichen communities. The direct effects on lichens are the immediate death from flame heat and intensity, the creation of new habitats for recolonisation, and a change in the nutrient status of the bark substrate through fire by-products. The indirect effects of fire on lichens include an alteration in phorophyte density, and therefore microclimate, and a change in the phorophyte species composition.

The present study shows that fire destroys lichens present within the flame zone, but outside this, lichens remain unharmed. For example, in an area protected from fire, lichens are present on different parts of the phorophyte trunk according to the microclimate. However, in areas subjected to fire, lichens are more commonly found on higher sections of the phorophyte trunk, above the flames. In the cases where a fire is homogeneous with high flame heights, lichens are typically found above $2 \mathrm{~m}$. Heterogeneous fires, on the other hand, allow considerable numbers of lichens to escape damage, and in some instances, depending on the direction of the flames, the lichens on one side of a phorophyte are completely destroyed, while the lichens on the other side are left unscathed (see Figure 8.1c). The study of fire patterns on phorophyte trunks clearly demonstrates the heterogeneous effects of fire. Temperature patterns vary randomly between different heights on the trunk of various phorophytes, and are different even between two adjacent individuals. This is probably due to the heterogeneity of combustible fuels at the ground level. Although temperatures of over $200^{\circ} \mathrm{C}$ were rarely recorded on the 
Figure 8.1 Lichens in cerrado denso: a) and b) rich lichen communities common in undisturbed areas; c) heterogeneous fires cause lichens to be destroyed on one side of the phorophyte, leaving healthy individuals on the other; d) lichen recolonisers after fire. (Photos by the author).

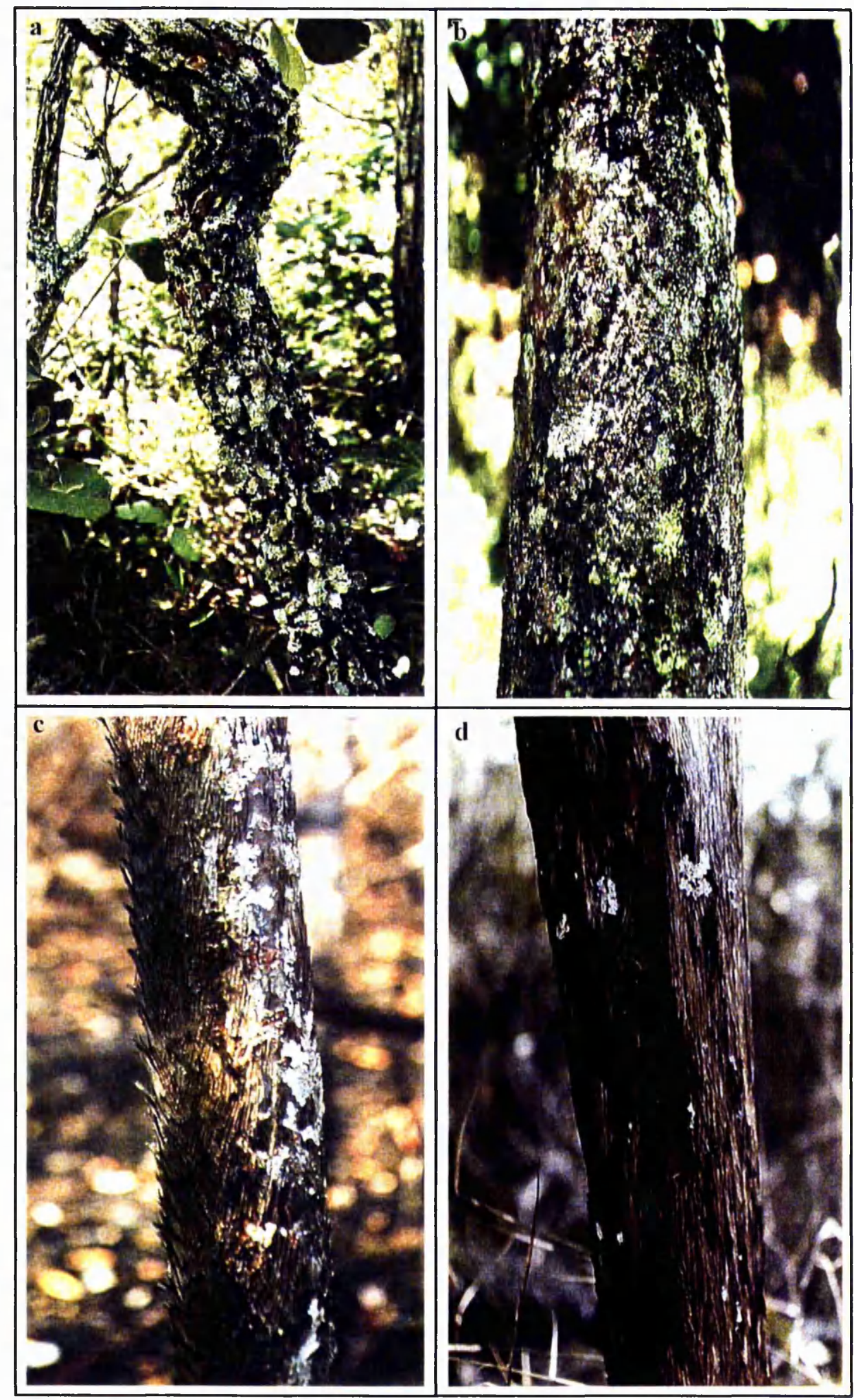


phorophyte trunk, temperatures of between 50 and $100^{\circ} \mathrm{C}$ were frequent. Many lichens with dry thalli (an adaptation to the dry season) can tolerate temperatures of up to $100^{\circ} \mathrm{C}$ without damage to their photosynthetic photobionts (Ahmadjian, 1993). These results suggest that the heterogeneity of flames, and a tolerance to heat from common temperatures, may allow many lichens to survive fires unharmed.

The surviving lichen populations readily promote recolonisation, and in this study, all the plots subjected to fire show varying degrees of recolonisation depending on their fire history (see Section 8.3). Recolonisation may occur through the transportation of propagules in the air and down phorophyte trunks by rain during the wet season, or by being actively carried to new habitats by fauna (Wolseley and Aguirre-Hudson, 1996b). If fire is uncommon, the bare burnt bark may be rapidly invaded, and secondary succession begins (see Figure 8.1d). But as fire frequency increases, the 'lichen source' i.e. the groups of older, more established lichens producing greater quantities of propagules above the fire zone, may be destroyed. Frequent fires also prevent succession as lichen recolonisers may be regularly killed, therefore hindering the establishment of a lichen community within the fire zone. Only a select number of invasive ' $r$-selected' species may be apparent in these zones.

The behaviour of fires will vary, in terms of homogeneity and flame heights, from burn to burn. If the burn is heterogeneous, the effect of various flame heights could be counteracted by the high number of phorophytes left unharmed. Healthy lichen communities on these undamaged phorophytes, and from above the fire zone, promote recolonisation on the burnt bark. A similar situation may arise where the fire is homogeneous, with low flame heights. Recolonisation occurs from the lichen populations above the fire zone. Alternatively, a complete burn of high flame heights may cause lichen populations in all phorophyte habitats to decline. If this reaches the point where lichens are severely diminished and isolated to the tops of a few scattered phorophytes, recolonisation could become very slow or may cease. These areas may then become 'lichen deserts', devoid of lichens (Wolseley and Aguirre-Hudson, 1996b).

The findings of this study indicate that in areas subjected to fire, significantly greater numbers of phorophytes with a large girth, high first branch height, and high scorch height have a partially restricted lichen distribution. A large girth may allow some lichens on the trunk to escape the flames, restricting them to certain parts of the phorophyte trunk. Phorophytes with a high first branch are more likely to be burned evenly below, due to the lack of structural complexity, and so restricting lichens to higher parts of the phorophyte. Higher scorch heights may restrict lichens to high areas (usually in the canopy) on the phorophyte.

In this study, most recolonisation after fire occurs on phorophytes with an intermediate height, first branch height and scorch height, of 1 to $2.9 \mathrm{~m}$. This height range may be the most accessible for lichens recolonising from above the flames, or it could be that the microclimate on these phorophytes e.g. higher light levels, are ideal for invasive species. Phorophytes with small girths are found to have the highest amount of recolonisation. This could be the consequence of two factors. Small girthed, but older individuals, may have higher proportions of lichens in general, and therefore a 
greater cover of lichens above the fire zone to aid recolonisation. There is also the fact that a small girthed individual is more likely to be burned completely, compared to a larger girthed individual, where only one aspect of the phorophyte may be burned. This in turn may make a larger area on a small girthed individual available for recolonisation.

The results of this study also show that phorophytes with 'smooth' bark have the greatest amount of lichen recolonisation. These findings are contrary to previous work. For example, Brodo (1974) considered the ease of recolonisation to be pronounced in rough, creviced bark when compared to smooth bark. This may be due to the moist microclimate within a crevice allowing lichens to survive any change in the environment outside. Wetmore (1983) and Wolseley and Aguirre-Hudson (1996b) also observed the survival of lichen thalli between bark fissures during fires, and suggest that these lichens aid subsequent recolonisation. The higher moisture availability of smooth bark, which is hard and impermeable (Wolseley and Aguirre-Hudson, 1996a), may be the controlling factor for recolonisation in the cerrado denso. Also, since lichens will be more easily damaged on smooth bark, it may be that the greater area available on this bark surface for invasion after a fire is important.

Each time a fire occurs in the cerrado denso, whether it be occasional or frequent, the immediate and direct effects involve the deposition of ash, containing high levels of nutrients such as nitrogen, carbon and sulphur, the production of particulate matter in smoke (Frost and Robertson, 1987), and the immediate disappearance of aluminium toxicity for up to 40 days at the soil surface (Coutinho, 1982a). As yet no information is available on the effects these processes have on lichen populations, although smoke was found to cause eutrophication to lichens in both an urban area of Britain (James, 1973), and in a burned oak savanna in North America (Wetmore, 1983). Wolseley and Aguirre-Hudson (1996b) demonstrated that the bark $\mathrm{pH}$ of the same species did not vary significantly between fire-protected and burned areas, and suggested that the following rains may remove any particulate matter from trees. In the case of aluminium toxicity, the results of this study indicate that lichens do recolonise burnt bark on aluminium-accumulating phorophyte species, though at a lower degree compared to other species. Although there is no data on aluminium levels in bark following a fire, it may be possible that aluminium is depressed or nullified, thereby allowing various lichen species to invade. Once aluminium begins to increase again, these may be replaced by aluminiumtolerant lichen species. However, the low amount of recolonisation on aluminium-accumulating phorophytes lends greater authority to the idea that bark aluminium levels are not markedly reduced after a fire, and that the recolonisers are actually those lichen species which are tolerant.

In the fire protected plot of this study, a high frequency of phorophytes have lichens restricted, or partially restricted, to different heights on the phorophyte, particularly to the lower sections of the trunk, near the base. This indicates older stages in lichen succession as microclimate changes and habitat specialisation occur. However, all the burned plots of this study show greater homogeneity in lichen distribution, with few or no phorophytes with lichens restricted or partially restricted to the lower sections of trunks. This suggests that lichen succession is limited once fire is 
introduced. Fire has the effect of opening up cerrado denso vegetation, since phorophytes in the more closed forms of cerrado are less adapted to fire, and therefore more frequently killed than phorophytes in the open cerrado physiognomies (Kauffman et al., 1994). This reduction in cover may directly influence the lichen microclimate. However, cerrado denso has a 20 to $50 \%$ canopy cover, and densely closed areas only occur as patches within the vegetation (Eiten, 1994). Under these dense canopies lichens become distributed along the trunk according to bark age and microclimate. Once fire reduces the canopy and increases the distance between individuals, insolation and temperatures on bark surfaces may increase, causing a reduction in moisture levels and atmospheric humidity within the forest, especially during the dry season. The lichens associated with the moist and shady areas (usually at the base of phorophytes) and on moist-barked trees may be lost, to be replaced by heliophilous, dryadapted lichens, typical of the illuminated areas and therefore competitively advantaged, and invasive ' $\mathrm{r}$ selected' species, which can colonise a wide range of niches (Rogers, 1988). If fire is then prevented, secondary succession may begin, and the lichen flora may advance to the state characteristic of before. If, on the other hand, there are subsequent fires, lichen cover may diminish, with only a select number of lichen species being able to tolerate the changing conditions.

Results of the present study show that some fire-adapted phorophytes with thick, corky bark (termed 'rough with deep crevices' in this study), such as Qualea grandiflora and $Q$. parviflora, become more important in burned areas compared to the fire protected area. However, as was discovered previously, many of these thick-barked species, including $Q$. grandiflora and $Q$. parviflora, are aluminium-accumulators, and have few lichens. This bark type also has a low waterholding capacity (Wolseley and Aguirre-Hudson, 1996a), thereby reducing the numbers of lichens which need high moisture levels. Therefore, an indirect effect of fire on lichen populations is the selection of certain fire-adapted phorophyte species which may pauperise lichen cover.

\subsubsection{Summary}

Overall, it is concluded that fire alters the conditions for cerrado denso lichen populations in the following ways:

1) the death of lichens within the flame zone and the creation of bare bark habitats for recolonisation;

2) a change in bark nutrient levels and aluminium concentrations, which may affect both surviving and recolonising lichens;

3) a change in phorophyte density causing microclimatic modifications;

4) the selection of certain fire-adapted phorophyte species which are characterised by a low lichen cover.

The frequency and behaviour of fire affects the above factors, which in turn determine the abundance, distribution and extent of recolonisation of lichens on phorophytes. The following section integrates these findings for the development of the LFH Key. 


\subsection{The LFH Key using lichen abundance, distribution and recolonisation}

Fire transforms the lichen environment from a situation where phorophyte species and bark age are the most important factors influencing lichen growth (no fire), to the state where the frequency and behaviour of fire are of major significance. The type of fire and its frequency can be ascertained by the way in which lichen abundance, distribution and recolonisation are affected as a consequence of the altered lichen environment. In other words, lichens can 'describe' the fire history of a particular site. The basis of the LFH Key are therefore the following:

1) a high lichen abundance can be attributed to a history of past fire protection, and a low lichen abundance to past frequent fires;

2) the homogeneity of a fire and the flame heights attained can be 'described' by the degree of lichen restriction to higher sections of the phorophyte;

3) both the frequency and behaviour of a fire can be ascertained by the levels of recolonisation.

These factors of lichen abundance, distribution and recolonisation are combined to give the preliminary LFH Key based on lichen populations (Figures 8.2 and 8.3). In Figure 8.2, the Mean Lichen Abundance (MLA) i.e. the mean frequency distribution of the lichen abundance categories 0 to 4 constructed for this study (see Section 4.3.3e), for each study plot is represented on the $\mathrm{x}$-axis. This is used as an indication of fire frequency. Plotted on the $y$-axis for each study plot is the Spatial Index of Fire (SIF), which expresses fire behaviour in terms of the homogeneity and flame heights of a burn. The SIF was calculated from the lichen distribution categories as follows :

$$
\text { Spatial Index of Fire }=\left|\left(A-a_{n}\right)\right|+\left|\left(B-b_{n}\right)\right|+\left|\left(C-c_{n}\right)\right|+\left|\left(D-d_{n}\right)\right|
$$

where,

$A=$ constant, frequencies of partially restricted and restricted to base lichen distribution in Plot 1.

$a_{n}=$ frequencies of partially restricted and restricted to base lichen distribution in Plot n.

$\mathrm{B}=$ constant, frequencies of partially restricted and restricted from base to $0.9 \mathrm{~m}$ lichen distribution in Plot 1.

$\mathrm{b}_{\mathrm{n}}=$ frequencies of partially restricted and restricted from base to $0.9 \mathrm{~m}$ lichen distribution in Plot $\mathbf{n}$.

$\mathrm{C}=$ constant, frequencies of partially restricted and restricted from 1 to $2 \mathrm{~m}$ lichen distribution in Plot 1.

$c_{n}=$ frequencies of partially restricted and restricted from 1 to $2 \mathrm{~m}$ lichen distribution in Plot n.

$\mathrm{D}=$ constant, frequencies of partially restricted and restricted above $2 \mathrm{~m}$ lichen distribution in Plot 1. 
$d_{n}=$ frequencies of partially restricted and restricted above $2 \mathrm{~m}$ lichen distribution in Plot $n$.

Since Plot 1 (74-control) has been protected from fire for over 20 years, each burned plot is compared to Plot 1 to see how much departure there is from its partially restricted and restricted lichen distribution. The greater the homogeneity and flame heights of a burned plot, the greater the restriction of lichen populations to higher parts of the phorophyte, and therefore the larger the departure from Plot 1 values. For example, for Plot 2 (74-91: Hom, H, M), $a_{n}=0, b_{n}=0, c_{n}=2 d_{n}=13$. Therefore, the SIF is $|4-0|+|12-0|+|19-2|+|2-13|=45$. This is a large digression from Plot 1 (which has a SIF of 0 ) indicating high fire homogeneity and flame heights. Plot 3 (74-92: Het, V, E), on the other hand, has the values $a_{n}=0, b_{n}=1, c_{n}=11 d_{n}=1$. The SIF in this case is $|4-0|+|12-1|+|19-11|$ $+|2-1|=24$. The lower value indicates greater heterogeneity and lower flame heights for this plot.

Figure 8.3 is the MLA divided by the SIF plotted against the percentage recolonisation for each study plot. Table 8.1 shows how various combinations of MLA, SIF and percentage recolonisation can estimate the fire history of an area. The fire histories of the ten plots used in this study will now be determined using the LFH Key i.e. Figures 8.2 and 8.3, and Table 8.1, and how they correlate with what is known about each plot will be discussed.

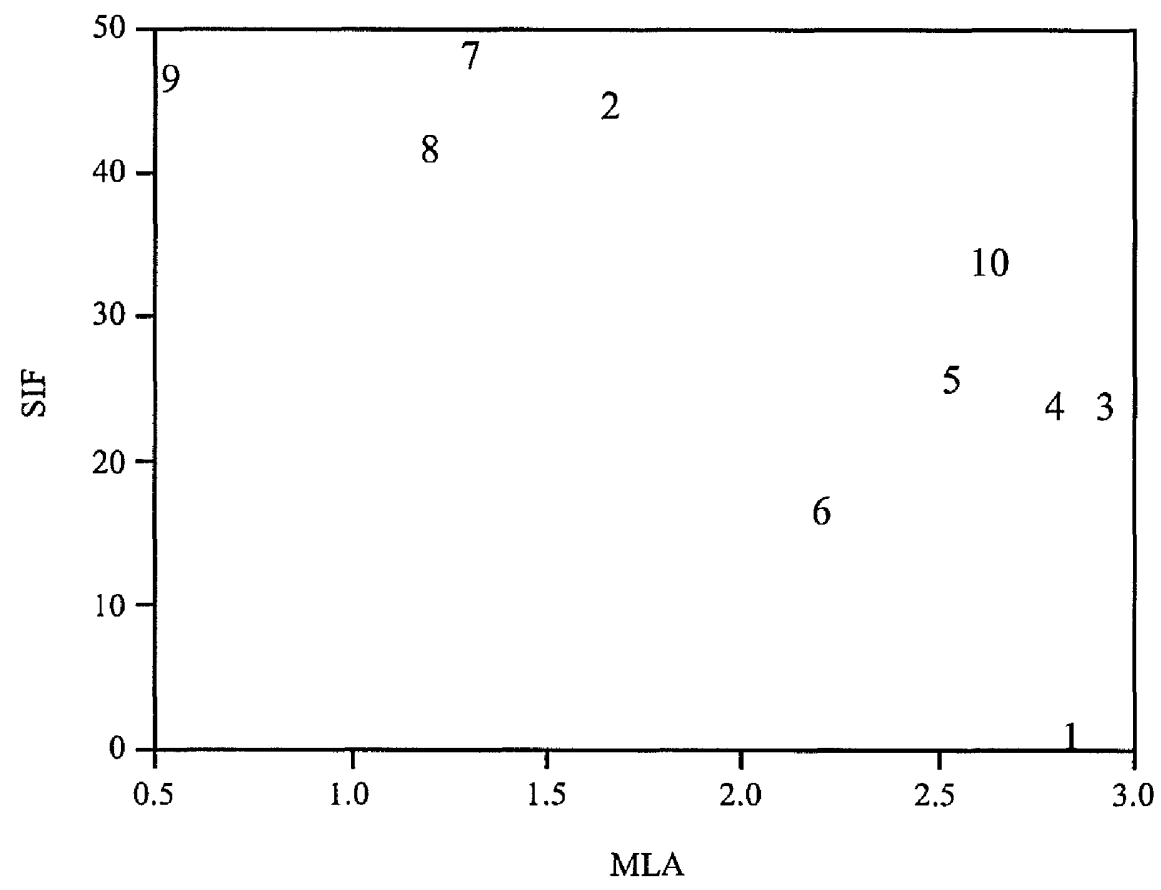

Figure 8.2 The Mean Lichen Abundance (MLA) and Spatial Index of Fire (SIF) for the ten plots. 


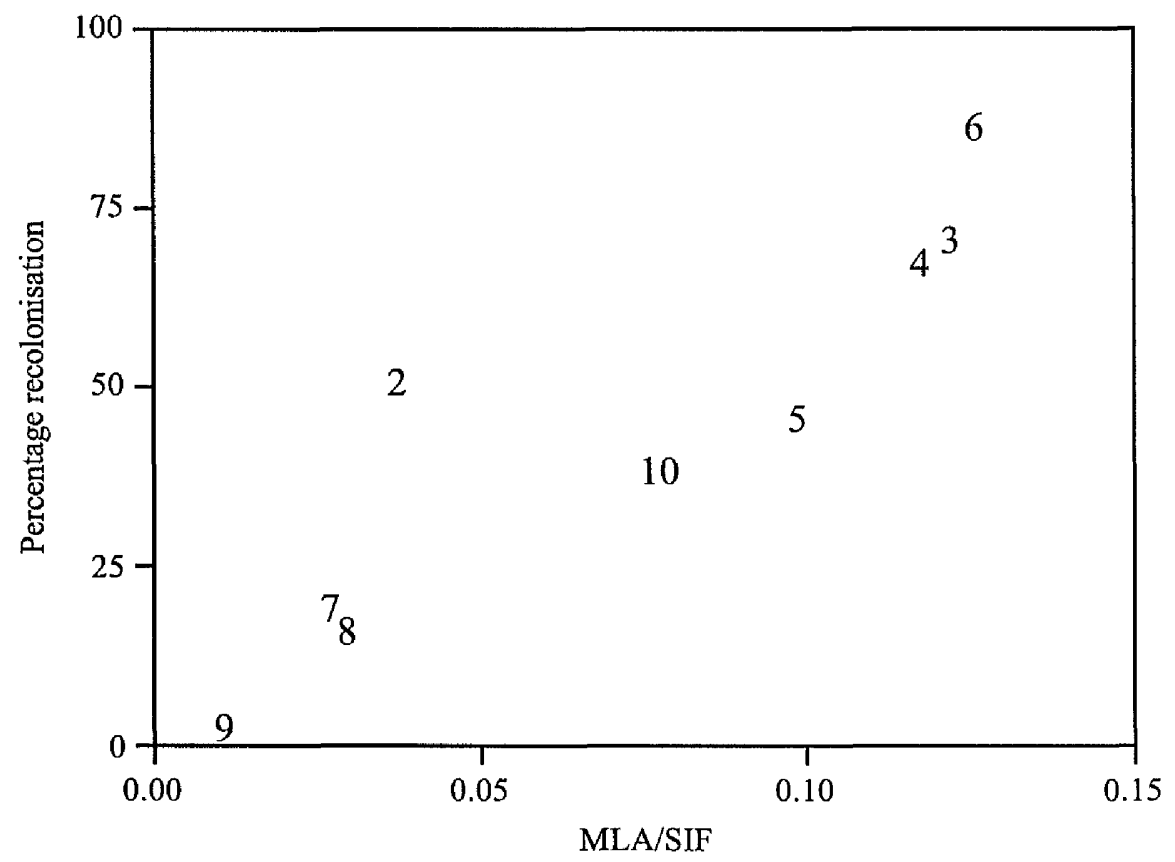

Figure 8.3 The Mean Lichen Abundance (MLA) divided by the Spatial Index of Fire (SIF), plotted against percentage recolonisation for the ten plots.

Fire protection, particularly over a long period of time, leads to an increase in lichen abundance and habitat specialisation on phorophytes. This is seen clearly in Plot 1 (74-control), where fires have been controlled for over 20 years. Figure 8.2 shows Plot 1 to have an extremely high lichen abundance (MLA of 2.84) and an SIF of 0, indicating the absence of fire from this area.

However, the greater presence of lichen communities in the absence of fire is not as apparent where fires have been frequent in the past i.e. Plot 6 (86-control). The lower MLA of 2.2 in this plot compared to Plot 1 (see Figure 8.2), suggests a greater frequency of fire. The SIF of 17 indicates a heterogeneous, low to medium flame height fire, and the high percentage of recolonisation (see Figure 8.3) signifies the recent absence of fires. This is in accordance with the known fire history of Plot 6. The regularity of fires in the past has prevented the establishment of high lichen cover values that are characteristic of fire protection. This is because the time between each fire in the past was probably too short to allow any lichen recolonisers to establish. Also, the varying nature of fire e.g. homogeneous or heterogeneous, and height of flames, probably eradicated lichens from many habitats on the phorophyte, thereby slowing down the process of recolonisation once fire was removed. Still, with time, increasing amounts of lichens began recolonising the burnt bark and it is for this reason that Plot 6 has the highest percentage recolonisation. 
Table 8.1 The Mean Lichen Abundance (MLA), Spatial Index of Fire (SIF) and percentage recolonisation for determining the fire history of an area.

\begin{tabular}{|l||l|l|l|}
\hline Fire history & MLA & SIF & $\%$ Recolonisation \\
\hline \hline $\begin{array}{l}\text { a. Fire protection for over } \\
20 \text { years }\end{array}$ & high & zero & none \\
\hline $\begin{array}{l}\text { b. Rare, heterogeneous } \\
\text { fire with various flame } \\
\text { heights }\end{array}$ & high & low-medium & high \\
\hline $\begin{array}{l}\text { c. Rare, homogeneous fire } \\
\text { with various flame } \\
\text { heights }\end{array}$ & low & medium-high & medium-high \\
\hline $\begin{array}{l}\text { d. Frequent fires, some } \\
\text { degree of recent protection }\end{array}$ & medium & low-medium & medium-high \\
\hline $\begin{array}{l}\text { e. Frequent, } \\
\text { heterogeneous fires with } \\
\text { various flame heights }\end{array}$ & medium & low-medium & low-medium \\
\hline $\begin{array}{l}\text { f. Frequent, homogeneous } \\
\text { fires with various flame } \\
\text { heights }\end{array}$ & low & medium-high & low-medium \\
\hline $\begin{array}{l}\text { g. Very frequent, } \\
\text { vomogeneous fires with }\end{array}$ & very low & high & low \\
\hline
\end{tabular}

For Plot 2 (74-91: Hom, H, M), a low MLA of 1.66 points to a moderate fire frequency, and a SIF of 45 to a homogeneous, high flamed fire (see Figure 8.2). However, the high percentage of recolonisation (over 50\%) on Figure 8.3 reveals a degree of protection in the past. This is confirmed by the known fire history, which reveals that Plot 2 has been protected in the past, but recently burned. The homogeneous nature of the fire means that most of the lichens on the phorophytes within reach of the flames will have been destroyed, and therefore few phorophytes have a high lichen cover. The lichens which escaped the fire were mostly above the flame height zone, and these undamaged communities probably aided rapid and extensive recolonisation on the bare bark below.

Figures 8.2 and 8.3 suggest that in Plot 3 (74-92: Het, V, E), Plot 4 (74-92: Het, V, M) and Plot 5 (74-92: Het, V, L) fire has been rare and heterogeneous, and of various flame heights. In fact, fire has been previously controlled in these plots, and the recent mosaic-like fire probably left many phorophytes unharmed, thereby preserving high lichen covers (high MLA values on Figure 8.2). This permitted a substantial degree of recolonisation on bare bark to occur quickly (high percentage recolonisation on Figure 8.3). However, most of the lichen communities at the base of phorophyte trunks were destroyed, and where fire had scorched a phorophyte, the lichens were confined above the flame height zone (SIF values between 24 and 26 on Figure 8.2). 
A high MLA of 2.63, together with a high SIF of 34 and only $39 \%$ recolonisation, signifies that Plot 10 (86-91,93: Het, V, L) has had infrequent, homogeneous and moderately highflamed fires in the past. This area is very similar to Plot 3 (74-92: Het, V, E), Plot 4 (74-92: Het, V, M) and Plot 5 (74-92: Het, V, L) in terms of fire frequency, but the nature of fire in this area has been of a more damaging nature.

The MLA, SIF and percentage recolonisation shown in Figures 8.2 and 8.3 for Plot 7 (86-91: Hom, H, M), Plot 8 (86-91,93: Hom, H, E) and Plot 9 (86-91,93: Hom, H, M) agree with the known fire histories for these areas. Regular fires have been homogeneous and with moderately high flame heights in Plot 7 and Plot 8, reducing lichen populations (very low MLA values in Figure 8.2) to habitats above the flame height zone (high SIF values). This promoted limited and short-lived recolonisation (low percentage recolonisation on Figure 8.3). This has developed into an extreme situation in Plot 9, where recurrent homogeneous and high-flamed fires have caused the few lichens remaining on the phorophytes to be confined above $2 \mathrm{~m}$ (extremely low MLA and high SIF value). These are too small in number for any significant recolonisation to take place, and thus 'lichen deserts' are evident on the majority of phorophytes (only $1 \%$ recolonisation on Figure 8.3).

The timing of a dry season fire does affect lichen communities, although the differences between early, middle and late season burns are not as apparent as the overall contrast between fire protection and frequent burning. Nevertheless, there are indications from Figures 8.2 and 8.3 that on the whole, a late season burn (Plot 5) is less favourable to lichens than an early (Plot 3) and middle season (Plot 4) burn. This is probably due to the higher flame heights and homogeneity of the fire (slightly higher SIF for Plot 5 than Plots 3 and 4 on Figure 8.2), as a result of the build-up of combustible fuels and elevated air temperatures during a late season burn. This fire behaviour causes a reduction in lichen abundance (lower MLA than in Plot 3 and Plot 4 on Figure 8.2), and recolonisation (only $46 \%$ recolonisation compared to $71 \%$ and $68 \%$ in Plot 3 and Plot 4 respectively - see Figure $8.3)$.

It should be noted here that fires during the dry season are largely governed by the prevailing environmental factors at the time. It is generally considered that the early season burn (end of June/beginning of July) may be subdued because of high moisture levels in the fuel from the end of the rainy season. This moisture may have dried by the middle season burn (August), and by the late season (September), the fuel is highly combustible. Also, temperatures are usually the highest during the late dry season, and humidity the lowest, with winds becoming stronger. These factors all contribute towards a more homogeneous fire of high flame heights in the late season. However, the rains vary from year to year, sometimes ending earlier in the rainy season, and at other times beginning earlier in the dry season. There are also spells of occasional rain during the actual dry season, and all these variations in climate will determine the nature of a fire. So, although the LFH Key does show differences between early, middle and late season burns, this is a response of lichen populations to the 
behaviour of fire during those burns (resulting from the climate and fuel conditions at the time), and not necessarily because of the fire timing.

Figures 8.2 and 8.3 reveal how lichen abundance, distribution and recolonisation together can be used to give a very good idea of past fire frequency and fire behaviour in an area of cerrado denso. From Figure 8.3 it is possible to see more clearly the difference between Plot 2 (74-91: Hom, H, M), and Plot 7 (86-91: Hom, H, M), Plot 8 (86-91,93: Hom, H, E) and Plot 9 (86-91,93: Hom, H, M). Though they were all burned homogeneously, Plot 2 has a much greater amount of recolonisation, due to the infrequent nature of burns in this area. It is also possible to see the differences between Plot 3 (74-92: Het, V, E) and Plot 4 (74-92: Het, V, M), and Plot 5 (74-92: Het, $V, L)$, the latter having had a fire of greater homogeneity and and of higher flame heights.

\subsection{Towards a LFH Key using lichen indicator species (columns $D, E$ and $F$ in} Table 8.3)

Although lichen populations in general are determined by certain substrate and environmental conditions, the actual lichen species present in any given area are primarily determined by the prevailing climatic conditions and the physiognomy of the vegetation (Wolseley and AguirreHudson, 1996a). One hundred and three species of lichens were found within the cerrado denso plots of this study. This rich cerrado denso lichen flora is characterised by the climate and the high altitude of the Distrito Federal, and the structure of cerrado denso vegetation.

Cerrado regions are subjected to a long dry season, which is accompanied by high air temperatures, little rain, and a low humidity. Even though the Distrito Federal has a typical cerrado climate, it is distinguished from other cerrado areas by its location on a high tableland. This high altitude of the Distrito Federal is from 1048 to $1150 \mathrm{~m}$ above sea level, and affects the climate, especially during the dry season by lowering the humidity to below $15 \%$, and by elevating temperatures. These climatic conditions may enforce dormancy on many lichen species during the dry season, since inactive dry thalli are able to tolerate high temperatures better than moist thalli (Rogers and Stevens, 1981). Morphological adaptations to the dry season, as cited in Wolseley and AguirreHudson (1996a), include:

1) a thallus closely appressed to the bark substrate, thereby reducing moisture loss from the underside e.g. species of Bulbothrix, Canoparmelia, Hypotrachyna, Parmelinella, Parmelinopsis and Pyxine;

2) the protection of spores with a thickened epithecial layer which is sometimes crystalline preventing spore release during the dry season e.g. Haematomma puniceum and Pyrrhospora russula, or with a powdery deposit (pruina) e.g. Lecanora species;

3) protection from high temperatures through lichen compounds such as depsidones e.g. Canoparmelia and Parmelinopsis species.

The high altitude of the Distrito Federal also determines the presence of some typical montane lichen species in the study plots, most notably of the genus Hypotrachyna (Hale, 1975). 
Many of these Hypotrachyna species contain solar radiation, including UV+, screening compounds, such as xanthones and usnic acid, which protect the algal partner from the increased levels of solar irradiation at high altitudes (Rundel 1978).

Although the cerrado denso has a high density of phorophytes, the different sizes of individuals restricts the formation of a continuous canopy cover, and light reaches many areas within the vegetation. This may explain the presence of many lichen species typical of well-lit areas, most prominently of the family Parmeliaceae (Swinscow and Krog, 1988), such as species of the genera Bulbothrix and Canoparmelia, common in the study plots.

Within areas of cerrado denso, lichen communities are governed by the absence or occurrence of fire, and along a gradient of increasing fire disturbance. This gradient will also affect lichen composition, and determine to what extent other factors, apart from fire, influence lichen species.

\subsubsection{General characteristics of the lichen community in the absence of fire}

The results of this study indicate that the greatest number of lichen species and individuals are found in fire protected areas of cerrado denso. This may be due to the continuity of the vegetation cover over a period of time allowing lichen succession to reach older stages, and particular populations of lichen species to distribute themselves within the vegetation according to their environmental needs. The Parmeliaceae family is found to be the most diverse in this study. This may be because Parmeliaceae is generally a light loving family (Hale, 1976a), and the insolation levels within cerrado denso vegetation are probably sufficient to hold a sizeable community. The fire protected area has a lower abundance of Parmeliaceae species, and a greater richness of lichen families, compared to the burned plots. This is possibly a result of the greater amount of shaded areas restricting Parmeliaceae from establishing, and the lack of disturbance allowing a larger range of available habitats to form, hence increasing the diversity of lichen families which can establish.

In this study, crustose and squamulose lichens are most abundant in the fire-protected area. This may be because many crustose lichens are moisture-dependent and shade tolerant (Wolseley and Aguirre-Hudson, 1996a), and so inhabit the denser patches of canopy in fire protected areas. The squamulose lichens found in the fire protected plot include species of the genus Cladonia, moistureand shade-loving species characteristic of phorophyte bases (Ahti, 1986). These lichens have high abundances in the fire protected plot probably due to the lack of disturbance, and the denser patches of vegetation providing shade and humidity.

The present study shows that cyanobacterial and Trentepohlioid lichens, characteristic of humid, shady conditions (Wolseley and Aguirre-Hudson, 1996a), are most abundant in a fire protected area of cerrado denso. The sensitivity of the lichen photobiont to drought or high temperatures is critical for the survival of a lichen thallus (Ahmadjian, 1993). Therefore, the high abundance of cyanobacteria and Trentepohlia algae in a fire protected area may be due to the lack of 
disturbance in this area allowing greater patches of dense canopy to establish, under which humidity may increase and light levels decrease.

The fire protected plot of this study has a much higher abundance of sexually reproducing lichen species than asexually reproducing species. This is probably due to the high overall abundance of the lichen community and the lack of disturbance, allowing many lichens to reach a certain stage of sexual maturity at which reproduction through fruiting bodies ensures successful propagation and survival.

\subsubsection{Absence of fire and lichen species composition}

Multivariate analyses were carried out in order to investigate the factors determining lichen composition in a fire protected plot. It is suggested from the DCA ordination that the primary determinant of lichen composition in a fire controlled area is phorophyte specificity. This phorophytelichen relationship was also found to influence the general characteristics of the lichen community, and factors associated with bark substrate are postulated to be the primary determinants (see Section 8.2.1). However, for sampling the lichen composition, five phorophyte species with the highest lichen abundances and variations in lichen abundance between fire histories were used (see Section 5.10), and as a result, the influence of phorophyte specific factors was reduced. The five phorophytes were Blepharocalyx salicifolius, Caryocar brasiliense, Guapira noxia, Sclerolobium paniculatum and Vellozia squamata.

Along the gradient of phorophyte specificity, three main groups are identified:

1) a $V$. squamata group, characterised by the lichens Coccocarpia dominguensis, C. imbricascens, Parmotrema jamesii, P. mellissii and Cladonia species;

2) a $C$. brasiliense and $G$. noxia group, containing the lichens Bulbothrix isidiza, B. fungicola, Canoparmelia caroliniana, C. crozalsiana, C. amazonica, Buellia myriocarpa, Pyrrhospora russula and Ochrolechia pallescens;

3) a S. paniculatum and B. salicifolius group, with the lichens Arthopyrenia sp. '2', Graphina sp., Bulbothrix suffixa and Gyalideopsis sp..

There are no obvious differences in bark type along the gradient from $V$. squamata to B. salicifolius. V. squamata, C. brasiliense and B. salicifolius all have rough bark textures, although each phorophyte has its own specific bark texture within this 'rough' bark category. S. paniculatum has smooth bark, and $G$. noxia has 'rough with deep crevices' bark. However, bark moisture, related to texture, may play a role in determining lichen species within these phorophytes. Coccocarpia species are characteristic of wet, humid habitats, and their cyanobacterial photobiont is sensitive to drought and high temperatures (Arvidsson, 1982). The occurrence of Coccocarpia species on $V$. squamata therefore suggests that this phorophyte may contain higher levels of bark moisture compared to the other species. The smooth bark of $S$. paniculatum may also retain higher quantities of bark moisture due to the impermeable nature of the bark, yet it has a different lichen composition compared to $V$. squamata. All 
the phorophytes have different bark pH values. This may partly explain the differentiation of lichen species on the phorophytes. For example, the lichen Ochrolechia pallescens is commonly found on acid bark in many areas of Europe (James et al., 1977). In this study it is characteristic of $C$. brasiliense and G. noxia, which have a higher bark acidity than $V$. squamata. However, B. salicifolius has the lowest $\mathrm{pH}$ of the five phorophytes, yet $O$. pallescens is not commonly found on this phorophyte. Differences in bark aluminium, nutrient content, presence of resins and bark shedding, may also control the lichen compositional units found on each phorophyte species, but no information is available to investigate these hypotheses.

The results of this study suggest that no one bark factor is influencing lichen composition in the absence of fire. A range of factors, each to a varying degree within a specific phorophyte bark type, probably determine the lichen compositions on the various phorophytes. These factors may include bark moisture, $\mathrm{pH}$, small-scale aluminium levels, nutrients, resins and tannins, and bark shedding.

Microclimate is suggested to be the second factor affecting lichen communities in an area controlled from fire (axis 2 on the DCA ordination graph). This may control which lichen species occupy particular parts of the trunk, made apparent by a vertical zonation of lichen species on the phorophyte. In this study, the lichen species Cladonia ochroclora, C. subradiata and C. ramulosa, are found to occur together at one end of the ordination axis. These species prefer the moist, shady conditions prevalent at phorophyte bases (Ahti, 1986). The ordination also indicates that lichen species such as Hypotrachyna velloziae, Parmotrema nylanderi and $P$. dilatatum are characteristic of higher sections on the phorophyte trunk (between 1.5 and $2 \mathrm{~m}$ ). These species are rapid invaders of open, dry habitats such as those present on higher parts of phorophytes (Hale, 1975; Swinscow and Krog, 1988). Therefore, microclimate (along a gradient from moist and shady to dry and open) may be an important determinant of lichen composition in the absence of fire.

\subsubsection{General characteristics of the lichen community in the presence of fire}

The present study demonstrates that in areas where there has been past fire protection, a rare heterogeneous burn will not greatly lower the total number of species, although lichen abundance is considerably reduced. This is because although lichen communities are destroyed, thereby lowering the abundance of lichens, many phorophytes escape the flames, and on these the diversity of lichen species may still be great. In other words, the high diversity of lichens within a phorophyte individual allows the number of lichen species to remain high after a heterogeneous fire. If the fire is homogeneous, a greater proportion of phorophytes are burned, so drastically diminishing both the lichen abundance and the species richness. In either case, the number of species may increase again if fire is prevented, and regain the level of a fire-protected area. Frequent fires will also lower the total number of species and lichen abundance, and depending on the behaviour of the fires, may cause 'lichen 
deserts' on phorophytes. Therefore, although fire reduces species richness and abundance (Wolseley and Aguirre-Hudson, 1996b), this depends on fire frequency and homogeneity.

Species of the family Parmeliaceae are found to have the highest abundance in a frequently burned area, and in an area where there has been a rare homogeneous fire. Fire in these two areas may have reduced the denser patches of canopy, thereby increasing light and insolation levels, ideal conditions for light-loving Parmeliaceae species (Hale, 1976a). Also, many Parmeliaceae species have vegetative means of reproduction (Hale, 1976a), aiding rapid colonisation of burnt bark.

Foliose lichens are most common in the burned plots within this study, especially where the fire has been homogeneous. Since foliose lichens are typically light demanding (Wolseley and Aguirre-Hudson, 1996a), the large decrease in canopy cover after a homogeneous fire may greatly increase insolation levels within the vegetation, thus favouring foliose lichens. Squamulose lichens are frequent where there has been some fire protection, or a rare heterogeneous fire. However, these are absent where the fire has been homogeneous. This may be due to the squamulose lichens in this study (species of the genus Cladonia) being characteristic of phorophytes bases (Ahti, 1986). The results show that in comparison to other fire histories, a homogeneous burn affects most phorophytes in an area, so destroying the majority of lichens at the phorophyte bases.

In areas where there has been past frequent burning, or a rare heterogeneous fire, lichens with cyanobacteria and Trentepohlia are lowered as a result of their intolerance to increased light levels and temperature, and decrease in moisture (Wolseley and Aguirre-Hudson, 1996a). This change in the lichen microclimate is more pronounced in an area subjected to a rare homogeneous fire, where no or few cyanobacterial and Trentepohlioid lichens are present. However, this area has the greatest abundance of lichens with Trebouxia, which suggests that lichens with Trebouxia algae may prefer greater insolation, and be tolerant of dry conditions.

Although the frequency of lichens employing sexual reproduction is equal between plots with varying fire histories, the proportion of lichens using asexual reproduction is greatest in a past frequently burned area and in an area subjected to a rare homogeneous fire. The advantages of a vegetative strategy are greater survival of propagules (due to their large numbers and because both bionts are dispersed together), and rapid invasion of new habitats (Bowler and Rundel, 1975). This is highly beneficial in a regularly burned area, where the lichen population may be reduced to the point that sexual reproductive methods become non-viable. Invasive r-selected recolonisers after fire may also employ vegetative means of dispersal (Rogers, 1990), in order to quickly inhabit large bare surfaces produced in areas of frequent burning, and homogeneous fires. In both areas, the altered microclimate, characterised by higher temperatures and insolation, may allow vegetative propagules, which have a broader ecological amplitude and habitat range, to germinate and establish (Bowler and Rundel, 1975).

Isidiate species are usually considered to be K-selected competitors, whereas sorediate species are r-selected ruderals (Rogers, 1990). The high abundance of isidiate species in a past frequently burned area, and in an area subjected to a rare homogeneous fire, is therefore difficult to 
explain. It may be that isidia are more easily dispersed by wind and rain, or that most recolonisation after fire is occurring on phorophytes from above the flame height. Isidia are larger and heavier than soredia (Bowler and Rundel, 1975), and may therefore determine only local recolonisation down the trunk.

\subsubsection{Presence of fire and lichen species composition}

Two separate ordination and classification analyses were carried out. The first used Plot 1 (74-control), Plot 6 (86-control), and Plot 2 (74-91: Hom, H, M). The second ordination employed Plot 3 (74-92: Het, V, E), Plot 4 (74-92: Het, V, E) and Plot 5 (74-92: Het, V, E).

\section{a) Analyses of Plots 1,2 and 6: the identification of lichen indicator species} for fire frequency and behaviour

The first axis of the ordination analysis indicates that the dominant factor affecting lichen species may be fire history. Along axis 1, there is a gradient from fire protection (Plot 1 samples), followed by past frequent fires (Plot 6 samples), through to a recent rare homogeneous fire (Plot 2 samples). This suggests that a history of fire occurrence compared to complete fire protection is an important element. This is underlined by the dendrogram of the classification divisions, where at the first division, Plot 2 is grouped with Plot 6, rather than with Plot 1. It is suggested that the second axis of the ordination is phorophyte specificity, the dominant factor affecting lichens where fire is absent. The same lichen species are found to favour certain phorophytes as in the fire protected plot e.g. Coccocarpia species and Cladonia ramulosa on Vellozia squamata, and Arthopyrenia sp. ' 2 ' and Graphina sp. on Sclerolobium paniculatum. However, the fire history of an area may determine the influence of phorophyte specificity on lichen species. The ordination indicates that phorophyte specificity has a significant control on lichens where fire is absent, is less relevant where there has been some fire protection after frequent fires, and is insignificant in an area where there has been a recent, rare fire. Therefore, once fire is introduced into an area of cerrado denso, it becomes the primary determinant affecting lichen communities, with the role of phorophyte specificity decreasing with an increase in fire occurrence.

The combination of lichen species found to be indicative, i.e. showing a distinct grouping, of a fire protected area include Coccocarpia species, Cladonia species, Pyrrhospora russula, Buellia myriocarpa, Lecanora myriocarpoides, Ochrolechia pallescens, Parmelinella versiformis, Parmelinopsis horrescens, Pertusaria sp. '2' and 'Sterile White Crust' sp. '2'. The occurrence of Coccocarpia and Cladonia species in a fire protected area of cerrado denso may be due to the constant conditions, and higher humidity under the patches of dense canopy cover (see Section 8.4.2). "Pyrrhospora russula, Buellia myriocarpa, Ochrolechia pallescens and Lecanora myriocarpoides practically identify the cerrado" (Marcelo Marcelli, pers. comm., 29/6/95), and their occurrence as indicators of a fire protected area may be in terms of their abundance. For example, the dendrogram of 
the classification divisions shows that low abundances of $P$. russula, B. myriocarpa and $O$. pallescens in the burned plots characterise the first division. Therefore, although these species occur in burned areas, high abundances of these lichens may be indicative of a fire protected cerrado denso. P. russula, $B$. myriocarpa and $L$. myriocarpoides are typical of the well-lit areas within the vegetation, possessing coloured fruiting bodies which may protect them from high temperatures and illumination (Wolseley and Aguirre-Hudson, 1996a). O. pallescens is also characteristic of humid habitats (James et al., 1977), and may be more frequent in the denser and moister areas of the vegetation. Parmelinella versiformis and Pertusaria sp. '2', together with $P$. russula, B. myriocarpa, $O$. pallescens and L. myriocarpoides, were found in this study to reproduce only by means of fruiting bodies. This means that they need stable and large populations in order to reproduce, conditions met in areas where fire is absent. Parmelinopsis horrescens is more common in illuminated areas (Marcelli, 1993), and 'Sterile White Crust' sp. '2' was unidentifiable, so nothing is known about this species. This species was found throughout the different plots, and it may be an indicator of a fire protected area due to its high occurrence there.

The combination of lichen species found to be indicative of an area subjected to frequent fires in the past are Bulbothrix isidiza, B. suffixa, Canoparmelia caroliniana, Parmelinopsis sp. '3' and Chrysothrix sp.. B. isidiza, B. suffixa and C. caroliniana are all characteristic of well-lit areas (Hale, 1976a,b; Marcelli, 1993), and frequent burning in an area would have caused a decrease in canopy cover and an increase in light reaching all sections of the vegetation. These species are closely attached to the substrate, thereby reducing moisture loss, an adaptation to higher temperatures in more insolated areas. B. isidiza, C. caroliniana and Parmelinopsis sp. ' 3 ' all have dense isidia on their thalli, allowing rapid invasion of new habitats (Bowler and Rundel, 1975), and therefore being able to quickly and easily colonise bare bark after subsequent fires. $C$. caroliniana is also abundant in heavily polluted areas within Brazilian cities (Marcelo Marcelli, pers. comm., 29/6/95), and so within this study it may show high eutrophication of bark surfaces as a result of past frequent fires. Chrysothrix species are also indicators of eutrophication (Gilbert, 1992), and so Chrysothrix sp. found in this study may express eutrophication of bark surfaces in a frequently burned area.

The dendrogram of the classification divisions shows that high abundances of Canoparmelia caroliniana and Bulbothrix fungicola and a low abundance of Chrysothrix sp. are indicators of the past frequently burned plot. C. caroliniana and Chrysothrix sp. have already been discussed. $B$. fungicola is characteristically abundant in well-lit areas, and the presence of dense isidia on its thallus, allows rapid invasion onto new habitats (Hale, 1976b). The lack of a dense vegetation canopy, and regular bare substrate surfaces in a frequently burned area, are probably the ideal conditions for this successful species.

An area where there has been a recent rare homogeneous fire is characterised by a combination of the lichen species Bulbothrix fungicola, Canoparmelia amazonica, Flavoparmelia amplexa, Rimelia reticulata and 'Sterile Green Crust' sp.. The increase in light within the vegetation 
and the creation of bare bark surfaces after a fire probably allow greater recolonisation of B. fungicola, as discussed above. C. amazonica is also indicative of increased light levels, having a thallus closely appressed to the bark, and has moderate to dense isidia to aid recolonisation after fire (Hale, 1976a). The dendrogram of the classification divisions shows that high abundances of $C$. amazonica differentiates the plot subjected to a recent rare homogeneous fire from the other plots. F. amplexa is frequent in open, illuminated areas, and also contains usnic acid (Hale, 1976a), which may allow it to tolerate high temperatures once a canopy cover is removed by fire. $R$. reticulata has soredia on its thallus, a vegetative means of reproduction which may allow rapid recolonisation after fire. This species is also frequently found in disturbed savanna forest areas of northern Thailand (Wolseley and AguirreHudson, 1994). The 'Sterile Green Crust' sp. was unidentifiable, so it is impossible to say why it is an indicator of an area where there has been a recent rare homogeneous fire.

\section{b) Analyses of Plots 3, 4 and 5: the identification of lichen indicator species} for fire patchiness

The first axis of the ordination is suggested to reflect fire history. Since all three plots (Plots 3, 4 and 5) were subjected to patchy fires, axis 1 is proposed to show a gradient from a low density of fire patchiness (Plot 4 samples), followed by an intermediate density of fire patchiness (Plot 3 samples), through to a high density of fire patchiness (Plot 5 samples). The second axis is postulated to be phorophyte specificity, with the same lichen species favouring the exact phorophyte species, as was found in the fire protected plot (see Section 8.4.2) and above in Section 8.4.4a. Also, similar to previous results, the influence of phorophyte specificity on lichen species gradually becomes less significant as fire becomes dominant. In these results, the greater the density of fire patchiness, the smaller the effect of phorophyte specificity.

The lichen indicator species of a low density of fire patchiness include Coccocarpia imbricascens, Bulbothrix sensibilis, Laurera sp. and Chrysothrix candelaris. The occurrence of $C$. imbricascens may be due to the scarcity of disturbance maintaining humid conditions under some dense patches of canopy, as was found in the fire protected plot (see Section 8.4.4a). B. sensibilis is frequent in open areas, and only reproduces through fruiting bodies (Marcelli, 1993). It therefore probably requires constant conditions to be able to survive. The appearance of Laurera sp. and Chrysothrix candelaris as indicators is difficult to explain due to the lack of literature on these species. Laurera species are generally found in well-lit areas (Wolseley and Aguirre-Hudson, 1994), but nothing else about its ecology is known. C. candelaris, on the other hand, is characteristic of eutrophicated areas (Gilbert, 1992), and therefore may indicate the occurrence of fire, even if it is just found at a low density of fire patchiness.

Lichen indicators of an intermediate density of fire patchiness are Haematomma puniceum, Lecanora myriocarpoides and Chrysothrix sp.. A dendrogram of the classification divisions shows that some samples from the plot of an intermediate density of fire patchiness are common with 
the low density of fire patchiness samples, and others are common with the high density of fire patchiness samples. This may explain the occurrences of H. puniceum and L. myriocarpoides, which were found to be indicative of fire protected areas, and Chrysothrix sp. which is indicative of eutrophication due to frequent burning.

A high density of fire patchiness is indicated by Canoparmelia amazonica, $C$. caroliniana, Bulbothrix fungicola and B. isidiza. All these species were found to be characteristic of well illuminated areas and rapid invaders on new habitats. These conditions are probably met where a fire has been of a high patch density, thus resulting in a decrease of phorophyte cover.

\subsubsection{Summary: lichen indicators of fire history}

Fire histories are a mixture of varying fire variables, namely the frequency and behaviour of fire. From the results of Section 8.4.4a, possible groups of lichen species indicative of fire protection and fire frequency were found. All the plots analysed in Section 8.4.4b, however, were subjected to heterogeneous burns. Although the results show that there were lichen groups indicative of a low and a high fire heterogeneity, these are less apparent for an intermediate fire heterogeneity. Therefore, it is difficult to clearly discriminate between areas not at the extremes in burn density. Consequently, lichen indicators can only be used for identifying homogeneously, in contrast to heterogeneously, burned areas.

The groups of lichen species indicative of fire protection, fire frequency and the spatial pattern of fire are identified as the following:

1) fire protected:- Coccocarpia species, Cladonia species, Pyrrhospora russula, Buellia myriocarpa, Lecanora myriocarpoides, Ochrolechia pallescens, Parmelinella versiformis, Parmelinopsis horrescens, Pertusaria sp. '2' and 'Sterile White Crust' sp. '2';

2a) low fire frequency:- as in (1), together with Bulbothrix fungicola, B. isidiza, Canoparmelia amazonica and C. caroliniana;

2b) high fire frequency:- Bulbothrix fungicola, B. isidiza, B. suffixa, Canoparmelia caroliniana, Parmelinopsis sp. '3' and Chrysothrix sp.;

3a) heterogeneous fire with various flame heights:- as in (1), together with Bulbothrix fungicola, $B$. isidiza, Canoparmelia amazonica and C. caroliniana;

3b) homogeneous fire with various flame heights:- Bulbothrix fungicola, Canoparmelia amazonica, Flavoparmelia amplexa, Rimelia reticulata and 'Sterile Green Crust' sp..

However, in order to detect more specifically the fire history of an area, it is necessary to look at the frequencies of particular lichen indicator species, rather than just their presence or absence. The best lichen indicators of fire history are the species which have a high abundance, and a high sensitivity to different fire histories. It is also important that the lichen may be easily identifiable in the field. Based on these criteria, the following twelve lichen species were chosen for the LFH Key: Parmelinella versiformis; Lecanora myriocarpoides; Ochrolechia pallescens; Parmelinopsis 
horrescens; Cladonia ochroclora; Pertusaria sp. '2'; Buellia myriocarpa; Pyrrhospora russula; Bulbothrix isidiza; Canoparmelia caroliniana; Bulbothrix fungicola; Canoparmelia amazonica.

Based on the changes in frequencies of these twelve lichen species to variations in the different fire variables from this study, it is derived that they will deviate in the following ways:

1) fire influence;

a) fire protected:- all twelve species have high frequencies;

b) fire:- Parmelinella versiformis, Lecanora myriocarpoides, Ochrolechia pallescens, Parmelinopsis horrescens, Cladonia ochroclora, Pertusaria sp. '2', Buellia myriocarpa and Pyrrhospora russula greatly decrease in frequency, and the other species may become lower or remain the same. The species which decrease in frequency due to fire are probably affected by the elimination of shady areas within the vegetation e.g. Cladonia ochroclora and the decrease in humidity as temperatures increase e.g. Ochrolechia pallescens;

2) low frequency vs high frequency;

a) low frequency of fire:- the frequencies of all twelve species become lower. This lower frequency may be the result of the death of all these species within the flame zone, but rapid recolonisation occurs due the rarity of fire disturbance;

b) high frequency of fire:- Bulbothrix fungicola and Canoparmelia amazonica have frequencies higher than the 'fire protected' plot. Lecanora myriocarpoides and Parmelinella versiformis have extremely low values, and all the other species have low values. After each fire, B. fungicola and C. amazonica, both employing vegetative reproduction and preferring increased light levels, quickly invade bare bark. As fire frequency increases, the populations of these two species may increase with a rise in new habitats and more areas of the vegetation being subjected to high illumination. Other indicator species have low values after repeated fires because the sexual reproductive method of these species may restrict rapid recolonisation, and as the overall abundance of these species declines, few individuals remain for recolonisation of bare surfaces. These responses to frequent fires may be accentuated in $L$. myriocarpoides and $P$. versiformis, thereby giving them very low frequencies;

3) spatial pattern of fire;

a) heterogeneous, various flame heights:- the frequencies of all twelve species become lower. This lower frequency may be the result of the death of all these species within the flame zone, but rapid recolonisation occurs from the many lichens which may have escaped;

b) homogeneous, various flame heights:- Bulbothrix isidiza, Canoparmelia caroliniana, Bulbothrix fungicola and Canoparmelia amazonica have intermediate frequencies, and all the other species have extremely low values. After a homogeneous fire with varying flame heights, $B$. isidiza, C. caroliniana, B. fungicola and C. amazonica may rapidly invade the large areas of bare bark as a result of their vegetative means of reproduction. This type of fire may also substantially reduce the canopy cover, and increase insolation within the vegetation, favourable for B. isidiza, C. caroliniana, B. fungicola and $C$. 
amazonica. The other indicator species have low frequencies since their abundance may have been dramatically reduced and their sexual reproductive method impedes rapid recolonisation.

\subsection{The LFH Key using lichen species}

After evaluating the changes in the frequencies of the twelve lichen indicator species, the following indices for fire impact, fire frequency and the spatial pattern of fire are proposed:

1) Fire Impact Index (FII) $=\underline{\mathrm{N}-\mathrm{a}}$

$$
\mathrm{a}+0.5
$$

where,

$\mathrm{N}=$ the total frequencies of Parmelinella versiformis, Lecanora myriocarpoides,

Ochrolechia pallescens, Parmelinopsis horrescens, Cladonia ochroclora, Pertusaria sp. '2', Buellia myriocarpa and Pyrrhospora russula in a fire protected plot (Plot 1

of this study).

$\mathrm{a}=$ the total frequencies of Parmelinella versiformis, Lecanora myriocarpoides, Ochrolechia pallescens, Parmelinopsis horrescens, Cladonia ochroclora, Pertusaria sp. '2', Buellia myriocarpa and Pyrrhospora russula in plot $\mathrm{n}$.

For a fire protected plot, the value for the FII will be 0 . As the impact of fire increases, the FII will also increase. High values will be obtained for areas which have had either a high fire frequency or a homogeneous fire with high flame heights.

2) Fire Frequency Index $(\mathrm{FFI})=\underline{\mathrm{Bf}+\mathrm{Ca}}$

$$
\mathrm{Lm}+\mathrm{Pv}+0.5
$$

where,

$$
\begin{aligned}
& \mathrm{Bf}=\text { frequency of Bulbothrix fungicola } \\
& \mathrm{Ca}=\text { frequency of Canoparmelia amazonica } \\
& \mathrm{Lm}=\text { frequency of Lecanora myriocarpoides } \\
& \mathrm{Pv}=\text { frequency of Parmelinella versiformis }
\end{aligned}
$$

The FFI will be the lowest for a fire protected area, but with the occurrence of a fire, the FFI will increase. The highest values will be obtained for areas where there have been frequent burns in the past, but recent protection. However, in areas which have been frequently burned up to the present time, the FFI will be low, reaching very low values in areas burned very frequently. 
3) Spatial Pattern of Fire Index $(\mathrm{SPFI})=\mathrm{Bi}+\mathrm{Cc}+\mathrm{Bf}+\mathrm{Ca}$

$$
\mathrm{Pv}+\mathrm{Lm}+\mathrm{Op}+\mathrm{Ph}+\mathrm{Co}+\mathrm{Pes}+\mathrm{Bm}+\mathrm{Pr}+0.5
$$

where,

$$
\begin{aligned}
& \mathrm{Bi}=\text { frequency of Bulbothrix isidiza } \\
& \mathrm{Cc}=\text { frequency of Canoparmelia caroliniana } \\
& \mathrm{Bf}=\text { frequency of Bulbothrix fungicola } \\
& \mathrm{Ca}=\text { frequency of Canoparmelia amazonica } \\
& \mathrm{Pv}=\text { frequency of Parmelinella versiformis } \\
& \mathrm{Lm}=\text { frequency of Lecanora myriocarpoides } \\
& \mathrm{Op}=\text { frequency of Ochrolechia pallescens } \\
& \mathrm{Ph}=\text { frequency of Parmelinopsis horrescens } \\
& \mathrm{Co}=\text { frequency of Cladonia ochroclora } \\
& \mathrm{Pes}=\text { frequency of Pertusaria sp. ' } 2 \text { ' } \\
& \mathrm{Bm}=\text { frequency of Buellia myriocarpa } \\
& \mathrm{Pr}=\text { frequency of Pyrrhospora russula }
\end{aligned}
$$

The lowest value for the SPFI will be for a fire protected area. As the spatial pattern of fire becomes increasingly homogeneous, with higher flame heights, the SPFI will increase. A high value of SPFI will be for an area which has been burned homogeneously, with extremely high flame heights.

Therefore, using the frequency values from Table 6.4 (see Section 6.4.1) the fire histories for Plots 1 to 6 may be estimated. These values are shown in Table 8.2. For Plot 1 (74control), a Fire Impact Index (FII) value is 0, a Fire Frequency Index (FFI) value is 3, and a Spatial Pattern of Fire Index (SPFI) is 1 . The FII clearly indicates that no fires have occurred in this area for a long time (over 20 years for this study). The FFI and the SPFI are also low, suggesting fire protection in Plot 1. Plot 2 (74-91: Hom, H, M) has an FII value of 21, a FFI value of 16, and a SPFI value of 10. This indicates a high fire impact, an intermediate fire frequency and a fire of high homogeneity and flame heights. This corresponds with the known fire history of this plot of a rare, homogeneous burn with various flame heights. For Plot 3 (74-92: Het, V, E), Plot 4 (74-92: Het, V, M) and Plot 5 (7492: Het, V, L), all the indices have low values, although the FII values indicate that compared to the Plot 1 values, fire has occurred in these plots. Out of these three plots, the indices suggest that Plot 3 has had the highest fire frequency, fire homogeneity and flame heights, although results from the general lichen characteristics indicated that this plot was least affected by fire (see Section 8.3). Plot 6 (86-control) has a low FII and SPFI value, but a very high FFI value. This suggests that fires have been frequent in this area, but they may have been recently controlled. This corresponds with the known fire history of Plot 6 i.e. past frequent fires but recent protection. 
Table 8.2 The Fire Impact Index (FII), Fire Frequency Index (FFI) and Spatial Pattern of Fire Index (SPFI) values for Plots 1 to 6 of this study.

\begin{tabular}{|c||c|c|c|}
\hline Plot & FII & FFI & SPFI \\
\hline \hline 1 & 0 & 3 & 1 \\
2 & 21 & 16 & 10 \\
3 & 1 & 5 & 2 \\
4 & 1 & 3 & 1 \\
5 & 0.4 & 3 & 1 \\
6 & 2 & 33 & 4 \\
\hline
\end{tabular}

Therefore, the FII indicates the difference between a fire protected, and a burned plot. The FFI for a fire protected area is low, increases where fires have been rare, and is high for an area of past frequent fires. The SPFI for a fire protected plot is low, increases where there have been heterogeneous fires with various flame heights, increases further where fires have been homogeneous, and is high for an area where fire has been homogeneous with high flame heights.

\subsection{Towards a LFH Key using the lichen genus Bulbothrix (Table 8.4)}

The present study reveals that a population of the lichen genus Bulbothrix has a higher density of individuals within a fire protected compared to a burned area of cerrado denso. The Bulbothrix individuals in a fire protected area are also found to be larger in thallus size, and found on all parts of the phorophyte, though more commonly between $>1$ and $1.5 \mathrm{~m}$. These findings of a large population size, large thallus sizes, and a lichen preference to particular parts of the phorophyte trunk, in a fire protected area, are characteristic of older stages in lichen succession (James et al., 1977). The continuity of a fire protected area i.e. lack of disturbance, allows high abundances of species to establish and persist, and niche specialisation of particular groups of lichen species on the phorophyte trunk. Lichens exhibit radial growth, and a large thallus size represents a long period of continuity of the lichen environment (Hale, 1983). Therefore, the abundance of large sized individuals in the protected area of this study lends further testimony that there has been no disturbance in that plot.

This study also shows that there is no significant difference in the abundance of Bulbothrix individuals between an area subjected to a rare recent homogeneous fire, and an area frequently burned in the past but recently protected. Frequent burning causes a reduction in lichen abundance as a consequence of the decrease in the 'lichen source' i.e. the older lichens which may facilitate rapid recolonisation of burned areas, and the isolation of lichens above the flame height zone (see Section 8.2.3). This may explain the low proportion of Bulbothrix individuals found in the area burned frequently in the past, and the highest occurrence of individuals between. 1.5 to $2 \mathrm{~m}$ on the phorophyte trunk. However, recent protection in this plot of past frequent burns accounts for the high proportion of large sized Bulbothrix individuals present, and their significant presence at higher levels 
on the phorophyte may reflect the avoidance and survival of individuals above the flame height zone from regular fires.

In an area subjected to a rare recent homogeneous fire, all the lichens within the flame zone may have been destroyed, and there is insufficient time since the fire to allow the establishment of a population. Also, the homogeneous nature of the fire may have killed many lichens from all sections of the vegetation (see Section 8.2.3), demonstrated by the restriction of Bulbothrix individuals to between 1.5 to $2 \mathrm{~m}$ on the phorophyte trunk. The large proportion of small sized Bulbothrix individuals in the recently burned area expresses a high degree of recolonisation, which is a result of past protection within the area allowing the 'lichen source' to remain and assist propagation.

\subsection{The LFH Key using Bulbothrix individuals}

Since lichens grow radially, the size of Bulbothrix individuals can be useful in estimating the 'time-since-last-fire'. A ratio of the smallest to the largest individuals is employed:

$$
\begin{aligned}
& \text { 'Time-since-last-fire' index }=\underline{\text { frequency of individuals in thallus size class } \leq 49 \mathrm{~mm}^{2}} \\
& \text { frequency of individuals in thallus size class } \geq 250 \mathrm{~mm}^{2}+0.5
\end{aligned}
$$

Therefore, the higher the index value, the more recent the burn. For the plot protected for over 20 years in this study, this index has a value of 6 . The plot protected for 8 years has a index of 8 , whereas the recently ( 3 years ago) burned plot has a index of 154 .

\subsection{The Lichen Fire History (LFH) Key}

The Lichen Fire History (LFH) Key is presented in Tables 8.3 and 8.4. It is comprised of indices derived from measurements at three levels: the lichen community, producing the Mean Lichen Abundance (MLA), the Spatial Index of Fire (SIF), and the percentage recolonisation; the lichen species composition, producing the Fire Impact Index (FII), the Fire Frequency Index (FFI), and the Spatial Pattern of Fire Index (SPFI); and the thallus size of Bulbothrix individuals, producing the 'time-since-last-fire' index.

Although the MLA, SIF and percentage recolonisation are obtained from general measurements about the lichen population, they can provide a reasonable estimate of the fire history of an area per se. However, the drawback of these indices is that it is difficult to tell whether an area was frequently burned in the past, but recently protected, or was protected in the past but subjected to a recent, homogeneous fire with varying flame heights. This is because the MLA is considered an index of fire frequency. In the case of past frequently burned plots, recent protection may lead to an increase in the overall lichen population (i.e. MLA) through recolonisation from areas which survived the past fires, usually high in the phorophyte canopy. This increase in lichen abundance therefore masks the history of past fires. In a recent homogeneous burn with various flame heights, the 'intense' nature of 
the burn destroys most of the lichens within the flame zone, severely reducing the overall lichen population. Therefore, in this area, the MLA also indicates that there have been frequent fires.

So, to differentiate between the two scenarios, it is necessary to look at the lichen species composition. Using lichen indicator species, the Fire Frequency Index (FFI) can indicate whether fires have been frequent in a plot or not, independent of the nature of the fire, or recent protection. This is because particular lichen species have specific responses to frequent fires which does not affect the overall lichen community. Lichen indicator species can also give a better idea of the nature of past fires in an area than general measurements about the lichen community. For example, in this study, plots subjected to rare heterogeneous burns had higher Spatial Index of Fire (SIF) values than a past frequently burned, but recently controlled plot (see Section 8.3). The opposite was found for the Spatial Pattern of Fire Index (SPFI) using lichen indicators. Therefore, the SPFI is a better indication of the behaviour of the past frequent burns (more homogeneous with varying flame heights) due to the specific responses of indicator lichens, than the SIF which is governed by the general characteristic of lichen distribution.

Although lichen indicators can make a distinction between a homogeneous and a heterogeneous burn, it is not possible to distinguish between various degrees of heterogeneous burns (see Section 8.4). On the other hand, the general lichen population indices are able to separate out heterogeneous burns of various patch densities. This may be because heterogeneous burns haphazardly destroy the lichen communities, and so depending on the degree of heterogeneity, the overall lichen abundance will vary. The mosaic nature of burns will also randomly determine which lichen species survive. Therefore, although a more heterogeneous burn (i.e. of a higher patch density) will produce greater bare areas for recolonisation by 'homogeneous fire' lichen indicators, it is not possible to decipher how many of these lichen species survived the fire. This means that the overall frequencies of these indicator lichens will not vary due to the degree of fire heterogeneity, but a result of the randomness of their location within the vegetation, and the direction of the fire. So, lichen community indices are the best indicators for heterogeneous burns.

Thallus size of Bulbothrix individuals is the only indication of the 'time-since-lastburn'. This is due to the effect of fire behaviour on the lichen community and on lichen indicator species. A homogeneous burn with various flame heights will reduce the lichen community, and the frequencies of some indicator species, and so show a recent burn. A heterogeneous burn with various flame heights will not reduce the lichen community substantially, or the frequencies of some indicator species, so will indicate an old burn. Therefore, if both a homogeneous and heterogeneous burn occurred at the same time, each would show a different 'time-since-last-burn'.

Although the 'time-since-last-fire' index does give an estimation of how long ago a fire occurred, it is not valid if the fire occurred more than 10 years ago. Within a period of 8 years, the Bulbothrix thalli seem to be almost as large as those undisturbed for over 20 years (see Section 8.7), 


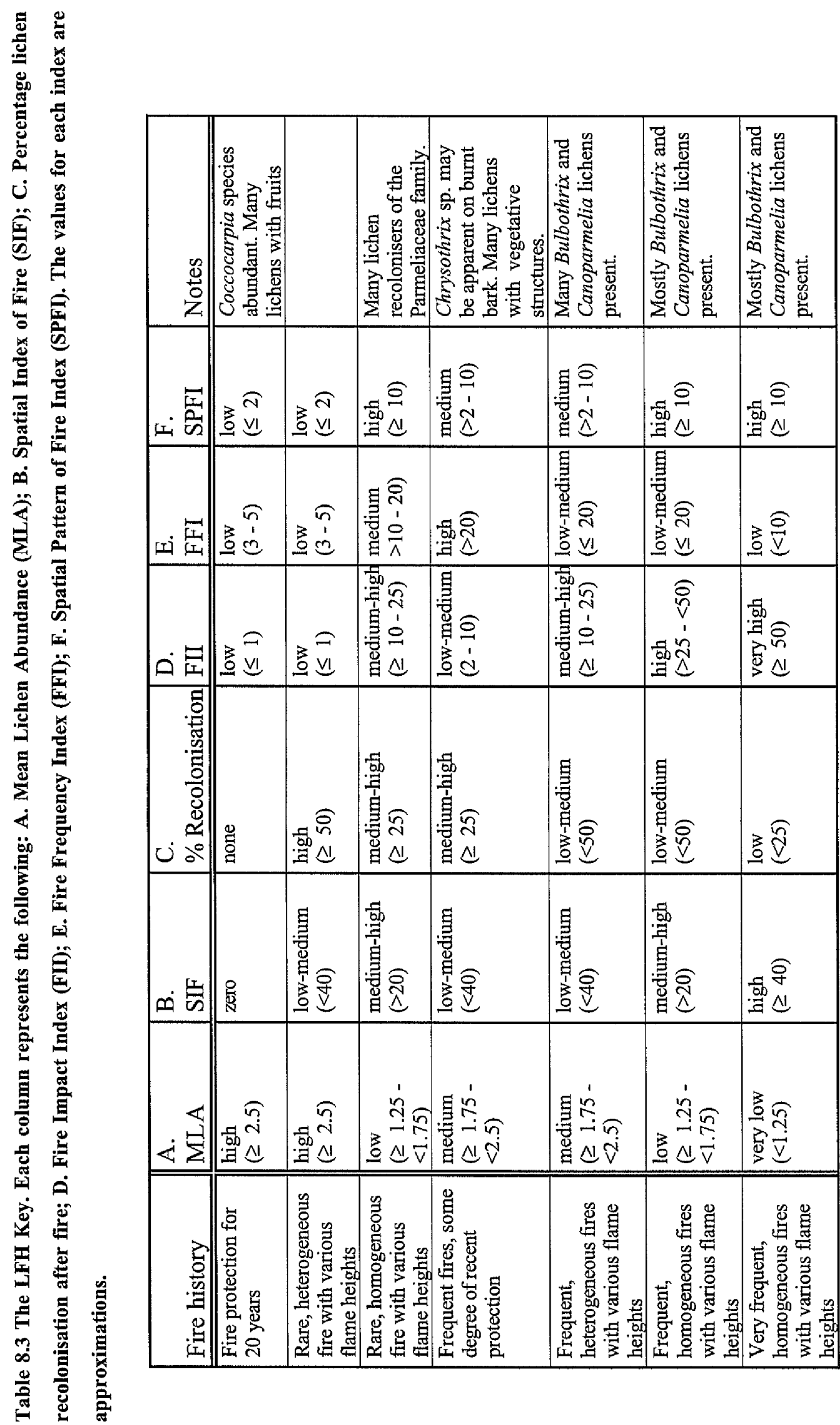


Table 8.4 The LFH Key: the 'time-since-last-fire' index. The values for the index are approximations.

\begin{tabular}{|l|l|l|l|l|l|}
\hline Fire history & $\begin{array}{l}\text { Protected from } \\
\text { fire for 20 yrs }\end{array}$ & $\begin{array}{l}\text { Last fire } 8 \\
\text { yrs ago }\end{array}$ & $\begin{array}{l}\text { Last fire 5 } \\
\text { yrs ago }\end{array}$ & $\begin{array}{l}\text { Last fire 3 } \\
\text { yrs ago }\end{array}$ & $\begin{array}{l}\text { Last fire } 1 \text { to } \\
2 \text { yrs ago }\end{array}$ \\
\hline \hline \multirow{2}{*}{ Index } & $\begin{array}{l}\text { very low } \\
(6)\end{array}$ & $\begin{array}{l}\text { low } \\
(8-<20)\end{array}$ & $\begin{array}{l}\text { medium } \\
(20-<100)\end{array}$ & $\begin{array}{l}\text { high } \\
(100-200)\end{array}$ & $\begin{array}{l}\text { very high } \\
(\geq 200)\end{array}$ \\
\hline
\end{tabular}

thereby giving similar index values. This may be because species within this genus are fast growing up to a number of years, after which growth slows down, so changes in thallus size are not great.

All the indices are necessary for the LFH Key. The more indices used, the more accurately can the fire history of an area be determined.

\subsubsection{The effectiveness of the LFH Key}

Data for the Mean Lichen Abundance (MLA), Spatial Index of Fire (SIF), and percentage recolonisation, indices using general lichen characteristics, can be collected very quickly and efficiently, since they rely on measurements taken by eye. For the MLA and SIF, scale measurements of the lichen abundance and distribution respectively were taken. However, this involves a degree of subjectivity, as each data recorder will have a personal bias. It is for this reason that the scales in this study were kept as concise and simple as possible. There were five levels for the lichen abundance, and three levels for the lichen distribution. Although presence/absence data is recorded for percentage recolonisation i.e. lichens on scorch, there are difficulties since the recorder has to first decide if scorch is present on the phorophyte. This is particularly problematic on phorophytes with naturally dark coloured bark types.

Frequency data on lichen indicator species and measuring the size of a Bulbothrix thallus is far more objective. However, although the indicator species were chosen for their easy identification, some recorders may still be unable to differentiate between two species of the same genus, or have problems with general identification. This problem of identification may also apply when measuring sizes of Bulbothrix individuals.

For the MLA, SIF and percentage recolonisation, 200 phorophytes were sampled. Calculations have shown that to obtain reliable results, 150 phorophytes need to be sampled, although the larger the sampling number, the better the results. For efficiency, 200 phorophytes are probably an ideal amount. Only 20 phorophytes were used for sampling the lichen indicator species, and recordings took place at four heights on each phorophyte. This may be a sufficient number, although the estimated fire histories would be more reliable if greater numbers, between 30 to 40 phorophytes were sampled. This is also true for measuring the thallus size of Bulbothrix recolonisers. Small-girthed phorophytes (between 5 and $12 \mathrm{~cm}$ in diameter) are the most appropriate for sampling. 


\subsubsection{The applicability of the LFH Key}

Even though the LFH Key has been developed for the Distrito Federal, it may be applied to other areas of the cerrado. The Distrito Federal has its own unique community of lichens as a result of the high altitude, but the species chosen as indicators may be commonly found throughout the cerrado region (Marcelo Marcelli, pers. comm., 29/6/95). However, it may be necessary to undertake an inventory of the lichen species within other cerrado areas in order to isolate indicator species of different fire histories which may be specific to a certain area. The phorophyte species of the LFH Key are also common in the denser forms of cerrado vegetation, so may be used throughout the cerrado range.

This LFH Key has been developed to detect fire histories only up to 20 years ago, but in some areas the fire history may be much longer. Here, the LFH Key may give a rough estimation of the fire history. For example, if an area of cerrado denso has been protected from fire for 40 years, the LFH key will detect fire protection for 20 years i.e. there has been long-term fire protection. However, the LFH will not reflect the true time-scale of the fire history.

Since the LFH Key is based on corticolous lichens, it is constrained to areas of cerrado which have a substantial woody presence. This includes the cerradão, cerrado sensu stricto and campo cerrado, and any variations or mosaics of these vegetation types.

In areas where other forms of disturbance may have taken place, the LFH Key may give false indications. For example, if an area of cerrado denso is cleared for agriculture, this will destroy the whole lichen community. However, if later, this same area is abandoned, and the vegetation achieves the status of cerrado denso once again, lichens will still be absent due to the death of the 'lichen source'. If fire does not occur in this area after being abandoned, it may be obvious that the cause of the 'lichen deserts' is a factor independent of fire. However, if fire does occur, the LFH Key will indicate that the 'lichen deserts' were formed due to past frequent, homogeneous fires with high flame heights, which is not true.

The LFH Key may be applicable in other areas of the world where fire is a determinant of the vegetation. These areas have to contain enough woody individuals to support a lichen population, and these lichen populations have to be abundant in order for changes in fire histories to be detected. Potential locations include the Mediterranean macchia, the Southern African fynbos, the North American chaparal, dry dipterocarp forests of South East Asia, and the Australian eucalypt forests.

\subsubsection{Suggestions for further research}

The work described here provides a means of rapidly assessing the fire history of an area, using general measurements about the lichen community, and a select number of lichen indicator species, without recourse to elaborate and expensive equipment. However, the development of the LFH Key was intended to be exploratory, and is based only on one relatively small area of cerrado denso. 
Other areas, both within the Distrito Federal, and in other cerrado regions, subject to different fire regimes, need to be sampled and incorporated into the LFH Key. Further insight is also needed on the reliability of the LFH Key by means of long-term monitoring of lichen communities. This may be carried out by setting up permanent plots in areas where fires are recorded or prescribed, and taking yearly or biennial measurements of any changes in the lichen communities.

\subsection{Presentation of the LFH Key booklet}

The LFH Key in the form of a working booklet is presented in Appendix 5, enclosed at the back of the thesis. It is divided into three parts: the use of general lichen characteristics; the use of lichen indicator species; and the use of Bulbothrix thallus sizes. Within these sections there are directions on how sampling should be carried out, the number and species of phorophyte species needed, and how to measure the different lichen variables. Following this is the LFH Key for determining the fire history of an area. At the end of the booklet are the Checksheets for each part of the LFH Key, and the Calculation Sheets. These can be pulled out of the booklet for making multiple copies.

This LFH Key is a simpler version of the one presented in Section 8.8. Identifying the lichen indicator species is one of the most difficult aspects of the LFH Key, so in this simple version, their number is reduced to only four. By using lichen abundance, distribution and recolonisation, a general picture of the fire history of an area can be formed. The four lichen indicators are used to estimate the fire frequency, as the general lichen characteristics can sometimes give a false indication of fire frequency (see Section 8.8). Thallus sizes of Bulbothrix individuals give the 'timesince-last-fire'.

\subsection{Conclusion}

This thesis has demonstrated that corticolous lichens can be used effectively to indicate the fire history of an area of cerrado denso. A Lichen Fire History (LFH) Key has been produced using the lichen-indicating characteristics of abundance, distribution, recolonisation, species composition, and thallus size of individuals within the genus Bulbothrix. This LFH Key is also presented in a simpler version as a working booklet to be used in the field. In order to investigate the reliability of the key, and its applicability in other areas of cerrado, long-term monitoring in different areas subjected to varying fire regimes needs to be carried out. This research demonstrates that corticolous lichens might be successfully employed as indicators of fire history in any area where the woody flora and fire are integral components of the ecosystem. The technique, therefore, is unlikely to be limited to savanna formations, but could potentially have world-wide applications. 


\section{Bibliography}

Aberg, B. and Hungate, F.P. (1967). Radioecological Concentration Processes. Pergamon Press. Oxford.

Abrams, M.D. and Nowacki, G.J. (1992). Historical variation in fire, oak recruitment, and postlogging accelerated succession in central Pennsylvania. Bulletin of the Torrey Botanical Club, 119: $19-28$.

Abrams, M.D., Orwig, D.A. and Demeo, T.E. (1995). Dendroecological analysis of successional dynamics for a presettlement-origin white-pine-mixed-oak forest in the southern Appalachians, USA. Journal of Ecology, 83: 123-133

Ab'Saber, A.N. (1971). A organização natural das paisagens inter e subtropicais brasileiras. In: Ferri, M.G. (org). III Simpósio sobre o Cerrado. pp. 1-14. Editora da Univ. de São Paulo. São Paulo.

--.--(1977). Espaços ocupados pela expansão dos climas secos na América do Sul por ocasião dos periodos glaciais quaternários. Paleoclimas, 3: 1-19.

-----(1983). O dominio dos Cerrados: uma introdução ao conhecimento. Revista do Serviço Público, 40: $41-55$.

Agee, J.K. (1991). Fire history along an elevational gradient in the Siskiyou Mountains, Oregon. Northwest Science, 65 (4): 188-199.

Ahmadjian, V. (1993). The lichen symbiosis. John Wiley \& Sons, Inc. Toronto, Canada.

Ahmadjian, V. and Jacobs, J.B. (1981). Relationship between fungus and alga in the lichen Cladonia cristatella Tuck. Nature, 289: 169-172.

Ahmadjian, V. and Paracer, S. (1986). Symbiosis: an introduction to biological associations. University Press of New England. Hanover, N.H.

Ahti, T. (1977). Lichens of the boreal coniferous zone. In: Seaward, M.R.D. (ed). Lichen Ecology. pp. 145-181. Academic Press. London.

-----(1986). New species and nomenclatural combinations in the lichen genus Cladonia. Annales Botanici Fennici, 23: 205-220. 
Alencar, G. de (1979). O programa de desenvolvimento de região dos cerrados. In: Marchetti, D. and Machado, A.D. (eds). Cerrados: uso e manejo. V Simpósio sobre o cerrado. pp. 37-58. Empresa Brasileira da Pesquisa Agropecuária, CPAC-CNPq, Brasilia.

Alexander, R.W. (1982). The interpretation of lichen and fungal response to decreasing sulphur dioxide levels on Merseyside. Environmental Education and Information, 2: 193-202.

Allen, M.F. (1991). The ecology of mycorrhizae. Cambridge Studies in Ecology. Cambridge University Press.

Almeida, S.P. and Silva, J.C.S. (1989). Influência do fogo sobre aspectos fenológicos de gramineas nativas dos cerrados. EMBRAPA/CPAC. Pesquisa em Andamento 28.

Alvim, P. de T. (1964). Tree growth periodicity in tropical climates. In: Zimmermann, M.H. (ed). The formation of wood in forest trees. pp. 479-495. Academic Press. New York, London and San Francisco.

Andersen, A.N. (1995). A classification of Australian ant communities, based on functional groups which parallel plant life-forms in relation to stress and disturbance. Journal of Biogeography, $22(1): 15-29$.

Andersen, A.N. and Lonsdale, W.M. (1991). Herbivory by insects in Australian tropical savannas: a review. Journal of Biogeography, 17 (4/5): 89-100.

Anderson, A.B. and Posey, D.A. (1985). Manejo de cerrado pelos indios Kayapó. Boletim do Museu Paraense Emilio Goeldi Botânica, 2(1): 77-98.

----(1987). Reflorestamento indigena. Ciência Hoje, 6: 44-50.

Araújo, G.M. de (1984). Comparação de estudo nutricional de dois cerradãos em solos distróficos e mesotróficos no planalto do Brasil. Tese de Mestre. Univ. de Brasilia.

Armstrong, R.A. (1973). Seasonal growth and growth rate- colony size relationships in six species of saxicolous lichens. New Phytologist, 72: 1023-1030.

-.---(1975). The influence of aspect on the patterns of seasonal growth in the lichen Parmelia glabratula spp. fuliginosa (Fr. ex Duby) Laund. New Phytologist, 75: 245-251.

-...--(1977). The responses of lichen growth to transplantation to rock surfaces of different aspect. New Phytologist, 78: 473-478. 
Arvidsson, L. (1982). A monograph of the lichen genus Coccocarpia. Opera Botanica, 67.

Ascaso, C. (1985). Structural aspects of lichens invading their substrata. In: Vicenti, C., Brown, D.H. and Estrella Legaz, M. (eds). Surface physiology of lichens. pp. 87-113. Universidad Complutense de Madrid. Madrid.

Askew, G.P., Moffatt, D.J., Montgomery, R.F. and Searl, P.L. (1970). Interrelationships of soil and vegetation in the savanna-forest boundery zone of north-eastern Mato Grosso. Geographical Journal, 136: 370-376.

Barbetti, M. (1986). Traces of fire in the archaeological record before one million years ago? Journal of Human Evolution, 15: 771-781.

Bargagli, R., Iosco, F.P. and Barghigiani, C. (1987). Assessment of mercury disposal in an abandoned mining area by soil and lichens. Water, Air and Soil Pollution, 36: 219-225.

Barkman, J.J. (1958). Phytosociology and Ecology of Cryptogamic Epiphytes. Van Gorcum. Assen.

Barros, C.J.G. (1994). Caracterização geológica e hidrogeológica. In: Novaes-Pinto, M. (org). Cerrado, Caracterização, Ocupação e Perspectivas (2a edição). pp. 265-284. Editora Universidade de Brasilia. Brasilia D.F.

Batchelder, R.B. (1968). Spatial and temporal pattern of fire in the tropical world. Proceedings of Tall Timbers Fire Ecology Conference, 1967(6): 171-207.

Bates, J.W. (1992). Influence of chemical and physical factors on Quercus and Fraxinus epiphytes at Loch Sunart, western Scotland: a multivariate analysis. Journal of Ecology, 80: 163-179.

Bates, J.W., Bell, J.N.B. and Farmer, A.M. (1990). Epiphyte recolonisation of oaks along a gradient of air pollution in south-east England, 1979-1990. Environmental Pollution, 68: 81-99.

Batmanian, G.T. (1983). Efeitos do fogo sobre a produção primária e a acumulação de nutrientes do estrato rasteiro de um cerrado. Mestrado tese, Dept. de Biologia Vegetal, Universidade de Brasilia, Brasilia D.F.

Beck, J.N. and Ramelow, G.J. (1990). Use of lichen biomass to monitor dissolved metals in natural waters. Bulletin of Environmental Contamination and Toxicology, 44: 302-308. 
Beckett, P.J., Boileau, L.J.R., Padovan, D. and Richardson, D.H.S. (1982). Lichens and mosses as monitors of industrial activity associated with uranium mining in Northern Ontario, CanadaPart 2: Distance dependent uranium and lead accumulation. Environmental Pollution (Series B), 4: 91-107.

Benedict, J.B. (1990). Winter frost injury to lichens-Colorado front range. Bryologist, 93: 423-426.

Berardi, A. (1994). Effects of the African grass Melinis minutiflora on the plant community composition and fire characteristics of a central Brazilian savanna. Unpublished MSc thesis. University College, University of London. London.

Beschel, R.E. (1973). Lichens as measures of the age of recent moraines. Arctic and Alpine Research, 5: 303-309.

Blyum, O.B. and Tyutyunnik, Yu.G. (1985). Istorichnii biomonitoring vmistu svintsyu v atmosferi z dopomogoyu lishainikiv. Dopovidi Akademii nauk URSR, ser.B., 10: 52-54.

Bourlière, F. (ed). (1983). Tropical Savannas. Ecosystems of the World 13. Elsevier Scientific Publishing Company. Amsterdam.

Bourlière, F. and Hadley, M. (1983). Present-day savannas. In: Bourlière, F. (ed). Tropical Savannas. Ecosystems of the World 13. pp1-17. Elsevier Scientific Publishing Company. Amsterdam.

Bowler, P.A. and Rundel, P.W. (1975). Reproductive strategies in lichens. Botanical Journal of the Linnean Society, 70: 325-340.

Brain, C.K. and Sillen, A. (1988). Evidence from the Swartkrans cave for the earliest use of fire. Nature, 336: 464-466.

Braithwaite, R.W. (1991). Aboriginal fire regimes of monsoonal Australia in the 19th century. Search, 22: $247-249$.

Bridges, E.M. (1978). World Soils. 2nd Edition. Cambridge University Press. Cambridge.

Brodo, I.M. (1961). Transplant experiments with corticolous lichens using a new technique. Ecology, 42: $838-841$. 
-.--(1968). The lichens of Long Island, New York: a vegetational and floristic analysis. N.Y. State Museum Bulletin, 410.

-----(1974). Substrate ecology. In: Ahmadjian, V. and Hale, M.E. (eds). The Lichens. pp 401-444. Academic Press. New York.

Brown, D.H. (1992). Impact of agriculture on bryophytes and lichens. In: Bates, J.W. and Farmer, A.M. (eds). Bryophytes and Lichens in a Changing Environment. pp. 259-283. Clarendon Press. Oxford.

Brown, D.H. and Kershaw, K.A. (1984). Photosynthetic capacity changes in Peltigera 2. Contrasting season patterns of net photosynthesis in two populations of Peltigera rufescens. New Phytologist, 96: 447-457.

Brown, K.S.Jr (1987). Soils and vegetation. In: Whitmore, T.C. and Prance, G.T. (eds). Biogeography and Quaternary history in tropical America. pp. 19-45. Oxford Science Publications. Oxford.

Brown, P.M. and Sewtnam, T.W. (1994). A cross-dated fire history from the coast Redwood near Redwood National Park, California. Canadian Journal of Forest Research, 24 (1): 21-31.

Büdel, B. (1992). Taxonomy of lichenized procaryotic blue-green algae. In: Reisser, W. (ed). Algae and Symbioses: Plants, Animals, Fungi, Viruses. Interactions Explored. pp. 301-324. Biopress Ltd. Bristol.

Büscher, P., Koedam, N. and Van Speybroek, D. (1990). Cation-exchange properties and adaptation to soil acidity in bryophytes. New Phytologist, 115: 177-186.

Bush, M.B. (1994). Amazonian speciation: a necessarily complex model. Journal of Biogeography, 21: 5-17.

Bush, M.B., Colinvaux, P.A., Wiemann, M.C., Piperno, D.R. and Liu, M.-B. (1990). Pleistocene temperature depression and vegetation change in Ecuadorian Amazonia. Quaternary Research, 34: 330-345.

Camargo, M.N. and Bennema, J. (1966). Delineamento esquemático dos Solos do Brasil. Pesquisa Agropecuaria Brasileira, 1: 47-54. 
Camenzind, R. and Wildi, E. (1991). The epiphytic lichen flora of the Gurnigel-Gantrisch forest (Canton of Berne, Switzerland). Botanica Helvetica, 101(2): 183-197.

Caniglia, G. and Drudi, C. (1984). Considerazioni sulla distribuzione dei licheni in laguma di Venezia. Rendiconti del Seminario della Facolta di Scienza dell'Universita di Cagliari, 54 (Suppl.): 197-213.

Carlisle, A., Brown, A.H.F. and White, E.J. (1967). The nutrient content of tree stem flow and ground flora litter and leachates in a sessile oak (Quercus petraea) woodland. Journal of Ecology, 55: 615-627.

Causton, D.R. (1988). Introduction to vegetation analysis. Unwin Hyman. London.

Cavalcanti, L.H. (1978). Efeito das cinzas resultantes da queimada sobre a productividade da estrato herbáceo subarbustivo do cerrado de Emas. Tese de doctorado. Univ. de São Paulo.

Cesar, H.L. (1980). Efeitos da Queima e Corte sobre a vegetação de um campo sujo na Fazenda Agua Limpa, Distrito Federal. Mestre tese. Universidade de Brasilia, Brasilia D.F.

Chuvieco, A.E. and Congalton, R.G. (1988). Mapping and inventory of forest fires from digital processing of TM data. Geocarto International, 4: 41-53.

Clark, J.S. (1988). Charcoal-stratigraphy analysis on petrographic thin sections: recent fire history in northwest Minnesota, Quaternary Research, 30: 67-80.

-----(1990). Patterns of fire occurrence during the last 750 years, northwestern Minnesota. Ecological Monographs, 60 (2): 135-159.

Clark, J.S. and Royall, P.D. (1994). Pre-industrial particulate emissions and carbon sequestration from biomass burning in North America. Biogeochemistry, 23: 35-51.

Clarkson, D.T. (1969). Metabolic aspects of aluminium toxicity and some possible mechanisms for resistance. In: Rorison, I.H. (ed). Ecological aspects of the mineral nutrition of plants. A symposium of the British Ecological Society. pp. 381-397. Blackwell Scientific Publications. Oxford and Cambridge. 
Cochrane, T.T., Porras, J.A., Henão, M.R. (1988). The relative tendency of the cerrados to be affected by Veranicos; a provisional assessment. In: VI Simpôsio Sobre o Cerrado. Savannas: Alimento e Energia. pp. 229-239. EMBRAPA, Planaltina, D.F.

Cochrane, T.T., Sánchez, L.G., Azevedo, L.G.d.,Porras, J.A., Garver,C.L (1985). Land in Tropical America, Cali, Colombia. Centro Internacional de Agricultura Tropical (CIAT). Empresa Brasileira de Pesquisa Agropecuária (EMBRAPA).

Cole, M.M. (1960). Cerrado, caatinga and pantanal: the distribution and origin of the savanna vegetation of Brazil. Geographical Journal (London), 126: 168-179.

Collins, C.R. and Farrar, J.F. (1978). Structural resistance to mass transfer in the lichen Xanthoria parietina. New Phytologist, 81: 71-83.

Connor, M., Dempsey, E., Smyth, M.R. and Richardson, D.H.S. (1991). Determination of some metal ions using lichen-modified carbon paste electrodes. Electroanalysis, 3: 331-336.

Constantino, R. (1988). Influência da macrofauna na dinâmica de nutrientes do folhedo em decomposição em cerrado sensu stricto. Tese de mestrado. Departamento de Biologia Vegetal, Universidade de Brasilia.

Cornelissen, J.H.C. and Ter Steege, H. (1989). Distribution and ecology of epiphytic bryophytes and lichens in dry evergreen forest of Guyana. Journal of Tropical Ecology, 5: 131-150.

Cottam , G. and Curtis, J.T. (1949). A method for making rapid surveys of woodlands by means of pairs of randomly selected trees. Ecology, 30: 101-104.

----(1956). The use of distance measures in phytosociological sampling. Ecology, 37: 451-460.

Cottam, G., Curtis, J.T. and Hale, B.W. (1953). Some sampling characteristics of a population of randomly dispersed individuals. Ecology, 34: 741-757.

Coutinho, L.M. (1976). Contribuição ao conhecimento do papel ecológico das queimadas na floração de espècies do cerrado. Livre-docente tese. Universidade de São Paulo, São Paulo.

-----(1977). Aspectos ecológicos do fogo no cerrado. II- as queimadas e a dispersão de sementes em algumas espècies anemocóricas do estrato herbáceo-subarbustivo. Boletim Botânica, Univ. S. Paulo, 5: 57-64.

-----(1978a). O conceito de cerrado. Revista Brasileira de Botânica, 1: 17-23. 
-----(1978b). Aspectos ecológicos do fogo no cerrado. I- A temperatura do solo durante as queimadas. Revista Brasileira de Botânica, 1(2): 93-96.

-----(1979). Aspectos ecológicos do fogo no cerrado. III- A precipitação atmosférica de nutrientes minerais. Revista Brasileira de Botânica, 2(2): 97-101.

-----(1982a). Ecological effects of fire in Brazilian Cerrado. In: Huntley, B.J. and Walker, B.H. (eds). Ecology of Tropical savannas. pp. 273-291. Ecological Studies, 42.

-.-.-(1982b). Aspectos ecológicos da saúva no cerrado - a saúva, as queimadas a sua possivel relação na ciclagem de nutrientes minerais. Boletim de Zoologia, Univ. São Paulo, 8: 1-9.

----(1990). Fire in the Ecology of the Brazilian Cerrado. In: Goldammer, J.G. (ed). Fire in the Tropical Biota. pp. 82-105. Springer-Verlag. Berlin.

Coutinho, L.M. and Jurkewics, I.R. (1978). Aspectos ecológicos do fogo no cerrado. V - O efeito de altas temperaturas ne germinação de uma espécie de Mimosa. Ciência e Cultura, 30 (resumos): 420 .

Coutinho, L.M., Pagano, S.N. and Sartori, A.A. (1978). Sobre o teor de água e nutrientes minerais em xilopódios de algumas espécies de cerrado. Ciência e Cultura, 30 (resumos): 349-350.

Cowan, I.R., Lange, O.L. and Green, T.G.A. (1992). Carbon dioxide exchange in lichens: Determination of transport and carboxylation characteristics. Planta, 187: 282-294.

Coxson, D.S. (1987a). The temperature dependence of photoinhibition in the tropical basidiomycete lichen Cora pavonia E. Fries. Oecologia, 73: 447-453.

-----(1987b). Photoinhibition of net photosynthesis in Stereocaulon virgatum and $S$. tomentosum, a tropical-temperate comparison. Canadian Journal of Botany, 65: 1707-1715.

Crawford, R.M.M. (1989). Studies in plant survival. Ecological case histories of plant adaptations to adversity. Blackwell Scientific Publications. Oxford.

Curtis, J.T. (1959). The vegetation of Wisconsin. An ordination of plant communities. Univ. of Wisconsin Press. Madison.

Curtis, J.T. and McIntosh, R.P. (1950). The interrelations of certain analytic and synthetic phytosociological characters. Ecology, 31: 434-455.

-.-.-.(1951). An upland forest continuum in the prairie-forest border region of Wisconsin. Ecology, 32: 476-496. 
Cutter, B.E. and Guyette, R.P. (1994). Fire frequency on an oak-hickory ridgetop in the Missouri Ozarks. American Midland Naturalist, 132 (2); 393-398.

Dansereau, P.R. and Bergeron, Y. (1993). Fire history in the southern boreal forest of northwestern Quebec. Canadian Journal of Forest Research, 23 (1): 25-32.

Da Silva, F.C. (1990). Compartilhamento de nutrientes em diferentes componentes da biomassa aérea em espécies arbóreas de um cerrado. Tese de mestrado. Departamento de Ecologia, Universidade de Brasilia. Brasilia-D.F.

Daubenmire, R. (1968). The ecology of fire in grasslands. Advanced Ecological Research, 5: 209-266.

Davies, F.B.M. and Notcutt, G. (1988). Accumulation of fluoride by lichens in the vicinity of Etna volcano. Water, Air and Soil Pollution, 42: 365-371.

Day, I.P. (1985). Lichens in Borrowdale and pollution. Report to the Nature Conservancy Council, Peterborough.

Dcosta, D.M. and Kershaw, A.P. (1995). A late Pleistocene and Holocene pollen record from Lake Terang, western plains of Victoria, Australia. Palaeogeography, Palaeoclimatology, Palaeoecology, 113 (1): 57-67.

De Bakker, A.J. (1987). Physcia stellaris (L.) Ach. in Nederland. Gorteria, 13: 210-215.

-----(1989). Effects of ammonia emission on epiphytic lichen vegetation. Acta Botanica Neerlandica, 38: $337-342$.

De Sloover, J. and LeBlanc, F. (1970). Pollutions atmosphériques et fertilité chez les mousses et chez les lichens épiphytiques. Academie et Société Lorraines de Sciences Bulletin, 9: 82-90.

Denton, G.H. and Karlen, W. (1973). Lichenometry: its application to holocene moraine studies in southern Alaska and Swedish Lapland. Arctic and Alpine Research, 5: 347-372.

Dias, B.F. de S. (1994). A conservação da natureza. In: Novaes-Pinto, M. (org). Cerrado. Caracterização, Ocupação e Perspectivas (2 ${ }^{a}$ edição). pp. 607-664. Editora Universidade de Brasilia. Brasilia D.F. 
Dietrich, M. (1991). The lichen flora of the Merli forest, Giswil Ow (central Switzerland). Botanica Helvetica, 101 (2): 167-182.

Diniz de Araújo Neto, M., Furley, P.A., Haridasan, M. and Johnson, C.E. (1986). The murundus of the cerrado region of central Brazil. Journal of Tropical Ecology, 2: 17-35.

Dionello, S.B. (1978). Germinação de sementes e desenvolvimento de plântulas de Kielmeyera coriacea Mart. DSc tese. Univ. de São Paulo. São Paulo.

Eden, M.J. (1990). Ecology and land management in Amazonia. Belhaven Press. London.

Egler, I. and Haridasan, M. (1987). Alteration of soil properties by Procornitermes araujoii (Isoptera, Termitidaei) in latosols of the Cerrado region of Brazil. In: San Jose, J.J. and Montes, R. (eds). La capacidad bioproductiva de sabanas. pp. 280-308. I.V.I.C. Caracas.

Eiten, G. (1972). The cerrado vegetation of Brazil. The Botanical Review, 38(2): 201-341.

-.-.-(1975). The vegetation of the Serra do Roncador. Biotropica, 7: 112-135.

----(1978). Delimitation of the cerrado concept. Vegetatio, 36: 169-178.

----(1982). Brazilian "Savannas". In: Huntley, B.J. and Walker, B.H. (eds). Ecology of Tropical Savannas. pp. 25-47. Ecological Studies, 42.

-...-.(1994). Vegetação. In: Novaes-Pinto, M. (org). Cerrado. Caracterização, Ocupação e Perspectivas (2@ edição). pp. 17-73. Editora Universidade de Brasilia. Brasilia D.F.

Eiten, G. and Goodland, R. (1979). Ecology and management of semiarid ecosystems in Brazil. In: Walker, B.H. (ed). Management of semiarid ecosystems. pp. 277-300. Elsevier. Amsterdam.

Elix, J.A. (1993). Progress in the Generic Delimitation of Parmelia sensu lato Lichens (Ascomycotina: Parmeliaceae) and a synoptic Key to Parmeliaceae. The Bryologist, 96(3): 359-383.

EMBRAPA. (1980). Avaliação da fertilidade dos solos do Distrito Federal. (Boletim Técnico no. 74). Rio de Janeiro.

-----(1987). Levantamento de reconhecimento dos solos do Distrito Federal. (Boletim Técnico no. 53). Rio de Janeiro.

Farkas, E., Lokos, L. and Verseghy, K. (1985). Lichens as indicators of air pollution in the Budapest agglomeration. Acta Botanica Hungarica, 31: 45-68. 
Farmer, A.M., Bates, J.W. and Bell, J.N.B. (1990). A comparison of methods for the measurement of bark pH. The Lichenologist, 22(2): 191-197.

----(1991). Seasonal variations in acidic pollutant inputs and their effects on the chemistry of stemflow, bark and epiphyte tissues in 3 oak (Quercus petraea (Mattuschka) Liebl Woodlands in NW Britain. New Phytologist, 118 (3): 441-451.

Farrar, J.F. and Smith, D.C. (1976). Ecological physiology of the lichen Hypogymnia physodes. III. The importance of the rewetting phase. New Phytologist, 77: 115-125.

Felfili, J.M. and Silva Jr, M.C. (1988). Distribuição dos diametros numa faixa de cerrado na Fazenda Agua Limpa (FAL) in Brasilia-D.F.. Acta Botânica Brasilica, 2(1-2): 85-104.

-----(1992). Floristic composition, phytosociology and comparison of cerrado and gallery forests at Fazenda Agua Limpa, Federal District, Brazil. In: Furley, P.A., Proctor, J. and Ratter, J.A. (eds). Nature and Dynamics of Forest-Savanna Boundaries. pp. 393-416. Chapman and Hall. London.

---(1993). A comparative study of cerrado (sensu stricto) vegetation in Central Brazil. Journal of Tropical Ecology, 9: 277-289.

Fenton, A.F. (1960). Lichens as indicators of atmospheric pollution. Irish Naturalists' Journal, 13: 153-159.

Ferri, M.G. (1944). Transpiração de plantas permanentes dos "cerrados". Univ. São Paulo, Fac. Filosofia, Ciências Letras, 41(4): 155-224.

-----(1973). Sobre a origem, a manutenção e a transformação dos cerrados, tipos de savana do Brasil. Revta Biologica, 9: 1-13.

Ferry, B.W. and Coppins, M.J. (1979). Lichen transplant experiments and air pollution studies. The Lichenologist, 11: 63-73.

Filgueiras, T. and Pereira, B.A.S. (1994). Flora do Distrito Federal. In: Novaes-Pinto, M. (org). Cerrado: Caracterização, Ocupação e Perspectivas (2â edição). pp. 345-404. Editora Universidade de Brasilia. Brasilia D.F.

Filion, L. and Payette, S. (1989). Subarctic lichen polygons and soil development along a colonisation gradient on eolian sands. Arctic and Alpine Research, 21: 175-184. 
Fisher, P.J. and Proctor, M.C.F. (1978). Observations on a season's growth in Parmelia caperata and P. sulcata in south Devon. The Lichenologist, 10: 81-89.

Foldats, E. and Rutkis, E. (1975). Ecological studies of chaparro (Curatella americana L.) and manteco (Byrsonima crassifolia H.B.K.) in Venezuela. Journal of Biogeography, 2: 159-178.

Freire, E. Maues da Serra (1979). Influència das propriedades do solo na distribuição de comunidades de vegetação em uma toposseqüencia, em área da $2^{a}$ Superficie de erosão do planalto central Brasileiro, na Fazenda Agua Limpa - D.F.. Tese de mestre. Univ. de Brasilia.

Freitas, F.G. and Silveira, C.O. da (1977). Principais solos sob vegetação de cerrado e sau aptidão agricola. In: Ferri, M.G. (ed). IV Simpósio sobre o Cerrado. pp. 155-194. Editora da Universidade de São Paulo, SP.

Friedmann, E.I. (1982). Endolithic microorganisms in the Antarctic cold desert. Science, 215: 10451053.

Fritts, H.C. (1976). Tree Rings and Climate. Academic Press. New York.

Frost, P.G. and Robertson, F. (1987). Effects of fire in savannas. In: Walker, B.H. (ed). Determinants of Tropical Savannas. pp. 93-140. IRL press. Oxford.

Frost, P.G.H., Medina, E., Menaut, J.C., Solbrig, O., Swift, M. and Walker, B. (1986). Responses of savannas to stress and disturbance. Biology Intern. Special Issue No.10. Intern. Union of Biol. Sci. Paris.

Furley, P.A. (1985). Notes on the soils and plant communities of Fazenda Agua Limpa (Brasilia, D.F., Brazii). Dept. of Geography Occasional Publications, NS, No. 5. University of Edinburgh.

Furley, P.A. and Ratter, J.A. (1988). Soil resources and plant communities of the central Brazilian cerrado and their development. Journal of Biogeography, 15: 97-108.

Galloway, D.J. (1992). Lichens of Laguma San Rafael, Parque Nacional 'Laguna San Rafael', southern Chile: indicators of environmental change. Global Ecology and Biogeography Letters, 2: 37 45 . 
-----(1993). Lichens as indicators of environmental change: a world review. In: Symoens, J.-J., Devos, P., Rammeloo, J. and Verstraeten, Ch. (eds). Proceedings of the Symposium "Biological Indicators of Global Change". pp. 223-232. Royal Academy of Overseas Sciences. Brussels.

Gärtner, G. (1992). Taxonomy of symbiotic eukaryotic algae. In: Reisser, W. (ed). Algae and Symbioses: Plants, Animals, Fungi, Viruses. Interactions Explored. pp. 325-338. Biopress Ltd. Bristol.

Gauch, H.G. (1982). Multivariate Analysis in Community Ecology. Cambridge Studies in Ecology. Cambridge University Press.

Gauch, H.G. and Whittaker, R.H. (1981). Hierarchial classification of community data. Journal of Ecology, 69: 135-152.

Geldenhuys, C.J. (1994). Bergwind fires and the location pattern of forest patches in the Southern Cape landscape, South Africa. Journal of Biogepgraphy, 21: 49-62.

Gerson, U. and Seaward, M.R.D. (1977). Lichen-invertebrate associations. In: Seaward, M.R.D. (ed). Lichen Ecology. pp. 69-119. Academic Press. New York.

Gibbs, P.E., Leitão Filho, H.F. and Shepherd, G. (1983). Floristic composition and community structure in an area of cerrado in SE Brazil. Flora, 173: 433-449.

Gilbert, O.L. (1976). An alkaline dust effect on epiphytic lichens. The Lichenologist, 8: 173-178.

-----(1986a). Lichens return to central London. Bulletin of the British Lichen Society, 58: 28-29.

-----(1986b). Field evidence for an acid rain effect on lichens. Environmental Pollution (Series A), 40: 227-231.

-.-.-(1992). Lichen reinvasion with declining air pollution. In: Bates, J.W. and Farmer, A.M. (eds). Bryophytes and Lichens in a Changing Environment. pp. 159-177. Clarendon Press. Oxford.

Goedert, W.J. (1983). Management of the cerrado soils of Brazil: a review. Journal of Soil Science, 34: $405-428$.

Goldammer, J.G. and Crutzen, P.J. (1993). Fire in the environment: scientific rationale and summary of results of the Dahlem Workshop. In: Crutzen, P.J. and Goldammer, J.G. (eds). Fire in the environment. The Ecological, Atmospheric, and Climatic Importance of Vegetation Fires. pp. 1-14. John Wiley \& Sons. Chichester. 
Goldstein, G., Menaut, J.C., Noble, I, and Walker, B.H. (1988). Exploratory research. In: Walker, B.H. and Menaut, J.C. (eds). Research procedure and experimental design for savanna ecology and management. pp. 13-20. Publication No.1. Responses of savannas to stress and disturbance. IUBS. Paris.

Goodland, R.J.A. (1969). An ecological study of the cerrado vegetation of south-central Brasil. $\mathrm{PhD}$ thesis. Dept. of Botany, McGill University, Montreal, Canada.

-----(1971a). A physiognomic analysis of the "cerrado" vegetation of Central Brazil. Journal of Ecology, 59: 411-419.

-(1971b). Oligotrofismo e aluminio no cerrado. In: Ferri, M.G. (ed). III Simpósio sobre o cerrado. pp. 44-60. Editora da Univ. de São Paulo. São Paulo.

Goodland, R. and Ferri, M.G. (1979). Ecologia do Cerrado. Itatiaia. Belo Horizonte.

Goodland, R. and Pollard, R. (1973). The Brazilian cerrado vegetation: a fertility gradient. Journal of Ecology, 61(1): 219-224.

Gordon, C.A., Herrera, R. and Hutchinson, T.C. (1995). The use of a common epiphytic lichen as a bioindicator of atmospheric inputs to two Venezuelan cloud forests. Journal of Tropical Ecology, 11 (1): 1-26.

Goward, T. (1994). Notes on oldgrowth-dependent epiphytic macrolichens in inland British Columbia, Canada. Acta Botanica Fennica, 150: 31-38.

Goyal, R. and Seaward, M.R.D. 91982). Metal uptake in terricolous lichens. III. Translocation in the thallus of Peltigera canina. New Phytologist, 90: 85-98.

Gradstein, S.B. (1992). The vanishing tropical rain forest as an environment for bryophytes and lichens. In: Bates, J.W. and Farmer, A.M. (eds). Bryophytes and Lichens in a Changing Environment. pp. 234-258. Oxford Scientific Publications. Oxford.

Green, T.G.A., Snelgar, W.P. and Wilkins, A.L. (1985). Photosynthesis, water relations, and thallus structure of Stictaceae lichens. In: Brown, D.H. (ed). Lichen physiology and cell biology. pp. 57-75. Plenum Press. New York.

Grodzinska, K. (1977). Acidity of tree bark as a bioindicator of forest pollution in southern Poland. Water, Air, Soil Pollution, 8: 3-7. 
---(1979). Tree bark sensitive biotest for environmental acidification. Environmental International, 2 : 173-176.

Guidon, N. and Delibrias, G. (1986). Carbon-14 dates point to man in the Americas 32,000 years ago. Nature, 321: 769-771.

Guttenberger, H., Hainzl, M., Grill, D. and Türk, R. (1991). Altitude dependence of thiol content of lichens. Flora, 185: 201-205.

Haertel, O. and Grill, D. (1972). European Journal of Forest Pathology, 2: 205-213.

Haffer, J. (1969). Speciation in Amazonian forest birds. Science, 165: 131-137.

Hale, M.E. (1952). Vertical distribution of cryptogams in a virgin forest in Wisconsin. Ecology, 33: 398-406.

--.-(1955). Phytosociology of corticolous cryptogams in the upland forests of southern Wisconsin. Ecology, 36: 45-63.

----(1975). A revision of the lichen genus Hypotrachyna (Parmeliaceae) in Tropical America. Smithsonian Contribution to Botany, Number 25. Smithsonian Institution Press. Washington.

(1976a). A monograph of the lichen genus Pseudoparmelia Lynge (Parmeliaceae). Smithsonian Contribution to Botany, Number 31. Smithsonian Institution Press. Washington.

-----(1976b). A monograph of the lichen genus Bulbothrix Hale (Parmeliaceae). Smithsonian Contribution to Botany, Number 32. Smithsonian Institution Press. Washington. ----(1983). The Biology of Lichens. 3rd Edition. Edward Arnold. London.

Hallingbäck, T. (1989). Bokfjädermossa, Neckera pumila, en försurningshotad mossa. Svensk Botanisk Tidskrift, 83: 161-173.

Haridasan, M. (1982). Aluminium accumulation by some cerrado native species of central Brazil. Plant and Soil, 65(2): 265-273.

-----(1992). Estresse nutricional. In: Dias, B.F. de S. (ed). Alternativas de desenvolvimento dos cerrados: manejo e conservação dos recursos naturais renováveis. pp. 27-30. Fundação prónatureza (FUNATURA). Brasilia, D.F..

-----(1994). Solos. In: Novaes-Pinto, M. (org). Cerrado. Caracterização, Ocupação e Perspectivas (2a edição). pp. 321-344. Editora Universidade de Brasilia. Brasilia D.F. 
Haridasan, M. and Araújo, G.M. (1988). Aluminium-accumulating species in two forest communities in the cerrado region of central Brazil. Forest Ecology and Management, 24: 15-26.

Haridasan, M., Hill, P.G. and Russel, D.G. (1987). Semi-quantitive estimates of Al and other cations in the leaf tissues of some $\mathrm{Al}$-accumulating species using electron probe microanalysis. Plant and Soil, 104: 99-102.

Harris, G.P. (1971). The ecology of corticolous lichens. I. The zonation on oak and birch in south Devon. Journal of Ecology, 59: 431-439.

Harris, G.P. and Kershaw, K.A. (1971). Thallus growth and the distribution of stored metabolites in the phycobionts of the lichens Parmelia sulcata and P. physodes. Canadian Journal of Botany, 49: 1367-1372.

Hawksworth, D.L. (1976). Lichen chemotaxonomy. In: Brown, D.H., Hawksworth, D.L. and Bailey, R.H. (eds). Lichenology: Progress and Problems. pp. 139-184. Academic Press. London. -n---(1990). The long-term effects of air pollution on lichen communities in Europe and North America. In: Woodwell, G.M. (ed). The Earth in transition. Patterns and processes of biotic impoverishment. pp. 45-64. Cambridge University Press. Cambridge.

Hawksworth, D.L. and McManus, P.M. (1988). Yet more lichens on trees in the Chelsea Physic Garden. British Lichen Society Bulletin, 63: 24-25.

-----(1989). Lichen recolonisation of London under conditions of rapidly falling sulphur dioxide levels, and the concept of zone skipping. Botanical Journal of the Linnean Society, 109: 99-109.

Hawksworth, D.L. and Rose, F. (1970). Qualitative scale for estimating sulphur dioxide air pollution in England and Wales using epiphytic lichens. Nature, 227: 145-148.

-----(1976). Lichens as Pollution Monitors. Studies in Biology No.66. Edward Arnold. London.

Haynes, C.D. (1984). The pattern and ecology of munwag: traditional Aboriginal fire regimes in northcentral Arnhem Land. Proceedings of the Ecological Society of Australia, 13.

Haynes, C.D. (1991). Use and impact of fire. In: Haynes, C.D., Ridpath, M.G. and Williams, M.A.J. (eds). Monsoonal Australia: landscape ecology and man in the northern lowlands. AA Balkema. Rotterdam. 
Heinselman, M.L. (1973). Fire in the virgin forests of the Boundary Waters Canoe Area, Minnesota. Quaternary Research, 3: 329-382.

Henderson-Sellers, A. and Seaward, M.R.D. (1979). Monitoring lichen reinvasion of ameliorating environments. Environmental Pollution, 19: 207-213.

Henriques, R.P.B. (1993). Organização e estrutura das comunidades vegetais de cerrado em un gradiente topográfico no Brasil Central. Tese de Doctorado. Universidade de Campinas, Campinas, São Paulo.

Herben, T. and Liska, J. (1986). A simulation study of the effect of flora composition, study design and index choice on the predictive power of lichen indication. The Lichenologist, 18: 349 362.

Heringer, E.P. (1971). Propogação e sucessao de especies arboreas do cerrado em função de fogo, do capim, da capina e de aldrin. In: Ferri, M.G. (org). III Simpósio sobre o Cerrado. pp. $167-$ 179. Editora da Univ. de São Paulo. São Paulo.

Heringer, E.P., Barroso, G.M., Rizzo, J.A. and Rizzini, C.T. (1977). A flora do cerrado. In: Ferri, M.G. (org). IV Simpósio sobre o Cerrado. pp. 211-232. Editora da Univ. de São Paulo. São Paulo.

Heusser, C.J. (1994). Paleoindians and fire during the late Quaternary in southern South America. Revista Chilena de Historia Natural, 67 (4): 435-443.

Hill, M.O. (1979). TWINSPAN - a FORTRAN Program for arranging Multivariate Data in an Ordered Two Way Table by Classification of the Individuals and the Attributes. Cornell University, Dept. of Ecology and Systematics. Ithaca. New York.

Hill, M.O. and Gauch, H.G. (1980). Detrended correspondance analysis, an improved ordination technique. Vegetatio, 42: 47-58

Hobbs, R.J., Currall, J.E.P. and Gimingham, C.H. (1984). The use of 'Thermocolour' pyrometers in the study of heath fire behaviour. Journal of Ecology, 72: 241-250.

Holopainen, T.H. (1984a). Cellular injuries in epiphytic lichens transplanted to air polluted areas. Nordic Journal of Botany, 4: 393-408. 
-----(1984b). Types and distribution of ultrastructural symptoms in epiphytic lichens in several urban and industrial environments in Finland. Annales Botanici Fennici, 21: 213-229.

Hope, G. and Tulip, J. (1994). A long vegetation history from lowland Irian-Jaya, Indonesia. Palaeogeography, Palaeoclimatology, Palaeoecology, 109 (2-4): 385-398.

Hopkins, M.S., Ash, J., Graham, A.W., Head, J. and Hewett, R.K. (1993). Charcoal evidence of the spatial extent of the Eucalyptus woodland expansions and rain forest contractions in North Queensland during the late Pleistocene. Journal of Biogeography, 20 (4): 357-372.

Horn, S.P. and Sanford, R.L. (1992). Holocene fires in Costa Rica. Biotropica, 24 (3): 354-361.

Howes, S. (1986). The effect of the herbicide dichlorophen on the physiology of the lichens: Peltigera horizontalis and Cladonia portentosa. Unpublished B.S.c thesis. University of Bristol.

Hutchinson, T.C., Dixon, M. and Scott, M. (1986). The effect of simulated acid rain on feather mosses and lichens of the boreal forest. Water, Air and Soil Pollution, 31: 409-416.

Jahns, H.M. and Neumann, K. (1981). Flechtenwachstum im Frankfurter Raum. Natur und Museum, 111: 333-338.

James, P.W. (1973). The effect of air pollutants other than hydrogen fluoride and sulphur dioxide on lichens. In: Ferry, B.W., Baddeley, M.S. and Hawksworth, D.L. (eds). Air Pollution and Lichens. pp. 143-175. Athlone Press. London.

James, P.W., Hawksworth, D.L. and Rose, F. (1977). Lichen communities in the British Isles: a preliminary conspectus. In: Seaward, M.R.D. (ed). Lichen Ecology. pp. 295-413. Academic Press. London.

Jochimsen, M. (1973). Does the size of lichen thalli really constitute a valid measure for dating glacial deposits? Arctic and Alpine Research, 5: 417-424.

John, E. and Dale, M.R.T. (1995). Neighbour relations within a community of epiphytic lichens and bryophytes. The Bryologist, 98 (1): 29-37.

Johnson, E.A. (1992). Fire and vegetation dynamics; Studies from the North American boreal forest. Cambridge University Press. Cambridge. 
Johnson, E.A. and van Wagner, C.E. (1985). The theory and use of two fire history models. Canadian Journal of Forest Research, 15: 214-220.

Joly, C.A. and Crawford, R.M.M. (1982). Variation in tolerance and metabolic responses to flooding in some tropical trees. Journal of Experimental Botany, 33: 799-809.

Jones. D. (1988). Lichens and pedogenesis. In: Galun, M. (ed). Handbook of Lichenology Vol III. pp. 104-124. CRC Press. Boca Raton.

Justice, C.O., Malingreau, J.P. and Setzer, A.W. (1993). Satellite remote sensing of fires: potential and limitations. In: Crutzen, P.J. and Goldammer, J.G. (eds). Fire in the environment. The Ecological, Atmospheric, and Climatic Importance of Vegetation Fires. pp. 77-88. John Wiley \& Sons. Chichester.

Kallio, S. and Wilkinson, R.E. (1977). The effects of some herbicides on nitrogenase activity and carbon fixation in two subartic lichens. Botanical Gazette, 138: 468-473.

Kanjanavanit, S. (1992). Aspects of the temporal pattern of dry season fires in the dry dipterocarp forests of Thailand. PhD thesis. Dept. of Geography, School of Oriental and African Studies, Univ. of London.

Kantvilas, G. (1985). Studies on Tasmanian rain forest lichens. Unpublished Ph.D. thesis. University of Tasmania.

Kantvilas, G, and Minchin, P.R. (1989). An analysis of epiphyte lichen communities in Tasmanian cool temperate rainforest. Vegetatio, 84: 99-112.

Kantvilas, G., James, P.W. and Jarman, S.J. (1985). Macrolichens in Tasmanian rain forests. The Lichenologist, 17: 67-83.

Kappen, L. (1973). Response to extreme environments. In: Almadjian, V. (ed). The Lichens. pp. 311 380. Academic Press. New York.

-.--(1988). Ecophysiological relationships in different climatic regions. In: Galun, M. (ed). Handbook of Lichenology. Vol. II. pp. 37-100. CRC Press. Boca Raton. Florida. 
Kappen, L. and Breuer, M. (1991). Ecological and physiological investigations in continental Antarctic cryptograms. II. Moisture relations and photosynthesis of lichens near Casey Station, Wilkes Land. Antarctic Science, 3: 273-278.

Kappen, L. and Redon, J. (1987). Photosynthesis and water relations of three maritime Antarctic lichen species. Flora, 179: 215-229.

Kappen, L., Lange, O.L., Schulze, E.D., Buschbom, U. and Evenari, M. (1980). Ecophysiological investigations on lichens of the Negev Desert. VII. The influence of the habitat exposure on dew imbibition and photosynthetic productivity. Flora, 169: 216-229.

Karenlampi, L. (1971). Studies on the relative growth of some fruticose lichens. Reports from the Kevo Subarctic Research Station, 7: 33-39.

Kärnefelt, I., Arup, U. and Lund, S.E. (1990). Retreating lichens in Southernmost Sweden. Stuttgarter Beiträge zur Naturkunde (Serie A (Biologie)), 456: 17-27.

Kauffman, J.B., Cummings, D.L. and Ward, D.E. (1994). Relationships of fire, biomass and nutrient dynamics along a vegetation gradient in the Brazilian cerrado. Journal of Ecology, 82: 519531.

Kauppi, M. (1976). Fruticose lichen transplant technique for air pollution experiments. Flora, 165: 407-414.

Kent, M. and Coker, P. (1992). Vegetation description and analysis. A practical approach. Belhaven Press. London.

Kershaw, K.A. (1985). Physiological ecology of lichens. Cambridge University Press. Cambridge.

Kershaw, K.A. and MacFarlane, J.D. (1980). Physiological-environmental interactions in lichens. X. Light as an ecological factor. New Phytologist, 84: 687-702.

Kershaw, K.A., MacFarlane, J.D., Webber, M.R. and Fovargue, A. (1983). Phenotypic differences in the seasonal pattern of net photosynthesis in Cladonia stellaris. Canadian Journal of Botany, 61: $2169-2180$.

Killham, K. (1994). Soil ecology. Cambridge University Press. Cambridge. 
Klink, C.A., Moreira, A.G. and Solbrig, O.T. (1993). Ecological Impact of Agricultural Development in the Brazilian Cerrados. In: Young, M.D. and Solbrig, O.T. (eds). The World's Savannas. Economic Driving Forces, Ecological Constraints and Policy Options for Sustainable Land Use. Man and the Biosphere Vol.12. pp. 259-282. UNESCO. Paris.

Köppen, W. (1931). Grundriss der Klimakunde. 2nd Ed. W. de Gruyter. Berlin.

Kovács, M. (1992). Biological indicators of environmental pollution. In: Kovács, M. (ed). Biological indicators in environmental protection. pp. 7-11. Ellis Horwood. London.

Kral, R., Kryzova, L. and Liska, J. (1989). Background concentrations of lead and cadmium in the lichen Hypogymnia physodes. Science of the Total Environment, 84: 201-209.

Laaksovirta, K, Olkkonen, H. and Alakuijala, P. (1976). Observations on the lead content of lichen and bark adjacent to a highway in southern Finland. Environmental Pollution, 11: 247-255.

Lange, O.L. and Redon, J. (1983). Epiphytic lichens in the region of a Chilean "Fog Oasis" (Fray Jorge). II. Ecophysiological characterisation of $\mathrm{CO}_{2}$ exchange and water relations. Flora, 174: 245-284.

Lange, O.L., Schulze, E.D. and Koch, W. (1970a). Experimentall-ökologische Untersuchungen an Flechten der Negev-Wüste. II. $\mathrm{CO}_{2}$-Gaswechsel und Wasserhaushalt von Ramalina maciformis (Del.) Bory am näturlichen Standort während der sommerlichen Trockenperiode. Flora, 159: 38-62.

-----(1970b). Experimentall-ökologische Untersuchungen an Flechten der Negev-Wüste. III. $\mathrm{CO}_{2}$ -Gaswechsel und Wasserhaushalt von Krusten- und Blattflechten am näturlichen Standort während der sommerlichen Trockenperiode. Flora, 159: 525-528.

Lange, O.L., Bilger, W., Rimke, S. and Schreiber, U. (1989). Chlorophyll fluorescence of lichens containing green and blue-green algae during hydration by water vapour uptake and by addition of liquid water. Botanica Acta, 102: 306-313.

Lange, O.L., Meyer, A., Zellner, H. Ullmann, I. and Wessels, D.C.J. (1990). Eight days in the life of a desert lichen: Water relations and photosynthesis of Teloschistes capensis in the coastal fog zone of the Namib Desert. Madoqua, 17: 17-30. 
Larson, D.W. (1982). Environmental stress and Umbilicaria lichens: The effect of high temperature pretreatments. Oecologia (Berlin), 55: 102-107.

-.-.-(1987). The absorption and release of water by lichens. In: Peveling, E. (ed). Progress and Problems in Lichenology in the Eighties. pp. 351-360. Bibliotheca Lichenologica, Vol. 25. J. Cramer. Berlin-Stuttgart.

Laxen, D.P.H. and Thompson, M.A. (1987). Sulphur dioxide in Greater London, 1931-1985. Environmental Pollution, 43: 103-114.

LeBlanc, F. and De Sloover, J. (1970). Relation between industrialisation and the distribution and growth of epiphytic lichens and mosses in Montreal. Canadian Journal of Botany, 48: 14851496.

Lechowicz, M.J. (1981). The effects of climatic pattern in lichen productivity: Cetraria cucullata (Bell.) Ach. in the arctic tundra of northern Alaska. Oecologia (Berlin), 50: 210-216.

----(1987). Resistance of the caribou lichen Cladina stellaris (Opiz.) Brodo to growth reduction by simulated acidic rain. Water, Air and Soil Pollution, 34: 71-77.

Ledru, M.P. (1993). Late Quaternary environmental and climatic changes in central Brazil. Quaternary Research, 39: 90-98.

Legaz, M.E., Vicente, C., Ascaso, C., Pereira, E.C. and Filho, L.X. (1986). Pigment analysis of sun and shade populations of Cladonia verticillais. Biochemical Systematics and Ecology, 14: $575-582$.

Lerond, M. (1978). Courbes d'isopollution de la région de Rouen obtenues par l'observation des lichenes epiphytiques. Bulletin de la Société Linné Normandie, 106: 73-84.

Lewis, H.T. (1989). Ecological and technological knowledge of fire: aborigines versus Park rangers in northern Australia. American Anthropologist, 91: 940-961.

Lindsay, D.C. (1977). Lichens of Cold Deserts. In: Seaward, M.R.D. (ed), Lichen Ecology. pp. 183210. Academic Press. London.

Lobato, E. (1980). Adubação fosfatada em solos sob vegetação de cerrado. EMBRAPA/CPAC. Planaltina, D.F., Brazil. 
Löfgren, A. (1898). Ensaio para uma distribuição dos vegetais nos diversos grupos floristicos no Estado de São Paulo. Boletim Comissão Geographica e Geologia de São Paulo, 11: 1-50.

Longton, R.E. (1992). The role of bryophytes and lichens in terrestrial ecosystems. In: Bates, J.W. and Farmer, A.M. (eds). Bryophytes and lichens in a changing environment. pp. 32-76. Clarendon Press. Oxford.

Looney, J.H.H. (1991). Effects of acidification on lichens. In: Woodin, S.J. and Farmer, A.M. (eds). The effects of acid deposition on nature conservation in Great Britain. pp. 45-55. Focus on Nature Conservation No. 26, Nature Conservancy Council, Peterborough, U.K.

Looney, J.H.H. and James, P.W. (1990). The effects of acidification on lichens. CSD Report 1057, Nature Conservancy Council, Peterborough, U.K.

Lopes, A.S. (1975). A survey of the fertility status of soils under "cerrado" vegetation in Brazil. MSc thesis. North carolina State Univ. Raleigh.

Lopes, A.S. and Cox, F.R. (1977). Cerrado vegetation in Brazil: an edaphic gradient. Agronomy Journal, 69: 828-831.

Lopes-Naranjo, H.J. (1975), Estrutura morfológica de Anacardium pumilum St. Hil. Anacardiaceae. Tese de mestre. Univ. de São Paulo. São Paulo.

Lorimer, C.G. and Frelich, L.E. (1989). A method for estimating canopy disturbance frequency and intensity in dense temperate forests. Canadian Journal of Forest Research, 19: 651-663.

Luke, R.H. and McArthur, A.G. (1978). Bushfires in Australia. Australian Government Publishing Service. Canberra.

Lukesch, A. (1969). Mito e vida dos indios Caiapós. Editora da Univ. de São Paulo. São Paulo.

MacFarlane, J.D. and Kershaw, K.A. (1980). Physiological-environmental interactions in lichens. IX. Thermal stress and lichen ecology. New Phytologist, 84: 669-685.

MacFarlane, J.D., Kershaw, K.A. and Webber, M.R. (1983). Physiological-environmental interactions in lichens. XVII. Phenotypic differences in the seasonal pattern of net photosynthesis in Cladonia rangiferina. New Phytologist, 94: 217-233. 
Mackenzie, D. (1986). The rad-dosed reindeer. New Scientist, 1539: 37-40.

Magomedova, M.A. (1980). Succession of communities of lithophilic lichens in the highlands of northern Ural. Ekologiya, 3: 29-38.

Maitelli, G.T. (1987). Balanço de energia e evapotranspiração de um cerrado (sens. strict.) no Distrito Federal. Tese de mestrado. Universidade de Brasilia, Brasilia D.F..

Malingreau, J.P. (1990). The contribution of remote sensing to the global monitoring of fires in tropical and subtropical ecosystems. In: Goldammer, J.G. (ed). Fire in the Tropical Biota. pp. 337-370. Springer-Verlag. Berlin.

Mann, D.H., Engstrom, F.B. and Bubier, J.L. (1994). Fire history and tree recruitment in an uncut New-England Forest. Quaternary Research, 42 (2): 206-215.

Marcelli, M.P. (1987). Ecologia dos liquens dos manguezais da região sul-sudeste do Brasil com especial atenção ao de Itanhaém (SP). Unpublished D.Phil. thesis. Universidade de São Paulo.

-..-(1991). Aspects of the foliose lichen flora of the southern-central coast of São Paulo State, Brazil. In: Galloway, D.J. (ed). Tropical lichens: their systematics, conservation and ecology. pp. 151-170. Oxford Science Publications. Oxford.

----(1992). Ecologia Liquênica nos Manguezais do Sul-Sudeste Brasileiro. Bibliotheca

Lichenologica, 47. J. Cramer. Berlin, Stuttgart.

----(1993). Pequenas Parmelia S.L. (Liquens: Ascomycotina) ciliadas dos cerrados brasileiros. Acta Botanica Brasileira, 7(2): 25-70.

Markham, K.R., Franke, A., Given, D.R. and Brownsey, P. (1990). Historical ozone level trends from herbarium specimens flavonoids. Bulletin de Liaison-Groupe Polyphénols, 15: 230-235.

McArthur, A.G. (1971). Aspects of fire control in the P. caribea and P. elliottii plantations of North Western Viti Levu Fiji Islands. ACT. Memeo Rep. Canberra.

Medina, E. (1987). Nutrients: requirements, conservation and cycles in the herbaceous layer. In: Walker, B. (ed). Determinants of savannas. pp. 30-65. IUBS Monograph Series No.3. IRL Press. Oxford. 
Mesquita, O.V. (1989). Agricultura. In: Duarte, A.C. (ed). Geografia do Brasil, região Centro-Oeste (v.1). Fundação Instituto Brasileiro de Geogrfia e Estatistica. pp. 149-170. Rio de Janeiro.

Minnich, R.A. (1983). Fire mosaics in southern California and northern Baja California. Science, 219: 1287-1294.

Miranda, A.C. (1988). Sistema automatico de aquisição de dados. Anais do V Congresso Brasileiro de Meterologia, Rio de Janeiro, Seção V. : 16-20.

Miranda, A.C. and Miranda, H.S. (1993). Efeitos de diferentes regimes de queima na estrutura $e$ dinâmica de comunidades de cerrado. Relatório final. Dept. de Ecologia, Univ. de Brasilia, D.F.

Miranda, A.C., Miranda, H.S., Dias, I.O. and Dias, B.F. (1993). Soil and air temperatures during prescribed cerrado fires in Central Brazil. Journal of Tropical Ecology, 9(3): 313-320.

Moreira, A.G. (1987). Aspectos demográficos de Emmotum nitens (Benth.) Miers. em um cerradão distrófico do Distrito Federal. MSc tese. Univ. de Campinas, São Paulo.

----(1992). Fire protection and vegetation dynamics in the Brazilian cerrado. PhD. thesis. Harvard University, Cambridge, Massachusetts.

Moser, T.J., Nash, T.H. and Clark, W.D. (1980). Effects of long-term field sulphur dioxide fumigation on arctic caribou forage lichens. Canadian Journal of Botany, 58: 2235-2240.

Moura, L., Pagani, M. and Campos, M. (1989). Avaliação de predação em algumas espécies vegetais de cerrado (Itirapina, SP). Congresso Nacional de Botânica, 40: 477.

Mueller-Dombois, D. and Ellenberg, H. (1974). Aims and methods of vegetation ecology. Joln Wiley \& Sons. Toronto.

Mukherjee, A.B. and Nuorteva, P. (1994). Toxic metals in forest biota around the steel works of Rautaruukki-Oy, Raahe, Finland. Science of the Total Environment, 151(3): 191-204.

Nascimento, M.T. (1987). Notas preliminares sobre a herbivoria foliar em Vochysia divergens Phol. Ciência e Cultura, 39 (7): 588-589. 
Nascimento, M.T. and Lewinsolnn, T.M. (1992). Impacto dos herbivoros. In: Dias, B.F. de S. (ed). Alternativas de desenvolvimento dos cerrados: manejo e conservação dos recursos naturais renováveis. pp. 38-42. Fundação pró-natureza (FUNATURA). Brasilia, D.F..

Nascimento, M.T., Villela, D. and Lacerda, L. (1990). Folia growth, longevity and herbivory in two cerrado species near Cuiabá, MT, Brazil. Revta. Brasileira Botanica, 13: 27-32.

Nash, T.H. (1988). Correlating fumigation studies with field effects. In: Nash, T.H. and Wirth, V. (eds). Lichens, Bryophytes and Air Quality. pp. 201-216. J. Cramer. Berlin-Stuttgart.

------(1971). Lichen sensitivity to hydrogen fluoride. Bulletin Torrey Botanical Club, 98: 103-106.

-----(1989). Metal tolerance in lichens. In: Shaw, J. (ed). Heavy metal tolerance in plants: evolutionary aspects. pp. 119-132. CRC Press. Boca Raton.

Neto, M.P. (1991). Boletim agroclimatologico da estação agroclimatologico numero 83.373. Instituto Brasileiro de Geografia e Estatistica.

Newsome, R.D. and Dix, R.L. (1968). The forests of the Cypress Hills, Alberta and Saskatchewan, Canada. American Midland Naturalist, 80: 118-185.

Nieboer, E., McFarlane, J.D. and Richardson, D.H.S. (1984). Modifications of plant cell buffering capacities by gaseous air pollutants. In: Koziol, M. and Whatley, F.R. (eds). Gaseous Air Pollutants and Plant Metabolism. pp. 313-330. Butterworths. London.

Ni Lamhna, E., Richardson, D.H.S., Dowding, P. and Ni Grainne, E. (1988). An air quality survey of the Greater Dublin Area carried out by second level students. An Foras Forbartha. Dublin.

Nimis, P.L., Castello, M. and Perotti, M. (1990). Lichens as biomonitors of sulphur dioxide pollution in La Spezia (Northern Italy). The Lichenologist, 22: 333-344.

Novaes-Pinto, M. (1994). Caracterização geomorfológica. In: Novaes-Pinto, M. (org). Cerrado. Caracterização, Ocupação e Perspectivas ( $2^{\underline{a}}$ edição). pp. 285-320. Editora Universidade de Brasilia. Brasilia D.F.

Ojasti, J. (1978). The relation between population and production of the Capybara. Dissertaçâ de Ph.D. Univ. Georgia, Athens. 
Oliveira, P.E. and Silva, J.C.S. (1993). Biological reproduction of two species of Kielmeyera (Guttiferae) in the cerrados of central Brazil. Journal of Tropical Ecology, 9(1): 67-80.

Oliveira, P.E., Ribeiro, J.F. and Gonzales, M.I. (1989). Estrutura e distribuição espacial de uma população de Kielmeyera coriacea Mart. no cerrados de Brasilia D.F.. Revista Brasileira de Botânica, 12: 39-48.

Oliveira-Filho, A.T. and Martins, F.R. (1986). Distribução, caracterização e composição floritica das formações vegetais da régião da Salgadeira, na Chapada dos Guimarães (MT). Revista Brasileira de Botânica, 9: 207-223.

Oliveira-Filho, A.T. and Martins, F.R. (1991). A comparative study of five cerrado areas in southern Mato Grosso, Brazil. Edinburgh Journal of Botany, 48: 307-332.

Oliveira-Filho, A.T. and Ratter, J.A (1995). A study of the origin of central Brazilian forests by the analysis of plant distribution patterns. Edinburgh Journal of Botany, 52 (2): 141-194.

Oliveira-Filho, A.T., Shepherd, G.H., Martins, F.R. and Stubblebine, W.H. (1989). Environmental factors affecting physiognomic and floristic variation in an area of cerrado in central Brazil. Journal of Tropical Ecology, 5(4): 413-431.

Orwig, D.A. and Abrams, M.D. (1994). Effects of land-use history (1720-1992) on forest composition and dynamics within the piedmont and coastal plain of northern Virginia. Canadian Journal of Forest Research, 24: 1216-1225.

Ovstedal, D.O. (1980). Lichen communities on Alnus incana in north Norway. The Lichenologist, 12: 189-197.

Papastefanou, C., Manolopoulou, M. and Sawidis, T. (1989). Lichens and mosses: Biological indicators of radioactive fallout from Chernobyl reactor accident. Journal of Environmental Radioactivity, 9: 19-207.

Parada, J.M. and Andrade, S.M. (1977). Cerrados: recursos minerais. In: Ferri, M.G. (org). IV Simpósio sobre o Cerrado: bases para utilização agropecuária. pp. 195-209. Editora da Univ. de São Paulo. São Paulo. 
Paterson, D.R., Paterson, E.W. and Kenworthy, J.B. (1983). Physiological studies on temperate lichen species. I. A mathematical model to predict assimilation in the field, based on laboratory responses. New Phytologist, 94: 605-618.

Pereira, B.A. da S., Furtado, P.P., Mendonça, R.C. de. e Rocha, G.I. (1989). Reserva Ecológica do IBGE (Brasilia-D.F.): aspectos históricos e fisiográficos. Boletim da Fundação Brasileira para Conservação da Natureza. Rio de Janeiro, 24: 30-43.

Pereira, B.A. da S., Silva, M.A. da, e Mendonça, R.C. de. (1993). Reserva Ecológica do IBGE, Brasilia (D.F.). Lista das Plantas Vasculares. IBGE. Rio de Janeiro.

Perkins, D.F. (1980). Accumulation and effects of airborne fluoride on the saxicolous lichen Ramalina siliquosa. 1979 Annual Report, Institute of Terrestrial Ecology. pp. 81-84. ITE. Cambridge.

Perkins, D.F, and Millar, R.O. (1987a). Effects of airborne fluoride emissions near an aluminium works in Wales: Part 1 - Corticolous lichens growing on broadleaved trees. Environmental Pollution, 47: 63-78.

(1987b). Effects of airborne fluoride emissions near an aluminium works in Wales: Part 2 Saxicolous lichens growing on rocks and walls. Environmental Pollution, 48: 185-196.

Piperno, D.R., Bush, M.B. and Colinvaux, P.A. (1990). Paleoenvironments and human settlement in late-glacial Panama. Quaternary Research, 33: 108-116.

Pivello, V.R. and Coutinho, L.M. (1992). Transfer of macro-nutrients to the atmosphere during experimental burnings in an open cerrado (Brazilian savanna). Journal of Tropical Ecology, 8(4): $487-497$.

Pivello-Pompêia, V.R. (1985). Exportação de macronutrientes para a atmosfera durante queimadas realizadas no campo cerrado de Emas (Pirassununga, S.P.). Mestre tese. Universidade de São Paulo, S.P.

Podani, J. (1992). Monitoring system. In: Kovács, M. (ed). Biological indicators in environmental protection. pp. 12-13. Ellis Horwood. London.

Poelt, J. (1973). Classification. In: Ahmadjian, V. and Hale, M.E. (eds). The Lichens. pp. 599-632. Academic Press. New York. 
Poelt, J. and Vezda, A. (1990). Ueber kurzlebige Flechten. Bibliotheca Lichenologica, 38: 377-394.

Prado, J. (1989). Herbivoria por insetos em um gradiente de cerrado com diferentes regimes de fogo. Tese de mestrado. Universidade de Brasilia. Brasilia D.F..

Prance, G.T. (1973). Phytogeographic support for the theory of Pleistocene forest refuges in the Amazon basin, based on evidence from distribution patterns in Caryocaraceae, Dichapetalaceae and Lecythidaceae. Acta Amazônica, 3: 5-28.

----(1982a). A review of the phytogeographic evidences for Pleistocene climate changes in the neotropics. Annales Missouri Botanical Garden, 69: 594-624.

-----(1982b). Forest refuges evidence from woody angiosperms. In: Prance, G.T. (ed). Biological diversification in the Tropics. pp. 137-156. Columbia University Press. New York. (1987). Biogeography of neotropical plants. In: Whitmore, T.C. and Prance, G.T. (eds). Biogeography and Quaternary history in tropical America. pp. 46-65. Oxford Science Publications. Oxford.

Prance, G.T. and Schaller, G.B. (1982). Preliminary study on some vegetation types of the Pantanal, Mato Grosso, Brazil. Brittonia, 34: 228-251.

Pruit, W.O. (1963). Lichen, caribou and high radiation in Eskimos. Audubon Magazine, 65: 284- 287.

Puckett, K.J. (1976). The effect of heavy metals on some aspects of lichen pliysiology. Canadian Journal of Botany, 54: 2695-2703.

Puckett, K.J., Nieboer, E., Flora, B. and Richardson, D.H.S. (1973). Sulphur dioxide: its effect on photosynthetic ${ }^{14} \mathrm{C}$ fixation in lichens and suggested mechanisms of phytotoxicity. New Phytologist, 72: 114-154.

Queiröz Neto, de J.P. (1982). Solos da região dos cerrados e suas interpretações. Revista Brasileira de Ciência do Solo, 6(1): 1-12.

Rachid, M. (1947). Transpiraçâo e sistemas subterrâneos da vegetação de verão dos campos Cerrados de Emas. Boletim de Faculdade de Filosofia, Ciências e Letras da USP, Botânica, 13: $37-69$.

Rachid-Edwards, M. (1956). Alguns dispositivos para proteção de plantas contra a sêca e o fogo. Boletim de Botânica, USP, 13: 35-68. 
Raison, R.J., Khanna, P.K. and Woods, P.V. (1985). Mechanisms of element transfer to the atmosphere during vegetation fires. Canadian Journal of Forest Research, 15: 132-140.

Ramos, A.E. (1990). O efeito da queima sobre a vegetação lenhosa da cerrado. Mestre tese. Universidade de Brasilia, Brasilia D.F.

Ranzani, G. (1971). Solos do cerrado do Brasil. In: Ferri, M.G. (ed). III Simpósio sobre o Cerrado. pp. 26-43. Editora da Universidade de São Paulo, SP.

Rassi, P. and Väisänen, R. (1987). Threatened animals and plants in Finland. Valtion painatuskeskus. Helsinki.

Ratter, J.A. (1971). Some notes on two types of cerradão occurring in north eastern Mato Grosso. In: Ferri, M.G. (org). III Simpósio sobre o Cerrado. pp26-43. Editora da Univ. de São Paulo. São Paulo.

----(1986). Notas sobre a vegetação da Fazenda Agua Limpa (Brasilia, D.F., Brazil). Editora UnB. Textos Universitários n.003. Brasilia.

-----(1987). Notes on the vegetation of the Parque Nacional do Araguaia (Brazil). Notes of the Royal Botanic Garden of Edinburgh, 44: 311-342.

-.---(1991). Notas sobre a vegetação da Fazenda Agua Limpa (Brasilia, D.F.). Royal Botanic Garden, Edinburgh.

Ratter, J.A. and Dargie, T.C.D. (1992). An analysis of the floristic composition of 26 cerrado areas in Brazil. Edinburgh Journal of Botany, 49 (2): 235-250.

Ratter, J.A., Askew, G.P., Montgomery, R.F. and Gifford, D.R. (1977). Observações adicionais sobre o cerradão de solos mesotróficos no Brasil Central. In: Ferri, M.G. (org). IV Simpósio sobre o Cerrado. pp. 303-316. Editora da Univ. de São Paulo. São Paulo.

-----(1978). Observations on the vegetation of northeastern Mato Grosso. II. Forests and soils of the Rio Suiá-Missu area. Proceedings of the Royal Society of London (Series B), 203: 191- 208.

Ratter, J.A., Richards, P.W., Argent, G. and Gifford, D.R. (1973). Observations on the vegetation of northeastern Mato Grosso. 1. The woody vegetation types of the Xavantina-Cachimbo expedition area. Philosophical Transactions of the Royal Society of London (B), 226: 449492. 
Ratter, J.A., Leitão Filho, H.F., Argent, G., Gibbs, P.E., Semir, J., Shepherd, G. and Tamashiro, J. (1988). Floristic composition and community structure of a southern cerrado area in Brazil. Notes of the Royal Botanic Garden of Edinburgh, 45(1): 137-151.

Rawitscher, F. (1942a). Problemas de fitoecologia com considerações especies sobre o Brasil meridional. Univ. São Paulo, Fac. Filosofia, Ciências Letras, 28 (3): 3-111.

-----(1942b). Algumas noções sobre a transpiração e o balanço d'água de plantes brasileiras. Anais da Academia Brasileira de Ciências, 14: 7-36.

----(1948). The water economy of the vegetation of the 'campos cerrados' in southern Brazil. Journal of Ecology, 36: 237-268.

Rawitscher, F. and Rachid, M. (1946). Troncos subterrâneos de plantas brasileiras. Anais da Academia Brasileira de Ciências, 17: 261-280.

Rawitscher, F., Ferri, M.G. and Rachid, M. (1943). Profundidade dos solos e vegetação em campos cerrados do Brasil meridional. Anais da Academia Brasileira de Ciências, 15(4): 267-294.

Raynor, E.M. (1988). Goldcrests eating lichen-covered bark. British Birds, 81 (5): 239-240.

Ribeiro, J.F. (1983). Comparação da concentração de nutrientes na vegetação arbórea e nos solos de um cerrado e um cerradão no Distrito Federal, Brasil. Tese de Mestre. Univ. de Brasilia.

Ribeiro, J.F., Silva, J.C.S. and Batmanian, G.J. (1985). Fitossociologia de tipos fisionômicos de cerrado em Planaltina, D.F. Revta Brasileira Botanica, 8(2): 131-142.

Richards, P.W. (1954). Notes on the bryophyte communities of Lowland Tropical Rain Forest, with special reference to Moraballi Creek, British Guyana. Vegetatio, 5-6: 319-328.

Richardson, D.H.S. (1988). Understanding the pollution sensitivity of lichens. Botanical Journal of the Linnean Society, 96: 31-43.

---(1991). Lichens and Man. In: Hawksworth, D.L. (ed). Frontiers in Mycology. pp. 187-210. International Mycological Institute. London.

------(1992). Pollution monitoring with lichens. Naturalists' Handbooks 19. Richmond Publishing Co. Ltd. England.

Richardson, D.H.S. and Nieboer, E. (1981). Lichens and pollution monitoring. Endeavour (New Series), 5: 127-133. 
Richardson, D.H.S. and Puckett, K.J. (1973). Sulphur dioxide and photosynthesis in lichens. In: Ferry, B.W., Baddeley, M.S. and Hawksworth, D.L. (eds). Air Pollution and Lichens. pp. 283-298. University of Toronto Press. Buffalo.

Richardson, D.H.S. and Young, C.M. (1977). Lichens and vertebrates. In: Seaward, M.R.D. (ed). Lichen Ecology. pp. 121-144. Academic Press. New York.

Rizzini, C.T. (1963). A flora do cerrado. Analise floristica das savanas centrais. In: Ferri, M.G. (org). III Simpósio sobre o Cerrado. pp. 125-177. Editora da Univ. de São Paulo. São Paulo.

Rizzini, C.T. and Heringer, E.P. (1962). Preliminares acerca das formaçoes vegetais e do reflorestamento do Brasil Central. Serviço de Informaçao. M. da Agricultura. Rio de Janeiro.

Roberts, S.J. (1995). Fire on the Gapalg (floodplain): Contemporary aboriginal and other burning patterns in Kakadu National Park, northern Australia. In: Cerulean, S.I. and Engstrom, R.T. (eds). Fire in wetlands: a management perspective. pp. 31-37. Proceedings of the Tall Timbers Fire Ecology Conference, 19. Tall Timbers Research Station, Tallahassee, FL.

Rogers, R.W. (1971). Distribution of the lichen Chondropsis semiviridis in relation to it's heat and drought resistance. New Phytologist, 70: 1069-1077.

-----(1977). Lichens of Hot Arid and Semi-arid Lands. In: Seaward, M.R.D. (ed). Lichen Ecology. pp. 211-252. Academic Press. London.

-----(1988). Succession and survival strategies in lichen populations on a palm trunk. Journal of Ecology, 76: 759-776.

----(1990). Ecological strategies of lichens. The Lichenologist, 22(2): 149-162.

Rogers, R.W. and Stevens, G.N. (1981). Lichens. In: Keast, A. (ed). Ecological Biogeography of Australia. pp. 593-603. W. Junk. The Hague.

Ronen, R. (1986). The effect of air pollution on physiological parameters of the lichen Ramalina duriaei. Unpublished $\mathrm{PhD}$ thesis. University of Tel Aviv.

Rose, F. (1974). The epiphytes of oaks. In: Morris, M.G. and Perring, F.H. (eds). The British Oak: Its History and Natural History. pp. 250-273. Botanical Society of the British Isles. Conference Reports 14. Faringdon. 
--(1976). Lichenological indicators of age and environmental continuity in woodlands. In: Brown, D.H., Hawksworth, D.L. and Bailey, R.H. (eds). Lichenology: progress and problems. pp. 279-307. Academic Press. London.

-----(1988). Phytogeographical and ecological aspects of Lobarion communities in Europe. Botanical Journal of the Linnean Society, 96: 69-79.

---11992). Temperate forest management: its effects on bryophyte and lichen floras and habitats. In: Bates, J.W. and Farmer, A.M. (eds). Bryophytes and Lichens in a Changing Environment. pp. 211-233. Oxford Scientific Publications. Oxford.

Rose, F. and James, P.W. (1974). Regional studies on the British lichen flora. I: The corticolous and lignicolous species of the New Forest, Hampshire. The Lichenologist, 6: 1-72.

Roy-Arcand, L., Delisle, C.E. and Briere, F.G. (1989). Effects of simulated acid precipitation on the metabolic activity of Cladina stellaris. Canadian Journal of Botany, 67: 1796-1802.

Rundel, P.W. (1978). The ecological role of secondary lichen substances. Biochemical Systematics and Ecology, 6: 157-170.

Saint-Hilaire, A. (1824). Histoire des plantes les plus remarcables du Brésil et du Paraguay, I. Belin Imprimeur-Libraire. Paris.

-.----(1827). Voyages dans l'interieur du Bresil, III partie - Voyages aux sources du Rio S. Francisco et dans la Province de Goyaz. Belin Imprimeur-Libraire. Paris.

Sanchez, P.A. (1976). Properties and management of soils in the tropics. Wiley Interscience. New York.

-----(1981). Soil management in the Oxisol savannas and Ultisols jungles of tropical South America.

In: Greenland, D.J. (ed). Characteristics of soils in relation to their classification and management for crop production: examples from some areas of the humid tropics. Clarendon Press. Oxford.

Sarmiento, G. (1983). The savannas of tropical America. In: Bourlière, F. (ed). Tropical Savannas. Ecosystems of the World 13. pp. 245-288. Elsevier Scientific Publishing Company. Amsterdam.

---(1984). The Ecology of Neotropical Savannas. Harvard University Press. Cambridge, Massachusetts. 
Sarmiento, G. and Monasterio, M. (1975). A critical consideration of the environmental conditions associated with the occurrence of savanna ecosystems in tropical America. In: Golley, F.B. and Medina, E. (eds). Tropical Ecological Systems. Trends in Terrestrial and Aquatic Research. (Ecological Studies 11). pp. 223-250. Springer-Verlag. Berlin.

Saunders, P.J.W. (1970). Air pollution in relation to lichens and fungi. The Lichenologist, 4: 337 349.

Savoye, D. and Leclerc, J.C. (1982). Apports de la spectroscopie d'absorption à haute résolution a l'étude taxonomique et écologique de quelques Trebouxia (Chlorophycees, Chlorococcales). Cryptogamie, Algologie, 3: 113-120.

Schiavini, I. (1984). Ciclagem de nutrientes no cerrado. I-Agua da chuva. Ciência Cultura, São Paulo, 36(Suppl.).

Schüle, W. (1990). Landscapes and climate in prehistory: interactions of wildlife, man, and fire. In: Goldammer, J.G. (ed). Fire in the Tropical Biota. pp. 273-318. Springer-Verlag. Berlin.

Schwendener, S. (1869). Die Algentypen der Flechtengonidien. Programm für die Rectorsfeier der Universität Basel, 4: 1-42.

Scott, M.G. and Hutchinson, T.C. (1987). Effects of a simulated acid rain episode on photosynthesis and recovery in the caribou-forage lichens, Cladina stellaris (Opiz.) Brodo and Cladina rangifera (L.) Wigg. New Phytologist, 107: 567-575.

Seaward, M.R.D. (1987). Effects of quantitative and qualitative changes in air pollution on the ecological and geographical performance of lichens. In: Hutchinson, T. (ed). The effects of atmospheric pollutants on forests, wetlands and agricultural ecosystems. pp. 439-450. Springer-Verlag. Berlin.

-----(1989). Lichens as monitors of recent changes in air pollution. Plants Today, March/April: 6469.

Seaward, M.R.D. and Letrouit-Galinou, M.A. (1991). Lichens return to the Jardin du Luxembourg after an absence of almost a century. The Lichenologist, 23: 118-126. 
Seaward, M.R.D., Heslop, J.A., Green, D. and Bylinska, E.A. (1988). Recent levels of radionuclides in lichens from southwest Poland with particular reference to ${ }^{134} \mathrm{Cs}$ and ${ }^{137} \mathrm{Cs}$. Journal of Environmental Radioactivity, 7: 123-129.

Selva, S.B. (1994). Lichen diversity and stand continuity in the northern hardwoods and spruce-fir forests of northern New-England and western New-Brunswick. The Bryologist, 97 (4): 424429.

Sernander, J.R. (1926). Stochholms Natur. Uppsala.

Sillett, T.S. (1994). Foraging ecology of epiphyte-searching insectivorous birds in Costa Rica. Condor, 96 (4): 863-877.

Sipman, H.J.M. (1983). A monograph of the lichen family Megalosporaceae. Bibliotheca Lichenologica, 18. Cramer. Vaduz.

-----(1986). Key to the genera occurring in the Guianas. Unpublished manuscript.

Sipman, H.J.M. and Harris, R.C. (1989). Lichens. In: Lieth, H. and Werger, M.J.A. (eds). Tropical Rain Forest Ecosystems. pp. 303-309. Elsevier. Amsterdam.

Slack, N.G. (1988). The ecological importance of lichens and bryophytes. In: Nask, T.H. and Wirth, V. (eds). Lichens, Bryophytes and Air Quality. pp. 23-54. Bibliotheca Lichenologica vol.30. J. Cramer. Berlin.

Sloof, J.E. and Wolterbeek, H.T. (1991). National trace-element air pollution monitoring survey using epiphytic lichens. The Lichenologist, 23: 139-166.

Smith, D.C. and Molesworth, S. (1973). Lichen physiology. XII. Effects of rewetting dry lichens. New Phytologist, 72: 525-533.

Smith, J.N. and Ellis, K.M. (1990). Time dependent transport of Chernobyl radioactivity between atmospheric and lichen phases in eastern Canada. Journal of Environmental Radioactivity, 11: 151-168.

Snelger, W.P., Green, T.G.A. and Beltz, K. (1981). Carbon dioxide exchange in lichens: Estimation of internal thallus $\mathrm{CO}_{2}$ transport resistances. Physiologia Plantarum, 52: 417-422. 
Snyder, J.R. (1991). Fire regimes in subtropical south Florida. In: Proceedings 17th Tall Timbers Fire Ecology Conference. pp. 303-319. Tall Timbers Research Station. Tallahassee, FL.

Solbrig, O.T. (ed). (1991). Savanna modelling for global change. Biology International Special Issue 24. IUBS. Paris.

Stearns, S.C. (1977). The evolution of life history traits: a critique of the theory and a review of the data. Annual Review of Ecology and Systematics, 8: 145-171.

Stott, P.A. (1986). The spatial pattern of dry season fires in the savanna forests of Thailand. Journal of Biogeography, 13: 345-358.

Strandberg, M. (1994). Radiocesium in a Danish pine forest ecosystem. Science of the Total Environment, 157 (1-3): 125-132.

Stringer, P.W. and Stringer, M.H.L. (1974). Air pollution and the distribution of epiphytic lichens and bryophytes in Winnipeg, Mannitoba. The Bryologist, 77: 405-426.

Sundstrom, K.R. and Hallgren, J.E. (1973). Using lichens as physiological indicators of sulphurous pollutants. Ambio, 2: 13-21.

Swinscow, T.D.V. and Krog, H. (1988). Macrolichens of East Africa. British Museum (Natural History). London.

Takala, K., Olkkonen, H., Jaaskelainen, J. and Selkainaho, K. (1990). The total chlorine content of epiphytic and terricolous lichens and birch bark in Finland. Annales Botanici Fennici, 27: 131-137.

Thomas, W. (1981). Entwicklung eines immissionemeibstsems für PCA, chlorokohlenwasserstoffe und spurenmetalle mittels eiphytischer moose-angewand fur den Raum Bayern. Bayreuther Geowissenschaftliche Arbeiten, 3: 144S.

Thomas, W., Rühling, A. and Simon, H. (1984). Accumulation of airborne pollutants (PAH, chlorinated hydrocarbons, heavy metals) in various plant species and humus. Environmental Pollution (Series A), 36: 295-310. 
Thompson, R.L., Ramelow, G.J., Beck, J.N., Langley, M.P., Young, J.C. and Casserly, D.M. (1987). A study of airborne metals in Calcasieu Parish using the lichens Parmelia praesorediosa and Ramalina stenospora. Water, Air and Soil Pollution, 36: 295-309.

Tibell, L. (1992). Crustose lichens as indicators of forest continuity in boreal coniferous forests. Nordic Journal of Botany, 12 (4): 427-450.

Topham, P.B. (1977). Colonisation, Growth, Succession and Competition. In: Seaward, M.R.D. (ed). Lichen Ecology. pp. 31-68. Academic Press. London.

Tothill, J.C. (1985). American savanna ecosystems. In: Tothill, J.C. and Mott, J.J. (eds). Ecology and management of the world's savannas. pp. 52-55. Australian Academy of Science. Canberra.

Trass, H. and Randlane, T. (1987). Extinct macrolichens of Estonia. Folia Cryptogamica Estonica, 25: $1-16$.

Tyler, G. (1989). Uptake, retention and toxicity of heavy metals in lichens. Water, Air and Soil Pollution, 47: 321-333.

Van Assche, F. and Clijsters, H. (1990). Effects of metals on enzyme activity in plants. Plant, Cell and Environment, 13: 19-206.

Van der Hammen, T. (1974). The Pleistocene changes of vegetation and climate in tropical South America. Journal of Biogeography, 1: 3-26.

Van der Knapp, W.O. and van Dobben, H.F. (1987). Veranderingen in de Epifytenflora van Rijnmond sinds 1972. RIN-rapport 87/1. Rijkinstinstituut voor Naturbeheer. Arnhem.

Van Wagner, C.E. (1978). Age-class distribution and the forest fire cycle. Canadian Journal of Forest, 8: $220-227$.

Van Wilgen, B.W., Everson, C.S. and Trollope, W.S.W. (1990). Fire management in southern Africa: some examples of current objectives, practices and problems. In: Goldammer, J.G. (ed). Fire in the Tropical Biota. pp. 179-215. Springer-Verlag. Berlin. 
Vernet, J.L., Wengler, L., Solari, M.E., Ceccantini, G., Fournier, M., Ledru, M.P. and Soubies, F. (1994). Fire, climate and vegetation in central Brazil during the Holocene - data from a soil profile with charcoal (Salitre, Minas Gerais). Comptes Rendus de l Academie des Sciences Serie II, $319(11,2)$ : 1391-1397.

Viles, H. (1987). A quantitative scanning electron microscope study of evidence for lichen weathering of limestone, Mendip Hills, Somerset. Earth Surface Processes and Landforms, 12: 467-473.

Villas-Boas, O. and Villas-Boas, C. (1976). Xingu - Os indios. Seus Mitos. Zahar Editores. Rio de Janeiro.

Villeneuve, J.P. and Holm, E. (1984). Atmospheric background of chlorinated hydrocarbons studied in Swedish lichens. Chemosphere, 13: 1133-1138.

Villeneuve, J.P., Holm, E. and Cattini, C. (1985). Transfer of chlorinated hydrocarbons in the foodchain reindeer-man. Chemosphere, 14: 1651-1658.

Villeneuve, J.P., Fogelqvist, E. and Cattini, C. (1985). Lichens as bioindicators for atmospheric pollution by chlorinated hydrocarbons. Chemosphere, 17: 399-403.

Vines, R.G. (1981). Physics and chemistry of rural fires. In: Gill, A.M., Groves, R.H. and Noble, I.R. (eds). Fire and the Australian Biota. pp. 129-149. Australian Academy of Science. Canberra.

Wagner, E. (1981). Politica de ocupação e utilização dos Cerrados. CPAC Documentos n. 1. EMBRAPA/CPAC. Planaltina, D.F.. Brasil.

Waithier, D.A., Ramelow, G.J, Beck, J.N., Young, J.C., Callahan, J.D. and Marcon, M.F. (1990). Temporal changes in metal levels of the lichens Parmotrema praesorediosum and Ramalina stenospora, southwest Louisiana. Water, Air and Soil Pollution, 53: 189-200.

Ward, D.E., Sussott, R., Kauffinan, J.B. et al., (1992). Emissions and burning characteristics of biomass fires for Cerrado and tropical forest regions of Brazil - BASE B Experiment. Journal of Geophysical Research, 97: 14601-14619.

Warming, E. (1892). Lagoa Santa: Et Bidrad til den biologiske plantegeografi. Det Kongelige danske Videnskabernes selskabs Skrifter, 6: 153-488. 
Werner, P.A., Walker, B.H. and Stott, P.A. (1990). Introduction. Journal of Biogeography, 17 (4/5): 343-344.

Wetmore, C.M. (1983). Lichen survival in a burned oak savanna. The Michigan Botanist, 22: 47-52.

White, J. and James, P.W. (1985). A new guide to microchemical techniques for the identification of lichen substances. British Lichen Society Bulletin (Suppl.), 57: 1-41+6 tables.

Wills, R.D. and Stuart, J.D. (1994). Fire history and stand development of a Douglas-Fir hardwood forest in northern California. Northwest Science, 68 (3): 205-212.

Will-Wolf, S. (1988). Quantitative approaches to air quality studies. In: Nash, T.H. and Wirth, V. (eds). Lichens, Bryophytes and Air Quality. pp. 109-140. J. Cramer. Berlin.

Wirth, V. and Türk, R. (1974). Über die $\mathrm{SO}_{2}$-resitenz von Flechten und die mit ihr interferierenden Faktoren. Verhandlungen der Gesellschaft für Ökologie, 1974: 173-179.

Wolf, J.H.D. (1994). Factors controlling the distribution of vascular and non-vascular epiphytes in the northern Andes. Vegetatio, 112: 15-28.

Wolseley, P.A. (1991). The 'Lobarion' in South East Asia. In: Galloway, D.J. (ed). Tropical Lichens and their Systematics, Conservation and Ecology. pp. 69-84. Clarendon Press. Oxford.

Wolseley, P.A. and Aguirre-Hudson, B. (1991). Lichens as indicators of environmental change in the tropical forests of Thailand. Global Ecology and Biogeography Letters, 1(6): 170-175.

-.--(1993a). Key to lichen genera in Thailand with special reference to epiphytic communities. Part I Macrolichens. Unpublished, draft copy.

---n--(1993b). Second workshop on lichens as indicators of forest health. Unpublished Workshop Paper. Dept. of Biology, Faculty of Science, Chiang Mai University.

-----(1994). Field key to characteristic and indicator epiphytic lichens in northern Thailand.

Unpublished, draft copy.

-----(1996a). The ecology and distribution of lichens in tropical deciduous and evergreen forests of northern Thailand. Journal of Biogeography (in press).

------(1996b). Fire in tropical dry forests: corticolous lichens as indicators of recent ecological changes in Thailand. Journal of Biogeography (in press). 
Wolseley, P.A. and O'Dare, A.M. (1990). The use of epiphytic lichens as environmental indicators in Exmoor woodlands. In: Ecology in Somerset. pp. 3-22. The Somerset Trust for Nature Conservation. Somerset.

Wolseley, P.A. and James, P.W. (1991). The effects of acidification on lichens. 1986-90. CSD Report 1247, Nature Conservancy Council, Peterborough, U.K.

Wolseley, P.A., Moncrieff, C. and Aguirre-Hudson, B. (1994). Lichens as indicators of environmental stability and change in the tropical forests of Thailand. Global Ecology and Biogeography Letters, 4: 116-123.

Xavier Filho, L. (1976). Contribuição ao conhecimento dos gêneros de liquens brasileiros. Chave de identificação. Mestre tese. Universidade Federal Rural de Pernambuco, Recife.

Yom-Tov, Y. and Galun, M. (1971). Note on the feeding habits of the desert snails Spincterochila boissieri Charpentier and Trochoidea (Xerocrassa) seetzeni Charpentier. Veliger, 14: 80-88. 


\section{Glossary}

Adnate: adjoining the surface.

Alga (pl. -gae): a heterogeneous group of eukaryotic unicellular colonial and multicellular organisms of simple structure, usually photosynthetic and traditionally included in the plant kingdom.

Allelopathic: the influence or effects (sometimes inhibitory or harmful) of a living organism on other nearby organisms.

Apothecium (pl. -cia): fruiting body of the fungal component of a lichen, often cup-shaped and usually open above, with the disc exposed.

Areola (pl. -lae): a small area.

Ascus (pl. -ci): sac-like vessel, usually clavate to obovate, containing spores.

Bioindicator: an organism which responds to environmental change, and thereby can provide information on both the change and the extent of change.

Bulbate: globose with a narrow, tapering neck.

$\mathrm{C}_{4}$ plants: species of higher plants in which the assimilation of atmospheric $\mathrm{CO}_{2}$ in the photosynthetic process is indirect, via the enzyme phosphoenol pyruvate carboxylase in the sheaths surrounding the veins of the leaves; the rate of photosynthesis in these plants continues to increase with the intensity of the photosynthetic active radiation (PAR) well beyond that normally found in nature.

Cataphylls: simple, scale-like leaves which act as a covering over buds.

Cephalodium (pl. -dia): a body composed of blue-green photobiont cells and fungal hyphae growing on the surface or within the thallus of lichens with a green photobiont.

Chlorophyll: principal photosynthetic pigment of green plants and algae.

Chloroplast: organelle in cytoplasm of all green plants where reactions of photosynthesis take place.

Cilia: hair-like outgrowths from the margins or upper surface of the thallus.

Coralloid: divided up into many short branches, like coral.

Cortex: a tissue of compacted hyphae, which may appear cellular or fibrous, forming the outer layer of the thallus.

Corticate: having a cortex.

Corticolous: growing on the bark of trees or shrubs.

Crustose: crust-like, i.e. thallus stretching over and firmly fixed to the substratum by the whole of their lower surface, and generally lacking rhizines.

Cyanobacteria (pl, -ium): a blue-green algal photobiont.

Cyphella (pl. -lae): a sharply bounded concave pore, on the underside of the thallus.

Dactyl: finger-like protuberance, bounded by a cortex, often opening at the apex to expose the medulla, sometimes producing soredia from the inner surface.

Dichotomous: dividing into two or more equal arms, usually repeatedly and successively.

Disc: exposed upper surface of the hymenium in an apothecium. 
Dorsiventral: flattened and having upper and lower surface of distinctly different structure.

Dystrophic: inhibiting adequate nutrition.

Ecorticate: without a cortex.

Endolithic: burrowing or existing in a stony substratum.

Endophloedal: part of the lichen thallus containing the photobiont living inside the bark.

Epithecium (pl. -cia): a lining of cells tightly bound together.

Ephemeral: short-lived.

Epilithic: attached on rocks.

Eutrophic: rich in nutrients.

Exciple: a tissue or tissues containing the hymenium of the apothecium, or forming the walls of a perithecium.

Fire history (in this thesis): the combination of fire frequency and fire behaviour (fire homogeneity and flame heights) of recent past fires (up to 20 years ago) in an area of vegetation; more generally - all occurrences of past fires in an area.

Foliose: leaf-like, with a distinct upper and lower surface, and larger than the arbitrarily distinguished squamulose lobes (up to $5 \mathrm{~mm}$ long and wide).

Fruticose: shrubby, with an upright or hanging thallus of a radial structure.

Fungus (pl. -gi): a kingdom of heterotrophic, non-motile, non-photosynthetic and chiefly multicellular organisms that absorb nutrients from dead or living tissues.

Globose: approximately spherical.

Hapter: an organ of attachment (of the thallus to the substrate).

Heliophilous: adapted to a relatively high intensity of light.

Heteromerous: (of a layered thallus) having the mycobiont and the photobiont in well-marked layers in the thallus.

Holdfast: an expanded often disc-like attachment of thallus to substrate.

Homoiomerous: (of an unlayered thallus) having the mycobiont and the photobiont evenly distributed through the thallus.

Hydrophilous: spore propagation through water.

Hygrophilous: inhabiting moist or marshy places.

Hymenium: that part of the fruiting body comprising the asci and the paraphyses.

Hypha (pl. -hae): a filament of fungal cells.

Hypothallus: a thick layer of hyphae, white to darkly coloured, on the underside of the thallus, often projecting beyond it's margins.

Isidium (pl. -dia): a pin-like vegetative propagule bounded by a true cortex, comprising both photobiont cells and fungal hyphae, usually concolourous with the upper surface of the thallus.

K-selected: species selected for their superiority in stable environments, having a slow development, a large size and the production of a small number of offspring. 
Laminal: the main body, in contrast to the margins.

Lecanorine: apothecium with a thalline rim around the disc.

Lecideine: apothecium without a thalline rim around the disc.

Lichen: an organism formed from the symbiotic association of certain fungi and a green alga or cyanobacteriun, forming a simple body.

Lirella (pl. -lae): long and narrow apothecium.

Lobe: a division of a foliose or squamulose thallus.

Lumina: internal space within a spore.

Maculae: spotted or blotched patterning on thallus due to uneven distribution of photobiont cells.

Mazaedium: a powdery mass of spores together with disintegrating asci and paraphyses.

Marginal: on the margins of a thallus.

Medulla: the loose layer of hyphae under the cortex and algal layer.

Mesotrophic: moderate quantity of nutrients.

Microconidium (pl. -dia): non-motile asexual spore.

Mitochondrion (pl. -dria): organelle in cytoplasm of eukaryotic cells, site of oxidative respiration, generating ATP i.e. energy.

Muriform: brick wall-like, having transverse and longitudinal septa.

Mycobiont: the fungal partner in the symbiosis that constitutes a lichen.

Oligotrophic: poor in nutrients.

Ostiole: cavity ending in a pore in the papilla or neck of a perithecium or pycnidium.

Paraphyses: hyphae originating from the base of the cavity, usually unbranched and not anastomosed.

Paraplectenchymatous: a tissue of isodiametric thin-walled fungal cells.

Peltate: shield-shaped.

Pendulous: hanging.

Penicillate: tufted, like a paint brush.

Perennial: persists for several years.

Periclinal: of hyphae, lying in the same plane as the surface.

Perithecium (pl. -cia): fruiting body of the fungal component of a lichen, more or less globose or flask-shaped, closed above except for a central (or rarely eccentric) ostiole.

Photobiont: the photosynthesising organism with which a fungus is in symbiosis to form a lichen.

Phyllidium (pl, -dia): a small vegetative, corticate, scale-like, dorsiventral structure developed at the margins or the upper surface of the thallus, narrowed or constricted at the point of attachment.

Podetium (pl. -tia): lichenised stem-like portion, bearing apothecia.

Prosoplechtenchyma: tissue with elongated longitudinally arranged hyphae (in L.S.).

Pruinose: having a frost-like or flour-like surface covering.

Pseudocyphella (pl. -lae): opening in the cortex of lichens where the medulla is exposed to the air, but lacking specialised cells surrounding the cavity. 
Pustule: swelling-like protuberance, formed from the thalline cortex.

Pycnidium (pl. -dia): flask-shaped with ostioles, containing conidiomata, consisting entirely of fungal tissue.

Reticulate: net-like.

Rhizine (pl. -nae): root-like hair or thread, the attachment organ of many foliose lichens.

r-selected: species typical of variable, unpredictable environments, characterised by a small body size, a rapid rate of increase and the production of large quantity of small-sized offspring.

Sclerophylly: condition of having hard leaves, which are resistant to drought through having a thick cuticle.

Septation: division into cells or compartments.

Sessile: having no stem, attached directly to the surface.

Soralia: soredia on lamina or margins of thallus in a variety of diffuse, delimited or figurate patterns.

Soredium (pl. -dia): a non-corticate combination of photobiont cells and fungal hyphae having the appearance of a powdery granule and capable of vegetative reproduction.

Spore: a uni- or multicellular reproductive structure (asexual or sexual) in fungi, bacteria and cryptograms.

Squamule: a small separate thallus scale or lobe (less than $5 \mathrm{~mm}$ long), with or without a lower cortex.

Squamulose: made up of squamules.

Squarrose: of branching at right angles, as in rhizines.

Suberisation: thickening of plant cell walls due to the deposition of suberin, a waxy substance characteristic of corky tissues.

Symbiosis (adj. symbiotic): a long-lasting association between two or more different species of organisms and includes mutualism, in which both symbionts benefit, and parasitism, in which one biont benefits at the expense of the other (Ahmadjian and Paracer, 1986).

Sympodial: of a thallus with a main axis and a succession of subsidiary lateral branches.

Terete: more or less circular in transverse section.

Terminal: at the ends of lobes.

Thallus (pl, -li): the vegetative part of a lichen.

Tomentum: a dense covering of entangled and appressed hyphal hairs. 


\section{Appendix 1 \\ List of phorophyte species found in this study}

\begin{tabular}{|c|c|c|c|}
\hline Family & Species & Local name & Form \\
\hline Annonaceae & $\begin{array}{l}\text { Annona coriacea Mart. } \\
\text { Annona crassiflora Mart. }\end{array}$ & Araticum & $\begin{array}{l}\text { Tree } \\
\text { Tree }\end{array}$ \\
\hline Apocynaceae & $\begin{array}{l}\text { Aspidosperma macrocarpon Mart. } \\
\text { Aspidosperma tomentosum Mart. } \\
\text { Hancornia speciosa Gomez. }\end{array}$ & $\begin{array}{l}\text { Peroba-do-campo } \\
\text { Mangaba }\end{array}$ & $\begin{array}{l}\text { Tree } \\
\text { Tree } \\
\text { Tree }\end{array}$ \\
\hline Araliaceae & $\begin{array}{l}\text { Didymopanax macrocarpum } \\
\text { (Cham. \& Sch1.)Seem }\end{array}$ & Mandiocao & Tree \\
\hline Bombacaceae & $\begin{array}{l}\text { Eriotheca pubescens } \\
\text { (Mart. \& Zucc.) Schott \& Endl. }\end{array}$ & Paineira & Tree \\
\hline Burseraceae & Protium ovatum Engl. & & Subshrub \\
\hline Caryocaraceae & Caryocar brasiliense Camb. & Pequizeiro & Tree \\
\hline Chrysobalanaceae & $\begin{array}{l}\text { Couepia grandiflora } \\
\text { (Mart. \& Zucc.) Benth. ex Hook f. } \\
\text { Hirtella grandulosa Spr. }\end{array}$ & Bosta-de-rato & $\begin{array}{l}\text { Tree } \\
\text { Tree }\end{array}$ \\
\hline Combretaceae & Terminalia brasiliensis Raddi & & Tree \\
\hline Compositae & $\begin{array}{l}\text { Eremanthus glomerulatus Less. } \\
\text { Eremanthus goyazensis Sch. Bip. } \\
\text { Piptocarpha rotundifolia } \\
\text { (Less.) Baker. }\end{array}$ & Cinzeiro & $\begin{array}{l}\text { Tree } \\
\text { Subshrub } \\
\text { Tree }\end{array}$ \\
\hline Connaraceae & $\begin{array}{l}\text { Connarus suberosus Planch. } \\
\text { Rourea induta Planch. }\end{array}$ & & $\begin{array}{l}\text { Tree } \\
\text { Shrub }\end{array}$ \\
\hline Cunnoniaceae & Lamanonia ternata Vell. & Cangalheiro & Tree \\
\hline Dichapetalaceae & Tapura amazonica Poepp. \& Endl. & & Tree \\
\hline Dilleniaceae & Davila elliptica St. Hil. & Sambaibinha & Shrub \\
\hline Ebenaceae & $\begin{array}{l}\text { Diospyros hispida } \\
\text { DC.(var camporum) }\end{array}$ & & Tree \\
\hline Erythroxylaceae & $\begin{array}{l}\text { Erythroxylum campestris St. Hil. } \\
\text { Erythroxylum suberosum St. Hil. } \\
\text { Erythroxylum tortuosum Mart. }\end{array}$ & $\begin{array}{l}\text { Mercurio-do-campo } \\
\text { Mercurio-do-campo }\end{array}$ & $\begin{array}{l}\text { Subshrub } \\
\text { Shrub } \\
\text { Shrub }\end{array}$ \\
\hline Euphorbiaceae & Pera glabrata (Sch.) Baill. & & Tree \\
\hline Guttiferae & $\begin{array}{l}\text { Kielmeyera coriacea Mart. } \\
\text { Kielmeyera speciosa } \text { St. Hil. }\end{array}$ & $\begin{array}{l}\text { Pau santo } \\
\text { Pau santo }\end{array}$ & $\begin{array}{l}\text { Tree } \\
\text { Shrub }\end{array}$ \\
\hline
\end{tabular}




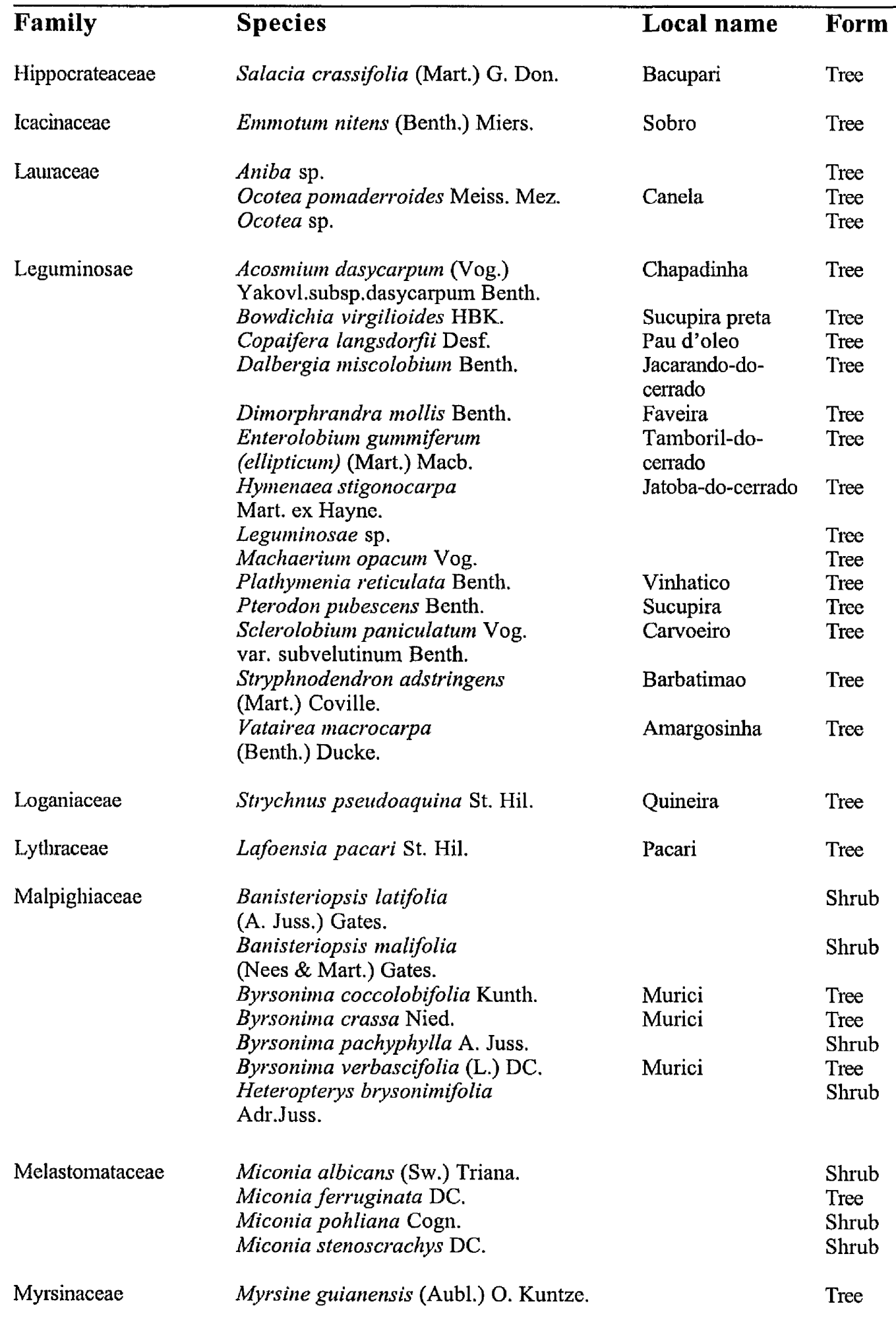




\begin{tabular}{|c|c|c|c|}
\hline Family & Species & Local name & Form \\
\hline Myrtaceae & $\begin{array}{l}\text { Blepharocalyx salicifolius } \\
\text { (H.B.K.) Berg. } \\
\text { Myrcia tomentosa (Aubl.) DC. } \\
\text { Psidium aerugineum Berg. } \\
\text { Psidium pohlianum Berg. }\end{array}$ & Maria preta & $\begin{array}{l}\text { Tree } \\
\text { Shrub } \\
\text { Shrub } \\
\text { Tree }\end{array}$ \\
\hline Nyctaginaceae & $\begin{array}{l}\text { Guapira graciliflora } \\
\text { (Mart. ex J.A. Schmidt) Lundel. } \\
\text { Guapira noxia (Netto) Lundel } \\
\text { Neea theifera Oerst. }\end{array}$ & Pau-de-lepra & $\begin{array}{l}\text { Tree } \\
\text { Tree } \\
\text { Shrub }\end{array}$ \\
\hline Ochnaceae & Ouratea hexasperma (St. Hil.) Bail. & & Tree \\
\hline Palmae & $\begin{array}{l}\text { Syagrus comosa (Mart.) Becc. } \\
\text { Syagrus flexuosa (Mart.) Becc. }\end{array}$ & $\begin{array}{l}\text { Camargo } \\
\text { Licuri }\end{array}$ & $\begin{array}{l}\text { Shrub } \\
\text { Shrub }\end{array}$ \\
\hline Proteaceae & Roupala montana Aubl. & Came-de-vaca & Tree \\
\hline Rubiaceae & $\begin{array}{l}\text { Alibertia concolor (Cham.) Schum. } \\
\text { Alibertia edulis (L.C. Rich.). } \\
\text { A. C. Rich ex DC. } \\
\text { Chomelia ribesioides Benth. } \\
\text { Palicourea rigida H.B.K. }\end{array}$ & $\begin{array}{l}\text { Marmeladinha } \\
\text { Marmelada }\end{array}$ & $\begin{array}{l}\text { Shrub } \\
\text { Shrub } \\
\text { Shrub } \\
\text { Tree }\end{array}$ \\
\hline Sapotaceae & $\begin{array}{l}\text { Pouteria ramiflora (Mart.) Radlk. } \\
\text { Pouteria torta (Mart.) Radlk. }\end{array}$ & $\begin{array}{l}\text { Curriola } \\
\text { Curriola }\end{array}$ & $\begin{array}{l}\text { Tree } \\
\text { Tree }\end{array}$ \\
\hline Styracaceae & Styrax ferrugineus Nees \& mart. & $\begin{array}{l}\text { Laranjinha-do- } \\
\text { campo }\end{array}$ & Tree \\
\hline Symplocaceae & $\begin{array}{l}\text { Symplocos lanceolata (Mart.) A.DC. } \\
\text { Symplocos nitens (Pohl) Benth. } \\
\text { Symplocos rhamnifolia A.DC. }\end{array}$ & & $\begin{array}{l}\text { Tree } \\
\text { Tree } \\
\text { Tree }\end{array}$ \\
\hline Velloziaceae & Vellozia squamata Mart ex Schult. & Canela-de-ema & Shrub \\
\hline Vochysiaceae & $\begin{array}{l}\text { Qualea dichotoma (Mart.) Warm. } \\
\text { Qualea grandiflora Mart. } \\
\text { Qualea multiflora Mart. } \\
\text { Qualea parviflora Mart. } \\
\text { Vochysia elliptica Mart. } \\
\text { Vochysia rufa Mart. } \\
\text { Vochysia thyrsoidea Pohl. }\end{array}$ & $\begin{array}{l}\text { Jacare } \\
\text { Pau terra } \\
\text { Pau terrinha } \\
\text { Pau terrinha } \\
\text { Pau doce } \\
\text { Gomeira }\end{array}$ & $\begin{array}{l}\text { Tree } \\
\text { Tree } \\
\text { Tree } \\
\text { Tree } \\
\text { Tree } \\
\text { Tree } \\
\text { Tree }\end{array}$ \\
\hline
\end{tabular}




\section{Appendix 2 \\ List of lichen species found in this study}

\section{Arthoniaceae}

Arthonia Ach. = Arthonia sp.

Arthothelium Massal, = Arthothelium sp. '1' and Arthothelium sp. '2'

\section{Arthopyreniaceae}

Arthopyrenia Massal. = Arthopyrenia sp. '1' and Arthopyrenia sp. '2'

Mycomicrothelia Keissl.

\section{Bacidiaceae}

Bacidia De Not. $=$ Bacidia sp.

\section{Candelariaceae}

Candelaria Massal. = Candelaria sp.

\section{Chrysotrichaceae}

Chrysothrix Mont. = Chrysothrix sp.

Chrysothrix candelaris (L.) Laundon

\section{Cladoniaceae}

Cladonia ochroclora Flörke

Cladonia ramulosa (With.) Laundon

Cladonia subradiata (Vainio) Sandst.

\section{Coccocarpiaceae}

Coccocarpia dominguensis Vain.

Coccocarpia erythroxyli (Sprengel) Swinscow \& Krog

Coccocarpia imbricascens Nyl.

Coccocarpia stellata Tuck.

\section{Gomphillaceae}

Gyalideopsis Vézda = Gyalideopsis $\mathbf{s p}$.

\section{Graphidaceae}

Graphina Müll. Arg. = Graphina sp.

Graphis Adans. = Graphis sp.

Medusulina Müll. Arg. = Medusulina sp. 
Sarcographa Fée = Sarcographa $\mathrm{sp}$.

\section{Gyalectaceae}

Dimerella Trevisan $=$ Dimerella sp.

\section{Haematommataceae}

Haematomma puniceum (Sw.) Mass.

\section{Lecanoraceae}

Lecanora myriocarpoides Vain.

Lecidella Körb. = Lecidella sp.

Maronina multifera (W. Nylander) J. Hafellner \& R.W. Rogers

Pyrrhosphora russula (Ach.) Hafellner

\section{Letrouitiaceae}

Letrouitia Hafellner \& Bellem. = Letrouitia sp.

\section{Opegraphaceae}

Chiodecton Ach. $=$ Chiodecton sp.

\section{Parmeliaceae}

Bulbothrix apophysata (Hale \& Kurokawa) Hale

Bulbothrix bulbochaeta (Hale) Hale

Bulbothrix coronata (Fée) Hale

Bulbothrix fungicola (Lynge) Hale

Bulbothrix hypocrae (Vainio) Hale

Bulbothrix isidiza (Nyl.) Hale

Bulbothrix linteolocarpa M.P. Marcelli

Bulbothrix sensibilis (Steiner \& Zahlbr.) Hale

Bulbothrix suffixa (Stirton) Hale

Canoparmelia amazonica (W. Nylander) J.A. Elix \& M.E. Hale

Canoparmelia caroliniana (W. Nylander) J.A. Elix \& M.E. Hale

Canoparmelia crozalsiana (M. Bouly de Lesdain) J.A. Elix \& M.E. Hale

Canoparmelia texana (E. Tuckerman) J.A. Elix \& M.E. Hale

Flavoparmelia amplexa (J.Stirton) Hale

Flavoparmelia subamplexa (Hale) Hale

Hypotrachyna (Vain.) Hale = Hypotrachyna sp. and Hypotrachyna sp. 'C'

Hypotrachyna deglii (Hale) Hale

Hypotrachyna ducalis (Jatta) Hale 


\section{Parmeliaceae continued.}

Hypotrachyna lythgoeana (Dodge) Hale

Hypotrachyna novella (Vainio) Hale

Hypotrachyna silvatica (Lynge) Hale

Hypotrachyna subaffinis (Zahlbruckner) Hale

Hypotrachyna velloziae (Vainio) Hale

Myelochroa (Asahina) Elix \& Hale = Myelochroa sp.

Parmelinella versiformis (Kremp.) M.P. Marcelli

Parmelinopsis Elix \& Hale = Parmelinopsis sp. and Parmelinopsis sp. ' 3 '

Parmelinopsis horrescens (Taylor) Elix \& Hale

Parmelinopsis jamesii (Hale) Elix \& Hale

Parmelinopsis minarum (Vainio) Elix \& Hale

Parmotrema Massal. = Parmotrema sp. 'A'

Parmotrema dilatatum (Vainio) Hale

Parmotrema gardneri (Dodge) Sérus.

Parmotrema mellissii (Dodge) Hale

Parmotrema nylanderi (Lynge) Hale

Parmotrema subisidiosum (Müll. Arg.) Hale

Parmotrema tinctorum (Nyl.) Hale

Pseudoparmelia wallichiana (T. Taylor) H. Krog \& T.D.V. Swinscow

Relicina abstrusa (Hale \& Kurok.) Hale

Relicinopsis Elix \& Verdon $=$ Relicinopsis sp.

Rimelia reticulata (T. Taylor) Hale \& Fletcher

Rimeliella subcaperata (Kremp.) Kurok.

Rimeliella subsumpta (Nyl.) Kurok.

Usnea Dill. ex Adans. = Usnea sp. 'A' and Usnea sp. 'B'

\section{Pertusariaceae}

Ochrolechia pallescens (L.) G. Clauzade \& C. Roux

Pertusaria DC. $=$ Pertusaria sp. ' 1 ', Pertusaria sp. '2' and Pertusaria sp. '3'

Porina Ach. = Porina sp.

\section{Physciaceae}

Buellia De Not. = Buellia $\mathrm{sp}$.

Buellia myriocarpa (DC.) De Not

Dirinaria (Tuck.) Clem. $=$ Dirinaria $\mathrm{sp}$.

Dirinaria picta (Swartz) Clements \& Shear

Heterodermia obscurata (Nyl.) Trevisan 


\section{Physciaceae continued.}

Physcia albicans (Pers.) Thoms.

Pyxine Fr. = Pyxine sp.

Pyxine daedalea H. Krog \& R. Santesson

Pyxine physciaeformis (Malme) Imsh.

Pyxine pungens Zahlbr.

Pyxine subcinerea Stirton

\section{Pyrenulaceae}

Parmentaria Fée $=$ Parmentaria $\mathrm{sp}$.

\section{Trapeliaceae}

Trapeliopsis Hertel \& Gotth. Schneid. = Trapeliopsis sp.

\section{Trypetheliaceae}

Laurera Reichenb. $=$ Laurera sp.

Trypethelium Sprengel $=$ Trypethelium sp.

\section{Unknown}

'Sterile Green Crust' sp.

'Sterile White Crust' sp ' 1 '

'Sterile White Crust' sp '2'

'Sterile White Crust' sp ' 3 '

'Sterile White Crust' sp '4'

'Sterile White Crust' sp '5'

'Sterile Yellow Crust' sp. 


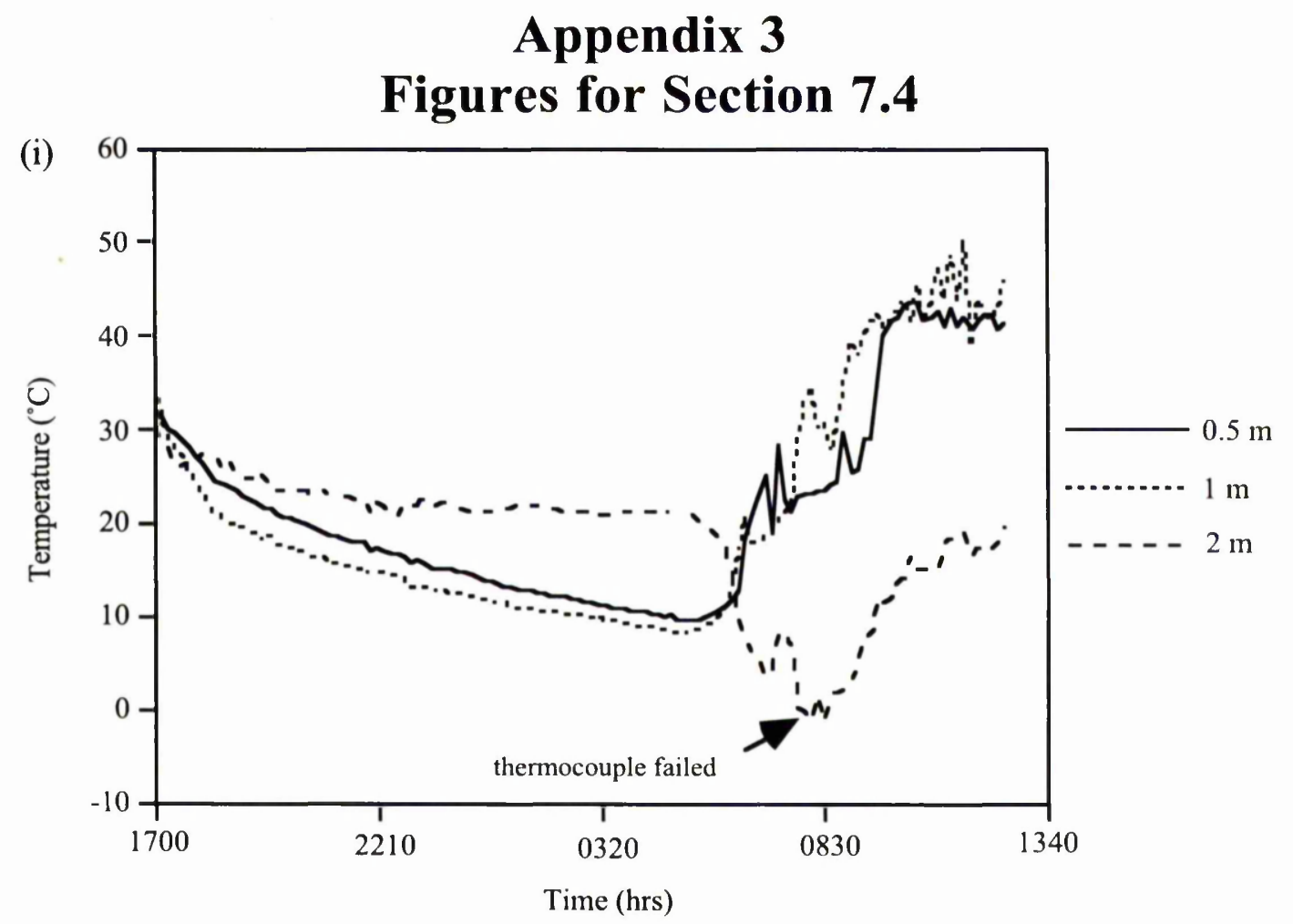

Figure 7.16a (i) Temperatures on the trunk of Caryocar brasiliense before the fire, Reserva Ecológica do IBGE, 24-25/11/95.

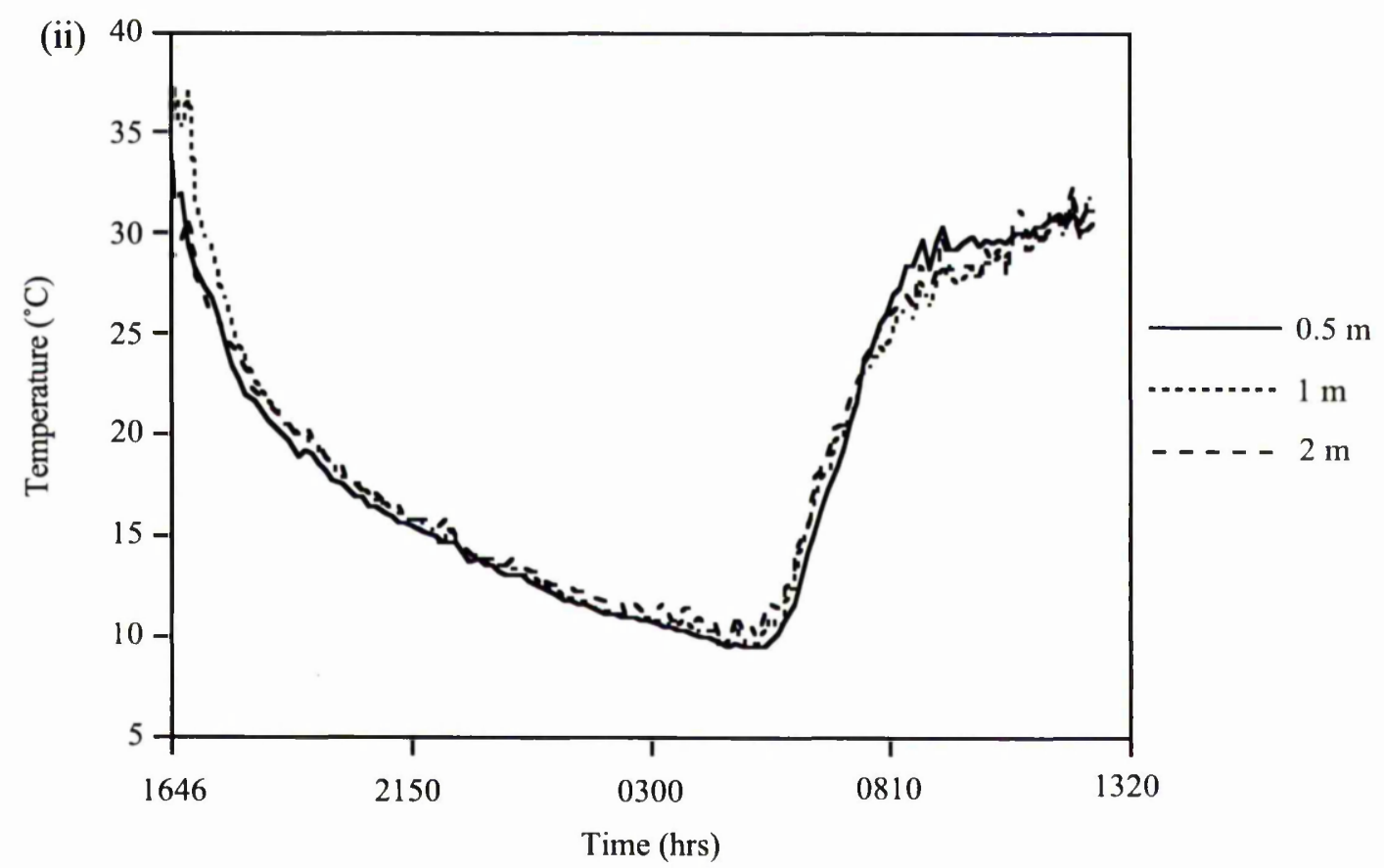

Figure 7.16a (ii) Temperatures on the trunk of Guapira noxia before the fire, Reserva Ecológica do IBGE, 24-25/11/95. 


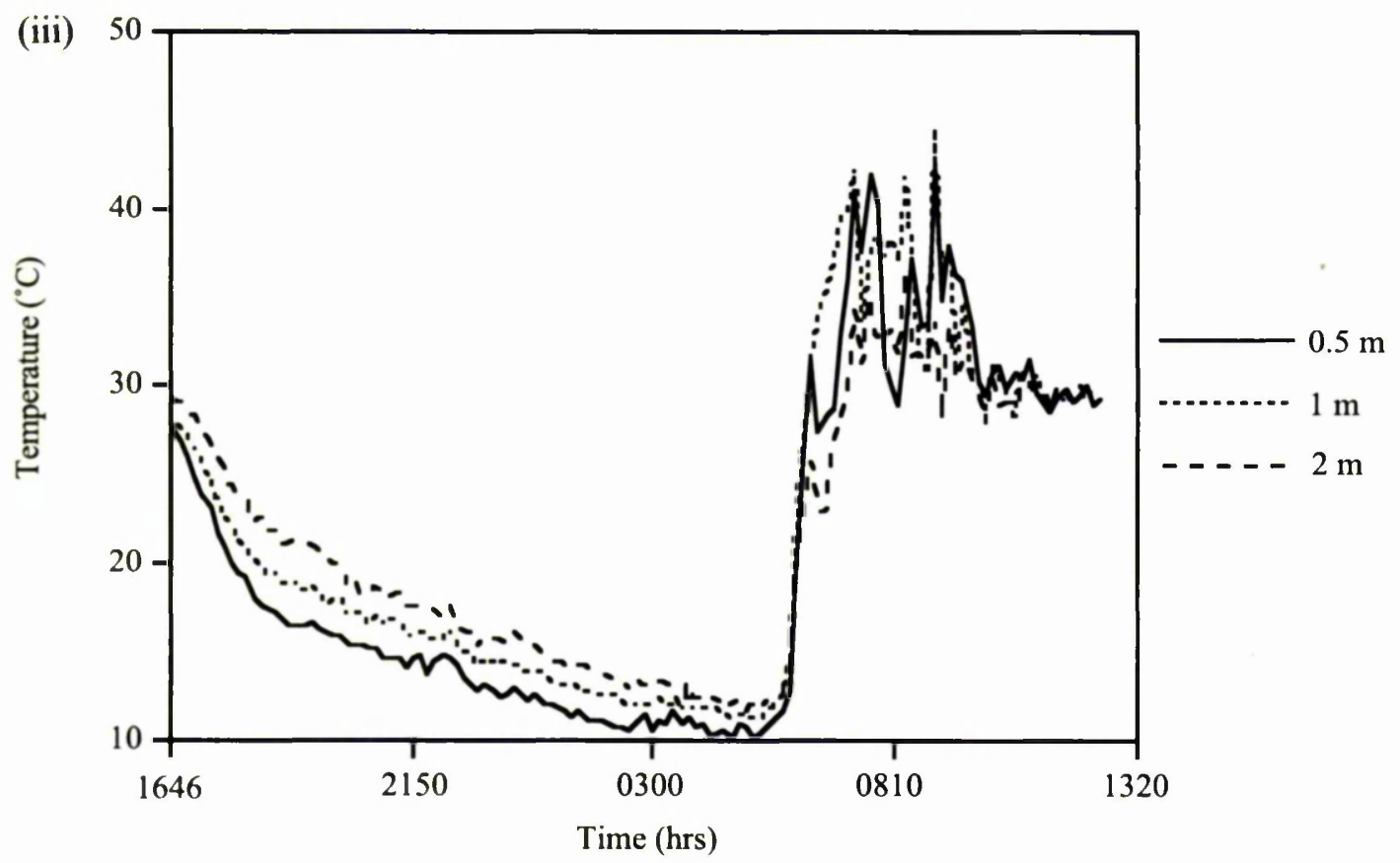

Figure 7.16a (iii) Temperatures on the trunk of Sclerolobium paniculatum before the fire, Reserva Ecológica do IBGE, 24-25/11/95.

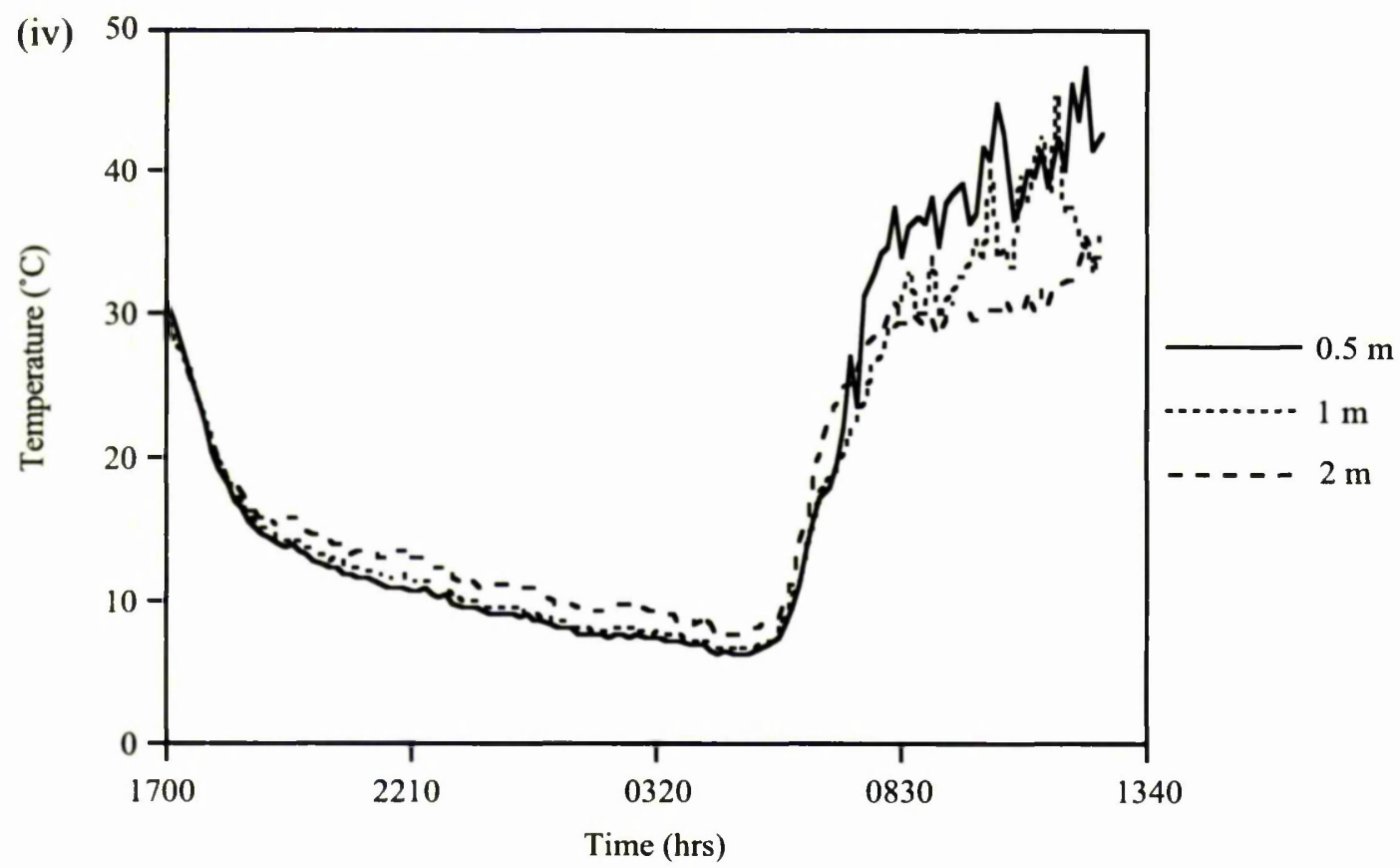

Figure 7.16a (iv) Temperatures on the trunk of Vellozia squamata before the fire, Reserva Ecológica do IBGE, 24-25/11/95. 


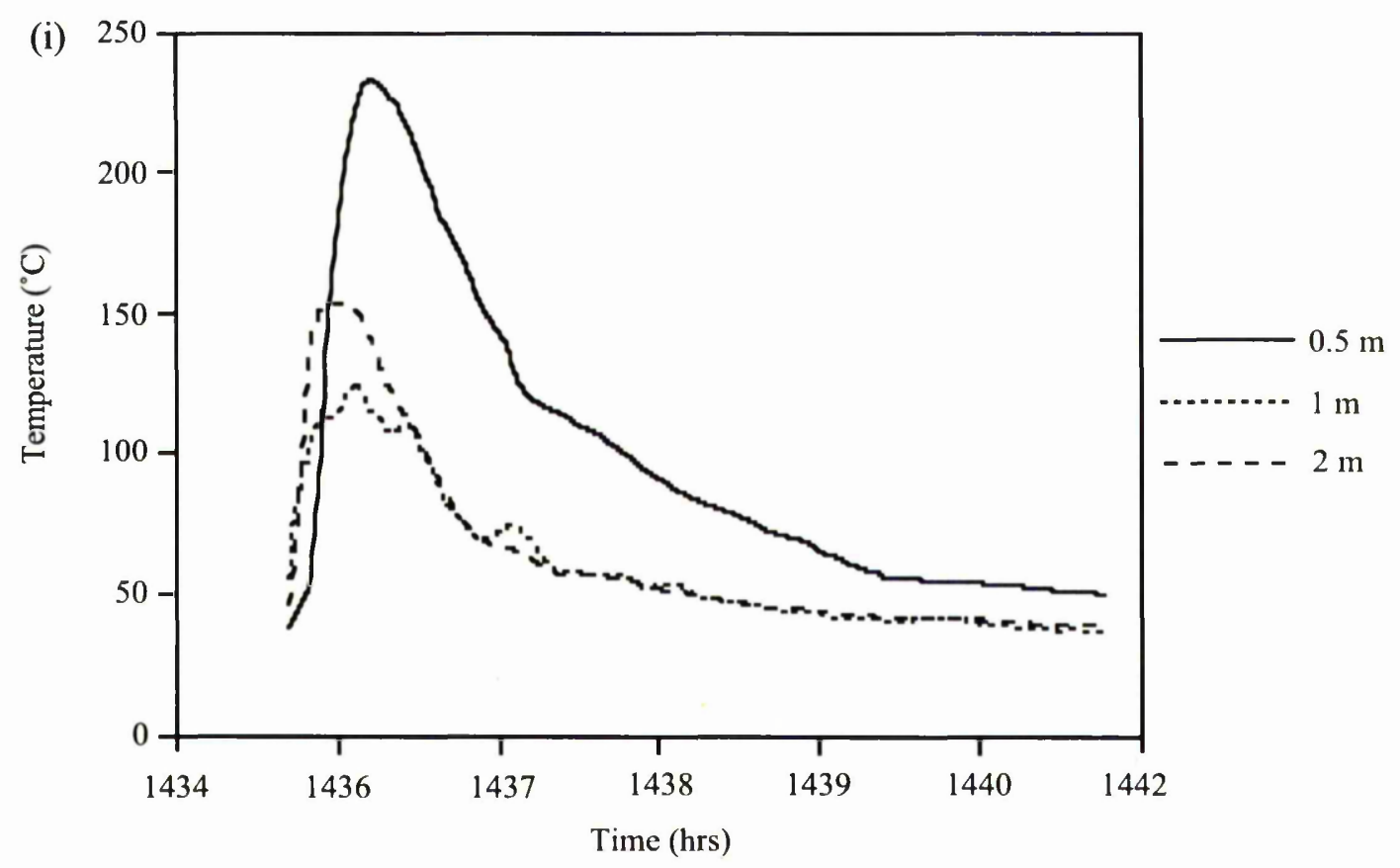

Figure 7.16b (i) Temperatures on the trunk of Caryocar brasiliense during the fire, Reserva Ecológica do IBGE, 25/11/95.

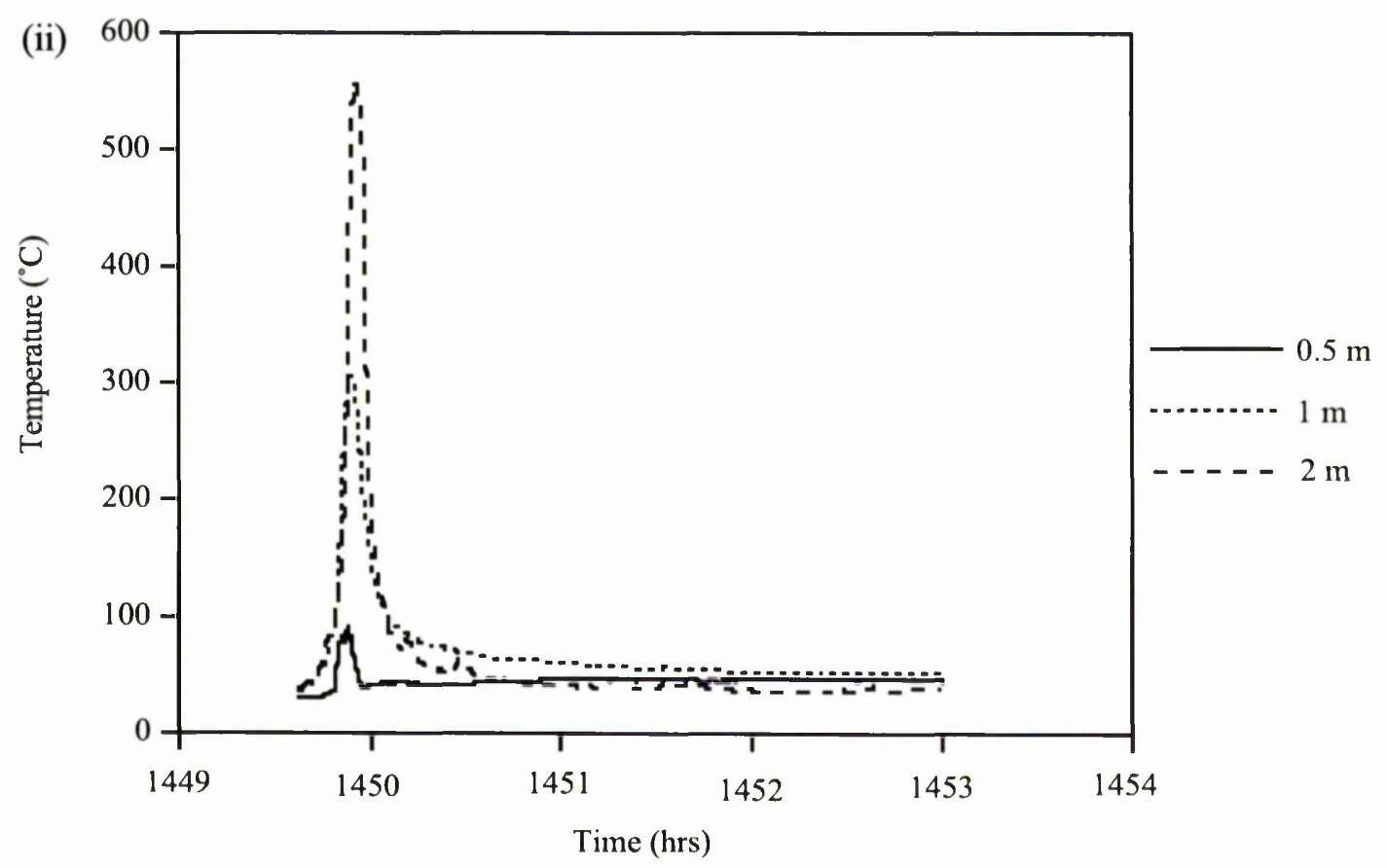

Figure 7.16b (ii) Temperatures on the trunk of Guapira noxia during the fire, Reserva Ecológica do IBGE, 25/11/95. 


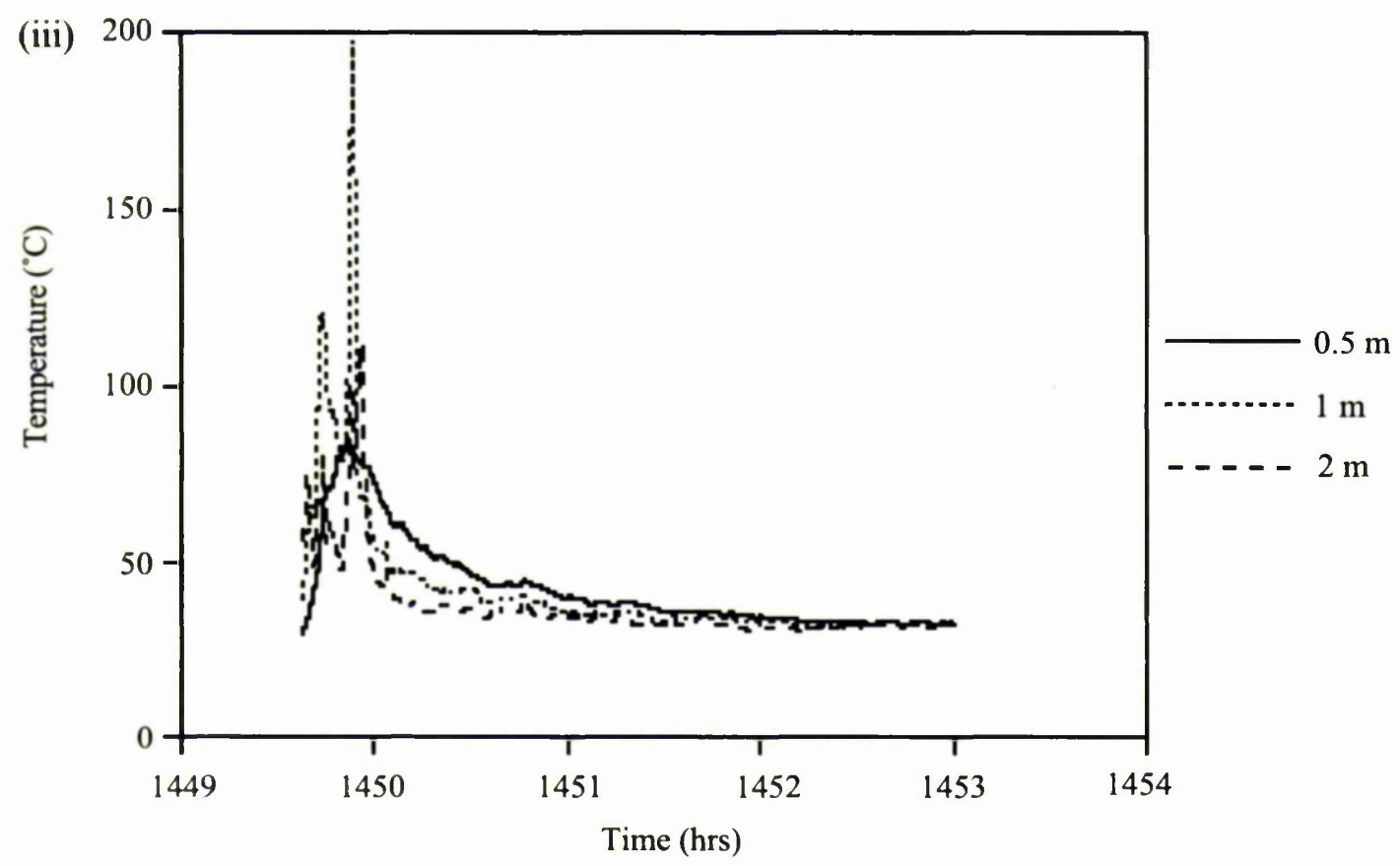

Figure 7.16b (iii) Temperatures on the trunk of Sclerolobium paniculatum during the fire, Reserva Ecológica do IBGE, 25/11/95.

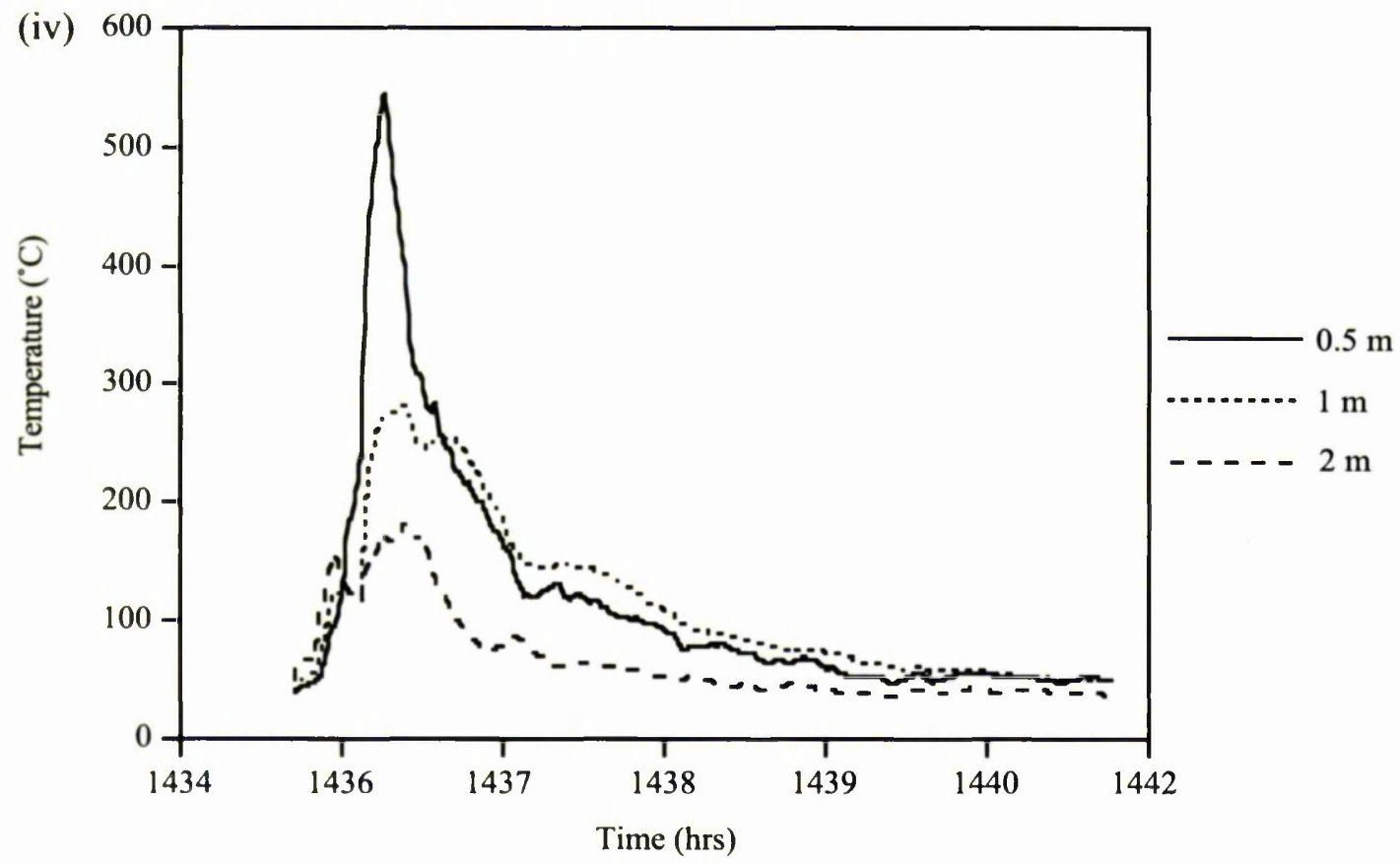

Figure 7.16b (iv) Temperatures on the trunk of Vellozia squamata during the fire, Reserva Ecológica do IBGE, 25/11/95. 


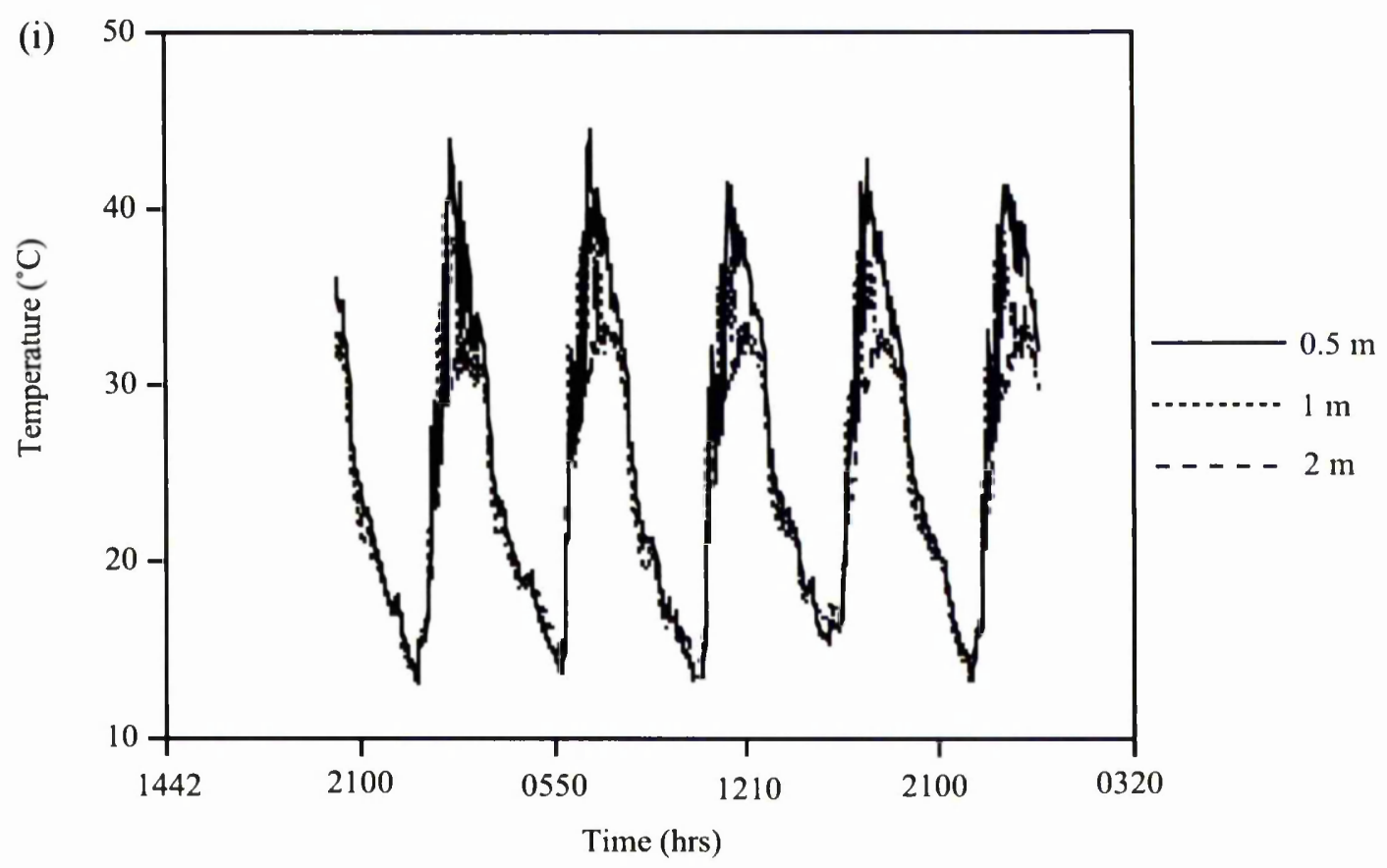

Figure 7.16c (i) Temperatures on the trunk of Caryocar brasiliense after the fire, Reserva Ecológica do IBGE, 25-30/11/95.

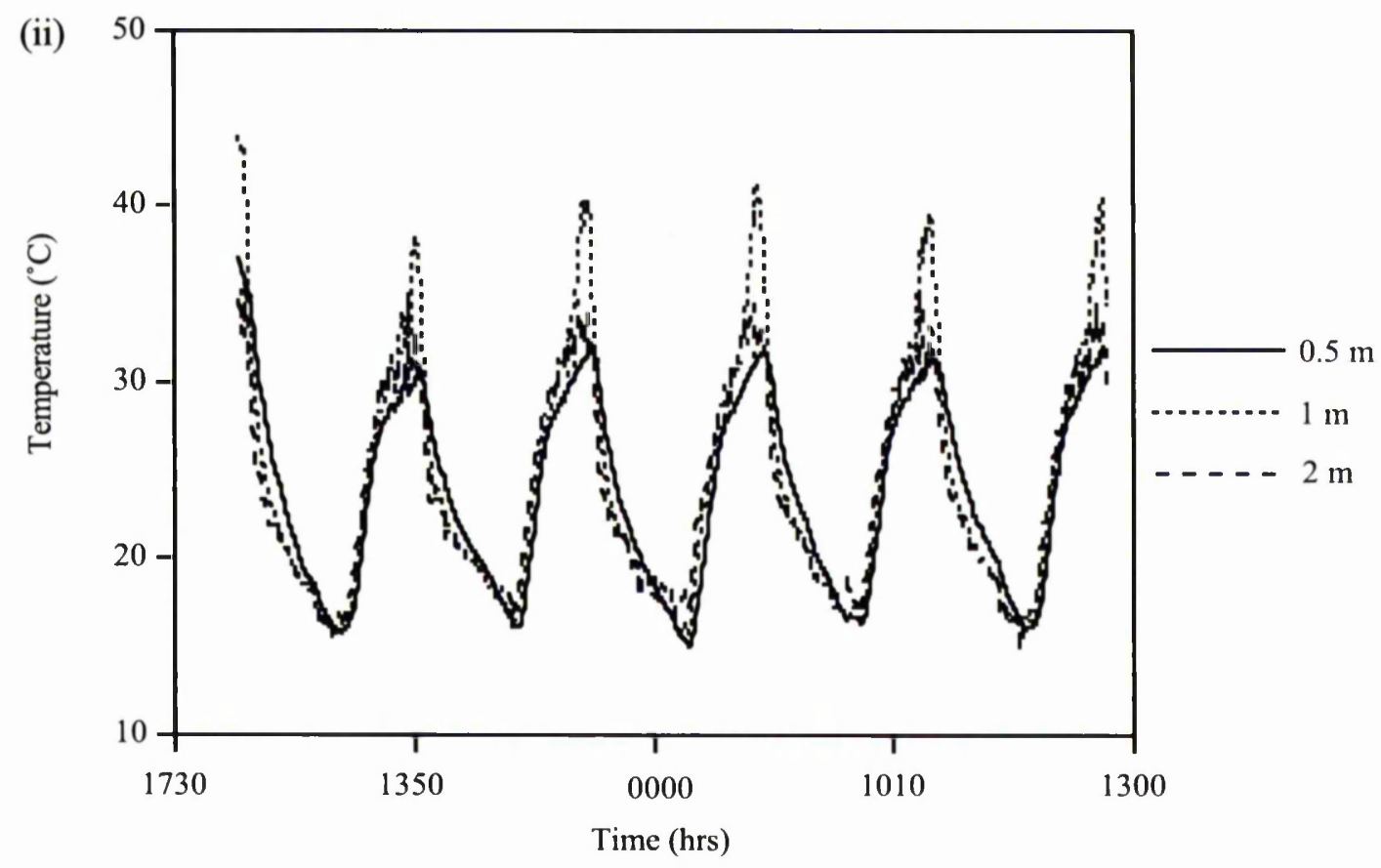

Figure 7.16c (ii) Temperatures on the trunk of Guapira noxia after the fire, Reserva Ecológica do IBGE, 25-30/11/95. 


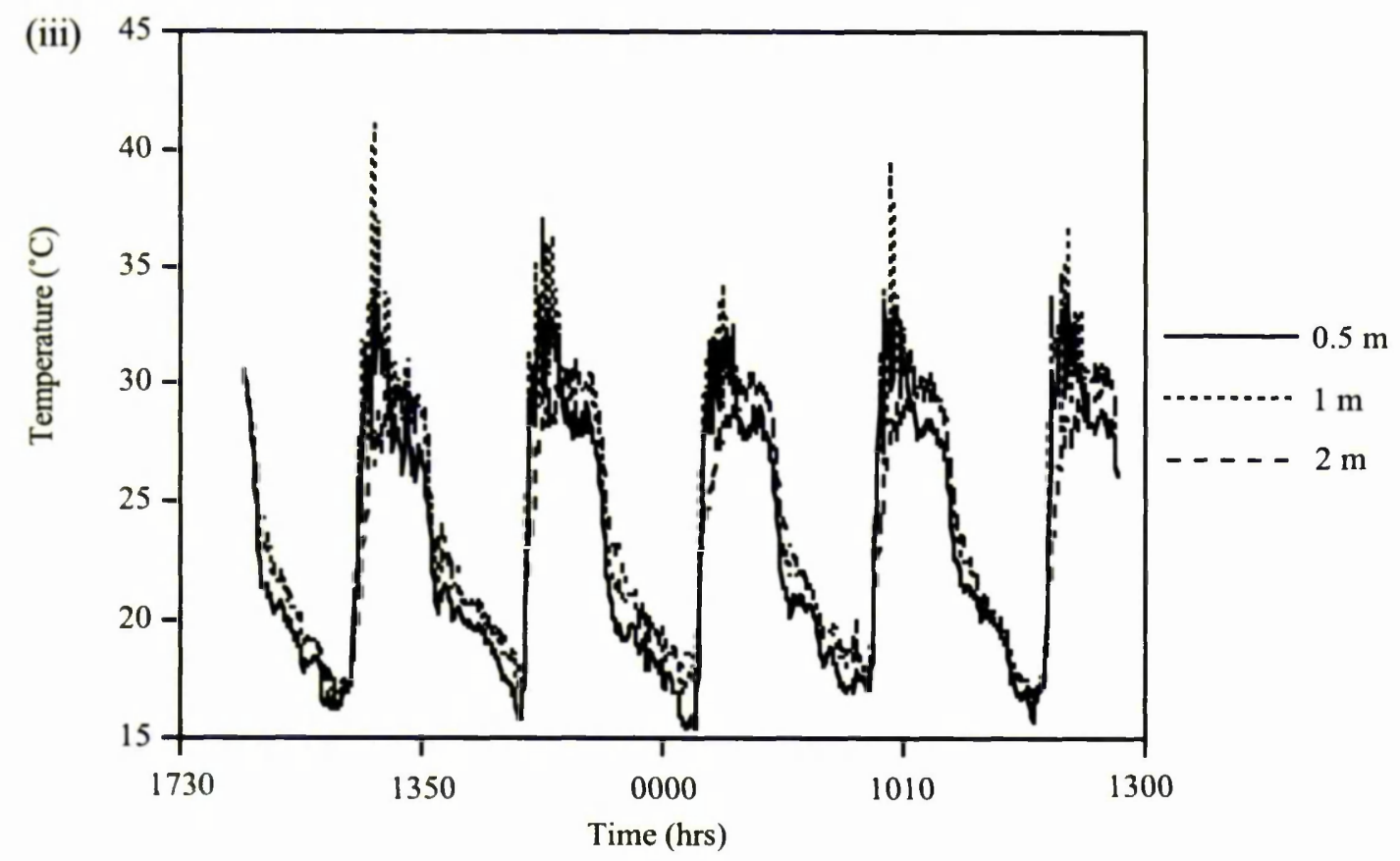

Figure 7.16c (iii) Temperatures on the trunk of Sclerolobium paniculatum after the fire, Reserva Ecológica do IBGE, 25-30/11/95.

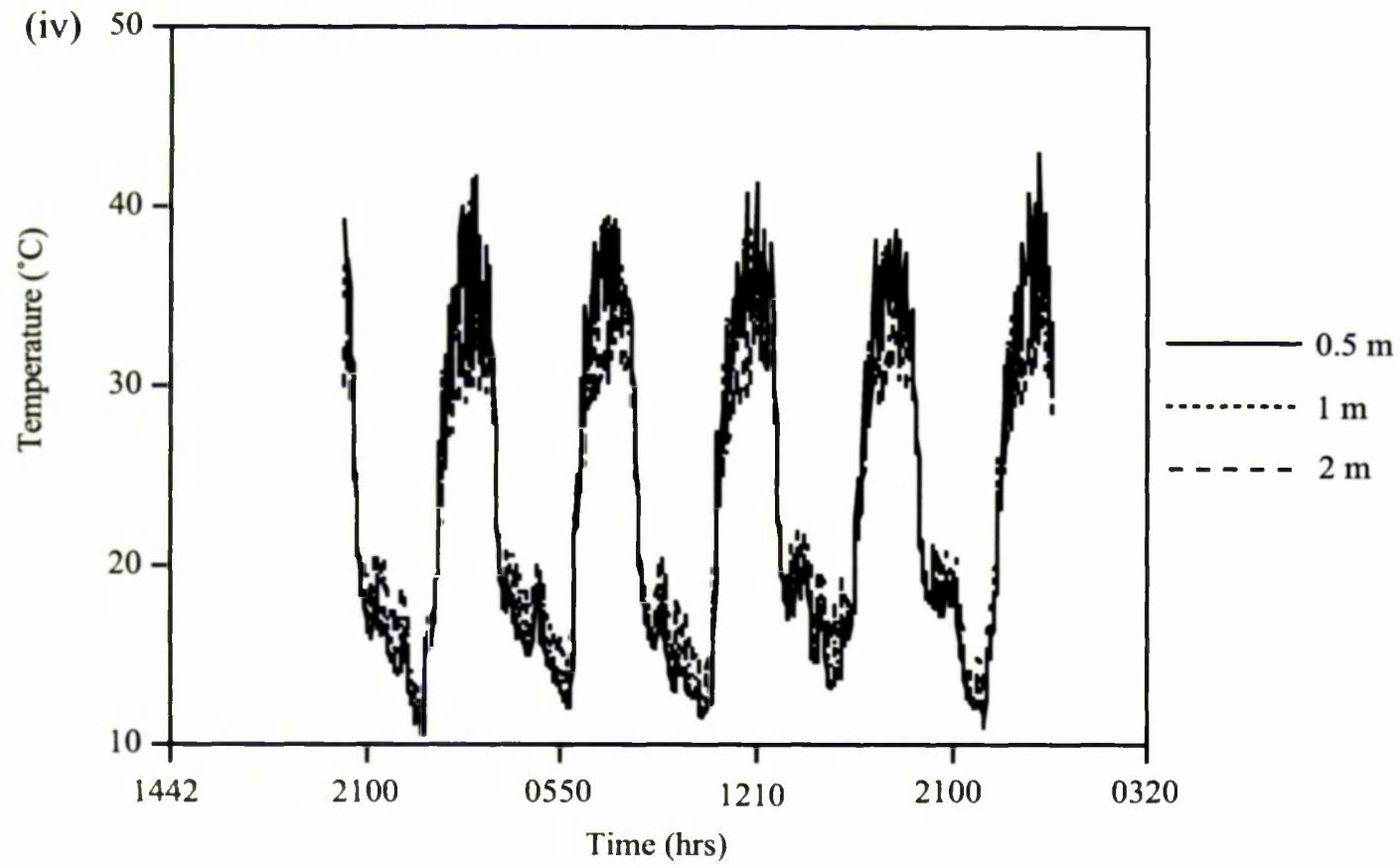

Figure 7.16c (iv) Temperatures on the trunk of Vellozia squamata after the fire, Reserva Ecológica do IBGE, 25-30/11/95. 


\section{Appendix 4 \\ The fire histories of the ten plots and their codes.}

\begin{tabular}{|c|c|c|c|}
\hline Area & Plot & Fire history & Code used in text \\
\hline \multirow{5}{*}{$\begin{array}{l}\text { IBGE - 'let-burn' } \\
\text { policy until } \\
1974\end{array}$} & 1 & $\begin{array}{l}\text { Protected since } 1974 \text { (for over } 20 \\
\text { years) }\end{array}$ & (74-control) \\
\hline & 2 & $\begin{array}{l}\text { Protected since } 1974 \text {, but } \\
\text { subjected to a rare middle dry } \\
\text { season homogeneous fire with } \\
\text { high flame heights in } 1991\end{array}$ & (74-91: Hom, H, M) \\
\hline & 3 & $\begin{array}{l}\text { Protected since } 1974 \text {, but } \\
\text { subjected to a rare early dry } \\
\text { season, heterogeneous fire with } \\
\text { various flame heights in } 1992\end{array}$ & (74-92: Het, V, E) \\
\hline & 4 & $\begin{array}{l}\text { Protected since } 1974 \text {, but } \\
\text { subjected to a rare middle dry } \\
\text { season, heterogeneous fire with } \\
\text { various flame heights in } 1992\end{array}$ & (74-92: Het, V, M) \\
\hline & 5 & $\begin{array}{l}\text { Protected since } 1974 \text {, but } \\
\text { subjected to a rare late dry season, } \\
\text { heterogeneous fire with various } \\
\text { flame heights in } 1992\end{array}$ & (74-92: Het, V, L) \\
\hline \multirow{5}{*}{$\begin{array}{l}\text { JBB - 'let-burn' } \\
\text { policy until } \\
1986\end{array}$} & 6 & $\begin{array}{l}\text { Frequently burned until } 1986 \text {, but } \\
\text { protected from fire since } 1986\end{array}$ & (86-control) \\
\hline & 7 & $\begin{array}{l}\text { Frequently burned until } 1986, \\
\text { subjected to a middle dry season } \\
\text { homogeneous fire with high } \\
\text { flame heights in } 1991\end{array}$ & (86-91: Hom, H, M) \\
\hline & 8 & $\begin{array}{l}\text { Frequently burned until } 1986, \\
\text { subjected to an early dry season } \\
\text { homogeneous fire with high } \\
\text { flame heights in } 1991 \text { and } 1993 \\
\end{array}$ & $(86-91,93:$ Hom, H, E) \\
\hline & 9 & $\begin{array}{l}\text { Frequently burned until } 1986, \\
\text { subjected to a middle dry season } \\
\text { homogeneous fire with high } \\
\text { flame heights in } 1991 \text { and } 1993 \\
\end{array}$ & $(86-91,93:$ Hom, H, M) \\
\hline & 10 & $\begin{array}{l}\text { Infrequently burned until } 1986, \\
\text { subjected to a late dry season } \\
\text { heterogeneous fire with various } \\
\text { flame heights in } 1991 \text { and } 1993\end{array}$ & $(86-91,93:$ Het, V, L) \\
\hline
\end{tabular}

Part submission for the degree of Ph.D.

by Jayalaxshmi Mistry

Title: Corticolous lichens as potential bioindicators of fire history: a study in the cerrado of the Distrito Federal, central Brazil.

Department of Geography, School of Oriental and African Studies,

University of London. 1996 


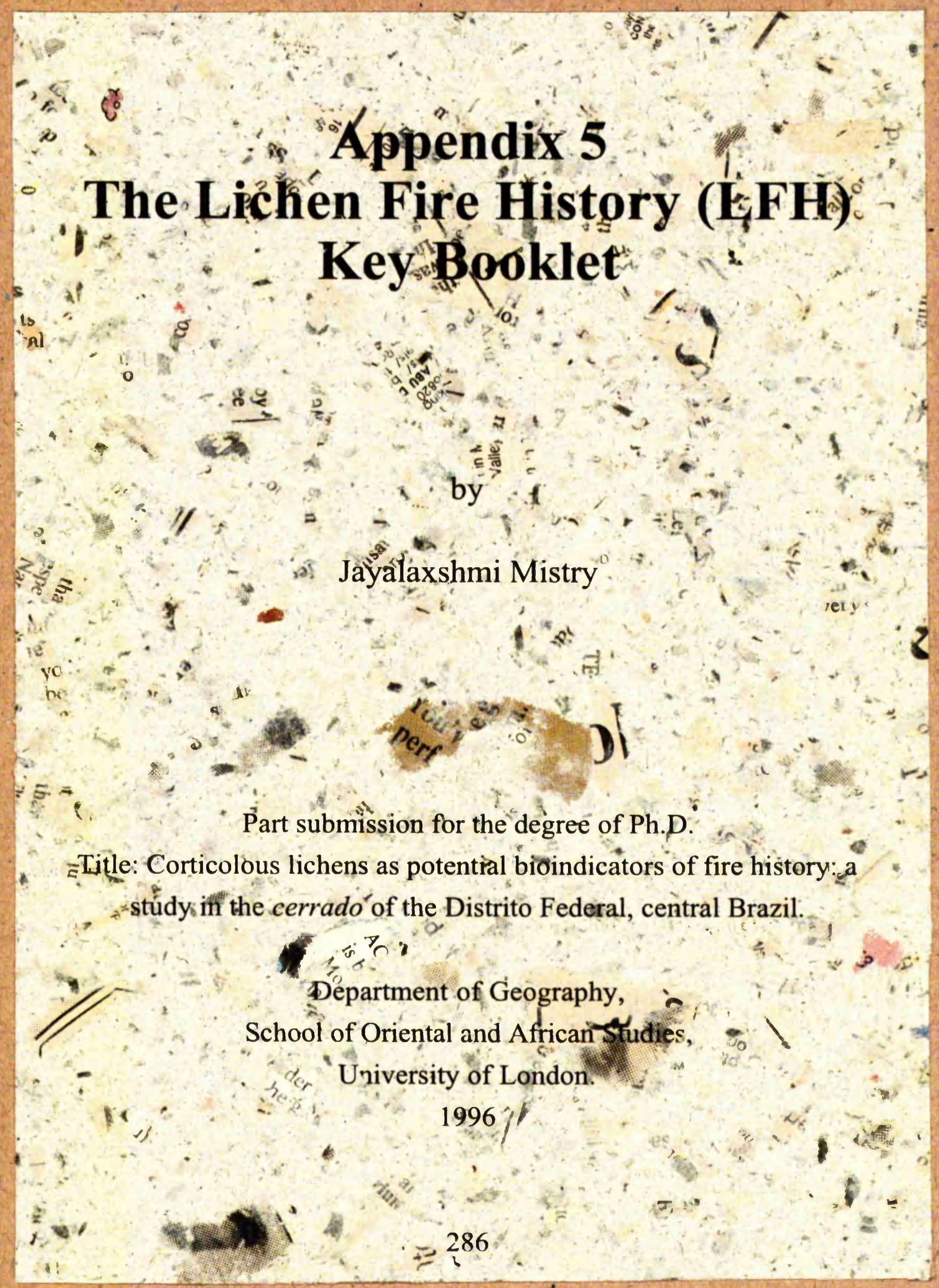



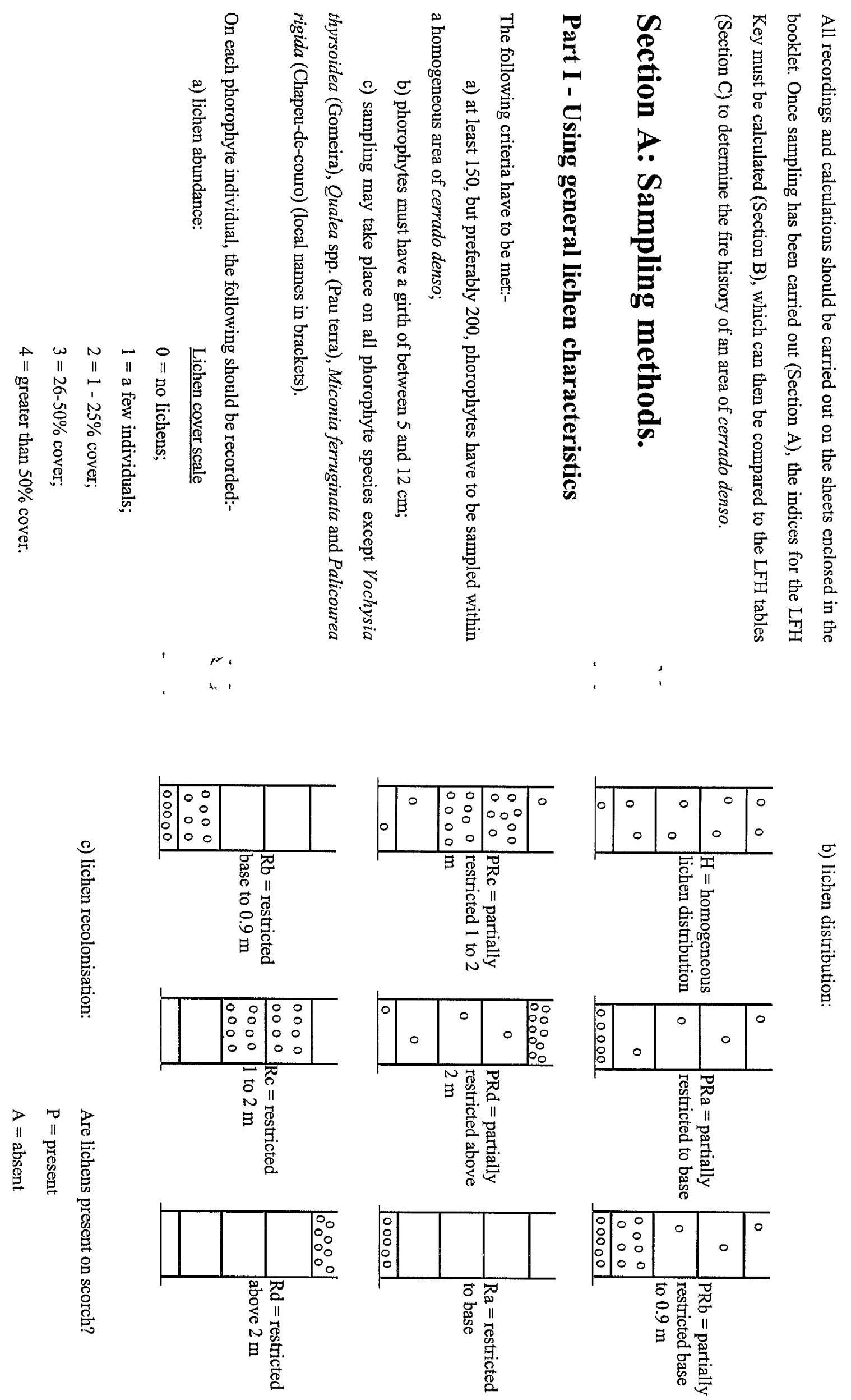

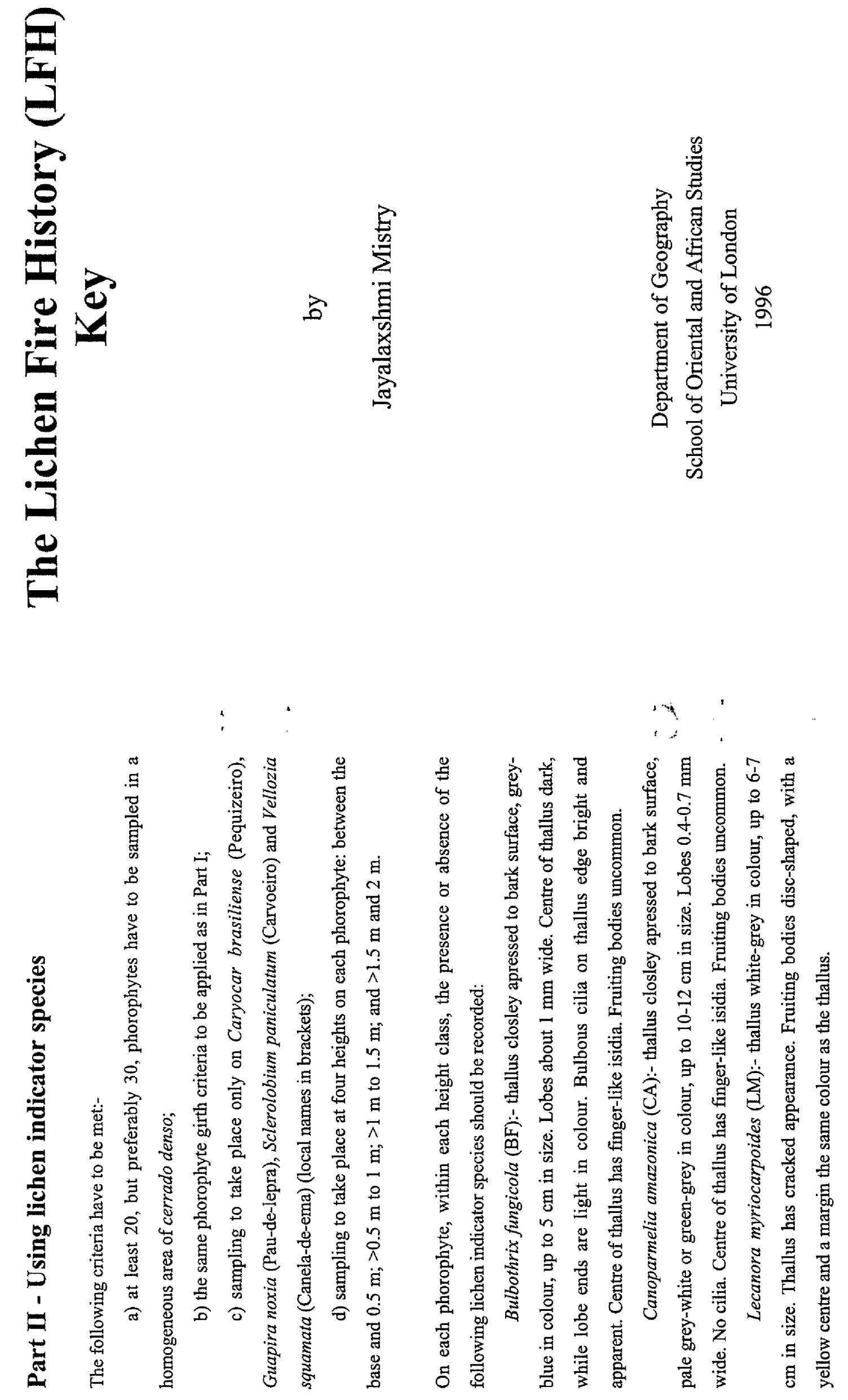

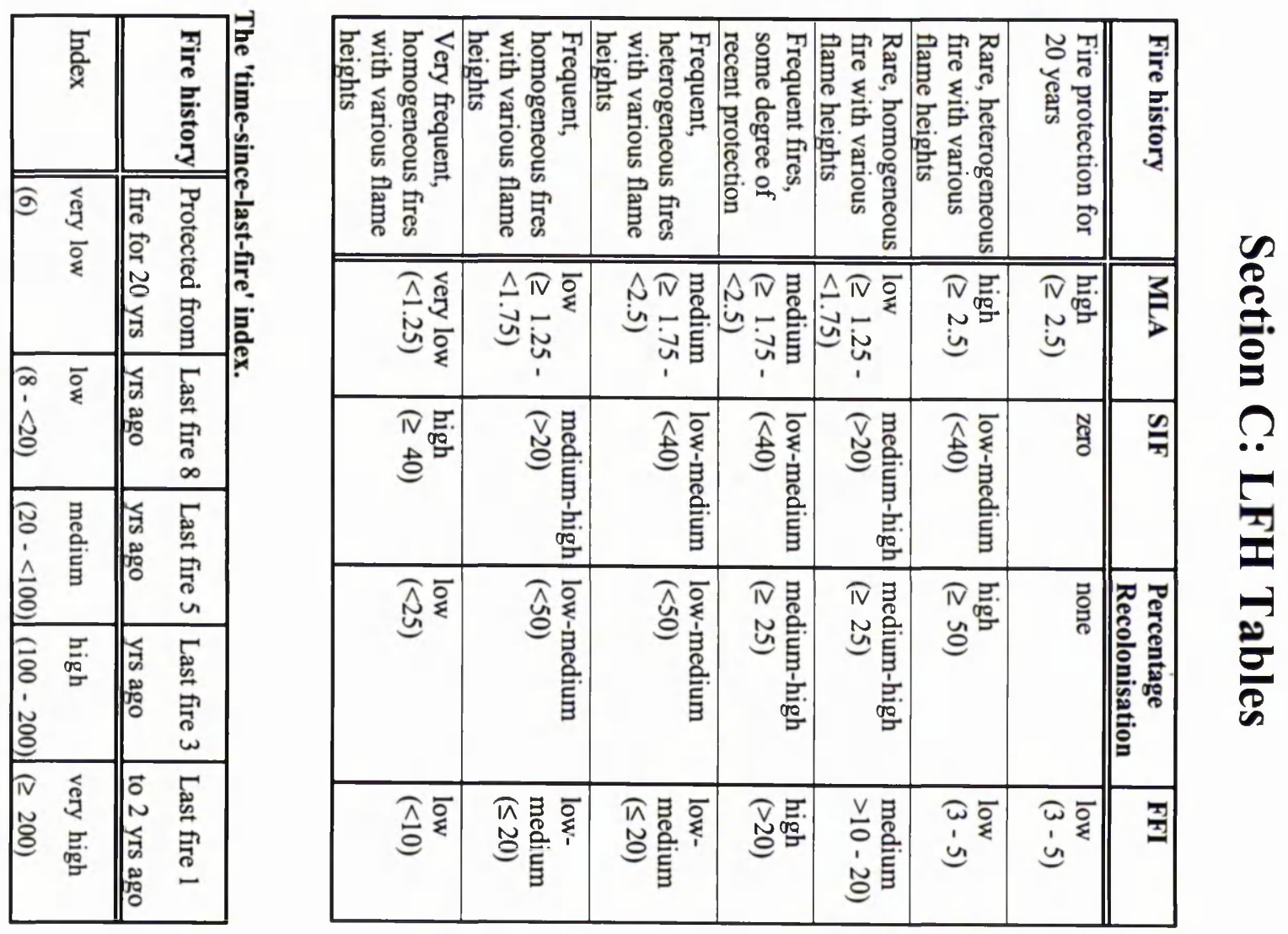

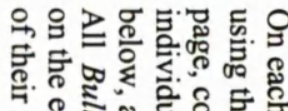

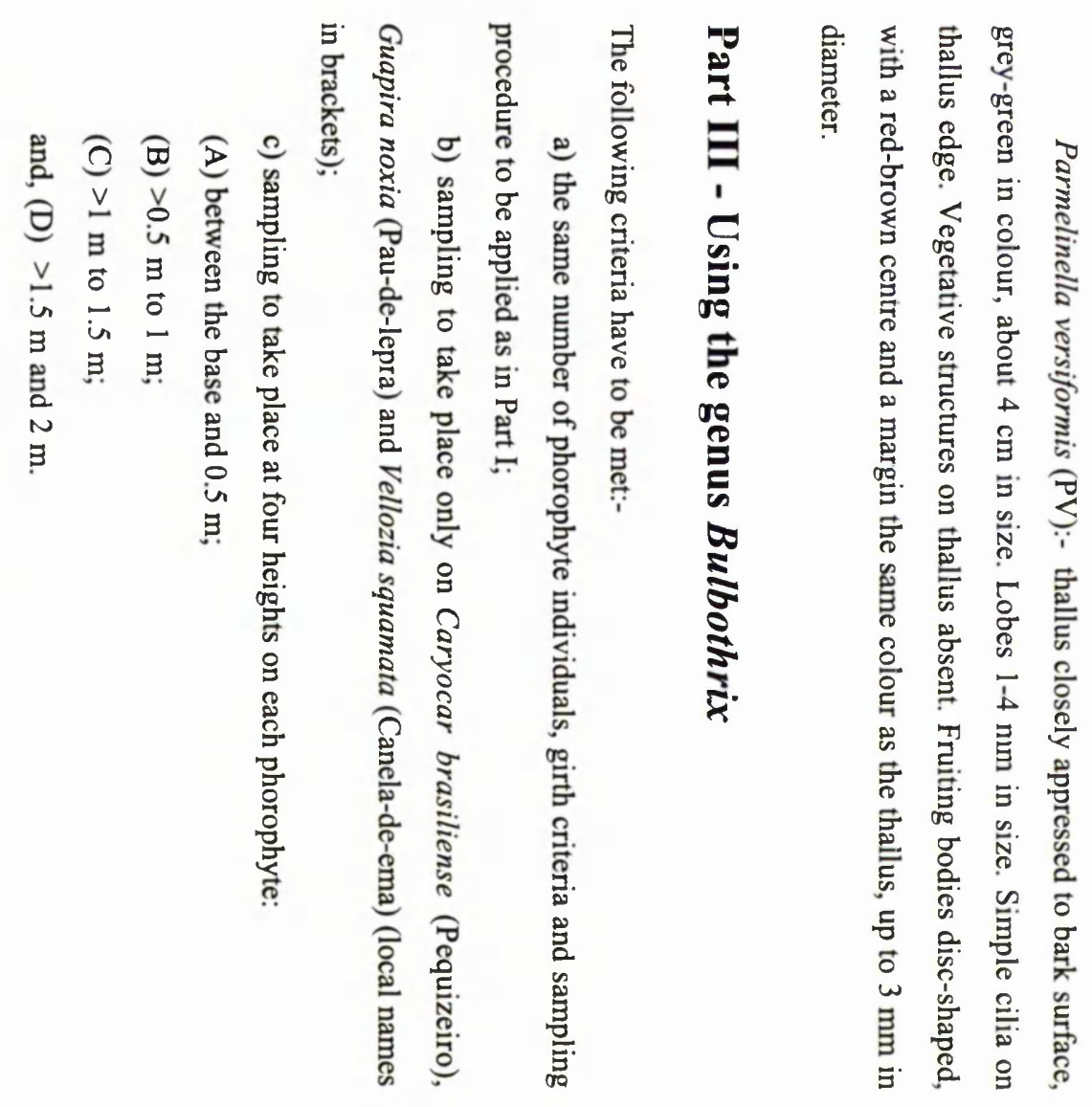



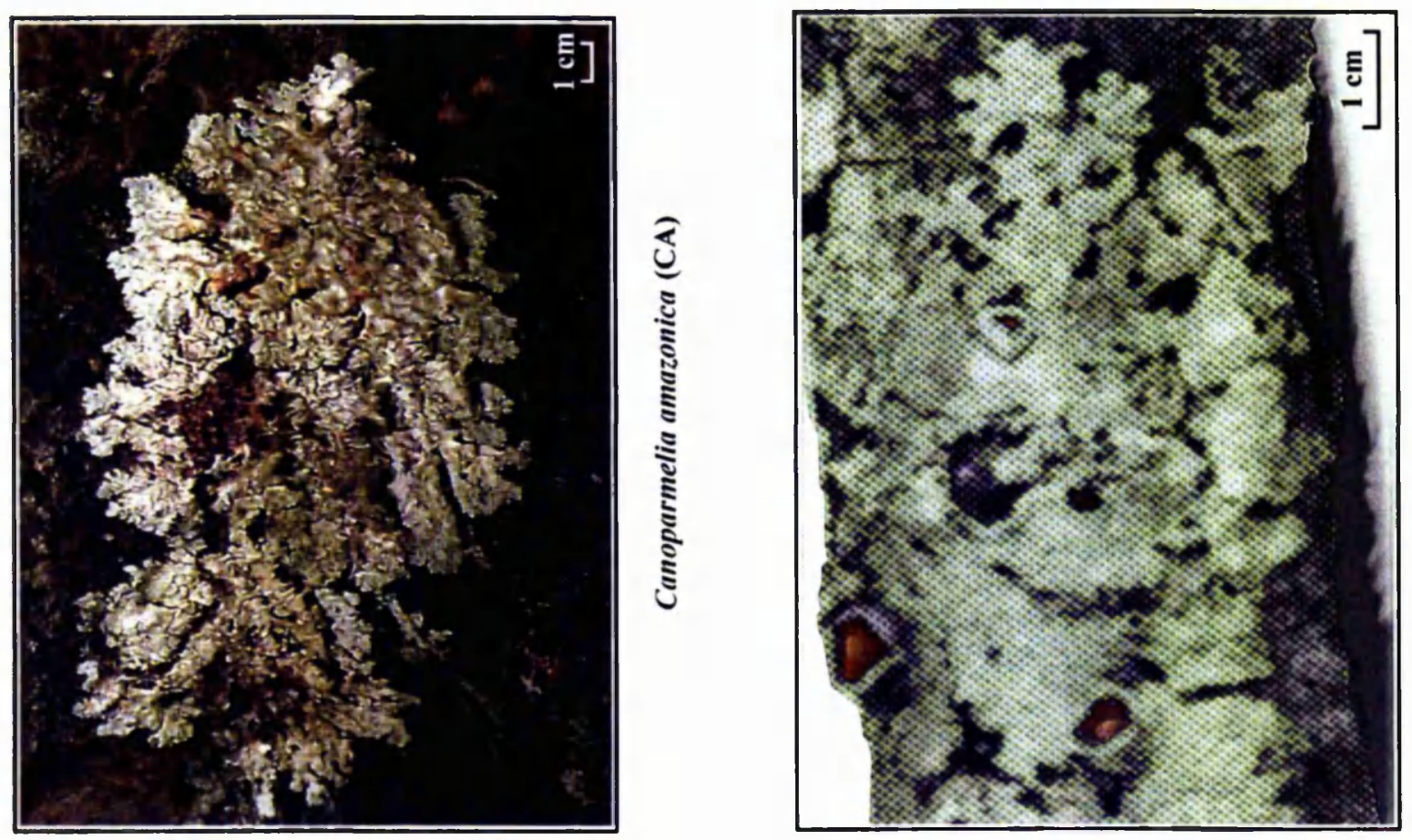

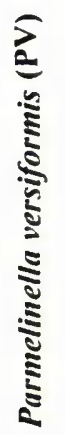
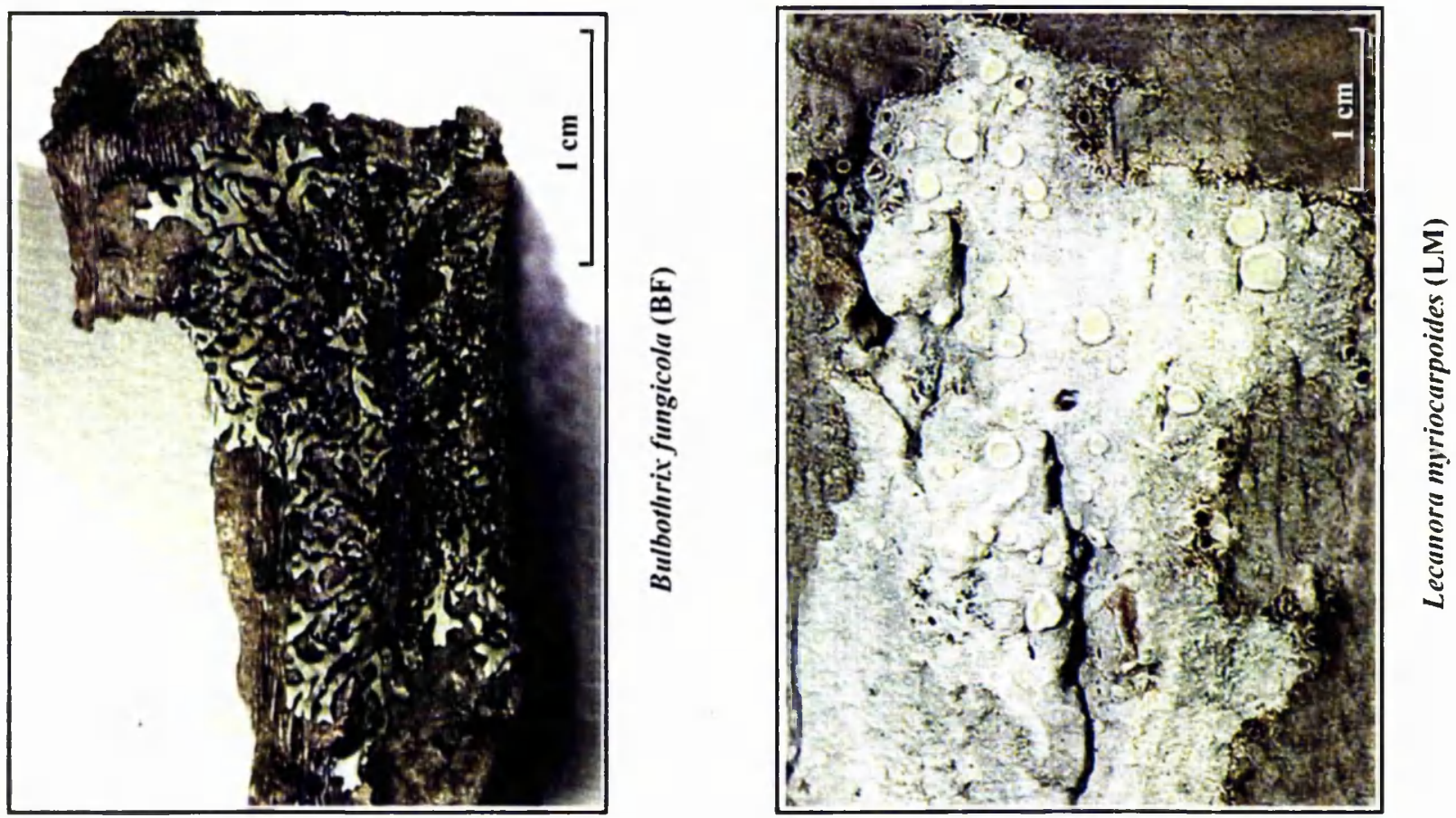


\section{Section B: Calculation sheets}

\section{Part I}

Lichen abundance:-

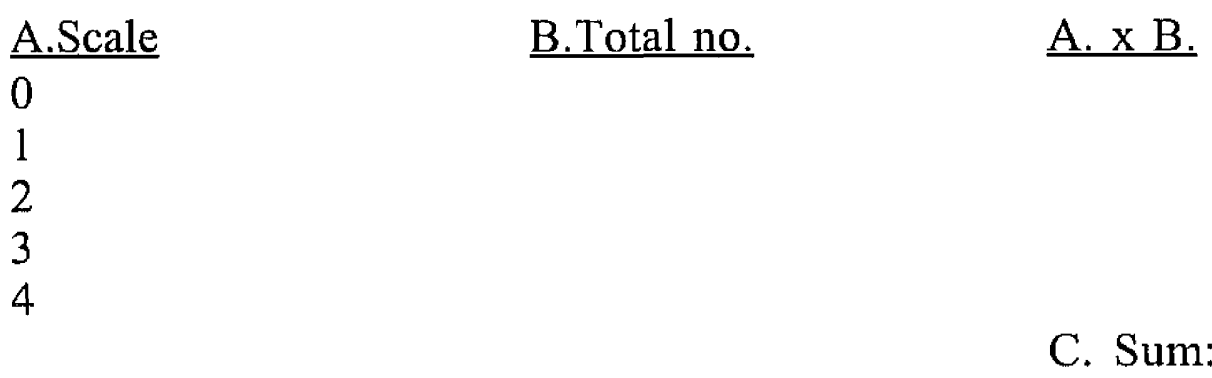

Mean Lichen Abundance = (MLA)

$=\frac{\mathrm{C}}{\text { Total no. of phorophytes }}=$

Lichen distribution:-

D.Scale

$\mathrm{PRa}+\mathrm{Ra}$

$\mathrm{PRb}+\mathrm{Rb}$

$\mathrm{PRc}+\mathrm{Rc}$

PRd + Rd
E.Total no.

D. $x E$.

F.

G.

$\mathrm{H}$.

I.

Spatial Index of Fire (SIF) $=$

$$
\mid(2 \text { - F. })|+|(6 \text { - G. })|+|(9.5 \text { - H. })|+|(1-\text { I. }) \mid=
$$

Lichen recolonisation:-

Scale

J.Total no.

$\mathrm{P}$

$\%$ Recolonisation $=$ $\mathrm{J}$. $\mathrm{x} 100=$

Total no. of phorophytes 


\section{Part II}

Lichen indicators:-

Total no. of phorophytes $\times 4=$

Indicators

$\mathrm{BF}$

L.Total no.

$\mathrm{M} .=\mathrm{L} . / \mathrm{K}$.

$\underline{\mathrm{M} \times 100}$

CA

LM

PV

$P$

Q.

Fire Frequency Index $(\mathrm{FFI})=\underline{\mathrm{N}}+\mathrm{O} . \quad=$ P. + Q. +0.5

\section{Part III}

Bulbothrix individuals:-

Total no. of phorophytes $\times 4=$

Thallus size $\underline{\text { S.Total no. }} \quad \underline{\mathrm{T}}=\mathrm{S} . / \mathrm{R} . \quad \underline{\mathrm{T}} \mathrm{x} 100$

$49 \mathrm{~mm}^{2}$

and below

$250 \mathrm{~mm}^{2}$

and above

$\mathrm{U}$.

V.

'Time-since-last-fire' index $=\frac{\mathrm{U} .}{\mathrm{V} .+0.5}=$ 


\section{Field checksheets for Part III}

\begin{tabular}{|c|c|c|c|c|c|c|c|c|c|c|c|c|c|c|c|c|c|c|c|c|}
\hline Phorophyte no. & 1 & & & & 2 & & & & 3 & & & & 4 & & & & 5 & & & \\
\hline Height & A & B & C & D & A & B & C & D & A & B & $\mathrm{C}$ & D & A & B & $\mathrm{C}$ & D & $\mathrm{A}$ & B & $\mathrm{C}$ & D \\
\hline$\leq 49 \mathrm{~mm}^{2}$ & & & & & & & & & & & & & & & & & & & & \\
\hline$\geq 250 \mathrm{~mm}^{2}$ & & & & & & & & & & & & & & & & & & & & \\
\hline
\end{tabular}

\begin{tabular}{|c|c|c|c|c|c|c|c|c|c|c|c|c|c|c|c|c|c|c|c|c|}
\hline Phorophyte no. & 6 & & & & 7 & & & & 8 & & & & 9 & & & & 10 & & & \\
\hline Height & $\mathrm{A}$ & B & $\mathrm{C}$ & D & $\mathrm{A}$ & B & $\mathrm{C}$ & D & $\mathrm{A}$ & B & $\mathrm{C}$ & $\mathrm{D}$ & A & B & $\mathrm{C}$ & D & $\mathrm{A}$ & B & C & $\mathrm{D}$ \\
\hline$\leq 49 \mathrm{~mm}^{2}$ & & & & & & & & & & & & & & & & & & & & \\
\hline$\geq 250 \mathrm{~mm}^{2}$ & & & & & & & & & & & & & & & & & & & & \\
\hline
\end{tabular}

\begin{tabular}{|c|c|c|c|c|c|c|c|c|c|c|c|c|c|c|c|c|c|c|c|c|}
\hline Phorophyte no. & \multicolumn{4}{|l|}{11} & \multicolumn{4}{|c|}{12} & \multicolumn{4}{|l|}{13} & \multicolumn{4}{|l|}{14} & \multicolumn{4}{|l|}{15} \\
\hline Height & $\mathrm{A}$ & $\mathrm{B}$ & $\mathrm{C}$ & $\mathrm{D}$ & $\mathrm{A}$ & $\mathrm{B}$ & $\mathrm{C}$ & $\mathrm{D}$ & $\mathrm{A}$ & $\mathrm{B}$ & $\mathrm{C}$ & $\mathrm{D}$ & $\mathrm{A}$ & $\mathrm{B}$ & $\mathrm{C}$ & $\mathrm{D}$ & $\mathrm{A}$ & $\mathrm{B}$ & $\mathrm{C}$ & $\mathrm{D}$ \\
\hline$\leq 49 \mathrm{~mm}^{2}$ & & & & & & & & & & & & & & & & & & & & \\
\hline$\geq 250 \mathrm{~mm}^{2}$ & & & & & & & & & & & & & & & & & & & & \\
\hline
\end{tabular}

\begin{tabular}{|c|c|c|c|c|c|c|c|c|c|c|c|c|c|c|c|c|c|c|c|c|}
\hline \multirow{2}{*}{$\begin{array}{l}\text { Phorophyte no. } \\
\text { Height }\end{array}$} & \multicolumn{4}{|l|}{16} & \multicolumn{4}{|l|}{17} & \multicolumn{4}{|l|}{18} & \multicolumn{4}{|l|}{19} & \multicolumn{4}{|l|}{20} \\
\hline & $\mathrm{A}$ & $\mathrm{B}$ & $\mathrm{C}$ & $\mathrm{D}$ & $\mathrm{A}$ & B & $\mathrm{C}$ & $\mathrm{D}$ & $\mathrm{A}$ & $\mathrm{B}$ & $\mathrm{C}$ & $\mathrm{D}$ & $\mathrm{A}$ & $\mathrm{B}$ & $\mathrm{C}$ & $\mathrm{D}$ & $\mathrm{A}$ & $\mathrm{B}$ & $\mathrm{C}$ & D \\
\hline$\leq 49 \mathrm{~mm}^{2}$ & & & & & & & & & & & & & & & & & & & & \\
\hline$\geq 250 \mathrm{~mm}^{2}$ & & & & & & & & & & & & & & & & & & & & \\
\hline
\end{tabular}

\begin{tabular}{|c|c|c|c|c|c|c|c|c|c|c|c|c|c|c|c|c|c|c|c|c|}
\hline Phorophyte no. & \multicolumn{4}{|l|}{21} & \multicolumn{4}{|c|}{22} & \multicolumn{4}{|l|}{23} & \multicolumn{4}{|l|}{24} & \multicolumn{4}{|l|}{25} \\
\hline Height & $\mathrm{A}$ & $\mathrm{B}$ & $\mathrm{C}$ & $\mathrm{D}$ & $\mathrm{A}$ & $\mathrm{B}$ & $\mathrm{C}$ & D & A & $\mathrm{B}$ & $\mathrm{C}$ & D & A & B & $\mathrm{C}$ & $\mathrm{D}$ & A & $\mathrm{B}$ & $\mathrm{C}$ & $\mathrm{D}$ \\
\hline$\leq 49 \mathrm{~mm}^{2}$ & & & & & & & & & & & & & & & & & & & & \\
\hline$\geq 250 \mathrm{~mm}^{2}$ & & & & & & & & & & & & & & & & & & & & \\
\hline
\end{tabular}

\begin{tabular}{|c|c|c|c|c|c|c|c|c|c|c|c|c|c|c|c|c|c|c|c|c|}
\hline Phoronhyte no & \multicolumn{4}{|l|}{26} & \multicolumn{4}{|l|}{27} & \multicolumn{4}{|l|}{28} & \multicolumn{4}{|l|}{29} & \multicolumn{4}{|c|}{30} \\
\hline Height & $\mathrm{A}$ & B & $\mathrm{C}$ & D & $\mathrm{A}$ & $\mathrm{B}$ & $\mathrm{C}$ & $\mathrm{D}$ & $\mathrm{A}$ & $\mathrm{B}$ & $\mathrm{C}$ & $\mathrm{D}$ & $\mathrm{A}$ & $\mathrm{B}$ & C & D & $\mathrm{A}$ & $\mathrm{B}$ & C & D \\
\hline$\leq 49 \mathrm{~mm}^{2}$ & & & & & & & & & & & & & & & & & & & & \\
\hline$\geq 250 \mathrm{~mm}^{2}$ & & & & & & & & & & & & & & & & & & & & \\
\hline
\end{tabular}




\section{Field checksheets for Part II}

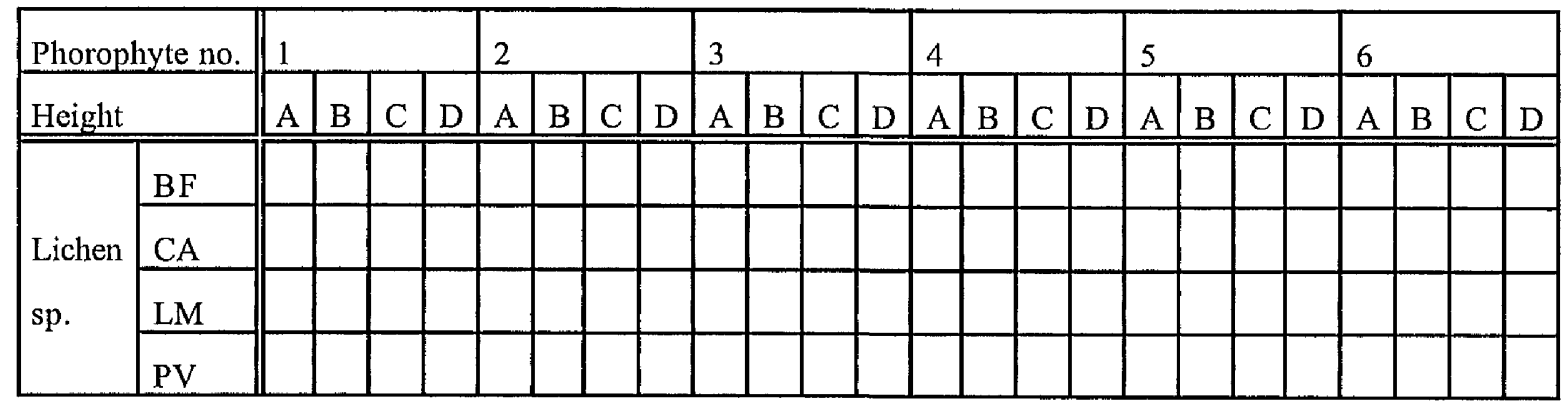

\begin{tabular}{|c|c|c|c|c|c|c|c|c|c|c|c|c|c|c|c|c|c|c|c|c|c|c|c|c|c|}
\hline \multirow{2}{*}{\multicolumn{2}{|c|}{$\begin{array}{l}\text { Phorophyte no. } \\
\text { Height }\end{array}$}} & \multicolumn{4}{|l|}{7} & \multicolumn{4}{|l|}{8} & \multicolumn{4}{|l|}{9} & \multicolumn{4}{|l|}{10} & \multicolumn{4}{|l|}{11} & \multicolumn{4}{|l|}{12} \\
\hline & & A & B & $\mathrm{C}$ & D & A & $B$ & $\mathrm{C}$ & D & A & B & $\mathrm{C}$ & D & A & $\mathrm{B}$ & $\mathrm{C}$ & D & $\mathrm{A}$ & B & $\mathrm{C}$ & D & A & B & $\mathrm{C}$ & D \\
\hline \multirow{4}{*}{$\begin{array}{l}\text { Lichen } \\
\text { sp. }\end{array}$} & $\mathrm{BF}$ & & & & & & & & & & & & & & & & & & & & & & & & \\
\hline & CA & & & & & & & & & & & & & & & & & & & & & & & & \\
\hline & LM & & & & & & & & & & & & & & & & & & & & & & & & \\
\hline & PV & & & & & & & & & & & & & & & & & & & & & & & & \\
\hline
\end{tabular}

\begin{tabular}{|c|c|c|c|c|c|c|c|c|c|c|c|c|c|c|c|c|c|c|c|c|c|c|c|c|c|}
\hline \multirow{2}{*}{\multicolumn{2}{|c|}{$\begin{array}{l}\text { Phorophyte no. } \\
\text { Height }\end{array}$}} & \multicolumn{4}{|c|}{13} & \multicolumn{4}{|l|}{14} & \multicolumn{4}{|c|}{15} & \multicolumn{4}{|l|}{16} & \multicolumn{4}{|l|}{17} & \multicolumn{4}{|l|}{18} \\
\hline & & A & B & $\mathrm{C}$ & $\mathrm{D}$ & A & $\mathrm{B}$ & $\mathrm{C}$ & $\mathrm{D}$ & A & B & C & $\mathrm{D}$ & $\mathrm{A}$ & $\mathrm{B}$ & $\mathrm{C}$ & $\mathrm{D}$ & $\mathrm{A}$ & B & $\mathrm{C}$ & $\mathrm{D}$ & A & B & $\mathrm{C}$ & $\mathrm{D}$ \\
\hline \multirow{4}{*}{$\begin{array}{l}\text { Lichen } \\
\text { sp. }\end{array}$} & $\mathrm{BF}$ & & & & & & & & & & & & & & & & & & & & & & & & \\
\hline & $\mathrm{CA}$ & & & & & & & & & & & & & & & & & & & & & & & & \\
\hline & LM & & & & & & & & & & & & & & & & & & & & & & & & \\
\hline & PY & & & & & & & & & & & & & & & & & & & & & & & & \\
\hline
\end{tabular}

\begin{tabular}{|c|c|c|c|c|c|c|c|c|c|c|c|c|c|c|c|c|c|c|c|c|c|c|c|c|c|}
\hline \multirow{2}{*}{\multicolumn{2}{|c|}{$\begin{array}{l}\text { Phorophyte no. } \\
\text { Height }\end{array}$}} & \multicolumn{4}{|c|}{19} & \multicolumn{4}{|l|}{20} & \multicolumn{4}{|l|}{21} & \multicolumn{4}{|l|}{22} & \multicolumn{4}{|l|}{23} & \multicolumn{4}{|l|}{24} \\
\hline & & $\mathrm{A}$ & B & C & $\mathrm{D}$ & A 1 & $\mathrm{~B}$ & C & D & A & B & $\mathrm{C}$ & D & A & $\mathrm{B}$ & $\mathrm{C}$ & $\mathrm{D}$ & A & $\mathrm{B}$ & $\mathrm{Cl}_{1}$ & $\mathrm{D}$ & A & $\mathrm{B}$ & $\mathrm{C}$ & $\mathrm{D}$ \\
\hline \multirow{4}{*}{$\begin{array}{l}\text { Lichen } \\
\text { sp. }\end{array}$} & $\mathrm{BF}$ & & & & & & & & & & & & & & & & & & & & & & & & \\
\hline & $\mathrm{CA}$ & & & & & & & & & & & & & & & & & & & & & & & & \\
\hline & LM & & & & & & & & & & & & & & & & & & & & & & & & \\
\hline & PV & & & & & & & & & & & & & & & & & & & & & & & & \\
\hline
\end{tabular}

\begin{tabular}{|c|c|c|c|c|c|c|c|c|c|c|c|c|c|c|c|c|c|c|c|c|c|c|c|c|c|}
\hline \multirow{2}{*}{\multicolumn{2}{|c|}{$\begin{array}{l}\text { Phorophyte no. } \\
\text { Height }\end{array}$}} & \multicolumn{4}{|c|}{25} & \multicolumn{4}{|l|}{26} & \multicolumn{4}{|c|}{27} & \multicolumn{4}{|l|}{28} & \multicolumn{4}{|l|}{29} & \multicolumn{4}{|l|}{30} \\
\hline & & A & $B$ & C & D & A & $\mathrm{B}$ & C & D & A & $B$ & $\mathrm{C}$ & D & A & $\mathrm{B}$ & $\mathrm{C}$ & $\mathrm{D}$ & $\mathrm{A}$ & $\mathrm{B}$ & Cl & $\mathrm{D}$ & A & $\mathrm{B}$ & $\mathrm{C}$ & $\mathrm{D}$ \\
\hline \multirow{4}{*}{$\begin{array}{l}\text { Lichen } \\
\text { sp. }\end{array}$} & $\mathrm{BF}$ & & & & & & & & & & & & & & & & & & & & & & & & \\
\hline & $\mathrm{CA}$ & & & & & & & & & & & & & & & & & & & & & & & & \\
\hline & LM & & & & & & & & & & & & & & & & & & & & & & & & \\
\hline & PV & & & & & & & & & & & & & & & & & & & & & & & & \\
\hline
\end{tabular}




\section{Field checksheets for Part I}

\begin{tabular}{|l||l|l|l|l|l|l|l|l|l|l|}
\hline Phorophyte no. & & & & & & & & & & \\
\hline \hline Abundance & & & & & & & & & & \\
\hline Distribution & & & & & & & & & & \\
\hline Recolonisation & & & & & & & & & & \\
\hline
\end{tabular}

\begin{tabular}{|l||l|l|l|l|l|l|l|l|l|l|}
\hline Phorophyte no. & & & & & & & & & & \\
\hline \hline Abundance & & & & & & & & & & \\
\hline Distribution & & & & & & & & & & \\
\hline Recolonisation & & & & & & & & & & \\
\hline
\end{tabular}

\begin{tabular}{|l||l|l|l|l|l|l|l|l|l|l|}
\hline Phorophyte no. & & & & & & & & & & \\
\hline \hline Abundance & & & & & & & & & & \\
\hline Distribution & & & & & & & & & & \\
\hline Recolonisation & & & & & & & & & & \\
\hline
\end{tabular}

\begin{tabular}{|l||l|l|l|l|l|l|l|l|l|l|}
\hline Phorophyte no. & & & & & & & & & & \\
\hline \hline Abundance & & & & & & & & & & \\
\hline Distribution & & & & & & & & & & \\
\hline Recolonisation & & & & & & & & & & \\
\hline
\end{tabular}

\begin{tabular}{|l||l|l|l|l|l|l|l|l|l|l|}
\hline Phorophyte no. & & & & & & & & & & \\
\hline \hline Abundance & & & & & & & & & & \\
\hline Distribution & & & & & & & & & & \\
\hline Recolonisation & & & & & & & & & & \\
\hline
\end{tabular}

